Agreement

in

Contemporary

Standard

Russian

by Dina B. Crockett 


\title{
From the Publisher
}

This book represents the ninth in a series of reprints of notable titles published by Slavica and long out of print. We are restoring these titles to print and making them available as free downloads from our web site, slavica.indiana.edu, in honor of Slavica's fiftieth anniversary. Yes, we are officially middle-aged. Founded by four graduate students at Harvard in 1966, Slavica published its first book in 1968, Studies Presented to Professor Roman Jakobson by His Students. To celebrate Slavica's jubilee, we are releasing in .pdf format, no strings attached, scans of twelve older titles that have been requested over the years. Enjoy these books, tell your friends, and feel free to share with colleagues and students.

Agreement in Contemporary Standard Russian was a tremendous book for its time. I relied heavily upon it the first time I got to teach Russian syntax (in 1987), and even today I continue to draw examples from its extensive corpus in teaching a more theoretical brand of Russian syntax. It provides a host of sensible descriptive generalizations about difficult cases of agreement for gender and number, and the statistical surveys that have been published in Russia and the Soviet Union in more recent years generally confirm the validity of Crockett's earlier, more intuitive generalizations.

Slavica would like to express its sincere thanks to Dina B. Crockett for graciously granting permission for this reprint. We welcome comments on this and other forthcoming titles to be released in this series.

\author{
George Fowler \\ Director, Slavica Publishers \\ Bloomington, Indiana \\ 12 September 2016
}




\section{AGREEMENT IN CONTEMPORARY STANDARD RUSSIAN}

Dina B. Crockett 
Other Slavica books are listed on the last two pages of this book. For a complete catalog with prices and ordering information, write to:

Slavica Publishers, Inc.

P. O. Box 312

Cambridge, Mass. 02139

ISBN: 0-89357-033-8

Copyright (C) 1976 by Slavica Publishers, Inc.

All rights reserved.

Editor of Slavica Publishers: Charles E. Gribble, The Ohio State University

Printed in the United States of America by LithoCrafters, Inc., Ann Arbor, Michigan 48106 
INTRODUCTION • • • • • • • • • • • • • • • • • 1

TRANSLITERATION • • • • • • • • • • • • • • 4

PART ONE: GENERAL PRINCIPLES

CHAPTER ONE: GRAMTATICAL GENDER • • • • • • • • • 7

1. Introduction . . . . . . . . 7

2. Gender in Association with Simple

Inanimate Declinable Nouns . . . . 9

2.1 Common Nouns • • • • . . . . 9

2.2 Proper Names • • • • • • • . 14

3. Gender in Association with Inanimate

Noun Combinations . . . . . . 15

3.1 Appositive Combinations • • • . 15

3.2 Non-Appositive Combinations . • 20

3.3 Combinations with Proper Names . . 22

3.4 Appositive Combinations versus
Appositive Constructions . . . 25

3.5 Proper-Name Combinations . . . . 31

4. Gender in Association with Inanimate

Indeclinable Nouns . . . . . . 31

4.1 Common Nouns • • • • • • • 32

4.2 Proper Names . . . . . . . . 39

4.3 Abbreviations . . . . . . . 45

5. Gender in Association with Sex-
differentiating Animate Nouns . . . 49

5.1 Declinable Common Nouns . . • . 50

5.2 Declinable Proper Nouns • • • • 52

5.3 Indeclinable Common Nouns .. . 58

5.4 Indeclinable Proper Names . . . 60

6. Gender in Association with Asexua1

Animate Nouns . . . . . . 62 
6.1 As exual Nouns Denoting Animals . . 62

6.2 Asexual Nouns Denoting Human Beings .......... 64

7. Contextually-Dependent Gender in Association with Second-Declension and Indeclinable Animate Nouns . . 69

7.1 Second-Declension Common Nouns • . 69

7.2 Second-Declension Proper Names • . 78

7.3 Related Phenomena .. . . . 79

7.4 Indeclinable Common Nouns . . 86

7.5 Indeclinable Proper Names . . 88

8. Contextually-Dependent Gender in Association with First-Declension Animate Nouns . . . . . . 92

9. Gender in Association with Animate Noun Combinations . . . . . . 105

10. Gender in Numerals, Partitive Constructions, and Nominal Predicates . 113 10.1 Numerals . . . . . . . 113 10.2 Partitive Constructions . . . 115 10.3 Nominal Predicates . . . . 119

CHAPTER THO: GRAMMATICAL NUMBER . • . . • • 138

1. Number in Association with Inherently Plural Nouns . . . . 138

2. Number in Association with Nouns with No Inherent Number . . . . . 142

3. Summary . . . . . . . . 159

CHAPTER THREE: ATTRIBUTIVES ASSOCIATED WITH TWO OR MORE NOUNS ......... 162

1. Animate Count Nouns ....... 163

2. Noncount Nouns . . . . . . 173

3. Inanimate Count Nouns . . . . . 188

4. Disjuncts ........... 197 
5. Postpositive Attributives . . . . 202

6. Summary ........... 207

CHAPTER FOUR: VERBAL PREDICATES ASSOCIATED WITH TWO OR MORE NOUNS . • . • . . 209

1. Prepositive Verbal Predicates Associated with Nouns Linked by $i$ and Verbal Predicates Associated with Nouns Linked by Other Conjunctive Connectives . . . . . . . 214

2. Postpositive Verbal Predicates Associated with Nouns Linked by $i$ or Asyndetically . . . . . . 265

3. Verbal Predicates Associated with Reductions of Conjoined Noun Phrases with Identical Nouns . . . . . 279

3.1 Postpositive Verbal Predicates • 279

3.2 Prepositive Verbal Predicates . . 292

4. Verbal Predicates Associated with Nouns Linked by $i I_{i}$ and Other Disjunctive Connectives . . . . . 297

5. Grammatical Person ....... 308

6. Summary . . . . . . . . 312

CHAPTER FIVE: ALTERNATIVE NUMBER MANIFESTATIONS

IN ASSOCIATION WITH NOUN PHRASES

INVOLVING PARTITIVE QUANTIFIERS • • 314

1. Alternatives in Sentences with Numerical Quantifiers . . . . . 315

2. Alternatives in Sentences with Adverbial Quantifiers . . . . . 368

3. Alternatives in Sentences with Nominal Quantifiers . . . . . 385

4. Copulative Verbs ... . . . . 404 4.1 Introduction . . . . . . 404

4.2 Sentences with Quantified Subjects . . . . . . 407 
iv

4.3 Sentences with kto . . . . . 413

4.4 Sentences with èto . . . . . 424

4.5 Summary •. •. • • • • . 427

CONCLUSION • • • • • • • • • • • • • • • • 429

BIBLIOGRAPHY • • • • • • • • • • • • • • 431

INDEX • • • • • • • • • • • • • • • 453 


\section{INTRODUCTION}

It is a curious fact that questions of grammatical agreement which often baffle the non-native speaker tend to be treated in an offhand manner in Russian grammars and have not attracted much scholarly attention to date. The present monograph attempts to rectify this oversight by providing a systematic description and analysis of manifestations of agreement in contemporary Russian, with special emphasis on contexts which allow alternative forms. The monograph should be useful to students and teachers of Russian in that it contains information on possible manifestations of agreement and the factors which determine them in a great variety of contexts, and it should be of interest to Slavic as well as general linguists in that it attempts to establish fundamental principles which account for the data.

Manifestations of agreement are, roughly, any endings which match features of sentence constituents other than the ones which bear them. Constituents which bear such endings are in the majority of cases either attributive modifiers or verbal predicates. Attributive modifiers are represented in sentences by adjectives and pronominal modifiers, and verbal predicates by finite verb forms, shortform adjectives, and short-form participles, all of which are referred to below indiscriminately as verbs, on the basis of their syntactic function. The constituents whose features are matched are nouns and noun phrases. The term "nouns," 1ike "verbs," is used below indiscriminately in reference to all elements which function in sentences as nouns, whether they are nouns by morphological criteria or not (e.g., pronouns are not nouns by morphological criteria but are nevertheless referred to as nouns).

Chapter One traces the features that are matched by manifestations of grammatical gender in attributive modifiers and verbal predicates associated with different nouns and noun phrases. The chapter concludes with an excursus on gender manifestations in numerals, partitive constructions, and nominal predicates. Manifestations of grammatical number and the features they match are discussed in Chapter Two. These first two chapters present basic principles and constitute Part One. 
Part Two deals with cases in which different manifestations of agreement in superficially identical environments are due to differences in constituent structure. Chapter Three focuses on phrases in which attributive modifiers are associated with two or more nouns, and Chapter Four deals with sentences in which verbal predicates are associated with two or more nouns. The last chapter, Chapter Five, turns to sentences in which the subject phrases involve "partitive quantifiers," i.e., lexical elements which can signify quantity within noun phrases and impose the genitive case on nouns and noun phrases which would otherwise be in the nominative case. This last chapter concludes with an excursus on sentences with copulative verbs which seem to agree with the predicate phrases rather than with their subjects.

While all endings which manifest agreement involve grammatical number and most involve grammatical gender, there are also endings which involve grammatical person and animacy. Manifestations of grammatical person are discussed especially in Section 5 of Chapter Four, and manifestations of animacy especially in Section 7.1 of Chapter One. Manifestations of case which may seem to involve agreement are discussed in Section 3.3 of Chapter One.

The model of grammar postulated in the present monograph is one which relates Russian sentences to "underlying" representations of their content in the form of predicates associated with any number of nominals as coconstituents within propositions. The meanings of the predicates and nominals in the underlying propositions are conceived of as complexes of elementary units of meaning-semantic features. "Surface" Russian sentences are related to the underlying propositions, or semantic representations, through series of intermediate stages dictated by the rules of Russian sentence structure and by idiosyncracies of the Russian lexicon.

The presentation in the chapters that follow is not offered in terms of an elaborate model. Such an approach would have complicated the exposition unnecessarily, for manifestations of agreement appear to be determined in Russian at a fairly superficial stage in the derivation of sentences from their underlying representations and the configurations in underlying representations are therefore of no consequence for agreement. On the other hand, underlying semantic representations cannot be altogether dispensed with in discussing agreement, because not all manifestations of agreement can be accounted for on the basis 
of sentence structure and lexical features alone. There are additional elements of meaning which play a role in the determination of agreement.

As the purpose of this work is to provide a comprehensive treatment of agreement in Russian, it inevitably includes also material from secondary sources, especially in the two introductory chapters. Much of this material is reinterpreted, however, and the bulk of the book contains new material, based on independent observations and sessions with educated Soviet Russians.

Research in preparation for this work was supported by a grant from the International Research and Exchange Board which made an extended sojourn in the USSR in 1970 possible, and also by grants from the Center for Russian and East European Studies and the Center for Research in International Studies at Stanford University.

For comments on an earlier draft of the book I am indebted to Catherine V. Chvany and Edith A. Moravcsik, and especially to Leonid L. Iomdin of Informelektro in Moscow, whose remarks were invaluable in the preparation of the final copy. 


\section{TRANSL ITERATION}

A11 examples and bibliographic references have been transliterated by System I. Names in the text and in translations have been transliterated by System II.

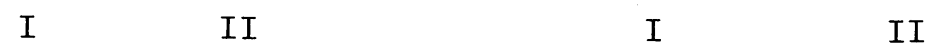

\begin{tabular}{|c|c|c|c|c|c|}
\hline$a$ & $a$ & $a$ & $\mathrm{p}$ & $r$ & $r$ \\
\hline 6 & $\mathrm{~b}$ & $\mathrm{~b}$ & $C$ & $\mathbf{s}$ & $\mathrm{s}$ \\
\hline B & $\mathrm{V}$ & $\mathrm{v}$ & $T$ & $t$ & $t$ \\
\hline$\Gamma$ & $\mathrm{g}$ & $\mathrm{g}$ & $\mathrm{y}$ & $\mathrm{u}$ & $\mathrm{u}$ \\
\hline д & $d$ & $\mathrm{~d}$ & $\Phi$ & $\mathrm{f}$ & $\mathrm{f}$ \\
\hline e & e & e & $x$ & $\mathrm{x}$ & $\mathrm{kh}$ \\
\hline$\ddot{e}$ & $\ddot{e}$ & yo & ц & $c$ & ts \\
\hline Ж & ž & $\mathrm{zh}$ & $\Psi$ & $\stackrel{v}{c}$ & $\mathrm{ch}$ \\
\hline 3 & $z$ & $\mathrm{z}$ & ய & $\stackrel{\vee}{S}$ & $\mathrm{sh}$ \\
\hline и & $i$ & $i$ & щு & ŠC & shch \\
\hline$\breve{\text { I }}$ & j & $\mathrm{y}$ & $\mathrm{b}$ & $" 1$ & \\
\hline $\mathrm{K}$ & $\mathrm{k}$ & $\mathrm{k}$ & ы & $\mathrm{y}$ & $\mathrm{y}$ \\
\hline$\pi$ & 1 & 1 & b & $I$ & \\
\hline $\mathbf{M}$ & $\mathrm{m}$ & $\mathrm{m}$ & $\ni$ & è & $\mathrm{e}$ \\
\hline $\mathrm{H}$ & $\mathrm{n}$ & $\mathrm{n}$ & ю0 & ju & $\mathrm{yu}$ \\
\hline O & o & 0 & Я & ja & уа \\
\hline$\Pi$ & $\mathrm{p}$ & $\mathrm{p}$ & & & \\
\hline
\end{tabular}

COMBINATIONS OF LETTERS IN SYSTEM II

$\begin{array}{lc}\text {-й } & -y \\ \text {-й̆ } & -y \\ \text {-ия } & -i a \\ \text {-ье } & -i e \\ \text {-ъи } & -y i \\ \text { кс } & x\end{array}$


PART ONE

GENERAL PRINCIPLES 



\section{CHAPTER ONE \\ GRAMMATICAL GENDER}

\section{Introduction}

Grammatical gender has three values in Russian--masculine, feminine, and neuter, and it must be manifested by certain singular forms of attributive modifiers and verbal predicates in any sentence. As illustrated by the sentences under (1), the specific gender manifested by an attributive modifier or verbal predicate is independent of the lexical unit which manifests it.
(1) (a) Belyj[masc] stakan polon [masc]. 'The white glass is ful1.'
(b) Belaja [fem] čaška polna [fem]. 'The white cup is ful1.'
(c) Beloe [neut] vedërko polno[neut]. 'The white bucket is full.'

The same lexical units manifest masculine in (1a), feminine in (1b), and neuter in (1c). ${ }^{1}$ The different genders manifested by these lexical units are due to the fact that they are associated with different nouns: with stakan 'glass' in (1a), časka 'cup' in (1b), and vedërko 'bucket' in (1c). These nouns also have masculine, feminine, and neuter endings, respectively, but the gender they manifest cannot vary: stakan is inherently masculine, caska is inherently feminine, and vedërko is inherently neuter.

These facts suggest the rule stated under (2). The nominative singular form of the noun must be specified in the rule, because in other forms the gender of nouns may

1

Singular endings of verbal predicates manifest feminine through $a$, neuter through 0 , and masculine through $\varnothing$ (zero), i.e., no vowel is added to the stem. Attributive modifiers manifest feminine in nominative singular endings through a or aja, neuter through 0 or ojo (the latter always written -oe), and masculine through $\phi, 0 j$, or $i j$. The $0 j$ and $i j$ endings can be represented on a more abstract level as $\emptyset j \emptyset$ (see Zaliznjak 1967b). 
(2) The gender manifested by attributive modifiers and verbal predicates must be identical to the gender manifested by the nominative singular form of the noun with which they are associated.

have no specific manifestation. The locative singular endings of the three nouns in (1), for example, are identical: stakane, caske, and vedërke.

Rule (2) indeed accounts for the gender of the attributives and predicates in the sentences under (1) and also for the gender of attributives and predicates in many other sentences, but it cannot account for the gender manifestations in sentences such as the ones under (3), for example.

(3) (a) V uglu komnaty stojalo[neut] udobnoe[neut] kreslokacalka.

'In the corner of the room stood a comfortable rocking chair.'

(b) Pervaja[fem] È'VM byla sozdana[fem] $v$ SSA.

'The first electronic computer was made in the USA.'

(c) $N a s ̌ a[f e m] ~ f e l ' d \breve{s e r ~ d o b r o s o v e s t n a[f e m] . ~}$

'Our medical attendant is conscientious.'

In (3a), the noun kresZo-kačalka 'rocking chair' (1it. 'armchair-rocker'), which is in its nominative singular form, has conflicting gender manifestations, for it is made up of a noun with a neuter ending and a noun with a feminine ending. Since attributive modifiers and verbal predicates can only manifest one gender at a time and kreslokacalka manifests two, rule (2) is inapplicable.

In (3b), the noun $E V M$ 'electronic computer' appears to have a masculine ending, yet the modifier and the predicate have feminine endings. This is only an apparent aberration, for EVM is an abbreviation for the noun phrase elektronnaja vyčislitel'naja mašina, in which the head noun does have a feminine ending. Nevertheless, rule (2) as it is stated cannot account for the feminine endings in (3b).

In $(3 c)$, the modifier and the predicate again do not manifest the gender manifested by the noun, masculine, and again rule (2) turns out to be inadequate.

The relationship between morphological manifestations of gender in nouns and the gender manifested by attributive modifiers and verbal predicates is traced systematically in the sections that follow. In Sections 2-4 the discussion focuses on gender manifestations in association with nouns denoting inanimate entities, and in Sections 5-9 the 
subject matter is gender manifestations in association with nouns denoting animate beings. Section 10 explores the processes which determine gender manifestations in numerals, partitive constructions, and nominal predicates.

2. Gender in Association with Simple Inanimate Declinable Nouns.

In considering the question of grammatical gender with respect to inanimate nouns, it is necessary to distinguish between declinable and indeclinable nouns. The present section and the following one deal with gender in association with declinable inanimate nouns, and Section 4 deals with gender in association with indeclinable inanimate nouns.

The discussion of gender in association with declinable inanimate nouns is divided between two sections because of differences between simple nouns and noun combinations such as kreslo-kačalka 'rocking chair.' The latter are discussed in Section 3, and the discussion in the present section is limited to gender in association with simple nouns.

\subsection{Common Nouns}

2.11 Rule (2), which states that the gender manifested by attributive modifiers and verbal predicates must be identical to the gender manifested by the nominative singular ending of the noun with which they are associated, holds with respect to most common declinable inanimate simple nouns, but not with respect to all. This is because inherently masculine nouns may end in affective suffixes which manifest a different gender, and also because zero endings are not always unambiguous gender markers. The facts are as follows.

Nouns in the nominative singular may end in $a, 0$, or $\phi$ (zero). (In Cyrillic orthography, the ending a is repre-

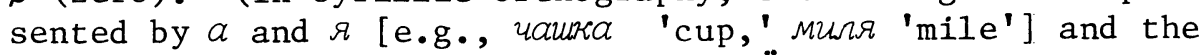
ending 0 is represented by $o, e$, and $\ddot{e}$ [e.g., пuсьмo 'letter,' mope 'sea,' pyocoë 'rifle'], and after palatalized $\mathcal{M}$ by $\mathcal{R}$ [e.g., uM 'name']. Nouns which have a zero ending either end in a consonant [including $\breve{u}$ ] or in a soft sign [b].)

When inanimate nouns end in a in the nominative singular, the gender manifested by modifiers and verbal predicates associated with them is almost always feminine. It 
is not necessarily feminine only in association with nouns formed of inherently masculine stems and the augmentative suffix -in-. Compare, for example, bezobraznyj [masc] dom 'ugly house' and bezobraznyj[masc] domina 'ugly big house,' tropičeskij [masc] doæd' 'tropical rain' and tropiceskij [masc] doždina 'tropical heavy rain' (Šanskaja 1961, 17). It is notable, however, that there is a strong tendency in current usage to treat such nouns too as feminine (see, e.g., Šanskaja 1961, 16-17; Zalinznjak 1967a, 149; and Maksimov 1969). 2

When inanimate nouns end in 0 in the nominative singular, the gender manifested by associated modifiers and verbal predicates is almost always neuter. Again, it is not neuter only in association with nouns formed of inherently masculine stems and affective suffixes. Such nouns remain inherently masculine, and singular attributive modifiers and verbal predicates associated with them must always have masculine endings.

There are three affective suffixes which end in 0 in the nominative singular and which can be attached to inherently masculine inanimate stems. They are - $i$ šc-, an augmentative suffix, -i乡̌k-, a diminutive suffix, and $-u \xi k-$, also a diminutive suffix, which, however, is apparently rare with masculine nouns (cf. Potixa 1970, 256). Compare krasnyj[masc] nos 'red nose' and krasnyj [masc]/*krasnoe [neut] nosišce 'red big nose,' siplyj[masc] golos 'hoarse voice' and siplyj[masc]/*siploe[neut] golosiłko 'hoarse small voice,' 'tëplyj[masc] $x$ leb 'warm bread' and tëplyj [masc]/*tëploe[neut] xlebusko 'nice warm bread.'

Inherently masculine stems retain their gender with these suffixes even when declined, colloquially, as feminine nouns; e.g., ètim[instr masc] gorodiškoj[instr fem] 'this town,' $i z$ starogo[gen masc] domiski[gen fem] 'from

${ }^{2}$ Inherently neuter stems, in distinction from inherently masculine stems, do not ever retain their gender with the augmentative suffix -in- (cf., e.g., Sanskaja $1961,16)$. Compare, for example, vjazkoe [neut] boloto 'muddy swamp' and vjazkaja[fem]/*vjazkoe[neut] bolotina 'muddy big swamp,' glubokoe[neut] koryto 'deep washtub' and glubokaja[fem]/*glubokoe[neut] korytina 'deep big washtub.' (An asterisk preceding a word, phrase, or sentence indicates that it is ungrammatical.) 
the old 1ittle house' (cf., e.g., Zaliznjak 1967a, 148-149; Rozenta1' 1971a, 167; and Kačevskaja 1969).3

Inherently masculine inanimate stems with non-affective suffixes in 0, e.g., the non-affective -ǐ̌c-, do not retain their gender. Compare, for example, strasnyj [masc] požar 'terrible fire,' strašnyj [masc] pozarišce 'terrible big fire,' and strašnoe[neut] pozarišče 'terrible site of fire.' Similarly, toporiše 'large axe' is treated as masculine (like topor 'axe'), but toporisce 'axe helve' is treated as neuter (cf., e.g., Sanskaja 1961, 15-16; Zaliznjak 1967a, 227-228; and Rozental' 1971a, 162).

Inherently feminine stems do not take affective suffixes in o (cf., e.g., Sanskaja 1961 and Potixa 1970, 250259).

When inanimate nouns do not end in a vowel in the nominative singular, i.e., when they end in $\phi$ (zero), the gender manifested by modifiers and verbal predicates associated with them is masculine if their stems end in $j$ or in any hard consonant that is not a palatal. Otherwise, i.e., if their stems end in a palatal ( $\check{Z}, \zeta$, or $\breve{C}$ ) or in a palatalized consonant, the gender manifested by modifiers and verbal predicates associated with them may be either masculine or feminine, for the nominative singular form of such nouns does not manifest gender unambiguously. The inherent gender of such nouns is only manifested unambiguously by certain oblique case endings, for inherently masculine nouns follow the First Declension (e.g., nom. den' 'day,' gen. $d n j a)$ and inherently feminine nouns follow the Third Declension (e.g., nom. ten' 'shadow,' gen. teni). (The only exception is the noun put' 'road, path,' which is inherently masculine but follows the Third Declension.)

2.12 Rule (2) as it is stated thus does not apply to inanimate nouns with affective suffixes which end in a or 0 in the nominative singular, for such nouns may be inherently masculine, and it does not apply to nouns which have a zero ending in the nominative singular and end in a palatal or palatalized consonant. The rule should apparently be amended to read as follows:

${ }^{3}$ This is in contrast to inherently neuter stems, which do not retain their inherent gender when declined as feminine nouns dialectally, e.g., Unas ploxaja [f em] položenija[fem] 'we have a bad situation' (for further illustrations and discussion see Mučnik 1971, 194-197). 
(4) The gender manifested by attributive modifiers and verbal predicates is the inherent gender of the noun with which they are associated.

This statement is more adequate because it makes no reference to nominal endings and treats the gender of nouns as an independent, intrinsic property. Indeed, though the inherent gender of inanimate nouns may occasionally be predicted from the structure of their stems, it is essentially an unpredictable property and entries for inanimate nouns in the lexicon of Russian (in a model of linguistic competence) must include gender specifications.

Declension paradigms, on the other hand, need not be specified for most inanimate nouns in the lexicon, for they are predictable from the gender specifications: masculine nouns follow the masculine variant of the First Declension, neuter nouns follow the neuter variant of the First Declension, and feminine nouns follow the Second Declension. Nouns whose declension paradigm cannot be predicted by this general rule can be assumed to be marked in the lexicon as exceptions to it. This would indicate that they follow the Third Declension. (There is only one masculine noun in this category--put' 'road, path,' and there are a dozen or so neuter nouns [the ones whose stems end in $\mathrm{m}^{\prime}$ ]; the remaining nouns are all feminine. [For statistical data on the distribution of Russian nouns by gender and declension paradigm see Lazova 1974, 942, and cf. also MuX̌nik 1971, 187 and 196-197.])

Only entries for nouns which follow the adjectival paradigm must include a specification of the declension paradigm. Nouns in this category are, for example, zapjataja 'comma,' vselennaja 'universe,' pridanoe 'dowry,' and skazuemoe 'predicate' (for additional examples and discussions of transitional cases see, e.g., GalkinaFedoruk 1964, 89-91 and Isačenko 1965, 233-240; cf. also the entries in Lazova 1974, e.g., 768-769).

It should be added in this connection that adjectival forms as in (5) are not lexical nouns.

(5) Staroe[neut] staritsja, molodoe[neut] rastët. old grows old young grows

'What is old grows older, what is young grows up.'

There are many adjectives which can be used with neuter endings like staroe 'what is old' and molodoe 'what is young' in (5) to signify entities within their domain, 
e.g., novoe[neut] 'what is new,' xorošee[neut] 'what is good,' prekrasnoe[neut] 'what is beautiful,' vozmožnoe [neut] 'what is possible,' etc. Such neuter adjectives do not represent lexical nouns because they do not refer to particular objects, and for the same reason they cannot be accounted for as attributive modifiers manifesting the gender of deleted nouns. Such forms can be assumed to derive as attributive modifiers associated with indefinite nominals which receive no lexical realization, i.e., there is no lexical noun with which they are associated and whose inherent gender they can manifest. They have neuter endings because neuter is the gender which attributive modifiers and verbal predicates manifest whenever they are not associated with any noun or when the noun with which they are associated has no inherent gender (for further discussion see Section 4.1 below).

The declension of noun stems modified by affective suffixes is determined by the suffixes (for such suffixes must apparently be treated as independent lexical units with their own inherent gender and corresponding declension paradigm). The gender manifested in association with noun stems modified by affective suffixes is also determined by the suffixes, but not when the suffixes modify inherently masculine stems. In such cases the gender of the suffixes is neutralized, and only the gender of the feminine affective suffix - in- is not consistently neutralized in this environment.

2.13 There are some nouns in Russian which do not follow one declension consistently and the gender manifested in association with them is also variable. This category comprises certain low-frequency nouns and nouns that usually occur in forms and constructions which do not manifest gender unambiguously, e.g., nouns such as staven' [masc]/stavnja[fem] 'shutter' and kiaviš[masc]/klaviša [fem] 'key (of instrument),' which are usually used in the plural, where gender distinctions blur. Such nouns cannot be said to be devoid of inherent gender, for the gender to be manifested in association with them cannot be chosen at random, nor can their declension paradigm be chosen at random; these nouns only allow specific alternatives.

In a lexicon which represents what a native speaker of Russian knows about his language such nouns must apparently appear with more than one inherent gender, and where one of the genders is obsolescent or dialectal, it must apparently be marked as such in a lexicon for the standard 
language. (For additional data on nouns within this category see Mučnik 1963, 51-54; Sanskaja 1964a, 5-6; and Gorbačevič 1971, 161-163.)

2.14 To sum up, the gender manifested by attributive modifiers and verbal predicates associated with a simple inanimate declinable common noun is always the inherent gender of the noun, and its particular value for each noun is essentially unpredictable. Inherent gender must be specified in the lexicon for each noun of this type along with its meaning and the phonological structure of the stem. The nominative singular endings of such nouns generally manifest their inherent gender, but not always, and when they do--not always unambiguously.

\subsection{Proper Names}

Proper names for inanimate entities do not constitute a special class with respect to gender and declension if they are morphologically simple declinable nouns. Names such as Leningrad or Simferopol', for example, are inherently masculine and follow the masculine variant of the First Declension; names such as Puškino and Šeremet'evo are inherently neuter and follow the neuter variant of the First Declension; and names such as Moskva and Angara are inherently feminine and follow the Second Declension. ${ }^{4}$ Proper names not subject to the general rule by which declension paradigm is predictable from inherent gender are, for instance, the river names Kuban' and $O b^{\prime}$, the city names Kazan' and Rjazan', and the territory names Rus' and Sibir', all of which are inherently feminine and follow the Third Declension. Proper names which follow the adjectival paradigm are, for example, the city names Gor'kij, Narodnaja, and Ramenskoe, which are inherently masculine, feminine, and neuter, respectively.

Singular forms of attributive modifiers and verbal predicates manifest the inherent gender of proper names just as they manifest the inherent gender of common nouns, as illustrated under (6).

\footnotetext{
${ }^{4}$ Inherently neuter Russian proper names such as Puškino and Šeremet'evo may be treated colloquially as indeclinable nouns. See Section 4.23 below.
} 
(6) (a) Moskva osnovana[fem] v 1147 godu.

'Moscow was founded in 1147.'

(b) Lenigrad osnovan[masc] $v 1703$ godu.

'Lenigrad was founded in 1703.'

The verbal predicate in (6a) has a feminine ending, manifesting the gender of Moskva, and the one in (6b) has a masculine ending, manifesting the gender of Lenigrad.

The sentences under (7) illustrate names of literary magazines.
(a) "Junost"" osnovana[fem] $v 1955$ godu. 'Junost' was founded in 1955.'
(b) "Oktjabr" osnovan [masc] v 1924 godu. 'Oktjabr' was founded in 1924.'

In (7a) the verbal predicate bears the gender of Junost', and in (7b) it bears the gender of Oktjabr'.

This concludes the discussion of gender in association with simple inanimate declinable nouns.

3. Gender in Association with Inanimate Noun Combinations

\subsection{Appositive Combinations}

The gender manifested in association with appositive combinations which function as single nouns is quite problematic, as illustrated in (8).

(8) Na kamennom postamente ... razmestilas' skul 'pturnaja gruppa iz bronzy, nad neju--monumental'naja[fem] raš-vodoëm, iz kotorogo[masc] naselenie bralo vodu. 'On a stone pedestal ... there is a bronze sculptured group, and over it--a monumental bowl-shaped reservoir, from which the population used to take water.'

This sentence, which occurs in a recent guidebook to Moscow (Kirillov 1970, 83), contains the combination čašavodoem 'bowl-shaped reservoir' (1it. 'bowl-reservoir'). The adjective which modifies it, monumental'naja 'monumental,' has a feminine ending, but the relative pronoun kotorogo 'which,' whose antecedent is the same combination, has a masculine ending (morphologically masculine or neuter). This is, however, an extreme, atypical example, most likely due to carelessness. More typically, such an 
appositive combination would be treated differently in different contexts or by different speakers.

Whether the gender manifested by attributive modifiers and verbal predicates associated with an appositive combination is that of the first noun or that of the last seems to depend on whether the combination is considered a compound or a composite. Compounds are treated like simple nouns and only have one inflected ending, that of the last noun. Composites have more than one inflected ending. The gender manifested in association with compounds is that of the last noun, and the gender manifested in association with composites is that of the first. 5

The sentences under (9) illustrate gender manifestations in association with compounds.

(9) (a) Oni ukrylis' brezentovoj[instr fem] plastpalatkoj[instr fem].

'They covered themselves with a tarpaulin poncho-tent.'

(b) Zurnalistu pozvonili iz novoj[gen fem] ritabkvartiry [gen fem] gruppy.

'The journalist received a call from the new headquarters of the group.'

(c) My včera zavtrakali v malen'koj[loc fem] avtomatzakusočnoj [loc fem].

'We had breakfast yesterday in a small automated snackbar.'

${ }^{5}$ Appositive combinations of more than two nouns are rare. Inanimate appositive combinations of more than two nouns typically contain a proper name as their third element, e.g., mueka-sputnik "Vostok-1" 'companion pen Vostok-1' (illustrated below in sentences (16c) and (17c)). A tripartite combination without a proper name is, e.g., beton-špric-mašina 'concrete spray machine.' Animate appositive combinations of more than two nouns typically contain either a proper name as third element or a noun which serves to indicate the sex of the referent, e.g., ðenščina inžener-stroitel' 'lady civil engineer.' Other animate tripartite combinations generally denote specialties, e.g., vrač-ortoped-ximurg 'doctor orthopedic surgeon' (for additional examples see Rozental' 1972, 14-15 or Bukčina and Kalakuckaja 1974, 63). 
(d) Povest' napě̌atana $v$ očerednoj [1oc fem] romangazete [1oc (fem)].6

'The story has been printed in the current newspaper-nove1.'

Gender manifestations in association with composites are illustrated in the sentences under (10).

(10) (a) Priexal direktor respublikanskoj[gen fem] školy [gen fem]-internata[gen (masc)].

'The principal of the Republic's boarding-school has arrived.'

(b) On vystupal s dlinnoj[instr fem] reč'ju[instr fem]-dokladom [instr (masc)]

'He gave a long oral report.'

${ }^{6}$ Gender is sometimes given within parentheses to indicate that the ending does not manifest it unambiguously.

It is noteworthy that the initial components in all of the compounds illustrated under (9) have zero endings and are inherently masculine. This seems to be characteristic of the great majority of compound combinations, though not all combinations which begin with masculine nouns are treated as compounds (cf., e.g., (10d)). Few if any regularly occurring combinations begin with feminine nouns with zero endings (i.e., Third-Declension nouns), and perhaps combinations beginning with masculine nouns are especially susceptible to being treated as compounds because noun forms with zero endings resemble raw stems. When combinations that begin with neuter nouns or SecondDeclension feminine nouns are treated as compounds, which is rare, their initial components also tend to be perceived as raw stems and their nominative-singular vocalic endings then assume the role of connecting vowels, which is evidenced by the alternative spelling of combinations with initial feminine nouns such as raketa-nositel'

'vehicle' (lit. 'carrier-rocket') and tonna-kilometr 'ton per kilometer' with $O$ instead of the ending $-a$, viz., raketonositel' and tonnokizometr (cf. Kotelova and Sorokin 1971, 391; Gorbačevič 1973, 517; and Rozental' 1971a, 37; combinations of measure units such as tonna-kilometr are discussed in Section 3.2 below). 
(c) Posle ètogo[gen (masc)] spektaklja[gen (masc)]igry[gen fem] emu podarili novoe imja-"Petmirecka".

'After this playful show he was given a new name-Petrushechka.'

(d) Rimma často vspominala o starom[1oc (masc)] dome [1oc (masc)]-razvaljuske[1oc (fem)].

'Rimma of ten recalled the old crumbling house.'

In general, well-established and frequently-used appositive combinations tend to be treated as compounds, especially in informal discourse (cf., e.g., Rozental' 1971a, 167-168; Rozental' and Telenkova 1973b, 38; and Gorbačevič 1973, 517-518). Appositive combinations that are less familiar, ad hoc, or typical of formal discourse tend to be treated as composites.

The fact that attributive modifiers and verbal predicates associated with compounds can only manifest the gender of the last, inflected noun has been noted by a number of Russian grammarians (cf., e.g., Sanskaja 1964a, 15; Rozental' 1971a, 229; Rozental' and Telenkova 1973a, 291; and Gorbačevič 1973, 517-518). The fact that in association with composites the gender of the first noun supersedes, however, is only stated explicitly in Sanskaja $1964 \mathrm{a}, 15$, although discussions in other sources all point in the same direction (see, e.g., Dobromyslov and Rozental' 1960, 200-201; Orlov 1961; Rozental' 1968, 258-259 and 278; Mučnik 1971, 188-189; and Gorbačevič 1973, 517-518).

There is an unquestionable correlation between the status of a combination as a compound or composite and the gender manifested in association with it. Consequently, different genders manifested in association with the same combination can be accounted for by the fact that some speakers consider it a compound while others consider it a composite.

There have been attempts to account for different gender manifestations in association with combinations by establishing semantic distinctions. For example, in Dobromyslov and Rozental' 1960, 200-201, it is suggested that the noun vagon-vystavka 'railroad-car exhibition' as used in (11a) below refers to an exhibition rather than to a railroad car, and this is why the verbal predicate bears the gender of vystavka 'exhibition.' In (11b), the authors say, the emphasis is on the railroad-car, vagon, and this is why the verbal predicate bears the gender of vagon. 
They make no reference to the declinability of the first noun in either case.

(11) (a) Vagon-vystavka pol'zovalas' [fem] bol'sim uspexom. 'The railroad-car exhibition was a great success.'

(b) Vagon-vystavka stojal[masc] na zapasnom puti. 'The railroad-car exhibition stood on the sidetrack.'

Such semantic considerations, though quite interesting in themselves, in fact play a very minor role in determining the gender of modifiers and predicates, if at all. This can be demonstrated in part by the fact that the semantic approach is also applied in Dobromyslov and Rozental' 1960 to combinations which do not allow alternative gender manifestations in association with them. The authors claim, for instance, that the predicate in (12) has a feminine ending because the emphasis is on palatka 'tent' rather than on plaš 'poncho' (p. 201).

(12) Plaక̌-palatka byla postavlena[fem] na opuške lesa. 'The poncho-tent was put up at the edge of the forest.'

Since the combination plaš-palatka is listed both in the four-volume Academy dictionary and in Ozhegov's dictionary as a feminine compound (and this indicates that any other gender manifestation in association with this combination is indisputably excluded), a semantic account for (12) seems vacuous.

The vacuity of the semantic approach is also demonstrated in Rozental' 1968, where it is stated that in conjunctive combinations like $x$ leb-sol' 'bread [and] salt' (discussed in Section 3.2 below), the second noun has greater semantic weight and therefore its gender is the one which supersedes (p. 259). In the very same volume, however, a counterexample (Brezgues' nasim[instr (masc)] $x$ Zebom[instr (masc)]-sol'ju[instr fem] 'you disdain our bread and salt') is accounted for by morphological rather than semantic criteria: the modifier is said to agree with the first noun rather than with the second because the first noun is declined (p. 278; cf. also Rozental' 1971a, 229).

What has been established in this section, then, is that when appositive noun combinations are viewed by speakers as compounds, i.e., combinations in which only the last noun should be declined, their gender is the inherent gender of the last noun. When they are viewed as 
composites, i.e., both nouns decline, their gender is the gender of the first noun. Different gender manifestations in association with the same combination are a consequence of its being considered a compound by some and a composite by others. In general, all ad hoc combinations tend to be viewed as composites and frequently-used combinations tend to be viewed as compounds, but there are no clear standards in this respect.

\subsection{Non-Appositive Combinations}

The observations in the preceding section apply not only to combinations of the appositive type but also to conjunctive and reduplicative combinations. (Internal relations within combinations are analyzed in Roses 1973 and Ward 1973.)

Conjunctive combinations are reductions of conjoined noun phrases, e.g., imja-otcestvo 'first name [and] patronymic,' raj-saxar 'tea [and] sugar,' and kupljaprodaza 'purchase [and] sale.' Conjunctive combinations in which the two nouns are of different genders are, for instance, $x$ leb-sol' 'bread [and] salt' = 'hospitality,' and priëm-vydača 'receipt [and] issue.'

Reduplicative combinations are tautological folkloric expressions such as pora-vremja 'time' (1it. 'time time'), put'-doroga 'road'(lit. 'road road'), and pravda-istina 'truth' (1it. 'truth truth').

Conjunctive and reduplicative combinations tend to be viewed as compounds, but they may occasionally be treated as composites (cf. Rozental' 1968, 259 and 278). The sentences under (13), one of which has already been cited earlier, illustrate different treatments of the combination $x$ Zeb-sol' 'bread [and] salt' (a11 three sentences are from Rozental' 1968, ibid.).

(13) (a) Brezgueš' našim [instr (masc)] xlebom [instr (masc)]-sol'ju[instr fem]. (Ovechkin)

'You disdain our bread and salt.'

(b) Blagodarju, čto vy moej[instr fem] $x$ Zeb-sol'ju [instr fem] ne prezreli. (Pushkin)

'I thank you for not having disdained my bread and salt.'

(c) Propadala darom svatovskaja [nom fem] $x$ Zeb-sol' [nom]. (Sholokhov)

'Gone to waste are the matchmaker's bread and salt.' 
The remaining two types of combinations only constitute compounds. One may be referred to as an attributive type, and the other combines measure units.

In attributive combinations, one of the nouns functions as modifier of the other, e.g., gore-vystavka 'poor exhibition,' '̌udo-mašina 'wonder machine,' vakuum-sušilka 'vacuum drier,' and èkspress-Zaboratorija 'express [=fastservice] laboratory.' The difference between such combinations and, for instance, appositive combinations such as kreslo-kačalka 'rocking chair' or vagon-vystavka 'railroadcar exhibition' is that while an object which is a kreslokacalka is equally a kreslo 'armchair' and a kačalka 'rocker,' and an object which is a vagon-vystavka is equally a vagon 'car' and a vystavka 'exhibition,' something which is a gore-vystavka is not equally gore 'grief' and vystavka 'exhibition,' and something which is an èkspress-Zaboratorija is not equally èkspress 'express' and Zaboratorija 'laboratory.' Only the modified noun can be inflected in attributive combinations, and their gender is that of the inflected noun (for some additional examples of attributive combinations see Rozental' 1971a, 36-37).7

Combinations of measure units are, for example, vol't-sekunda 'volt per second,' gramm-molekula 'gram per molecule,' and tonna-kilometr 'ton per kilometer.' These are always treated as compounds, e.g., dve[fem] grammmolekuly[gen fem] 'two grams per molecule,' dva[(masc)] tonna-kilometra[gen (masc)] 'two tons per kilometer' (cf. Rozental' 1968, 278 and Gorbačevič 1973, 518).

\section{${ }^{7}$ Concatenations such as mini-jubka 'miniskirt' or} netto-ves 'net weight' fall into a different category, for their initial elements, unlike the initial elements in attributive combinations such as, e.g., vakuum sušilka 'vacuum drier,' can be postposed (cf. jubka mini and ves netto) and, more crucially, the initial elements cannot function as independent nouns (in a sentence such as Ona byla $v$ krasnoj[fem] "mini" 'she was wearing a red mini,' "mini" is most likely a reduction of mini-jubka, for the modifier manifests the gender of jubka; concatenations with such indeclinable attributives are discussed in Panov 1968, 105-111; Rozental' 1972, 11-13; and Bukčina and Kalakuckaja 1974, 69-71). 
3.3 Combinations with Proper Names

Combinations in which one of the nouns is a proper name are usually of the appositive type, but they may also be attributive, e.g., Volga-matußka 'mother Volga,' or Cna-golubuška 'darling Tsna.' Attributive combinations of this type can only constitute composites (see, e.g., Galkina-Fedoruk 1964, 371)--in distinction from attributive combinations of common nouns (see above).

Appositive combinations in which one of the nouns is a proper name are not hyphenated unless the proper name precedes the common noun; compare, e.g., reka Dunaj and Dunaj-reka 'the Danube River' (cf. Pravila musskoj orfografii $i$ punktuacii 1962, 40). When the proper name occupies the initial position, a combination may also sometimes be written as one word, e.g., Segozero 'Seg Lake,' or Sjamozero 'Syam Lake' (for additional examples see ožegov 1955).

When the proper name precedes, appositive combinations constitute compounds: the proper name is not inflected and the gender manifested by associated modifiers and predicates is that of the righthand, common noun, as in (14).

\section{(14) Il'men'-ozero $\left\{\begin{array}{c}\text { raspoloženo[neut] } \\ \text { *raspoložen [masc] }\end{array}\right\}$ Novgorodskoj oblasti. \\ 'Ilmen Lake is located in the Novgorod Province.'}

Only appositive combinations in which the common noun following the proper name is reka 'river' (e.g., Dunajreka, Donec-reka, Moskva-reka) constitute a special case, for they may also be treated as composites. In fact, prescriptive grammarians allow the treatment of such combinations as compounds only in informal, colloquial discourse (see, e.g., Ožegov 1955; Galkina-Fedoruk 1964, 371;

Rozental' 1971a, 168; and Gorbačevič 1973, 518).

Appositive combinations in which the proper name follows the common noun are always treated as composites: the common noun is inflected, and the gender manifested by attributive modifiers and verbal predicates is the gender of the common noun. Combinations with place names (toponyms) are illustrated under (15), and combinations with names other than toponyms are illustrated under (16). 
(15) (a) Gorod Moskva $\begin{gathered}\text { osnovan [masc] } \\ * \text { osnovana [fem] }\end{gathered}$ v 1147 godu. 'The city of Moscow was founded in 1147.'

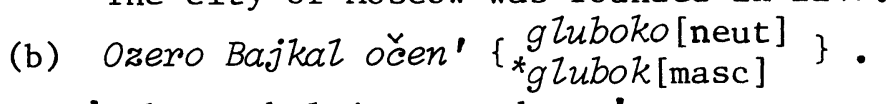

'Lake Baykal is very deep.'

(c) $\left.\begin{array}{r}\text { Rjazanskoe[neut] } \\ \text { *jazanskaja[fem] }\end{array}\right\} \begin{aligned} & \text { selo Culkovka naxoditsja } \\ & \text { nedaleko otsjuda. }\end{aligned}$

'The Ryazan village of Chulkovka is not far from here.'

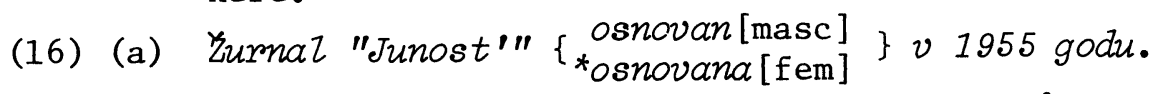

'The 'magazine Junost' was founded in 1955.'

(b) Gostinica "Nacional'" \{ $\begin{gathered}\text { by Za postroena[fem] } \\ * b y Z \text { postroen[masc] }\end{gathered}$ $v 1903$ godu.

'Hotel Natsional was built in 1903.'

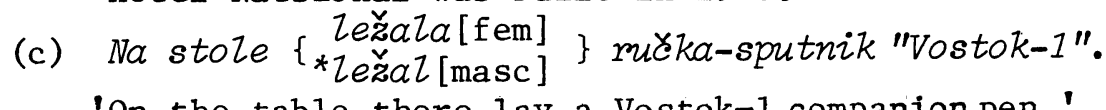
'On the table there lay a Vostok-1 companion pen.'

Sentences (15a) and (16a) contrast with sentences (6a) and ( $7 a)$ above (p. 15), where the same proper names occur independently and the predicates do manifest their gender.

What distinguishes composites with proper names from composites which only consist of common nouns is the fact that in many cases proper names in composites are not inflected. Proper names that are not toponyms are never inflected (see, e.g., (17)), and toponyms also tend to remain uninflected. (This phenomenon is sometimes described as lack of agreement in case; see, e.g., Rozental' $1971 \mathrm{a}, 235-237.)^{8}$

${ }^{8}$ In general, the case endings of nouns can be accounted for as manifestations of case specifications lowered to noun stems in the underlying structures of sentences from the NPs (Noun Phrases) that dominate them, which in their turn receive the case specifications by rules that are sensitive to their role in the sentence structure as well as to government features. Stems of proper names have to be distinguished as such in the lexicon, let us say by the specification [-Common]. This specification can be assumed to block the lowering of case specifications to these stems under certain conditions, and the stems are then (cont.) 
(17) (a) Rasskaz napečatan v ¿urnale [1oc] \{ "Junost'" "Junosti" [1oc] $\}$. 'The story appears in the magazine Junost'.'

(b) My ostanovilis'vgostinice [1oc] \{ "Nacional'" 'We stayed at the Hotel Natsional.'

(c) Otec pišet mickoj[instr]-sputnikom [instr] \{ "Vostok-1"

'Father writes with a Vostok-1 companion pen.'

The tendency not to inflect toponyms in composites is apparently due not only to simple analogy with other proper names but also, in large part, to regulations during World War II which forbade the declension of place names in order to prevent ambiguities and misunderstandings (see, e.g., Ožegov 1955, 221; Švedova 1966, 37-38; and Panov 1968, 56-57). It seems that in current usage the inflectibility of a place name in a composite generally depends on the degree to which the name is widely known (for recommended usage in specific cases see, e.g., Lebedeva 1968, 60-61, 71-72, 215-217, and 223-225, and Rozental' 1971a, 236-237). Thus in reference to the capital of the Soviet Union one would say $v$ gorode [1oc] Moskve [1oc] 'in the city [of] Moscow,' for instance, rather than $v$ gorode[1oc] Moskva, but in reference to the town of Moscow in the USA the latter variant is preferable, as in (18).

(18) Zumalisty pišut o maZen'kom[1oc] gorode[1oc] Moskva, naxodjaščemsja $v$ somom centre SŠA.

'The journalists write about the small town of Moscow, located in the very center of the USA.

This principle is not applied consistently, however, for even the name of the most famous lake in the Soviet Union can remain uninflected, as illustrated by (19) (from a recent newspaper article).

(19) Ot ètogo zavisit i sud'ba somogo[gen] ozera[gen] Bajkal.

'The fate of Lake Baykal itself also depends on this.'

assigned nominative specifications, for this is the "unmarked" case (see, e.g., the analysis in Jakobson 1958). 
Combinations in which common nouns are followed by names of species are analogous to combinations with place names, for names of species may also remain uninflected, e.g., formirovanie volokna[gen] kapron 'the formation of the fiber kapron,' or proizvodstvo volokna[gen] Zavsan 'the production of the fiber lavsan' (cited in Panov 1968, 254). Such combinations are invariably treated as composites (cf. (20)), like combinations in which common nouns are followed by proper names in the strict sense of the term (the sentences in (20) are cited in Rozental' 1971a, 219).

(20) (a) Travazveroboj $\left\{\begin{array}{r}\operatorname{ros} l a[\mathrm{fem}] \\ \text { ros }[\mathrm{masc}]\end{array}\right\}$ po vsej poljane. 'The herb St.-John's-wort grew all over the glade.'

(b) Derevobaobab $\left\{\begin{array}{c}\text { raskinulo [neut] } \\ \text { raskinul[masc] }\end{array}\right\}$ svoi mogučie vetvi. 'Thebaobab tree spread its powerful branches.'

3.4 Appositive Combinations versus Appositive Constructions

It will be useful at this point to distinguish between appositive combinations and appositive constructions. Consider (21).

(21) (a) Vot znomenityj gorod Leningrad.

'Here is [the] famous city [of] Leningrad.'

(b) Vot znomenityj gorod, Leningrad. 'Here is $\left\{\left[\begin{array}{l}{[\mathrm{the}]} \\ \mathrm{a}]\end{array}\right\}\right.$ famous city, Leningrad.'

Sentence (2la) illustrates an appositive combination, sentence (21b)--an appositive construction. What distinguishes the appositive construction from the appositive combination is the intonational break between its components. As a consequence of this intonational break, the modifier in (21b) only applies to gorod--not to gorod Leningrad as a unit, as in (21a). Furthermore, gorod in (21b) can be read as either definite or indefinite--not only as definite, as in (2la), and Leningrad in (21b) can take on a separate modifier, as in (22b), which is impossible in $(21 a)$ (see $(22 a))$. 
(22) (a) *Vot znomenityj gorod veiikolepnyj Leningrad. 'Here is [the] famous city [of] beautiful Leningrad.'

(b) Votznomenityj gorod, velikolepnyj Leningrad. 'Here is $\{[\mathrm{the}]\}$ famous city, beautiful Leningrad.'

The structure of the noun phrase with the appositive combination can be represented as in (23a), and the structure of the noun phrase with the appositive construction as in (23b).

(23) (a)
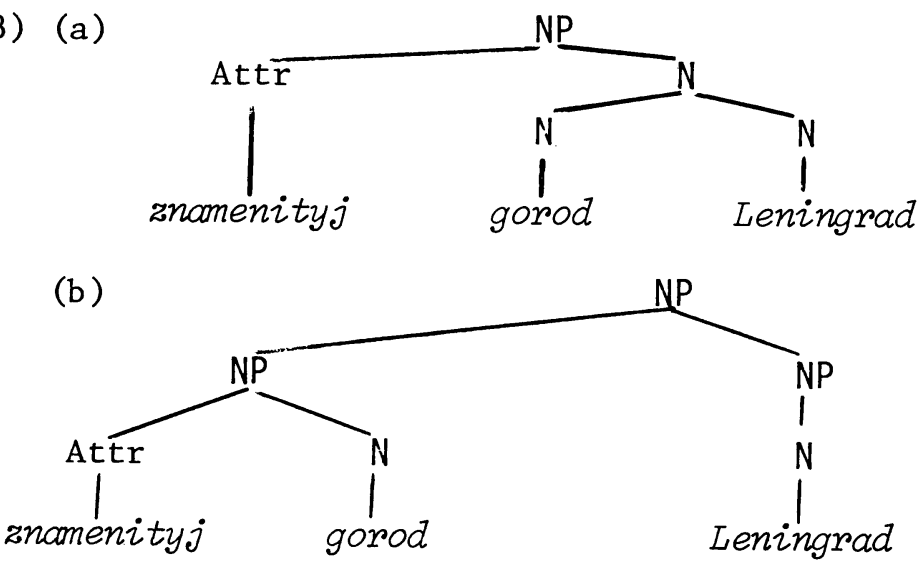

The structure under (23a) is apparently representative of the structure of all composite noun combinations, not only combinations with proper names. The structure of a phrase such as udobnoe kreslo-kacalka 'comfortable rocking-chair,' for example, would be identical. (The intonational unity in combinations of common nouns is pointed out in Šanskij 1967, 5-6).9

In compounds, the component nouns fuse. Compounds are therefore structurally indistinguishable from simple nouns. The structure of a noun phrase with a compound such as brezentovaja plašč-palatka 'tarpaulin poncho-tent' would thus be as shown under (24).

${ }^{9}$ An attributive may evidently also be associated just with the initial component in an appositive combination, as in the configuration below: (cont.) 
(24)

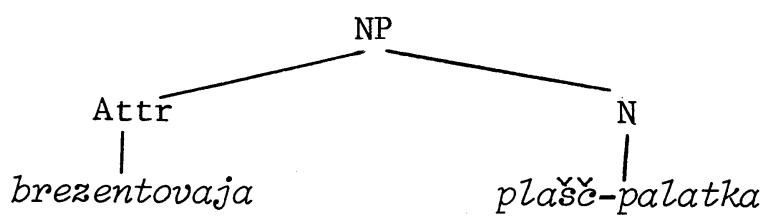

Note that (23a) only represents the surface structure of appositive combinations. In a model of grammar which relates sentences to underlying representations, the underlying representation of combinations with proper names must be different from that of combinations consisting of only common nouns, for the internal relations are obviously different within a combination such as gorod Leningrad '[the] city [of] Leningrad,' for example, and a combination such as kreslo-kačalka 'rocking chair.' Underlying representations of appositive combinations must also be different from those of conjunctive combinations and combinations of other types. The underlying representations of different combinations will not be explored here, however, because the gender manifested in association with different combinations is determined by their surface structure regardless of differences in underlying configurations.

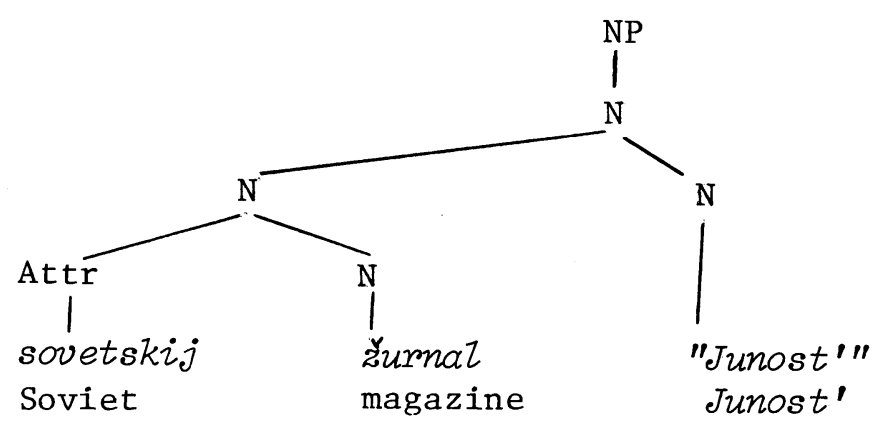

Note that in the concatenation sovetskij žumal "Junost"" 'the Soviet magazine Junost"' there is no intonational break between Zurnal and "Junost". This indicates that the phrase does not have the structure of (23b). On the other hand, the attributive does not seem to apply to the proper name, and the concatenation therefore does not have the structure of (23a). A configuration as above is apparently especially typical in references to animate beings (see pp. 109-110 below). 
As for appositive constructions, they have generally been treated as a consequence of the reduction of appositive relative clauses, but this may be an inadequate account, as indicated by the arguments in Delorme and Dougherty 1972. The gender manifested in association with appositive constructions is the gender of the head noun in the initial noun phrase (cf. (25) below). (This only applies to verbal predicates, since attributive modifiers cannot be associated with appositive constructions in toto [cf. (21b) above].) ${ }^{10}$

(25) Starinnyj centr[masc] Moskvy, Krasnaja plošad'[fem], dolgo byl[masc] odnim iz glavnyx torgovyx mest goroda.

'The old center of Moscow, Red Square, was for a long time one of the main trading spots in the city.'

A different pattern is illustrated by the sentences under (26) ((a) and (b) are from reading passages in Soviet textbooks for foreigners, and (c) is cited in Rozental' 1971a, 219 from the magazine Nedelja).

(26) (a) Starinnyj centr [masc] Moskvy--Krasnaja ploščad' [fem] dolgo byla[fem] odnim iz glavnyx torgovyx mest goroda.

'The old center of Moscow, Red Square, was for a long time one of the main trading spots in the city.'

(b) Vaßnejక̌ee sredstvo[neut] proizvodstva--zemlja [fem]--byZa[fem] sobstvennost'ju feodala.

'The most important means of production--1and-was the property of the feudal lord.'

(c) Bridz [masc], kartočnaja igra [fem], ocen: populjarnaja v Pribaltike, privlekla[femj" Tallin mnogo ljubitelej iz dmugix gorodov strany.

'Bridge, the card game which is very popular around the Baltic Sea, has attracted to Tallin many fans from other cities in the country.'

10 The fact that in sentence (25) it is a copulative verb (byl 'was') which manifests the gender of centr 'center' has no significance, for copulative verbs manifest the gender of subject noun phrases like regular verbal predicates (see Section 4 in Chapter Five below). 
The noun phrases at the beginning of each of the sentences under (26) refer to the same entities (they are coreferential), yet they do not seem to be in apposition, i.e., to be constituents of the same noun phrase, because the verbs in these sentences do not manifest the gender of the head nouns in the initial noun phrases (masculine, neuter, and masculine, respectively). The coreferential noun phrases in the sentences under (26) seem to be related to one another not like the coreferential noun phrases in (25), which are indeed in apposition (cf. the tree diagram under (29) below), but rather like the noun phrases in sentence (27) (cited in Rozental' 1968, 260), whose structure is shown under (28).

(27) Doroga[fem] ot Stavrova, vernee, otsutstvie[neut] dorogi ${ }_{*}^{\text {otrezalo[neut }]}$ otrezala[fem] nas ot nix.

'The road from Stavrov, or rather the absence of a road cut us off from them.'

(28)

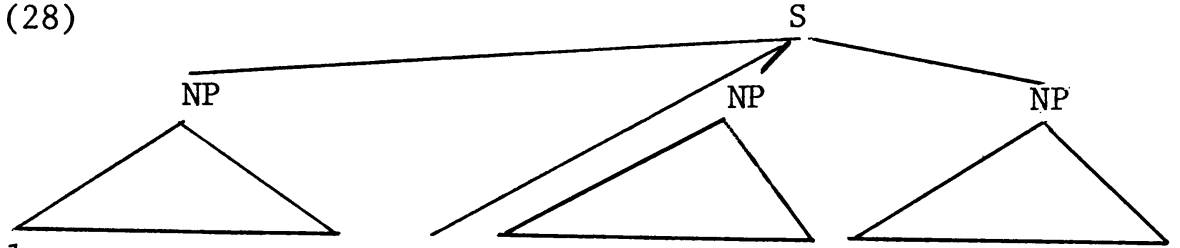

doroga ot Stavrova vernee otsutstvie dorogi otrezalo nas ot nix road from Stavrov rather absence of road cut us off from them

The noun phrases in (28) are constituents of the same sentence, but not of the same noun phrase; they do not constitute an appositive construction. The initial noun phrase can be described as a dislocated subject, and the noun phrase which follows vernee 'rather' is the proper subject of the sentence. The verb can only manifest the gender of the latter noun phrase, i.e., the gender of the head noun in it.

The relationship between the noun phrases at the beginning of the sentences under (26) is not quite like the relationship between the dislocated subject and the proper subject in (27), however, for in the latter sentence the phrase otsutstvie dorogi 'absence of [a] road' constitutes an amendment to the phrase doroga ot Stavrova '[the] road from Stavrov,' whereas in (26) the second noun phrases merely specify the initial ones and do not amend them in 
any way. The noun phrases are indeed coreferential, and in this respect they do not resemble (27) but rather appositive constructions, e.g., (25) above. The surface structure of (25) is perhaps as in (29).

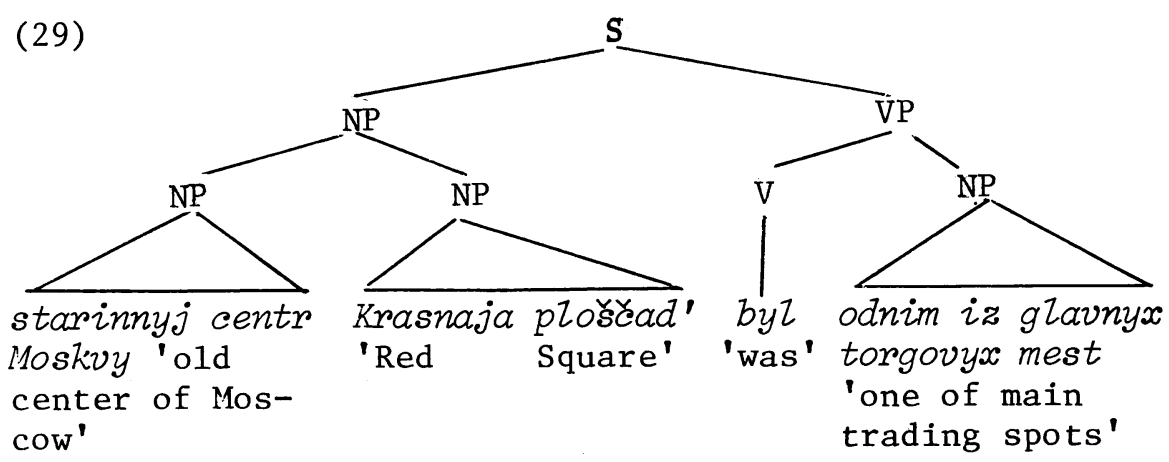

Despite the coreferentiality of the collateral noun phrases in (26), the gender manifestations in (26) indicate a structure such as (28) rather than (29), for in the latter the verb has to manifest the gender of the head noun in the initial noun phrase within the appositive construction. The phenomenon illustrated by (26) can be accounted for by postulating an optional transformation which moves the initial noun phrase in an appositive construction to the position of a dislocated subject, leaving the remaining noun phrase in the appositive construction as proper subject, as shown under (30).
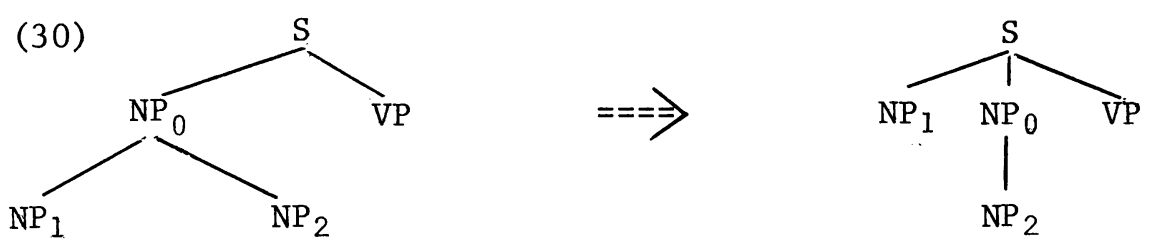

As a consequence of this transformation, a phrase such as starinnyj centr Moskvy 'the old center of Moscow' in (25), for example, can become a dislocated subject and the appositive phrase Krasnaja plošcad' 'Red Square'

becomes its replacement. The verb must then manifest the gender of plošad', as in (26a).

The question whether there is other evidence for the postulated transformation and whether it is applicable to all appositive constructions or subject to certain 
constraints requires further investigation. It should be emphasized, however, that the postulated transformation only applies to appositive constructions, not to appositive combinations. Appositive combinations constitute single nouns and cannot be taken apart.

\subsection{Proper-Name Combinations}

Combinations which function as proper names tend to be treated as compounds but may also be treated as composites. According to Rozental' 1967, for example, the genitive forms of the names of the cities Kzyl-Orda, Sol'-Ileck, and Ust'-Komenogorsk should be, respectively, Kzyl-Ordy, Sol'-Ilecka, and Ust'-Kamenogorska, i.e., these names should be treated as compounds. The proper genitive form for the name of the city Orexovo-Zuevo, on the other hand, is given in Rozental' 1967 as OrexovaZueva, i.e., this name should be treated as a composite. Solzhenitsyn treats the name Alma-Ata in Arxipelag GULag as a composite, writing Almy[gen]-Aty[gen], yet in Rozental' 1967 the genitive form for this name is given as $A$ Ima-Aty [gen]. There are thus variations in usage, though combinations in which the components manifest different gender, like the first three cited in this section, appear to be treated consistently as compounds.

Attributive combinations which function as proper names, e.g., car'-puška 'King Cannon,' or plakun-trava 'willow herb' (1it. 'weeper herb'), are always treated as compound, 1ike regular attributive combinations (see Section 3.2 above; cf. also the comment at the end of Section $3.3)$.

4. Gender in Association with Inanimate Indeclinable Nouns

Indeclinable nouns always have the same form in sentences, regardless of their grammatical number and their relations to other constituents. Indeclinable nouns denoting inanimate entities fall into three classes with respect to grammatical gender. The first class consists of common nouns, e.g., radio 'radio,' taksi 'taxi,' ragu 'ragout'; the second class consists of proper names, e.g., Tokio, Mali, Baku; and the third class consists of abbreviations, e.g., NII<Naueno-issledovatel'skij institut 'scientific research institute,' or ËVM<èlektronnovyčislitel 'naja masina 'electronic computer.' Common nouns 
will be discussed first, then proper names, and then abbreviations.

\subsection{Common Nouns}

While the stems of declinable nouns all end in a consonant (or $\mathrm{J}$ ), the stems of all indeclinable common nouns that denote inanimate entities end in a vowel. They are all borrowed, though they are not necessarily regarded as foreign by Russian speakers (see Panov 1968, 49-55). Some examples: radio 'radio,' metro 'subway,' atel'e 'studio, boutique,' boa 'stole,' ragu 'ragout,' interv'ju 'interview, ' menju 'menu,' taksi 'taxi,' and viski 'whiskey' (for additional examples see, e.g., Stankiewicz 1968, 91-93 or Mučnik 1971, 251-252).

Attributive modifiers and verbal predicates associated with such nouns almost always manifest neuter. The exceptions are very few. The noun avenju 'avenue,' for example, is inherently feminine (cf., e.g., na Pjatoj[fem] avenju 'on Fifth Avenue'), apparently because it is identified with the declinable feminine noun ulica 'street.' The noun taksi 'taxi' is treated by some speakers as inherently masculine, apparently by analogy with the declinable masculine avtomobiz' 'automobile' (Gorbačevič $1971,161)$. Kofe 'coffee' may also be treated as masculine (this is the preferred usage), since its original forms in Russian were $k o f e j$ and $k o f i j$ (on current usage see Lebedeva 1968, 124-126). Other exceptions listed in reference works (see, e.g., Rozental' 1971a, 165) appear to belong in the class of proper names (see Section 4.23 below).

There is no reason to assume that the neuter endings of attributive modifiers and verbal predicates associated with indeclinable inanimate nouns reflect an inherent gender. These neuter endings can be accounted for as a consequence of the fact that indeclinable nouns have no inherent gender.

Neuter is the gender manifested by adjectives of general reference as in (5) above (Staroe[neut] staritsja, molodoe [neut] rastët 'what is old grows older, what is young grows up'), and it is also the gender manifested in association with ad hoc nouns, i.e., words and phrases that do not normally function as nouns and have no inherent gender. This is illustrated in the sentences under (31). 
(31) (a) Pjat' nikak ne delilos'[neut] na tri.

'Five could not be divided by three.'

(b) Zimoj, kogda burovaja vyška rabotaet, dizel' daleko raznosit svoë[neut] nepreryvnoe [neut] $b u-b u, b u-b u, b u-b u$.

'In the winter, when the derrick works, the diesel engine carries its incessant bu-bu, bu-bu, bu-bu far away.'

(c) Razdalos'[neut] gromkoe[neut] "ura".

'A loud "Hurrah" resounded.'

(d) Tvö̈[neut] "ne mešaj" menja razdra‡alo[neut]. 'Your "don't disturb" irritated me.'

Neuter is the gender manifested in association with verb infinitives (as in (32a)) and sentential subjects (as in $(32 \mathrm{~b}))$, and also in sentences in which there is no grammatical subject, as in (33).

(32) (a) Putełestvovat' byzo[neut] moej mečtoj[instr] $s$ rannego detstua.

'To travel was my dream from early childhood.'

(b) A čto glaza xorošie, bylo vidno [neut] dǎ̌e na ètix ljubitel'skix snimkax.

'And that [her] eyes [were] beautiful was evident even in these amateur photographs.'

(33) StemneZo[neut]

'[It] got dark.'

The neuter endings in (31)-(33) are clearly not manifestations of inherent gender. These endings can be accounted for in a formal model of Russian grammar by labelling all NP and VP nodes in underlying structures as [-Masculine, -Feminine], i.e., devoid of positive gender specifications ([Masculine] and [Feminine] are the only gender features in the postulated model; for a discussion of gender feature specifications and feature systems in general see Bierwisch 1967). When an attributive modifier is not associated with any noun, or the noun with which it is associated has no inherent gender, then it receives the negative gender specifications of the dominating NP, and these specifications are manifested as neuter. A verbal predicate receives the negative gender specifications of the dominating VP under similar conditions. In underlying structures which do contain nouns with inherent gender, 
the negative gender specifications on related nodes remain inoperative.

To illustrate, the putative gender specifications in the underlying structure of (1b) (Belaja[fem] čaška polna [fem] 'the white cup is ful1') are shown under (34). 11

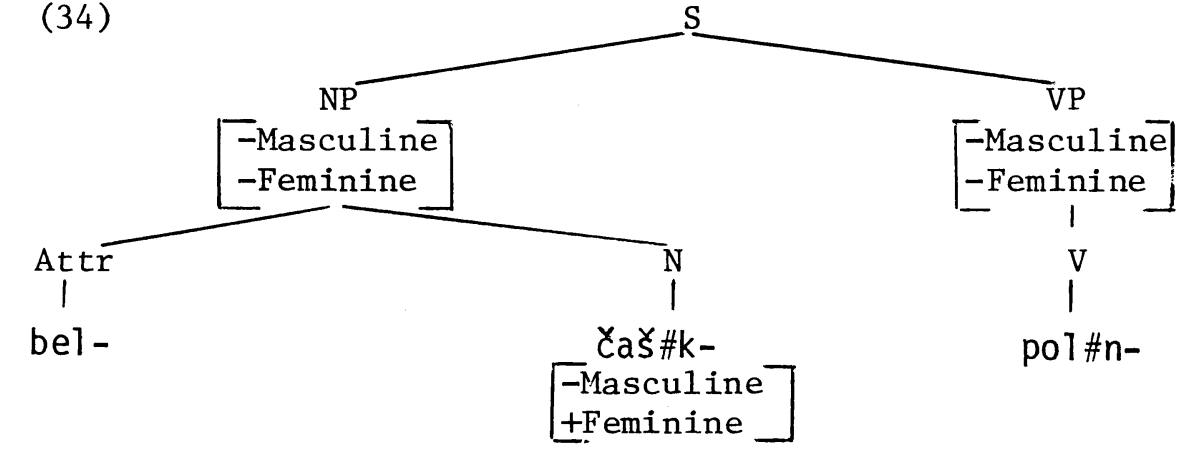

white

cup

fu11

Of the three stems in (34), only the noun stem has gender--feminine, which in terms of feature specifications is represented as [-Masculine, + Feminine]. This is the inherent gender of the noun stem, and it must be copied on to the $\mathrm{N}$ and NP nodes which dominate it. It supersedes the "provisional" features on the NP node, and the gender specifications are then as shown under (35).12

11 The terms "underlying structure" and "underlying representation" are used in reference to any level in the putative derivation of a sentence, not necessarily its ultimate source. The configuration in (34), for example, cannot be considered an ultimate underlying representation of (1b); it represents a shallow level, a late stage in the derivation of the sentence.

The lexical units in this and other underlying structures illustrated in the present work are represented by their stems, which, in order to simplify the presentation, are also not given in their most abstract form.

The symbol 非 in stems represents a fleeting vowel.

12 The processes suggested here are essentially the ones proposed in Vanek 1970 for Czech, though there are some differences. Vanek, for example, proposes that gender features (as well as other features) are not copied but raised from stems to the nodes which dominate them (cont.) 
(35)

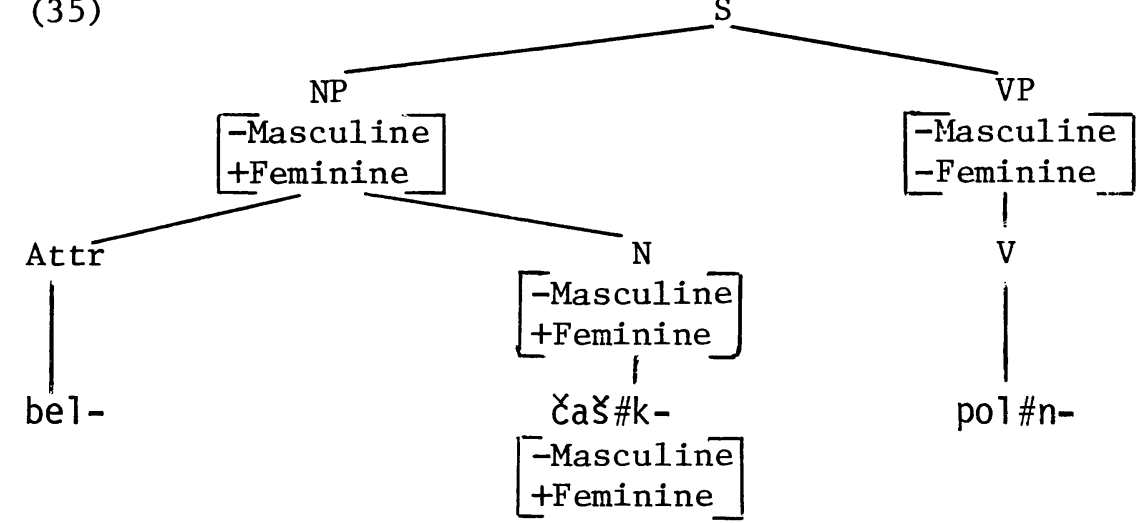

white

cup

ful1

The attributive node and the $\mathrm{V}$ node now have to receive gender specifications for the stems they dominate, and this is accomplished by two processes: Attributive Agreement and Verb Agreement. In Attributive Agreement the gender features of the $\mathrm{N}$ node are copied onto the adjoining Attributive node, and in Verb Agreement the gender features of the NP node are copied onto the $V$ node dominated by the adjoining VP node. The gender specifications are then lowered from the Attributive node and the $\mathrm{V}$ node to the respective stems and realized by the appropriate

(see esp. p. 44). Since in the present account the declension of nouns is determined by their gender and since raising the features would leave stems without their gender, Vanek's proposal cannot be adopted--unless declension paradigms are to be specified before raising. Having gender features copied rather than raised renders this condition unnecessary. Another difference is that Vanek proposes negative gender features for $\mathrm{N}$ and NP nodes, not for VP nodes (pp. 6 and $15[\mathrm{n} .8]$ ). This would not account for the neuter endings of verbal predicates not associated with any noun phrase (in terms of constituent structure, verbal predicates dominated by a VP node which has no NP node marked [Nominative] as a sister constituent). A neuter ending as in (33), for example, would not be accounted for. (To account for the fact that the endings in sentences like (33) are singular, it will be suggested below that NP and VP nodes also bear a negative number specification.) 
endings. The negative gender features on the VP node remain inoperative. 13

In the derivation of (33) (Stemnelo[neut] '[it] got dark'), the negative gender features on the VP node do not remain inoperative. Whatever the ultimate source of this sentence, at the derivational stage where the $\mathrm{V}$ node must receive gender specifications the configuration must be as in (36) (with irrelevant details not shown).

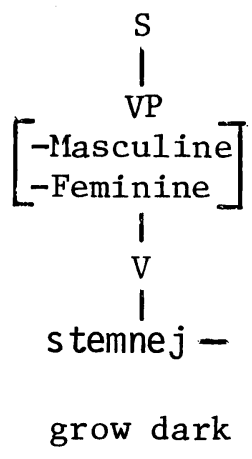

13 This whole procedure must take place whether the gender features can be realized by a distinct ending or not. (See Babby 1976 for a discussion of the disadvantages of an alternative approach, according to which Agreement would only involve in each particular operation the features which would have a surface manifestation. For a survey of traditional approaches to the phenomenon of agreement and more recent ones, where it is viewed as a process of feature copying, see Dingwall 1969.)

Babby (1973a and 1975) argues for a theory according to which there is only one process of agreement, SubjectVerb Agreement, and attributive modifiers assume the features of the nouns with which they are associated by Subject-Verb Agreement before they are moved to attributive position from the position of underlying verbal predicates in relative clauses. However, Subject-Verb Agreement cannot account for the features manifested by attributive modifiers which cannot derive as verbal predicates in relative clauses, e.g., èta in èta[fem] ̌̌ałka 'this cup' (cf. *caska, kotoraja èta 'the cup which is this') or glavnaja in glavnaja[fem] pricina '[the] main reason' (cf. *pričina, kotoraja glavna 'the reason which is main'). A process of Attributive Agreement thus cannot be dispensed with. In the present monograph it is assumed that (cont.) 
The $\mathrm{V}$ node cannot receive gender specifications through Verb Agreement, since there is no NP to provide such specifications. In this case, the VP node supplies specifications instead.

Now consider (37), where the subject noun, atel'e 'studio,' is an indeclinable noun.

(37) Beloe[neut] atel'e polno[neut].

'The white studio is full.'

There is no evidence that the neuter endings of the attributive and the predicate in (37) represent an inherent gender of the noun, for in distinction from declinable nouns, whose gender can be manifested by at least some of their endings (exceptions are discussed in footnote 1 in Chapter Two)--atel'e cannot manifest gender. The neuter endings manifested in association with this noun can be accounted for as simply realizations of the "provisional" gender specifications. When Attributive Agreement and Verb Agreement apply in the underlying representation of (37), the gender specifications would be as shown in (38).

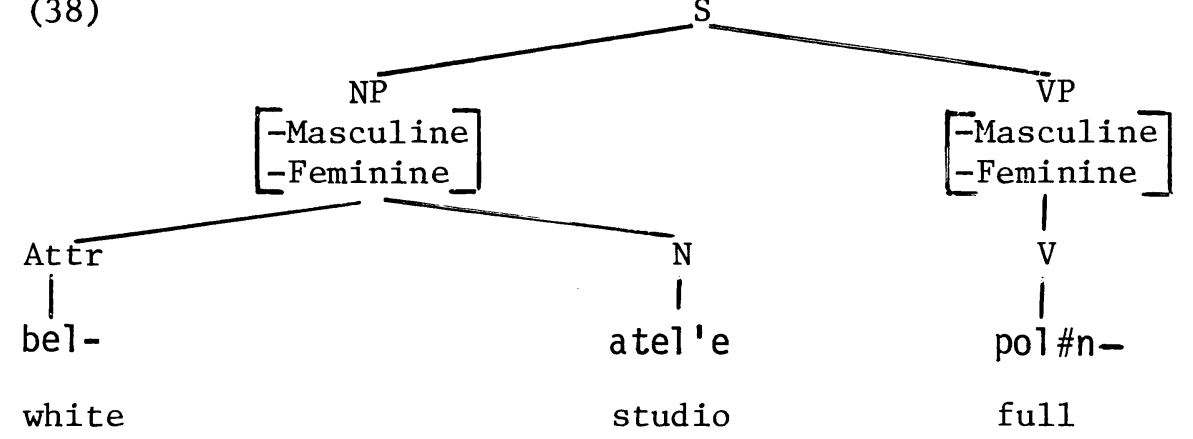

The negative specifications on the VP node remain inoperative, for Verb Agreement provides the $\mathrm{V}$ node with the "provisional" gender specifications of the NP node.

attributive modifiers undergo Attributive Agreement, whether they derive from underlying verbal predicates or not. (Even if all attributive modifiers could be shown to derive as verbal predicates, there would still be problems with Babby's theory. One problem is pointed out by Babby himself in Babby 1973b.) 
The Attributive node, on the other hand, cannot receive gender from the $\mathrm{N}$ node through Attributive Agreement, for no specifications had been copied from the noun stem onto this node. Gender specifications for the Attributive node must come from the NP instead.

This procedure can be assumed to take place in association with any inanimate indeclinable common noun, with the exception of the few indeclinable nouns which do have inherent gender, e.g., avenju 'avenue,' which must be considered inherently feminine, for the feminine gender manifested in association with it can have no other source. Entries in the lexicon for the great majority of inanimate indeclinable common nouns need not include gender specifications. 14

14 There are thus three possible sources for a neuter ending when it is manifested by a verbal predicate: the inherent gender of the head noun in the subject phrase (as in, e.g., Vedërko polno[neut] 'the bucket is full'); (2) the "provisional" gender specifications of the VP node (as in Stemnelo[neut] 'it got dark'); and (3) the "provisional" gender specifications of the NP node (as in Atel'e polno[neut] 'the studio is full' or Razdalos'[neut] "ura" 'a "Hurrah" resounded'). It is noteworthy that there are predicates which have two different neuter endings--one stressed, one unstressed--to distinguish the source of the gender. Compare, for example, (i) and (ii).

(i) Stalo[neut] svetló[neut]. 'It got light.'

(ii) Svétzo[neut] nebo $v$ den' inoj...;

In (i), where the source of the gender is the VP node, the ending is stressed (svetló); in (ii), where the predicate manifests the gender of the subject noun, the ending is unstressed (svét $\left.{ }^{\circ}\right)$. Another predicate in this category is dolY\#n- 'necessary,' which has an unstressed neuter ending when the source is a VP node (dólzno), a stressed neuter ending otherwise (dolæro) (see Chvany 1974, 116 [n. 18] and Chvany 1975, 213 [n. 1-27] and 275-276 [n. 4-34]). 
4.2 Proper Names

4.21 The gender manifested in association with indeclinable proper names for inanimate entities distinguishes them from indeclinable common nouns. Consider, for example, the sentences under (39).

(39) (a) Tokio sil'no razrossja[masc] $v$ poslednee vremja. 'Tokyo has grown a lot lately.'

(b) Dvenadcat' let Tobago byz[masc] Zatvijskim vZadeniem.

'For twelve years Tobago was a Latvian possession.'

(c) Kongo široko razlilas'[f em].

'The Kongo overflowed extensively.'

(d) "Jumanite" dva‡dy napominala [fem] čitateljam ob ètix vyvodax.

'Humanité reminded its readers twice about these findings.'

The verbs in (39a) and (39b) have masculine endings, and the verbs in (39c) and (39d) have feminine endings. Kongo and Jumanite in (39c) and (39d), however, do not seem to share any features which distinguish them from Tokio and Tobago in (39a) and (39b). The sources of the feminine endings in (39c) and (39d) are indeed the generic designations for Kongo and Jumanite--the feminine nouns reka 'river' and gazeta 'newspaper,' respectively. The generic designations for Tokio and Tobago are gorod 'city' and ostrov 'island,' respectively, both of which are inherently masculine, and this is why the verbs in (39a) and (39b) have masculine endings. Constituents associated with indeclinable proper names thus manifest the gender of their generic designations. (For some additional examples see, e.g., Rozental' 1971a, 166-167.)

This phenomenon can be most adequately accounted for by deriving proper names from composite combinations in which the first element is their generic designation (cf. Sections 3.1 and 3.3 above). The subject nouns in the underlying structures of the sentences under (39) would then be, respectively, gorod Tokio 'the city of Tokyo,' ostrov Tobago 'the island of Tobago,' reka Kongo 'the Kongo river,' and gazeta "Jumanite" 'the newspaper Humanite.' The inherent gender specifications of the common nouns in these composite combinations must be copied onto the $\mathrm{N}$ and NP nodes which dominate the 
combinations before the common nouns are deleted (optionally). The initial and final stages of this process are illustrated under (40).

(40)

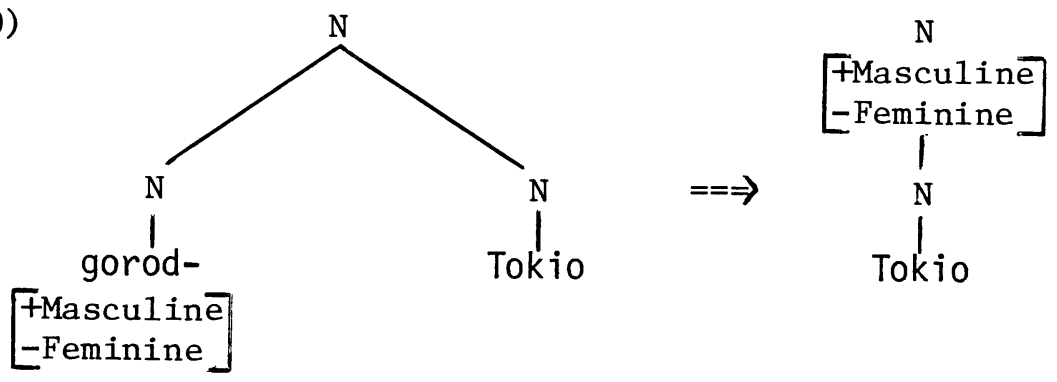

The sentences under (39) demonstrate the consequences of this process.

4.22 Declinable proper names must also derive from composite combinations, for otherwise it would be difficult to account for the fact that only indeclinable proper names derive from such combinations. A sentence such as (6a) (Moskva osnovana[fem] $v 1147$ godu 'Moscow was founded in $\left.1147^{\prime}\right)$, accordingly, should derive from a structure in which Moskva is the second element in the composite gorod Moskva 'the city of Moscow.' However, the predicate in (6a) manifests the gender of Moskva, not the gender of gorod (cf. (15a): Gorod Moskva osnovan[masc]/*osnovana [fem] $v 1147$ godu 'the city of Moscow was founded in $\left.1147^{\prime}\right)$. Why, then, does the predicate in (6a) manifest the gender of Moskva, and in (39a), where the proper noun is indeclinable, it manifests the gender of gorod?

We can assume that the process illustrated under (40) takes place also in the derivation of (6a), as shown under (41).

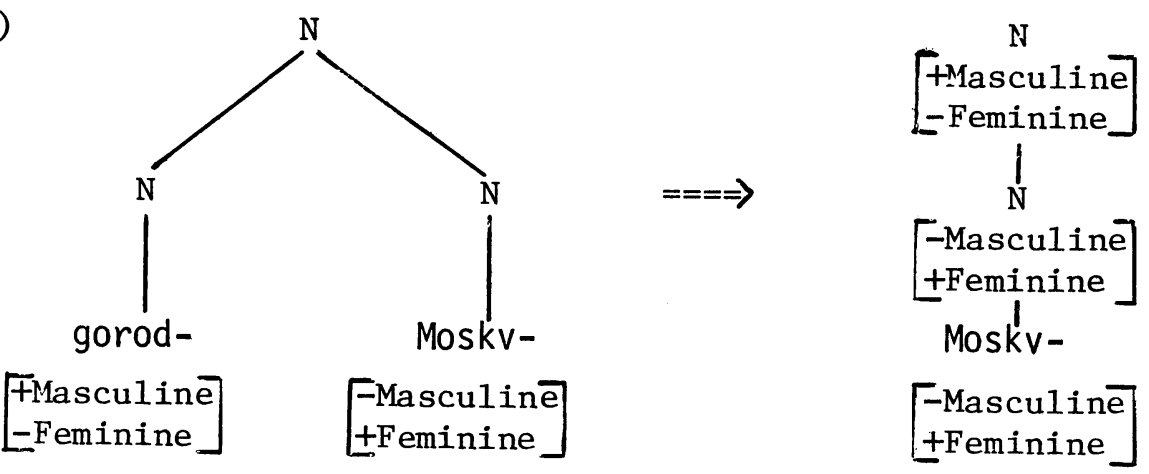


In (41), in distinction from (40), deletion of the generic noun results in a structure in which the gender specifications on the superordinate $\mathrm{N}$ node conflict with specifications on the $\mathrm{N}$ node it dominates. This conflict must trigger a mechanism which adjusts the specifications on the higher $\mathrm{N}$ node to match the lower specifications-in other words, to match the inherent gender of the proper noun. Consequently, the gender manifested in association with declinable proper names is their inherent gender, whereas in association with indeclinable proper names, which have no inherent gender, the manifested gender is that of their generic designation. (In phrases such as provincija Verxnee[neut] Kongo '[the] province [of] Upper Congo' or reka Lakskoe[neut] Kojsu '[the] river Laksian Koysu,' the generic designations precede an attributive modifier which constitutes part of the proper name and it therefore manifests neuter rather than the feminine gender of the generic noun; cf. the comments [and somewhat contradictory recommendations] in Superanskaja 1969, 112.)

4.23 One of the formal properties which distinguish declinable proper names from declinable common nouns is that the former may remain uninflected under certain conditions. As noted in Section 3.3 above, declinable proper names which follow common nouns in appositive combinations must remain uninflected unless they are place names, and place names also remain uninflected in many cases. Potentially declinable proper names may also remain uninflected when they occur independently, if they are inherently neuter Russian place names such as Vnukovo, Seremet'evo, Razino, or Puškino (in current colloquial usage; see, e.g., Panov 1968, 56-61 or Mučnik 1971, 272-276, and also Krysin 1974, 187-193), or if they are foreign names, e.g., the names of the magazines Tajm and Bjuxerpost, or the names of the newspapers Unita, Tajms, and Mond (such foreign names are inflected in colloquial usage, but Russian grammarians refer to them as indeclinable; cf., e.g., Vomperskij 1962, 181-182 and Rozental' 1968, 87-88 and 94). (Note that the gender manifested in association with inherently neuter Russian place names remains neuter even when they are not inflected, but the gender manifested in association with foreign names that are not inflected is the gender of their generic designations. The gender manifested in association with Tajm, for instance, is masculine--the gender of 'curnal 'magazine,' and the gender 
manifested in association with Tajms is feminine--the gender of gazeta 'newspaper' [cf. Vomperskij, ibid. and Rozental', ibid.].)

Hence if a potentially declinable noun (a noun whose stem does not seem to end in a vowel) occurs with a nominative ending in a construction in which another noun would have an oblique case ending, this noun can be identified as a proper noun, i.e., its entry in the lexicon can be assumed to include the specification [-Common]. By this criterion, for example, names of species can be identified as proper nouns, for in combinations with generic designations they may remain uninflected (e.g., formirovanie volokna[gen] kapron 'the formation of the fiber kapron'; see Section 3.3 above).

Another possible criterion for distinguishing proper from common nouns only applies to nouns whose stems end in a vowel. This criterion is based on the fact that the gender manifested in association with indeclinable proper names for inanimate entities is the gender of their generic designations, whereas the gender manifested in association with common indeclinable nouns denoting inanimate entities is neuter. Consider (42).
(42) (a) Oni izucajut sovremennyj[masc] suaxizi. 'They are studying Modern Swahili.'
(b) Beri-beri svjazana[fem] s pitaniem "polirovannym" risom.
'Beriberi is related to a diet of polished rice.'
(c) Ol'ga kupila vkusnyj[masc] suluguni.
'0lga bought [some] tasty Suluguni [=kind of cheese].'

The gender manifested in association with suaxili 'Swahili' in (42a) is the gender of jazyk 'language'; in $(42 \mathrm{~b})$, the gender of the predicate is determined by bolean' 'disease'; and in (42c) the gender manifested by vkusnyj 'tasty' is the gender of syr 'cheese' (cf. also the discussion in Unbegaun 1947, 138 and Rozental' 1971a, 165). Sentences such as the ones under (42) can be taken as evidence that names of languages, diseases, and kinds of cheese are proper names in Russian grammar, even though orthographically they are indistinguishable from common nouns (i.e., they are not capitalized).

Negative evidence is provided by the gendermanifested in association with names of letters of the alphabet (i.e., $a$, bè, vè, gè, dè, etc.), the names of musical notes (do, 
re, $\left.m i, f a, s o l ', Z_{j a}, s i\right)$, and names of dances (e.g., ča-ða-ða 'cha-cha-cha,' tango 'tango,' bugi-vugi 'boogiewoogie'). The gender manifested in association with names in these categories is not the gender of their generic designations (bukva 'letter,' nota 'note,' and tanec 'dance,' respectively), but rather neuter--the gender manifested in association with common indeclinable nouns. (Interestingly enough, names of dances are also not distinguished as proper names in English orthography, that is, they are not capitalized, although names of languages and kinds of cheese are.)

There is no consistency in the treatment of nouns within certain categories as proper names, however. The indeclinable èsperanto, for example, is sometimes treated as a proper name, like names of other languages, and sometimes as a common noun: the gender manifested in association with èsperanto may be the gender of jazyk 'language' (masculine), or neuter (cf. Rozental' 1971a, 165). Similarly, the names of the dances pa-de-de 'pas de deux' and pa-de-trua 'pas de trois' may be treated not only as common nouns, like names of other dances, but also as proper names, in which case the gender manifested in association with them is masculine--the gender of tanec 'dance' (cf. Rozental', ibid.).

4.24 Proper names are not necessarily always combined with the same generic designations. Consequently, the gender manifested in association with a proper name may vary. For example, the generic designation combined with Missisipi may either be reka 'river,' which is a feminine noun, or కtat 'state,' which is a masculine noun. The generic designation combined with Mali may either be strana 'country,' which is feminine, or gosudarstvo 'state,' which is neuter--as illustrated in (43a) and (43b) (both from Rozental' 1971a, 166).

(43) (a) Mali doľ̈na[fem] rasšityvat' preimušestvenno na dve osnovnye otrasti èkonomiki.

'Mali has to rely chiefly on two basic industries.'

(b) Mali prisoedinilos'[neut] $k$ rezoljucii. 'Mali joined the resolution.'

Different genders in association with the same proper names also occur in association with names which consist of phrases that do not contain a noun in the nominative 
case and names which consist of whole sentences, e.g., $N a$ dne [1oc] 'At the Bottom' (known in English as "The Lower Depths"), Mnogo šuma[gen] iz ničego 'Much Ado about Nothing,' and Ne brani menja, rodnaja 'Do not scold me, dear' (the first two are plays, the last one--a song). Such names are sometimes treated as proper names, in which case the gender manifested in association with them is the gender of their generic designation, e.g., p'esa 'play,' pesnja 'song,' and sometimes they are treated as ad hoc common nouns, in which case the gender manifested in association with them is neuter (cf. Section 4.1 above). The latter is the more typical treatment for such names (cf. Rozental' 1971a, 224; Peshkovksy asserted that agreement with names of "plays, dramas, comedies, vaudevilles, farces, etc." could never be determined by their commonnoun definitions [Peškovskij 1956, 203], but according to Vinogradov and Istrina 1960, 512 and Skoblikova 1971, 188 this is not so, at any rate not in current usage). 15

15 In substandard usage, indeclinable proper names are not always treated as such. Non-Russian names with stems ending in $i$, for example, may be treated as declinable, inherently plural nouns, with the $i$ identified as nominative plural ending (e.g., names such as Soči, Saki, Mali; cf. Zaliznjak 1967a, 217 and Rozental' 1971a, 166). Attributives and predicates then receive plural endings and do not manifest the gender of generic nouns (on inherently plural nouns see Chapter Two).

In standard usage, the endings of attributives and predicates associated with indeclinable proper names do not always manifest the gender of generic nouns either, for proper names may be used as common nouns on occasion, and then the gender manifested in association with them is neuter, as in association with common nouns which have no inherent gender. Compare, for example, Francija prevrašcaetsja $v$ ogromnoe[neut] tikago' 'France is turning into an enormous Chicago' (the generic noun for t $\rangle_{i k a g o}$ would be the masculine gorod 'city'; this example is from Rozental' 1971a, 166, where it is classified as a "deviation," but it is clearly well-motivated). 
4.3 Abbreviations

The composition of abbreviations is discussed in Section 4.31 and the gender manifested in association with them is discussed in Section 4.32. Section 4.33 deals with transitional cases, and non-Russian abbreviations are the subject of Section 4.34.

4.31 The great majority of indeclinable abbreviations are acronyms, that is, clusters made up either wholly or partially of initial letters (for a historical survey of the use of the term "acronym" see Borisov 1972, 169-172). A cluster wholly made up of initial letters is, for example, GSSR<Gmizinskaja Sovetskaja Socialisti eskaja Respublika '[the] Georgian Soviet Socialist Republic.' A cluster partially made up of initial letters is LitSSR< Litovskaja Sovetskaja Socialističeskaja Respublikka '[the] Lithuanian Soviet Socialist Republic,' where Litovskaja 'Lithuanian' is not represented by its initial letter but rather by a whole syllable: Lit.

Acronyms fall into three categories with respect to declension. The first subsumes acronyms pronounced letter by letter, e.g., SSSR ([èsèsèsèr]) 'USSR' or VDNX ([vèdènxa])<Vystavka dostizenij narodnogo xozjajstva 'Exhibition of Economic Achievements.' Acronyms pronounced letter by letter do not decline. Only in isolated cases can such acronyms be declined colloquially, provided they end in a consonant phonologically or in a--e.g., SSSR ([èsèsèsèr]) 'USSR,' èrès<reaktivnyj snarjad 'rocket mortar,' CK ([ceka])<centraz'nyj komitet '[The] Central Committee.' The declension of such acronyms, however, is a very marginal phenomenon (cf. Alekseev 1966, 33 and Panov 1968, 64-65).

The second category subsumes acronyms which end in a vowel and are pronounced as words, e.g., SMU<stroitel'nomontažnoe upravlenie 'building and construction administration,' SSA ([š̌a])<Soedinënnye Štaty Ameriki 'USA,' NII <naučno-issledovatel'skij institut 'scientific research institute,' and rono<rajonnyj otdel narodnogo obrazovanija 'District Office of the Ministry of Education.' Such acronyms also do not decline, apparently quite consistently (see, e.g., Panov 1968, 60).

The third category subsumes acronyms which end in a consonant and are pronounced as words. Such acronyms, though potentially declinable, often do not decline either. When they do decline, they are indistinguishable 
from regular declinable nouns: they follow the masculine variant of the First Declension and are treated as inherently masculine (e.g., vuz[masc]<vyš̌ee učebnoe zavedenie [neut] 'institution of higher education,' zags [masc]<zapis' [fem] aktov grazdanskogo sostojanija 'Registry Office,' GIZ[masc] <gosudarstvennoe izdatel'stvo[neut] 'State Publishing House,' BAM[masc]<Bajkalo-Amurskaja magistral' [fem] 'The Bayka1-Amur Railroad,' and GULag[masc]< GLavnoe upravlenie ispravitel'no-trudovyx lagerej 'Chief Administration of Corrective Labor Camps'). It seems that the prevalent tendency is to decline acronyms which end in a consonant (see, e.g., Alekseev 1966; Gorbačevič 1971, 163168; and Rozental' 1971b, 107), though there is no consensus among Russian grammarians on this point and some claim that the prevalent tendency is not to decline such acronyms (see Šanskaja 1964b and Panov 1968, 60-64 or Mučnik 1971, 276-280).

A small number of indeclinable abbreviations are not acronyms but rather abbreviations formed by truncation. There are two types within this category. The first is best illustrated by Glavsevmorputi<Glavnoe upravlenie Severnogo morskogo puti 'Central Administration of the Northern Sea Route,' which consists of three truncated stems (glav, sev, mor) and a full noun in the genitive case (puti 'route'). All abbreviations of this type end in a full noun with an oblique case ending and this is why they cannot decline. The second type of abbreviations formed by truncation is used in brand names, e.g., TU-104 (for Tupolev airplanes), SU-2 (for Sukhoy airplanes), and MI-8 (for Mil helicopters). There do not seem to be many truncations of this type and it is therefore difficult to generalize. The three illustrated in this paragraph are treated as masculine, but it is not clear whether this is because masculine is the gender of the full names (Tupolev, Suxoj, and Mil') or because it is the gender of the generic designations scomolët 'airplane' and vertolët. 'helicopter.' Abbreviations of this type are excluded from the discussion below. 16

${ }^{16} \mathrm{Also}$ excluded is the unique abbreviation $g a$ for gektar 'hectare.' The gender manifested in association with ga (which is indeclinable) is the gender of the source noun gektar--masculine. 
4.32 The gender manifested in association with indeclinable abbreviations is the gender of the head noun in their source phrase, as illustrated in the sentences under (44).

(44) (a) Pervaja[fem] ÈVM [<èzektronno-vyčislitel'naja mašina(fem)] byla[fem] sozdana[fem] $v$ SŠA.

'The first electronic computer was built in the USA.'

(b) V Lenigrade byla[fem] znomenitaja[fem] ŠKID [<skola (fem) imeni Dostoevskogo].

'In Leningrad was the famous Dostoevsky School.'

(c) V $1940 \mathrm{~g}$. MGU [<Moskovski.j gosudarstvennyj universitet (masc)] byz [masc] nagrazden [masc] ordenom Lenina. 17

'In 1940 Moscow State University was awarded the Order of Lenin.'

(d) Rono [<rajonnyj otdel (masc) narodnogo obrazovanija] zakryt [masc].

'The district office of the Ministry of Education is closed.'

(e) Pozdno večerom pjatogo sentjabrja slučilos' [neut] CP [<̌̌rezvyčajnoe proisšestvie(neut)].

'Late at night on the 5th of September an unusual happening occurred.' (For some observations on ¿P 'unusual happening' see Bragina 1973, 175.)

Indeclinable abbreviations can be viewed as reductions of underlying phrases, with the processes of gender assignment applying before reduction. This would account for the gender manifestations in sentences such as (44) without postulating new processes or an idiosyncratic class of indeclinable nouns.

4.33 Indeclinable abbreviations may assume an independent identity and become dissociated from the source phrases. They then become regular nouns. If they end in a consonant, they come to be treated as declinable, inherently masculine nouns (on the correlation between

${ }^{17}$ As noted in Alekseev 1963b, 151, the acronym MGU no longer represents the official name for Moscow University, which is now Moskovskij ordena Lenina gosudarstvennyj universitet imeni V.M. Lomonosova. 
declinability and inherent gender see Alekseev 1963a, 5 and 19; Alekseev 1966, esp. 30-35; and also Rozental' 1971a, 223-224). For example, MID<ministerstvo inostrannyx del 'Ministry of Foreign Affairs' is treated not only as an indeclinable abbreviation, in which case the gender manifested in association with it is neuter, the gender of ministerstvo 'ministry,' but also as a declinable masculine noun (cf. Alekseev 1963a, 6; Alekseev 1966, 32-33; and Gorbačevič 1971, 164). The abbreviation GESS<

gidroèlektričeskaja stancija 'hydroelectric power station' is normally indeclinable and the gender manifested in association with it is feminine, the gender of stancija 'station,' but it may occasionally be treated as a declinable masculine noun, e.g., na Kujbysevskom[1oc (masc)] GESe[1oc] 'at the Kuybyshev hydroelectric power station' (cited in Skoblikova 1967, 44).

Indeclinable abbreviations which end in a vowel become devoid of gender when they assume an independent identity. In other words, the gender manifested in association with them is then neuter (cf. Alekseev 1963b, 152; Alekseev 1966, 31; Sanskaja 1964b, 67-68; and GorbačeviC 1971, 164-165). For example, the gender manifested in association with rono<rajonnyj otdel narodnogo obrazovanija 'district office of the Ministry of Education' is generally masculine, as in (44d) above, but may also be neuter (see, e.g., Šanskaja 1964b, 68; Gorbačevič 1971, 164-165; and Rozental' 1971a, 167). Similarly, GAI<gosudarstvennaja avtomobil'naja inspekcija 'State Motor Vehicle Inspection Office' may be treated as a regular noun, and the gender manifested in association with it is then neuter rather than feminine--the gender of inspekcija 'inspection,' the head noun in the source phrase (cf., e.g., Gorbačevič 1971, 165).

The gender manifested in association with indeclinable abbreviations treated as regular nouns is thus masculine if they become declinable, neuter otherwise.

4.34 Non-Russian indeclinable abbreviations can only be treated as regular nouns, because their source phrases are in a foreign language. In most cases they are treated like proper names and the gender manifested in association with them is the gender of their generic designations, as illustrated in (45).

(45) (a) JUNESKO prislala[fem] svoego predstavitelja. 'UNESCO has sent its representative.' 
(b) V 1929 godu TPK byla[fem] pereimenovana[fem] $v$ "Irak petroleum kompani" (IPK).

'In 1929 the TPC [Turkish Petroleum Company] was renamed "Iraq Petroleum Company" (IPC).'

(c) "ĎE" pričastna[fem] i k kul'turnym kontaktam. 'G.E. is also involved in cultural contacts.'

(d) Bi-bi-si sama[fem] prodemonstrirovala[fem] èto. 'The BBC itself has demonstrated this.'

The predicate in (45a) manifests the gender of organizacija 'organization,' in (45b) and (45c) the predicates manifest the gender of kompanija 'company,' and in (45d) the manifested gender is that of korporacija 'corporation.'

However, non-Russian indeclinable abbreviations, especially names of organizations and federations whose generic categories are not clear, may also be treated as common nouns. The gender manifested in association with them is then neuter, for they are devoid of inherent gender. This applies to JUNESKO 'UNESCO,' to Bi-bi-si 'BBC' (1isted as neuter in Kotelova and Sorokin 1971), to NATO, SEATO, NASA, FIA (<Fédération Internationale de l'Automobile), and to FISU (<Fédération Internationale des Sports Universitaires) (cf. Alekseev 1966, 35; Rozental' 1971a, 224; and Gorbačevic 1971, 166).

Note that non-Russian abbreviations can also be translated into Russian abbreviations. The FBI, for example, is $F B R<F e d e r a l$ 'noe bjuro rassledovanij 'Federal Bureau of Investigations' and its gender is the gender of bjuro 'bureau.' The CIA also has a Russian equivalent-CRU<Central'noe razvedyvatel'noe upravlenie 'Central Intelligence Administration,' and the gender manifested in association with this abbreviation is determined by upravlenie 'administration.'

This concludes the discussion of gender manifestations in association with nouns denoting inanimate entities.

5. Gender in Association with Sex-differentiating Animate Nouns

Sex-differentiating animate nouns are nouns which denote either males or females exclusively. The gender manifested in association with such nouns corresponds to the sex of the beings they denote: it is masculine in association with nouns denoting males, feminine in 
association with nouns denoting females. If the meaning of nouns is assumed to be represented in the lexicon as a complex of semantic features which include <tmale> for nouns denoting males and <-male> for nouns denoting females, then the gender of nouns marked either <tmale> or <-male> need not be specified, for it is predictable from the sex specifications (the semantic features of nouns are given in angular brackets in order to distinguish them from grammatical features, e.g., gender features, which are given in square brackets).

What follows is a brief survey of the relationship between the gender of sex-differentiating animate nouns and their declension paradigm, the gender manifested by their nominative singular endings. Declinable common nouns are considered first, then declinable proper names, then indeclinable common nouns, and finally, in Section 5.4 , indeclinable proper names.

\subsection{Declinable Common Nouns}

Declinable common nouns which must be marked in the lexicon <thuman, tmale> are, for instance, the nouns djadja 'uncle,' francuz 'Frenchman,' korol' 'king,' and krasavec 'handsome man.' Declinable common nouns marked <tanimate, -human, +male> are ¿erebec 'stallion,' kot 'tomcat,' kozël 'billy-goat,' and borov 'hog.' Declinable common nouns marked <thuman, -male> are tëtja 'aunt,' francuzenka 'Frenchwoman,' koroleva 'queen,' and krasavica 'a beauty,' and declinable common nouns marked <tanimate, -human, -male> are kobyla 'mare,' gusynja 'female goose,' verbljudica 'she-came1,' and slonixa 'she-elephant.'

The great majority of nouns denoting females end in feminine suffixes (cf. Mučnik 1971, 212) and hence follow the Second Declension. The few nonsuffixed nouns which denote females also follow the Second Declension, with very few exceptions (essentially the <thuman> nouns doc' 'daughter,' mat' 'mother,' bogomater' 'Mother of God,' svekrov' 'husband's mother,' and mamzel'/mademuazel' 'mademoiselle' [cf. Galkina-Fedoruk 1964, 34-35]). Thus the nominative singular forms of nouns denoting females almost always manifest their gender (for they end in a), in distinction from inanimate nouns of the same gender, of which a considerable proportion follow the Third Declension and end in $\emptyset$ in the nominative singular.

Nouns denoting males differ from inanimate masculine nouns in that they do not necessarily follow the masculine 
variant of the First Declension: there are some <+human, tmale> nouns which follow the Second Declension, e.g., papa 'papa,' djadja 'uncle,' mižina 'man,' junosa 'young man,' sluga 'manservant,' and paša 'pasha.' The fact that these nouns follow the Second Declension is an idiosyncratic feature and as such must be specified in the lexicon in the entries for these nouns.

All <tmale> nouns not specified as following the Second Declension follow the masculine variant of the First Declension--unless modified by nonmasculine affective suffixes. When modified by feminine or neuter affective suffixes, they follow the Second Declension or the neuter variant of the First Declension, respectively. Unlike inanimate masculine nouns, however, whose gender may shift to feminine when modified by the feminine affective suffix -in-, <+male> nouns always remain masculine-whether modified by $-i n$ - or by any other affective suffix, e.g., bednyj[masc] starik/staričina/starikaška 'poor old man,' bol'noj[masc] ded/dedka/deduška/dedusja 'sick grandfather,' and besstydnyj[masc] paren'/parniška/parnjugal parniscé 'shameless fellow.' (Note that while inanimate masculine stems only take one feminine affective suffix, -in-, <tmale> stems take quite a few, and while inanimate masculine stems take three neuter affective suffixes [-ǐ̌č-, $-i \check{s} k-$, and $-u \check{s} k-]$, <tmale> stems only take one [-išč-]; for lists of affective suffixes and illustrations of nouns modified by such suffixes see Stankiewicz 1968, 97-142 and Potixa 1970, 247-259.)

Finally, there are also sex-differentiating nouns which follow the adjectival paradigm, all <thuman>. Nouns which denote males in this category are, for example, musskij 'Russian man,' znakomyj 'male acquaintance,' slepoj 'blind man,' and sumasšedsij 'madman.' The <-male> counterparts of these nouns are musskaja 'Russian woman,' znakomaja 'female acquaintance,' slepaja 'b1ind woman,' and sumaš̌edsaja 'madwoman.'

Assuming that such forms are not adjectives which simply manifest the gender of deleted nouns but rather bona fidenouns, there are two possible approaches to the fact that only case endings distinguish nouns denoting females from their <tmale> counterparts. According to one approach, the gender manifested by the endings is determined by contextual factors and the stems are asexual and have no inherent gender. According to this approach, forms such as znakomyj 'male acquaintance' and znakomaja 'female acquaintance,' for example, both represent the 
same stem, znakom-, which has no specified sex feature and no gender. According to the other approach, which seems somewhat preferable, forms such as znakomyj 'male acquaintance' and znakomaja 'female acquaintance' or russkij 'Russian man' and musskaja 'Russian woman' are fully analogous to nouns such as francuz 'Frenchman' and francuženka 'Frenchwoman,' i.e., they represent two distinct, though closely related stems--one marked <tmale>, and the other--<-male> (this also applies to some nouns not within the category of "adjectival" nouns, e.g., suprug 'male spouse' and supruga 'female spouse,' Kum 'godfather' and Kuma 'godmother'; for further discussion see Mučnik 1971, 206-210, and see also Section 5.21 below).

\subsection{Declinable Proper Names}

5.21 Any Russian speaker would know that Boris, Aleksej, and Savva, for example, are names for males, and Nade $d_{d a}$, Katerina, and Marija are names for females, or that a pet called Berta is a female, whereas a pet called Bobik is a male. Hence given names can be sex-differentiating and should be included in the lexicon and marked <tmale> or <-male> like common nouns.

As for surnames, all surnames specific to females have corresponding male forms which only differ in their case endings, i.e., in their declension paradigm. For example, the female surnames Tarasova, Lidina, and Zemskaja correspond to the male surnames Tarasov, Lidin, and Zemskij, respectively. There are no morphologically distinct female surname stems, and surnames therefore raise the question considered above with regard to noun pairs such as musskij 'Russian man' and musskaja 'Russian woman,' namely, do the male and female forms represent a single stem, unspecified for sex or gender, or do they represent two sex-differentiating stems? The same question can also be asked with regard to certain given names, e.g., Aleksandr and Aleksandra, Valentin and Valentina, Evgenij and Eugenija.

It seems simpler to treat all surnames which have female and male forms and the few given names which have dual forms as representing distinct sex-differentiating stems, becasue if such names were to be treated as representing single stems, that would require a special rule for determining their declension paradigm in each sentence. A rule of this type is not necessary for any other noun 
class (with the possible exception of nouns such as musskij 'Russian man' and musskaja 'Russian woman' or suprug 'male spouse' and supruga 'female spouse') and it can be dispensed with if the names in question are treated as representing <-male> or <tmale> stems.

The stems of sex-differentiating surnames all follow the adjectival paradigm or else end in -ov- or -in- and follow either the First Declension (when marked <tmale>) or the Second Declension (when marked <-male>); e.g., Musorgskij-Musorgskaja, Tolstoj--Tolstaja, Kazakov-Kazokova, Prokof'ev--Prokof'eva, Borodin--Borodina, and Pčelincyn--P̌elincyna.

Given names for males are like <tmale> common nouns in that the majority follow the masculine variant of the First Declension (e.g., Vladimir, Vitalij, Igor') and some follow the Second Declension (e.g., Nikita, $I l^{\prime} j a$ ), and in that they take several feminine affective suffixes and one neuter affective suffix, -išč- (and remain masculine), e.g., for Igor'--Igor'ka, Igomułka, Igorëxa, Igorjuxa, Igorjaša, Igorjuša, and Igoriše (cf. Petrovskij 1966, 291). Given names for males are unlike common nouns only in that there are none which follow the adjectival paradigm.

Given names for females also correspond to <-male> common nouns in that almost all follow the Second Declension (e.g., Vera, Ol'ga, Lidija) and only a, few follow the Third Declension (e.g., Ljubov', Ruf', and Esfir'; cf. Zaliznjak 1967a, 216), and they differ from <-male> common nouns in that there are no proper names which follow the adjectival paradigm. There is, however, an additional difference: given names for females can take masculine affective suffixes; e.g., for Vera--Verok, Verunok, for Nina--Ninčik, Ninoček, Ninulik, Ninul'čik (cf. Petrovskij 1966, 261 and 332). What is more, the names then become masculine, for masculine supersedes feminine and neuter whether it is inherent to stem or suffix. Igorjaša and Igorišče therefore remain masculine, and Ninčik becomes masculine.

The gender manifested in association with female names modified by masculine suffixes must thus be masculine, as illustrated under (46) (cf. also Janko-Trinickaja 1966, 200 and Nikitevič 1963, 35).

(46) (a) Prixodi so $\left\{\begin{array}{c}\text { svoim [masc instr] } \\ \text { svoej[fem instr] }\end{array}\right\}$ Ninčikom[instr] . 'Come with your Ninchik.' 


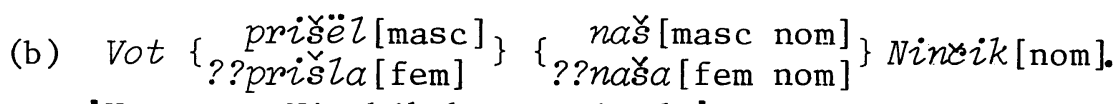
'Here our Ninchik has arrived.'

Masculine affective forms of female names are most commonly used as vocatives, in direct address, but when used in sentences such as (46a), the modifier must have a masculine ending. In a sentence such as (46b), where Nincik is in the nominative case, its modifier and the verb must also have masculine endings, but, as the question marks indicate, there are speakers who hesitate to rule out feminine endings altogether, perhaps by analogy with certain First-Declension nouns which do allow feminine manifestations in association with them when used in the nominative in reference to females (for additional comments on masculine forms of female names see footnote 36 and Section 10.37 below).

5.22 As a whole, given names differ from other noun classes in allowing the formation of variants--derivative nicknames. In distinction from affective forms of given names, e.g., Ninčik, or Igomiska, in which the stems of the given names essentially remain intact, derivative nicknames only contain elements of the stems of given names. Possible derivative nicknames for Igor', for example, are Gorja, Igoša, Goša, Goga, Gotja, Igulja, Gulja, Igusja, Gusja, and Ira (Petrovskij 1966, 118).18 As suggested by the following passage (from "Odin bilet do Moskvy" in Inna Goff, Junoša s perčatkoj [Moscow, 1974], 75), Russian speakers may perceive nicknames as independent names.

\footnotetext{
[Жену Жени] тоже звали Үеня, но доманиие, чтобы не путать, звали ее Евой. Настя никак не могла понять, как из Жени могла образоваться Ева, пока одесситы еци не объяснили, что имя-то полное Евгения! Вот отспда и Ева.

и придумать это, и дать подобное объяснение могли только одесситы!
}

${ }^{18}$ To be precise, there are also a few common nouns which allow such derivatives; see Superanskaja 1969, 140. 
'The name [of Zhenya's wife] was also Zhenya, but at home, in order to avoid confusion, she was called Eva. Nastya could not for the life of her understand how Eva could be derived from Zhenya until the Odessans explained to her that the full name was Evgenia! So this was where Eva came from.

Only Odessans could think that up and only Odessans could give such an explanation!'

Many derivative nicknames are indeed derivationally opaque: they do not in themselves reflect any specific given name. Eva, for example, can be a nickname not only for Evgenija but also for Evangelina, Evdokija, and Evstolija, and also for Evstignej and Evtropij (Petrovskij 1966, 282). A common nickname such as Lenja can be derived from no less than fourteen male given names-Aleksandr, Aleksej, Lev, Leonid, and others--as well as from six female names, among them Aleksandra, Leonida, and Ol'ga (Petrovskij 1966, 308). Since such nicknames often function as regular substitutes for given names and, moreover, can be modified by affective suffixes just like given names, it would be more plausible to assume that they constitute independent entities (for a discussion of the formation of derivative nicknames see Stankiewicz 1968, 143-179).

Nicknames such as Eva and Lenja, and many others, are not sex-differentiating, for they are applicable to males as well as to females. There are, however, nicknames which are restricted to males or females, e.g., Gavrik, Borja, Kolja, and Mitja are <tmale> names, and Dunja, Katjuša, and Nadja are <-male> names. The gender manifested in association with such names and their affective forms corresponds to their sex specifications, but again with the exception of female nicknames modified by masculine affective suffixes, e.g., Musënok (a derivative of Marija), or Galë̌cek (a derivative of Galina). The masculine gender of the suffixes supersedes. ${ }^{19}$

${ }^{19}$ Another exception are names with the suffix -at-, e.g., Vasjata (for the nickname Vasja--a derivative of the male name Vasilij). This suffix is inherently plural and its number supersedes, as in, e.g., Vasjata segodnja ne pridut[pl] 'Vasyata will not come today,' where the (cont.) 
5.23 A marginal phenomenon worth mentioning in this connection is the occurrence of male names which end in -o (orthographically) in the nominative singular, e.g., Gavrilo, Danilo, Mixajlo, and Somojlo. Such names are remarkable because declinable names for males--whether given or derivative--end in $\phi$ or $a$ in the nominative singular as a rule, not in 0 (except for names modified by the neuter affective suffix -i ð̌-).

Indeed, names such as Gavrilo, Danilo, Mixajlo, and Scomojlo do not follow the neuter variant of the First Declension but rather the Second Declension (cf. the respective entries in Petrovskij 1966 and see also Rozental' 1971a, 168). Furthermore, even the nominative singular forms of these names conform to the Second Declension phonologically (an unstressed final - 0 is phonologically indistinguishable from a realization of $a$ in the same position). From the point of view of the contemporary standard language, then, these names in -o represent no more than aberrant spellings for Gavrila, Danila, Mixajla, and Samojla. The forms spelt with $-a$ are indeed classified in Petrovskij 1966 as the standard colloquial variants for the given names Gavriil, Daniil, Mixail, and Sarmil, while the forms spelt with -0 are labelled "old colloquial" (ibid.; the forms in $-a$ can perhaps be viewed as a type of derivative nicknames).

There are also male names in -0 which cannot be accounted for as Second-Declension nouns. They are names such as Saškó, Vasil'kó, Pavló, and Petró, whose final -o is stressed and is thus unquestionably not a disguised a (these names are especially prevalent among Ukranians, who, unlike Russians, do not always stress the -0 [Superanskaja 1966, 81-82]).

According to Zaliznjak 1967a, 216 and Rozental' 1971a, 168, such names follow the First Declension--though they cannot follow the neuter variant, only the masculine variant, which shows in their accusative forms. The accusative forms of Saško and Pavlo, for example, would be Saška and Pavla rather than Saško and Pavlo. Cf., e.g., the accusative form of the name Levko in Gogol's "Majskaja noč', ili Utoplennica" (Gogol' 1959, 85): Prikazyvaju

has a plural ending despite the fact that there is no more than one referent. 
tebe sej že čas Zenit' tvoego syna, Levka[acc] Mokogonenka, na kozačke iz vašego že sela, Ganne Petryčenkovoj 'I order you to marry right away your son Levko Mokogonenko to the Cossack girl from your village Ganna Petrychenkova' (cf. also the same pattern in the declension of the masculine noun podmaster'e 'apprentice' [e.g., in Vinogradov et al. $1960,158])$.

Informants indicate, however, that such names tend to be treated as indeclinable in current usage. Gorky indeed did not decline the name Sadko in his story "Serdce Sadko [sic.]" (The Heart of Sadko), and cf. also the sentences under (47), from a recent program of the Bolshoy Theater.

\section{(47) (a) Korabl' Sadko neołidanno ostanavlivaetsja. 'Sadko's ship suddenly stops.' \\ (b) Nad spjaščim[instr] Sadko Morskaja carevna poët kolyber'nuju pesnju. \\ 'Over Sadko, who is sleeping, the Princess of the Seas is singing a lullaby.'}

The final $O$ of Sadko is treated in (47) as a stem vowel rather than a nominative singular ending, although according to, e.g., Petrovskij 1966, 193, this name should follow the First Declension (see also the entry Sadko in Rozental' 1967, 504).

Names which end in stressed -0 are thus not fullfledged declinable nouns in present-day usage. Since names which end in unstressed -0 can be accounted for as ending in $a$, it turns out that declinable male names are indeed essentially restricted to $-\varnothing$ or $-a$ endings in the nominative singular. (The gender manifested in association with male names which end in $-O$ can be neuter only by way of metaphor, to signify reference to a thing rather than a human being [cf. Nikitevič 1963, 34].)

5.24 Finally, it may be interesting to note that although common nouns which denote male animals all follow the masculine variant of the First Declension (only nouns which denote human males may follow the Second Declension), proper names for male animals do follow also the Second Declension, apparently because giving an animal a name is tantamount to endowing it with human properties.

In general, it seems that animal names are essentially metaphoric (in the broad sense of the term), for when they are not arbitrary sound sequences, they have some independent significance in the language--whether as 
names for human beings or as common nouns (cf. the pet names Pušk, Barsik, Musket, and Radza and the corresponding common nouns pušok 'fluff,' bars 'snow leopard,' mušket 'musket,' and rad̋a 'rajah'). Animal names can therefore be viewed as having inherent <+male> or <-male> features only if they are sex-differentiating as names for humans or as common nouns. Thus the gender manifested in association with the animal names Berta and Bor'ka, for example, would be feminine and masculine, respectively, because Berta is a female human name and Bor'ka is a male human name (a derivative of Boris), and the gender manifested in association with the animal name Radža would be masculine because radž 'rajah' denotes a male person. ${ }^{20}$

\subsection{Indeclinable Common Nouns}

Very few indeclinable common nouns are sex-differentiating. The majority are semantically "asexual," though they may often be used in reference to males only. Nouns such as lauli 'coolie' or attałe 'attaché,' for example, are used exclusively in reference to males, but sex is nevertheless not a component of their meaning, for in principle such nouns are also applicable to females--in distinction from nouns such as dendi 'dandy' or Zedi 'lady,' which must be marked <tmale> and <-male>, respectively. Indeclinable common nouns which denote animals are all "asexual."

Sex-differentiating indeclinable nouns must have an inherent gender corresponding to the sex they denote, for constituents associated with such nouns always manifest the gender which corresponds to their sex. Such nouns differ from sex-differentiating nouns that do decline only in their indeclinability, and they differ fromindeclinable nouns which denote inanimate entities in that they do possess inherent gender (though there may be isolated inanimate indeclinable nouns which also possess inherent gender, e.g., avenju 'avenue').

20 I have also come across the name Aktivnyj for a pet bird, a name which follows the adjectival declension and means "active" as a common adjective. Perhaps in this case the name can be viewed as having the feature <tmale> by virtue of being the name of a male animal. 
More importantly, sex-differentiating indeclinable nouns differ from inanimate indeclinable nouns in that they comprise not only stems which end in a vowel but also stems which end in a consonant, e.g., madom, miss, missis, and frejlen/frejlejn (Ger. Fräulein 'young lady, miss') (Zaliznjak 1967a, 214 also lists freken [Swed. fröken 'miss'] and al'ma-mater [a sex-differentiating noun etymologically], and the seventeen-volume Academy dictionary includes moman 'mama'). 21 The indeclinability of such stems is evidently a function of their denoting females, for their counterpart <+male> nouns (mister, sen'or, sèr 'sir') do decline.

Non-Slavic surnames which end in a consonant exemplify the relationship between sex and declension even more clearly, for they can only be declined in reference to males. The dative form of Dłonson, for example, would be $D$ Æonsonu in reference to a male but $D$ Konson in reference to a female (such surnames are discussed in Section 7.5 below).

As pointed out above, stems of nouns listed in the lexicon as denoting females are predictably inherently feminine, and such stems predictably follow the Second Declension unless marked as exceptions to this general rule, in which case they follow the Third Declension, and unless marked as following the adjectival paradigm. Borrowed nouns which end in a consonant and denote females are also predictably feminine, but they do not decline-despite the fact that their stems end in a consonant like stems of declinable feminine nouns (the stem of mama 'mama' for example, is mam-). How can this fact be accounted for in a formal model? Perhaps by postulating

${ }^{21}$ Some Russian dictionaries do list a few inanimate nouns which end in a consonant and do not decline, but the indeclinability of such nouns is apparently due to the fact that they are not regular common nouns; they function as proper names and are analogous to Tajm, for example, which does not decline either (cf. Section 4.23 above). Such indeclinable nouns are, for instance, rokajl' (a style in architecture), zakob (a style in furniture), and befstroganov 'Beef Stroganoff.' Rokajl' is labelled in dictionaries as feminine and the other two nouns are labelled as masculine, which is also evidence that they are not regular indeclinable common nouns: the gender manifested in association with them is the gender of generic nouns. 
a feature [-Dec1 II] for all borrowed nouns which end in a consonant. This feature would prevent nouns which denote females and are therefore feminine from following the Second Declension.

Borrowed feminine nouns ending in a palatal or palatalized consonant could in principle follow the other feminine declension--the Third Declension, and there are indeed speakers who treat momzel' and mademuazel' as ThirdDeclension nouns, but these nouns are often not declined (cf. the entries momzel' and mademuazel' in the fourvolume Academy dictionary and the entry mademuazel' in ožegov 1973). The fact that they are not declined as Third-Declension nouns can be accounted for by their not constituting exceptions to the general rule by which declension paradigm is determined by gender specification (on1y stems marked as exceptions to the general rule follow the Third Declension; see Section 2.1 above). The fact that they are declined by some speakers may be viewed as a consequence of the replacement of the feature [-Dec1 II] by the exception feature borne by Third-Declension stems. For further data in support of the postulated [-Dec1 II] feature and the processes suggested here see Sections 5.4 and 7.5 below.

\subsection{Indeclinable Proper Names}

Gender manifestations in association with indeclinable names that are sex-differentiating are determined by the principles which govern gender manifestations in association with all other sex-differentiating nouns. Thus names such as Meri and NeZZi, for example, are <-male> and therefore feminine, hence the gender manifested in association with them is always feminine. Correspondingly, male names such as Pablo or the are masculine and the gender manifested in association with them is always masculine (such names do not decline because their stems end in a vowel, that is, the final $-o$ and $-e$ in Pablo and $t_{e}$ are not case endings; on declinable names in -o see Section 5.23 above).

The only indeclinable names which merit special attention are female names which end in a consonant. In the preceding section it was suggested that all entries for borrowed stems which end in a consonant include the negative feature [-Dec1 II]. This feature can indeed account for the indeclinability of borrowed female names 
like Lilian, Ėdit, BZanš, Ingrid, and Iren. 22 Borrowed female names which end in a palatalized consonant (invariably 1 ) may follow the Third Declension, as do the names Adel' and ''izel', for example, whose [-Dec1 II] feature can be assumed to have been replaced by the exception feature, but names in this category generally resist declension. A name such as Ljusiz', for example, may follow the Third Declension, but it may also remain indeclinable (cf. Zaliznjak 1967a, 216). It is also interesting that the female name Ninel', which is not borrowed but rather made up of Lenin's name written backwards (cf. e.g., Petrovskij $1966,167)$ also sometimes does not decline (Superanskaja 1965, 126 and Zaliznjak 1967a, 216). In this case, the exception feature can be assumed to have been replaced by a [-Dec1 II] feature in the lexicon of some speakers.

Suffixed female names such as Nadik or Verunok do decline and follow the First Declension because the affective suffix renders them masculine. This is what distinguishes them from borrowed female names such as Ingrid or Iren, which are feminine and therefore cannot follow the First Declension.

As a footnote to this discussion it might be added that indeclinable given names or nicknames are rarely used in reference to Russians. Girls called Veronika or Lilija, for example, are not nicknamed Viki or Lili (cf. Petrovskij 1966). The name Ninel', which, as mentioned above, is not always considered declinable, is an uncommon name nowadays (cf. Šajkevič 1970, 88), its etymology

22 The term "borrowed" is used broadly in this chapter to signify all non-Russian elements which occur in Russian discourse. Non-Russian names that are "borrowed" in this sense thus often cannot be considered sex-differentiating from the point of view of Russian speakers even though they may be in fact restricted to the members of one sex. Names such as DZejn (Jane) or DZennifer (Jennifer), for example, are restricted to females and therefore inherently female from the point of view of speakers of English, but not necessarily so for Russian speakers.

There is no clear boundary line between sex-differentiating and "asexual" non-Russian names. The names used to illustrate the discussion in the text are thus not necessarily sex-differentiating for all Russian speakers, though many speakers would probably identify them as such. 
notwithstanding, and names such as Mariam or NeZli are also uncommon (cf. Petrovskij 1966, 150 and Bondaletov $1970,103)$. When given, names such as Ninel', Mariom, and NelZ $i$ tend to be replaced in daily usage by declinable nicknames, e.g., Nina, Mara, and Nelja (cf. Petrovskij 1966). Indeclinable male names are avoided altogether-even for animals, apparently.

"Asexual" indeclinable names are discussed in Section 7.5 below.

\section{Gender in Association with Asexual Animate Nouns}

"Asexual" animate nouns are nouns which denote human beings or animals without reference to biological sex. Their inherent gender must be considered unpredictable and idiosyncratic like the gender of inanimate nouns, though the probability of its being neuter is much lower. Asexual nouns denoting animals are discussed in Section 6.1 , and asexual nouns denoting humans are discussed in Section 6.2.

\subsection{Asexual Nouns Denoting Animals}

Sentence (48) illustrates the use of the noun sobaka 'dog,' which does not differentiate sex, in contrast with the nouns surka 'bitch' and kobel' 'male dog,' the sexdifferentiating counterparts of sobaka.

(48) Sobaku priobreti, nepremenno sučku, potomu ěto sučka zlee kobelja.

'Get yourself a dog, [but] be sure it is a bitch, because a bitch is more ferocious than a male dog.'

Both sobaka 'dog' and sučka 'bitch' are inherently feminine, yet only the latter is a <-male> noun denoting only female dogs; sobaka is the generic term. ${ }^{23}$ Similarly,

${ }^{23}$ An additional, masculine generic term for a dog is pës, illustrated in the fragment below.

Teper' u menja Vega. Otziěnyj[masc] pës.

'Now I have Vega. An excellent dog.'

The name of the dog referred to by the speaker, Vega, indicates that it is a bitch, and the speaker can use the masculine noun $\ddot{p} \ddot{s}$ in reference to it because the (cont.) 
koška 'cat' is a feminine noun, but it does not denote female rather than male cats, as illustrated in (49).

(49) Ďonson Zaskovo gladit Barsika--košku, kotoruju [fem] on privëz s soboj iz Sovetskogo Sojuza. "Ona tri dnja drozala posle našego priezda sjuda,--govorit on,--no teper' u丸e vsë v porjadke".

'Johnson affectionately strokes Barsik--the cat he brought with him from the Soviet Union. "It [1it. she] trembled for three days after we came here," he says, "but now everything is all right."

The relative pronoun kotomuju 'whom, which' in (49) manifests the feminine gender of koska 'cat,' as does also the personal pronoun ona 'she,' despite the fact that the cat referred to is a male, as indicated by its name-Barsik.

Very few of the asexual nouns denoting animals are inherently neuter. As noted by Jakobson, neuter nouns in this category are, semantically, "the widest generic designations of animate beings" (Jakobson 1971, 184), e.g., ¿ivotnoe 'animal,' nasekomoe 'insect,' mlekopitajušcee 'mammal' (all three follow the adjectival paradigm). The gender manifested in association with neuter nouns can only be neuter, as illustrated in (50).

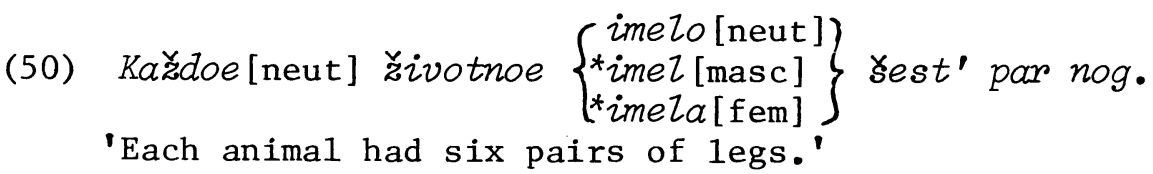

Nouns denoting animal species cannot be neuter; they can only be masculine or feminine. The following nouns, for example, are semantically asexual and grammatically masculine: bars 'snow leopard,' moræ 'walrus,' okun' 'perch,' gus' 'goose' (cf. the sex-differentiating gusak 'gander' and gusynja 'female goose'), zajac 'hare' (with a feminine affective suffix: zajčiska), solovej 'nightingale' (with feminine affective suffixes: solovejka, solovuška), and pouk 'spider' (with a neuter affective suffix: paučišce); the following are semantically asexual

noun has no specific sex associated with it--it is asexual, like sobaka. 
and grammatically feminine: zmeja 'snake,' Zisa 'fox,' obez'jana 'monkey,' belka 'squirrel,' ‘erepaxa 'turtle,' muxa 'fly,' sëmga 'salmon,' myš' 'mouse,' and Zošad' 'horse' (cf. the sex-differentiating žerebec 'stallion' and kobyla 'mare'). Gender manifestations in association with all of these nouns bear no relation to biological sex. (For more extensive discussions of the relationship between the semantic and grammatical gender features of nouns denoting animals see, e.g., Svedova 1970, 320-321 and Mučnik 1971, 180-183, and cf. also Peškovskij 1956, 193 and Nikitevič 1963, 33.)

\subsection{Asexual Nouns Denoting Human Beings}

Most asexual nouns denoting human beings are "contextually dependent," that is, the gender manifested in association with them may be determined by the sex of the person referred to. Gender manifestations in association with contextually dependent nouns are discussed in Sections 7 and 8 below. The present section deals with asexual nouns which do not allow contextual interference. Such nouns most .. typically denote either immature human beings (e.g., rebënok 'child,' priëyš 'foster child,' podrostok 'teenager') or persons of unspecified identity--whether directly (e.g., čelovek 'person,' persona 'person') or metonymically (e.g., figura 'figure; person,' ličnost' 'personality; person,' and znomenitost' 'celebrity'). Less typical, and more restricted in use, are asexual nouns such as gost' 'guest' and drug 'friend,' nouns which characterize human beings as actants, i.e., by their actions, and are inherently masculine.

6.21 Asexual nouns which characterize human beings as actants are more restricted in use because they cannot be used in specific references to female persons. A sentence such as Prišël gost' 'a guest has come,' for example, can only refer to a male guest. In reference to a female guest one would have to say Prišla gost'ja, using the sexdifferentiating noun gost'ja 'female guest.' Nouns such as gost' 'guest' and drug 'friend' are nevertheless classified here as asexual because they can apply to females as modifiers--as predicates or appositives, for example-which <+male> nouns cannot, as illustrated under (51). 
(51)

(a) Vera-- $\left\{\begin{array}{l}n a s ̌ s ~ g o s t ' \\ n a s ̌ a ~ g o s t ' j a \\ \text { tnas student } \\ n a s ̌ a ~ s t u d e n t k a\end{array}\right\}$.

'Vera is our $\left\{\begin{array}{l}\text { guest } \\ \text { female guest } \\ \text { *male student } \\ \text { female student }\end{array}\right\}$ '

(b) Ona $\left\{\begin{array}{l}\text { moj Zučsij dmug } \\ \text { moja Zučsaja podmuga } \\ \text { *moj sosed } \\ \text { moja sosedka }\end{array}\right\}$.

'She is my $\left\{\begin{array}{c}\text { best friend } \\ \text { best girlfriend } \\ \text { *male neighbor }_{\text {female neighbor }}\end{array}\right\}$.

Consider also (52).

(52) Posle razvoda mǚ̌ina poroj terjaet veru $v$ ženščinu kak $\left\{\begin{array}{c}\text { druga } \\ \text { xpodmugu }\end{array}\right\}$.

'After a divorce, a man sometimes loses his faith in women as $\left\{\begin{array}{c}\text { friends } \\ * \text { female friends }\end{array}\right\} . '$

The entries for student 'student' and sosed 'neighbor' must include the feature <tmale> and these nouns are indeed inappropriate characterizations for female referents, as illustrated in (51). The fact that the nouns gost' and drug are not unacceptable in the same contexts indicates that they are not specified <tmale>.

What (52) demonstrates is that in certain contexts the unmarked drug may be the only appropriate noun even in reference to a woman, and a sex-differentiating noun can be ruled out.

It should be noted in this connection that in nonspecific, general references, the <tmale> specification 
of nouns like student or sosed can be neutralized. In the following sentence, for example, the scope of kazdyj student 'every student' is not restricted to males: Kazdyj student dolžen èto znat' 'every student [male or female] must know this.' Similarly, sosedi in the following sentence is not restricted to male neighbors: Sosedi $u$ nas šumnye 'we have noisy neighbors.' (Note that the <+male> specification is not automatically neutralized in plural forms; cf., e.g., Vse studenty $i$ studentki $i z$ Japonii zivut na vos'mom ètaze 'all of the male students and female students from Japan live on the eighth floor' [on neutralization of sex features cf. also Janko-Trinickaja 1966, 195 and Mučnik 1971, 181].) ${ }^{24}$

6.22 Unlike asexual nouns which characterize human beings as actants and cannot function as specific references to females, nouns which denote immature human beings or human beings of unspecified identity can function in any context. In the sentences under (53), for example, the referents of rebënok 'child' in (a), osoba 'person' in (b), persona 'person' in (c), and ličnost' 'person' in (d) may be males or females: these sentences are vague in this respect.

(53) (a) Rebënok u nas bolen[masc].

'Our child is sick.'

(b) Vas xvalila[fem] odna[fem] vałnaja[fem] osoba. 'A certain important person praised you.'

(c) $V$ gorode naxodilas' [fem] kakaja-to [fem] vysokopostavlennaja [fem] persona.

'A certain high-ranking person was in town.'

${ }^{24}$ In Janko-Trinickaja 1966, 170 the nouns sosed 'neighbor' and gost' 'guest' are treated as members of the same class with respect to sex differentiation, apparently because contexts as in (51) are not taken into account.

Note that sex specifications are also amenable to neutralization in nouns denoting animals. Moreover, in distinction from human nouns, where only <tmale> specifications can be neutralized, <-male> specifications can also be neutralized in nouns denoting animals; e.g., plural forms of korova 'cow' and koza 'she-goat' can be applicable to males as well (cf. Švedova 1970, 320-321 and Mučnik 1971, 182). 
(d) Nekaja[fem] Ziěnost' pozvonila[fem] i skazala [fem], cto direktora net.

'Some person called and said that the director is out.'

The sentence under (54) (from a newspaper discussion of marital problems) demonstrates the applicability of čelovek 'person' to either sex.

(54) Zivët čelovek odin, i niěego. A potom vdrug vstrečaet kogo-to $i$ vyxodit zomǐ. Ili ženitsja.

'A person lives alone, and it's all right. And then all of a sudden [that person] meets someone and becomes a married woman. Or a married man.'

According1y, the sex of the referent in a sentence such as Vas xvaliz[masc] odin[masc] čelovek 'a certain person praised you' is vague--the referent could be a man or a woman.

6.23 What is important from the point of view of agreement is that the gender manifested in association with all such asexual nouns corresponds neither to inherent sex features of the nouns nor to the sex of the persons referred to in the sentences; the manifested gender is the inherent gender of the nouns, and it is an unpredictable, arbitrary feature. 25

The gender manifested in association with asexual masculine nouns (e.g., rebënok 'child,' čelovek 'person,' drug 'friend,' urod 'monstrous person,' and molodec 'fine person') is thus always masculine, the gender manifested in association with feminine nouns (e.g., persona 'person,' bezdarnost' 'talentless person,' and svoloč' 'scum') is always feminine, and the gender manifested in association with neuter nouns is always neuter. The only neuter nouns denoting human beings are apparently ditja 'child,' čado 'child,' and, metonymically, Zico 'face; person,' all

${ }^{25}$ Russian seems to differ from Czech in this respect, for in Czech, according to Vanek (1970, 77-82), asexual nouns denoting humans and animals are all masculine, with only one exception (osoba 'person'). 
three restricted in use. 26 There are, however, other neuter nouns which may be used in reference to human beings metonymically, as in (55) (cited in Proťenko 1961, 123, from Leonov's novel Russkij les).

(55) Nesmotrja na rannij ěas, načal'stvo naxodilos' [neut] $u$ sebja $v$ kabinete $i$ zavtrakalo [neut] iz bumažki. Eto byl očen' molodoj čelovek $v$ zašitnoj gimnastërke.

'In spite of the early hour, the management was already sitting in its office and having breakfast out of a piece of paper. It was a very young man in a khaki tunic.'

The noun nacal'stvo 'management' is used in reference to a young man, but the verbs associated with it can only manifest its inherent gender--neuter.

The following two sections contain some further observations on the nouns discussed above.

${ }^{26}$ There are two other nouns which end in 0 in the nominative singular and denote humans, but they are inherently masculine. Both are quite marginal. One is podmaster'e 'apprentice,' which Soviet speakers consider totally obsolete, and the other is poludur'e 'simpleton,' labelled as dialectal in Ushakov's dictionary and in Zaliznjak 1967a (229 and 281), and as substandard (prostorečie) in the four-volume Academy dictionary and in Zaliznjak 1967a, 141 (sic!).

Note also that in the first half of the nineteenth century, gender manifestations in association with neuter nouns such as ditja 'child' or lico 'person' were not always neuter. Such nouns occur also with masculine verbs and attributives in Pushkin's and Gogol's prose (cf. Peškovskij 1956, 190-191 and 193, and Vinogradov 1947, 477; Vinogradov suggests [ibid.] that Gogol may have treated značitel'noe lico 'important person' in "The Overcoat" as a proper name and that that is why the gender manifested in association with this phrase was masculine, but Vinogradov's account is questionable, for not all gender manifestations in association with this phrase were masculine, cf. Bednoe [neut] značitel'noe lico čut' ne umer [masc] 'the poor important person almost died' and odno [neut] značitel'noe $Z_{i c o}$, kotoroe [neut] ... edva $l_{i}$ (cont.) 
7. Contextually-Dependent Gender in Association with Second-Declension and Indeclinable Animate Nouns

Contextually-dependent gender in association with Second-Declension common and proper nouns is discussed in Sections 7.1 and 7.2 , respectively, then some related phenomena (in Section 7.3), and then contextually-dependent gender in association with indeclinable common and proper nouns (Sections 7.4 and 7.5).

\subsection{Second-Declension Common Nouns}

7.11 Consider the gender manifestations in association with plaksa 'crybaby' in (56).

(56) (a) ¿̇tot[masc] plaksa revel[masc] vsju noč'. Eta[fem] plaksa revela[fem] vsju noč'.

'This crybaby howled all night.'

The difference between (a) and (b) is due to the fact that (a) refers to a male and (b) refers to a female. Sentence (a) would also be ungrammatical in reference to a female and (b) would be ungrammatical in reference to a male.

The noun plaksa 'crybaby' is representative of a class of nouns known as epicenes. Epicenes, all of which follow the Second Declension and denote humans, are analogous to the nouns discussed in the preceding section in that they are semantically unspecified for sex--they are applicable to persons of either sex and the sex of their referents can only be determined by contextual clues. They differ from the nouns discussed in the preceding section in that they have no inherent gender and the gender manifested in association with them is determined by contextual factors.

Semantically, almost all epicenes are epithetic nouns, characterizing individuals by some personal trait, of ten negative, e.g., Zadina/Žadjuga 'greedy person,' krivljaka 'poseur,' nerjaxa 'sloven,' rastjapa 'bungler,' p'janica 'drunkard,' Zakomka 'gourmand,' sonja 'sleepyhead,' and tupica 'dummy, dumbbe11.' Epicenes such as sirota 'orphan'

ne byz[masc] pričinoju ...' 'a certain important person, who ... was almost the cause ...' [cited in Peškovskij $1956,191])$. 
and maljutka 'baby, little one' are atypical in their semantic content. (Epicenes are characterized semantically and morphologically in, e.g., Sanskaja 1959, 14-15; Nikitevič 1963, 38; and Galkina-Fedoruk 1964, 36-37. For a representative list see Mučnik 1971, 211.)

As illutstrated in (56) above, the gender manifested in association with epicenes must correspond to the sex of the individual they refer to: masculine in reference to males, feminine in reference to females. When epicenes are used as generic, nonspecific references, the gender manifested in association with them must be masculine, as in, e.g., (57).

(57) Sprosite $\left\{\begin{array}{c}\text { Zjubogo[masc }] \\ * \text { ijubuju[fem }]\end{array}\right\}$ p'janicu.
'Ask any drunkard.'

The asterisked form can be acceptable only if all drunkards within the world of reference are women.

When epicenes are used as modifiers, most typically as predicate nouns, they are not used referentially. The gender manifested by attributives associated with them then can either be feminine--apparently a reflex of the fact that epicene nouns follow the second, essentially feminine declension,--or, which is considered preferable in formal discourse, it can be the gender which corresponds to the sex of the referent of the subject phrase (cf., e.g., Galkina-Fedoruk 1964, 364; Rozental' 1971a, 228; and Gorbačevič 1973, 515).

Consider (58) (these sentences are cited in GalkinaFedoruk 1964, 364 and Gorbačevič 1973, 515 to illustrate the acceptability of feminine attributives wi.th epicene nouns applied to males).
(a) On $\left\{\begin{array}{l}\text { izvestnaja[fem] } \\ \text { izvestnyj[masc] }\end{array}\right\}$ Zakomka.
'He is a well-known gourmand.'
(b) Etot mal'cik-- $\left\{\begin{array}{l}\text { takaja[fem] } \\ \text { takoj[masc] }\end{array}\right\}$ rastjapa.
'This boy is such a bungler.' 
(c) Ėtot Ljutov-- $\left\{\begin{array}{l}\text { prexitraja[fem] } \\ \text { prexitryj[masc] }\end{array}\right\}$ kanal'ja. 'That Lyutov is a shrewd rascal.'

Consider also (59).

(59) Ona $\left\{\begin{array}{c}i z v e s t n a j a[\mathrm{fem}] \\ \text { izvestnyj[masc] }\end{array}\right\}$ Zakomka.

'She is a well-known gourmand.'

Sentences (58) and (59) demonstrate the difference between epicene nouns used as modifiers, where the manifested gender cannot be masculine unless there is a male referent, and epicene nouns used as generic references, as in (57) above, where the manifested gender must be masculine.

How can these facts be accounted for? Zaliznjak 1967a (67-68) suggests the possibility of postulating two different lexical units for each epicene noun--one marked <tmale> and hence inherently masculine, the other--<-male> and therefore feminine. This would account for (56) and (57), but not for (58) and (59). Rothstein (1973) suggests postulating a single lexical unit for each epicene noun, unspecified for sex but inherently both masculine and feminine. This would account for (56) and possibly for (57), but again (58) and (59) would not be accounted for.

What could account for all of the facts presented above is perhaps an assumption that epicenes have neither sex features nor gender features but are labelled as following the Second Declension: [Decl II]. The processes which determine the gender manifested in (56)-(59) would then be as outlined in the next section (7.12).

7.12 First, consider the accusative forms in (57) (reproduced below).

(57) Sprosite Zjubogo[masc acc] p'janicu[acc]. 'Ask any drunkard.'

The noun unquestionably has an accusative ending, but the attributive associated with it has what looks like a genitive ending. Since the attributive cannot possibly be in the genitive case, what must account for its ending is 
the fact that masculine attributives receive genitive endings to manifest the feature combination [+Animate, Accusative].

The question, then, is where does the [+Animate] specification come from. It cannot be an inherent feature of the attributive in (57), because this attributive also occurs with accusative endings that do not manifest animacy, e.g., Voz'mite Zjuboj[acc masc] žrnal[acc] 'take any magazine.' The only possible source for the [+Animate] specification manifested by the attributive in (57) is the noun, which bears this specification as an inherent feature, and the attributive must assume it through Attributive Agreement. 27

All of the processes which apply to gender features thus apply to the feature [Animate] as well. This feature can be assumed to be copied from noun stems to the $\mathrm{N}$ and NP nodes which dominate them and to be involved in Attributive Agreement and Verb Agreement (its manifestations through Verb Agreement are discussed later on).

As the following analysis will show, the [+Animate] specification of epicene nouns is crucial in the assignment of gender to attributives and verbal predicates associated with them.

7.121 The simplest case is represented by (56), where the gender manifested in association with plaksa 'crybaby' corresponds to the sex of its referents. The relevant specifications in the underlying representation of (56a) (Etot[masc] plaksa revel[masc] vsju noc' 'this crybaby howled all night') after the specifications of the noun stem have been copied onto the higher nodes are as shown in $(60)$.

${ }^{27}$ Note that the [+Animate] specification is a grammatical, not semantic feature. A noun such as narod 'people,' for example, is grammatically [-Animate] (its accusative forms are not identical to its genitive forms), though semantically it is <+animates, and a noun such as mertvec 'corpse' is grammatically [+Animate], as demonstrated by the fact that its accusative and genitive forms are identical. (We know that p'janica 'drunkard' bears this feature because its accusative form in the plural is identical to the genitive form.) 
$(60)$

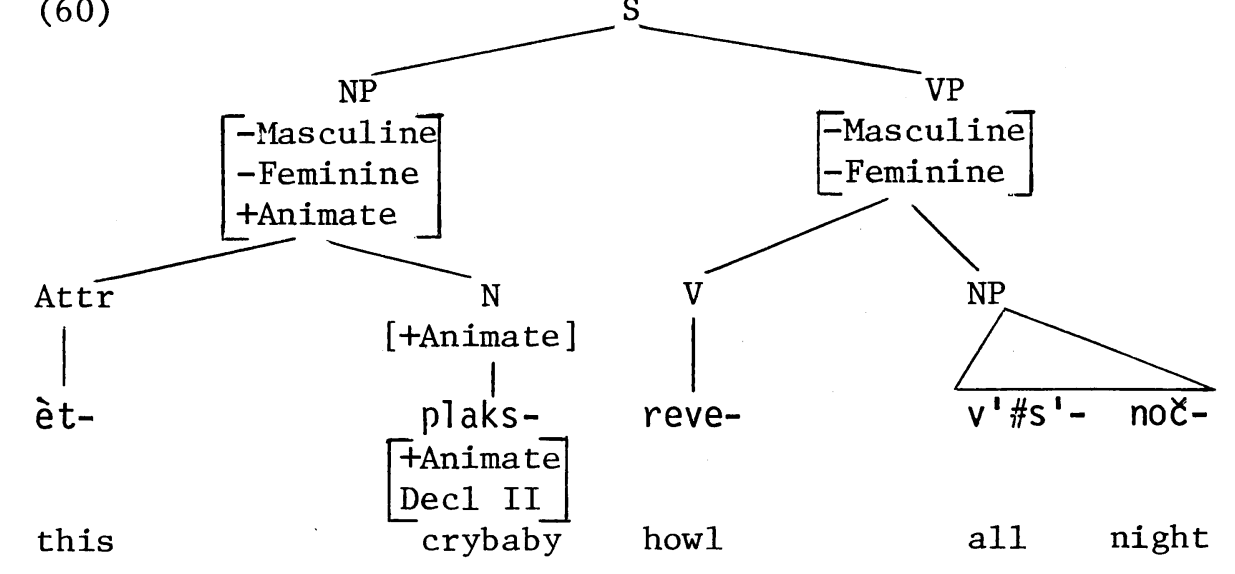

According to the account suggested above, the noun stem has no sex or gender specifications, and its pertinent features are only [+Animate] and [Decl II]. As shown in (60), the former has been copied onto the $\mathrm{N}$ and NP nodes. The negative gender specifications on the NP and VP nodes are the "provisional" ones (see Section 4.1 above).

The feature combination on the NP node is anomalous, for the [+Animate] specification is generally incompatible with negative gender specifications. One of the gender specifications must therefore become positive; but which one? The only other relevant grammatical feature in the sentence is [Dec1 II]. The Second Declension is usually associated with feminine nouns, but since there are animate Second-Declension nouns which are not feminine (e.g., djadja 'uncle,' junosa 'young man'), it is not a reliable index for the proper NP gender. The gender of the NP is therefore resolved by a switch to "contextual sex"--the sex of the referent.

"Contextual sex" can be represented as a feature attached to NP nodes and originating in ultimate underlying representations. It will be shown hereafter within curly brackets, i.e., as $\{-$ male $\}$ or $\{+$ male $\}$, to distinguish it from the inherent sex of lexical items, signified by angular brackets (as <-male> or <tmale>).

In (60), the contextual sex specification is evidently \{tmale\} (for (56a) clearly refers to a male), and the [-Masculine] specification on the NP node thus becomes positive. The verb receives the NP specifications through Verb Agreement, and the attributive receives them through the rule which follows Attributive Agreement when it fails 
to provide the Attributive node with sufficient specifications. This rule provides the Attributive node with specifications from the NP node (cf. Section 4.1 above).

7.122 Sentence (57) (Sprosite Zjubogo[masc]/*Zjubuju [fem] p'janicu 'ask any drunkard') differs from the sentences under (56) in that the epicene noun has no specific referent. In other words, the NP node dominating Zjubogo p'janicu 'any drunkard' in the underlying representation has no contextual sex specification. The feature combination [-Masculine, -Feminine, tAnimate] cannot be resolved by a switch to contextual sex, and it therefore undergoes an elementary rule which converts its [-Masculine] feature to [+Masculine].

This is a rule which applies whenever an NP node which bears the combination [-Masculine, -Feminine, tAnimate] cannot be resolved by a switch to contextual sex (as in (60) above) and does not dominate a node which bears the same combination. The latter condition is necessary in order to prevent the application of the rule in the few isolated cases where the head noun in the subject phrase is an animate neuter noun (e.g., Zivotnoe 'animal,' ditja 'child') and the combination (-Masculine, -Feminine, +Animate] on the NP node represents its inherent features. (The switch to contextual sex is excluded then too; cf., e.g., bednoe [neut]/*bednyj[masc]/*bednaja[fem] ditja 'poor child.')

The rule applies not only in association with epicenes in sentences like (57) but also in association with indeclinable nouns (see below) and in the underlying representations of sentences such as (61a) and (61c).

$$
\begin{aligned}
& \left\{\begin{array}{l}
\text { Sytyj[masc nom] } \\
* \text { Sytoe [neut nom] }
\end{array}\right\}\left\{\begin{array}{c}
\text { golodnogo[masc acc] } \\
\text { golodnoe [neut acc }]
\end{array}\right\} \text { ne } \\
& \text { fu11 } \\
& \text { hungry }
\end{aligned}
$$

'A person who is full cannot understand a person who is hungry.'

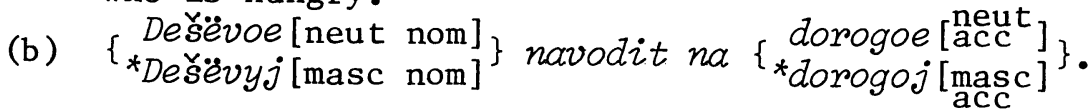

'A cheap thing [ultimately] leads to an expensive one.' 


\section{(c) Kto $\left\{\begin{array}{c}\text { ZezaZ[masc] } \\ * \text { ZezaZo[neut] }\end{array}\right\}$ na divane? \\ 'Who was lying on the couch?' \\ (d) tto $\left\{\begin{array}{l}\text { Zezalo[neut] } \\ * \text { ZezaZ[masc] }\end{array}\right\}$ na divane? \\ 'What was lying on the couch?'}

In (61b), dexëvoe 'what is cheap' and dorogoe 'what is expensive' represent underlying attributives associated with indefinite nouns which have no lexical realization, and their neuter endings manifest the initial negative node features [-Masculine, -Feminine] (cf. Section 2.12 above). In (61a), sytyj 'full' and golodnogo 'hungry' also represent underlying attributives, but the underlying nouns with which they are associated are apparently not completely unspecified, for neuter endings are excluded in this sentence.

The underlying nouns with which the attributives of (61a) are associated can be assumed to be specified \{thuman\}; in other words, the referents are labelled as human beings. This single feature can be lexically realized through the noun čelovek 'person,' or remain with no lexical exponent. In the latter case, the \{thuman feature is interpreted as [+Animate], and the NP nodes which dominate the attributives in the underlying structure of (61a) then bear the feature combination [-Masculine, -Feminine, +Animate] and are subject to the rule referred to above, which might be called the Unmarked Animate Gender Rule. The rule converts the negative masculine specifications to positive ones. This can be considered an obligatory rule, since neuter endings are excluded in (61a).

Sentences (61c-d) illustrate gender manifestations in association with interrogative pronouns. In (61c), the interrogative pronoun kto 'who' indicates the specification \{thuman\} in the underlying representation, and the NP node dominating it must be labelled [+Animate]. The unmarked Animate Gender Rule yields a masculine ending for the verb. (Gender and number manifestations in association with kto are also discussed in Chapter Five.) In (61d), where the verb is associated with the unmarked interrogative ěto, it can only have a neuter ending. (On masculine as the unmarked gender in association with animate nominals see also, e.g., Peškovskij 1956, 201-202.) 
7.123 Sentence (59), reproduced below, illustrates an epicene noun as modifier, as predicate noun.

(59) Ona $\left\{\begin{array}{c}\text { izvestnaja[fem] } \\ \text { izvestnyj[masc] }\end{array}\right\}$ Zakomka.
'She is a well-known gourmand.'

The unacceptability of a masculine attributive for Zakomka 'gourmand' indicates that the Unmarked Animate Gender Rule is inapplicable: the attributive must have a feminine ending in this sentence. This feminine ending can only be accounted for as determined by the sex of the referent of the subject phrase, for predicate nouns can have no referent of their own; their function is always to characterize the referent of the subject phrase (cf. also the comments in McCawley 1973, 274-275).

The relevant specifications in the putative underlying representation of (59) after inherent stem specifications have been copied onto higher nodes are shown below (the node PredP [Predicate Phrase] serves to distinguish predicate NPs from all other NPs; it may be unnecessary in a full grammar where predicate NPs can be distinguished in other ways, but within the schematic framework presented in this monograph it is quite useful).

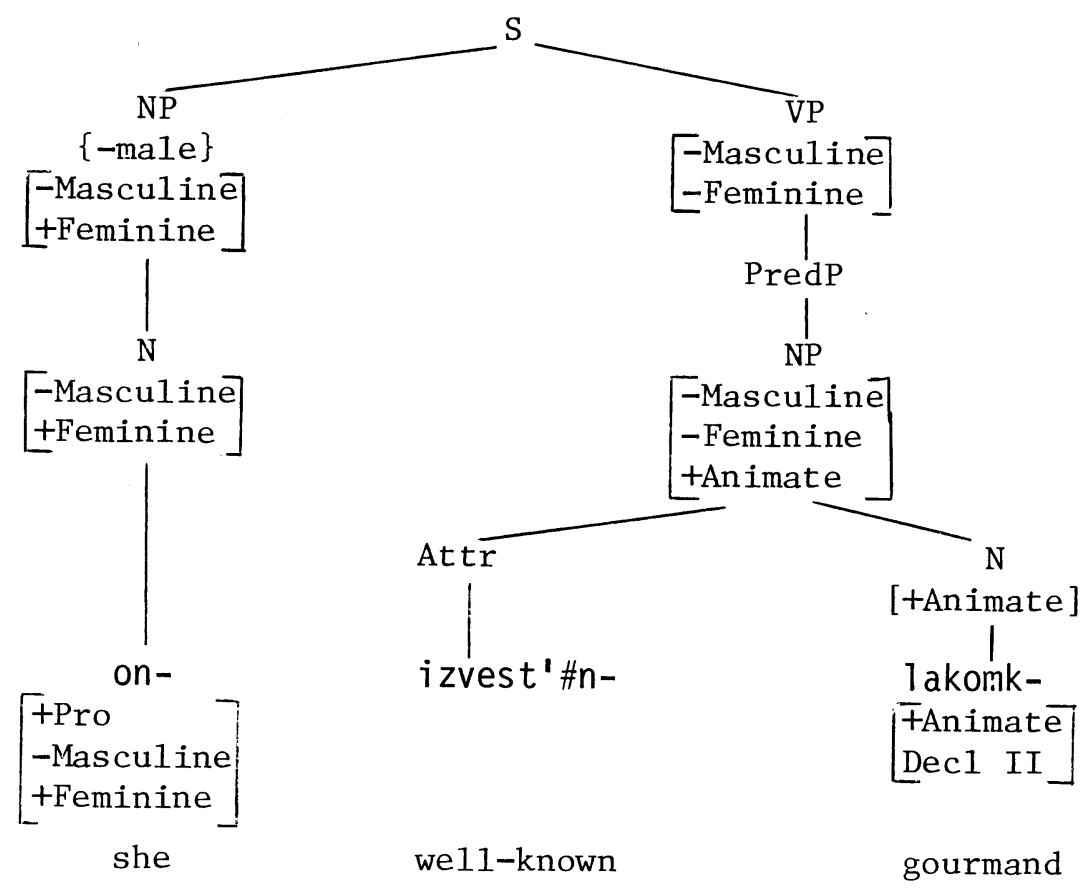


The Unmarked Animate Gender Rule cannot apply to the feature combination on the predicate NP node in this structure even though there is no contextual sex specification on the node. A switch to the contextual sex specification on the subject NP must take place, and this switch resolves the gender of the predicate NP as feminine.

Now the data in (58) have to be accounted for. A representative sentence is (58a), reproduced below.

$$
\begin{aligned}
& \text { On }\left\{\begin{array}{l}
i z v e s t n a j a[\mathrm{fem}] \\
i z v e s t n y j[\mathrm{masc}]
\end{array}\right\} \text { Zakomka. } \\
& \text { 'He is a we11-known gourmand.' }
\end{aligned}
$$

The masculine ending in (58a) corresponds to the underlying contextual sex of the subject and presents no problem, but the feminine ending is problematic. Its source appears to be the [Dec II] feature of the noun. In a model of the dialects (or styles) which allow a feminine attributive in sentences such as (58a), the switch to contextual sex from within a predicate phrase must apparently be considered optional, with a possible alternative switch to the lexical noun in the predicate phrase. The [Dec II] feature is then interpreted as [+Feminine]. Such a switch must be considered permissible only in predicate phrases. 28

${ }^{28}$ Nikitevič 1963 seems to imply that feminine endings in association with epicenes which have male referents also occur with verbal predicates ( $p .37$ ), but other grammarians stress the unacceptability of feminine verbs unless there is a feminine referent--from Peshkovsky and Vinogradov (Peškovskij 1956, 189 and Vinogradov 1947, 476-477) down to Gorbachevich (Gorbačevič 1973, 515). The informants I have consulted also confirm the restriction to attributives in predicate phrases.

Vinogradov and Istrina 1960, 513 and Rozental' 1971a, 228 cite from Goncharov the sentence ... ciničeski zametil [masc] ěto pronicatel'naja[fem] šel'ma, Mark '... cynically remarked this the perceptive scoundrel, Mark,' where an epicene noun which seems to have a male referent is modified by a feminine attributive. However, pronicatel 'naja šel 'ma 'perceptive scoundrel' is apparently a preposed appositive phrase. As such it has no referent and can be shown to derive from an underlying 
To recapitulate, it can be assumed that epicene nouns have no inherent sex or gender but do have an inherent declension paradigm. Constituents associated with them when they have a specific referent manifest the gender which corresponds to the sex of that referent, as in (56). Constituents associated with them when they have no specific referent have masculine endings, as in (57), for masculine is the unmarked animate gender (this is, incidentally, where animacy is manifested--though indirectly-by verbal predicates). Attributives associated with epicene nouns as predicates either manifest the gender which corresponds to the sex of the referent of the subject phrase or have feminine endings determined by the declension paradigm of the nouns.

\subsection{Second-Declension Proper Names}

Contextually dependent Second-Declension proper names differ from epicenes only in that they cannot be used nonreferentially (except in sentences such as $M 0 \ddot{e}$ imja Sała 'my name is Sasha' or Menja zovut Sała 'I am called Sasha,' where proper names are mere sound sequences). The gender manifested in association with such names thus always corresponds to the sex of the referents, e.g., Naš[masc] vesëlyj[masc] Saša postarel[masc] 'our cheerful Sasha has aged' refers to a man named Sasha, and the same sentence with feminine endings (Naša[fem] vesëlaja[fem] $S a \check{s} a$ postarela[fem]) would refer to a woman.

Contextually dependent Second-Declension proper names subsume surnames (e.g., Skovoroda, Lumumba, Gevara) and

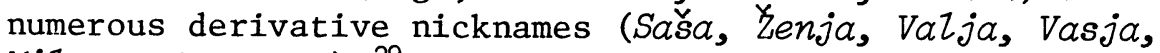
MiZa, and others). 29

predicate, so that this sentence in fact may support the statement that the declension paradigm of epicenes can only determine the gender associated with them within predicate phrases.

${ }^{29}$ Given names are almost all either exclusive to males or exclusive to females and there are very few asexual ones like Mina, for example, which is a male as well as a female name (Petrovskij 1966, 158). Asexual SecondDeclension proper names (whether given, derivative, or surnames) could be viewed as homonymous sex-differentiating names, i.e., as pairs of <tmale> and <-male> names, 


\subsection{Related Phenomena}

There are gender manifestations which seem to follow the pattern of gender manifestations in association with epicene nouns although the nouns with which the constituents are associated are not genuine epicenes. Such gender manifestations occur in association with inherently masculine nouns with the feminine augmentative suffix -in-, inherently masculine nouns which follow the Second Declension, and Second-Declension feminine nouns used metaphorically in reference to males.

7.31 When masculine nouns which denote males are modified by the feminine augmentative suffix -in-, e.g., stariěina '(very) old man,' Kupčina '(big) merchant,' kulačina '(big) kulak,' they remain semantically <tmale> and hence grammatically masculine, but masculine nouns which do not denote specifically males, e.g., celovek 'person,' urod 'monstrous person,' and molodec 'fine person,' become epicene-like with this suffix (cf. Sanskaja 1961, 17): gender manifestations in association with Celovečina '(big) person,' urodina '(very) monstrous person,' and moloděina '(very) fine person' follow the pattern observed in association with epicene nouns, though somewhat inconsistently (cf. the data in Maksimov 1971).

The suffix -in- in such nouns could be regarded as an epicene suffix distinct from the augmentative feminine suffix (as in, e.g., Nikitevič 1963, 38), but the partial

but since a mechanism for determining gender by contextual sex is available anyway--for operation in association with epicene nouns, with personal pronouns (cf. Ja postarel [masc]/postarela[fem] 'I have aged'), and with other classes of nouns to be discussed below--there is no reason to assume that it does not operate in association with such proper names (proper names are also classified as epicenes in, e.g., Galkina-Fedoruk 1964, 37).

Homonymous affective forms of sex-differentiating given names (e.g., Valentinka as affective form for the male name Valentin as well as for the female name Valentina) should apparently not be viewed as epicenes (for a brief discussion of the question see Sanskaja 1959, esp. 15). 
"epicinization" of nouns such as čelovek, urod, and molodec with the augmentative feminine suffix -in- is actually predictable from the fact that inanimate masculine nouns modified by the same suffix have an uncertain gender and may be treated as either masculine or feminine (see Section 2.1 above). In association with nouns which denote humans, the conflict between the masculine gender of the stem and the feminine gender of the suffix tends to be resolved by the sex of the referent. Gender manifestations in association with <+human> masculine nouns modified by the augmentative feminine suffix -in- thus turn out to follow the pattern observed in association with epicene nouns.

There is another Second-Declension suffix -in- which is indeed an epicene suffix, e.g., in zadina 'greedy person.' The difference between a bona fide epicene noun like zadina and a noun with the augmentative suffix -inlike urodina '(very) monstrous person' is that in the former, as in all bona fide epicenes, the suffix is what makes the stem morphologically a noun: Kad- in itself is not a noun stem. Nouns like urodina, then, are only superficially analogous to epicene nouns.

It should be emphasized that only nouns which denote humans can be analogous to epicenes, for there are no $<$-human> epicenes. Masculine nouns which denote animals may thus be treated as either masculine or feminine when modified by the feminine augmentative -in-, if they have no inherent sex, but they are then analogous to inanimate nouns rather than to human nouns with the same suffix, i.e., they are not contextually dependent.

The uncertain gender of such nouns can be illustrated by the fact that somina 'large sheat-fish' is labelled in Ushakov's dictionary as both masculine and feminine, zverina 'large beast' is labelled in the four-volume Academy dictionary as feminine but illustrated with a masculine attributive (this noun is also classified as masculine in Sanskaja 1961, 17), and psina '(big) dog' is labelled as both masculine and feminine in Ushakov's dictionary, as feminine in the four-volume Academy dictionary and in Ozhegov's dictionary, and in Evgen'eva 1971 (p. 450) it is cited from a contemporary story with a masculine verb.

Feminine affective suffixes other than - in- have no effect on the gender of nouns denoting males (e.g., syniška 'sonny,' djadečka 'uncle,' and soldatuskka 'soldier' remain masculine), and they apparently have no effect on 
the gender of asexual nouns either, though the situation is not immediately obvious.

A noun such as soseduska 'neighbor,' for example, is an affective variant of both sosed 'male neighbor' and sosedka 'female neighbor' (according to the four-volume Academy dictionary) and it is thus applicable to both males and females and gender manifestations in association with it seem contextually determined. Should it then be viewed as a single, epicene noun (as presented in Ozhegov's dictionary) or as representing two homonymous nouns, one <tmale> and the other <-male>? The latter view seems more tenable, for soseduška as predicate in a sentence in which the subject has a male referent cannot have a feminine attributive, cf. (62).
(a) On $\left\{\begin{array}{c}\text { prexitryj[masc] } \\ \text { prexitraja[fem] }\end{array}\right.$ soseduška.
'He is a shrewd neighbor.'
(b) On $\left\{\begin{array}{l}\text { prexitryj }[\mathrm{masc}] \\ \text { prexitraja[fem] }\end{array}\right\}$ kanal'ja.
'He is a shrewd rascal.'

In $(62 b)$, where the predicate noun is a true epicene, its attributive can be masculine or feminine. In (62a), the unacceptability of a feminine attributive can be taken as evidence that soseduskka in that sentence is not an epicene noun but a variant of sosed 'male neighbor.'

The homonymity illustrated by soseduska can also be illustrated by golyška 'naked child, naked person,' though the source of homonymity in the latter case is different. Golyška represents on the one hand an affective form of the asexual masculine noun golyš 'naked child, naked person,' an affective form which remains masculine, and on the other hand it represents a non-affective feminine counterpart of golyš, applicable to females only (cf. the four-volume Academy dictionary). Superficially golyška may thus appear to be an epicene noun, but, like soseduška, it is not. (Soseduška and golyšk a are indeed not included in the list of epicene nouns in Mucnik 1971, 211.)

There are several other nouns with feminine suffixes which appear to be epicenes but in fact represent homonyms. All in all, feminine affective suffixes other than -in- do not alter the inherent gender of masculine nouns, though 
there are some isolated deviations, e.g., the affective forms of the masculine asexual noun zver' 'beast,' zveruska and zverjuška, are labelled in the seventeen-volume Academy dictionary as both feminine and masculine, and in the other major dictionaries as feminine. (The fact that the gender of feminine affective suffixes is neutralized when attached to masculine stems stands out especially when there is no potential homonymity, as in designations of small birds, e.g., the hypocoristic forms vorobuska, skvoruška, and solovuška for the nouns vorobej 'sparrow,' skvorec 'starling,' and solovej 'nightingale,' respectively, can only be treated as masculine. For quick reference on gender labels in the major dictionaries see Lazova 1974. On the inaccuracy of dictionary gender labels for SecondDeclension animate nouns see Šanskaja 1959.)

7.32 A different phenomenon related to epicene nouns is the use of certain Second-Declension masculine nouns as epicenes, or perhaps semi-epicenes. Take the nouns sud'ja 'judge,' starosta 'head,' and kollega 'colleague.' These nouns were restricted to males in the past and were consequently masculine. They are now applicable also to females, for there are female judges, heads, and colleagues, and there are no other nouns to denote them. Gender manifestations in association with these three nouns when used in reference to females tend to be feminine, although they do not resemble epicenes semantically or derivationally (cf. Švedova 1970, 320 and Mučnik 1971, 211; sud'ja 'judge' and starosta 'head' are labelled as masculine in all of the major dictionaries, and kollega 'colleague' is not labelled masculine only in the four-volume Academy dictionary and in the latest editions of Ozhegov's dictionary).

These nouns are not genuine epicenes not only because they were formerly restricted to males and they do not resemble epicenes semantically or derivationally, but also because as predicate nouns modifying female referents (as in (63a)) they may have masculine attributives, which are even preferable, and as predicate nouns modifying male referents (as in (63b)) they cannot have feminine attributives.

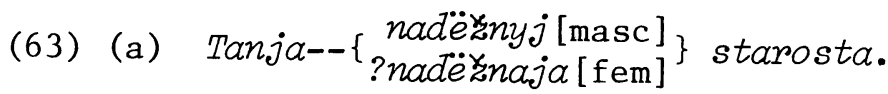


(b) Boris-- $\left\{\begin{array}{c}\text { nadëznyj [masc] } \\ \text { *nadëznaja [fem] }\end{array}\right\}$ starosta. ' $\left\{\begin{array}{l}\text { Tanya } \\ \text { Boris }\end{array}\right.$ is a reliable head.'

These nouns are apparently indeed masculine, but because they are Second-Declension nouns (and must be marked as such in the lexicon, for otherwise they would follow the First Declension), and because they do not specifically denote males, the gender manifested in association with them when there is a female referent may be determined by the principles which apply in association with epicene nouns. The inherent masculine gender can be assumed to be neutralized, or perhaps superseded.

Interestingly enough, bona fide epicene nouns that are semantically close to nouns such as sud'ja, starosta, and kollega, i.e., nouns which, roughly, identify individuals by some social function, may be treated occasionally as masculine nouns, as in (64).

\section{(64) Umerla Nina Vladimirovna Smirnova--naš[masc] škol'nyj[masc] zavodila. \\ 'Nina Vladimirovna Smirnova, our school's livewire, is dead.'}

The noun zavodiza 'livewire' is classified in all dictionaries and reference works as epicene, yet in (64), taken from a recent story in the Soviet magazine Junost', the noun is apparently mistaken for a masculine noun. There is no other possible explanation for the masculine attributives associated with zavodila in (64).

There is thus no fixed boundary line between genuine epicenes and asexual masculine nouns which follow the Second Declension and are applicable to females. (It goes without saying that the phenomenon is not restricted to the nouns mentioned in this section.)

7.33 A third and last phenomenon related to the principles which apply in association with epicene nouns can be observed in sentences in which Second-Declension feminine nouns apply to males metaphorically. Most commonly the vehicles in such metaphoric usage are nouns which signify animals, e.g., gadina 'reptile,' gadjuka 'viper,' zmeja 'snake,' svin'ja 'pig,' krysa 'rat,' Zisa 
'fox,' and others. Nouns which signify inanimate objects are less amenable to such usage but do occur. Passive men may be characterized, for instance, as kvašnja 'leavened dough' (in reference to heavy, lethargic men), trjapka 'rag,' or šljapa 'hat' (the latter two in reference to spineless men). 30 Least common as metaphoric characterizations of men are nouns denoting human females, for example, baba 'woman,' krasnaja devica 'fair maiden.'

Strictly speaking, gender manifestations in association with inherently feminine nouns must always be feminine and contextual sex should have no effect. Russian grammarians indeed emphasize that nouns as above do not become epicenes when applied to males (cf., e.g., Vinogradov 1947, 78; Vinogradov and Istrina 1960, 529; Galkina-Fedoruk 1964, 38; and also Sanskaja 1959, 13 and 16). In fact, however, Russian speakers do not always treat metaphoric Second-Declension feminine nouns with human male referents or modificands as inherently feminine and they hesitate when asked about proper usage, especially with respect to verbal predicates associated with figurative Second-Declension feminine subjects, as illustrated in (65).

(65) (a) NeZ'zja že byt' $\left.\begin{array}{c}\text { takoj[fem] } \\ \text { ?takim[masc] }\end{array}\right\}$ trjapkoj.

'But one can't be such a rag.'

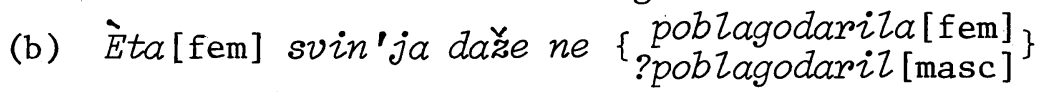
Ninu AZekseevnu.

'That pig did not even thank Nina Alekseevna.'

(c) Eta[fem] staraja[fem] baba ne $\left.\begin{array}{c}\text { tronulas'[fem] } \\ \text { ?tronulsja[masc] }\end{array}\right\}$ $s$ mesta.

'That old woman did not make a move.'

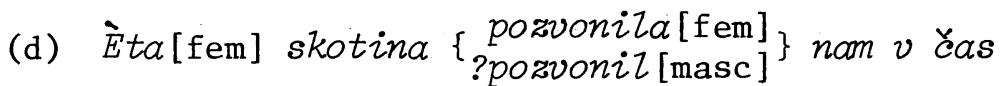
noči.

'That bovine called us at one a.m.'

${ }^{30}$ The noun golova 'head' also falls within this category when used with a modifier metonymically, e.g., gorjačaja golova 'hothead.' 
Speakers vary in their judgments and do not respond uniformly with respect to all nouns. A masculine verb in association with skotina 'bovine' in a sentence such as (65d), for instance, is generally found more acceptable than a masculine verb in association with baba 'woman' in a sentence such as (65c), and masculine attributives in association with both skotina and $b a b a$ in sentences such as $(65 c-d)$ are found considerably less acceptable than a masculine: attributive in association with trjapka 'rag' in a sentence such as (65a). Note also the masculine attributive modifying svin'ja 'pig' in the following sentence from Che:khov's "Xameleon" (cited in Efimov 1969, 133): Ona, moǐset byt', doragaja, a ě̌eli každyj[masc] svin'ja budet ej $v$ nos sigarkoj tykat' ...' 'it may be an expensive one, and if every pig sticks a cigarette into its nose ...' The noun svin'ja 'pig' is used in this sentence generically, and the masculine ending of the attributive may possibly represent unmarked animate gender rather than the sex of a referent.

In $(65 b-d)$, since the subject phrases are metaphoric references to males, they may be accounted for as proper names, as phrases analogous to nicknames such as Krasnaja Sapočka 'Little Red Riding Hood' or Sinjaja Boroda 'Blue Beard.' Gender manifestations in association with such nicknames are not determined by the inherent gender of the stems but by the sex of the referents (if Krasnaja Sapočka 'Little Red Riding Hood' were a boy, constituents associated with the name would have masculine endings).

Phrases such as etta skotina 'that bovine' or eta staraja baba 'that old woman' can thus be accounted for as ad hoc nicknames.

In (65a) and in the sentence from Chekhov's story, the nouns trjapka 'rag' and svin'ja 'pig' are not used as specific references and cannot be viewed as proper names. In these sentences, speakers who accept masculine attributives apparently do not consider the illustrated nouns metaphoric but rather independent, inherently <+human> nouns, and these nouns are treated as epicenes because their semantic content is typical of epicenes and, like epicenes, they follow the Second Declension. This conception shows minimal linguistic sophistication, for it discounts metaphor. Perhaps this is why masculine attributives are generally less acceptable than masculine verbs (cf. also Gorbačevič 1973, 515). Be that as it may, these 
epicene-related phenomena are quite marginal and we will not dwell on them any further. 31

\subsection{Indeclinable Common Nouns}

Contextually-dependent gender manifestations may occur with any indeclinable animate noun whose denotation is not restricted to members of one sex only, i.e., any indeclinable animate noun which is not sex-differentiating. Indeclinable nouns such as ledi 'lady' and dendi 'dandy,' for example, should be marked in the lexicon <-male> and <tmale>, respectively; they are therefore feminine and masculine, respectively, and gender manifestations in association with them cannot be contextually dependent (excluding metaphoric use). Nouns such as proteðe 'protege' and šimpanze 'chimpanzee,' on the other hand, are asexual and there is no reason to assume that they have inherent gender features. The gender of constituents associated with them can either correspond to the sex of their referents or be masculine.

Such nouns can be assumed to bear the specification [+Animate] (manifested by attributives associated with them in the accusative case), and the gender of associated constituents can be assumed to be determined essentially as in association with epicenes: NP nodes which dominate asexual indeclinable nouns bear the combination

${ }^{31}$ Note also that feminine Second-Declension nouns may be especially susceptible to metaphoric usage in reference to human males because of the potential analogy with epicene nouns.

In Nikitevič 1963 (p. 34) there is a sentence cited from Mamin-Sibiryak in which a masculine verb is used in association with the neuter noun cucelo 'scarecrow' as metaphoric reference to a person: Ej pokazalos', čto proß̌la celaja večnost', poḱa čučelo vël [masc] peregovory 'it seemed to her that a whole eternity passed while the slob [1it. scarecrow] was negotiating.' The masculine ending of the verb can perhaps be taken as evidence that metaphoric neuter nouns also lend themselves to treatment as proper names, but it is more likely that cučelo is treated as epicene in this sentence by association with $i$ ts substandard Second-Declension variant čučela (cf. Mučnik 1971, 194-195 and Rozental' 1971a, 161). 
[-Masculine, -Feminine, +Animate] after the [+Animate] specification has been copied onto them from the dominated stem, the anomalous combination is resolved by a switch to contextual sex, and if there is none--by the Unmarked Animate Gender Rule.

The gender manifested in association with most asexual indeclinable nouns denoting humans or animals is almost always masculine in actual usage, and such nouns are therefore generally classified as masculine (just as inanimate indeclinable nouns are classified as neuter on the basis of the unmarked gender manifested by constituents associated with them), though some grammarians add with respect to indeclinable nouns the caveat that although such nouns are masculine, constituents associated with them may have feminine endings when their referents are female (see, e.g., Nikitevič 1963, 41; Rozental' 1971a, 166; and Valgina et al. 1971, 171; cf. also the critical comments in Mućnik 1971 , 282-283, with regard to gender labels in the fourvolume Academy dictionary and statements on gender in the Academy grammar.)

Constituents associated with asexual nouns denoting humans almost always manifest masculine because of what might be called today "sexism"--there are no women to whom nouns such as kmp'e 'croupier,' guru 'guru,' or xobo 'hobo' can apply. Such nouns are nevertheless not inherently sex-differentiating and not inherently masculine and could apply to women, in which case the gender manifested in association with them would be feminine (but see footnote 38 below). A noun such as konferans'e 'master of ceremonies,' for example, is labelled in all dictionaries as masculine, yet in reference to a lady one would say, e.g., Na scenu vyšla[fem] konferans'e 'on stage appeared the master of ceremonies,' with a feminine verb, rather than $\mathrm{Na}$ scenu vyšel[masc] konferans'e, with a masculine verb, which could only be appropriate in reference to a man (or in reference to a master of ceremonies of indefinite sex--if the stage was dark, for example).

Constituents associated with asexual nouns denoting animals almost always manifest masculine because in most contexts sex is an irrelevant parameter for animals such as zebu 'zebu,' gnu 'gnu,' poni 'pony,' or flomingo 'flamingo.' Classical examples for the use of such nouns in reference to females are Šimpanze kormila[fem] detënyša 'the chimpanzee was nursing [her] baby' and Kenguru nesla [fem] $v$ sumke kengurënka 'the kangaroo was carrying in her pouch a little one' (see, e.g., Rozental' 1971a, 166). 
Another source of feminine endings in association with indeclinable nouns denoting animals are generic nouns, for in association with certain indeclinables the manifested gender can be the gender of their generic designations. The nouns in question can be said to function as proper names (by virtue of their being names of species; cf. Section 4.2 above).

The noun cece 'tsetse,' for example, is labelled as feminine in all dictionaries and can be assumed to derive in sentences from the combination muxa[fem] cece 'the fly tsetse.' The noun ivasi 'iwashi' is also labelled as feminine in all dictionaries and can be assumed to derive in sentences from the combination ryba[fem] ivasi ' the fish iwashi' (Stankiewicz [1968, 90] suggests also possible association with sardinka 'sardine,' and Rozental' 1968 [p. 86] suggests sel'd' 'herring' [cf. also Rozental' 1971a, 166]). The noun kolibri 'colibri,' labelled masculine and feminine in the four-volume Academy dictionary and in Ozhegov's dictionary, apparently functions either as a regular common noun, in which case constituents associated with it manifest the unmarked animate gender, masculine, or as proper name, in which case constituents associated with it have feminine endings--the gender of ptica 'bird.' (Skoblikova [1967, 43] cites Vsporscnula [fem] kolibri 'a colibri took to the air,' where the verb has a feminine ending, to illustrate colloquial, casual usage; kolibri is classified as only masculine in the seventeen-volume Academy dictionary and in Ushakov's dictionary. A few additional indeclinable animate nouns which fall in this category are mentioned in Rozental' 1971a, 166 and Sanskaja 1964a, 17.)

\subsection{Indeclinable Proper Names}

Gender manifestations in association with indeclinable proper names for animate beings are determined by the sex of the referents when the names are not inherently sex-differentiating. The principles which determine the manifested gender are thus the principles which apply in association with declinable asexual proper names, e.g., Saša (see Section 7.2), and also in association with indeclinable common nouns which denote animate beings without differentiating sex, e.g., proteze 'protegé,' except that in association with nouns of the latter category gender may also be determined by the Unmarked Animate Gender Rule (see Section 7.4). 
It is noteworthy that proper names for animate entities differ from proper names for inanimate entities in that they identify the referents directly and are not associated with generic nouns. A name such as SanFrancisko, for example, can be assumed to derive from the combination gorod San-Francisko 'the city [of] San Francisco,' for the gender manifested in association with it must be masculine, but it would be implausible to assume that a name such as Dðerri, for example, derives from combinations such as devuskka Dæerpi 'the girl Jerry' or mužina D̋erri 'the man Jerry.' Furthermore, if D̋erri were the name of a pet animal, the gender manifested in association with the name would not be the gender of a generic noun such as sobaka 'dog,' enot 'racoon,' or ptička 'birdie,' but rather the gender which corresponds to the animal's sex. Why this is so is beyond the scope of the present investigation. 32

The sentences under (66) illustrate verbal predicates with endings determined by the sex of the persons referred to by the proper names o'Brajen and Silkvud.

(66) (a) O'Brajen napisala[fem] roman "Noč", soderžanie kotorogo-vospominanija starejuščej" damy.

'O'Brien has written a novel [entitled] "Night," which relates the memories of an elderly lady.'

(b) Sizkvud obratilas'[fem] $v$ profsojuz $i$ vmeste $s$ rabočimi načala[fem] sobirat' dannye.

'Silkwood turned to the labor union and together with the workers began collecting data.'

There are essentially three categories of asexual indeclinable names. The first subsumes surnames such as Sedyx, Molodyx, Dolgix, and Russkix, which cannot decline because their stems end with what looks like an inflectional ending (historically a genitive ending) and they are apparently perceived as oblique case forms. One might assume that the declension of such stems is blocked by a morpheme boundary before the sequence -ix (and that

${ }^{32}$ Names for animate entities do resemble names for inanimate entities in that in combinations they may remain uninflected, e.g., ot generala[gen] de Golzja[gen]/de Golz' 'from General de Gaulle' (Unbegaun 1947, 139). 
speakers who do decline such names [Superanskaja 1965, 128 and Rozental' 1971a, 169] do not recognize a morpheme boundary within the stems).

The second category subsumes names whose stems end in a vowel, e.g., Dzerri, Verdi, Gjugo (Hugo) Bize (Bizet), Sou (Shaw), Sotá, Djumá, and Fonda, the last name illustrated in (67). (Note that in names of Slavic origin such as Glinka or Verşigora the final $-a$ is not a stem vowel and they do decline.)

(67) Mne prijatno videt' v Zice Ďejn Fonda čerty ëe otca--znamenitogo amerikanskogo aktëra Genri Fonda. 'I find it pleasant to see in Jane Fonda's face the features of her father--the famous American actor Henry Fonda.'

What sentence (67) illustrates in that Fonda in itself is not sex-differentiating, and also that it does not decline, for otherwise it would have genitive endings in both instances. (The sentence also illustrates the indeclinability of the names Genri and DZejn, the latter because it cannot follow the Second Declension [see below].)

Non-Slavic names which end in unstressed $-\alpha$ following a consonant, as in Fonda, of ten do decline, for the final $-a$ can be perceived as a nominative Second-Declension ending, as in Slavic names such as Glinka. The surnames Lumumba, Gevara, Lorka, and Kurosava (Kurosawa), for example, do normally decline--though, interestingly enough, Kurosawa's first name, Akira, may remain indeclinable, as in, e.g., Teper' my otpravimsja s Akira Kurosavoj [instr] 'now we will set out with Akira Kurosawa' (on the declinability of names ending in $-a$ see Zaliznjak 1967a, 216 and Rozental' 1971a, 169).

The category of indeclinable names whose stems end in a vowel also subsumes Russian surnames such as Yivago and Durnovo (cf. Sections 5.23 and 5.4 above on sex-differentiating names which end in -0 ), and it also subsumes Ukranian surnames which end in $-k o$, e.g., Avereenko, Makarenko, though such Ukranian surnames have a somewhat uncertain status with respect to declension (cf. Unbegaun 1947, 139; Isačenko 1965, 59; Superanskaja 1965, 126-127; Zaliznjak 1967a, 216; Mučnik 1971, 271; Rozental' 1971a, 170; and Krysin 1974, 193-199).

The third and last category of asexual indeclinable names is an interesting one, for it subsumes surnames 
whose stems end in a consonant (including j, e.g., Adžubej) and do not decline only when identifying females. The names O'Brajen and Silkvud, for example, illustrated in (66) above, do not decline in reference to females but do decline in reference to males, e.g., in $J a$ govorila $s$ O'Brajenom[instr] 'I spoke to O'Brien,' the name has an instrumental ending and therefore can only refer to a man, for in reference to a woman one would say $\mathrm{Ja}$ govorila $s$ o'Brajen, with the name unaltered.

Names in this category can be assumed to be marked [-Decl II]. They can also be assumed to have no inherent sex, no gender, and no positively specified declension paradigm. Such names are thus deficient, in a sense, and they require further specification. The basis for further specification is the sex of the referent (and there are in fact speakers who do not decline such names at all, regardless of the referent's sex [Superanskaja 1965, 121]). If the sex of the referent is $\{+$ male\}, then the name is masculine and follows the First Declension; if it is $\{-$ male\}, then the name is feminine. It cannot follow the Second Declension because of the [-Decl II] feature and remains indeclinable.

Names which end in a palatalized consonant and have female referents could in principle follow the Third Declension, e.g., names such as C̈ëręiz' (Churchill), Gogol', or Belokon', but they do not. This can be accounted for by the fact that they are not specified as exceptions to the general rule by which the declension paradigm of a stem is determined by its gender, and, moreover, they have no inherent gender and therefore cannot be so specified (cf. Sections 5.3 and 5.4 above).

There are numerous surnames which fall within the category of names with the feature [-Dec1 II], not only foreign but also of Slavic origin, e.g., Begun, Belous, Borodič, Zaliznjak, Komejěuk, Kulik, Münik, Rubec, and Černjak (Mučnik 1971, 253). There are also given names and nicknames within this category, e.g., Vivian, Nevin, and Džin (Jean, Gene), which decline in reference to males and cannot decline in reference to females (see also footnote 22 above). 33

${ }^{33} \mathrm{An}$ alternative approach would be to consider all indeclinable proper names that are applicable to males as well as to females homonymous sex-differentiating names, in which case the name Silkvud, for example, would (cont.) 
8. Contextually Dependent Gender in Association with First-Declension Animate Nouns

8.1 Contextually-dependent gender manifestations are admissible in association with the First-Declension nouns vrač 'doctor,' direktor 'director,' kosmonavt 'astronaut,' muzykoved 'musicologist,' fel'ď̌er 'medical attendant,' fotograf 'photographer,' and others which identify individuals by their specialty or social function. These nouns resemble First-Declension nouns such as rebënok 'child,' podrostok 'teenager,' čelovek 'person,' or drug 'friend' in that they are semantically unspecified for sex and can be used in reference to males as well as females, but they differ from the latter in that gender manifestations in association with them are sensitive to the sex of the referents. In this respect they resemble Second-Declension nouns such as plaksa 'crybaby,' Zakomka 'gourmand,' or zaika 'stutterer,' but they differ from the latter in that contextually-determined gender manifestations are inadmissible in association with these nouns when in oblique cases, cf. (68).
(a) My govorilis $\left\{\begin{array}{c}\text { vašim[instr masc] } \\ \text { vašej[instr fem] }\end{array}\right.$ sekretarëm [instr].
'We spoke with your secretary.'

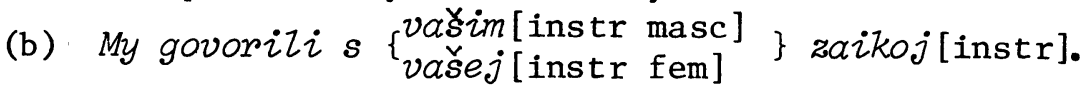 'We spoke with your stutterer.'

The secretary referred to in (68a) may be a woman, yet a feminine modifier is excluded (though a feminine modifier would not be excluded in the nominative case; see

represent an inherently male, masculine name as well as an inherently female, feminine name, with the feature [-Dec] II] blocking its declension in the latter case. Perhaps it could then be assumed that somehow only feminine common and proper nouns bear the negative declension feature. The primary argument against such an account is that it encumbers the system unnecessarily and misses the analogy with epicenes. 
below). In (68b), in contrast, the gender of the modifier must correspond to the sex of the referent and is determined solely by it.

Another difference between asexual Second-Declension nouns and the First-Declension nouns discussed in the present section is that in association with nouns of the latter category, gender manifestations are not necessarily determined by the sex of the referent even when the nouns are in the nominative case. Consequently, while the masculine gender of the verb in (69a) signifies that the referent is male, the masculine gender of the verb in (69b) does not--the referent in this sentence could be a woman (cf., e.g., Nikitevič 1963, 37 and Mučnik 1971, 234).

(69) (a) Zaika eščë ne prił̌Z[masc].

'The stutterer has not arrived yet.'

(b) Sekretar' ešče ne prišël[masc].

'The secretary has not arrived yet.'

In (70), the noun sekretar' 'secretary' is illustrated with contextually-determined gender manifestations.

(70) Novaja[fem] sekretar' vsë $\left\{\begin{array}{r}\text { pereputala[fem] } \\ \text { pereputal[masc] }\end{array}\right.$.

'The new secretary got everything mixed up.'

This sentence is cited in Švedova 1970 (p. 555) to illustrate that a feminine verb is mandatory in association with a First-Declension noun which has a feminine modifier.

The inconsistency of gender manifestations in association with First-Declension nouns which identify individuals by their specialty or social function and refer to women is in part due to the fact that the use of such nouns in reference to women is a relatively new phenomenon. It dates back to the twenties of the present century, and the acceptability of feminine endings in association with such nouns is even more recent. The 1960 Academy grammar, for instance, still considered feminine verbs in association with First-Declension nouns an outright violation of the norms of agreement (Vinogradov and Istrina 1960, 510), and feminine modifiers were not even mentioned as a possibility in the section on the agreement of attributive modifiers (ibid., 529). As late as the mid-sixities, the noted Russian linguist Reformatsky condemned feminine 
verbs in association with First-Declension nouns as "an abominable corruption of the language" (Panov 1968, 29). The 1970 Academy grammar, in contrast, goes so far as to assert the mandatoriness of feminine verbs in association with First-Declension nouns which have feminine modifiers and it cites sentence (70) as a linguistic fact; only in another section (Švedova 1970, 489) are feminine modifiers characterized as colloquial and informal. (For historical surveys see Janko-Trinickaja 1966; Panov 1968, 19-41; Mučnik 1971, 212-244; and Gorbačevič 1971, 253-256; for a representative list of First-Declension nouns in association with which feminine endings are acceptable see Panov $1968,23-24$ or Mučnik 1971, 224-225.)

In current usage, then, verbal predicates in association with First-Declension nouns of the category under discussion in most cases have feminine endings when the referent is a female (statistical data on speakers' preferences in the mid-sixties are given in Panov 1968, 27-30 [=Mučnik 1971, 229-230]). The following sentences thus represent typical usage.

(71) (a) Komnata ved' toæe ne moja: u nas načal'nik cexa uexala[fem] na dva goda za granicu i ostavila [fem] menja tom ð̌it'.

'The room is not mine either: the head of our shop went abroad for two years and let me stay there.'

(b) Kogda kassir skazala[fem], rto tol'ko za perevozku nado zaplatit' tri mublja, ... to volej-nevolej prišlos' obratit'sja za pomošc'ju $k$ "levaku".

'When the cashier said that just for transportation one had to pay three rubles, ... there was no choice but to turn to a "moonlighter" for assistance.'

(c) Etot nomer zurnala avtor pis'ma prjataZa[fem] pod matrac.

'This issue of the magazine was hidden by the author of the letter under a mattress.'

Verbal predicates with masculine rather than feminine endings seem to occur chiefly in formal discourse. Sentence (72) is a typical example: the author of a scientific article acknowledges helpful comments from colleagues, and although the author is a woman, the verbal predicate associated in the acknowledgement with the noun 
avtor 'author' has a masculine ending. Moreover, even the personal pronoun associated with avtor is masculine. ${ }^{34}$

(72) Avtor gluboko priznatelen[masc] N.N. Leont'evoj, M.V. Lomkovskoj, .... i E.D. Stockomy, s kotorymi on imel vozmoznost' obsudit' ètu rabotu.

'The author is deeply grateful to N.N. Leontieva, M.V. Lomkovskaya, ... and E.D. Stotsky, with whom he [the author] has had the opportunity to discuss this work.'

The gender manifested by attributive modifiers associated with First-Declension nouns such as avtor can be feminine only when the modifiers apply to the referents of the nouns, but not when they apply to the specialities or social

${ }^{34}$ The relationship between pronouns and their antecedents is outside the scope of the present study, but on 'he' in (72) in reference to an authoress cannot be passed over. This pronoun seems to provide indisputable evidence in support of the view that at least some pronouns are products of syntactic transformations. One could perhaps argue with respect to the feminine pronouns ona 'she' in (i) below and ta 'the latter' in (ii), for example, that they derive independently of their antecedents avtor 'author' and zoatexnik 'livestock specialist,' respectively, but it would be quite difficult to account for the masculine pronoun in (72) in the same way.

(i) Postepenno avtom pis'ma, kak ona sama i govorit, stalo jasno, čto obsuždenie ljubovnyx kollizij v p'ese--liš' pervyj, poverxnostnyj sloj.

'It gradually became clear to the author of theletter, as she herself says, that the discussion of amorous conflicts in the play was only its outer, superficial layer.'

(ii) Ivanov poručil zootexniku razobrat'sja, v čëm tam delo, no $i$ ta[fem] prišla ni s cem.

'Ivanov charged the livestock specialist to find out what was going on, but she too did not come up with anything.'

The most plausible account for the pronoun in (72) seems to be that it represents an underlying second occurrence of avtor 'author' and derives transformationally. 
functions denoted by the nouns (on referent versus reference modifications see Bolinger 1967). In the sentences under (73), for example, the attributive modifiers in the subject phrases do not apply to the referents individually; they are reference modifiers. Hence they cannot have feminine endings even though the verbs do have such endings.
(a) $\left\{\begin{array}{c}\text { GZavnyj[masc] } \\ \text { GZavnaja[fem] }\end{array}\right\}$ vrač polikliniki skazala[fem], čtoby ja prošla VTËK.
'The head doctor at the clinic said that I should be examined by a medical commission of
experts.'

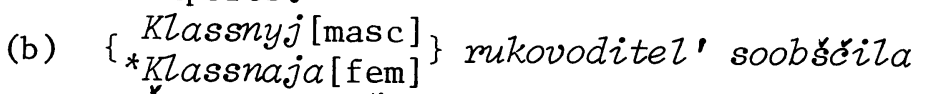 Česnokovu, ¿to on perevedën $v$ devjatyj klass. 'The class supervisor informed Chesnokov that he had been promoted to the ninth grade.'
(c) $\left\{\begin{array}{c}\text { Priiskovyj[masc] } \\ * \text { Priiskovaja[fem] }\end{array}\right\}$ sčetovod ser'ëzno zabolela [fem].
'The mine accountant has come down with a serious illness.'

The sentences under (74) illustrate determiner-type modifiers and other attributive modifiers which do apply to the individual referents and have feminine endings (sentences (a) and (b) are cited in Skoblikova 1971, 182; (c) is cited in Panov 1968, 38; and (d) is from a recent story in Junost'; see also (70) above).

(74) (a) Ėta[fem] prodavec medlenno otpuskaet.

'This salesperson works slowly.'

(b) Odin raz naša [fem] počtal'on zabolela [fem]. 'Once our mail-carrier fell sick.'

(c) Muzyku k našemu fil'mu pišet molodaja[fem], no izvestnaja[fem] kompozitor.

'The musical score for our film is being written by a young but wel1-known composer.' 
(d) Vot tolstaja[fem], kruglolicaja[fem], s jamočkami na ščekax, brigadir brigady prjadil'šcic.

'Here is the stout, round-faced captain of the spinners' team, with dimples in her cheeks.'

Sentence (75) below illustrates the First-Declension noun vrač 'doctor' with two modifiers, only the first of which applies to the referent and has a feminine ending (this sentence is cited in Skoblikova 1971, 183; Skoblikova seems to be the only investigator to have noticed that attributive modifiers differ in their sensitivity to contextual sex in association with First-Declension nouns [ibid.]; Protchenko [Protčenko 1961, 121] only notes that it is determiner-type modifiers which have feminine endings).

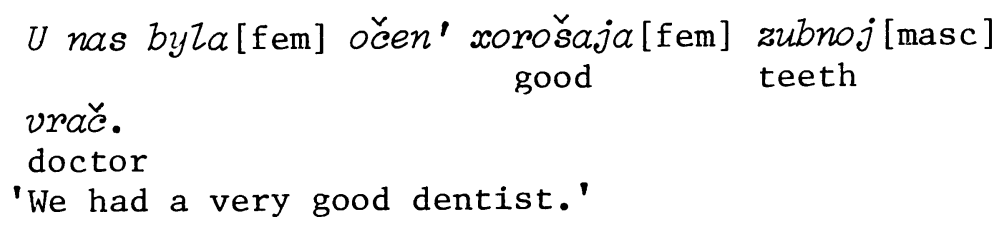

U nas byZa[fem] očen' xorošaja[fem] zubnoj[masc] vrač. good teeth doctor

'We had a very good dentist.'

Feminine endings for attributive modifiers associated with First-Declension nouns are generally avoided, however, not only in formal discourse but also in informal contexts (cf., e.g., the statistical data on speakers' preferences in Panov 1968, 39 or Mučnik 1971, 242-243). The sentences under (76) below are thus most typical, for the verbs have feminine endings corresponding to the sex of the referents but the attributive modifiers associated with the subject nouns have masculine endings although they are not reference modifiers.

(76) (a) Naš[masc] sekretar' vyšla[fem] zamiž i uezžaet. 'Our secretary got married and is going away.'

(b) Molodoj[masc] agronom načala[fem] prosmatrivat' plastinki.

'The young agronomist began to look through the records.'

8.2 Nouns such as sekretar' 'secretary,' agronom 'agronomist, ' vrač 'doctor,' etc. were referred to in 8.1 as First-Declension rather than masculine nouns, for it seems that what distinguishes such nouns from other First-Declension nouns which apply to females but do not allow 
contextually-determined gender manifestations is the fact that they have no inherent gender. .A verb associated with a First-Declension noun such as rebënok 'child,' for example, cannot possibly have a feminine ending in reference to a female, but in association with a noun such as agronom 'agronomist' a feminine ending is acceptable. The difference can be accounted for by assuming that the noun rebënok and others like it have an inherent gender, whereas the noun agronom and others like it are only specified [Dec I] .35

Nouns of the latter type are analogous to nouns such as plaksa 'crybaby' or zaika 'stutterer,' which also only have an inherent declension paradigm and no inherent gender. Gender manifestations in association with agronomtype nouns do not follow the pattern observed in association with Second-Declension epicenes, however, because the relation of the two declensions to gender is not parallel: while there are Second-Declension nouns which are masculine, there are no First-Declension nouns which are feminine. This fact can explain why contextually-determined gender manifestations are obligatory in association with Second-Declension nouns of unspecified gender but optional in association with First-Declension nouns, and also why contextually-determined gender manifestations in association with First-Declension nouns are characteristic of verbal predicates rather than attributive modifiers (see below). 36

${ }^{35}$ Rothstein (1973) also suggests that nouns such as agronom are not specified for sex, but he views such nouns as inherently masculine, which does not account for their difference from First-Declension nouns which do not allow contextually-determined gender manifestations, nouns such as rebënok 'child' and celovek 'person.'

${ }^{36}$ The differences between gender manifestations in association with agronom-type nouns and plaksa-type nouns also extend to related phenomena. When a Second-Declension masculine noun such as sud'ja 'judge,' for example, is treated as analogous to plaksa-type nouns (cf. Section 7.32 above), an attributive modifier associated with it may have a feminine ending also in oblique cases (cf. ob étoj[1oc fem] sud'e[1oc] 'about this judge'). When a First-Declension name such as Nineik or Verok is treated as analogous to agronom-type nouns (cf. pp. 53-54 above), an attributive modifier associated with it cannot possibly have a feminine ending in oblique cases. 
To take a concrete example, the relevant specifications in the underlying representation of the sentence Naš [masc] sekretar' moľcala[fem] 'our secretary was silent' after the specifications of the noun stem have been copied up can be assumed to be as shown under (77).

(77)

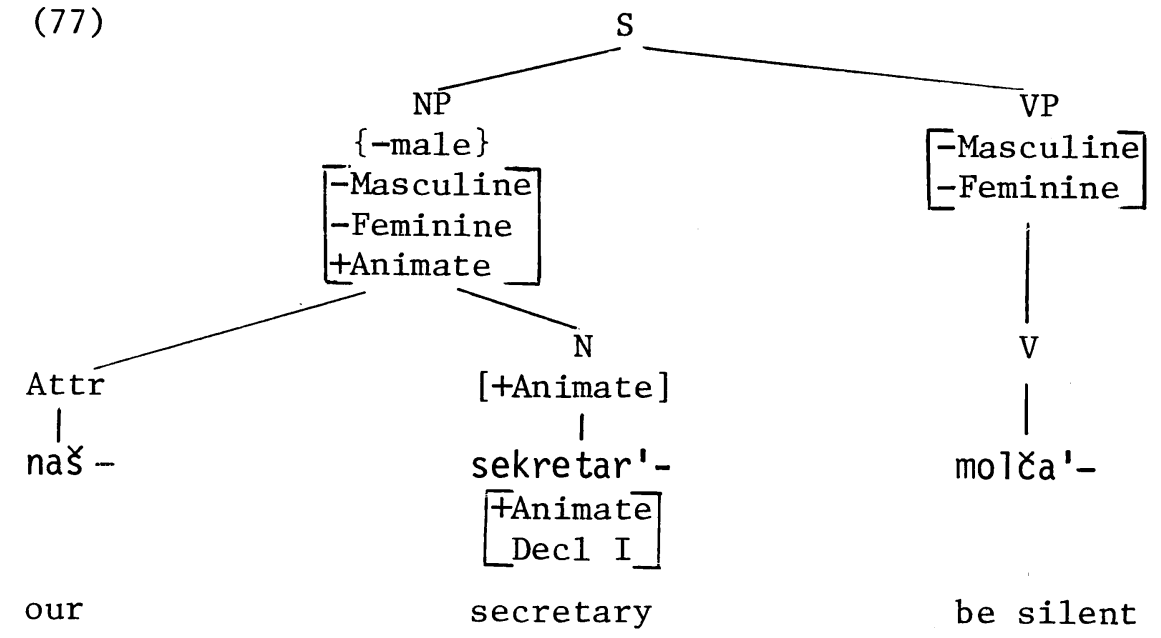

Attributive Agreement fails to provide the Attributive node with gender specifications, because the $\mathrm{N}$ node has none, but in this case, in distinction from similar cases discussed above, the declension paradigm of the stem can provide specifications: the Attributive node receives masculine specifications on the basis of the [Decl I] feature of the stem.

In Verb Agreement, the $\mathrm{V}$ node must assume the features of the subject NP node, which in this case bears an anomalous combination. The combination is resolved as feminine on the basis of the contextual sex specification on the same node, and the $\mathrm{V}$ node thus receives feminine specifications.

This can be considered the standard procedure in informal discourse, and it accounts for the gender manifestations in the sentences under (76).

In formal discourse, and in the speech of some speakers, nouns such as sekretar' are treated as inherently masculine and the gender manifested by constituents associated with them must be masculine (cf. (72) above). There are several possible ways of accounting for this phenomenon. The most plausible one seems to be by postulating a rule which specifies such nouns as masculine on 
the basis of the feature [Dec1 I] (this rule is the inverse of the rule which specifies inherently masculine nouns as following the First Declension). This rule can be considered obligatory in formal style.

Feminine attributive modifiers in association with First-Declension nouns in the nominative case (as in (78) above) are of marginal acceptability yet prevalent enough to merit attention. All one can say about such gender manifestations, however, is that in general they can be accounted for as a consequence of determining the gender of Attributive nodes by the sex of the referent on the higher NP node, as in association with epicene nouns (rather than by the declension paradigm of the noun dominated by the associated $\mathrm{N}$ node).

This procedure for determining the gender of Attributive nodes can only take place within nominative subject phrases, for attributive modifiers with feminine endings are excluded in association with First-Declension nouns in oblique cases (cf. (68) above), and nominative predicate phrases have no contextual sex; consider (78).

$$
\text { Ona }\left\{\begin{array}{c}
\text { xorošsij [masc] } \\
\text { *xorošaja[fem] }
\end{array}\right\} \text { vrac. }
$$

'She is a good doctor.'

As mentioned above, the 1970 Academy grammar points out that masculine verbs are excluded in association with First-Declension nouns modified by feminine attributives (e.g., Novaja[fem] sekretar' vsë pereputala[fem]/*pereputal [masc] 'the new secretary got everything mixed up'). This observation follows from the account offered above, for a feminine attributive can only be determined by the sex of the referent, a procedure which is only possible when the $\mathrm{N}$ node with which the Attributive node is associated has no gender specifications. There is then no possible source for masculine specifications to be assigned to the verb. The NP node could possibly be specified as masculine by the Unmarked Animate Gender Rule, but then that rule is only applicable when no contextual sex is available (see Section 7.122 above), as in, e.g., (79).

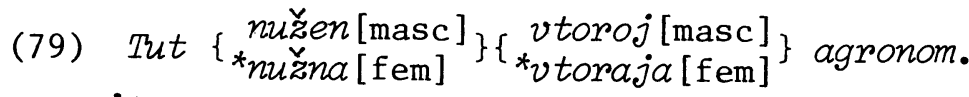
'A second agronomist is needed here.' 
Another phenomenon which calls for additional comment is the restriction of attributive modifiers used as reference modifiers to masculine endings in association with First-Declension nouns of unspecified gender, as illustrated in (73) above with respect to glavnyj[masc]/ * glavnaja[fem] vrac 'head doctor,' klassnyj[masc]/ * Klassnaja[fem] mikovoditel' 'class supervisor,' and priiskovyj[masc] / 'priiskovaja[fem] sčetovod 'mine accountant.'

This phenomenon can be accounted for if reference modifiers are treated as initial components of composite nouns, analogous to the initial components in composite noun combinations such as kreslo-kačalka 'rocking chair' (1it. 'armchair-rocker'). The view of reference modifiers as components of composites is motivated by the semantic and syntactic cohesion of such modifiers with the nouns they modify (cf. Bolinger's statement [1967, 32]: "There is no way to draw a line between reference-modification and compounds"). 37

According to this assumption, the underlying configuration of the subject phrase in (73c) (Priiskovyj[masc] sčetovod ser'ëzno zabolela[fem] 'the mine accountant has come down with a serious illness') and the relevant specifications after the stem specifications have been copied would be as in (80).

37 Molinsky 1973 (p. 21, citing Babby 1975) suggests that all relational adjectives constitute composites with the nouns they modify, but there is no evidence to justify such an assumption. Reference modifiers are often relational adjectives, as in klassnyj mkovoditel' 'class supervisor,' priiskovyj sčetovod 'mine accountant,' or zubnoj vrač 'dentist' (1it. 'teeth doctor'), but not always; cf., e.g., glavnyj vrač 'head doctor,' staršij lejtenant 'senior lieutenant.' (For an exploration of possible ultimate underlying sources for relational adjectives in Russian see Sussex 1974.)

Note that reference modifiers in Russian do not constitute compounds with the nouns they modify, for they do decline. 
$(80)$

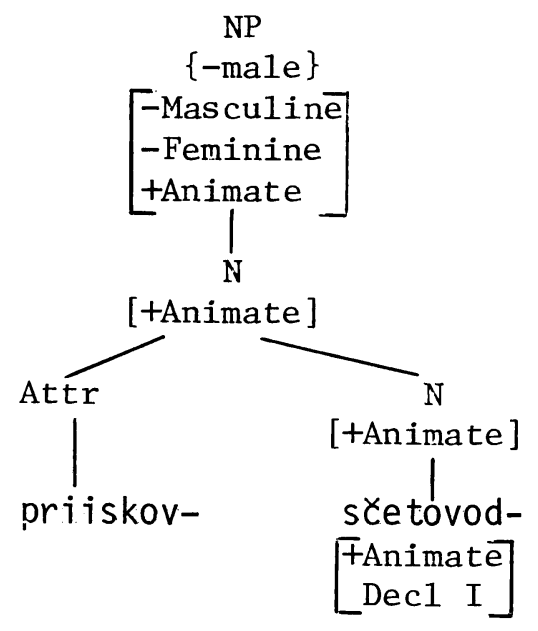

mine

accountant

The gender of the Attributive node cannot be determined by a switch to the sex of the referent on the NP node because there is an intervening $N$ node: the attributive does not modify the referent of the noun phrase. 38

The corresponding configuration for the subject phrase of (75) (U nas byla[fem] očen' xorošaja[fem] zubnoj [masc] vrač 'we had a very good dentist') would be:

${ }^{38}$ The assumption that reference modifiers are elements of composite combinations in underlying structures and are dominated by $\mathrm{N}$ nodes applies not only to modifiers of First-Declension nouns of unspecified gender. A lady cultural attaché, for example, should be referred to as kul'turnyj [masc] attaše, with a masculine modifier, most probably not because the noun attase is inherently masculine (cf. Section 7.4 above), but because the noun has no inherent gender (and no declension paradigm) and the Attributive node dominating the modifier undergoes the Unmarked Animate Gender Rule. The same account apparently applies also to the masculine ending in narodnyj[masc] sud'ja 'people's judge' when used in reference to a lady by speakers who would not hesitate to say èta[fem] sud'ja 'this judge' (cf. Section 7.32 above and footnote 36). (In narodnaja[fem] sud'ja, cited in Švedova 1970, 320, sud'ja is perhaps treated as a full-fledged epicene, which makes a switch to contextual sex mandatory regardless of the distance of the NP node.) 


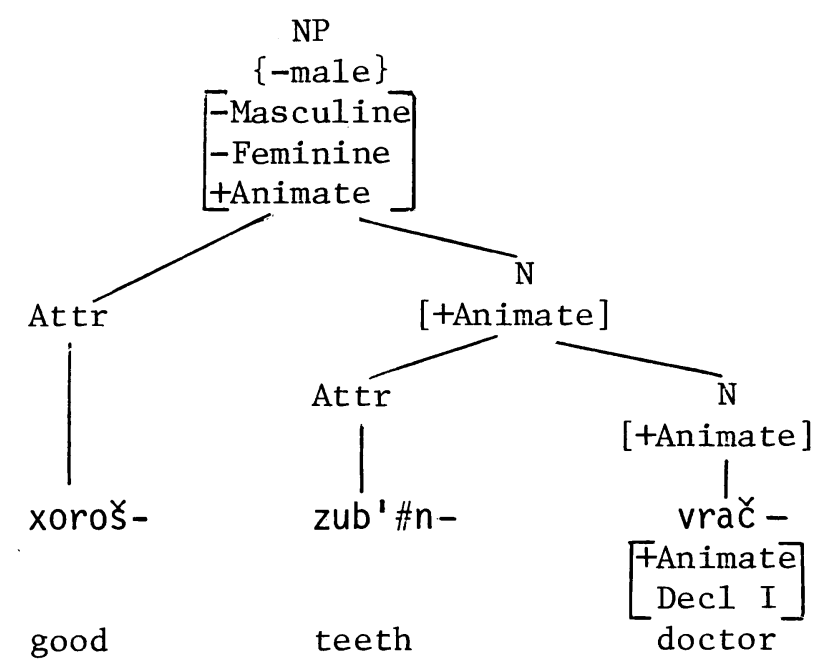

In (81), the Attributive node dominating xoroš- is not separated from the NP node by an $\mathrm{N}$ node and its gender can thus be determined by the sex of the referent. (Note that although the attributive dominated by this node applies to the referent as dentist rather than as human being, it is nevertheless an individual, referent modifier; it does not qualify the notion "dentist" in abstraction [cf. Bolinger 1967].)

The pattern of gender manifestations in association with First-Declension nouns of unspecified gender can also be observed in association with abbreviations such as pomdirektora 'assistant director' (from pomošcnik direktora), predkolxoza 'collective-farm chairman' (from predsedate $($ ' kolxoza), and zaministra 'deputy minister' (from zomestitel' ministra), which consist of the truncated stem of a First-Declension noun of unspecified gender and a full noun in the genitive case (cf. Protčenko 1961, 119; for further examples of abbreviations of this type see Molinsky 1973, 82-86 and 91-92).39 These

${ }^{39}$ In abbreviations with instrumental endings, e.g., zavlaboratoriej 'laboratory manager' and upravdelcomi 'business manager,' the initial elements (zav, uprav) do not represent First-Declension nouns but rather participial forms (zavedujuscij, upravljajušcij). These have feminine counterparts (zavedujuščja and uprovljajuščaja) but, apparently by analogy with First-Declension nouns, the masculine participial forms can also be used in 
abbreviations, which cannot be declined (cf. p. 46), evidently are not bona fide indeclinable nouns but rather reduced phrases, and gender manifestations in association with them must be determined before their reduction--as in association with inanimate indeclinable abbreviations (Section 4.32 above). (This method of abbreviation is not a very productive one, according to Alekseev 1966, 32.)

8.3 Finally, a few words about devices for avoiding the need to determine gender for constituents associated with First-Declension nouns which have female referents and no inherent gender. There are two devices employed in colloquial and substandard usage and two which are characteristic of fully normative discourse. The first two are suffixation and dislocation.

Suffixation converts First-Declension nouns of unspecified gender into Second-Declension feminine nouns, e.g., vrač>vračixa 'lady doctor,' agronom>agronomša 'lady agronomist,' počtal'on>počtal'onša 'mailwoman' ('lady mailcarrier'), and geolog >geologinja 'lady geologist' (for historical background and further data on such suffixation in current usage see Nikitevič 1963, 31-32; JankoTrinickaja 1966, 180-181; Šanskij 1967, 8; Panov 1968, 3738; Gorbačevič 1971, 143-144; Mučnik 1971, 220-222; Rozental' 1971a, 163-165; and Krysin 1974, 277-296).

Dislocation is an operation which results in sentences such as (82).

$$
\begin{aligned}
& \text { Direktor-- }\left\{\begin{array}{l}
\text { ona } \\
\text { ta[fem] }
\end{array}\right\} \text { nam ničego ne skazala[fem]. } \\
& \text { 'The director- }\left\{\begin{array}{l}
\text { she } \\
\text { that [one] }
\end{array}\right\} \text { told us nothing.' }
\end{aligned}
$$

A First-Declension noun which has a female referent is moved out of the sentence in which it occurs in the underlying structure and is replaced by a personal or

reference to females, as asexual nouns; e.g., upravijajuščij[masc] trestom Nikitina' the trust manager Nikitina' (Rozental' 1971a, 164; cf. also Mučnik 1971, 206). The abbreviations may apparently represent participial forms of either gender. 
demonstrative pronoun which matches the sex of the referent (for an extensive discussion of this phenomenon in general in contemporary Russian see Zemskaja 1973, 272-285 [sentences such as (82) are referred to on p. 279]; cf. also pp. 29 - 31 above).

The two devices characteristic of fully normative discourse involve the substitution of sex-differentiating noun combinations for single First-Declension nouns. Such combinations are discussed in the following section.

\section{Gender in Association with Animate Noun Combinations}

9.1 Consider the gender manifested in (83) in association with the composite combinations devuška-sekretar' 'gir1 secretary' and predok-tëtka 'ancestral aunt' (lit. 'ancestor aunt') ((83b) is from a humoristic story in Junost').
(a) Za stolom $\left\{\begin{array}{c}\text { sidela[fem] } \\ * \text { sidel[masc] }\end{array}\right\}\left\{\begin{array}{c}\text { simpatiǒnaja[fem] } \\ \text { simpatiönyj[masc] }\end{array}\right\}$ devuška-sekretar'.
'At the table sat an amiable girl secretary.' predka-deda.
'Finally the ancestral aunt overcame the ancestral uncle.'
(b) $V$ konce koncov predok-tëtka $\left\{\begin{array}{c}\text { odoleZa[fem] } \\ \text { odolel[masc] }\end{array}\right\}$

What the sentences under (83) illustrate is that the gender manifested in association with a composite noun combination denoting a human being is not the gender of the initial noun within the combination, as in association with inanimate composites (Section 3.1 above), but rather the gender of the sex-differentiating noun within the combination: devuška 'girl' in (83a), and tëtka 'aunt' in $(83 b)$.

The awkwardness involved in the use of First-Declension nouns in reference to females can thus be avoided by using these nouns in combination with nouns denoting females. Most commonly they are used in combination with Ženščina 'woman' or devuška 'girl,' as in ženščina-vrač 'lady doctor,' ¿enక̌ina-agronom 'lady agronomist,' devuška-bibliotekar' 'gir1 librarian,' and devuškasekretar' 'girl secretary.' Nouns denoting females 
usually precede First-Declension nouns in combinations, as also in devočka-podrostok 'teenage girl' (1it. 'girl teenager'), stamuška-docent 'old-woman lecturer,' aspirantkageolog 'female graduate student in geology' (1it. 'femalegraduate-student geologist'), and pisatel'nica-satirik 'female-writer satirist.' The gender manifested in association with combinations of this sort is therefore usually the gender of the initial noun, as in association with inanimate composites. However, the gender manifested in association with atypical combinations such as predoktëtka 'ancestral aunt,' as in (83b), or sekretar'mašinistka 'secretary typist,' as in černoglazaja[fem] sekretar'-mašinistka 'black-eyed secretary-typist' (cited in Protčenko 1961, 121), where the "female marker" is not the initial component, demonstrates that it is the gender of the sex-differentiating stem which must be manifested by associated constituents.

An interesting combination of a male sex marker and a Second-Declension noun is considered in Rozental' 1968, 277. It involves the noun pračka 'launderer,' which in the Soviet Union is a female designation, i.e., it signifies 'launderess.' In India there are male launderers, and Rozental' suggests using in reference to an Indian launderer the combination mǚcina-pračka 'man-launderer,' as in, e.g., そ̌ena ètogo[masc] muðčiny-prački 'the wife of that man-1aunderer.' Such usage strips pračka of its <-male> feature, for otherwise the combination would be anomalous. (A less desirable variant he suggests is žena ètogo[masc] "prački," where the noun is stripped not only of its sex but also of its gender and is treated as epicene.)

When a combination consists of two (or more) sexdifferentiating nouns, they inevitably signify the same sex and thus have the same gender, e.g., ženšdina-mat' 'woman [and] mother,' vdova nemka 'German widow' (1it. 'widow German-woman'), brat amerikanec 'American brother' (1it. 'brother American-man'), or starik otec 'old father' (1it. 'old-man father'). When a combination denoting human beings contains no sex-specified nouns, it typically consists of First-Declension nouns of unspecified gender, e.g., inžener-èlektrik 'electrical engineer' (1it. engineer electrician'), or vrač-ximik 'doctor [and] chemist,' and the gender manifested in association with it is determined as in association with single First-Declension nouns of unspecified gender. 
9.2 The principles presented so far only apply to composite combinations which denote human beings. They do not apply to compound combinations, i.e., combinations in which only the terminal constituent noun declines, and they do not apply to composite combinations denoting animals.

Compounds denoting humans subsume attributive combinations, e.g., boj-baba 'lively woman,' čudo-rebënok 'marvellous child,' and gore-mikovoditel' 'miserable leader' (Orlov 1961, 90-92; Sanskaja 1964a, 15; and see also Section 3.2 above on attributive combinations), and they subsume set appositive combinations, e.g., צef-povar 'chef' (lit. 'chief-cook'), general-Zejtenant '1ieutenant general,' and, in colloquial usage, ělen-korrespondent 'corresponding member [of the Academy]' (Gorbačevič 1973, 518). Compounds denoting animals are, e.g., molot-ryba 'hammerhead fish' and meč-ryba 'swordfish.' The gender manifested in association with all compounds is that of the terminal noun, as in association with inanimate compounds.

Composite combinations denoting animals are treated as inanimate combinations, i.e., the gender manifested in association with them is the gender of the initial noun. This applies not only to combinations of nouns of unspecified sex, e.g., akula-molot 'hammerhead shark' (1it. 'shark hammer'), ptica sekretar' 'secretary bird,' or ryba ërs 'ruff fish' (illustrated in $(84 a-b)$ ), but also to combinations which include a sex-differentiating proper name, as in (84c) (the three sentences are cited in Rozental' 1968, pp. 258, 282, and 259).40

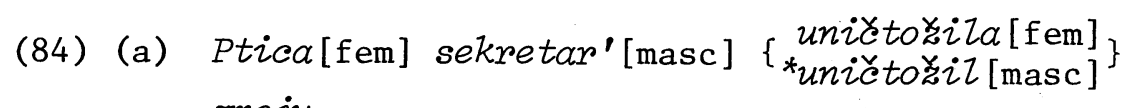
zmeju.

'The secretary bird did away with the snake.'

${ }^{40}$ Note that akula-molot 'hammerhead shark,' where the initial component is a Second-Declension noun, is a composite, as are also pila-ryba 'sawfish' and igla-ryba

'needlefish,' whereas molot-ryba 'hammerhead fish' and meč-ryba 'swordfish,' where the initial components are First-Declension nouns, are compounds. This distribution jibes with the observations in footnote 6 above. 
(b) Deti prosili rasskazat' im o \{ zamě̌atel'noj

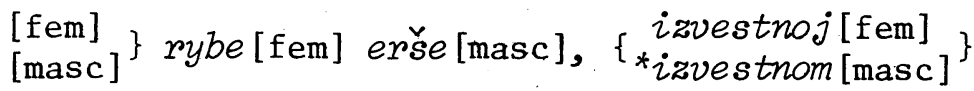
im po skazkam.

'The children asked to be told about the remarkable ruff fish, known to them from folk tales.'

(c) Sobaka[fem] Polkan[masc] $\left\{\begin{array}{l}\text { ZajaZa[fem] } \\ \text { ZajaZ[masc] }\end{array}\right.$

'The dog Polkan barked.'

There is apparently a tendency to avoid combinations as in (84c), where the gender of the initial stem does not correspond to the sex indicated by the proper name. In a story in the last issue of Junost' for 1973, for example (Vladislav Titov, "Razdel"), a male dog named Mišket is referred to throughout the story as either lišket or sobaka 'the dog.' When the common noun is to be accompanied by the proper name, however, it is replaced by the masculine pës 'dog' (both pës and sobaka are asexual), as, e.g., at the end of the story: Utrom na mogize Praskov' $i$ Tixonovny Rybaevoj sdox staryj, poluoslepšij pës Musket 'in the morning, the old, half-blind dog Mushket died on Praskovya Tikhonovna Rybaeva's grave.'

9.3 In combinations with sex-differentiating names which have human referents, the names do determine the gender manifested by associated constituents and there is therefore no corresponding tendency to avoid the use of FirstDeclension nouns with female names. This is indeed the second normative way of avoiding the use of First-Declension nouns in reference to females, for when they occur in combination with proper names, e.g., vrač Petrova 'doctor Petrova,' bibliotekar' Vera Vasil'evna 'librarian Vera Vasilievna,' the gender manifested by associated constituents must be that of the proper names, as illustrated in (85).

(85) (a) Staršij[masc] Zejtenant milicii Ol'ga Koloskova $\left.{ }_{* \text { razyskala[fem] }}^{\text {razask }}\right\}$ Vitju vo dvore u samoškinyx. 'The militia's senior lieutenant 0lga Koloskova found Vitya in Samoshkins' backyard.' 
(b) Izvestnyj[masc] skul'ptor Muxina $\begin{array}{r}\text { sozdala[fem] } \\ { }_{\text {sozdal [masc] }} \text { sozd }\end{array}$ zomečatel'nyj pomjatnik trudu.

'The famous sculptor Mukhina has created a remarkable monument to labor.'

(c) Zomečatel'nyj[masc] sprinter Tamara RyZova snova $\left\{\begin{array}{c}\text { pobedila[fem] } \\ \text { pobedil[masc] }\end{array}\right\}$ na distancii $v 500$ metrov. metrov.

'The remarkable sprinter Tamara Rylova again won the 500-meter race.'

9.4 The sentences under (85) also illustrate the fact that First-Declension nouns in combination with proper names typically have attributive modifiers associated just with them (cf. footnote 9 above). Such attributives can be accounted for as dominated by an $\mathrm{N}$ node, as shown in (86), and hence they cannot receive feminine endings to match the sex of the referents.

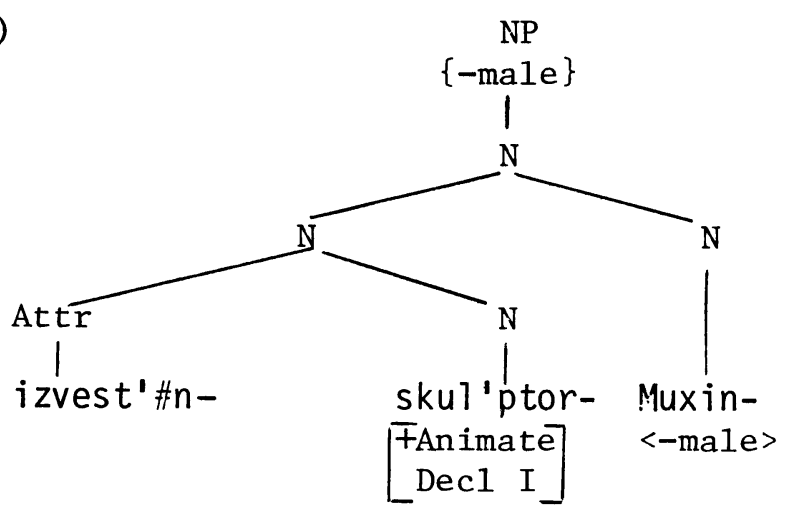

In (86), which shows the putative configuration and relevant features in the underlying representation of the subject phrase in (85b), the gender of the Attributive node can only be determined by the [Decl I] specification of the noun stem dominated by the sister $\mathrm{N}$ node. The gender of the NP node, however, must be the gender of the sex-differentiating noun in the combination, i.e., the proper name. The NP node thus receives feminine specifications, and these are the specifications copied onto the 
verb by Verb Agreement. Note that the sex of the referent actually plays no role in these processes.

The sex of the referent can only play a role indetermining the gender of an attributive if the attributive is associated with an independent noun, as in (87).

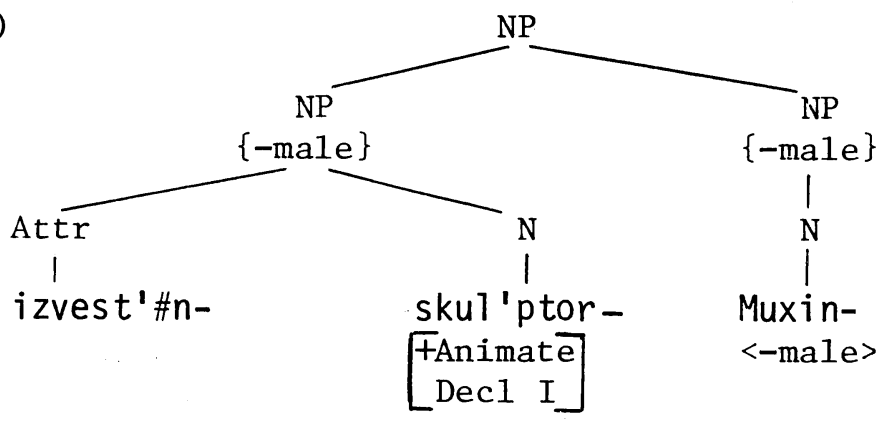

The configuration in (87) is that of an appositive construction (see Section 3.4 above), and the nouns skul'ptor and Muxina would be separated by a comma intonation in the surface phrase--an intonational break absent from (85b). In informal discourse, the attributive can receive a feminine ending in this case, as in (88), but the feminine ending is of marginal acceptability (see Section 8.1 above).

(88) Izvestnaja[fem] skul'ptor, Muxina, molčala[fem] ves' vecer.

'The well-known sculptor, Mukhina, was silent all evening.'

In formal discourse, not only the attributive but also a verbal predicate associated with (87) à subject phrase must receive a masculine ending, as in (89) (cf. also Protčenko 1961, 125).

(89) Ètot pamjatnik sozdal[masc] izvestnyj[masc]

this monument created famous

skul'ptor, Muxina.

sculptor

'This monument was created by a famous sculptor, Mukhina.'

The pattern in (89) is due to the fact that the gender of an appositive construction is the gender of the lefthand NP within it (Section 3.4 above), and in formal 
discourse the gender of an NP dominating a First-Declension noun must be masculine regardless of contextual sex. ${ }^{41}$

The feminine endings of the underlined attributives in (90) are fully acceptable, in distinction from the feminine ending of the attributive in (88), because the attributives in these sentences have a different syntactic position (cf. also Rozental' 1968, 278).

(90) (a) Izvestnaja[fem] vsem nom skul'ptor Muxina known to-all us sculptor sozdala novyj pamjatnik trudu.

'The sculptor Mukhina, whom we all know, has created a new monument to labor.'

(b) Vošeď̌aja[fem] v palatu vrač Petrova napravilas' entered into ward doctor $k$ bol'nomu.

'Doctor Petrova, who had entered the ward, went over to a patient.'

(c) Buxgalteru zavoda V.V. Borodinovoj, prorabotavšej [fem] zdes' 32 god, vydelili kvartim.

'The factory bookkeeper V.V. Borodinova, who has worked here for thirty-one years, has been allotted an apartment.'

The constituent structure of the subject phrase in (90a), for example, can be represented as in (91).

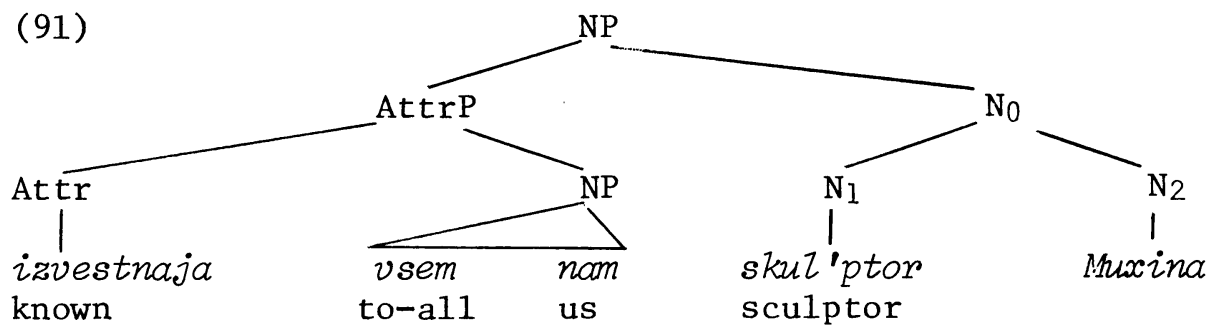

${ }^{41}$ It is difficult to explain why (88) would be an unlikely sentence with a masculine verb (assuming a masculine attributive). The fact that the verb immediately follows the feminine proper name may have something to do with it, and perhaps, more fundamentally, in formal discourse an independent First-Declension noun would not be used as a vehicle of reference in a context where reference is made to a specific female individual. 
The Attributive node must receive feminine specifications because it is dominated by an AttrP (Attributive Phrase) node associated with $\mathrm{N}_{0}$, which in turn must bear the feminine specifications of the sex-differentiating noun in the composite. What this means is that the attributive in (90a) modifies the First-Declension noun as well as the proper noun. It is associated with the composite combination as a whole, which can be demonstrated by the fact that the attributive phrase can be postposed, cf. Skul'ptor Muxina, izvestnaja vsem nom, sozdala novyj pamjatnik trudu.

The foregoing analysis of (90a) also applies to the remaining sentences under (90) (differences between the illustrated attributives have no bearing on the gender they manifest and are hence disregarded in the present discussion).

To recapitulate, a phrase in which a First-Declension noun is preceded by an attributive modifier and followed by a proper name has three possible analyses: the attributive is only associated with the First-Declension noun and together they constitute the lefthand component of a composite noun; (2) the attributive is only associated with the First-Declension noun and together they constitute the lefthand noun phrase in an appositive construction; (3) the attributive is associated with a composite noun consisting of the First-Declension noun and the proper name and it may be moved around the composite noun. In a phrase which fits the first analysis the attributive must have a masculine ending. In a phrase which fits the second analysis it also must have a masculine ending, but a feminine ending may be marginally acceptable colloquially. In a phrase which fits the third analysis, the attributive can only have a feminine ending. 42

${ }^{42}$ When a proper name in a combination has no inherent sex specification, as in, e.g., skul'ptor Sinegub 'the sculptor Sinegub,' the gender and declension of the name must be determined on the basis of the sex of the referent (cf. Section 7.5 above), regardless of the number of $\mathrm{N}$ nodes which may separate the name from the sex specification on the dominating NP node. Once its gender is specified, the name is treated as a sex-specified noun, evidently because it is a proper noun, and its gender becomes the gender of the combination. 
9.5 In conclusion, a few words about the First-Declension noun tovariš 'comrade' are in order. This noun has little semantic content in comparison with other First-Declension nouns of unspecified gender, and phrases in which it is preceded by an attributive and followed by a proper name indeed differ from phrases with other First-Declension nouns in that they tend to fit the third analysis offered above rather than the first, even when the attributive cannot be moved around and has no complement. This is evident in the full acceptability of feminine attributives in phrases such as uvazaemaja[fem] tovarił̌ Petrova

'respected Comrade Petrova' = 'dear Comrade Petrova' (for discussion of this phrase see Panfilov 1965, JankoTrinickaja 1967, and Rozental' 1968, 278).

A related phenomenon is the colloquial tendency to treat combinations of tovarišc and a proper name as compounds, i.e., not to decline tovarišč, as in (92) (cited in Protčenko 1961, 117).

(92) (a) Ne sogZasen s mneniem tovarišc Ivanovoj[gen]. '[I] do not agree with the opinion of Comrade Ivanova.'

(b) Slovo predostavijaetsja tovarišc Petrovoj[dat]. '[I] give the floor to Comrade Petrova.'

This concludes the discussion of gender in association with animate noun combinations.

10 Gender in Numerals, Partitive Constructions, and Nominal Predicates

\subsection{Numerals}

The numerals which manifest gender are 1 lodin[masc], odno [neut], odna[fem]), 1-1/2 (poltora[masc/neut], poltory [fem]), and 2 (dva[masc/neut], dve[fem]). Oba 'both' is not quite a numeral, although it shares some properties with numerals (see, e.g., Suprun $1969,36-38$, and see also footnote 8 in Chapter Five), but it manifests gender like 2. Its nominative forms are oba[masc/neut] and obe [fem]. Odin 'one' can be assumed to receive gender specifications like regular attributive modifiers. Poltora 'one and a half' and dva 'two,' and also oba 'both,' differ from other attributive modifiers, for they are also sensitive to the declension paradigm of the noun they modify. Especially revealing is $d v a$, for it also has a third, 
so-called "collective" form: dvoe. (The "collective" forms of poltora and oba, póltoro or póltora and oboi, respectively, are considered substandard [Zaliznjak 1967a, 77], though there is no consensus with respect to póltoro/ póltora [see, e.g., Kozyreva and Xmelevskaja 1972, 69, and cf. also Butorin 1968].) The chart on the following page shows which nominative forms of $d v a$ can be associated with nouns of different declensions and different sexes. 43 Lexical sex is indicated in angular brackets, and contextual sex--in curly brackets. A plus sign signifies full acceptability, a minus sign--unacceptability, and a question mark--uncertain or marginal acceptability. (The chart is based on informant responses and on JankoTrinickaja 1966, 206; Lebedeva 1968, 66; Suprun 1969, 106-110; Šcerbakov 1969; and Gorbačevič 1973, 104.)

What the chart shows is that the form dve can only be used when the numeral modifies a noun marked <-male> or an asexual noun which has a female referent and follows the Second Declension. Asexual nouns which have female referents and do not follow the Second Declension cannot be modified by dve. The form $d v a$ is fully acceptable only when the numeral modifies a First-Declension noun, regardless of the sex of the referent. The form dvoe is used whenever neither $d v e$ nor $d v a$ are fully acceptable, i.e., when the numeral modifies a Second-Declension noun which can only denote males or has male referents, and when it modifies an asexual masculine noun which follows the adjectival declension (see footnote 39 above).

To put it differently, dve is not merely a feminine form and $d v a$ is not exactly a masculine form either. The nominative forms of the numeral in sentences are determined not only on the basis of the features relevant for regular attributive modifiers but also on the basis of the declension paradigm of the modified noun--a phenomenon no doubt related to the fact that the numeral cannot modify a noun which has a nominative ending, which also applies to poltora 'one and a half' and $o b a$ 'both' (for further discussion see Section 1.4 in Chapter Five).

${ }^{43}$ Indeclinable and Third-Declension nouns are not represented in the chart because they are of no interest in this respect. 
First

Declension

Second Declension

\begin{tabular}{|c|c|c|c|c|c|c|}
\hline & $\begin{array}{c}\text { vrač } \\
\{+ \text { male }\} \\
\text { doctor }\end{array}$ & $\begin{array}{c}\text { vrač } \\
\{\text {-male }\} \\
\text { doctor }\end{array}$ & $\begin{array}{c}\text { mužcina } \\
<+ \text { male> } \\
\text { man }\end{array}$ & $\begin{array}{c}\text { devuška } \\
<- \text { male> } \\
\text { girl }\end{array}$ & $\begin{array}{l}\text { Zakomka } \\
\text { tmale\} } \\
\text { gourmand }\end{array}$ & $\begin{array}{l}\text { Zakomka } \\
\{\text {-male }\} \\
\text { gourmand }\end{array}$ \\
\hline$d v e$ & - & - & - & + & - & + \\
\hline$d v a$ & + & + & $?$ & - & ? & - \\
\hline dvoe & + & + & + & - & + & - \\
\hline
\end{tabular}

Adjectival Declension

$\begin{array}{ccc}\text { zavedujuščij } & \text { zavedujuščij } & \text { zavedujuščaja } \\ \begin{array}{c}\text { t+male\} } \\ \text { manager }\end{array} & \text { manager } & <- \text { male> } \\ \text { manager }\end{array}$

\begin{tabular}{llll}
$d v e$ & - & - & + \\
$d v a$ & $?$ & $?$ & - \\
$d v o e$ & + & + & - \\
\hline
\end{tabular}

\subsection{Partitive Constructions}

In the partitive constructions under (93), attributives which have nominative singular endings seem to manifest the gender of nouns which they do not modify and which have genitive plural endings.
(a) pervyj[nom masc] iz kolxozov[gen]
'the first of the collective farms'
(b) pervaja[nom fem] iz brigad[gen]
'the first of the brigades'
(c) pervoe[nom neut] iz predprijatij[gen]
'the first of the industrial enterprises'

In (94), the attributives in the partitive constructions seem to agree not only in gender but also in animacy with nouns they do not modify. 


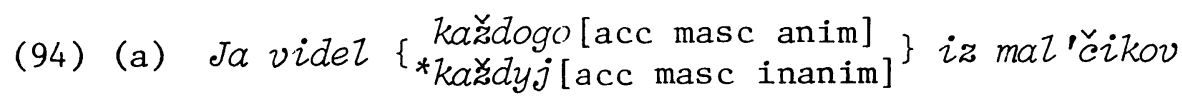
[gen].

'I saw each of the boys.'

(b) Ja videl \{kazdyj[acc masc inanim] \} iz muzeev [gen].

'I saw each of the museums.'

In the following partitive construction, the defective declension paradigm of the noun jasli 'nursery school,' which has no singular forms, seems to determine the form of a numeral which does not modify the noun.

\section{dvoe}

\{*dva\} iz jaslej 'two of the nursery schools' *dve

The peculiar patterns of agreement illustrated in (93)-(95) (on these patterns see also Safaev 1962, Zaliznjak 1964, and Zaliznjak 1967a, 71-72) can be accounted for quite simply if partitive constructions are assumed to contain an additional noun in their underlying representations. Evidence in support of such an assumption is provided by sentences as in (96).

(96) (a) Ostalas' odna banka iz dvadcati. 'There remained one jar out of twenty.'

(b) Ostalas' odna iz dvadcati banok. 'There remained one out of twenty jars.'

The synonymy of the two sentences can be most simply accounted for by relating them to a single underlying representation with two occurrences of the noun banka 'jar,' an underlying representation which could also be realized as Ostalas' odna banka iz dvadcati banok 'there remained one jar out of twenty jars.' As demonstrated by (96), either of the two underlying occurrences of the noun may be deleted from the sentence, for each occurrence is associated with a modifier which can manifest its features and signal its presence in the underlying structure (see Stockwell et al. 1973, esp. 114-122, for arguments in support of a similar approach to partitive constructions in English). 
Partitive constructions as in (93)-(95) can be assumed to derive from, e.g., pervyj kolxoz iz kolxozov 'the first collective farm of the collective farms,' pervaja brigada iz brigad 'the first brigade of the brigades,' etc., but in these phrases only the first occurrences of the nouns may be deleted, because the second occurrences have no modifiers associated with them (cf., e.g., *pervyj kolxoz $i_{z}$ 'the first collective farm of').44 Since there is no reason to assume that deletions of this type precede the processes of gender assignment, attributives and numerals in phrases such as (93)-(95) can be assumed to undergo Attributive Agreement and all of the related processes before the nouns with which they are associated are deleted.

Partitive constructions in which an attributive or a numeral is followed by a prepositional phrase with a pronoun, e.g., kazdaja[fem] $i z$ vas 'each of you,' or odna [fem] $i z$ nas 'one of us,' can be accounted for by postulating a pronominal modificand which has no lexical realization, with features such as $\{+$ pro, thuman, -male\}. The $\{-$ male $\}$ specification is interpreted as [-Masculine, + Feminine], and the \{thuman\} specification as [+Animate], a feature which can be exhibited in masculine accusative case endings and also in masculine nominative forms of numerals which have no surface nouns associated with them. Compare Ja videl kazdogo[acc masc anim]/*kazdyj[acc masc inanim] $i z$ vas 'I saw each of you' and Ja videl kazdyj [acc masc inanim] $i z n i x$ 'I saw each of them' in reference to inanimate objects; and $d v o e /{ }^{*} d v a$ iz $v a s$ 'two of you' versus $d v a$ iz nix 'two of them' in reference to inanimate objects. 45

${ }^{44}$ Note that references to "first occurrence" and "second occurrence" only apply to the posited underlying structures, for in surface structures the prepositional phrase may be preposed, as in, e.g., Iz tvoix podrug samaja terpelivaja--Zina 'of your girlfriends, the most patient [one] is Zina.'

${ }^{45}$ Colloquially, sentences such as (i)-(ii) are not unacceptable. (cont.) 
(i) Ona odna [fem] iz moix symyx lučšix $\left\{\begin{array}{l}\text { studentov } \\ \text { druzej }\end{array}\right\}$. 'She is one of my best $\left\{\begin{array}{l}\text { students } \\ \text { friends }\end{array}\right\} . '$

(ii) Laboratoriej zaveduet odna [fem] iz našix $\left\{\begin{array}{l}\text { studentov } \\ d r u z e j\end{array}\right.$. 'The laboratory is managed by one of our $\left\{\begin{array}{l}\text { students } \\ \text { friends }\end{array}\right\} . '$

The deleted nouns in (i)-(ii) cannot be fully identical to the partitive nouns, for the latter are inherently masculine and the gender manifested by odna 'one' is feminine; the deleted nouns are apparently studentka 'gir1 student' and podruga 'girlfriend.' Now consider (iii).

(iii) *Laboratoriej zaveduet odin[masc] iz našix $\left\{\begin{array}{l}\text { studentok } \\ \text { podrug }\end{array}\right.$.

- The laboratory is managed by one of our $\left\{\begin{array}{l}\text { girl students } \\ \text { girlfriends }\end{array}\right\}$

Sentence (iii) is impossible because the plural forms of studentka and podruga remain sex-differentiating. Sentences (i) and (ii), in contrast, are possible because the plural forms of the masculine nouns in these sentences function as asexual nouns (note that student is otherwise a sex-differentiating noun; cf. Section 6.21 above). Thus (i)-(ii) illustrate partitive constructions based on incomplete identity.

Perhaps analogy with sentences such as (i)-(ii) accounts for the widespread colloquial use of feminine modifiers in partitive constructions with First-Declension nouns such as agronom 'agronomist,' vrač 'doctor,' direktor 'director,' etc., as in (iv) and (v), even though these nouns have no feminine counterparts in the standard language and the deleted nouns must be identical to them.

(iv) Bekman-Šcerbina--odna[fem] iz starejšix one of oldest

muzykal'nyx pedagogov. musical teachers

(cont.)

'Bekman-Shcherbina is a veteran music teacher.' 


\subsection{Nominal Predicates}

10.31 The relationship between the gender of nominal predicates, i.e., predicate nouns or predicate adjectives (long-form adjectives) and the gender of the subjects with which they are associated differs from the relationship between the gender of verbal predicates and their subjects, as demonstrated by the sentences under (97), where the subject is the polite vy 'you.'

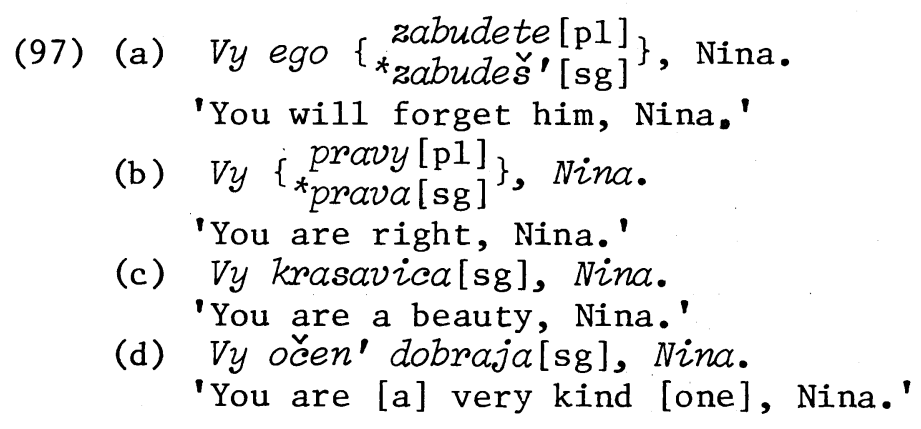

In (97a-b) the predicates are verbal and must have plural endings, whereas in $(97 c-d)$, where the predicates are nominal, plural endings are excluded when vy refers to a single individual. (Deviations from the pattern illustrated in (97) are rare and may only occur in substandard discourse [cf. Vinogradov and Istrina 1960, 517-518 and Finkel' and Baženov 1965, 360]; for perceptive analyses of semantic and syntactic differences between short-form,

(v) Mnogo let otdala zavodu odna[fem] iz pervyx ego direktorov $v$ period načala stroitel'stva A.P. Drjamova.

'Many years were spent at the plant by one of its first directors in the initial construction period, A.P. Dryamova.'

In formal discourse, the feminine form odna in (iv)(v) should be masculine (see Lebedeva 1968, 163-164 and Rozental' 1971a, 229; the phenomenon illustrated in (i)(iii) seems to have gone unnoticed in the literature). 
verbal adjectives and long-form, nominal adjectives see Zemskaja 1973, 196-214 and Babby 1973a and 1975.) 46

${ }^{46} \mathrm{An}$ interesting transitional predicate is odin in the sense of "alone," which may be treated either as verbal predicate, as in (i), or as nominal predicate, as in (ii).

(i) Nina, ja ne znal, čto vy byzi odni[p1]. (ii) Nina, ja ne znal, čto vy byli odna[sg fem]. 'Nina, I did not know that you were alone.'

Informants asked which of the two sentences was right were not unanimous in their responses. Some preferred (i), and others--(ii) (they were all university-educated Soviet Russians in their thirties).

The transitional status of odin is apparently due to the fact that in the sense of "alone" (=solitarily) it does not behave like a regular long-form adjective, as illustrated in (iii)-(iv), while in other senses it does, as illustrated in (v) (cf. Cesnokova 1972, 82; Kozyreva and Xmelevskaja 1972, 52-53; and Comrie 1974).

(iii) (a) On ostalsja nervnym[instr].

'He remained nervous.'

(b) On ostalsja \{ $\left.\begin{array}{c}\text { odin[nom] } \\ \text { odnim[instr] }\end{array}\right\}$.

(iv) (a) Sovetuju emu poexat' $\{$ pervym [instr] $\}$ pervomu[dat] . 'I advise him to go first.'

(b) Sovetuju emu poexat' \{ odnomu[dat] $\left.{ }_{\text {odnim }[\text { instr] }}\right\}$. 'I advise him to go alone.'

(v) (a) Ja sejčas čitaju odru[acc fem] naǔrnuju [acc fem] Ziteraturu.

'I now read only scientific literature.'

(b) Mne nǔno bylo uvidet' brata po odnomu[dat masc] očen'važnomu [dat masc] delu.

'I had to see [my] brother about a certain very important matter.'

(c) My učizis'v $\left\{\begin{array}{l}\text { odnoj[loc fem] } \\ \text { etoj[loc fem] }\end{array}\right\}$ škole.

'We went to $\left\{\begin{array}{l}\text { the same } \\ \text { this }\end{array}\right.$ school.' 
There are two questions which should be answered with respect to the gender of nominal predicates. The first is whether there is any relationship between the gender of predicate nouns and the gender of their subjects, and the second and more difficult one is how predicate adjectives receive the gender they manifest.

10.32 The sentences under (98) suggest an answer to the first question.

(98) (a) Sosna[fem]-vě̀nozelënoe derevo[neut].

'The pine is an evergreen tree.'

(b) Nedelja[fem]--bol'šoj srok[masc].

'A week is a long time.'

Now consider the sentences under (vi).

(vi) (a) Vy odna[sg fem] tol'ko mokete sostavit' ego sčast'e.

'You alone [=only you] can make his happiness.'

(b) Vy odna [sg fem] ne poddalis' mne.

'You alone [=only you] did not submit to me.'

(c) Vy ¿ivëte odni[p1], Anna?

'Do you live alone [= solitarily], Anna?'

Sentence (a), in which odna is attributive modifier to $v y$, is cited in the 1960 Academy grammar (Vinogradov and Istrina 1960,517$)$ as the only illustration to the statement that odin as predicate [sic] to the polite vy should be in the singular. Sentence (b), which is very similar to (a), is cited in Borras and Christian 1971, 288, to illustrate that although odin must usually be pluralized when following the polite $v y$, as they illustrate with (c), "the feminine singular form of odin is also used after vy."

odin is thus a potentially ambiguous element both semantically and syntactically, and the coexistence of (i) and (ii) in the language may be due to this potential ambiguity.

Note that the emphatic sam 'oneself' also varies in association with the polite $v y$ between singular (vy som [sg masc]/scoma[sg fem] 'you yourself') and plural (vy sami [p1]) and is similar to odin also in some other respects (cf. Skoblikova 1967, 57 and Comrie 1974). 
(c) Boris [masc]--važnaja osoba [fem].

'Boris is an important person.'

(d) Vaša mat'[fem]--dobryj čelovek[masc].

'Your mother is a kind person.'

(e) Naš [masc] vrač--francǚenka [fem].

'Our doctor is a Frenchwoman.'

(f) Ėta francuženka[fem]--zubnoj [masc] vrač.

'This Frenchwoman is a dentist.'

(g) Ženix [masc ]-- $\left\{\begin{array}{c}\text { francuz [masc }] \\ \text { francuženka }[\mathrm{fem}]\end{array}\right\}$.

'The bridegroom is a $\left\{\begin{array}{c}\text { Frenchman } \\ * \text { Frenchwoman }\end{array}\right\}$. '

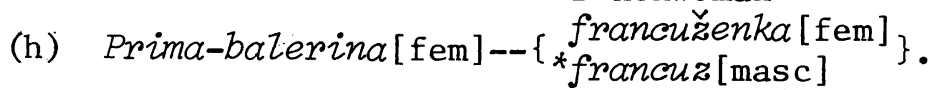

'The prima ballerina is a $\left\{\begin{array}{c}\text { Frenchwoman } \\ * \text { Frenchman }\end{array}\right\} . '$

The picture that emerges is the following. There is no correspondence in gender when the subject noun and the predicate noun are both inanimate $(98 \mathrm{a}-\mathrm{b})$, and also when both are animate and only one is sex-differentiating $(98 c-f)$. When both subject and predicate are represented by sex-differentiating nouns $(98 \mathrm{~g}-\mathrm{h})$, then the gender of these nouns must coincide, but only as a consequence of the fact that their sex specifications must coincide.

This is only an incomplete picture, however, for in fact the sex specification of the predicate noun must coincide with the sex of the referent of the subject phrase rather than with the sex specification of the lexical noun in the subject phrase. Sentence (98g), for example, would be perfectly acceptable with francuženka 'Frenchwoman' as predicate noun if the bridegroom were a role played by an actress on stage, and (98e) would be a bad sentence in reference to a male doctor. The restriction is then that the sex specification of the lexical noun in the predicate (if it is sex-differentiating) must correspond to the sex specification of the referent of the subject phrase (if there is one), as shown in (99) (the symbol $\alpha$ is used to indicate either "plus" or "minus" for both features). Note that this restriction is indeed 
predictable, for nominal predicates modify the referents of their subject phrases (cf. Section 7.123 above). 47

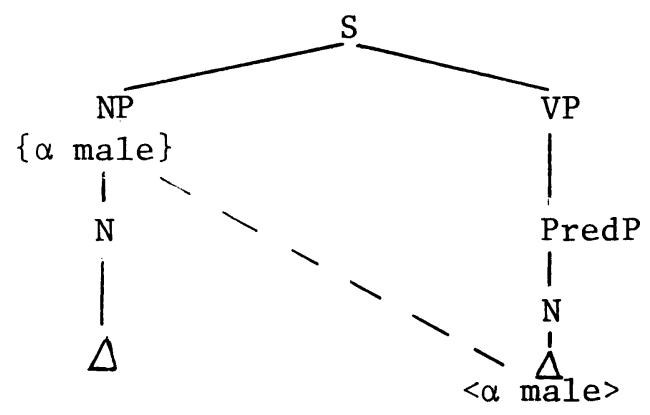

10.33 The second question with respect to nominal predicates relates to predicate (long-form) adjectives: what is the source of the gender they manifest? Sentences with the polite vy 'you' as subject (cf. (97) above) seem to indicate that predicate adjectives are assigned gender by some process other than Verb Agreement. Sentences with complex subjects, as in (100), corroborate this observation (for an extensive discussion of sentences with such complex subjects see Chapter Five below).

${ }^{47} \mathrm{Cf}$. also the discussion in Skoblikova 1971, 211-214. As observed by Skoblikova, when inanimate objects are personified, their sex is assumed to correspond to the gender of the noun which denotes them, and predicate nouns associated with personified subjects may then appear to agree with them in gender, as in, e.g., Kommunističeskaja partija[fem] Venesuèly vsegda byla storonnicej [fem] mira 'the Communist Party of Venezuela has always been a "supporteress" of peace.' It is in fact only the sex-specification of the predicate noun which matches the sex ascribed to the personified object.

It is also noteworthy that when predicate nouns are used metaphorically, their sex may conflict with the sex of the referent, as in, e.g., Ol'ga--nastojaščij müčina '01ga is a real man.' The relationship between the inherent sex of a predicate noun and the sex of the referent of its subject phrase thus holds only in non-figurative language. 
(100) Bol'šinstvo[neut] domov[p1] v ètom rajone

(a) prinadležalo[neut] Ibn-Battute.

(b) dorogo [neut].

(c) dorogie [p1]/*dorogoe [neut].

'The majority of the houses in this area

(a) belonged to Ibn-Battuta.'

(b) is expensive.'

(c) are expensive [ones].'

In (a) and (b), where the predicates are verbal--a bona fide verb in (a) and a short-form adjective in (b)-the gender they manifest is neuter. In (c), where the predicate is a long-form adjective, it cannot manifest neuter; it can only have a plural ending. A predicate noun in (100) would also have a plural ending, e.g., Bol'šinstvo domov $v$ ètom rajone--osobnjaki[p1]/*osobnjak [sg] 'The majority of the houses in this area are singlefamily residences.' Hence both in (97), where the subject is the polite $v y$, and in (100), where the subject is a complex one, predicate adjectives have the same endings as predicate nouns.

The gender of predicate nouns, as demonstrated above, is independent of the gender of their subjects. The logical conclusion is that the gender of predicate adjectives is also independent of the gender of their subjects. But then predicate adjectives must draw the gender they manifest from a noun other than the head of the subject phrase, for adjectives do not possess gender inherently like nouns. A possible solution is that predicate adjectives manifest the gender of predicate nouns with which they are associated as attributive modifiers in underlying representations, predicate nouns which are identical to the subject nouns and therefore deleted (for arguments in support of the view that predicate adjectives are essentially attributive modifiers see esp. Isačenko 1963 and Babby 1975 [briefly in Babby 1973a], and cf. also Zemskaja 1973, 196-199).

The similarity between predicate adjectives and attributive adjectives is especially striking when one compares pairs of sentences such as (101) and (102), where headless attributives in subject phrases alternate with headless attributives in predicate phrases ((101) is from Zemskaja 1973, 211, and (102) is patterned after a sentence in Isačenko 1963,84$)$. 
(101) (a) PosZednjaja[fem]--xorošaja[fem] vešč'.

'The last [one] is [a] good work.'

(b) Poslednjaja[fem] vešč'-xorošaja[fem].

'The last work is [a] good [one].'

(102) (a) Kitajskij[masc] očen' trudnyj[masc] jazyk.

'[The] Chinese is a very difficult language.'

(b) Kitajskij[masc] jazyk ǒcen' tmudnyj[masc].

'[The] Chinese language is [a] very difficult [one].'

The only condition on deleting predicate nouns which have attributives associated with them is that they be lexically identical to a noun in the subject phrase; differences in case or number have no effect. In $(100 \mathrm{c})$, for example (Bol'šinstvo[nom sg] domov[gen p1] $v$ ètom rajone dorogie [nom pl] 'the majority of the houses in this area are expensive [ones]'), the predicate adjective can be assumed to modify attributively an underlying doma 'houses,' a noun which would have a nominative ending were it not deleted, and the lexically identical noun in the subject phrase has a genitive ending.

In $(103 a)$, the deleted predicate noun would have an instrumental ending, yet it is deleted under identity to slovo 'word,' which exhibits a nominative ending.

(103) (a) Ėto slovo[nom neut] bylo ego poslednim[instr (neut)].

'This word was his last [one].'

(b) Mnogo Amerik [gen p1 (fem]] snova stanut edinoj [instr sg fem].

'[The] many Americas shall again become one.'

In (103b), which is the Russian title for Harrison E. Salisbury's The Many Americas Shall Be One (New York, 1971), the putative deleted predicate noun would be realized as Amerikoj[instr sg], differing in both case and number from the controlling Amerik[gen p1] (on the grammatical number of the verb see Section 4.2 in Chapter Five). 48

${ }^{48}$ It is not clear whether stanut 'will become' in (103b) functions as a copula--a perfective inchoative counterpart of byt' 'to be' (cf., e.g., Cernov 1971, 86 and also Vendler 1967,63 )--or whether it represents an underlying verb, in which case the adjective possibly derives from an embedded complement sentence (cf., e.g., 
Comrie 1974 and the references therein). If the latter view is taken, then the adjective is most likely an attributive modifier to Amerika in an embedded sentence (the underlying representation at a certain stage is presumably something like [ mnogo Amerik stanut [ mnogo $\mathrm{S}$

Amerik--edinaja Amerika ] j), so that whatever the struc$\mathrm{S} \mathrm{S}$

ture underlying (103b)--the adjective in its surface structure manifests the gender of a deleted Amerika.

The distinction between the role of a copula and the role of a main verb (a verbal predicate) can be demonstrated by the following sets of sentences.

(i) (a) Ona priexala otdoxnuvšaja[nom].

'She arrived rested.'

(b) Ona kazalas' otdoxnuv̌̌ej[instr].

'She seemed rested.'

(c) * Ona byla otdoxnuvšaja[nom]/otdoxnuvšej [instr].

'She was rested.'

(ii) (a) Ona kazalas' vesëloj, govorja èti slova.

'She seemed cheerful, saying these words.'

(b) Ona byla vesela, govorja èti slova.

'She was cheerful, saying these words.'

(c) * Ona byla vesëloj[instr]/vesëlaja[nom], govorja èti slova.

'She was [a] cheerful [one], saying these words.'

What the sentences under (i) demonstrate is that while verbs such as priexat' 'arrive' and kazat'sja 'seem' can be followed by adjectival participles modifying their subjects, byt' 'be' cannot, even though (c) parallels (103a) in the text, where bylo 'was' is followed by a longform adjective. Briefly, (c) demonstrates that byt' is not a main verb when it occurs in sentences such as (103a), only a copula for a nominal predicate; (c) is ungrammatical because adjectival participles cannot function as nominal predicates in simplex sentences.

Sentences as in (iii) may appear to be counterexamples, for zabrǒ̌ennaja 'neglected' and ugrožajušcee 'threatening' resemble participles, but these are in fact adjectives, which can be demonstrated by the fact that (a) cannot take an instrumental agent (*Komnata byla (cont.) 
One more fact which ought to be cited in support of the theory that predicate adjectives represent underlying attributive modifiers is illustrated by (104). (104) (Ona ne kurit ǔ̃e tri nedeli.) Èto \{ neverojatno [short form] . [long form]

'(She hasn't smoked in three weeks.) That is incredible.'

zabrošennaja xozjajkoj[instr] 'the room was [a] neglected [one] by the mistress of the house'), and by the fact that it is impossible to say *Položenie ugrožaet (nom) 'the situation threatens (us)' (cf. also Galkina-Fedoruk 1964, 338 and Cernov 1971, 84).

(iii) (a) Komnata byla zabrošennaja.

'The room was [a] neglected [one].'

(b) Polozenie ugrozajušee.

'The situation is [a] threatening [one].'

The participles in the first two sentences under (i) apparently derive from embedded complement sentences in which they are verbal predicates, since they cannot function as nominal predicates (on the transformational derivation of participles from verbs see Babby 1973a and 1975; for further comments on sentences of this type see the following footnote).

The sentences under (ii) demonstrate the copulative function of byt' through the fact that an adverbial participle can only occur in a sentence which contains a verbal predicate and is excluded when there is only a nominal predicate (cf. the observations in Cernov 1971, 87). The verbal predicate in (a) is kazalas' 'seemed,' in (b) it is the short-form adjective vesela 'cheerful,' and in (c) there is none, for (c) has a nominal predicate and byla 'was' is a copula, as it is also in (b), where the predicate is a short-form adjective. One of the reasons for regarding stat' 'become' as possibly a copula when associated with nominal predicates is indeed the fact that it is the only verb besides byt' which can occur with short-form adjectives in contemporary Russian (the use of other verbs with short-form adjectives is quite rare now; cf. Černov $1971,86-87$. 
If all predicate long-form adjectives are assumed to be associated with modified predicate nouns identical to their subjects, then it is clear why a long-form adjective is excluded in (104): èto 'that' is a "pro-sentence." As such it cannot take an attributive modifier, just as a sentence cannot; compare also To, tto ona ne kurit uže tri nedeli--neverojatno [short form]/*neverojatnoe[long form] 'that she hasn't smoked in three weeks is incredible' (cf. the analysis of such sentences in Babby 1975). (In equative sentences such as Eto byla moja sestra 'that was my sister,' èto is not a pro-sentence; for further discussion see Section 4.4 in Chapter Five).

10.34 The assumption that long-form adjectives in the predicate manifest the features of deleted predicate nouns also applies to other attributive categories which occur in the predicate. It applies to possessive pronouns, as in, e.g., Etot [masc] portfe $I^{\prime}$ moj [masc] 'this briefcase is mine' (the form mine in the English gloss can also be accounted for as due to a deleted noun; cf. Stockwell et al. 1973, 171-172), and it also applies to numerals. Consider (105).

(105) Kartin[gen p1]--vsego odna[nom fem], a časov[gen]-dvoe [nom].

'Of pictures [there is] only one, and of clocks [there are] two.'

The numeral odna in (105) can only have a feminine ending. The noun kartin 'pictures' is inherently feminine, but the numeral "disagrees" with it not only in case but also in number. The most plausible account for the gender manifested by odna is that it is the gender of a deleted noun which it modifies attributively.

A deleted noun must also be postulated to account for the fact that dvoe 'two' in (105) can only have the "collective" form--the form which the numeral must assume when it modifies pluralia tantum nouns. The noun casov 'clocks' is indeed such a noun, but it would be quite difficult to explain how its declension can affect the form of the numeral unless another occurrence of the noun is postulated (for an extensive discussion of sentences like (105) see Section 1.3 in Chapter Five).

10.35 This proposal does not seem applicable to sentences in which the subject noun is a personal pronoun 
or a proper name, as in (106), for personal pronouns and proper names do not normally function as predicate nouns (this does not apply, of course, to equative sentences such as $J a--D \check{z} e k$ 'I am Jack'; for a brief statement of differences between equative sentences and sentences with modificatory predicates see Halliday 1970, 154-155).

$$
\begin{aligned}
& \text { (a) Vy očen' }\left\{\begin{array}{l}
\text { dobraja[fem] } \\
\text { dobryj[masc] }
\end{array}\right. \\
& \text { 'You are [a] very kind [one], }\left\{\begin{array}{l}
01 \mathrm{ga} \\
\mathrm{Oleg}
\end{array}\right\}^{\prime} \\
& \text { (b) oz'ga očen' dobraja[fem]. } \\
& \text { 'Olga is [a] very kind [one].' }
\end{aligned}
$$

It has been suggested that in sentences like (106a), where the subject is the polite plural vy, predicate adjectives are associated with deletable generic nouns such as čelovek 'person, man' or そenščina 'woman' (Babby 1973b and 1975). This solution is also applicable to sentences such as (106b) and seems quite plausible at first sight. However, it is inadequate, as demonstrated by $(107)-(109)$.

(107) (a) Vy ǒ̃en' dobryj[masc] čelovek, oz'ga.

'You are a very kind person, 01ga.'

(b) *Vy ołen' dobryj[masc], oz'ga.

'You are [a] very kind [one], Olga.'

(108) (a) Mušket porodistaja[fem] sobaka.

'Mushket is a purebred dog.'

(b) *Mǔket porodistaja [fem].

(c) Mušket porodistyj [masc].

'Mushket is [a] purebred [one].'

(109) (a) Dnepr širokaja[fem] reka.

'The Dnepr is a wide river.'

(b) *Dnepr širokaja[fem].

(c) Dnepr širokij[masc].

'The Dnepr is [a] wide [one].'

Generic nouns in the predicate cannot be deleted when their gender does not coincide with that of the subject noun $((108)-(109))$ or does not correspond to the sex of the referent, as in (107). It does not seem likely that 
the deletability of generic nouns in the predicate is conditioned by the subjects' gender and sex specifications, for then the assumption that deleted generic nouns account for the gender of predicate adjectives would be vacuous. Furthermore, while in (108c) the predicate adjective could possibly be assumed to manifest the gender of the masculine generic noun pës 'dog,' there is no generic noun which could be postulated to account for (109c).

It seems that predicate adjectives in sentences which have personal pronouns or proper names for subjects can be assumed to represent underlying attributive modifiers to dummy nouns, nouns unspecified except for a feature marking them as identical to the subject nouns, perhaps $\{+$ pro\}. Such a feature is necessary because of sentences such as the following.

\section{(110) Mat' dZja čeloveka samoe [neut] dorogoe[neut]. 'A person's mother is for him the most precious thing.'}

Dorogoe 'precious' in (110) must represent an underlying attributive modifier to a completely unspecified noun, for it manifests the "provisional" negative specifications (cf. Sections 2.12 and 7.122 above).

An $\mathrm{N}$ node which dominates a predicate noun only specified as \{tpro\} should assume the features of the head I node in the subject phrase. The process is a fairly simple one when the subject $\mathrm{N}$ node dominates a proper name or pronoun with inherent gender specifications, e.g., Dnepr, Mišket, ol'ga, oleg, on 'he,' or ona 'she.' When the proper name is an asexual one, e.g., $S a$ ša, the gender assigned to the predicate $\mathrm{N}$ node must be determined by the sex of the referent, as also when the subject $N$ node dominates the pronouns $j a$ ' $I$ ' or ty 'you[sg].' What happens when the subject $\mathrm{N}$ node dominates the polite $v y$ 'you' is rather problematic. We can only assume that there is a certain feature or feature combination associated with the use of this pronoun which renders the sex of the referent relevant in determining the gender of a predicate $\mathrm{N}$ node but does not affect the assignment of plural number to a $\mathrm{V}$ node. 49

${ }^{49}$ Even more problematic are sentences such as $V y$ kazalis'[p1] otdoxnuvšej[sg fem] 'you seemed rested,' where a participle manifests gender like a (cont.) 
10.36 The assumption that predicate adjectives that are associated with pronouns or proper names modify abstract, nonrealizable nouns can be extended to a claim that predicate adjectives in such sentences are interpreted as associated with an implied pronominal element somewhat equivalent to one in English. A sentence such as Vy nervnaja, accordingly, means "you are a nervous one" rather than "you are nervous"; or, more explicitly, "you are a nervous one of your kind" (this is in line with Babby's claim that predicate adjectives are essentially restrictive modifiers [1973a and 1975]). The data in (111)-(112) seem to support this account.
(111) (a) ?*Afiny takie malen'kie [long form].
'Athens is such a small one.'
(b) Afiny tak maly[short form].
'Athens is so small.'
(c) Afiny takoj malen'kij gorod.
'Athens is such a small city.'
(d) Gorod takoj malen'kij[1ong form].
'The city is such a small one.'
(112) (a) Kolxoz "Zarja" očen' bogatyj[long form].
'The collective farm Zarya is a very rich one.'
(b) ??"Zarja" očen' bogataja[long form].
'Zarya is a very rich one.'
(c) "Zarja" očen' bogata[short form].
'Zarya is very rich.'

predicate adjective even though it cannot function as predicate adjective in a simplex sentence and most probably derives from a verb (see the preceding footnote). It seems premature to attempt to account for gender manifestations in such sentences and also in other sentences with complex underlying structures, e.g., Esli $b$ tol'ko vy imeli[pl] dobrosovestnost' byt' posledovatel'noj[sg fem] 'if only you had the decency to be consistent,' or Oni zastali vas gotovoj[fem] uexat' 'they found you ready to leave' (both patterned after sentences in Babby 1973b), for the structure of such sentences is still not clear and requires much further study (on some of the difficulties involved in attempting to account for patterns of agreement in such sentences within a transformational-generative framework see Andrews 1971 and Babby 1973b, and cf. also Borkin and Peterson 1972, 70-71). 
Speakers' judgments vary, but it does seem that when the subject of a sentence is a proper name for an inanimate entity, a long-form adjective as predicate generally tends to be considered not fully acceptable or at least somewhat awkward. This is an elusive phenomenon and it is difficult to say why (112b), for example, is considered not as bad as (111a), and why a sentence such as Moskva bol'saja[long form] 'Moscow is a large one' is considered better than (112b), but the problem seems to stem from the elliptic nature of long-form adjectives in the predicate, which must be associated with a modificand representing the class of which the entity referred to by the subject phrase is a member. This is an area which merits further investigation. 50

10.37 Another intriguing phenomenon which can only be outlined here briefly concerns predicate adjectives in sentences in which the head subject nouns are First-Declension nouns of unspecified gender, i.e., nouns like agronom 'agronomist,' vrač 'doctor,' direktor 'director,' etc. Consider (113).
(a) Naš novyj vrač xorošij [masc].
'Our new doctor is a good one.'
(b) Naš vrač molodoj[masc].
'Our doctor is a young one.'
(c) Naš vrač ođen' dobryj[masc]. 'Our doctor is a very kind one.'

In $(113 a)$, the doctor referred to may be male or female. The remaining two sentences, however, tend to be

${ }^{50} \mathrm{~A}$ tangential fact which jibes with the comments in the preceding two footnotes is that while sentence (111a) was considered anomalous by all but one of the informants questioned about it, the following sentence was judged acceptable: Afiny nam kazalis' malen'kimi 'Athens seemed small to us.' Note also that it is only in the predicate that long-form adjectives are restricted; there are no restrictions on their occurrence within subject phrases, as in Afiny, takie prekrasnye[1ong form] letom, zimoj mne pokazalis' odnoobraznymi 'Athens, so beautiful in the summer, in the winter seemed drab.' 
considered only applicable to males, especially (113c). In reference to a lady-doctor, an overt predicate noun would be used, as in (114).

\section{(114) (a) Naš vrač--moZodaja ženščina. 'Our doctor is a young woman.' \\ (b) Naš vrač očen' dobraja ženščina. 'Our doctor is a very kind woman.'}

In standard, normative discourse, there is no alternative to $(113 b-c)$ other than (114). In colloquial, informal style, however, sentences such as $(115 b-c)$ do occur, though (115a) is not a likely sentence.
(a) ?*Naš (novyj) vrač xorošaja [fem].
'Our (new) doctor is a good one.'
(b) Naš vrač molodaja [fem].
'Our doctor is a young one.'
(c) Naگ vrač ołen' dobraja [fem].
'Our doctor is a very kind one.'

Sentences such as $(115 b-c)$ are a recent phenomenon and may seem vulgar to some'speakers, but their prevalence is undeniable. 51

Note that feminine predicate adjectives are only possible in association with First-Declension nouns which have no inherent gender. Predicate adjectives associated with other First-Declension nouns must have masculine endings regardless of the referent's sex. Sentence (116a), for example, may have a female referent, but rebënok

${ }^{5 l}$ These observations are based on interrogation of informants. Examples of feminine predicate adjectives in association with First-Declension nouns in the literature (Skoblikova 1971, 183-184, and also Švedova 1970, 555) are structurally ambiguous, e.g., Sekretar' u nego novaja[fem] 'the secretary he has is a new one.' Such sentences are indeed more typical than sentences such as $(115 b-c)$, but the adjectives in sentences of this type may be postposed attributive modifiers from the subject phrase rather than predicate adjectives, i.e., the sentence above may be a variant of $U$ nego novaja sekretar' 'he has a new secretary' (on structural ambiguities of this type see also Zemskaja 1973, 211). 
'child' is an inherently masculine noun and the adjective can only have a masculine ending. Similarly, the female name Nadik in (116b) has an inherently masculine suffix and the gender manifested by a predicate adjective associated with it must be masculine. (However, for speakers who do not consider anomalous the sentence ??Vot prišla [fem] naša [fem] Ninčik 'here our Ninchik has arrived,' the feminine form in (116b) is not unacceptable; cf. Section 5.21 above.)

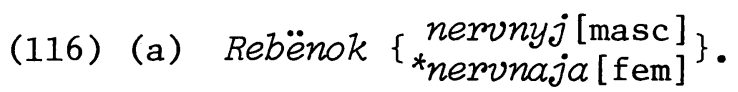 \\ 'The child is a nervous one.' \\ (b) (Naš) Nadik \{ ${ }_{* \text { nervnajaj }[\mathrm{masc}]}^{\text {nem }]}$ \}. \\ '(Our) Nadik is a nervous one.'}

The question now is why (115a) is a worse sentence than (115c) (at least informally); alternatively, why (113a) is much better than (113c) in reference to a woman. Apparently, these differences are due to the fact that xorošij 'good' as predicate to vrač 'doctor' characterizes the referent as doctor, whereas dobryj 'kind' in the same position characterizes the referent as human being. A similar contrast is exhibited by, e.g., opytnyj 'experienced' and nemunyj 'nervous': a person referred to as a doctor and characterized as experienced is experienced as doctor, whereas if characterized as nervous he is a nervous person. (And note that a person characterized as revnivyj 'jealous,' for example, is not likely to be identified by his profession at all; a sentence such as, e.g., Naš vrač revnivyj 'our doctor is a jealous one' would be odd, at any rate unless provided with an appropriate context.)

A possible way of formalizing this difference is suggested by sentences such as Ëtot vrač--zubnoj 'this doctor is a teeth one' = 'this doctor is a dentist.' The putative underlying representation and relevant specifications of this sentence before Attributive Agreement applies are shown in (117) (to demonstrate the fact that this sentence would be equally applicable to a doctor of either sex, the contextual sex is given as $\{-$ male $\})$. 


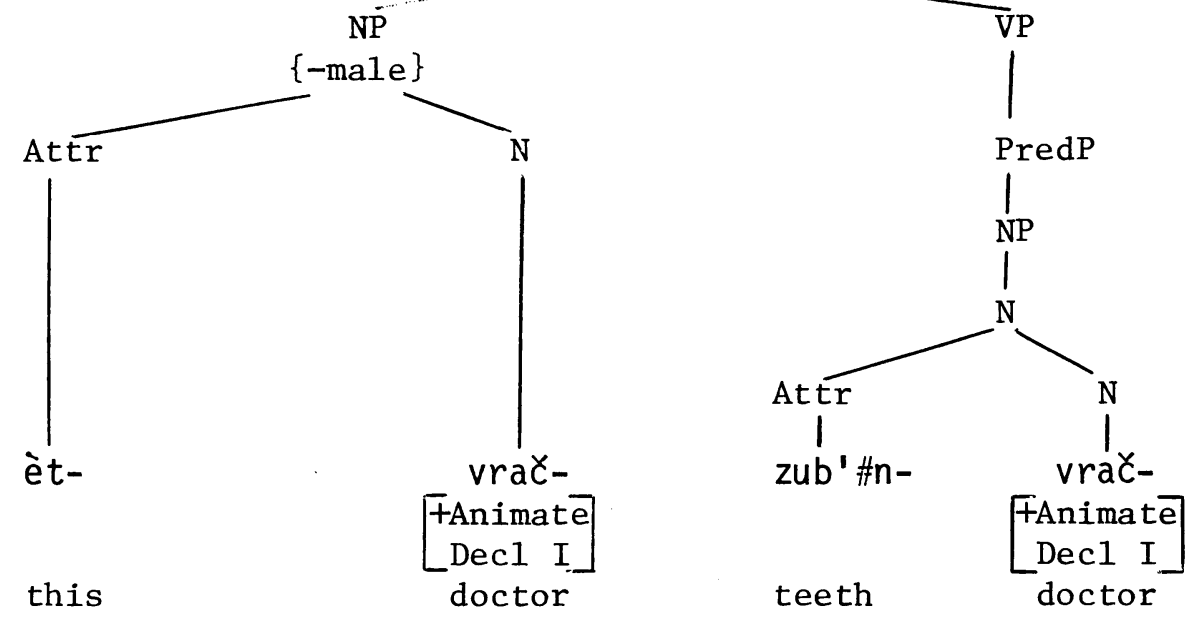

The gender of the attributive in the predicate phrase can only be determined by the declension paradigm of the adjoining noun (cf. the last part of Section 8.2 above), and the predicate noun can then be deleted (the fact that it is a component in a composite noun makes no difference).

A predicate adjective such as xorošij 'good' may apparently also constitute a composite with vrač 'doctor': xorošij vrắ 'good doctor' as predicate can be assumed to represent a single, composite noun signifying a type of doctor like zubnoj vrač 'dentist,' though in subject phrases the collocation xorošij vrač does not necessarily constitute a composite (cf. (81) on p. 103).

A predicate adjective like dobryj 'kind,' on the other hand, cannot constitute a composite with a noun such as vrač 'doctor,' and the underlying structure of a sentence such as Naš vrač dobraja[fem] 'our doctor is a kind one' must therefore be as in (118), where the Attributive node and the $\mathrm{N}$ node are dominated by an $\mathrm{NP}$, not an $\mathrm{N}$ node.

The fact that the noun in the predicate phrase has no inherent gender may trigger a switch to the contextual sex on the subject NP, as in association with Second-Declension epicenes in the predicate (p. 76). In normative style, however, only the declension paradigm of the noun can determine the gender to be manifested by the attributive in the predicate. Why, then, do sentences such as (113c) seem not quite appropriate in reference to females? We can only speculate that perhaps this is due to the fact that predicate adjectives like dobryj 'kind' do occur with 
feminine endings in reference to females identified by First-Declension nouns.

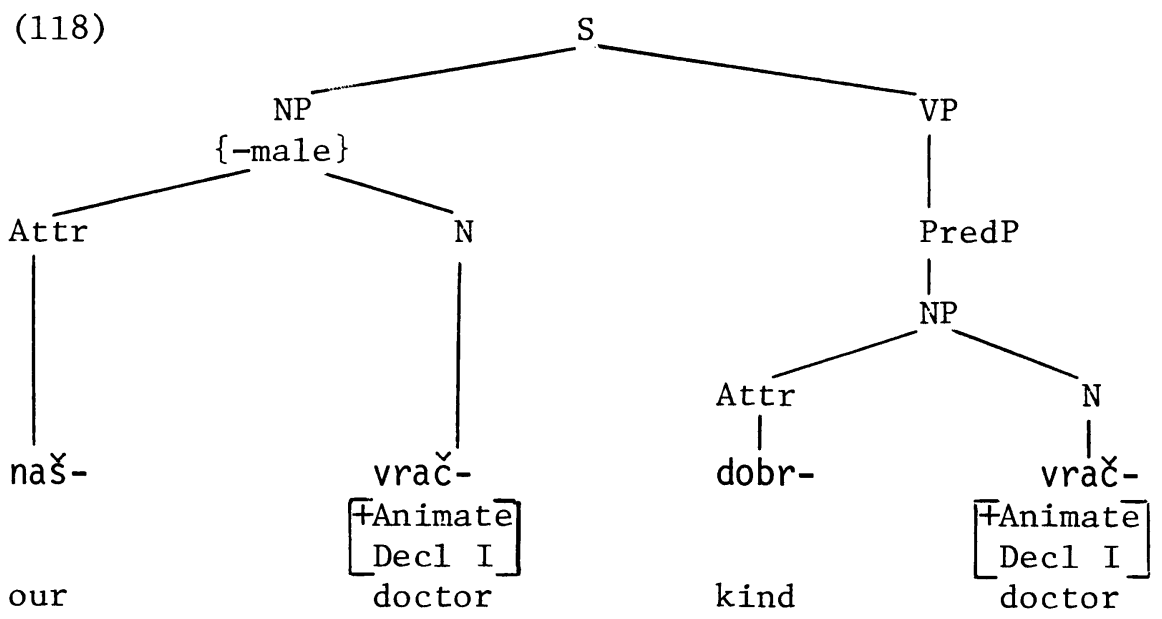

The whole question of predicate adjectives in association with vrač-type nouns does not lend itself to rigorous treatment, for usage fluctuates and the facts are elusive. It therefore seems futile to dwell on this matter any further or to consider alternative accounts at this stage. 52

${ }^{52}$ For the same reason there is no point in going into the question of the gender manifested by relative pronouns such as kotoryj 'who, which,' which is problematic, as illustrated in (i) and (ii).

(i) Vrǎ̀, $\left\{\begin{array}{r}\text { kotoryj[masc] } \\ ? * \text { kotoraja }[\mathrm{fem}]\end{array}\right\}$ menja lečit, sejěas naxoditsja $v$ otpuske.

'The doctor who is treating me is now on vacation.'

(ii) Gde paritmaxer, $\left\{\begin{array}{c}\text { kotoraja[fem] } \\ \text { kotoryj[masc] }\end{array}\right.$ menja podstrigla?

'Where is the hairdresser who cut my hair?'

It can be assumed that relative pronouns are assigned gender by Attributive Agreement (cf. Perlmutter 1973), and the gender they manifest may indeed reflect the patterns exhibited by attributives in subject phrases (see (cont.) 
This concludes the discussion of gender as it is manifested in association with different nouns, its sources, and its relation to the gender manifested by the nouns.

Section 8.2 above), but a definitive description is impossible at present. (For some examples from periodicals in the twenties see Janko-Trinickaja 1966, 193-194.) 


\section{CHAPTER TWO}

\section{GRAMMATICAL NUMBER}

0 . The number manifested by attributive modifiers and verbal predicates not associated with any noun or assocciated with an ad hoc noun is singular, as illustrated above in (31)-(32) and (61) (pp. 33 and 74). A11 NP and VP nodes can therefore be assumed to bear the "provisional" number specification [-Plural] (along with the "provisional" negative gender specifications; cf. Section 4.1 above). The question which this chapter attempts to answer is, in essence, how the presence of nouns can render the negative number specification inoperative and what then determines the manifested number.

Inherent number specifications of nouns can only be [+Plural] (see the discussion in Section 2.2 below). Nouns which bear this specification and the number manifested in association with such nouns are discussed in Section 1. Section 2 deals with the lexical and contextual features which determine number manifestations in association with nouns which have no inherent number.

\section{Number in Association with Inherently Plural Nouns}

1.1 Inherently plural nouns, also called pluralia tantum, can only take plural endings and constituents associated with them must always manifest plural. Consider (1).

(1) (a) Vorota byli[p1] otkryty[p1].

'The $\left\{\begin{array}{l}\text { gate was } \\ \text { gates were }\end{array}\right.$

(b) U nas xorošie [p1] jasli.

'We have $\left\{\begin{array}{l}\text { a good nursery school } \\ \text { good nursery schools }\end{array}\right\}$

As the translations under (1) indicate, there is no relationship between the number manifested in association with inherently plural nouns and "contextual number," i.e., the number of intended referents. The manifested number is merely an arbitrary grammatical feature of the nouns, which can be symbolized as [+Plural]. Like inherent gender and animacy features, this feature can be assumed to be copied from noun stems which bear it onto the $N$ and NP nodes which dominate them and then copied by Attributive 
Agreement and Verb Agreement onto associated Attributive and $\mathrm{V}$ nodes and manifested as a plural ending. ${ }^{1}$

As an inherent feature, [+Plural] is arbitrary, for although it can only belong to inanimate stems and seems more characteristic of certain semantic classes than of others (see, e.g., Svedova 1970, 324), it is not a predictable feature. Nouns denoting paired objects, for example, are most likely to be inherently plural, e.g., šcipcy 'tweezers,' noznicy 'scissors,' brjuki 'pants,' džinsy 'jeans,' kolgotki 'tights,' očki 'glasses,' nosilki 'stretcher,' and sani 'sled,' but velosiped 'bicycle' is not an inherently plural noun, nor is the noun binokl' 'binoculars.' (It is significant, however, that the indeclinable noun galife 'riding breeches' is treated as inherently plural, apparently because it denotes a paired object [cf. Unbegaun 1947, 137; no other indeclinable noun is considered inherently plural]. For a discussion of the place of pluralia tantum nouns in the Russian noun system see Zaliznjak 1967a, 75-80; on the nonoccurrence of singular endings in association with such nouns see Peškovskij 1956, 193; and for some further discussion and additional examples see Skoblikova 1971, 191-192.)

1.2 The number manifested in association with an appositive combination consisting of an inherently plural noun and a noun with a singular ending is the number of the initial noun if the combination is a composite, i.e., a combination in which both nouns decline, and the number of the terminal noun otherwise, i.e., if it constitutes a compound. Sentences $(2 a-c)$ illustrate number manifestations in association with composites, and (2d) illustrates

${ }^{1}$ Since plural endings do not manifest gender and no other endings are possible in association with pluralia tantum nouns, there are never any gender manifestations in association with such nouns. Furthermore, there are pluralia tantum nouns whose endings do not manifest gender (e.g., jasli 'nursery school' and šci 'cabbage soup' [gen. $j a s[e j, \zeta ̌ c e j])$, and there is no evidence that these nouns possess inherent gender. However, since pluralia tantum nouns do not all have the same nominative and genitive endings, it can be assumed that they possess gender like other nouns and that they are assigned a declension paradigm on that basis like other nouns, except that (cont.) 
the combination vagon-vesy 'weighing car' (1it. 'railroadcar scales') treated as compound. (Sentences (2c-d) are from Rozental' 1971a, 220. The inconsistency they exhibit with respect to vagon-vesy is not unusual; see the discussion of appositive noun combinations in Section 3.1 of Chapter One.)

(2) (a) 10 nojabrja 1939 goda $v$ Moskve otkrylis' kursy[p1]-konferencija[sg] SSP dlja pisatelej RSFSR.

'On November 10, 1939, there opened in Moscow a study conference [1it. courses-conference] of the Soviet Writers' Organization for the writers of the RSFSR.'

(b) Vse znajut zdanie s bol'šimi[instr p1] časami [instr pl]-globusom[instr sg] nad vxodom.

'Everyone knows the building with the big globeclock [lit. clock-globe] over [its] entrance.'

(c) Vagon[sg]-vesy[p1] priceplën[sg] $k$ sostcou.

'The weighing car [1it. car-scales] is attached to the train.'

(d) Skonstmirovany [p1] tipovye [p1] vagon[p1]-vesy [p1], točno otmerjajušcie[p1] zadannoe količestvo mudy, izvestnjaka $i$ t.d.

'There has been designed a standard model of weighing cars [1it. car-scales] which measure accurately given quantities of ore, limestone, etc.'

1.3 The number manifested in association with inherently plural proper names must also always be plural, regardless of the fact that proper names have unique referents. Discussions of inherently plural proper names have traditionally cited only place names such as Afiny (Athens; cf. (111) in Section 10.36 of Chapter One), Saloniki (illustrated in (3a)), Alpy (The Alps), Sokol'niki (a park in Moscow), or Lubny (a town in the Ukraine) (see, e.g., Svedova 1970, 324), but is seems that names as in (3b-e) also belong in this category.

(3) (a) SaZoniki raspoloženy [p1] $v$ jǚnoj lakedonii; 'Saloniki is situated in Southern Macedonia.'

they have no singular forms and their gender is therefore not always manifested unambiguously. 
(b) "Izvestija" zdes' ne prodajutsja[p1].

'Izvestia is not sold here.'

(c) Mne pozarez raizny [p1] ego "Osnovy jazykoznanija". 'I desperately need his Foundations of Linguistics.'

(d) "Pereulki moego detstva" zanimajut [p1] osoboe mesto $v$ sbomike.

'"Alleys of My Childhood" occupies a special place in the collection.'

(e) Vspomnim xotja by velikolepnye[p1] "Cistye prudy". 'Just recall the magnificent "Clear Ponds."

The rames in (3b-e) have semantic motivation and resemble regular noun phrases, but while their head nouns are not inherently plural as common nouns (cf. izvestie 'news item,' osnova 'foundation,' pereulok 'alley,' and prud 'pond'), as proper names, or components of proper names, their reference is independent of their meaning and their number is invariable. (According to Peškovskij 1956, 202, proper names of this type can also be treated as indeclinable nouns and constituents associated with them should then have neuter singular endings. He illustrates with Stavilos'[neut sg] "Volki $i$ ovcy" '"Wolves and Sheep" was presented,' but he seems to imply that this is only possible in principle, not in practice. Cf. also the recommendations for proper usage in Senkevic 1964, 8 and Rozental' 1971a, 224.)2

${ }^{2}$ Note that the name of the new Soviet car Kiguli is also an inherently plural name, e.g., in Vot naši[pl] "Yiguli" 'Here is/are our Zhiguli' the modifier must have a plural ending, regardless of the number of cars referred to.

The inherent plurality of proper names which have plural endings distinguishes them from proper names which consist of conjoined singular nouns, e.g., Vojna $i \mathrm{mir}$ (War and Peace), Romeo $i$ Dzul'etta. Such names cannot be treated as plural (cf., e.g., Senkevič 1964, 8 and Rozental' 1971a, 224-225; both sources recommend the use of generic nouns with such names in order to provide gender for associated singular endings, e.g., Roman "Vojna $i$ mir" napisan[sg masc] $v$ seredine prošlogo veka 'the novel War and Peace was written in the middle of the last century'). Cf. also the footnote in Gorbačevic 1971, 167 on the brand name KVN<Kenigson, Varsavstiij, Nikolaevskij for television sets; it is not a plural name. 
The sentences under (4) illustrate the use of an abbreviation for an inherently plural proper name.

(4) (a) $S S A$ načali[p1] vojnu s malen'koj stranoj, naxodjaščejsja gde-to za tysjaču mil'.

'The USA has started a war against a small country somewhere a thousand miles away.'

(b) SŠ, očevidno, dostigli[p1] s Kitaem ponimanija po takim voprosam, kak členstvo KNR v OON $i$ v'etnamskaja vojna.

'The USA has apparently reached an understanding with China concerning such questions as the membership of the Chinese People's Republic in the U.N. and the war in Vietnam.'

In these typical sentences, the plural number of the verbs can be assumed to be determined in the underlying representations by the inherent number of the full name-Soedinënnye Staty Ameriki 'The United States of America' (cf. Section 4.32 in Chapter One).

In (5), which is less typical, the abbreviation VJa apparently does not represent the full name (Voprosy jazykoznanija [Issues in Linguistics]) but rather an independent indeclinable name, for the number manifested by the verb is the number of the generic noun zumal 'magazine' (cf. Alekseev 1963a, 18, and also Section 4.21 in Chapter One).

(5) VJa vyxodit [sg] 6 raz $v$ god.

'VJa comes out six times a year.'

Pluralia tantum nouns are also illustrated below in (8) and (9).

2. Number in Association with Nouns with No Inherent Number

2.1 The number manifested in association with nouns which have no inherent number is generally singular when they have single referents and plural otherwise. Hence in (6), for example, the plural endings indicate reference to more than one wa1l-1amp.

(6) Kartinu[acc] osveščli [p1] starinnye [nom p1] bra. 'The picture was illuminated by old wall-1amps.' 
The noun in this sentence does not manifest number (nor case) because it is indeclinable. If it were declinable, it would manifest number like the constituents associated with it.

What determines the number manifested by declinable nouns which have no inherent number is thus the number of intended referents, which can be represented as a specification on NP nodes. Reference to more than one entity can be symbolized by \{taggregate\}, and reference to a single entity by -aggregate\}. 3

The number specifications in the underlying representation of the sentence Studenty[p1] sporjat[p1] 'the students are arguing' before the noun is assigned grammatical number would be, accordingly, as in (7).

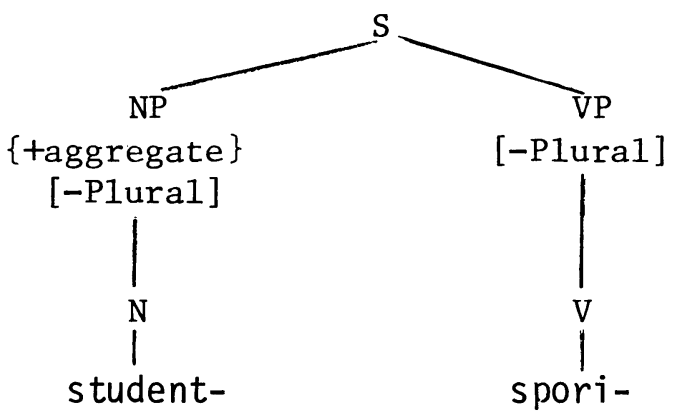

The noun stem in (7) has no inherent number, and the grammatical number of the $\mathrm{N}$ and $\mathrm{NP}$ nodes which dominate it must be determined by the contextual number specification on the NP node, as [+Plural]. The [+Plural] specification cancels out the negative "provisional" specification on the NP node. It is copied onto the $\mathrm{V}$ node by Verb Agreement, and the [+Plural] specifications are then lowered from the $\mathrm{N}$ and $\mathrm{V}$ nodes to the stems they dominate, to be realized as plural endings (note that number specifications differ in this respect from gender specifications, which are only lowered to attributive and verbal stems). The "provisional" specification on the VP node remains inoperative.

${ }^{3}$ The number of intended referents has been referred to in some recent discussions in terms of the opposition of an individual referent to a set (cf. McCawley 1968, 146ff. and Stockwell et al. 1973, 383-386), but since in principle a set may also consist of a single element (or, for that matter, be an empty one), the opposition (cont.) 
2.2 An inherent lexical feature which interferes with this procedure is a feature possessed by mass nouns such as vinograd 'grapes,' izjum 'raisins,' kartofel' 'potatoes,' gorox 'peas,' morkov' 'carrots,' malina 'raspberries,' ‘emeug 'pearls,' or odezda 'clothes,' which are not pluralized even though they may refer to aggregates-and there is no reason to believe that grapes or clothes, for example, cannot be perceived as aggregates by Russian speakers. The absence of underlying semantic motivation for the fact that such mass nouns are not pluralized can be demonstrated by sentences such as (8), where a singular Russian mass noun must be matched by a plural noun in English. (And note that otxody--an inherently plural noun--corresponds to a singular mass noun in English. The verbal predicate in (8) manifests the number and gender of syr' $\ddot{e}$, the head noun in the initial noun phrase [on agreement with appositive constructions see Section 3.4 in Chapter One].)

Dešëvoe[sg] syr'̈̈[sg]--otxody[p1] promyక̌Zennosti-scmo[sg] šlo[sg] v muki.

'Cheap raw materials--industrial waste--came into [his] hands by themselves.'

The grammatical number manifested by mass nouns and constituents associated with them is thus singular regardless of the number of intended referents, and this fact can be accounted for by postulating the feature <homogeneous> as a component of the meaning of such nouns: a stem which possesses this feature signifies a homogeneous, uniform entity, and the distinction between an aggregate and an individual object becomes irrelevant. It can be assumed that a stem specified <homogeneous> must be assigned [-Plural] on the basis of this feature, and the [-Plural] specification then supersedes contextual, semantic number specifications.

There are two reasons for not considering such nouns inherently [-Plural] but rather accounting for the fact that they are not pluralized on the basis of the feature $<$ homogeneous>. First, the feature <homogeneous > can also account for the fact that these nouns cannot be modified

\{-aggregate\}/\{+aggregate\} seems more appropriate to symbolize the distinction between one referent, which does not constitute an aggregate, and more than one--an aggregate. 
by numerals (and are therefore also referred to as "noncount" nouns), and the same feature can account for the fact that certain inherently plural nouns cannot be modified by numerals (e.g., otxody 'waste,' duxi 'perfume,' den'gi 'money,' slivki 'cream,' and others). (Note that the occurrence of nouns such as čaj 'tea' or kofe 'coffee' with numerals cannot be taken as evidence that their denotation is not homogeneous, for in expressions such as, e.g., dva čaja 'two teas' or dva kofe 'two coffees' the nouns are used metonymically--for individual cups of tea or coffee. Cf. also dve govjadiny 'two portions of beef' [1it. 'two beefs'].)

The feature <homogeneous> thus captures a more fundamental property than [-Plural], a property shared by mass nouns that are not pluralized and certain inherently plural nouns. What distinguishes the latter is the inherent feature [+Plural], which prevents the assignment of [-Plural] on the basis of the <homogeneous> specification, for the number manifested by and in association with such nouns can only be plural. The sentence under (9) illustrates černila 'ink.'

(9) U menja èernila[p1] vse [p1] vy̌̌ $Z i[\mathrm{p} 1]$. 'My ink is all used up.'

The second reason for not considering nouns such as vinograd 'grapes,' izjum 'raisins,' etc. inherently [-Plural] is that such nouns can in principle be pluralized (as pointed out in Zaliznjak 1967a, 57-58 and Švedova $1970,323)$. And such nouns do occur occasionally with plural endings, as in, e.g., vysokokačestvennye [p1] stali [p1] 'high-quality [types of] steel,' stolovye [p1] vina [p1] 'table wines,' smazočnye[p1] masla[p1] 'lubricating oils, ' beskonečnye [p1] snega[p1] 'endless snows,' and as in (10) (these examples are all from Rozental' 1971a, 179; (10) is credited to A.N. Tolstoy).

(10) Solnce zakatizos', i $v$ mokryx [p1] raax[p1] kriěali perepela.

'The sun had gone down, and in the wet rye quails were calling.'

Plural forms of nouns such as stal' 'steel,' vino 'wine,' or maslo 'oil' are usually said to signify reference to different varieties of the entities they denote, and plural forms of nouns such as sneg 'snow,' pesok 
'sand,' or rož' 'rye' are said to signify very large quantities of the denoted entities (see, e.g., Rozental', $i b i d$. and Švedova 1970, 324, and cf. also Arbatskij 1972).4 It seems that what may account for the pluralization of these nouns in both cases is their reference to non-homogeneous matter, which can be represented by a specification \{-homogeneous\} on the NP node. In other words, the underlying semantic representation of sentences with nominals realized as pluralized mass nouns can be assumed to include a nonhomogeneity feature. 5 The interaction of the various number-related specifications in underlying structures is discussed in greater detail later on.

While the nouns cited so far to illustrate homogeneous denotation denote concrete objects or substances, there are also abstract nouns to which the observations above seem applicable, e.g., vysota 'height,' radost' 'joy,' stradanie 'suffering,' šum 'noise,' iskusstvo. 'art,' xolod 'cold,' Zingvistika '1inguistics,' smex 'laughter,' Zjubov' 'love,' or pomošc' 'aid.' Such abstract nouns can also be assumed to be marked <homogeneous>, and they also appear to assume plural endings only in reference to heterogeneous entities.

One might suggest that such nouns are not pluralized in reference to aggregates because they are abstract, but then there are abstract nouns which do assume plural endings regularly in reference to aggregates, e.g., ideja 'idea,' isključenie 'exception,' princip 'principle,' preimušcestvo 'advantage,' or srcunenie 'comparison.' One might also suggest that such nouns simply denote entities

"Rozental' 1971a (p. 179) also mentions the use of plural forms of mass nouns in reference to objects identified through the material of which they are made, e.g., bronzy 'bronzes,' xrustali 'crystals,' and farfory 'porcelains,' but such usage is metonymic and this evidently neutralizes the homogeneity feature (cf. also Vinogradov 1947, 158 and Galkina-Fedoruk 1964, 28).

${ }^{5}$ This feature must also be postulated to account for the fact that noun phrases which contain $Z_{j u b o j}$ 'any,' nekotorye 'some,' or indefinite pronouns with -nibud' or koe- are only acceptable in reference to nonhomogeneous aggregates (Seliverstova 1964, esp. 83 and 88). 
which cannot be perceived as aggregates, as pluralities. But consider, for example, an English sentence such as The height of the tables is different. As pointed out by Bierwisch (1971, 431), the singular noun height in this sentence "refers to a set of extensions, not to a single one." It is in the singular not because it has a single referent but rather because its denotation is such that an aggregate of different heights is represented as a homogeneous unit. The noun can only be pluralized in specific references to non-homogeneous aggregates--in English as well as in Russian, as illustrated in (11) (from the fourvolume Academy dictionary [I, 374]).

(11) $V$ severnoj časti jǚnogo ostrova Novoj Zemli vstręajutsja[p1] vysoty[p1] svyše $2000 \mathrm{~m}$.

'In the northern part of the southern island Novaya Zemlya there occur heights of over 1,000 meters.'

Plural forms of such abstract nouns, nouns which seem to have homogeneous denotata, are usually said to refer to concrete or intense manifestations of the denoted entities (see, e.g., Rozental' 1971a, 179 and Švedova 1970, 324). Typical examples are, e.g., izobrazitel'nye[p1] iskusstva [p1] 'the fine arts,' radosti[p1] Žizni 'the joys of life,' zimnie xoloda[p1] 'winter colds,' and boli[p1] v zivote 'pains in the stomach.' What such plural forms seem to signify are indeed aggregates of discrete elements--nonhomogeneous aggregates (cf. also the comments in Zaliznjak 1967a, 58 and Skoblikova 1971, 215).

A further distinction which can be made in this connection is based on the fact that while mass nouns such as vino 'wine,' Kon'jak 'cognac,' or čaj 'tea' and abstract nouns such as radost' 'joy,' gorest' 'sorrow, misfortune,' or nesčast'e 'misery, misfortune' are freely pluralized to signify nonhomegeneity, nouns such as moloko 'milk,' sčast'e 'happiness,' and gore 'grief, sorrow, misfortune,' which seem semantically very close to the nouns in the former group and just as likely to signify nonhomogeneity, are normally not pluralized (cf. the comments on moloko in Zaliznjak 1967a, 57-58; gore is included in a list of abstract nouns which "do not have plural forms" in GalkinaFedoruk 1964, 31). As emphasized in Zaliznjak, ibid., and in Svedova 1970, 323, it is not the grammatical features of such nouns which prevent their pluralization. What may account for the difference is perhaps the fundamental inapplicability of nouns such as moloko 'milk,' sčast'e 
'happiness,' and gore 'grief, sorrow, misfortune' to heterogeneous entities, which can be represented as a positive, <+homogeneous> specification in their semantic matrix. Nouns such as čaj 'tea' or radost' 'joy,' which do occasionally signify heterogeneous entities, can be assumed to bear an unspecified feature, <homogeneous> (a distinction between positively specified and unspecified features is also suggested in, e.g., Langendoen 1969 [see esp. p. 36]). The unspecified feature can be conceived of as susceptible to neutralization when the dominating NP node is specified \{-homogeneous\}, i.e., the stem can receive a [+Plural] specification on the basis of the \{-homogeneous\} feature despite the fact that its denotation is homogeneous and it should therefore be marked [-Plural]. The positively specified feature, in contrast, would not allow a [+Plural] specification for the stem. (Some mass nouns which belong in the category of <thomogeneous> nouns are listed in Rozental' 1971a, 179 [ris 'rice,' proso 'millet,' zoloto 'gold,' serebro 'silver,' and others] and some abstract nouns in the same category are listed in Galkina-Fedoruk 1964, 31 [gmust' 'sadness,' blesk 'brilliance,' mest' 'vengeance,' and others].)

2.3 Collective nouns, which denote aggregates of animate beings as homogeneous entities, can apparently all be assumed to be marked <+homogeneous>, for such nouns do not seem to be susceptible to pluralization. Nouns in this category are, for example, krest'janstvo 'peasantry,' studenčestvo' 'students, student body,' čelovečestvo 'mankind,' bab'ë 'womenfolk,' pexota 'infantry,' proletariat

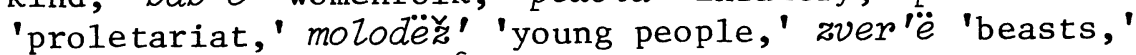
and dǐc' 'game birds.' 6

${ }^{6}$ There are nouns which belong in this class by morphological criteria but do not denote animate beings, e.g., Zistva 'foliage,' trjap'ë 'rags,' vetoš' 'old things,' and zelen' 'greens' (cf., e.g., Galkina-Fedoruk 1964, 26-27 and Švedova 1970,323$)$. Such nouns constitute a subclass of mass nouns from the point of view of grammatical number manifestations, and from this point of view only nouns which denote animate beings constitute a separate class (see below).

Note that the nouns discussed in the text denote animate beings but are not grammatically animate. The noun proletariat, for example, can have verbs such as znaet 'knows' or dumaet 'thinks' associated with it (cont.) 
These <+homogeneous> nouns can perhaps be referred to as bona fide collectives, to distinguish them from nouns such as kollektiv 'collective,' ansambl' 'ensemble,' gruppa 'group,' sem'ja 'family,' èkipaž 'crew,' or komissija 'committee,' which are also often referred to as collective nouns and should perhaps be termed "pseudocollectives." Pseudocollectives differ from bona fide collectives in that they can be modified by numerals (cf., e.g., dva kollektiva 'two collectives' and *dva proletariata 'two proletariats') and are regularly pluralized, for they do not denote homogeneous entities. While the elements of the <+homogeneous> proletariat, for example, are proletarii 'proletarians,' the elements of the <+homogeneous> krest'janstvo 'peasantry' are krest'jane 'peasants,' and the elements of the <homogeneous> pexota 'infantry' are pexotincy 'infantrymen,' the elements of pseudocollectives such as kollektiv, ansambl', or gruppa may be heterogeneous and cannot be identified through their membership in the group defined by the pseudocollective noun (cf. Galkina-Fedoruk 1964, 26-27).7

because its semantic matrix can be assumed to include the feature <tanimate>, required by the selectional restrictions of such verbs, but the accusative form of this noun is identical to its nominative form, not to its genitive form; it is grammatically inanimate: [-Animate]. (On the distinction between semantic and grammatical inherent features with respect to selectional restrictions see also McCawley 1968, esp. 133-135.) Most of the collective nouns in question, however, cannot manifest animacy anyway, since they are not masculine (and are not pluralized). The "pseudocollectives" discussed below (e.g., kollektiv 'collective,' ansambl' 'ensemble,' narod 'nation,' etc.) are also grammatically inanimate.

${ }^{7}$ Elements in the denotata of inanimate mass nouns can often be referred to through so-called "singulative" suffixes, most commonly the feminine suffix -in-, as in, e.g., vinogradina '[one] grape,' izjumina '[one] raisin,' gorošina '[one] pea,' and zemčuzina '[one] pearl.' Cf. also pylinka '[one] speck of dust,' pesčinka '[one] grain of sand,' morkovka '[one] carrot,' and kartoška '[one] potato.' (The nouns referred to in the preceding footnote indeed constitute a subclass of mass nouns because the nouns [or collocations] which denote their elements are not their derivatives.) (cont.) 
The grammatical number of pseudocollectives is determined by their reference: a singular ending represents reference to a single entity (symbolized (-aggregate\}), and a plural ending represents reference to more than one entity (symbolized \{taggregate\}). While the number manifested in association with plural pseudocollectives is always plural, the number manifested in association with singular pseudocollectives and also in association with bona fide collectives requires special comment.

In the standard language today, only singular attributives and verbal predicates are considered acceptable in association with singular collective nouns (whether bona fide or pseudo), as exemplified in (12) (the noun publika 'public' in (12a) must apparently be classified as a bona fide collective, even though the elements of the entity it denotes are identified by nouns not morphologically related to it, e.g., zriteli 'spectators,' or slusateli 'listeners').

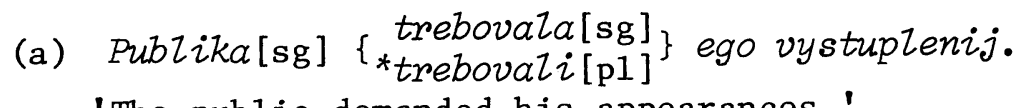 'The public demanded his appearances.'

Note also that the noun sem'janin 'family man,' which superficially might seem to be a counterexample to the assertion that elements of pseudocollectives are not identifiable in terms of the collective, is in fact not a counterexample. It is an evaluative term, not a term identifying any family member as such.

Some noteworthy special cases are: junošestvo 'youth,' a bona fide collective whose elements are junosi 'youths' as well as devuški 'girls'; the abusive terms spana 'rabble' and svoloč' 'scum,' bona fide collectives which are also used in reference to individual persons, i.e., as their own singulatives; and žjuri 'jury'--an indeclinable pseudocollective noun. (The gender manifested in association with ¿juri must be neuter, for it is grammatically inanimate; cf., e.g., Mezdunarodnoe [neut] Zjuri ne ispytyvalo[neut] bol'six trudnostej vo vremja svoego otkrytogo zasedanija 'the international jury did not have much difficulty during its open meeting.') 
(b) U vyxoda na trap nas $\begin{gathered}\text { obstupila[sg] } \\ \text { obstupili[p1] }\end{gathered}$ molodëz' [sg].

'By the exit to the ladder, the young people surrounded us.'

(c) V svobodnoe vremja $\left.\begin{array}{c}\text { našs }[\mathrm{sg}] \\ \text { naši }_{[\mathrm{p} 1]}\end{array}\right\}$ èkipă̌[sg] $\left\{\begin{array}{c}\text { zanimaetsja[sg] } \\ \text { *animajutsja[pl] }\end{array}\right\}$ sportom.

'In [its] free time our crew goes in for sports.'

Plural number in association with singular collectives does occur, but only in the speech of uneducated speakers and in regional dialects, and only in verbal predicates. Plural attributives are rare, as also in 01d Russian, where verbal predicates were regularly pluralized in association with bona fide collectives (see, e.g., Peškovskij 1956, 188; Borkovskij and Kuznecov 1965, 352-358; Degtjarev 1966; Skoblikova 1967, 52-56; and Bogdanov 1968, 68). Sentences as in (13) thus represent substandard usage (cited in Skoblikova 1967, 56 and Skoblikova 1971, 192).8

(13) (a) Rabočij[sg] klass[sg] borolis'[p1] za svoi prava. 'The working class struggled for their rights.'

(b) Naša[sg] brigada[sg] xorošo rabotajut [p1]. 'Our brigade work well.'

(c) Molodëz'[sg]-to dopozdna guljajut[p1]. 'The young people walk [around] till late [at night ].'

Plural number in association with singular collectives may also appear in standard usage, but only indirectly, i.e., not as a consequence of the operation of Agreement, and only in informal discourse. Consider, for example, (14) ((a) is from the definition of passion pit in Galperin's English-Russian dictionary [II, 175]; (b) is from a story published in Junost' 1973, No. 12 [p. 22], and (c) is cited in Lebedeva 1968, 168, to illustrate

${ }^{8}$ Note that in British English and in some dialects of American English the situation is quite similar: verbal predicates are pluralized while attributives are not; cf. The crowd were unruly vs. *those crowd (Perlmutter 1972; cf. also Traugott 1972, 85 and 175). 
incorrect, though common usage [mentioned and condemned also in Rozental' 1971a, 192-193]). ${ }^{9}$

(14) (a) Publika[sg] smotrit[sg] fil'm iz svoix avtomobilej[p1].

'The public watches the movie from their cars.'

(b) Vyzovem èkspertizu, ocenim dom, soberëm po rublju, po desjatke so vsej arteli[sg].

'Let us call in a commission of experts, evaluate the house, and collect a ruble or ten [per person] from the entire cooperative.'

(c) Počemu ne prinimaete mer, čtoby sozdat' molodëzi [sg] uslovija dlja kul'turnogo, soderžatel'nogo dosuga, dlja togo, čtoby oni[pl] rosli duxovno. 'Why don't you take measures to create for the young people conditions for cultural, meaningful recreation, so that they would develop spiritually.'

Sentences such as (15), where a singular collective noun is dislocated and matched by a plural pronoun, are also typical of colloquial standard discourse (Zemskaja 1973, 279-281; cf. also Section 8.3 in Chapter One).

(15) Molodëz'[sg], oni[p1] v xolodnoj komnate poživut. 'Young people, they would [even] live in a cold room.'

Clearly there is an element of plurality in the semantic content of collective nouns and in their reference which makes it possible to say, as in (14a), that the entity denoted by publika watches movies from multiple cars, or, as in (14b), to say that a ruble or ten per person will be collected from the entity denoted by artel'

${ }^{9}$ Again there are parallels in English. Most speakers of American English, for example, are likely to agree with Paul Chapin's statement (in a footnote to a review in Language 48 [1972], 647) that he finds the interpretation of nouns denoting collectives of human beings as "singular for purposes of number agreement and plural for purposes of anaphora ... the most natural." The example he gives is The class has read the assignment, and they are ready to take the test. Such sentences are indeed extremely common, as are also sentences like the English equivalent of $(14 a)$. 
(on the meaning of po as used in (14b) see Crockett 1976). In (14c) and (15), the plurality of molodëz' 'young people' surfaces in plural pronouns. Consider also (16).

(16) (a) Ėti studenty [p1]--vesëlyj narod[sg].
'These students are a cheerful bunch.'
(b) Ėkipaz[sg]--vesëlyj narod[sg].
'The crew are a cheerful bunch.'
(c) *Etot student[sg]--vesëlyj narod[sg].
'This student is a cheerful bunch.'

These sentences indicate that a collective noun as nominal predicate requires a plurality of referents, which can be signified either by a pluralized noun, as in (16a), or by a collective noun, as in (16b) (cf. also Langendoen $1969,51)$. (These sentences also illustrate the fact that the grammatical number of nominal predicates, like their grammatical gender [see Section 10.32 in Chapter One], is independent of the number of the head noun in the subject phrase, as also emphasized by Skoblikova [1971, 214-215], who cites sentences such as Eti strojaščiesja korpusa[p1] --naša novaja bol'nica[sg] 'these buildings in construction are our new hospital,' and Palatki na beregu--lager' geologov 'the tents on the shore are a geologists' camp.' These observations also apply to English [cf., e.g., Stockwell et al. 1973, 157], but they are apparently not applicable to all languages; in Hungarian, for example, *Hârom vendég [sg] tanár-ok[p1] volt-ak 'three guest teachers were' is ungrammatical, and only Három vendég[sg] tanár [sg] volt 'three guest teacher was' = 'three guests were teachers' is grammatical [Comrie 1975].)

All collective nouns, then, can be assumed to have the feature <+plurality> as a component of their meaning, and this feature accounts for sentences such as (14a-b). (It also renders collective nouns compatible with verbs such as sobirat'sja 'gather' or vstrečat'sja 'meet.') The pluralization of verbal predicates associated with singular collectives in substandard Russian could perhaps also be ascribed to this lexical feature, except that attributives modifying singular collectives are rarely pluralized even in substandard discourse. This fact indicates that it is not the lexical plurality of the nouns which pluralized predicates manifest but rather a feature of the NP nodes which dominate them. This feature must define the referents as $\{+$ plurality $\}$ even though they may at the same time be defined as a single total 
entity, as shown in (17), the putative underlying representation of (13b) (with the "provisional" negative specifications omitted, and the adverb represented by its surface form for greater lucidity).

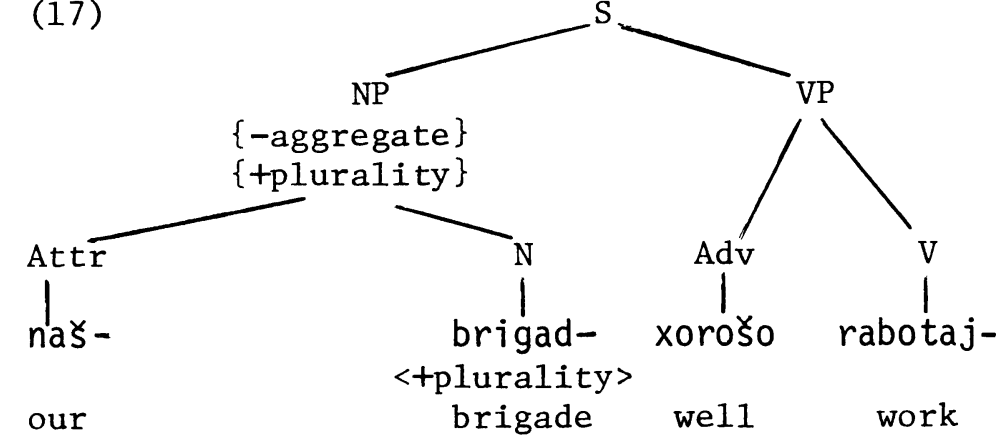

The attributive in the surface sentence cannot be pluralized in any dialect, and it can be assumed that once the grammatical number of the $\mathrm{N}$ node is determined by the \{-aggregate\} specification on the NP node as [-Plural], the grammatical number of the Attributive node must match it (through Attributive Agreement). In standard Russian, the grammatical number of the NP node must also be determined by the -aggregate\} specification as [-Plural] and the grammatical number of the verb must match it through Verb Agreement, yielding $\mathrm{Naša}[\mathrm{sg}]$ brigada[sg] xorošo rabotaet [sg]. In substandard discourse, the $\{+$ plurality\} specification can be assumed to interfere with this process: its presence may render grammatical number assignment to the NP node unnecessary, with the number of the $V$ node determined by this feature as if it were a grammatical feature. In the underlying representation of a sentence such as (13c) (Molodëz'[sg]-to dopozdna guljajut[p1] 'the young people walk [around] till late [at night]'), the subject noun, a bona fide collective, can be assumed to be specified <+homogeneous>. In standard discourse, not only the grammatical number of the $\mathrm{N}$ node should be determined by this feature but also the grammatical number of the INP node, regardless of any other specifications it might have. In substandard discourse, the putative \{tplurality\} feature on the NP node can apparently block the assignment of grammatical number to this node and function as a grammatical number specification in Verb Agreement.

Plural pronouns coreferential with singular collectives, as in (14c) and (15), can be viewed either as 
representing independent underlying elements or as substitutes to repeated underlying occurrences of the collective nouns (cf. footnote 34 in Chapter One). As substitutes, pronouns should generally realize the grammatical features of the nodes which dominate the lexical elements they replace. In informal discourse, however, pronouns which replace lexical elements dominated by NP nodes may apparently realize contextual features instead. Thus if the pronouns in (14c) and (15) are viewed as transformationally-derived substitutes for molodëz', they can be accounted for as realizations of the contextual feature \{tplurality\}. (This account is also applicable to sentences such as (82) in Chapter One: Direktor--ona/ta nam ničego ne skazala 'the director--she/that [one] told us nothing.' )

An interesting related phenomenon, reported in Bogdanov 1968, is the use of noncollective nouns as collectives in some dialects, as in (18).

(18) $M 0 j[\mathrm{sg}]$ brat $[\mathrm{sg}]$ tom $\left.\check{z} i i_{[\mathrm{pl}}\right]$.

'My brother [and his family] lived there.'

The noun brat 'brother,' which does not denote a plurality and does not bear the feature <+plurality> in the standard language, is used in (18) in reference to a plurality, the brother's family. The NP node which dominates $\operatorname{moj}[\mathrm{sg}]$ brat [sg] in the putative underlying representation of the sentence must be specified \{-aggregate\}, to account for the singular number of the noun and its modifier, but the node is apparently also specified $\{+$ plurality\}, and this feature can account for the pluralized verb.

2.4 A discussion of the sources of grammatical number cannot be complete without at least a few words about the occurrence in standard Russian of sentences with singular nouns which signify multiple entities although they denote neither homogeneous matter nor pluralities. Since number manifestations in association with such nouns are always singular and sentences of this type therefore present no problem from the point of view of agreement, this phenomenon will only be considered briefly. It is exemplified by the sentences under (19) ((19a) is cited under the entry višnja in Ushakov's dictionary; (19b-d) are cited in Panov $1968,165,170$, and 172, (b) and (d) from works by Babe1 and Soloukhin, respectively). 
(19) (a) Na bazar privezli mnogo višni [gen sg]. to market [they]-brought much cherry

'A lot of cherries have been brought to the market.'

(b) Bez Zošadi[gen sg] net armii. without horse there-is-no army 'An army is no army without horses.'

(c) Naš zavod bolee pjatidesjati let vypuskaet ručnuju švejnuju iglu[sg] i rybolovnye krjučki.

'Our factory has been manufacturing handsewing needles [lit. needle] and fishing hooks for over fifty years.'

(d) Rybak-intelligent[sg] čašče vsego gruppiruetsja [sg] po 5-6 čelovek vokmug odnoj častnoj "Pobedy" ili "Volgi". 10

'Fishermen [1it. fisherman] of the educated classes gather [1it. gathers] mostly in groups of five or six persons around one private Pobeda or Volga.'

The singular forms of višnja 'cherry,' Zošad' 'horse,' igla 'needle,' and the (composite) noun rybak-intelligent 'fisherman with education' signify multiple entities even though singular forms of these nouns normally have single referents. Why are these nouns not pluralized in (19) and how can they be interpreted as mass or collective nouns in these sentences? These are not simple questions to answer, especially since little is known about the phenomenon as a whole (as noted also in Panov 1968, 165, in an introductory note to a chapter containing numerous illustrations of sentences with singular nouns which have a "generalized collective meaning" [obobščënno-sobiratel'noe značenie]).11

What the problematic singular nouns in (19) seem to have in common is the fact that they have no particular

${ }^{10}$ On the use of po in this sentence see Crockett 1976, and see Chapter Three on the grammatical number of attributives in a position such as that of častnoj 'private,' which applies to two nouns.

${ }^{1}$ The central thesis of the chapter in Panov 1968 is that the use of singular nouns in a "generalized collective meaning" is on the increase, at the expense of bona fide collectives. For some comments on the phenomenon in general see also Moravcsik 1971, A20. 
referent or referents: they are used nonreferentially. They only identify classes of entities and may therefore be labelled generic, though only (19c) is a generic sentence in the sense that it is meant to be applicable to anyone who can be referred to as rybak-intelligent. 12

The nonreferential, generic nature of singular nouns which signify multiple entities in sentences even though they do not denote homogeneous matter or pluralities is also evident in store signs such as Detskaja igruška[sg] 'children's toys,' Mužskaja soročka[sg] 'men's shirts,' or Avtomickka[sg] 'pens' (cf. Panov 1968, 170), in proverbs such as (20a), and in negative sentences such as (20b) ((20b) is from Chvany 1975, 262).
(a) GZupyj[sg] umnogo[sg] ne trezvogo [sg].
'[One who is] stupid dislikes [one who is] clever, and [one who is] drunk [dislikes one who is] sober.'
(b) Ona nikogda ne nosit కZjapy [gen sg]/šljapu [acc $\mathrm{sg}$ ].
'She never wears a hat.'

Perhaps the singular endings of nonreferential nouns can be viewed as a consequence of the absence of contextual number specifications, as realizations of the "provisional" number specifications. Another possible account is that the singular endings in these instances are a consequence of the presence of the feature combination \{taggregate, thomogeneous $\}$ on the underlying NP nodes. The latter approach seems more adequate for three reasons. First, it accounts for the fact that the singular number in these instances is recognized as having a "generalized collective meaning" and is not interpreted as simply indicating unspecified number, something like "either one or more than one." Secondly, it accounts for the fact that in many cases (e.g., in (19a-d) and (20a)) such singular endings can be replaced by plural endings with no significant change in the meaning of the sentences: the only difference between plural and singular forms in such sentences is that plural forms are ambiguous with respect to homogeneity--they may represent either homogeneous or

12 On some applications of the term "generic" in linguistics see Stockwell et al. 1973, 82-92. 
heterogeneous entities (cf., e.g., Zaliznjak 1967a, 58).

The third reason for preferring an account based on the feature combination \{taggregate, thomogeneous\} rather than on the absence of number-related features is the occurrence of sentences like (21), where singular forms of nonhomogeneous nouns signify multiple entities even though they are used in reference to particular objects and not generically ((21a) is from Rozental' 1971a, 178; (21b) is from Axmanova 1966, 147).

\section{(21) (a) Zerno[sg] ǔ̌e nalilos'. 'The seeds have already ripened.' \\ (b) Deti, podnimite provuju ruku[sg]. 'Children, raise [your] right hand.'}

The nouns zerno 'seed' and ruka 'hand' are not mass nouns, they are "count" nouns, and the most plausible source for their singular endings is the feature combination \{taggregate, thomogeneous\}, for indeed both zerno and mika seem to represent homogeneous aggregates in these sentences. The singular form ruka in (21b) represents what is known as "the distributive singular" (see, e.g., Axmanova 1966, 147 and Rozental' 1971a, 178), for the aggregate it signifies consists of elements distributed over the elements of another aggregate; more specifically, the noun refers to an aggregate of hands, each of which belongs to a different child. The distributive singular can be considered a special case of the more general use of the singular number to represent homogeneous aggregates --whether generically or referentially. Other distinctions between the various uses of the singular in this basic sense and the question how such singular forms are recognized and distinguished from singular forms which do represent single referents must await further investigation. In any case, these matters are not within the scope of the present monograph.13

13 Another aspect of this phenomenon which should be investigated is the substitutability of the singular forms by plural forms in different contexts. In many cases the singular forms are substitutable, but in (20b), for example, a plural form seems to be excluded, and in (21b) too the distributive singular cannot be replaced by a plural form.

Paducheva (Padučeva 1967, 1475) notes that a literal translation of The counselzors put the spectacles on their noses would be "unnatural" in Russian and she asterisks 
3. Summary

To recapitulate, the number manifested by attributive modifiers and verbal predicates associated with nouns is always identical to the number manifested by the nouns in standard Russian, except when the nouns are indeclinable and cannot manifest number. The number manifested by nouns is determined by their inherent number specification if they have one, and otherwise by "contextual number," i.e., the number of intended referents, though not if the nouns belong to classes which can be assumed to bear the lexical feature <thomogeneous>. The gramatical number of such nouns is always singular. Nouns which can be assumed to bear the lexical feature <homogeneous> are only pluralized to manifest reference to heterogeneous aggregates. Finally, nouns which cannot be assumed to bear <thomogeneous> or <homogeneous> may have singular endings in reference to homogeneous aggregates.

Sovetniki nadeli na nosy[p1] očki; the proper Russian equivalent, she says, is Sovetniki nadeli na nos [sg] očki (očki 'glasses' is an inherently plural noun). A similar comment is made in Rozental' and Telenkova 1973b, 40, in reference to Vse prisutstvujuščie obnažili golovu[sg] 'all those present uncovered [their] heads,' where a plural form for "heads" (golovy) should be inappropriate. My own inquiry into this question indicates that informants vary in their judgments and the distinction between singular and plural in such sentences cannot be drawn in absolute terms. (For some additional comments relevant to this question see Revzin 1969, 107-108.) 



\section{PART TINO}

STRUCTURE-RELATED ALTERNATIVES 
ATTRIBUTIVES ASSOCIATED WITH TWO OR MORE NOUNS

0. Logically, any attributive associated with two or more nouns that are not coreferential should be pluralized, for it modifies more than one entity. Consider, for example, (1).

(1) On osobenno gorditsja staršimi[instr p1] synom [instr sg] $i$ dočer'ju[instr sg].

'He is especially proud of [his] oldest son and daughter.'

The attributive staršimi 'oldest' is associated with both synom 'son' and dočer'ju 'daughter' and is indeed pluralized. Why, then, did Ovsyaniko-Kulikovsky in 1907 classify the pluralized possessive pronoun in (2a) as incorrect, characterizing it as "un-Russian and grating on the ear" ("ne po-russki i režet uxo"; cited in Rozental' 1968, 287), and why did Revzin several years ago refer to the pluralized modifier detskie 'children's' in (2b), from Tolstoy's War and Peace, as "artificial" (Revzin 1970, 234)?

(2) (a) ?Ja davno ne vidal moix [acc p1] brata[acc sg] i sestru[acc sg].

'I have not seen my brother and sister in a long time.'

(b) Iz sosednej komnaty poslyšalis' detskie [nom p1] smex[nom sg] i golosa[nom pl].

'From the neighboring room one could hear children's 'laughter and [children's] voices.'

Dreyzin, a Russian linguist aware of this congruence, studied the grammatical number of all attributives associated with two or more singular nouns in Volume $\mathrm{P}$ of Nauka $i$ čelovečestvo (Moscow, 1963). He reports (Drejzin 1966) that while Russian graduate students he asked about the proper grammatical number for attributives associated with two or more singular nouns considered plural the proper number, his findings showed an entirely different picture: out of seventy-four attributives preposed to coordinate singular nouns and clearly applicable not only to the nearest noun, only eight were pluralized; the rest had singular endings and exhibited the gender of the nearest noun. 
Russian grammars and style manuals provide little illumination, only calling attention to the fact that when singular nouns are connected by $i$ 'and,' the scope of a preceding singular attributive may be ambiguous, whereas a plural attributive eliminates potential ambiguicy (cf., e.g., Vinogradov and Istrina 1960, 527; Galkina-Fedoruk 1964, 477-478; and Rozental' 1971a, 234). One wonders how a singular attributive can apply to more than one noun and why plural attributives are not mandatory. In fact, there are contexts in which pluralized attributives are completely excluded or would be quite unnatural. The grammatical number of attributives associated with more than one noun (where the nearest noun is singular) appears to depend on whether the modified nouns denote animate or inanimate entities and on whether they denote homogeneous or nonhomogeneous entities, and it also depends on several other factors.

The present chapter represents an attempt to provide a systematic exposition of the facts and to suggest some general principles which may account for them. Attributives associated with "count" nouns denoting animate entities are discussed in Section 1, attributives associated with "noncount" nouns, i.e., nouns denoting homogeneous entities, are discussed in Section 2, and attributives associated with "count" nouns denoting inanimate entities are discussed in Section 3. The modified nouns discussed in the first three sections are connected by $i$ 'and,' but the discussion also applies to nouns connected by $d a$ 'and' or by $s$ 'with.' 1 Attributives associated with nouns connected by $i i_{i}$ 'or,' disjuncts, are discussed in Section 4, and Section 5 contains some comments on postposed attributives.

1. Animate Count Nouns

Though the animate nouns illustrated below are animate both grammatically and semantically, it is their

${ }^{1}$ As in, e.g., Na smenu dolgoletnemu[sg] nedoveriju da prigljadyvaniju teper' javilas' novaja beda 'in place of the longstanding distrust and suspiciousness there has now appeared a new trouble,' and as in Vyxodjaščie[p1] iz vorot ded $s$ babuskoj 'coming out of the gate grandfather with grandmother' = 'grandfather with grandmother, coming out of the gate' (the latter example is from Rozental' 1971a, 235). 
semantic animacy which counts, that is, the fact that they denote animate beings. In general, an attributive which precedes or succeeds two or more such nouns connected by $i$ 'and' must be pluralized, unless it only applies to the nearest noun and that noun has a singular ending, and unless the conjoined nouns have a single referent, e.g., moj drug $i$ soratnik 'my friend and comrade-in-arms.' This principle is illustrated by the sentences under (3) ((3a) from Vagner and Ovsienko 1967, 363).

(3) (a) Tetyre mesjaca naucnye sotrudniki ... nabljudajut neobycnoe $v$ mire zivotnyx javlenie: mirnoe sožitel'stvo $v$ odnoj kletke podopytnyx [gen p1] kota[gen sg] $i$ myš $i$ [gen sg].

'For four months research workers ... have been observing a phenomenon unusual in the animal world: the peaceful cohabitation in one cage of an experimental cat and mouse.'

(b) On bespokoitsja o bol'nyx[1oc p1] syne[1oc sg] i dočeri[loc sg].

'He is worried about [his] sick son and daughter.'

(c) On osobenno gorditsja talantlivymi synom[instr sg] $i$ dočer'ju[instr sg].

'He is especially proud of [his] talented son and daughter.'

(d) Nam očen' nravjatsja datskie[nom p.1] aktër[nom sg] $i$ aktrisa[nom sg].

'We very much like the Danish actor and actress.'

(e) Zavtra ko mne priež̃ajut dvojurodnye [nom p1] secondarily-related

brat [nom sg] $i$ sestra [nom sg]. brother and sister

'Tomorrow my female cousin and male counsin are coming to see me.'

The plural attributives in the sentences above represent proper, correct usage and their plural number is mandatory in the standard language. In casual discourse, however, attributives in such contexts are not necessarily pluralized. They generally have singular endings and manifest the gender of the nearest nouns. Consequently, while the singular attributive in a sentence such as (4), for example, would be interpreted in standard discourse as applicable just to the nearest noun, i.e., as only qualifying the son, in casual discourse the same attributive would be likely to be interpreted as applicable to both 
nouns, i.e., as qualifying the son as well as the daughter.

(4) On osobenno gorditsja talantlivym[instr sg (masc)] synom[instr sg] $i$ dočer'ju[instr sg].

'He is especially proud of [his] talented son and daughter.'

It is notable that in casual discourse pluralization is never mandatory. Any of the plural attributives illustrated under (3) (and also the attributive in (1)) could have a singular ending in casual discourse.

Both the "correct" (3c) and its "casual" version in (4) can be assumed to derive from an underlying structure in which the attributive occurs twice--as a modifier of syn 'son' and as a modifier of doč' 'daughter.' This underlying structure could also be realized as (5).

(5) On osobenno gorditsja talantlivym synom $i$ talantlivoj dočer'ju.

'He is especially proud of [his] talented son and talented daughter.'

Both (3c) and (4) can be accounted for as reductions of (5). The process which reduces the structure underlying (5) to the structure underlying (3c) must involve a regrouping of the constituents, to yield a structure in which the two nouns modified by the same attributive are conjoined and thus add up to a [+Plural] entity. The putative input and output structures in this process are shown under (6) (with irrelevant details omitted).

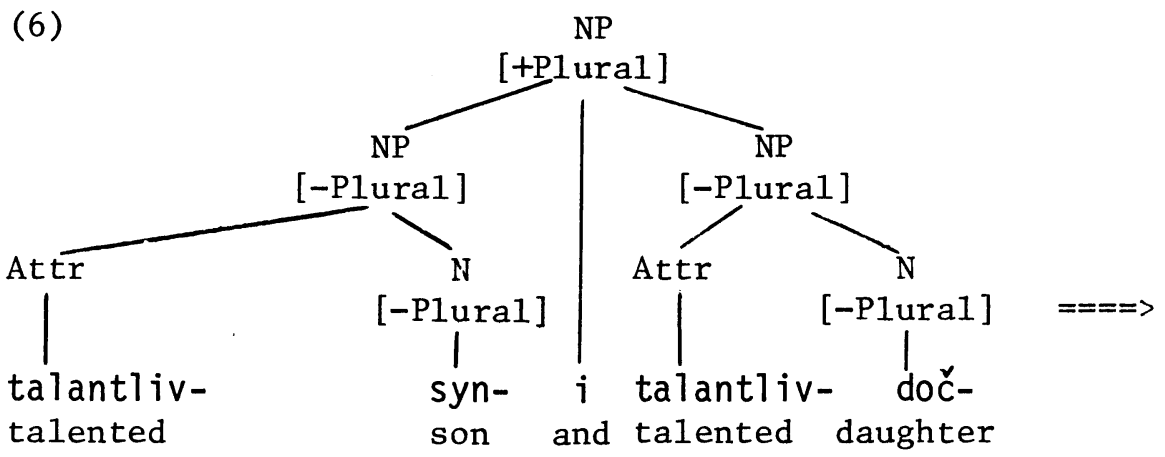




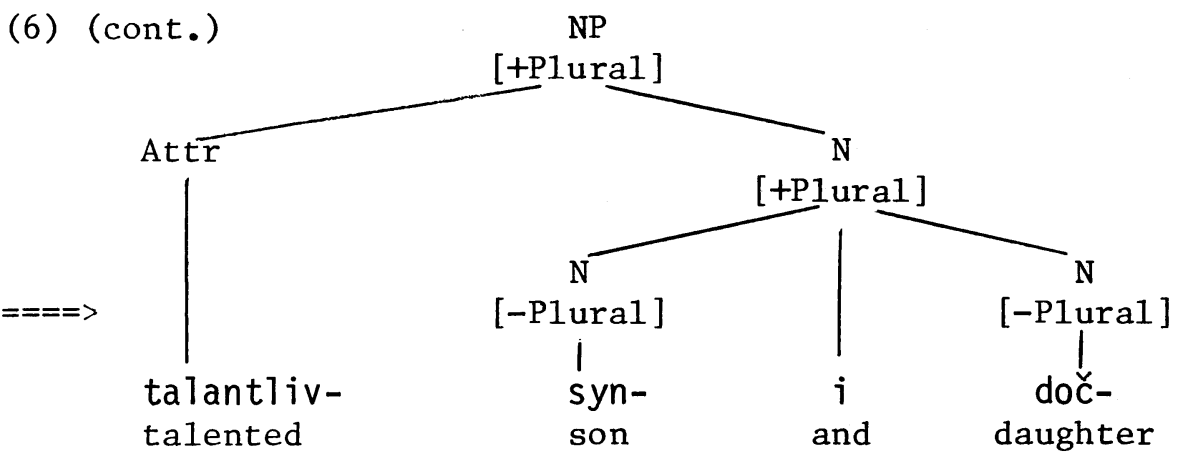

An intermediate structure in this process would be the one under (7) (both the process illustrated in (6) and the intermediate structure in (7) are proposed and motivated in Postal 1967; the term "regrouping" is from Tai 1969 [and 1971] and Koutsoudas 1971).

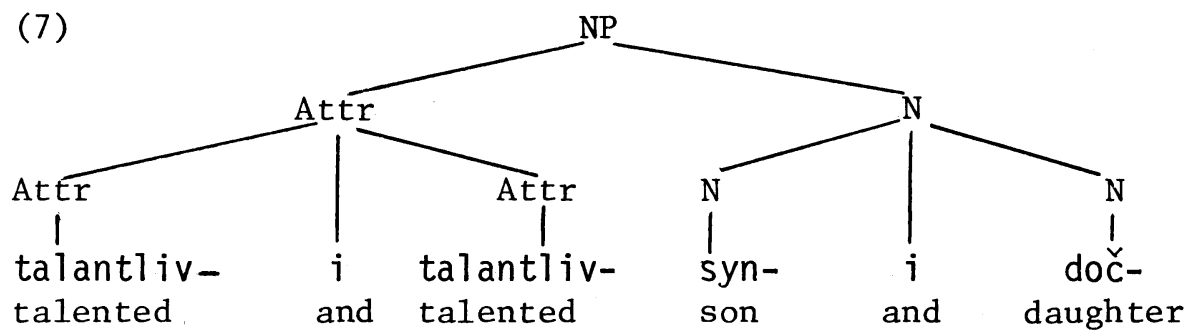

Since the conjoined Attributive nodes in (7) dominate identical adjectives, they must be collapsed--by a rule which might be called Identity Reduction (Postal 1967, 8) or Identical-Conjunct Collapsing (Stockwell et al. 1973, 381)--to yield the output structure shown in (6). The Attributive node in the output structure then receives the [+Plural] specification of the adjoining $\mathrm{N}$ node by Attributive Agreement. As to the [+Plural] specification on the $\mathrm{N}$ node, such a specification can be assumed to be attached to any $\mathrm{N}$ or NP node which comes to dominate coordinate $\mathrm{N}$ or NP nodes as a consequence of Regrouping (further evidence is given later on).2

${ }^{2}$ The [+Plural] specification on the higher NP node in the input structure is also apparently a consequence of Regrouping (in this case the reduction of conjoined verb phrases with an identical verb, viz., On osobenno gorditsja talantlivym synom $i$ osobenno gorditsja talantlivoj dočer'ju 'he is especially proud of (cont.) 
The process which reduces the structure underlying (5) to the structure underlying (4) (On osoberno gorditsja talantlivym[sg] synom $i$ dočer' $j u$ 'he is especially proud of [his] talented son and daughter') is considerably simpler. Its input and output structures are shown under (8).

NP
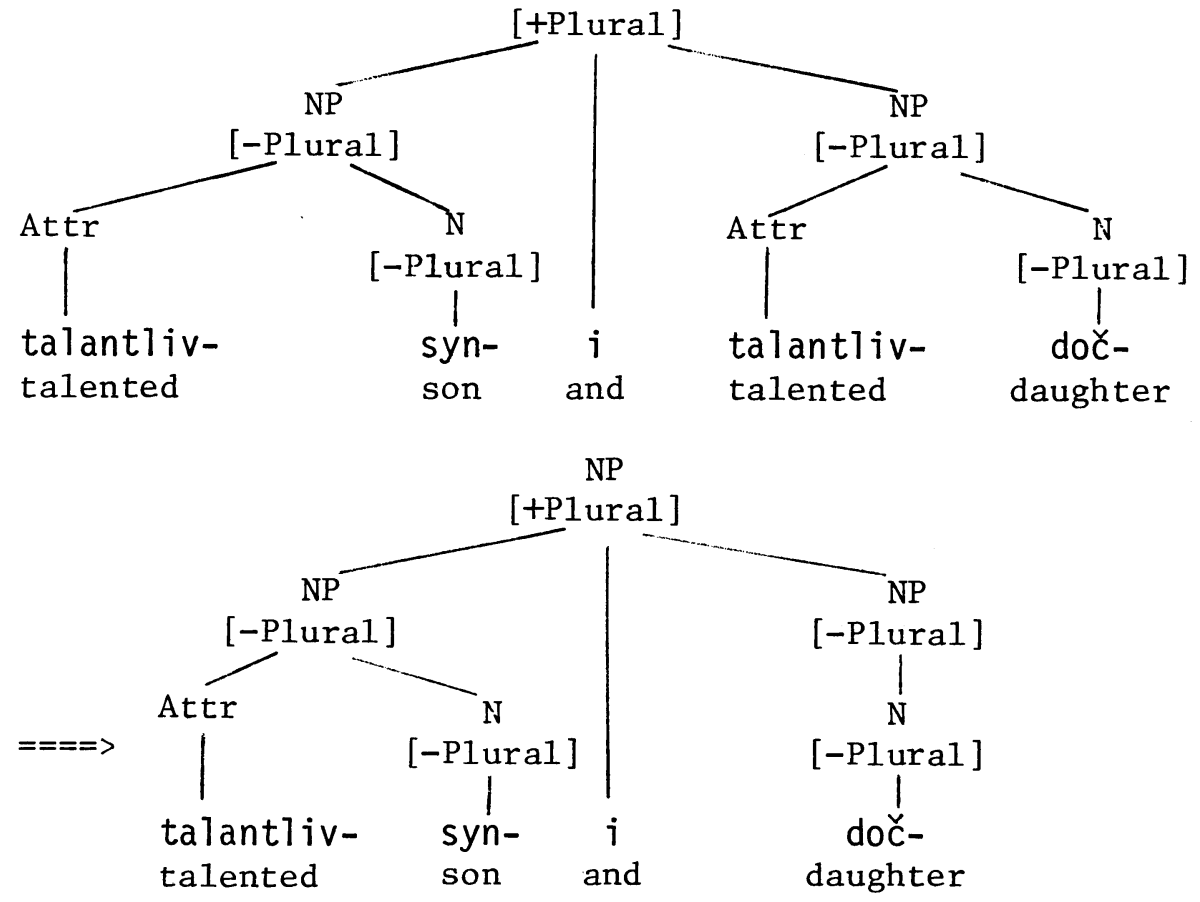

What happens in this case is that the Attributive node in the righthand conjunct of the input structure is simply deleted--by a rule which can be called Identity

[his] talented son and especially proud of [his] talented daughter'), though the conjunction within this noun phrase could also be viewed as primary, in which case the [+Plural] specification matches a \{taggregate\} feature on the node. On primary, or "phrasal" conjunction versus secondary, or "sentential," see especially Lakoff and Peters 1969 and Lakoff and Ross 1970. 
Deletion. ${ }^{3}$ The remaining attributive is then only associated with the lefthand noun, syn-, and cannot be assigned a [+Plural] specification.

The two reduction processes outlined above--Regrouping and Identity Deletion--can thus account, respectively, for the pluralization of an attributive associated with more than one noun in standard, "correct" discourse, where Regrouping can be considered mandatory in the reduction of conjoined constituents, and for the singular number of such an attributive in casual discourse, where the simpler reduction process, Identity Deletion, is also permissible. Identity Deletion, however, is also permissible in the standard language when the identical attributives in the conjoined noun phrases are determiner-type attributives, most typically demonstrative pronouns (ètot 'this,' tot 'that'), possessive pronouns (moj 'my,' nas 'our,' etc.), deictic adjectives such as takoj 'such,' drugoj 'another,' and sledujuščij 'the following,' or "basic" (in distinction from "partitive") quantifiers, of which only the distributive ones--každyj 'every,' Zjuboj 'any,' and vsjakij 'any'--seem to occur as modifiers of animate nouns in conjoined phrases. Distributive quantifiers in fact cannot be pluralized (unless the modified nouns constitute a single entity and represent primary conjunction), and they can therefore be assumed to block Regrouping. Thus in a sentence such as My posylaem posylki každomu mal'čiku $i$ každoj devočke 'we send packages to every boy and every girl,' the conjoined phrase každomu mal'čiku i každoj devočke 'to each boy and each girl' can only be reduced by Identity Deletion, to yield každomu[sg (masc)] mal'čiku $i$ devočke 'to each boy and girl,' for pluralization of the determiner would be inadmissible in a reduction of this sentence.

${ }^{3}$ The phenomenon of Identity Deletion was also referred to above in the discussion of predicate adjectives (Section 10.33 in Chapter One). For some recent discussions of Identity Deletion and Coordination Reduction as linguistic processes see, e.g., Jackendoff 1971a, Koutsoudas 1971, Tai 1971, Crockett 1972, Maling 1972, Hankamer 1973, Perlmutter 1973, Bach et al. 1974, Kuno 1974, Schachter 1974, and Channon 1975, and cf. also Stockwe11 et al. 1973, 294-420. In the Soviet Union, especially Paducheva has been interested in these questions; see Padučeva 1969, 1971, and 1974, 161-192, and Kore1'skaja and Padečeva 1973; see also Leont'eva 1967 and the (cont.) 
Determiner-type attributives other than quantifiers can in principle be pluralized when they apply to more than one singular noun--in other words, they do not block Regrouping, but sensitive native speakers consider the pluralization of such attributives artificial, contrived. Thus a sentence such as Let's ask this boy and (this) girl can in principle be translated logically as Sprosim ètix [p1] parnja $i$ devušku, with a pluralized modifier, but there is something odd about this sentence, which accords with Ovsyaniko-Kulikovsky's assessment of (2a) above ( $\mathrm{Ja}$ davno ne vidal moix[p1] brata $i$ sestru 'I have not seen my brother and sister in a long time') as "grating on the ear."

In careful, precise style, determiner-type attributives (hereafter "determiners") are often simply repeated before each noun (in other words, the underlying conjoined phrases are not reduced), but in regular usage Identity Deletion operates to yield sentences such as Sprosim ètogo [sg masc] parnja $i$ devušku, where the determiner has a singular ending and bears the gender of the nearest noun. ${ }^{4}$

These observations are based not only on judgments of native speakers but also on the fact that in five years of studying contemporary Russian publications representing different styles and listening to Russian formal and informal speech $I$ have only come across one pluralized determiner, in the sentence under (9).

(9) Otčestuo obrazovano ot imeni otca, kotoroe, v svoju očered', emu dali ego roditeli--naši[p1] deduška $i$ babuška.

'The patronymic is formed of the father's name, which, in its turn, was given to him by his parents--our grandfather and grandmother.'

observations in Saumjan 1965, 163-164 and Zolotova 1973, 340-344. (Note that Identity Deletion represents a fairly superficial process in the derivation of sentences from underlying representations, in distinction from the deletion of constituents from embedded sentences in underlying structures, as, for instance, Equi-NP Deletion, which deletes the subject of an embedded sentence when identical to a noun phrase in the next higher sentence [see, e.g., Bach 1974, 116 ff.].)

${ }^{4}$ Referring to determiner-type attributives as determiners implies that they constitute a distinct (cont.) 
In this sentence, however, the conjoined nouns deduska $i$ babuška 'grandfather and grandmother' seem to represent primary conjunction rather than reduction through Regrouping. These nouns are in apposition to roditeli 'parents,' and they are therefore presumably nominal predicates to roditeli 'parents' in an underlying embedded sentence which could be realized as Ego roditeli --naç i deduška $i$ babuška 'his parents are our grandfather and grandmother.' This sentence cannot be accounted for as a reduction of *Ego roditel' naš deduška $i$ ego roditel' naša babuska 'his parent is our grandfather and his parent is our grandmother,' and the conjunction in the predicate phrase is thus basic. One could still suggest that the conjoined nouns are reduced from the primary conjunction naš deduška i naša babuška 'our grandfather and our grandmother.' This is possible, but informants confronted with plural determiners in phrases like naši [p1] deduška $i$ babuška 'our grandfather and grandmother' invariably interpret the conjoined nouns as representing a single entity, a pair, and it would therefore be more plausible to account for the plural determiner in (9) as a modifier of primarily conjoined nouns (which constitute a single plural noun).5

syntactic category. Indeed this seems to be the case, but this question is beyond the scope of the present monograph.

${ }^{5}$ The unacceptability of naš [sg masc] duduška $i$ babuška in (9) would clinch the argument, but it is rather difficult to establish. Rozental' 1971a (p. 234) cites from Chekhov the sentence Zdes' žili moi[p1] otec $i$ mat' 'here lived my father and mother' with a plural determiner. The conjoined otec $i$ mat' 'father and mother' in this sentence may very well represent primary conjunction, but the plural determiner can also be accounted for as a consequence of reduction by Regrouping, for Chekhov's was a careful style. In any case, the suggestion in Rozental' $1971 a$ ( $i b i d$.$) that the nominative case may account for the$ pluralized determiner cannot be substantiated.

For some comments on the grammatical number of determiners and their reduction in French and in English see B1inkenberg 1950, 164-166, Schane 1966, 21, and Crockett 1972, 56-57. (Schane, incidentally, uses the term "primary conjunction" in reference to the conjunction of major constituents as a consequence of the reduction of coordinate sentences, as distinct from "secondary (cont.) 
There is yet another class of attributives which allow Identity Deletion in the standard language and even seem to block Regrouping entirely. Consider (10).

(10) (a) My videzi $\left.\begin{array}{c}\text { staryx }[\mathrm{p} 1] \\ \text { starogo[sg masc] }\end{array}\right\}$ korolja $i$ korolevu.
'We saw the old king and queen.'
(b) My videli datskogo[sg masc] $\}$ korolja $i$
korolevu.
'We saw the Danish king and queen [= the king and
queen of Denmark].'

In (10a), the modifier must be pluralized and a singular form is only marginally acceptable, in casual discourse. In (10b), in contrast, though the modifier can perhaps be pluralized in the sense of "the king and queen who are Danish" (as in (3d) above), it cannot be pluralized in the sense of "the king and queen who reign in Denmark."

The internal relationship between this modifier and the nouns it applies to is clearly of a special kind, which can be demonstrated by the fact that datskij korol' $i$ koroleva 'the Danish king and queen' is paraphrasable as korol' $i$ koroleva Danii 'the king and queen of Denmark'; the phrase in (3d), datskie aktër $i$ aktrisa 'Danish actor and actress,' where the attributive is pluralized, cannot be paraphrased as *aktër $i$ aktrisa Danii 'the actor and actress of Denmark.' Attributives as in (10b) have in fact been called "pseudo-adjectives" (Postal 1969a and 1969b). 6 However, it appears that the fact that datskogo in (10b) is a "pseudo-adjective" is insufficient to account for the fact that it cannot be pluralized, for there are similar nonpluralizable attributives which are not "pseudo-adjectives." Consider (11).

conjunction"--the conjunction of lower-level constituents as a consequence of the reduction of coordinate major constituents.)

${ }^{6}$ On the meaning and possible derivation of different types of relational adjectives see esp. Levi 1973 and 1974 and Sussex 1974. 
Dikij[sg masc]
*Dikie[p1] gus' i utka prizeteli pervymi.

'The wild goose and [wild] duck flew in first.'

This sentence, which is cited from a nineteenthcentury work in Galkina-Fedoruk 1964, 477, is still representative of current usage. As in (10b), the attributive can be pluralized, but only in the sense of "goose and duck who are wild." In other words, it can be pluralized as a characterization of the individual referents but not as a definition of the subspecies, as a reference modifier (see pp. 95-97 above). Apparently the attributives in (10b) and (11) cannot be pluralized because the underlying conjunctions datskij korol' $i$ datskaja koroleva 'the Danish king and Danish queen' and dikij gus' $i$ dikaja utka 'wild goose and wild duck' cannot be reduced through Regrouping, and this can be accounted for by deriving the repeated attributives as components of composite nouns, as in $(12) .7$

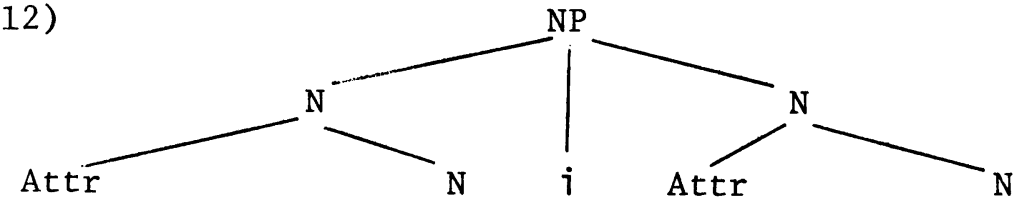

Identical attributives in conjoined composite nouns can only be reduced by Identity Deletion. Regrouping is impossible in such cases, for this process is inapplicable to conjoined nouns.

In summary, an attributive which modifies more than one singular animate noun must generally be pluralized in standard discourse--whether the nouns are primarily conjoined or conjoined through reduction by Regrouping. When the attributive is a determiner, it must be pluralized if the nouns are primarily conjoined, but otherwise singular forms are preferable, i.e., Regrouping does not take place and reduction by Identity Deletion is the normal procedure. When the attributive is "definitional," constituting a single lexical unit with each of the modified nouns, as in (12) above, it is never pluralized, for Regrouping

'Note that if korol' $i$ koroleva and gus' $i$ utka were conjoined through primary conjunction rather than (cont.) 
is inapplicable, and primary conjunction of the modified nouns is also excluded (as each is bound to the attributive). Only Identity Deletion is acceptable as a reduction process in such cases. An additional context where Identity Deletion is permissible in the standard language is discussed in Section 2.1 below.

\section{Noncount Nouns}

"Noncount" is the conventional name for nouns which denote homogeneous entities (see Section 2 in Chapter Two). In general, an attributive followed by such a noun cannot be pluralized, no matter how many nouns it is supposed to modify. Occasional deviations from this principle do occur, and they are analyzed in what follows. The exposition begins with nouns denoting animate entities, continues with nouns denoting abstract entities, and ends with nouns which denote concrete entities.

2.1 Nouns which denote homogeneous pluralities of animate beings, e.g., proletariat 'proletariat,' krest'janstvo 'peasantry,' etc., are apparently generally not susceptible to conjunction. As noted in Panov 1968 (172-173), such nouns are generally going out of use and are being replaced by singular forms of count nouns, and this also applies to conjunctions. Instead of, for instance, sovetskij rabočij klass $i$ krest'janstvo 'the Soviet working class and peasantry' (where klass is a pseudocollective noun and krest'janstvo a bona fide collective), one normally encounters sovetskij rabočij $i$ krest'janin 'the Soviet worker and peasant,' where the same homogeneous pluralities are signified by singular count nouns. What is notable about the latter phrase is that the attributive need not be pluralized. The putative \{thomogeneous\} specifications on the conjoined underlying NP nodes (see (13)) apparently "discourage" Regrouping and the phrases are reduced by Identity Deletion, as shown in (13).

reduction, then the attributives would have to be pluralizable, for even determiners are pluralized in association with primarily conjoined nouns (cf. (9)). 

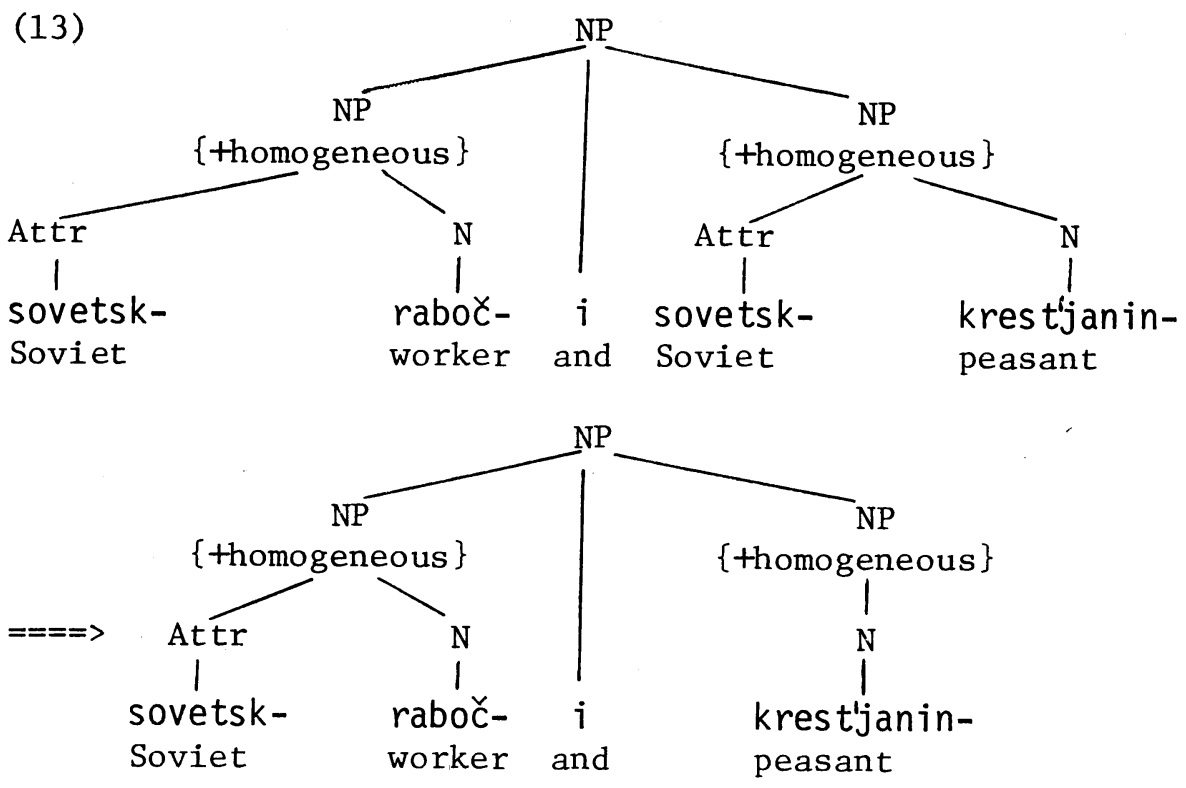

Consider also (14).

(14) Russkij[sg] slušatel'[sg] i čitatel'[sg] sčitali[pl] estestvennoj ètu raznicu $v$ dialektax.

'The Russian hearer and reader considered this difference in dialects natural.'

The subject phrase in (14) is presumably the product of a derivation as in (13), but the verb must be pluralized, for the superordinate NP node dominates conjoined NPs and must be specified [+Plural] regardless of their homogeneity (see also footnote 2). Regrouping is apparently permissible in both (13) and (14), i.e., the attributives may be pluralized, but pluralization is stylistically inferior in such contexts.

Sentence (15) illustrates a bona fide collective in a conjunction.

(15) Ona uspela ešče pozvonit' moskovskoj[sg fem] rodne Moscow relatives

[sg fem] $i$ druz'jom[p1]. and friends

'She managed to call [her] Moscow relatives and friends.' 
The attributive in this sentence can only be interpreted as applicable to rodne 'relatives' as well as to druz'jam 'friends' and the sentence can be paraphrased as ona uspela eł̌̈e pozvonit' moskovskoj rodne $i$ moskovskim druz'jam 'she managed to call [her] Moscow relatives and Moscow friends,' yet a plural attributive is excluded (cf. *moskovskim [p1] rodne [sg] $i$ dmuz'jam[p1]). Evidently the <+homogeneous> feature of rodnja 'relatives' blocks Regrouping, thereby rendering Identity Deletion the only possible, and therefore standard reduction process.

2.2 Unlike nouns which denote homogeneous animate entities, nouns which denote homogeneous abstract entities are highly susceptible to conjunction, as are abstract nouns in general. In each of the illustrative sentences under (16), the attributive preceding the conjoined nouns is unquestionably applicable to the two nouns, but it cannot be pluralized. Again, the inherent homogeneity of the leftmost noun (whether <thomogeneous> or just <homogeneous $>$ ) can be assumed to block Regrouping in the underlying conjunction, leaving Identity Deletion as the only possible method of reduction.

(16) (a) Vstrěca organizovana, čtoby obsudit' voprosy

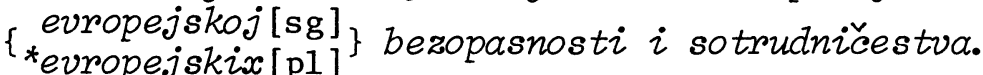

'The meeting has been organized in order to discuss questions of European security and cooperation.'

(b) V osnove rasprostranenija russkogo jazyka lezali ne tol'ko potrebnosti torgovli $i$ diplomatii, no $i$ potrebnost' znat' $\left.\begin{array}{c}\text { musskuju[sg] } \\ \text { russkie }[\mathrm{p} 1]\end{array}\right\}$ nauku $i$ Ziteraturu.

'The basis for the dissemination of the Russian language was not only the needs of trade and diplomacy but also the need to know Russian science and 1iterature.'

(c) Režissëra rassprašivali o ego vagljadax na $\left.\begin{array}{c}\text { sovremennyj }[\mathrm{sg}] \\ \text { *sovremennye }[\mathrm{pl}]\end{array}\right\}$ kinematograf $i$ literaturu.

'The director was questioned about his views on contemporary cinematography and literature.' 
(d) Kletki imejut $\left\{\begin{array}{c}\text { različrnuju[sg] } \\ { }_{\text {razlichye }}[\mathrm{p} 1]\end{array}\right\}$ veličinu[sg] $i$ formu [sg].

'The cells have different sizes and shapes.'

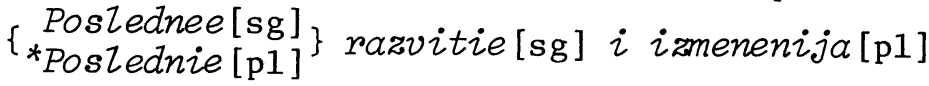
latest development and changes poražajut [p1] svoej bystrotoj. are striking [in] their speed

'The speed of the latest development and latest changes is striking.'

The attributives in these sentences have different ultimate underlying sources, for their internal relation to the nouns they modify is different in each case. It would therefore be futile to attempt to account for their resistance to pluralization on the basis of their underlying sources. For example, the underlying source of the attributive in (16b), musskuju 'Russian,' may be the noun Rossija, perhaps as in nauka Rossii $i$ literatura Rossii 'the science of Russia and the literature of Russia,' but the attributive in (16d) (razlicrauju 'different') cannot be related to a noun in this way. Furthermore, the attributive evropejskoj 'European' in (16a) seems to represent two different underlying relations, namely, the security of Europe and cooperation in Europe. There are also no grounds for considering the attributives in (16) "definitional," like datskij in (10b) and dikij 'wild' in (11), for these attributives do not classify the nouns intrinsically. The only plausible account for the singular number of the attributives in (16) thus seems to be that Regrouping is blocked by the presence of the homogeneity feature in the conjoined phrases and only Identity Deletion can apply.

Perhaps the reason for this phenomenon is simply the superficial fact that a pluralized modifier immediately followed by a noun which normally cannot be pluralized would be anomalous (cf. the comment in Blinkenberg 1950, 142), and perhaps, more fundamentally, the reason is that the process of Regrouping conjoins nouns to form a plurality and homogeneous entities cannot be added up to form a plurality.

Determiners of various kinds are especially typical as modifiers of conjoined noncount abstract nouns. Some illustrative examples are given under (17). 
(17) (a) Rastračivanie svobodnyx časov vpustuju, poroj ne na pol'zu, a vo vred $\left\{\begin{array}{c}\text { svoemu }[\mathrm{sg}] \\ \text { svoim }[\mathrm{pl}]\end{array}\right\}$ zdorov'ju $i$ intellektu, protivorečit vsemu duxu našego obščstva.

'The waste of one's leisure hours in vain, at times not to the benefit but to the detriment of one's health and intellect, 'is in contradiction to the whole spirit of our society.'

(b) On uxodil ot brata $s$ \{ nekotoroj $\left.[\mathrm{sg}]_{\text {nekotorymi }[\mathrm{p} 1]}\right\}$ grust'ju $i$ neponimaniem.

'He left [his] brother with some sadness and perplexity.'

(c) My povermuli na Nejpls, na $\left\{\begin{array}{c}\text { toj[sg] } \\ \text { tex }[\mathrm{p} 1]\end{array}\right\}$ že skorosti $i$ vysote.

'We turned toward Naples, at the same speed and altitude.'

(d) $\left\{\begin{array}{c}\grave{E} t a[\mathrm{sg}] \\ * t i[\mathrm{pl}]\end{array}\right\}$ pročnost' $i$ ustojěivost' peredajutsja [p1] vsemu ego telu.

'This firmness and steadiness are transmitted to his whole body.'

Note that the verb in (17d) and also the verb in (16e) above are pluralized. In the sentences under (18), however, the verbal predicates are not pluralized.

(18) (a) Takaja[sg] semantireskaja[sg] svjazannost' $i$ vaaimoobuslovlennost' $i$ delaet [sg] vozma:nym slijanie ètix dvux členov predlozenija $v$ odin komponent.

'Such semantic connection and interdependence make possible the merging of these two sentence constituents into a single component.'

(b) Osnovnaja[sg] cennost' $i$ značenie recenzimuemoj knigi zakljucaetsja[sg] ne tol'ko $v$ glubokom $i$ samostojatel'nom videnii mira.

'The basic value and significance of the book under review lie not only in the profound and original view of the world.' 
(c) Naše [sg] vospitanie i obrazovanie doľ̌no [sg] byt' postroeno tak, čtoby ne voznikali tam, gde ne nado, èti ustojèivye svjazi.

'Our upbringing and education must be set up so that these fixed relations would not form at the wrong places.'

(d) Eto novaja[sg] arxitektura i planirovka druzno idët[sg] $v$ složivšujusja vekami samuju central 'nuju čast' goroda.

'It is the new architecture and planning which are coming in full swing to the very center of the city, formed in the course of centuries.'

The singular number of the verbal predicates in these sentences indicates that the conjoined nouns represent single entities, for otherwise the predicates would be pluralized (cf. Chapter Four). The conjoined nouns in these sentences indeed overlap semantically and can be accounted for as primarily conjoined nouns which constitute a single noun, a composite--as suggested with respect to deduška $i$ babuška 'grandfather and grandmother' in (9) above, except that primarily conjoined composites of animate nouns are marked [+Plural], and similar configurations of inanimate nouns remain grammatically singular. 8

Further evidence for the proposition that conjoined nouns which overlap semantically may derive as components of single nouns that are grammatically singular is offered by (19).

(19) Vot ona[sg], glubina i vjazkost' perezitogo.

'Here it is, the depth and weight of what has been experienced.'

The anticipatory pronoun ona 'it' (1it. 'she') is singular. The fact that it is not anomalous can be accounted for by viewing the conjoined nouns as representing

${ }^{8} \mathrm{Cf}$. also pp. 193-194, and cf. the corresponding phenomenon in the French sentence Le pour et le contre $n$ 'est pas $i c i$ à sa place (Blinkenberg 1950, 30) and in the English sentences Ice cream and cake is my favorite dessert (Dik 1968, 210), Bread and butter is served at most meals (Schane 1966,5), and Bacon and eggs is a popular breakfast, isn't it? (Stockwell et al. 1973, 384). 
an underlying inanimate composite. Cf. the unacceptability of a singular pronoun in (20a), where the conjoined nouns denote animate beings, and in (20b), where the conjunction cannot possibly constitute a single noun.

(20) (a) Vot $\left\{\begin{array}{c}\text { oni }[\mathrm{p} 1]] \\ \text { ona }[\mathrm{sg}]\end{array}\right\}$, mat' i sestra velikogo pisatelja. 'Here they are, the mother and sister of the great writer.'

(b) Vot $\left\{\begin{array}{c}\text { oni }[\mathrm{p} 1] \\ \text { on }[\mathrm{sg}]\end{array}\right\}$, pis'mennyj stor $i$ dnevnik velikogo pisatelja.

'Here they are, the desk and diary of the great writer.'

While the singular number of the verbal predicates in (18) and of the pronoun in (19) can be taken as evidence that the conjoined nouns with which these elements, are associated derive as components of single nouns, the singular number of an attributive associated with conjoined nouns denoting homogeneous entities is opaque in this respect, for such an attributive must bear the number (and gender) of the nearest noun whether the conjoined nouns constitute a single lexical unit in the underlying representation or are a consequence of reduction. It can only be assumed that if the conjoined nouns overlap semantically, and especially if the overlap is considerable (as in the sentences under (21) below), then the nouns represent a single underlying noun, and this may also be the case if they are nouns which frequently occur in conjunction with one another, as illustrated in the sentences under (22) (and as in the examples from English in footnote 8$)$.

(21) (a) Teper' žizn' $v$ derevne dlja menja polna osobennogo[sg] značenija i smysla.

'Life in the country is now full of special meaning and significance for me.'

(b) Nekotorye iz kritikov uprekajut menja $v$ tom, ěto ja budto by sliškom "prosvetljaju" Sekspira, Zišaja ego izvestnoj[sg] temnoty $i$ zagadočnosti. (Samuil Marshak)

'Some of the critics chide me for ostensibly rendering Shakespeare too "lucid," [thereby] depriving him of a certain obscurity and impenetrability.' 
(c) Na XXIV s"ezde govorilos' o vysokoj[sg] dejstvennosti $i$ operativnosti vystuplenij èstonskogo televidenija.

'At the 24 th Congress of the Party there was discussion of the high effectiveness and operativity of the programs on the Estonian television.'

(d) Imenno ona zastavljaet ego voevat' protiv vsjakoj[sg] kosnosti i zastoja.

'It is that which forces him to fight against all stagnation and inertia.'

(22) (a) Neskol'ko glotkov ukrepili naš[sg] dux i telo. 'A few gulps fortified our spirit and body.'

(b) Prezident OAR Anvar Sadat vystupil segodnja po kairskomu[sg] radio i televideniju.

'The President of the UAR, Anwar Sadat, spoke today on Cairo radio and television.'

(c) Každye 12 minut $v$ pomeščenie podaëtsja čistyj vozdux neobxodimoj[sg] temperatury $i$ vlaznosti.

'Every 12 minutes the room receives fresh air of the right temperature and humidity.'

(d) Vlasti ǔe rasporjadilis' o merax po zašcite ozera Bajkal v Sibiri, znamenitogo svoej neobyčajno čistoj vodoj $i$ zomečatel'noj[sg] faunoj $i$ floroj. 9

'The authorities have already taken measures for the protection of Lake Baykal in Siberia, which is famous for its unusually clear water and remarkable fauna and flora.'

In distinction from the conjoined nouns in (21) and (22), which can be assumed to be conjoined also in the underlying representations of these sentences, the conjoined nouns in the sentences under (16), which were cited to illustrate the consequences of reduction from conjoined noun phrases with identical attributives, seem to derive independently, for there is little semantic overlap

${ }^{9}$ Note the singular svoej 'its,' which applies to the water as well as to the flora and fauna, and note also the difference between Russian and English in the order of the set conjuncts both in this sentence (fauna $i$ flora in Russian vs. flora and fauna in English) and in (22b) (dux $i$ telo 'spirit and body' in Russian vs. body and spirit in English). 
between them and they do not appear to constitute set conjunctions--though, of course, there is some internal relationship between them, for otherwise their conjunction would be impossible. However, only with respect to the conjoined nouns in (16e) (Poslednee[sg] razvitie $i$ izmenenija porazajut[p1] svoej bystrotoj 'the latest development and changes are striking in their speed' = 'the speed of the latest development and latest changes is striking') can one be certain that they are not components of a composite noun, because the verbal predicate associated with them is pluralized. This also applies to (17d) (Ëta[sg] pročnost' $i$ ustojeivost' peredajutsja[p1] vsemu ego telu 'this firmness and steadiness are transmitted to his whole body'), where despite the semantic overlap of the conjoined nouns they must be viewed as conjoined through reduction. 10

Two additional sentences in which conjoined nouns modified by a singular attributive control pluralized verbal predicates and must therefore be viewed as connected by $i$ through reduction are cited in (23).

$$
\begin{aligned}
& \text { Etrusskaja[sg] } \\
& \text { *Etrusskie [pl] } \\
& \text { okazali[pl] ogromnoe vozdejstvie na kul'turu } \\
& i \text { jazyk rimljan. } \\
& \text { 'The Etruscan culture and language have had } \\
& \text { tremendous influence on the culture and language } \\
& \text { of the Romans.' }
\end{aligned}
$$

${ }^{10}$ Reduction in this and in other sentences is not necessarily from ultimate sentential conjunction. This can be demonstrated by sentences such as the following: Neobxodim akademičeskij slovar' russkoj[sg] idiomatiki[sg] $i$ aforističeskix vyraženij 'we need an Academy dictionary of Russian idioms and aphoristic expressions.' This sentence cannot be the product of sentential conjunction, i.e., of two conjoined sentences, because it refers to a single dictionary and cannot possibly be paraphrased as a conjunction of two sentences. On the other hand, the conjuncts are such that they cannot constitute a composite noun. Since the attributive clearly modifies both conjuncts, the phrase can be accounted for as a reduction of the primary conjunction misskaja idiomatika $i$ russkie aforističeskie vyraženija 'Russian idioms and Russian aphoristic expressions.' 
(b) $\left.\begin{array}{c}\text { Afrikanskaja[sg] } \\ { }^{*} \text { Afrikanskie }[\mathrm{pl}]\end{array}\right\}$ kul'tura $[\mathrm{sg}]$ i nauka $[\mathrm{sg}]$ preziralis'[p1] kolonizatorami.

'African culture and science were scorned by the colonizers.'

There seem to occur very few deviations from the principle that an attributive followed by a singular noun which denotes an abstract homogeneous entity cannot be pluralized--or, in terms of grammar, that Regrouping of conjoined noun phrases with identical attributives is blocked when the leftmost noun denotes an abstract homogeneous entity. One deviation, from Tolstoy's War and Peace, was cited as (2b) above and is repeated as (24) below. Another, from an article by a Soviet sociologist named Arab-Ogly (a non-Russian name) in Literaturnaja gazeta, is cited as (25).

(24) Iz sosednej komnaty poslyšalis' detskie[p1] smex[sg] $i$ golosa[p1].

'From the neighboring room one could hear children's laughter and [children's] voices.'

(25) Popytka ̌̌e ostanovit' časy istorii, zatormozit' naučnotexničeskij progress označala by ... osuždenie milliardov ljudej na postojannye [p1] nużdu[sg] $i$ obezdolennost'[sg] imenno $v$ tot istoriceskij moment, kogda vpervye stalo vozmoznym ix osvoboždenie $i$ sozdanie izobizija. ${ }^{11}$

'An attempt to stop the clock of history, to impede the progress of science and technology would mean ... the condemnation of milliards of people to permanent indigence and destitution at the very historical moment when their liberation and the creation of affluence have for the first time become possible.'

Both in (24) and in (25) the pluralized attributives seem to be a consequence of rationalization, a consequence of conscious correction of the "natural," intuitively chosen number. What supports this hypothesis is the fact that (24) was indeed classified by Revzin as "artificial"

11 The singular number of the predicate in the last clause is discussed on p. 270 . 
(p. 162 above) and the pluralized attributive in (25) was classified as "very bad" or "impossible" by all of the informants questioned about it (all Soviet Russians with advanced degrees). ${ }^{12}$

I have also come across a few cases of pluralized participles, as in rastuščie[p1] drǔ̌ba i sotrudničestvo mezdu Sovetskim Sojuzom $i$ Indiej 'the growing friendship and cooperation between the Soviet Union and India,' and nepreryvno razvivajušciesja[p1] pressa i televidenie "priblizajut" mir $k$ čelovečeskim glazam ... 'the continuously developing press and television bring the world "closer" to man's eyes ... .' The putative derivation of participles from verbs (see, e.g., Babby 1973a and 1975) apparently has nothing to do with their pluralization in these phrases, for there also occur in fully standard discourse sentences with nonpluralized participles, as illustrated under (26).

(26) (a) Lenin bystro sdelal rasčèt i poprosil izgotovit' majatnik po vyčislennomu[sg] im razmem [sg] $i$ vesu[sg]. figured out by him size and weight

'Lenin quickly made a calculation and asked to have a pendulum made according to the size and weight he had figured out.'

(b) Sledovalo by vključit' $v$ čislo form predloženija modifikacii s leksičeski vyražennoj[sg] dolżenstvovatel'nost'ju, neobxodimost'ju, vozmožnost'ju $i$ t.d.

'One should include among the forms of the sentence modifications with lexically expressed obligation, necessity, possibility, and so on.'

(c) On ... vnov' vernët s takim trudom zavoëvannoe with such difficulty won

[sg] doverie i uvaženie odnosel'čan. trust and respect village-peers

'He ... again will bring back the trust and respect of his village peers, which he had won with so much difficulty.'

12 For an additional illustration of a pluralized attributive in association with conjoined abstract homogeneous nouns see Rozental' 1971a, 234. 
(d) Suščestuitel'nye s nejtralizovannym [sg] čislom i rodom neizvestny.

'Nouns with neutralized number and gender are unknown.'

If the participles in (26) were pluralized, they would not be more acceptable than any other pluralized attributive in their place, but perhaps participial attributives in general are more susceptible to pluralization than other attributives (and do not seem as artificial) because they are more typical of conscious linguistic usage, of bookish, precise discourse, where Identity Deletion is generally avoided.13

2.3 Attributives associated with conjoined mass nouns, i.e., nouns which denote homogeneous concrete entities, are illustrated under (27).

(27) (a) Mama kupila $\left.\begin{array}{c}\text { sladkuju[sg] } \\ \text { * }^{*} \text { sladkie }[\mathrm{pl}]\end{array}\right\} \operatorname{malinu[sg]} i$ zemijaniku [sg].

'Mama bought sweet raspberries and strawberries.'

(b) Boris podariz Zine $\left\{\begin{array}{c}\text { francuzskoe }[\mathrm{sg}] \\ \text { francuzskie }[\mathrm{pl}]\end{array}\right\}$ myzo $[\mathrm{sg}]$ $i$ duxi [p1].

'Boris gave Zina French soap and perfume.'

(c) Semirovka poistine knjažeskaja, vernee grafskaja, -- $\left.\begin{array}{r}\text { sploł̌noj [sg] } \\ \text { splošnye [p1] }\end{array}\right\}$ kraxmal[sg], farfor [sg], serebro [sg] $i$ xrustal'[sg]. 'The table was truly befitting a prince, or rather a count--all starch, porcelain, silver, and crystal.'

The fundamental difference between concrete and abstract nouns with respect to grammatical number seems to be that concrete nouns are more likely to be interpreted as representing discrete entities in conjunctions. The conjunction malina[sg] i zemljanika[sg] 'raspberries and strawberries' in (27a), for example, unquestionably refers to two entities, whereas in conjunctions like kul'tura $i$

${ }^{13}$ Note that while the participles in (a), (c), and (d) under (26) may be claimed to modify primarily conjoined nouns, (b) can only be a consequence of reduction. 
nauka 'culture and science' or grust' $i$ neponimanie 'sadness and perplexity' the dividing line is not as clear. As a consequence of this difference, pluralized attributives in association with conjoined mass nouns are not as anomalous as in association with conjoined noncount abstract nouns. Thus in recipes and lists of foods recommended for people with various ailments, for example, one comes across phrases as in (28).
(a) melkonarezannye [p1] zelen'[sg] i mjaso[sg] 'minced greens and meat'
(b) otvarnye [pl] morkov'[sg], svëkla[sg], repa[sg], cvetnaja kapusta[sg]
'boiled carrots, beets, turnip, and cauliflower'
(c) nekrepkie[p1] čaj[sg] i kofe [sg]
'weak tea and coffee'

The homogeneity feature of concrete nouns, then, may be disregarded in underlying conjoined phrases with identical attributives to allow reduction through Regrouping. However, this is so only in the grammar of formal discourse, for phrases as in (28) only occur in deliberate, precise discourse and would be out of place in spontaneous discourse. In spontaneous, informal discourse, only singular attributives may be used (i.e., the homegeneity feature does block Regrouping), and, curiously enough, in phrases such as nekrepkij[sg] čaj $i$ kofe 'weak tea and coffee,' sladkaja[sg] malina i zemljanika 'sweet raspberries and strawberries,' or (29) (from Drejzin 1966), the singular attributives are interpreted by most speakers as unquestionably applicable to both nouns despite the potential ambiguity (but note that only gorjačij 'hot' in (29) can be applicable to both nouns).

(29) gorjačij[sg masc] goroxovyj[sg masc] sup [sg] $i$ p̌̌̈nnaja[sg fem] kaša[sg]

'hot pea soup and millet kasha'

In deliberate discourse, pluralization of an attributive modifying conjoined mass nouns is apparently especially likely to occur when the attributive follows a pluralized verb, as in (30) (cited in Galkina-Fedoruk 1964, 478 and Rozental' 1971a, 234 from Chekhov). 
(30) Paxlo polem. ZeZeneli[p1] molodye[p1] rož'[sg] i smelled of field showed-green young rye and p̌senica[sg].

wheat

'There was a smell of fields. The young rye and wheat showed green.'

The sentence with the pluralized attributive, which is characteristic of current usage in nonspontaneous discourse, can be accounted for as a reduction of the structure underlying the conjoined sentences under (31), where there is an identical verb as well as an identical attributive.

(31) ZeZenela molodaja rož' i zelenela molodaja p̌̌enica. 'Showed-green young rye and showed-green young wheat.'

Reduction must take place in two stages: first the verb phrases are reduced, and then the noun phrases (cf., e.g., Schane 1966 and Tai 1969). In the structure underlying (31), the verb phrases can be reduced either by Regrouping or by Identity Deletion (for details see the following chapter). The pluralized verb in (30) indicates reduction by Regrouping, and the choice of Regrouping as a reduction process for the verb phrases in this sentence apparently predisposes toward Regrouping for the noun phrases as well. This correlation between the reduction process of prepositive verb phrases and the subsequent reduction process of the noun phrases is evident in sentences with mass nouns as well as in sentences with animate and inanimate count nouns (cf. (3d-e) above and (36) below).14

2.4 In summary, noncount nouns in underlying conjoined phrases with identical attributives resist Regrouping and such phrases are reduced by Identity Deletion as a rule. The nouns are then superficially conjoined and modified by an attributive which manifests the number and gender of the nearest noun. This applies to underlying phrases with

${ }^{14}$ Note also that if the verb phrases in (31) were reduced by Identity Deletion, the constituent structure of the resultant sentence would be as in (i), where the noun phrases with the identical attributive are not conjuncts and reduction by Regrouping is therefore inapplicable (cf. (ii)). (cont.) 
noncount nouns denoting animate beings, abstract entities, or concrete inanimate entities, and most consistently to phrases with nouns denoting abstract entities. In certain cases, singular attributives modifying conjoined inanimate nouns can be accounted for as modifiers of primarily conjoined nouns, that is, modifiers of single composite nouns. The components of such nouns must overlap semantically or constitute set collocations.

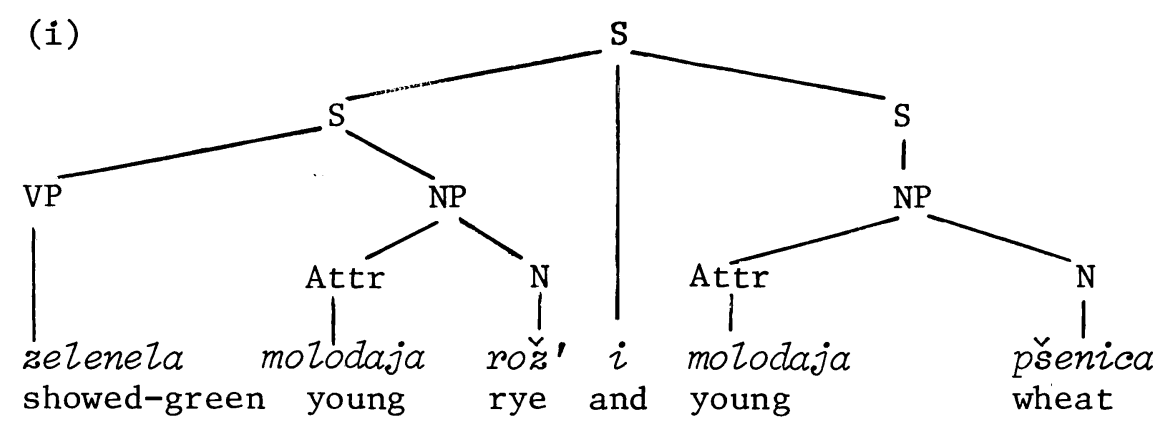

(ii) *Zelenela[sg] molodye [pl] rož i pšenica.
showed-green young rye and wheat

Only Identity Deletion can be applicable to noun phrases with identical attributives in structures like (i), and only in informal discourse. The consequences of such reduction in the underlying structures of (3d) and (3e) above, for example, would be the sentences under (iii), which are colloquially acceptable but inappropriate in fully standard discourse (since (30) is a sentence unlikely to occur in informal, casual discourse, it is also unlikely to have this type of variant).

(iii) (a) Nam očen' nravitsja[sg] datskij[sg] aktër i to us very pleasing Danish actor and aktrisa. actress

'We very much like the Danish actor and actress.'

(b) Zavtra ko mne priezžat [sg] dvojurodnyj[sg] tomorrow to me come secondarily-related brat $i$ sestra. brother \& sister

'Tomorrow my female cousin and male cousin are coming to see me.' 


\section{Inanimate Count Nouns}

The sentences under (32) illustrate the difference between attributives associated with conjoined animate count nouns and attributives associated with conjoined inanimate count nouns.

(32) (a) On osobenno gorditsja $\begin{gathered}\text { talantlivymi[instr } \mathrm{pl} \text { ] } \\ \text { ?talantlivym[instr sg] }\end{gathered}$ synom[instr sg] i dočer'ju[instr sg].

'He is especially proud of [his] talented son and [talented] daughter.'

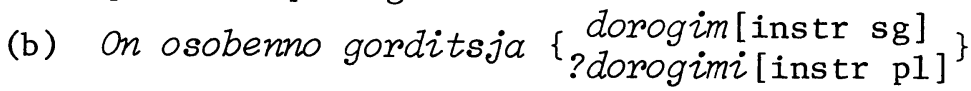
avtomobilem[instr sg] i katerom [instr sg]. 'He is especially proud of the expensive car and boat.'

Note that the singular attributive in (32a) (identical to (3c) above) is only questionable as applicable to both nouns, and only in fully standard discourse (see Section 1); it is not questionable as a modifier of synom 'son' alone.

What the sentences under (32) illustrate is that while attributives associated with conjoined animate count nouns should be pluralized, attributives associated with conjoined inanimate count nouns should manifest the number of the nearest noun. In other words, the preferred reduction process for conjoined noun phrases with identical attributives is Regrouping when the modified nouns are animate count nouns, and Identity Deletion if the modified nouns are inanimate count nouns.

The sentences under (33) indicate that the internal relationship between the attributive and the modified nouns does not affect the reduction process. These sentences in comparison with (32b) also indicate that the reduction process is not affected by the degree to which the hearer is expected to have previous knowledge of the objects referred to (and note also that the difference in gender between the modified nouns in (33a) has no effect either). The sentences under (34) provide further evidence to that effect. 
(33) (a) V muzee my videli $\left\{\begin{array}{l}\left\{\begin{array}{l}\text { afrikanskuju[sg fem] } \\ \text { drevnjuju[sg fem] } \\ \text { krasivuju [sg fem] }\end{array}\right. \\ \left\{\begin{array}{l}\text { afrikanskie [p1] } \\ ? \text { drevnie }[\mathrm{p} 1] \\ \text { ?krasivye }[\mathrm{p} 1]\end{array}\right.\end{array}\right\}$ sabZju[sg fem] $i$ meč [sg masc].

'In the museum we saw $\left\{\begin{array}{l}\text { an African } \\ \text { an ancient } \\ \text { a beautiful }\end{array}\right\}$ sabre and sword.'

(b) Ona kupila sebe $\left.\begin{array}{l}\text { serstjanuju[sg] } \\ \text { velikolepraju[sg] }\end{array}\right\}$ koftočku i jubku.

'She bought herself a $\left\{\begin{array}{l}\text { woolen } \\ \text { magnificent }\end{array}\right\}$ cardigan and skirt.'

(34) (a) Ot tëtki ona polučila $\left.\begin{array}{c}\text { serebrjannuju[sg] } \\ \text { ?serebrjannye [p1] }\end{array}\right\}$ Zožku $i$ vilku.

'From [her] aunt she received a silver spoon and fork.'

(b) Daj mne $\left\{\begin{array}{c}\text { serebrjannuju [sg] } \\ \text { serebrjannye [p1] }\end{array}\right.$ Zozku $i$ vizku.

'Give me the silver spoon and fork.'

The plural forms in (32b) and (34b) are marked with a question mark rather than with an asterisk, because pluralization is not excluded in precise discourse: pluralized attributives in association with conjoined inanimate count nouns are considerably less anomalous than pluralized attributives in association with noncount nouns. Thus phrases such as (35) are cited as appropriate for formal discourse in Rozental' 1968, 287, and a pluralized attributive in a sentence such as (36) is said to prevent potential ambiguity (ibid.; note also the analogy between (36) and (30) above).

(35) (a) postroit' komennye [p1] dom $i$ garaž

'to build a stone house and garage'

(b) posetit' peredovye [p1] kolxoz $i$ sovxoz

'to visit a leading kolkhoz and sovkhoz' 
(36) V komnate stojali[p1] koriěnevye [p1] škaf i komod. 'In the room [there] stood a brown wardrobe and chest of drawers.'

All of the native speakers questioned about the pluralized attributives in (35) and (36) considered them somewhat odd, though indeed unambiguous and not incorrect. On the other hand, an editor asked to evaluate the singular attributive in (37) (from a newspaper feature) found it incorrect.

(37) Vot reklama neizmennogo[sg] "Fillips" $i$ "Pepsi".

'Here are the advertisements for the perennial

Phillips and Pepsi.'

The only pluralized attributives in such contexts which I have come across is printed texts (none occur in oral discourse) were participles, as in the sentences under (38).15

(38) (a) Esli obez'jana iz predložennyx[p1] ej jabloka $i$ if monkey of offered to her apple and banana vybirala jabloko, to ona polucala šokolad. banana picked apple then she received chocolate 'If the monkey, when offered an apple and a banana, picked the apple, then it received choco1ate.'

(b) [Kogda v gorodskom transporte pojavilsja tramvaj, on smenil konku.] No pojavivśiesja[p1] vsled za tramvaem avtobus, trollejbus, metro sosušcestoujut.

'[When the tram appeared in the urban transportation system, it replaced the horse-drawn tram.] But the bus, trolley, and subway which followed the tram exist side by side.'

${ }^{15}$ To be precise, I have also come across one pluralized attributive which was not a participle, in the fo1lowing sentence: Na slovenskom jazyke govorit okolo 1.5 mln. slovencev, proßivajušcix $v$ respublike Slovenija (Julijskaja Krajna, Gorica, južnye[p1] Karintija i Śtirija, Severnaja Istrija) 'The Slovenian language is spoken by around 1.5 million Slovenians, who live in the republic of Slovenia (Yuliskaya Krayna, Goritsa, southern Karintia and [southern] Shtiria, Northern Istria).' Note that the pluralized attributive južnye 'southern' is not (cont.) 
There also occur, however, singular participles in association with inanimate count nouns, as in association with nouns denoting homogeneous entities (cf. the examples under (26) above). For example:

(39) (a) Kogda voda zakipit, položite tuda melkonarezannuju[sg] lukovicu i morkovku. 'When the water boils, put in it a minced onion and [a minced] carrot.'

(b) On zanjat rassmatrivaniem tol'ko čto kuplennogo he busy examining just bought [sg] sombrero $i$ pleda s kožanymi nakladkami. sombrero and shawl with leather trimmings

'He is busy examining the sombrero and shawl with leather trimmings which he has just bought.'

It thus seems that, as suggested above with reference to participles associated with conjoined nouns denoting homogeneous entities, participles are more likely to be pluralized not because the processes through which they acquire grammatical number are different, but simply because they are generally characteristic of precise discourse.

Determiners can be considered the antithesis of participles in this respect, for they resist pluralization--in terms of the posited grammar, they resist Regrouping--not only in casual discourse but also in formal, precise discourse, as in association with animate count nouns and noncount nouns (cf. pp. 168-171 and 177-178 above). Distributive quantifiers, i.e., kazdyj 'every,' Zjuboj 'any,' or vsjakij 'any,' can only undergo Identity Deletion; cf. (40).

(40) (a) $V$ zale tekuš̌cej periodiki mǒno pročitat' $\left\{\begin{array}{c}\text { Zjubuju }[\mathrm{sg}] \\ \text { * jubye }[\mathrm{pl}]\end{array}\right\}$ gazetu $i$ zurnal.

'In the room of current periodicals one can read any newspaper and [any] magazine.'

capitalized; it is a genuine modifier and not a component of the proper names. Its plural number is apparently due to the deliberate, nonspontaneous nature of the discourse and to its "referential" orientation (in terms of the classification suggested in Jakobson 1960). 


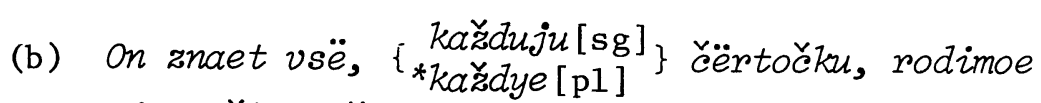
pjatnyško $i$ šrom, ne vidimye postoronnemu grazu. 16

'He knows everything, every line, birth mark, and scar which a stranger cannot see.'

The sentences under (41) illustrate the possessive pronoun svoj in sentences in which its pluralization would be highly questionable (cf. the comments in Revzin 1970, 234), despite the fact that the sentences are representative of formal discourse and svoj applies to all of the conjoined nouns (the fact that there is no overt conjunction in (4la) is a trivial one; see Chapter Four).

(41) (a) Napišite $\left\{\begin{array}{r}s v o j[\mathrm{sg}] \\ \text { ? }^{\text {svoi }}[\mathrm{p} 1]\end{array}\right\}$ adres, imja, otčestvo. 'Write down your address, name, [and] patronymic.'

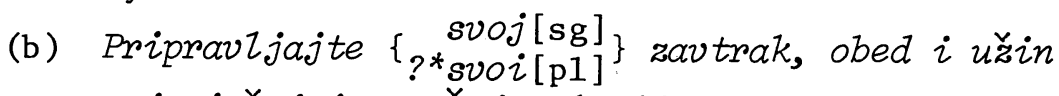
pojaviv̌̌ejsja svě̃ej zelen'ju.

'Flavor your breakfast, dinner, and supper with the new fresh greens.'

It should be emphasized, however, that pluralized determiners are not completely excluded in sentences like (41). Pluralized determiners are in principle possible in association with conjoined inanimate count nouns and do occur occasionally. Pluralization is completely excluded only when the conjoined nouns refer to metonymically related entities. Consider, for example, (42).

(42) (a) Namerenno vybrali $\left\{\begin{array}{c}\text { ètot }[\mathrm{sg}] \\ \text { èti }[\mathrm{p} 1]\end{array}\right\}$ zavod $i$ cex, čtoby poskoree zarabotat' deneg.

'On purpose we have chosen this factory and [this] shop, in order to earn money quickly.'

${ }^{16}$ On the number of the postpositive attributive see Section 5 below. 
(b) $V$ jarkij aprel'skij den' 2962 goda po $\left.\begin{array}{c}\text { ètoj }[\mathrm{sg}] \\ \text { *ettim [p1] }\end{array}\right\}$ doroge $i$ ploščadi ... Jurij Gagarin soveršil triumfal'nyj rejs po likujušcej stolice.

'On a bright April day in 1961, along this road and [this] square, ... Yuri Gagarin went on a triumphant ride in the exultant capital.'

(c) --Tolja, pokazi Serë̋̃e $\left\{\begin{array}{c}s v o j u[\mathrm{sg}] \\ *_{s v o i[\mathrm{p} 1]}\end{array}\right\}$ komnatu $i$ knigi,--poprosil papa posle čaja.

'--Tolya, show Seryozha your room and [your] books,--asked papa after tea.'

In these sentences, the righthand nouns in the conjunctions refer to entities which are included in the entities referred to by the lefthand nouns. The fact that attributives modifying such conjoined nouns cannot be pluralized is thus a consequence of the fact that the referents of the nouns cannot add up to a plurality-because of the metonymic relation between them. This fact can perhaps be accounted for by postulating an underlying composite structure for these conjunctions, though this can only be a tentative postulate at this point.

Additional metonymically-related conjoined nouns which seem to derive from grammatically singular composite nouns are illustrated in (43), modified by miscellaneous attributives.

(43) (a) Vstretilis' oni v uslovZennyj[sg] den' $i$ čas. 'They met at the appointed day and [appointed] hour.'

(b) Novaja ograda okmužala uxožennyj[sg] sad i ogorod.

'A new fence surrounded a cultivated [ornamental] garden and kitchen-garden.'

(c) Promyšlennost' Belomussii ... vypuskaet sejěas každyj pjatyj sovetskij traktor, každyj vos'moj metallorežušcij stanok, každyj[sg] trinadeatyj [sg] radiopriëmnik $i$ televizor, kazdyj šestoj motocikl ...

'The Byelorussian industry ... produces now every fifth Soviet tractor, every eighth metal-cutting machine, every thirteenth radio receiver and television set, every sixth motorcycle ...' 
(d) $V$ pokušenii na senatora Kennedi... prinimali učastie dva naëmnika, streljav̧̌ie iz dvux pistoletov odinakovogo[sg] tipa i kalibra. 'In the attack on Senator Kennedy ... took part two hired men who shot from two pistols of the same type and caliber.'

(e) Est'odezda dlja ljudej s raznoj[sg] figuroj $i$ polnotoj. different figure and fullness

'There are clothes for people with various figures and waists.'

In none of the sentences under (43) can the attributives which modify the conjoined nouns be pluralized. In (43a), the righthand conjunct refers to a part of the lefthand conjunct. In ( $43 \mathrm{~b})$, the sentence cannot derive from a conjunction of sentences, for the fence referred to surrounds the sad and the ogorod together, and the most likely interpretation of the conjoined nouns is that they refer to a single entity and the underlying representation of the sentence thus contains a composite rather than a conjunction of phrases with identical attributives. In $(43 c)$, there is no question that the conjunction radiopriëmnik $i$ televizor 'radio receiver and television set' represents a single entity, for it is counted explicitly as such. The conjunctions in (43d) and (43e) are similar in that the righthand nouns in both denote entities which fall within the scope of the lefthand nouns. In all of the sentences under (43), then, the relationship between the conjoined nouns is such that they are inseparable from one another; they do not represent discrete entities and cannot add up to pluralities. This relationship is reflected by the fact that the attributives which modify them cannot be pluralized. The conjoined nouns can therefore be viewed as components of composite nouns which, like composites of noncount nouns, are grammatically singular. There is no evidence that inanimate count nouns are grammatically singular.

In the sentences under (44), the attributives cannot be pluralized not because the conjoined nouns constitute grammatically singular composites, but apparently because the attributives are of the "definitional" type and constitute composites in the underlying structures with each of the modified nouns, as shown under (45) (identical to (12) above). Regrouping is then impossible. 
((44b) is from Vagner and Ovsienko 1967, 533, and (44c) is cited in Mučnik 1971, 188 from Vs. Ivanov.)

(44) (a) Boris prinës $\left\{\begin{array}{c}\text { armjanskij[sg] } \\ \text { armjanskie[p1] }\end{array}\right\}$ kon'jak $i$ vino.

'Boris brought Armenian cognac and wine.'

(b) $V$ gorode est' muzykal'no-dramaticeskij teatr imeni Gor'kogo, telestudija, ${ }_{*_{\text {muzykal'nye [p1] }} \text { muzykal'noe }[\mathrm{sg}]}$ učilišce $i$ škola, mnogo kinoteatrov, Dvorec sporta, Dom kul'tury.

'The city has a musical and dramatic theater named after Gorky, a television studio, a music college and [music] school, many movie theaters, a Palace of Sports, a Cultural Center.'

(c) Čelovek $v\left\{\begin{array}{c}\text { soldatskoj[sg] } \\ \text { soldatskix }[\mathrm{pl}]\end{array}\right.$ šineli i furažke ... proxodit bystro čerez prixožju v kabinet professora.

'A man in a soldier's coat and cap ... passes quickly through the entrance hall to the professor's study.'

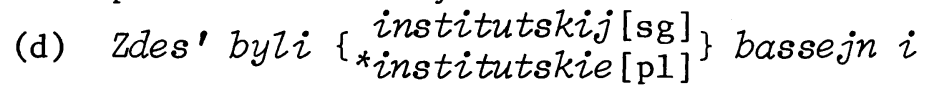
sportivnyj zal.

'Here were the institute's pool and gymnasium.'

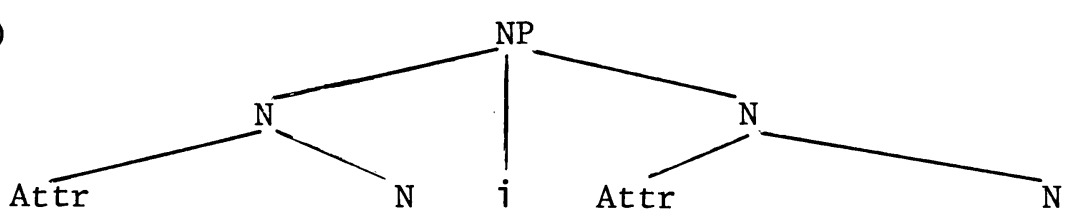

Pluralized attributives in sentences like (44) may seem acceptable at times, but then the relationship of the attributives to the modified nouns is a different one. In (44a), for example, a pluralized attributive would be marginally acceptable, but only in the sense of "from Armenia," not as an identification of particular kinds of cognac and wine. The attributive in (44b) does not seem to lend itself to other interpretations in the given context, but note the difference between its relationship to učilišce 'college, vocational school' and škola 'school' in (44b) and its relationship to, e.g., klass in muzykal'nyj klass 'musical class,' where it can also be modified by the intensifier očen' 'very' (cf. očen' 
muzykal'nyj klass 'very musical class' and *očen' muzykal'noe učilišče $i$ škola 'very musical college and school' in the context of. (44b)).

The attributives in (44c) and (44d) can only have "definitional" interpretations in the given contexts. In (44c), soldatskoj 'soldier's' identifies the kind of coat and cap referred to; in (44d), institutskij 'institute's' is roughly analogous to datskij in datskij korol' $i$ koroleva 'Danish king and queen' in that it identifies what may be classified as the "affiliation" of the modified nouns.

The fact that the attributives in (44) are not pluralizable cannot be accounted for as the corresponding phenomenon in (42) and (43) was accounted for, i.e., by viewing the conjoined nouns as representing underlying composites, because while in (42) and (43) pluralization would be excluded for any attributive, this is not the case in (44). As noted above, the attributive in (44a) could be pluralized in the sense of "from Armenia," and the attributives in the remaining sentences can be replaced by attributives which would be pluralizable, e.g., prekrasnye [pl] učilišce i škola 'marvellous college and school,' prekrasnye [p1] bassejn i sportivnyj zal 'marve1lous pool and gymnasium,' though in actual usage pluralization is generally avoided in any context. It thus appears that the sentences under (44) are not analogous to the sentences under (42) and (43) and represent a different phenomenon--"definitional" attributives which constitute composites with each of the modified nouns in underlying structures and are only subject to Identity Deletion.

While the majority of modified conjoined inanimate count nouns illustrated in the present section have been concrete nouns, all of the observations are especially applicable to abstract nouns. In other words, pluralized attributives in association with abstract count nouns are even less likely to occur than in association with concrete count nouns, which may explain why Dreyzin, who studied a text entitled Nauka $i$ čelovečestvo (Science and Humanity), found that only some ten percent of the attributives associated with conjoined nouns were pluralized, despite the fact that the text clearly did not represent spontaneous discourse (see p. 163 above). In fact, abstract count nouns seem very close to abstract noncount 
nouns both in susceptibility to conjunction in general and in resistance to Regrouping. ${ }^{17}$

\section{Disjuncts}

An attributive followed by coordinate nouns connected by $i Z_{i}$ 'or,' that is, disjuncts, must exhibit the number and gender of the nearest noun. This is the rule given in Russian grammars and style manuals (cf., e.g., GalkinaFedoruk 1964, 477; Senkevič and Feller 1968, 152-153; and Rozental' 1971a, 234). It allegedly applies not only to distributive quantifiers (as in, e.g., (46a)), to other determiner-type attributives (as in, e.g., (46b)), and to "definitional" attributives (as in (46c)), but also to al1 other attributives, regardless of whether the modified nouns denote animate or inanimate entities, homogeneous or nonhomogeneous entities. Some examples from printed texts are given under (47) $((47 \mathrm{e})$ is a model sentence in Senkevič and Feller 1968, 152).

(46) (a) Ne každaja[sg fem] provincija[fem] ili gorod [masc] privodjat dannye o tom, skol'ko molodëži napravieno $v$ derevni.

'Not every province or city provide data on how many young people have been sent to villages.'

(b) On priedet $v$ siedujuščju[sg fem] subbotu[fem] ili voskresen'e [neut].

'He will come next Saturday or Sunday.'

(c) Očen' nǔ̃dajus' v tom, čtoby imet' sokraščënnyj [sg masc] rabočij[sg masc] den'[masc] il $i$ nedelju[fem].

'I very much need to have a shortened work day or [shortened work] week.

(47) (a) V ètom slučae professional'noe [sg neut] slovo [neut] ili oborot[masc] priobretajut osobuju stilističeskuju okrasku.

'In this case a technical word or expression acquire a special stylistic coloring.'

${ }^{17}$ This is also indicated by the findings reported in Skoblikova 1961b, 182-183, though Skoblikova's assertion that conjoined concrete nouns tend to be modified by plural attributives cannot be accepted without qualification. 
(b) Malejšaja[sg fem] iskra[fem] ili peregrev[masc] vlekut za soboj katastrofu, $i$ togda more pylaet vmeste $s$ korablëm.

'The slightest spark or overheating lead to a catastrophe, and then the sea is in flames together with the ship.'

(c) Sledy poroška udaljajutsja slegka smočennoj [sg fem] trjapkoj[fem] ili vetos'ju[fem].

'The traces of the powder are removed with a slightly dampened cloth or old rags.'

(d) Pricina tvoix nevezenij $v$ tom, čto ty doverjaeš'sja pervomu[sg (neut)] popavšemusja [sg (neut)] atel'e ili masterskoj[fem].

'The reason for your bad luck is that you trust the first fashion house or shop you happen to run across.'

(e) Perežityj[sg masc] strax[masc] ili mgnovennyj ispug[masc] ǔ̃e čerez minutu kažetsja i smešnym $i$ strannym.

'An experienced fear or momentary alarm seems a minute later both ridiculous and strange.'

Disjunctive phrases will be analyzed in the following chapter with reference to the number of verbal predicates associated with them, and this section therefore only contains some brief comments. In the illustrative sentences under (46) and (47), the attributives preceding the disjunctions are all interpreted by native speakers as applicable not only to the nearest noun but also to the coordinate noun associated with it, its disjunct. While in some cases disjoined nouns could be claimed to represent underlying composites and the attributives associated with them in the surface sentences would then. represent no more than one underlying attributive, i.e., the underlying structures would be as in (48), this does not seem to be a plausible underlying structure for all disjuncts modified by prepositive attributives.

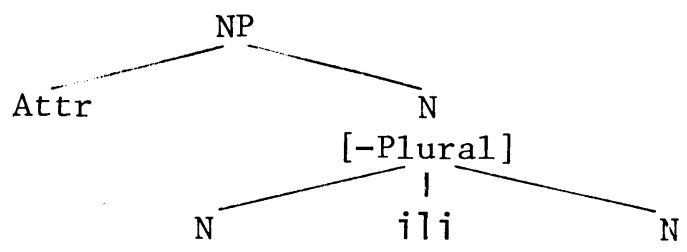


In (47c), for example, the disjuncts are trjapka 'cloth' and vetoš' 'old rags.' The first is a singular count noun and the second is a mass noun, and such different nouns apparently cannot form composites. In (47b), the disjuncts iskra 'spark' and peregrev 'overheating' do not belong to the same semantic categories and therefore could not form a composite, and in any case the plural number of the verbal predicate associated with these disjuncts (vlekut 'lead') is evidence that they do not constitute a composite, for there would be no way of accounting for the fact that an attributive associated with the composite has a singular ending and the verbal predicate is pluralized. This also applies to $(47 a)$, where the pluralized verb can be taken as evidence that the disjuncts do not constitute a composite in the underlying structure.

To account for the fact that the attributives in these sentences are interpreted as applicable to both nouns, we can assume that Identity Deletion operates to eliminate repeated identical attributives in coordinate noun phrases connected by $i l_{i}$ just as it operates when the connective is $i_{0} 18$ The underlying structure of the subject phrase in (47b), for example, would be as in (49).

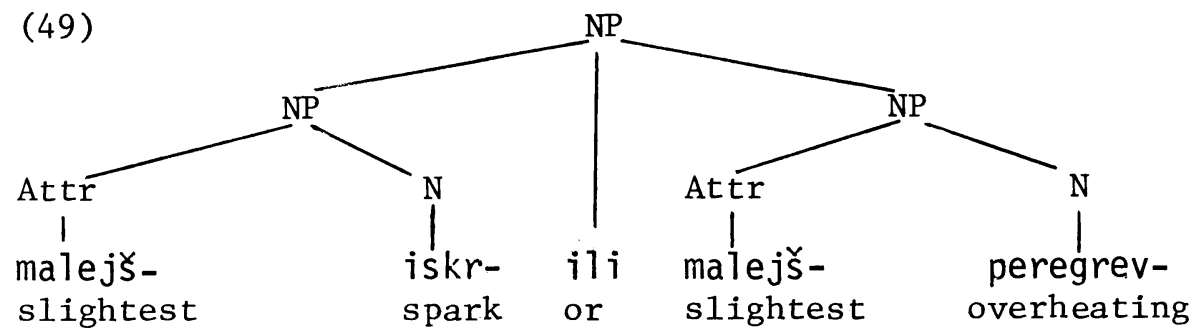

What the rule given in grammars and style manuals means, then (the rule that an attributive preceding coordinate nouns connected by $i I_{i}$ can only manifest the number of the nearest noun), is that only Identity Deletion is applicable to structures such as (49) and Regrouping is inapplicable, and composites as in (48), if they occur at all--for which there is no evidence--should be grammatically singular (and their gender should be that of the lefthand noun).

${ }^{18}$ Following Geach 1972 (487 ff.), I use the term "connective" in reference to elements such as $i$ 'and,' $i \tau_{i}$ 'or,' etc. rather than the conventional term (cont.) 
As a matter of fact, pluralized attributives do occur in association with disjuncts. Consider (50).

(50) (a) U telefona-avtomata oni išcut $v$ karmane dve kopejki, a ne davno isčeznuvšie [p1] pjatialtynnyj ili semišnik.

'At a pay phone they look in their pockets for two kopecks and not for the long extinct pjatialtynnyj [fifteen-kopeck piece] or semišnik [two-kopeck piece].'

(b) Prizoženie--èto zanimajušcaja otnositel'noe polozenie $v$ strukture predlozenija appozitivnaja sintaksičeskaja edinica, vyražennaja

suščestvitel'nym, substantivno ispol'zovannymi as-substantive used

[p1] prilagatel'nym ili pričastiem, a taǩ̌e adjective or participle slovosočetanijami s nimi, prisoedinjaemaja $v$ parallel'nyx formax $k$ gospodstvujuščemu[sg] dominating slovu ili slovosočetoniju $v$ celjax opredelenija word or phrase ili utočnenija, ili pojasnenija.

'An appositive is a syntactic unit which occupies a relative position in the structure of a sentence, is expressed by a noun, by an adjective or a participle used as a noun, or also by a phrase containing one of these, and is adjoined in parallel form to a head word or phrase for the purpose of qualification, specification, or explication.'

(c) Semantičeskie vozmožnosti sogZasovanija ograničivajutsja vyraženiem togo, kakomu to which predmetu prinadležat oboznačaemye [p1] object pertain signified podčinënnym slovom priznak ili dejstvie. by subordinate word property or action

'The semantic possibilities of agreement are restricted to the identification of the object to which the property or action signified by the subordinate word pertains.'

\footnotetext{
"conjunction," for the latter term also has other
} uses. 
The pluralized attributives in (50) seem to contradict the rule given in Russian grammars and style manuals. They cannot be considered accidental, because all three sentences represent careful, deliberate style ( $(50 a)$ is from a book review in Literaturnaja gazeta; (50b) and (50c) are from dissertations). The fact that the pluralized attributives are participles appears to be significant, but note that ( $50 \mathrm{~b}$ ) also contains a nonpluralized participle in association with disjuncts (gospodstvujušcmu[sg] slovu ili slovosočetaniju 'dominating word or phrase'), and in sentences $(47 c)-(47 e)$ above the singular attributives are participles. Moreover, (47e) is from a textbook on editing, and the authors explicitly point out that a pluralized form (perežitye) would be incorrect (Senkevic and Feller 1968, 152). It seems that the pluralized participles in (50) are simply a consequence of the writers' conscious attempt to write precisely, to avoid the ambiguity which would have resulted from the use of singular participles, for then the righthand disjuncts could have been interpreted as being outside their scope. In (51), for example, the righthand disjunct is indeed outside the scope of the singular attributive, for the underlying disjuncts are the composite molodoj čelovek 'young man' and the unmodified noun devuška 'young woman' (this is the only possibility, because celovek by itself means "person," it includes "young woman" logically, and a disjunctive relationship between noun phrases whose head nouns are čelovek and devuška would be anomalous in a context as in (51)).

(51) V naš vek ǔ̃e ne možet udovletvorit' molodogo [sg masc] čeloveka ili devušku ni rabota na primitivnoj ¿ivotnovoďeskoj ferme, ni rol' raznorabočego $v$ polevodstve, ni dol:znost' pastuxa.

' In our age, a young man or a girl can no longer be satisfied with work on a primitive stockbreeding farm, with the role of an unskilled laborer in the fields, or with the duties of a shepherd.'

A sentence such as (51), then, demonstrates that a singular attributive is indeed not necessarily applicable to both disjuncts.

In the derivation of the sentences under (50), the writers can be assumed to have applied Regrouping rather than Identity Deletion regardless of the nature of the connective. Regrouping of $\mathrm{N}$ nodes apparently always 
involves their attachment to a higher $\mathrm{N}$ node marked [+Plural] (cf. p. 167 above), and attributives associated with regrouped nouns must therefore always be pluralized regardless of the connective.

The fact that the attributives in (50) are participles is apparently significant only because participles are more typical of precise discourse (cf. also pp. 182184 above). One could perhaps suggest that the participles in (50) are pluralized in postposition or in some other underlying position and then preposed, but then one would still have to account for the fact that in $(47 c-e)$, which represent normative usage, the participles are not pluralized, and for the fact that the second participle in (50b) is not pluralized. There are no obvious syntactic or semantic differences which distinguish the pluralized participles in (50) from the nonpluralized participles, and there is therefore little to be gained by a more sophisticated account for the plural number of the participles in (50).

Underlying noun phrases with identical attributives are thus generally reduced by Identity Deletion when connected by $i i_{i}$ 'or,' to yield superficially disjoined nouns and an attributive manifesting the number and gender of the nearest noun. Regrouping is also a possible reduction process, and its output is disjoined nouns modified by a pluralized attributive.

\section{Postpositive Attributives}

Postpositive attributives are generally rare in Russian (cf., e.g., the comments in Kovtunova 1969, 26-28). When coordinate nouns--whether conjoined or disjoined--are followed by an attributive which applies not just to the nearest noun, it is typically a participle separated from the nouns by a pause (cf. the data in Skoblikova 1961b, 186ff. and Drejzin 1966, 29), as in the sentences under (52) ( $(52 a)$ is from Vagner and Ovsienko 1967, 382; the remaining sentences are from Literaturnaja gazeta [(52b) has already been cited above as (40b)]).

(52) (a) Stroenie važnejšix belkov--central'naja problema, izučaemaja sovremennoj[sg] biologiej $i$ medicinoj, 
stremjašimisja[p1] raskryt' velikuju tajnu zarożenija ¿̌izni.

'The structure of the most important proteins is the central problem studied by modern biology and medicine, which seek to discover the great secret of the origin of life.'

(b) On znaet vsë, každuju čërtočku, rodimoe pjatnyško $i$ sram, ne vidimye [p1] postoronnemu grazu. not visible to stranger's eye

'He knows everything, every line, birth mark, and scar which a stranger cannot see.'

(c) Nüno podobrat' plat'e ili kostjum, sootvetstvujušcie [p1] figure $i$ vozrastu. 'One has to select a dress or suit which are appropriate for one's figure and one's age.'

(d) Vam pokazyvajut $v$ muzee ili knigoxranilišce knizku ili vešcicu, izgotoviennye[p1] 200 let nazad.

'You are shown in a museum or a book repository a book or some object produced 200 years earlier.'

In each of these sentences the participial phrase modifies coordinate noun phrases which are evidently constituents of a single noun phrase that is grammatically plural, as shown in the skeletal structure under (53). (Since there is no evidence that participles do not assume grammatical number and gender like nonparticipial attributives, except perhaps for minor variations, the putative derivation of participial phrases from underlying embedded sentences is not considered in the present discussion.)

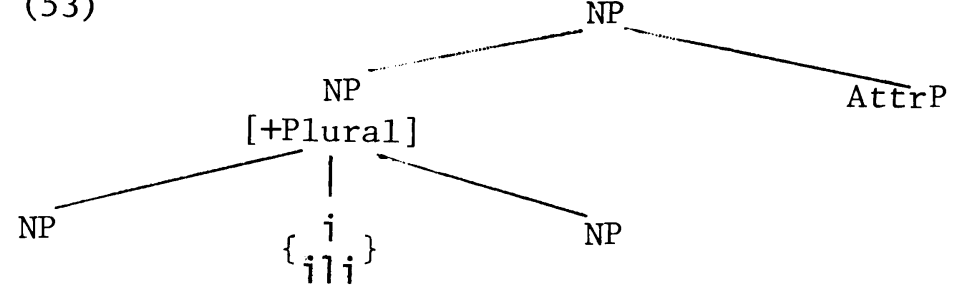

The modified phrase is grammatically plural regardless of the nature of the connective, apparently as a consequence of Regrouping. According to Galkina-Fedoruk 
1964, 477 and Rozental' 1971a, 234, postpositive attributives associated with conjoined or disjoined phrases should always be pluralized, i.e., such constructions always represent the configuration shown in (53). Although this may be the typical configuration, there must be other possible configurations, for conjoined and disjoined phrases can also be followed by singular attributives, as illustrated under (54) ((54a) is a model sentence in a textbook on translation [Katcer and Kunin 1964, 23], (54b) is from Junost', and (54c) is from Babajceva $1968,73-74)$.

(54) (a) Sejčas v SSSR široko vvoditsja[sg] kompleksnaja [nom sg] mexanizacija[nom sg] $i$ avtomatizacija [nom sg] proizvodstvennyx processov, oblegčajušcaja[nom sg] trud $i$ vysvoboždajuščja [nom sg] bol'šoe količestvo rabočej sily dlja nǚd našego narodnogo xozjajstva.

'In the USSR now there is being introduced on a wide scale comprehensive mechanization and automation of production processes, which makes work easier and releases considerable labor force for the needs of our economy.'

(b) Devuška[nom sg] iZi ¿enščina[nom sg], nadelënnaja[nom sg] individual'nost'ju, ne pozvolit[sg] sebe slepo kopirovat' pričësku ili poxodku dake samoj velikoj aktrisy.

'A girl or woman endowed with individuality will not allow herself to copy blindly the hairdo or gait of even the greatest actress.'

(c) Mne--to passivnoe lico, kotoroe ispytyvaet dejstvie[sg] ili sostojanie[sg], navjazannoe [sg] emu so storony, pomimo ego voli $i$ želanija. 'Me is the passive person who undergoes an action or state imposed on him from the outside, apart from his will or desire.'

In $(54 b-c)$, the disjoined phrases apparently represent primary disjunction and the disjuncts in each case are therefore constituents of a grammatically singular noun phrase. Note that in (54b), where the disjuncts are in the subject phrase, the verb indeed has a singular ending. Primary disjunction is discussed in Section 4 of Chapter Four and will therefore not be elaborated upon here. 
In (54a), the phrase modified by the singular postpositive attributives is also a subject phrase, as in (54b), and the verb associated with it is also in the singular, as in (54b), except that the connective in this case is $i$ rather than $i l_{i}{ }^{19}$ In view of the semantic overlap of the conjoined nouns, the most plausible account for the singular number manifestations in association with them is that they represent a single underlying noun--a grammatically singular composite. 20

Postpositive attributives not separated by a pause do not seem to occur at all in association with disjuncts. In association with conjuncts such attributives do occur, though infrequently. Consider, for example, (55) (discussed in Revzin 1970, 238).

(55) Na nëm šapka i šuba mexovye [p1].

on him hat and coat of fur

'He is wearing a fur hat and coat.'

The absence of a pause indicates that the conjoined nouns and the attributive are within the same noun phrase, and the fact that the attributive is pluralized indicates that the nouns are dominated by a node marked [+Plural], as shown in (56).

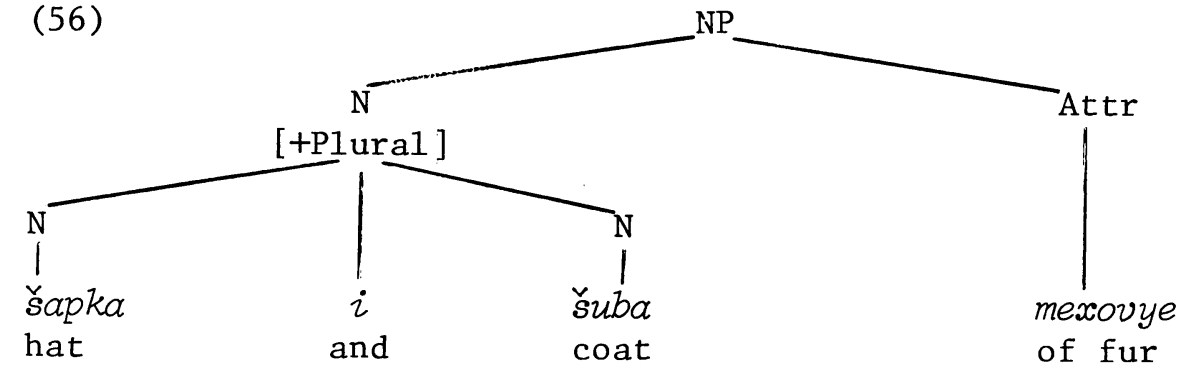

${ }^{19}$ Interestingly enough, Katcer and Kunin (1964, 23-24) offer several possible English versions for (54a) with the singular verb in the Russian sentence translated as "are being introduced," but their analysis contains no comment on this difference in grammatical number.

${ }^{20}$ This account is not suggested for (54b) primarily because there is no evidence that disjoined nouns ever derive as composites. On the other hand, while an underlying primary conjunction (of noun phrases) is conceivable as the source of (54a), the semantic closeness of the (cont.) 
The only possible derivation for (56) is through the regrouping of conjoined noun phrases with identical attributives, i.e., through the regrouping of noun phrases which could be realized as (57).

(57) šapka mexovaja $i$ šuba mexovaja hat of fur and coat of fur

The only reduction process applicable to phrases such as (57) is Regrouping, for if deletion were to take place, as in (58a) or (58b), the attributive would be interpreted as only applicable to the immediately preceding noun.

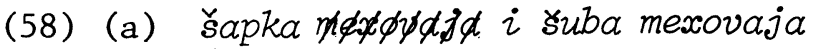

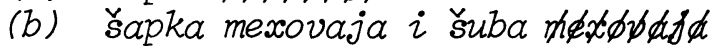 hat of fur and coat of fur}

Now consider (59) (from Skoblikova 1961b, 187, where Skoblikova notes that if moi[p1] were preposed, the phrase would be quite odd).

(59) Detstvo[neut] i junost'[fem] moi[p1] prošli[p1] $v$ Tbizisi.

'My childhood and youth were spent in Tbilisi.'

At first glance this sentence appears to be completely analogous to (55) and hence its subject phrase appears to represent the structure in (56). However, the conjunction detstvo $i$ junost' 'childhood and youth' could also represent a grammatically singular underlying composite noun, because the conjuncts are often combined and they denote abstract entities. The plural number of the attributive in this sentence cannot be taken as evidence that the nouns do not constitute a composite, because, as noted in Skoblikova 1961b, 188, a postpositive attributive must be pluralized whenever it has to manifest gender and the coordinate nouns it modifies are not of the same gender. Detstvo 'childhood' is inherently neuter, and junost' 'youth' is inherently feminine. The gender of composites is always the gender of the lefthand noun and the gender manifested by the possessive pronoun would have had to be

conjoined nouns and the fact that such noun combinations occur regularly as single units seem to provide sufficient motivation for favoring the account offered in the text. 
neuter, thereupon conflicting with the gender of the noun nearest to it--an unacceptable conflict (cf. *detstvo [neut] $i$ junost'[fem] moë[neut]).

The unacceptability of such conflict applies not only to postpositive attributives but also to postpositive verbal predicates (cf. Chapter Four). It apparently represents a "surface constraint," and we can assume that whenever such conflict arises, whether as a consequence of Attributive Agreement or as a consequence of Verb Agreement, it triggers a mechanism which pluralizes the postpositive attributive or verbal predicate. The possessive pronoun in (59) may thus be pluralized either because it modifies regrouped, grammatically plural nouns, or through this mechanism, if the modified nouns constitute a composite and the possessive pronoun has been assigned singular neuter specifications by Attributive Agreement. The phrase is ambiguous in this respect.

\section{Summary}

In summary, a prepositive attributive associated with two or more coordinate nouns the first of which is singular receives a singular ending if: (1) the coordinate nouns represent a single unit, i.e., an underlying composite noun--unless they are connected by $i$ and denote animate beings, in which case the grammatical number of the composite is plural; (2) the nouns are coordinated as a consequence of the reduction of coordinate noun phrases with identical prepositive attributives through deletion of repeated occurrences of the lefthand attributive. Such deletion is especially likely to occur if: (a) the repeated attributive is "definitional," constituting a composite with each of the modified nouns; (b) the repeated attributive is a determiner; (c) the modified nouns denote homogeneous entities, i.e., they are noncount nouns; and (d) the connective is izi 'or.'

Reduction of coordinate noun phrases with identical prepositive attributives through Regrouping yields a grammatically plural coordination of nouns preceded by a single attributive which must be pluralized. Regrouping is especially likely to occur when the repeated attributive is neither "definitional" nor a determiner, the modified nouns denote individual animate beings or individual eoncrete entities, and the connective is $i$ 'and.' 
Finally, a postpositive attributive associated with two or more coordinate singular nouns can receive a singular ending only if: (1) the coordinate nouns represent primary disjunction; or (2) they represent an underlying inanimate composite. In either case, if the attributive manifests gender, the coordinate nouns must be of the same gender.

This schematic summary and the body of the chapter only represent preliminary findings and are by no means complete. A more comprehensive description must await further research. 


\section{VERBAL PREDICATES ASSOCIATED WITH TWO OR MORE NOUNS}

0. Like attributives associated with two or more nouns, verbal predicates associated with two or more nouns or noun phrases are often not pluralized. This is especially true of verbal predicates which precede their subjects, and not only in sentences where the subjects seem to be coordinated as a consequence of afterthought, as, for instance, in (1), or where succeeding nouns or noun phrases in the coordination amplify the initial noun or noun phrase, as in the sentences under (2), but also in sentences where the coordinate subjects are clearly not the consequence of an afterthought or amplification and are not disjuncts. 1

(1) (a) $B y Z a[s g$ fem] sem'ja[nom sg fem], svoj dom[nom sg masc].

'[There] was a family, [my] own house.'

(b) Cuvstvovalos' [sg neut] nekotoroe osuzdenie[nom sg neut], usmeska[nom sg fem].

' [There] was sensed a certain condemnation, mockery.'

(c) Ostalas'[sg fem] odna Zǐs' ustalost'[nom sg fem], stremlenie [nom sg neut] pozabyt' obo vsëm $i$ ne vspominat', ne vspominat' ....

'[There] remained only fatigue, a desire to forget about everything and not remember, not remember ...'

${ }^{l}$ Nonpluralized prepositive verbal predicates are accounted for as due to lack of premeditation in, e.g., Peškovskij 1956, 451. Amplification is usually referred to by Russian grammarians as either pojasnenie 'explication' or utočnenie 'specification' (for definitions of the two terms and illustrations see, e.g., Galkina-Fedoruk 1964, 502-504). As noted in Kamyšev 1968, however, there are no objective criteria for distinguishing between pojasnenie and utočnenie and the terms are often used interchangeably. (For recent explorations of the phenomena designated by the two terms see, e.g., Xrolenko 1972 and Uxanov 1974.) 
(d) U tebja byla[sg fem] kosa[nom sg fem] i rozovoe plat'e [nom sg neut] $v$ beluju kletočlsu.

'You had a braid and a pink dress with a white check pattern.'

(e) Eto byl[sg masc] pervyj poceluj[nom sg masc] $i$ pervaja ljubov'[nom sg fem]. ${ }^{2}$

'This was [her] first kiss and first love.'

(f) Posetitelju nüna [sg fem] bumaga[nom sg fem], konverty [nom $\mathrm{p} 1$ ] $i$ mark $i$ [nom $\mathrm{p} 1$ ].

'The visitor needs paper, envelopes, and stamps.'

(g) Vozle kryl'ca stojala[sg fem] nebol'saja tolpa [nom sg fem] i mašina[nom sg fem] "skoroj pomošči".

'Near the porch stood a small crowd and an ambulance.'

(h) Nastupila[sg fem] tišina[nom sg fem] i rasterjannost'[nom sg fem].

' [There] fell silence and perplexity.'

(i) Ctoby ponjat', čto takoe bezličnoe predloženie, neobxodimo vyjasnit', $v$ kakom otnošenii stoit [sg] jazyk[nom sg] k myšleniju i predloženie [nom sg] $k$ sǚdeniju.

'In order to understand what an impersonal sentence is, it is necessary to find out in what relationship language stands to thought and the sentence to the proposition.'

(2) (a) $V$ nej budet pokazana[sg fem] belorusskaja. derevnja[nom sg fem] našix dnej, ëe problemy [nom $\mathrm{p} 1$ ], ee Zjudi[nom $\mathrm{p} 1$ ].

'In it will be shown the Byelorussian village of our times, its problems, its people.'

(b) Proisxodit[sg] demokratizacija[nom sg] musskoj Ziteraturnoj reči, nejtralizacija[nom sg] stilističeski okrašennoj leksiki.

'[There] is taking place a democratization of the Russian literary language, a neutralization of stylistically colored words.'

${ }^{2}$ Sentences introduced by èto are discussed in Section 4 of Chapter Five. 
(c) Menja podkupaet[sg] $v$ nix kak raz individual'nost' [nom sg], svoeobrazie [nom sg], ¿̇to vsegda javljaetsja priznakom bol'šogo talanta.

'What wins me over in them is precisely [their] individuality, [their] originality, which is always a sign of great talent.'

(d) $S$ gorodom na reke Neve nerazryvno svjazana[sg fem] ¿izn'[nom sg fem] $i$ dejatel'nost'[nom sg fem] Vladimira Il'iča Lenina.

'With the city on the Neva River is inseparably bound the life and activity of Vladimir Ilyich Lenin.'

(e) V 30-e gody načinaetsja[sg] ukreplenie [nom sg] i stabilizacija[nom sg] norm literaturnogo jazyka.

'In the thirties [there] began the consolidation and stabilization of the norms of the literary language.'

(f) ... takie stroki, ot kotoryx rożaetsja[sg] radostnoe $i$ šcemjašee cuvstuo [nom sg] svobody $i$ oscušenie [nom sg] udivitel'nogo polëta nad zemlëju.

' ... such lines from which [there] arises a joyful and painful feeling of freedom and a sensation of amazing flight above ground.'

In (3a), for example (from Vagner and Ovsienko 1967, 381 ), the nonpluralized verb precedes an enumeration which cannot possibly be considered spontaneous or not premeditated in the given context. This also holds for ( $3 b$ ) (from Sanskij 1967, 5-6) where an exhaustive enumeration is preceded by a nonpluralized verb even though the sentence represents scientific, precise discourse. In (3c), the coordinate subject following a nonpluralized verb cannot be the consequence of an afterthought because the coordination is introduced by the particle $i$, which is an anticipatory conjunction marker. The same pattern is also illustrated by (3d). Finally, in (3e) (from Konopelkin $1970,49)$, the plurality of the subject is anticipated by the preposed plural predicate noun, yet the verb is nevertheless in the singular. (According to Skoblikova 1961a, 173 , this sentence should be ungrammatical, but my informants found it faultless. It is also significant that the sentence appears in a Soviet Russian textbook for foreign students, where the texts are meant to be exemplary.) 
(3) (a) Iz polimerov i plastikov sozdajutsja detali kosmičeskix raket $i$ mašin, delaetsja[sg] odežda [nom sg], obuv'[nom sg], posuda[nom sg], ukrašenija [nom $\mathrm{p} 1]$.

'Polymers and plastics are used to manufacture parts of space rockets and machines, to make clothing, footwear, china, ornaments.'

(b) Ot konstrukcij s prizozenijomi ix [složnosostavnye slova] čëtko $i$ opredelënno otliéaet[sg] naličie [nom sg] $v$ nix odnogo (a ne dvux!) osnovnyx udarenij, otsutstvie[nom sg] sintaksičeskix oinošenij meždu sostavljajuščimi ix častjami i svojstvennaja im smyslovaja cel'nost' [nom sg].

'Composites differ from appositive constructions clearly and definitely by the presence of one rather than two primary stresses, by the absence of syntactic relations between their components, and by their special semantic unity.'

(c) Mne casto vspominaetsja[sg] i èta témnaja reka [nom sg], zatenënnaja skalistymi gorami, i ètot ¿ivoj ogonëk [nom sg].

'I often remember both this dark river, shaded by rocky mountains, and this bright light.'

(d) V pole ego zrenija byla[sg fem] i političeskaja zizn'[nom sg fem] molodoj socialističeskoj respubliki, $i$ geroičeskij trud[nom sg masc] sovetskix ijudej, $i$ stroitel'stvo[nom sg neut] novogo byta, $i$ vałnejšie javlenija[nom p1] kuz'tury.

'Within his field of vision were [not only] the political life of the young socialist republic, [but also] the heroic labor of the Soviet people, the construction of a new way of life, and the central cultural phenomena.'

(e) Učebnymi posobijami[instr p1] na takix zanjatijax sluzilo [sg neut] vedërko [nom sg neut] $s$ abrikosami $i$ kubiki[p1] raznoj veličiny.

'The teaching aids at such lessons were a bucket with apricots and blocks of various sizes.'

Statements in Russian grammars and style manuals on the grammatical number of verbs associated with two or more nouns tend to be cursory, vague, and inconclusive, and may even seem to contradict one another. In Vinogradov and Istrina 1960, 497, for example, the sentence 
cited under (4a) (from Lermontov's "Taman'") is classified as archaic, but the sentence under (4b), which seems very similar to (4a), is cited in Rozental' 1968, 269, as fully acceptable.

(4) (a) Vyšel[sg masc] urjadnik[nom sg masc] i desjatnik [nom sg masc].

'[There] came out the policeman and the foreman.'

(b) $V$ komnatu vošla [sg fem] molodaja ¿enščina[nom sg fem] i malen'kij mal'čik [nom sg masc].

'Into the room came a young woman and a little boy.'

Both in Vinogradov and Istrina 1960, 497 and in Rozental' 1968, 272 and 1971a, 228 it is pointed out that when a predicate "signifies an action performed by several persons," it must be pluralized whether postposed or preposed (cf. also Galkina-Fedoruk 1964, 466). This statement seems incongruent with the fact that Rozental' himself cites (4b) as acceptable and Švedova 1970, 554 cites the sentences under (5) as acceptable.

(5) (a) $K$ beregu bezal[sg] Vanja[nom sg] i Kolja [nom sg]. 'Towards the shore were running Vanya and Kolya.'

(b) Slušaet[sg] menja korrespondent [nom sg] $i$ sekretar' [nom sg].

'Listening to me are the correspondent and the secretary.'

The inconclusiveness of the statements in the sources can be most aptly illustrated by the qualification in Rozental' 1971a, 226, following the observation that a postpositive predicate is usually pluralized and a prepositive predicate is usually not pluralized: "Указанные полохения не нослт категорического характера: постпозитивное сказуемое может стоять в форме единственного (см. нихе), а препозитивное--в форме мнокественного числа" (the principles noted above are not categorical: a postpositive predicate can be in the singular [see below], and a prepositive predicate--in the plural).

The purpose of the present chapter, then, is to try to present a more precise and coherent picture of the facts and to offer some fundamental principles to account for the data. Section 1 deals with prepositive verbal predicates in association with two or more nouns linked by $i$ and ends with comments on verbal predicates associated 
with nouns linked by other conjunctive connectives. Section 2 deals with postpositive verbal predicates in association with two or more nouns linked by $i$ or only intonationally (asyndetically). In Section 3 the discussion focuses on verbal predicates associated with reductions of conjoined noun phrases with identical nouns, as in, e.g., (6) (from Rozental' 1971a, 232).

(6) Tjaそ̋̈laja[sg fem] i lëgkaja[sg fem] promyšZennost' [sg fem] perevypolnili[p1] svoi plany.

'The heavy [industry] and light industry have overfulfilled their plans.'

Verbal predicates associated with nouns connected by $i i^{2}$ 'or' or by other disjunctive connectives are discussed in Section 4, and the chapter ends with a section on grammatical person. 3

1. Prepositive Verbal Predicates Associated with Nouns Linked by $i$ and Verbal Predicates Associated with Nouns Linked by Other Conjunctive Connectives

1.0 Consider (7) ((7b) from Rasul Gamzatov's "Moj Dagestan").

(7) (a) Blestjat stvoly sosen i blestit vozdux. sparkle trunks of pines and sparkles air 'The trunks of the pines sparkle and the air sparkles.'

(b) Kryl'ja perelomalis', no serdce bilos', ucelel wings broke but heart beat remainedintact ostryj kljuv, uceleli zeleanye kogti. sharp beak remained-intact iron claws 'The wings broke, but [his] heart was beating, the sharp beak remained intact, the iron claws remained intact.'

${ }^{3}$ For some data on verbal predicates in association with coordinate subjects in 01d Russian see Borkovskij and Kuznecov 1965, 358-360, and see also Barsov, forthcoming, for some very interesting eighteenth-century data on various number manifestations in association with coordinate nouns. 
Sentence (7a) consists of two conjoined sentences with an identical prepositive verb, but the sentences are not reducible despite the identity of the verb (cf. * Blestjat stvoly sosen $i$ vozdux 'the trunks of the pines and the air sparkle'). ${ }^{4}$ They are not reducible because the subjects do not have any semantic features in common, apparently.

The situation is different in (7b). The subjects of the repeated prepositive verb ucelet' 'remain intact' do share semantic features and the coordinate sentences with the identical verb could be reduced. They could be reduced either through Regrouping (cf. pp. 165-166 above), in which case the subject phrases would be coordinated within a grammatically plural noun phrase and the remaining verb would be pluralized, as in (8a), or through Identity Deletion, in which case the repeated verb would be deleted from the second sentence and the first sentence would remain intact. The verb in this case would manifest the number and gender of its pre-reduction subject phrase, as in (8b).

(8) (a) Kryl'ja perelomalis', no serdce bilos', uceleli [p1] ostryj kljuv[nom sg] $\left.{ }_{\{i}\right\}$ ¿eleznye kogti [nom pl].

'The wings broke, but [his] heart was beating, the sharp beak $\{$ and $\}$ the iron claws remained intact.

(b) Kryz'ja perelomalis', no serdce bilos', ucelel

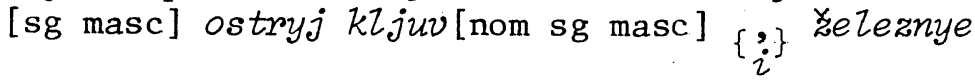
kogti[nom p1].

'The wings broke, but [his] heart was beating, the sharp beak $\{\underset{\text { and }}{ }\}$ the iron claws remained intact.'

The connective $i$ is given in (8) as an optional variant to the intonational break represented by the comma in order to show that the break is essentially conjunctive and could be replaced by $i$ in these sentences with no significant change in meaning.

${ }^{4}$ The reduced sentence is acceptable, however, with an intonational break before $i$. This fact is discussed in Section 1.16 below. The reduction considered in the text has no intonational break. 
The fact that in (7a) and (7b) the coordinate sentences with identical verbs are not equally amenable to reduction although structurally quite similar indicates, then, that the reduction of such coordinate sentences is conditioned not only by their structural identity and lexical identity of the verbs but also by semantic features of the subject phrases. Semantic features of the subject phrases also seem to play a role in the choice between reduction by Regrouping and reduction by Identity Deletion. In ( $7 b)$, both processes of reduction are applicable, but this is not always the case. Consider, for instance, the sentences under (9).

(9) (a) Na stole $\left\{\begin{array}{l}\text { stojali[p1] } \\ \text { stojala[sg fem] }\end{array}\right\}$ pepel'nica[nom sg fem] $i$ pustoj stakan[nom sg masc].

'On the table stood an ashtray and an empty glass.'

(b) Vo dvore $\left\{\begin{array}{c}\text { stojali[p1] } \\ \text { stojala[sg fem] }\end{array}\right\}$ Valja[nom sg fem] $i$ Nina[nom sg fem].5

'In the courtyard stood Valya and Nina.'

The pluralized verbs in (9) must manifest the number of INP nodes which dominate conjoined nouns phrases, and the conjoined noun phrases can be viewed as a consequence of reduction by Regrouping, though they may also represent primary conjunction, in which case the superordinate NP nodes are not a product of the regrouping process and their plural number is determined by a \{taggregate\} specification. The singular verbs presumably indicate Identity Deletion.

In the derivation of (9a), both Regrouping and Identity Deletion are evidently applicable, but in the derivation of (9b) Identity Deletion is inapplicable. ${ }^{6}$

${ }^{5}$ Again, the singular verb in this sentence would be acceptable with an intonational break before $i$ (see Section 1.16 below). Without a break, however, it is unacceptable, in distinction from (9a), where the singular verb does not require an intonational break to be acceptable.

${ }^{6}$ The fact that paraphrases of the sentences under (9) as conjoined sentences with identical verbs ( $i$ ) and (ii), respectively) may seem unlikely in comparison with, e.g., (7b), cannot be taken as evidence that (9a-b) are not derived by reduction. In $(7 b)$, repetition of the same verb 
In (9a) the grammatical subjects represent inanimate entities, and in (9b) the grammatical subjects represent animate beings. But it is not only the animacy feature of the subjects in (9b) which renders Identity Deletion inapplicable, as demonstrated by the acceptability of singular verbs in the sentences under (10) (the singular verbs in (4) and (5) above, which also have animate subjects, will be discussed later on; $(10 a)$ is from a piece in Literaturnaja gazeta, (10b) is from Skoblikova 1961a [citing Kochetov], (10c) is from Konopelkin 1970, 32, and (10d) is from Kirillov 1970, 164).

(10) (a) U nego byla[sg fem] mjagkaja mat'[nom sg fem] $i$ grubyj avtoritarnyj otec [nom sg masc].

'He had a gentle mother and a coarse authoritarian father.'

(b) Kogda-to ... na xutore ziza[sg fem] devocka[nom $\mathrm{sg} \mathrm{fem}]$ let odinnadcati-dvenadcati $i$ ë brat [nom sg masc], godomi šest'ju starše sestry.

'Once ... in a small village [there] lived a girl of eleven or twelve and her brother, some six years older than [his] sister.'

(c) Vmeste so mnoj na kosmodrom letel [sg masc] German Titov[nom sg masc], ešc̈ë neskol'ko kosmonavtov, gruppa[nom sg fem] naučnyx rabotnikov $i$ vrač [nom sg masc].

'With me to the launching site flew German Titov, several other cosmonauts, a group of scientists, and a doctor.'

in adjacent coordinate structures is consonant with the epic style of the narrative, but such redundancy is usually eliminated unless it serves some specific purpose. Note that (i) and (ii) are flawless as emphatic sentences.

(i) Na stole stojala pepel'nica i (na stole) stojal pustoj stakan.

'On the table stood an ashtray and (on the table) stood an empty glass.'

(ii) Vo dvore stojala Valja i (vo dvore) stojala Nina. 'In the yard stood Valya and (in the yard) stood Nina.' 
(d) Bliðe $k$ plošăadi naxoditsja dom (No. 24), gde godom ran'še poselilsja[sg masc] vidnyj muzykal'nyj dejatel' N.G. Rubinštejn[nom sg masc] i veličajšee muzykal'noe svetilo mira-P.I. Cajkovskij[nom sg masc]. [Zdes' $i x$ často naveščali Genrix Venjavskij, A.P. Borodin $i$ drugie muzykanty $i$ kompozitory.]

'Closer to the square is a house (No. 14) where a year earlier took up residence the prominent figure in the world of music N.G. Rubinshtein and the illustrious musical luminary P.I. Chaikovsky. [Here they were often visited by Genrikh Veniavsky, A.P. Borodin, and other musicians and composers.]'

Section 1.1 explores the difference between (10) and (9b) which accounts for the acceptability of nonpluralized verbs in (10) and considers its ramifications. Section 1.2 contains some observations on sentences in which coordinate subject nouns or noun phrases are linked by conjunctive connectives other than $i$.

1. 1 When underlying sentences connected by $i$ are structurally identical, have the same prepositive verbal predicates and have subjects which share sufficient semantic properties to allow reduction, then the choice of reduction process seems to hinge on the role of the entities signified by the subject phrases (i.e., the phrases assigned the nominative case) in relation to the action, event, state, or process signified by their predicate-more precisely, on the role of the subject entities as perceived by the speaker. ${ }^{7}$ When the subject entities are perceived as responsible for the action, event, state, or process signified by the predicate, then Identity Deletion cannot apply and Regrouping is mandatory. In the great majority of all other cases, both Identity Deletion and

${ }^{7}$ This view of relations between nominal entities and predicates as dependent on the speaker's perspective is also advocated now by Charles Fillmore, who has done seminal work on underlying roles (see, e.g., Fillmore 1968 and 1971a, and see also Fillmore 1971b). Fillmore's current ideas were presented at the annual conference of the California Linguistics Association in San Jose on May 3-4, 1975, in a keynote address entitled "The Case for Case Reopened." 
Regrouping are applicable, but Identity Deletion is more typical, especially in informal discourse, though it is by no means restricted to informal discourse (cf., e.g., the sentences under (3) above). There are only some isolated cases where additional factors may be involved.

1.11 Entities which can be "responsible" for predicates must be animate. Hence this category does not subsume inanimate entities which may be conceived of as "responsible" through having their own internal power, i.e., natural forces such as sun, wind, rain, etc., and objects such as, e.g., ship in the ship destroyed the pier. ${ }^{8}$ Compare, for example, the sentences under (11).
(a) $\left\{\begin{array}{l}\text { Sume } Z i[\mathrm{p} 1] \\ \text { Sume } Z[\mathrm{sg} \text { masc] }\end{array}\right\}$ veter[nom sg masc] $i$ dožd'[nom made-noise wind and rain $\mathrm{sg}$ masc].
'The wind and rain were whooshing.'
(b) $\left\{\begin{array}{l}\text { Sume } Z i[\mathrm{p} 1] \\ \text { Sume }[\text { [sg masc] }\end{array}\right\}$ Vanja[nom sg masc] $i$ Petja[nom made-noise Vanya sg masc].
'Vanya and Petya were making noise.'

Ultimate responsibility is, of course, a complex philosophical and moral question, but it appears that in the use of language, animate beings are treated as responsible for their actions, while natural forces such as wind and rain are not: the verb in (11b) must be pluralized, but in (11a) the verb need not be pluralized. The verb is identical in both sentences and the only difference is in the nature of the subjects.

One could suggest that the verb is in fact not identical, that the noise made by wind and rain is fundamentally different from the noise made by Vanya and Petya, but it seems that this difference is a function of the difference between the subjects rather than an independent phenomenon. It is analogous to the difference observable in (9), reproduced below as (12).

${ }^{8}$ This example and the notion of internal power come from Chafe 1970, 109. For a development of this notion see Cruse 1973, esp. 16-17. Potent natural forces have also been labelled "force" in discussions of underlying roles (cf. Halliday 1970, 148-149 and Fillmore 1971b, 42). 
(12) (a) Na stole $\left\{\begin{array}{l}\text { stojali[p1] } \\ \text { stojala[sg] }\end{array}\right\}$ pepel'nica $i$ pustoj stakan.

'On the table stood an ashtray and an empty glass.'

(b) Vo dvore $\left\{\begin{array}{c}\text { stojali }[\mathrm{pl}] \\ \text { stojala[sg] }\end{array}\right\}$ Valja i Nina. 'In the courtyard stood Valya and Nina.'

The verb in (12a) and (12b) is lexically identical, yet it refers to substantially different states--because the subjects in (12a) are not aware of their position, whereas the subjects in $(12 b)$ can be considered responsible for their position.

What distinguishes the role of "responsible" animate beings from all other roles can be defined as volition. The centrality of volition as an operant in the grammar of Russian has also been demonstrated by Emily Klenin in her study of reflexivization in Russian (Klenin 1974). Phenomena other than coordination and reflexivization which may be conditioned by volition are illustrated under (13)(15) ((13) and (14) are from Adamec 1973, 89 and Stepanov 1973,73 [(14b) somewhat modified]; (15) is from Zolotova 1973,340 [(15a) somewhat modified]).

(13) (a) Posudy[gen sg] na stole ne stojalo[sg neut]. of china on table not stood

'There was no china (standing) on the table.'

(b) *Devuški[gen sg] na uglu ne stojalo[sg neut]. of girl on corner not stood

'There was no girl standing on the corner.'

(14) (a) Pisem[gen p1] ne prixodilo[sg neut]. of letters not came

'No letters came.'

(b) *Mamy [gen sg] ne prixodilo[sg neut]. of mama not came

'Mama did not come.'

(15) (a) PavZa[acc] Pëtr[nom] Zjubit.

'Pyotr does like Pavel.'

(b) *Pavla[acc] volnenie[nom] oxvatilo.

'Excitement did sieze Pavel.' 
An analysis of (13)-(15) is beyond the scope of the present study, but these sentences may turn out to provide additional evidence for the centrality of the distinction between nonvolitional and volitional entities in Russian grammar.

Volitional animate subjects will be hereafter referred to as Agents. 9

1.12 Agent subjects need not necessarily be active or actually do something--awareness appears to be the key criterion. In the sentences under (16), for example, the verbs must be pluralized, and this is apparently because the subjects are considered responsible in some sense for their attitudes, Agents, even though they do not initiate them. (As noted earlier, an intonational break before the connective $i$ may render nonpluralized verbs acceptable in some cases. This phenomenon is discussed later on.)

(16) (a) $V$ boga u nas \{verizi[pl]
in God at home believed
$i$ tëtja[nom sg fem].
and aunt
'Those who believed in God at home were grand-
mother and [my] aunt.'

${ }^{9}$ Note, however, that the term "Agent" has also been used in other senses. Fillmore (1971a, 376), for example, defined it as "the animate instigator of events referred to by the associated verb." Anderson $(1971,40)$ gives a somewhat similar definition, though he prefers the term "Ergative" and does not restrict its application to animate entities. His definition is: "The $\mathrm{N}$ that is regarded as the initiator of the 'action' associated with the $\mathrm{V}$ in ['transitive'] clauses." The use of the term in the present work to signify an animate being perceived as volitionally responsible for the predicate is more or less in line with its use in Jackendoff 1972 (see esp. 32-33) and Klenin 1974. For a discussion of the difficulties involved in defining the notion of agency see Cruse 1973. 


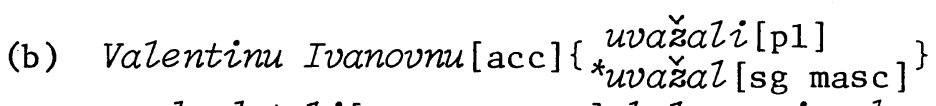
predsedatel'[nom sg masc] kolxoza i sekretar' [nom sg masc] rajkoma.

'Valentina Ivanovna was respected by the kolkhoz chairman and by the secretary of the district committee.'

(c) VaZju[acc] togda $\left\{\begin{array}{c}\text { Zjubili[p1] } \\ * \text { jubil[sg masc] }\end{array}\right\} S a$ ša[nom sg masc] $i$ Kolja[nom sg masc].

'Valya was loved at that time by Sasha and Kolya.'

(d) Poexat' na jug $\left\{\begin{array}{c}\text { xotjat }[\mathrm{p} 1] \\ \text { xocet }[\mathrm{sg}]\end{array}\right\}$ Saša[nom] i Kolja to go to south want [nom].

'Those who want to go to the south are Sasha and Kolya.'

The fact that the verbs in (16) must be pluralized cannot be accounted for by the fact that they are preceded by their grammatical objects, because in the structurally similar sentences under (17), where the subjects are not Agents, the verbs do not have to be pluralized ((17a) and (17b) are from stories by Turgenev and Chekhov, respectively, but are not obsolete in any way; (17c) is from a contemporary story). 10

(17) (a) Menja[acc] osobenno porazila[sg fem] čistota[nom sg fem] i glubina[nom sg fem] neba, sijajušcaja prozračnost'[nom sg fem] vozduxa.

'I was especially struck by the clarity and depth of the sky, by the radiant transparency of the air.'

(b) Kogda staZo sovsem temno, Kaštankoj[instr] ov ZadeZo[sg neut] otěajanie[nom sg neut] $i$ üas [nom sg masc].

'When it became completely dark, Kashtanka was overcome by desperation and terror.'

(c) Ix[acc] tomila[sg fem] tišina[nom sg fem] $i$ monotonnost'[nom sg fem] dorogi.

'They were depressed by the silence and monotony of the road.'

${ }^{10}$ The fact that the subject nouns in these sentences denote abstract homogeneous entities is of marginal significance. 
It is true, though, that most sentences with Agent subjects also contain Patients, or Goals (cf. the underlying roles suggested in, e.g., Halliday 1970, Langendoen 1970, and Fillmore 1971a), and sentences with Agent subjects which do not contain Patients or Goals are uncommon. Thus sentences such as (16) above or (18) below are numerous, whereas sentences such as (19) represent isolated cases. $((19 c)$ is adapted from a sentence in a Chekhov story.)

(18) (a). Stixi[acc] $\left\{\begin{array}{r}\text { piřut }[\mathrm{p} 1] \\ \text { pišet[sg] }\end{array}\right\}$ Svetlov[nom] i Romanov [nom].

'Those who write poetry are Svetlov and Romanov.'

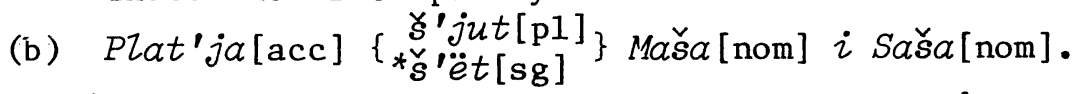
'Dresses are being sewn by Masha and Sasha.'

(c) Ob ètom často $\left\{\begin{array}{c}\text { govorjat }[\mathrm{pl}] \\ \text { govorit }[\mathrm{sg}]\end{array}\right\}$ Andrej[nom $i$ Kolja[nom].

'This [subject] is often talked about by Andrey and Kolya.'

(19) (a) Na večere $\left\{\begin{array}{c}i g r a l i[\mathrm{pl}] \\ \text { igral [sg masc] }\end{array}\right\}$ Andrej[nom] i Kolja [nom].

'Andrey and Kolya played at the party.'

(b) Segodnja $\left.\begin{array}{c}\text { de žurjat [p1] } \\ \text { dežurit }[\mathrm{sg}]\end{array}\right\}$ Saša[nom] i Alëša[nom]. 'On duty today are Sasha and Alyosha.'

(c) $\left\{\begin{array}{c}P e Z i[\mathrm{p} 1] \\ * \operatorname{Pe} Z[\mathrm{sg} \text { masc }]\end{array}\right\} d^{\prime} j a c ̌ o k[$ nom $] i$ pis'movoditel' [nom] .

'[Those] singing were the sexton and the clerk.'

1.13 It should be emphasized that the mandatory pluralization in (16), (18), and (19) cannot be attributed to joint endeavor by the subjects, i.e., these sentences differ from sentences such as (20), where primary conjunction must be postulated, for the subjects are responsible for their actions jointly and these sentences cannot be paraphrased as conjoined sentences. ${ }^{11}$

${ }^{11}$ Note that joint subjects need not necessarily be animate, as illustrated by (i) and (ii). 


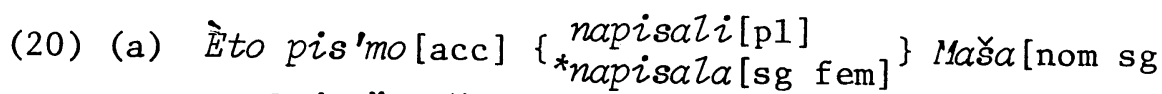
fem] $i$ ë miz[nom sg masc].

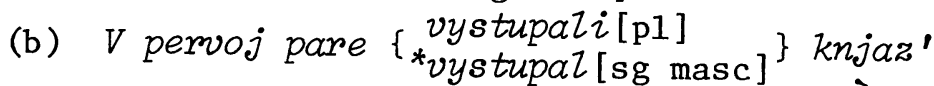
Obolenskij[nom sg masc] i Gercoginja Érgil'skaja [nom sg fem].

'In the first pair stepped forward Prince Obolensky and the duchess Ergilskaya.'

(c) očen interesnyj èpizod[acc] $\left\{\begin{array}{c}\text { privodjat [pl] } \\ * \text { privodit }[\mathrm{sg}]\end{array}\right\}$ svoej stat'e V.G. Kostomarov[nom] i A.A. Leont'ev[nom].

'A very interesting episode is cited by V.G. Kostomarov and A.A. Leontiev in their article.'

The verbs illustrated in (16)-verit' 'believe,' uzažat' 'respect,' Zjubit' 'love,' and xotet' 'want'-represent internal states and cannot possibly involve

(i) Derevo[acc] $\left\{\begin{array}{c}\text { pogubili[p1] } \\ \text { pogubil[sg masc] }\end{array}\right\}$ veter [nom sg masc] $i$ molnija[nom sg fem].

'The tree was destroyed by wind and lightning.'

(ii) Volej režissëra Natalii Sac i xudožnika P. Belova pomenjalis'[p1]

*pomenjalos'[sg neut] $\}$ mestami dejstvitel'noe [nom sg neut] $i$ mečta[nom sg fem].

'By the will of the director Natalia Sats and the artist P. Belov, reality and dream exchanged places.'

The predicate in (ii) is representative of predicates which can only be associated with a plurality and require either plural or conjoined subjects (though some predicates of this type may also occur with a singular collective noun or with a singular noun and a "comitative" phrase; cf., e.g., Devuški[p1] vstrečajutsja po sredam 'the girls meet on Wednesdays,' Valja[sg] i Varja[sg] vstrečajutsja po sredam 'Valya and Varya meet on Wednesdays,' Naša gruppa[sg] vstrečaetsja po sredam 'our group meets on Wednesdays,' Valja[sg] vstrełaetsja s Varej po sredom 'Valya meets with Varya on Wednesdays,' but not *Valja[sg] vstrečaetsja po sredarm 'Valya meets on Wednesdays'). 
joint agency. 12 Sentences (18) and (19) do possibly refer to joint actions, but they may also refer to individual actions, which can be demonstrated by the fact that these sentences allow the particle $i$ before the first conjunct; cf. (21a) and (21b) below, corresponding to (18a) and (19a), respectively. The sentences under (20), which have joint agents, do not allow this $i$ before the first conjunct, as demonstrated by (22a) and (22b), corresponding to $(20 \mathrm{a})$ and $(20 \mathrm{~b})$, respective1y.13

${ }^{12} \mathrm{Cf}$. the contrast in English, pointed out in Lakoff and Peters 1969, 116, between John and Mary's arrival and *John and Mary's knowledge of the facts, apparently due to the fact that knowledge cannot be a joint undertaking. (The distinction between stative and nonstative predicates discussed by Lakoff and Peters does not seem directly relevant to the question of grammatical number and reduction processes.)

${ }^{13}$ The fact that the introductory $i$ marks individual involvement can also be demonstrated by juxtaposing sentences such as (i) and (ii) (from Andreyewsky 1973, 46).

(i) Robert i Griša podralis' (drug s drugom).

'Robert and Grisha got into a fight (with one another).'

(ii) *I Robert $i$ Griša podralis' (drug s drugom).

'Both Robert and Grisha got into a fight (with one another).'

Cf. also the corresponding signification of both in English, as illustrated in (iii) and (iv) (from Lakoff and Peters 1969, 115).

(iii) John and Mary left together.

(iv) *Both John and Mary left together.

An interesting effect of the introductory $i$ is that it renders pluralization (and hence Regrouping) optional: the sentences under (21) would also be acceptable with singular verbs, although the corresponding sentences without the introductory $i((18 a)$ and $(19 a))$ would not be. For further discussion see Section 1.22 below. 
(21) (a) Stixi[acc] pišut i Svetlov[nom] i Romanov [nom]. 'Poetry is being written both by Svetlov and by Romanov.'

(b) Na večere igrali $i$ Andrej i Kolja.

'Both Andrey and Kolya played at the party.'

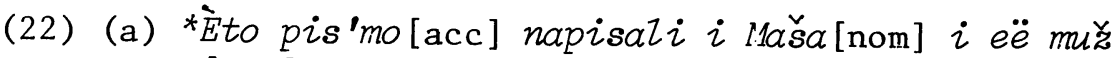
[nom].

'This letter has been written both by Masha and by her husband.'

(b) 'V pervoj pare vystupali i knjaz' Obolenskij $i$ Gercoginja Èrgil'skaja.

'In the first pair stepped forward both Prince Obolensky and the duchess Ergilskaya.'

Thus while in the sentences under (20) the fact that the verbs must be pluralized is a direct consequence of the fact that they have joint, primarily conjoined subjects in the underlying representations, the pluralized verbs in (16), (18), and (19) cannot be accounted for in the same way. It is therefore indeed the Agent role of their subjects which apparently determines their mandatory pluralization.

1.14 Before comparing sentences with Agent subjects to sentences with non-Agent animate subjects, it will be useful to consider examples of sentences with inanimate subjects (which are by definition not Agents) and nonpluralized prepositive verbal predicates.

Most typical are the first three sentences under (23), where the prepositive verb is the existential byt' 'to be' ((23a) from Aksyonov's "Katapul'ta"; (23c) from comments by the writer Panova about her work [published in 1975 in Literaturnaja gazeta]).

The next three sentences illustrate verbs of position, which can also be classified as essentially existential (the first two occur in Russian textbooks for foreigners [(d) in Šcukin and Zlatkina 1970, 9; (e) in Vagner and Ovsienko 1967, 409], and the third is from a 1972 story in Junost').

The next sentence, ( $g)$, which occurs in another textbook for foreign students (Vorob'eva 1973, 34), illustrates another existential verb, and (h) illustrates rasti 'to grow' used as an existential verb (cited from a work by Panova in Skoblikova 1961a). Sentence (i), also cited in Skoblikova 1961a, illustrates the use of a motion verb 
as an inchoative existential verb, in the sense of "come into being."

Sentences $(j-n)$ illustrate conjoined Patient subjects following passive verb forms with $-s j a$ ( $(j)$ from Vorob'eva 1973, 34; (k) is a typical weather forecast; (1) is from a a 1971 book review in Junost'; (m) occurs in Kirillov 1970, 45; and ( $\mathrm{n}$ ) is from an introductory note by Aksyonov). Sentences (o-q) illustrate conjoined Patient subjects following predicative passive participial forms ((o) occurs in Vorob'eva 1973, 35; (p) in Vagner and Ovsienko 1967, 491; and (q) in Zaliznjak 1967a, 206).

The next five sentences illustrate conjoined subjects following short-form adjectives. The role of the subjects in $(\mathrm{r}-\mathrm{s})$ is analogous to their role in the preceding passive sentences, $(j-q)$, for they represent Patients $((r)$ from Literaturnaja gazeta, (s) is cited from a work by Aksyonov in a discussion of word order in Kovtunova 1969, 31). The role of the subject in ( $t)$, cited from a work by Paustovsky in a thesis abstract, may be defined as Cause (cf. Babcock 1972). In (u), the role of the subjects can also be defined as that of Patients (this sentence, which is similar to sentence ( $1 f$ ) at the beginning of the present chapter, is cited in Panov 1968, 71, in a discussion of the grammatical number of nouns). In (v), from Literaturnaja gazeta, the role of the subjects can perhaps be defined as Essive (cf. Langendoen 1970, 102). (Essive may also be the role of the subjects in $(a-i)$. )

In the last three sentences, the prepositive predicates are active verb forms--in $(\mathrm{w}-\mathrm{x})$ they are intransitive, and in ( $y$ ) the verb is transitive. In (w) (from Vagner and Ovsienko 1967, 223) the subjects may be defined as Locatives, and in the last two sentences (both from Literaturnaja gazeta) the subjects may be defined as Patients and Causes, respectively (the last sentence is analogous to (17a) and (17c) above).

The sentences below illustrate not only subjects linked by $i$ but also asyndetic subjects (only linked by intonation), since the difference between the two types of linkage is of minor significance for the phenomenon under discussion.

(23) (a) Zdes' bylo[sg neut] vodoxranilišce [nom sg neut] $i$ šljuzy [nom pl], gidrosiancija[nom] i malen'kij gorodok[nom] pri nej.

'Here [there] was a water reservoir and sluices, a hydroelectric power station, and a small town next to it.' 
(b) Na nej byz [sg masc] belyj sviter [nom sg masc] $i$ belaja korotkaja jubka [nom sg fem].

'She was wearing a white sweater and a white short skirt.'

(c) U menja byz[sg masc] namëtannyj glaz[nom sg masc] i sposobnost'[nom sg fem] točno opisat' uvidennoe.

'I had a trained eye and the ability to describe exactly what I saw.'

(d) Na zurnal'nom stolike ležit[sg] gazeta[nom sg] "Pravda" $i$ žurnal[nom sg] "Sovetskij Sojuz", stoit [sg] vaza[nom sg] i pepel'nica[nom sg].

'On the magazine table [there] lie [a copy of] the newspaper Pravda and [a copy of] the magazine Sovetskij Sojuz, [there] stand a vase and an ashtray.'

(e) Na stole ležit[sg] marka[nom sg], koromuju vypustili $v$ čest' Kuz'minoj-Karavaevoj, i sbornik[nom sg] ëe stixov, kotoryj izdali vo Francii.

'On the table [there] 1ie a stamp which was issued in honor of Kuzmina-Karavaeva and a collection of her poems which was published in France.'

(f) Devuška sidela na čemodane, vozle në stojal[sg masc] ešc̈ë odin čemodan[nom sg masc], pletënaja korzina[nom sg fem] iz prut'ev.

'The girl was sitting on a suitcase, [and] next to her [there] stood another suitcase [and] a woven basket [made] of twigs.'

(g) V universitete imeetsja[sg] institut [nom sg] povyšenija kvalifikacii prepodavatelej vuzov, podgotovitel'nyj fakul'tet [nom sg] dlja inostrannyx grażdan, podgotovitel'nye kursy [nom p1].

'At the university there is an institute for improving the qualification of teachers at institutions of higher education, a preparatory school for foreign citizens, [and] preparatory courses.'

(h) Na dvux dlinnyx grjadkax rastët[sg] Zuk[nom sg] $i$ rediska [nom sg].

'In two long rows [there] grow onions and radishes.' 
(i) $V$ publike poš̈̈l[sg masc] š̈̈pot[nom sg masc] $i$ smex [nom sg masc].

'In the audience [there] started whispering and laughter.'

(j) Okončivšim[dat] universitet vmǐadetsja[sg] diplom[nom sg] i nagrudnyj značok[nom sg].

'Graduates of the university are handed a diploma and a badge.'

(k) Ozidaetsja[sg] peremennaja oblačnost'[nom sg], na zapade oblasti nebol'soj dozd'[nom sg], veter

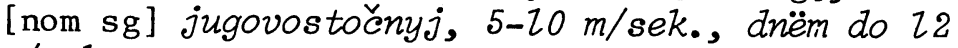
$\mathrm{m} / \mathrm{sek}$.

' [There] is expected variable cloudiness, in the western parts of the province some rain, [and] southwestern winds, 5-10 meters per second, in the afternoon up to 12 meters per second.'

(1) Stixotvorenie central'noe, potomu čto $v$ nëm, kak $v$ zerkale, otrazilas'[sg fem] mnogoplanovost' [nom sg fem] knigi i raznoplanovost' [nom sg fem] poèzii Kirsanova.

'The poem is a central one, because in it, as in a mirror, are reflected the many levels of the book and the different levels of Kirsanov's poetry.'

(m) Količestvo poezdov $v$ čas $v$ každom napravlenii budet dovedeno do $40 \ldots$... dlja čego vnedrjaetsja [sg] "Elektronnyj mašinist" [nom sg] i novaja avtomatičeskaja lokomotivnaja signalizacija [nom sg].

'The number of trains per hour in each direction will reach $40 \ldots$ for which [there] are being introduced an "electronic engine-driver" and a new automatic system of locomotive signals.'

(n) V romane ... široko ispol'zuetsja[sg] xronika [nom sg] sobytij 1905-1907 godov, perepiska[nom sg], protokoly [nom p1] i dmugie dokumenty [nom $\mathrm{p} 1]$.

'In the novel ... wide use has been made of the chronicle of events in 1905-1907, correspondence, records, and other documents.'

(o) Sozdan [sg masc] studenčeskij teatr [nom sg masc], akademičeskij xor [nom sg masc], internacional'nyj studenčeskij teatr [nom sg masc].

' [There] have been formed a student theater, an academic chorus, [and] an international student theater.' 
(p) Gruppa sovetskix učenyx predpoloziza, ěto $v$ konce mezozojskoj èry ... imelo mesto očen' sil'noe kosmičeskoe oblučenie Zemli, v rezul'tate kotorogo byl zaraæ̌en [sg masc] celyj sloj[nom sg masc] počvy $i$ okeany. [nom pl].

'A group of Soviet scientists has conjectured that at the end of the Mesozoic age ... there was a very intense cosmic irradiation of the earth, as a result of which were infected a whole layer of earth and the oceans.

(q) $V$ naborax ètogo klassa ne zapolnena[sg fem] neatributivnaja rast' [nom sg fem] ètalona i kletki[nom p1] parnogo roda.

'In sets of this class, the nonattributive parts of the paradigm and the squares of the "pair" gender have not been filled out.'

(r) Izvestna[sg fem] ëe èmbZema[nom sg fem] $i$ ëe deviz[nom sg masc]: "Progress $i$ garmonija dlja čeloverestua".

'We11-known are its emblem and its motto: "Progress and harmony for mankind."'

(s) V okoško byl viden [sg masc] kusoček [nom sg masc] neba i mercajušcij sklon[nom sg masc] sopki.

'Through the window were visible a piece of the sky and the glimmering slope of the hill.'

(t) Redaktor ne čital stat'i, -v ètom byla vinovata [sg fem] ¿ara[nom sg fem] $i$ ego legkoverie [nom sg neut].

'The editor did not read the article,--the heat and his gullibility were to blame for it.'

(u) Im dlja raboty nužen [sg masc] stol [nom sg masc], stul [nom sg masc] i čemila[nom p1].

'For work they need a table, a chair, and ink.'

(v) Takov [sg masc] uz ego pisatel'skij udel [nom sg masc] i literaturnaja sud'ba[nom sg fem].

'Such are his lot as a writer and literary fate.'

(w) U menja bolela[sg fem] golova[nom sg fem] $i$ by me hurt head and gorlo[nom sg neut]. throat

'I had a headache and a sore throat.'

(x) Casto ot togo, kak sšito plat'e, kostjum, pal'to, zavisit [sg] naše nastroenie [nom sg] i povedenie [nom sg], a sledovatel'no, $i$ scomočuvstvie [nom sg].

'Often our mood and conduct, and consequently our sense of well-being, depend on the way in 
which a dress, suit, [or] coat have been sewn.'

(y) Putešestvennika[acc], progulivajuščegosja po moskovskim ulicam $v$ načale 70-x godov prošlogo veka, ne tak ǔ̃ často bespokoil [sg masc] krik [nom sg masc] mladencev $i$ vesëlyj šum [nom sg masc] igrajušcix detej.

'The traveller strolling through the streets of Moscow during the early seventies in the last century was rarely disturbed by the cry of babies and the gay noise of children playing.'

The sentences above do not represent slips, or usage which their writers would consider incorrect upon reflection. They are fully grammatical sentences which educated native speakers find quite natural. The singular predicates illustrated in these sentences could be pluralized-except perhaps for the verb ožidaetsja 'is expected' in the weather forecast in (23k), which follows a set formula. 14 What these sentences illustrate, then, is that Identity Deletion is a permissible method of reduction for coordinate sentences which have identical prepositive verbal predicates and inanimate subjects and are linked by $i$ or not linked by any connective (provided they are reducible; cf., e.g., the irreducibility of (7a) above). Regrouping is also possible in such cases but is not obligatory.

The following examples illustrate the same phenomenon in sentences with preposed nominal predicates followed by copulative-type verbs and conjoined subjects. The predicate nouns in (24) are grammatically singular, and in (25) they are grammatically plural. $((24 a)$ is cited in

${ }^{1.4} \mathrm{~A}$ somewhat similar set formula is apparently represented by the slogan $D a$ zdravstuuet [sg] druzba[nom sg] $i$ solidarnost'[nom sg] narodov 'long live friendship and solidarity among nations.' Pluralization of the verb in this slogan is admissible, but would be unusual (cf. also the comments in Dobromyslov and Rozental' 1960, 199-200). (Note that $d a$ zdravsturet in this sentence is not a set form as, for instance, the French vive in Vive[sg] Zes vacances[p1] 'long live the holidays' [B1inkenberg 1950, $50]$, for it must be pluralized in association with plural nouns, cf. Da zdravstvujut[p1]/*zdravstvuet[sg] kanikuly [p1] 'Iong live the holidays.' The derivation of the slogan is not clear, however, for the conjoined nouns in this case may represent a single, composite noun. 
Rozental' 1971a, 227 from a work by Goncharov [and has been verified by informants as representative of current usage]; the next two sentences are from recent newspapers; (24d) occurs in Vagner and Ovsienko 1967, 517. (25a) is from Konopelkin 1970, 49 and has already been cited at the beginning of the present chapter as (3e) [see also the comments on pp. 209-210]; (25b) is cited for contrast.)

(24) (a) GZavnoj zabotoj[instr sg] byZa[sg fem] kuxnja [nom sg fem] $i$ obed[nom sg masc].

'The main concerns were the kitchen and dinner.'

(b) Vað̌noj zadačej[instr sg] novogo pjatiletija javljaetsja[sg] povyšenie[nom sg] kačestva $i$ sokrałcenie[nom sg] srokov stroitel'stva, ulučšnie [nom sg] arxitektury $i$ vnešnej otdelki zdanij.

'An important task of the new five-year period is to raise the quality of construction and decrease the time it takes, [and] to improve the architecture and the external appearance of buildings.'

(c) Povodom [instr sg] dlja sensacii okazalas' [sg fem] pokupka[nom sg fem] idemonstracija[nom sg fem] po sovetskomu televideniju anglijskogo telefil'ma "Saga o Forsajtax".

'The cause for the sensation turned out to be the purchase and showing on Soviet television of the English film for television The Forsyte Saga.'

(d) Materialom[instr sg] dlja sozdanija organičeskix veščesto služit [sg] uglekislyj gaz[nom sg], pogZoščennyj rasteniem iz okmüajušcej atmosfery, $i$ voda[nom sg], $v$ kotoroj soderzatsja mineral'nye veščestua, usvaivaemye rasteniem.

'The [raw] materials for (the creation of) organic substances are carbonic acid gas, absorbed by the plant from the atmosphere around it, and water, which contains mineral substances assimilated by the plant.'

(25) (a) Učebnymi posobijami[instr p1] na takix zanjatijax slüilo [sg neut] vedërko[nom sg neut] $s$ abrikosami i kubiki[nom pl] raznoj veličiny. 'The teaching aids at such lessons were a bucket with apricots and blocks of various sizes.' 
(b) [Xozjajstvennoj edinicej byla bol'šaja patriarxal'naja sem'ja.] Bolee krupnymi obščestvennymi edinicami[instr pl] byli[p1] rod [nom sg] $i$ zatem plemja[nom sg].

'[The household unit was the large patriarchal family.] Larger social units were the clan and then the tribe.'

Analysis of (24) and (25) must await further research, for the derivation and constituent structure of these sentences are not clear (cf. footnote 48 in Chapter One).

1.15 Animate subject nouns that are not Agents most typically occur with existential verbs, as in (26) (cited above under (10)), where their role is perhaps Essive (see p. 227 above).

(26) (a) U nego byZa[sg fem] mjagkaja mat'[nom sg fem] $i$ grubyj avtoritarnyj otec [nom sg masc].

'He had a gentle mother and a coarse authoritarian father.'

(b) Kogda-to ... na xutore そ̌ila[sg fem] dev̌ocka[nom sg fem] let odinnadcati-dvenadcati $i$ ë̈ brat [nom $\mathrm{sg}$ masc], godami šest'ju starše sestry.

'Once ... in a small village [there] 1ived a gir1 of eleven or twelve and her brother, some six years older than [his] sister.'

Motion verbs such as Zetet' 'fly' or běat' 'run,' illustrated in (27a-b) (cited earlier as (10c) and (5a), respectively), apparently also lend themselves to use as existentials in certain contexts.

(27) (a) Vmeste so mnoj na kosmodrom letel[sg masc] German Titov[nom sg masc], eščë neskol'ko kosmonavtov, gruppa [nom sg fem] naǔcnyx rabotnikov i vrač [nom sg masc].

'With me to the launching site flew German Titov, several other cosmonauts, a group of scientists, and a doctor.'

(b) K beregu bežal [sg masc] Vanja[nom sg masc] $i$ Kolja[nom sg masc].

'Towards the shore were running Vanya and Kolya.'

The sentences under (27) do not assert what the referents of the subject nouns were doing or what they were 
aware of experiencing but rather identify the individuals who were in existence in certain spaces. The fact that they were in motion appears to be secondary and not necessarily implying volition. This also applies to perfective verbs of motion and similar verbs which can be used in the sense of "come into being" without necessarily involving volition on the part of the individuals referred to. Consider (28) ((28a) was cited above as (4b); (28b) was cited as $(10 d))$.

(28) (a) V komnatu vošZa[sg fem] moZodaja ženščina[nom sg fem] $i$ malen'kij mal'čik[nom sg masc].

'Into the room came a young woman and a little boy.'

(b) Blǐ̌e $k$ ploščadi naxoditsja dom (No. 14), gde godom ran'še poselilsja[sg masc] vidnyj muzykaZ'nyj dejatel' N.G. Rubinstejn[nom sg masc] i veličajšee muzytial'noe svetilo mira--P.I. Cajkovskij[nom sg masc].

'Closer to the square is a house (No. 14) where a year earlier took up residence the prominent figure in the world of music N.G. Rubinshtein and the illustrious musical luminary P.I. Chaikovsky.'

What (28a) asserts is that there appeared in the room a young woman and a little boy. It does not assert what the woman and the boy did or were aware of doing; to assert that, the verb would have to be postposed, viz., Molodaja zenšcina $i$ malen'kij mal'čik vošli $v$ komnatu 'the young woman and the little boy entered [the/a] room.' (28a) is a purely existential sentence, and this is why the verb can be singular and Regrouping is not mandatory (see also pp. 242-243 below). The perspective in (28b) too is one of existence rather than of action and what the clause asserts is that Rubinshtein and Chaikovsky came to be in the house. The perspective is not what the two celebrities did but who became residents of the house at a certain time. 15

${ }^{15}$ The susceptibility of motion verbs to existential use is not unique to Russian and has also been observed in English. Consider, for instance, (i)-(iii) (from Kimball 1973, 265). 
Animate subjects in the role of Patients are rare in Russian, and sentences with passive verb forms as in $(23 j-q)$ above have no analogues with animate subjects (cf., e.g., the statement in Kočetkova and Matveeva 1970, 8; there are very few exceptions). One example is (29) (from a text in Anpilogova et al., 1968, 179).

(29) [Potom zabolela mat', ona to we ne vstala s posteli.] Zabolel[sg masc] starצij syn[nom sg masc] $i$ starsaja dor'[nom sg fem]--mat' dvux malen'kix detej. '[Then the mother became sick; she too did not rise from [her] bed.] The older son and older daughter-a mother of two small children--became sick.'

Individuals who become sick do not will it; they are mere Patients. As demonstrated by (29), animate subjects defined as Patients need not be regrouped.

1.16 Sentence (5b), reproduced below as (30), seems to belong in a different category, for the connective in this sentence must apparently follow a certain pause or some intonational signal for the sentence to be grammatical with a nonpluralized verb. This pause or signal can be labelled "afterthought marker," and there are no constraints on Identity Deletion when a sentence with a

(i) There $\left\{\begin{array}{l}\text { entered } \\ \text { exited }\end{array}\right\}$ a squirrel.

(ii) There ran a man $\left\{\begin{array}{l}\text { into the room } \\ \text { from the building }\end{array}\right\}$.

(iii) *There ran a man around the track.

In the acceptable sentences, the motion verbs signify "coming into being." Running around the track, however, is apparently not susceptible to existential reading and requires an Agent. The last sentence is therefore ungrammatical, for the existential there is incompatible with Agent noun phrases (as formulated in Lee 1971, 34, "thereinsertion cannot apply to sentences with agents"). Perhaps further evidence for the special status of motion verbs is the fact that they can sometimes be preposed in English declarative sentences, as in (iv) (from Hockett 1958, 206-207).

(iv) (a) Away ran John.

(b) Here comes the train. 
repeated verb follows such an "afterthought marker." More specifically, a repeated verb may be deleted even if its subject is Agent; Regrouping is no longer mandatory. In (31), for example, the subjects seem to be Agents, yet the prepositive verb is not pluralized. In this sentence, the "afterthought" nature of the second conjunct is signalled lexically--by a potom $i$ 'and then also.'

(30) Slušaet[sg] menja korrespondent [nom sg] i sekretar' [nom sg].

'Listening to me are the correspondent and the secretary.'

(31) Vpervye rasskazala[sg fem] mne o nej Anna Alekseevna Sever'janova[nom sg fem], byvsaja $v$ tu pom direktorom tekstil'nogo kombinata "Trexgornaja manufaktura", a potom i Vladimir Ivanovič Vorošin [nom sg masc], pomoščnik mastera tkackoj fabriki. '[The] first [one who] told me about her [was] Anna Alekseevna Severyanova, who at that time was director of the textile industrial complex Trekhgornaya Manufaktura, and then also Vladimir Ivanovich Voroshin, foreman assistant at the weaving factory.'

We can now return to (9b), reproduced below as (32a).

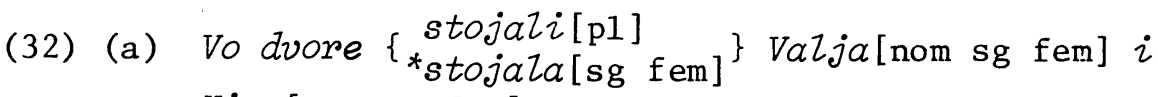
Nina[nom sg fem].

'In the courtyard stood Valya and Nina.'

(b) Vo dvore stojala[sg fem] Valja[nom sg fem], $i$ Nina [nom sg fem].

'In the courtyard stood Valya, and Nina [too].'

In (32b), the connective is preceded by an "afterthought marker" (symbolized by the comma), and the verb does not have to be pluralized--in distinction from (32a), where there is no break between the conjuncts and pluralization is mandatory. Compare also the following sentences ((33a) was cited above as (16a), (34a) was cited as (18a)).

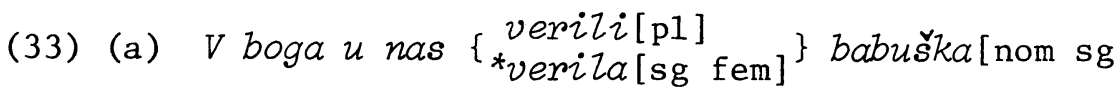
in God at home believed fem] $i$ tëtja[nom sg fem]. grandmother and aunt 
(b) V boga u nas verila[sg fem] babuška[nom sg fem], in God at home believed grandmother $i$ tëtja[nom sg fem]. and aunt

(34) (a) Stixi[acc]\{ $\left.\begin{array}{c}\text { pišut }[\mathrm{pl}] \\ \text { pišet }[\mathrm{sg}]\end{array}\right\}$ Svetzov[nom sg] i Romanov poetry write Svetlov and Romanov [nom sg].

(b) Stixi[acc] pišet[sg] Svetlov[nom sg], i Romanov poetry writes Svetlov and Romanov [nom sg].

(35) (a) Tebja[acc] $\{\underset{* \check{z} d u t[p 1]}{\check{z} d[\mathrm{sg}]}\}$ Kolja[nom sg] $i$ Gena[nom [for] you wait Kolya and Gena sg].

'Kolya and Gena are waiting for you.'

(b) Tebja[acc] ¿̌dët[sg] Kolja[nom sg], i Gena[nom sg].

'Kolya is waiting for you, and Gena [too].'

In printed texts, the "afterthought marker" is not always represented by a comma, especially when the (superficially) conjoined subjects refer to individuals identified as "nonjoint"--as independent of one another or known as such. One example is (30), which has no comma in Svedova 1970,554 and stands in contrast to, e.g., *Nas [acc] slušala[sg fem] Valja[nom sg fem] i Nina[nom sg fem] 'we were listened to by Valya and Nina.'16 Additional typical examples are given under (36). The first, (36a), stands in contrast to (32a); (36b) stands in contrast to (35a). (Sentence (36c) is from a recent article by the writer Fyodor Abramov in Literaturnaja gazeta.)

16 The differences between this sentence and (30) are insignificant: Nas[acc] slušl[sg masc] korrespondent [nom] $i$ sekretar' [nom] 'we were listened to by the correspondent and the secretary' would be as acceptable as (30). The reason for the difference in tense is that I have found the past tense generally more reliable when checking with informants, because present-tense forms do not distinguish gender and of ten also number (orally). The difference in word order is simply to render the sentence more natural out of context. 
(36) (a) Vo dvore stojala[sg fem] Valja[nom sg fem] $i$ Valina podruga[nom sg fem].

' In the courtyard stood Valya and a friend of Valya's.'

(b) Tebja żët[sg] Kolja[nom sg] i ešc̈e kto-to[nom]. [for] you waits Kolya and more someone

'Kolya and someone else are waiting for you.'

(c) Čerez slovo vozvrašcaetsja ko mne mö̈ detstvo, otkryvaetsja ta sreda, otkuda vyšel[sg masc] ja [nom] $i$ vse moi geroi [nom p1].

'[That] speech returns me to my childhood, unfolds the environment from whence issued $I$ and all of my heroes.'

In (36c), the conjoined subjects are not Agents, but the sentence is a good illustration for subjects which are clearly not of equal rank and not jointly involved in the process indicated by the predicate.

The difference between conjoined noun phrases with and without an intonational break is subtle and elusive, but its reality is unquestionable, as is the fact that a prepositive verbal predicate followed by conjoined subject noun phrases can be in the singular even without an intonational break so long as the subjects are not Agents (with very few exceptions). The exact nature of the intonational break and its possible variants requires further investigation, but what concerns us here is the source of this prosodic feature. In other words, why in certain cases the connective $i$ is not preceded by an "afterthought marker" while in others it is.

It is a question for which I can offer no satisfactory answer at this point other than suggesting that when the connective $i$ follows some sort of an intonational break or signal it represents a logical relationship which differs from the one represented by the truly conjunctive $i$--whatever the ultimate underlying representation of these relationships might be. On a more shallow level, perhaps the "afterthought" $i$ can be assumed to follow a sentence boundary marker which is absent when sentences are connected by the conjunctive $i$. This boundary marker may account for the fact that the deletion of redundant elements from the righthand conjunct is not as sensitive 
to syntactic parallelisms or other factors as when there is true conjunction. 17

1.17 Finally, to conclude the present discussion, a few words are in order on the question of word order in Russian and the correlation between the factors which determine word order and the factors which determine the grammatical number of prepositive verbs followed by conjoined subjects, a correlation suggested by Peshkovsky's statement (Peškovskij 1956, 451) that for prepositive verbs to manifest the number of just the nearest conjunct is the norm in colloquial Russian (except in sentences with verbs which can only be associated with pluralities, e.g., ponagrjanut' 'appear unexpectedly one after the

${ }^{17}$ Another possibility is that the "afterthought" $i$ is not attached to the superordinate $S$ node like the "truly conjunctive" $i$ but rather to an $S$ node which only dominates the sentence introduced by the connective, as shown under ( $i$ ) (this is the configuration argued for in Ross 1967 as the shallow representation of all conjoined structures).

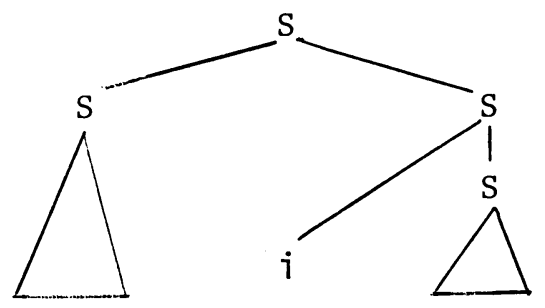

Note also that in general the discussion in the present monograph is restricted to deletion phenomena which may affect grammatical number manifestations. Deletions resulting in sentences such as, e.g., (ii) and (iii), are therefore outside the scope of this work. (The phenomenon illustrated by these sentences was labelled "gapping" in Ross 1970 [in circulation since 1967] and has attracted much attention in recent years. For a fairly recent lucid discussion see Hankamer 1973.)

(ii) Ja vodu[acc] pil, a Anna vodku[acc]. I water drank and Anna vodka

(iii) Ja vodu[acc], a Anna vodku[acc] pila[fem]. I water and Anna vodka drank

'I drank water, and Anna drank vodka.' 
other,' possorit'sja 'quarrel,' or s"exat'sja 'assemble [intrans]' [Peshkovsky's examples; see also footnote 11 above]).

Word order, or rather constituent order, in Russian declarative sentences is determined to a large degree by the relative amount of information conveyed by the constituents of each sentence in context, i.e., by relative communicative weight (or "scale of communicative dynamism" [Sgall 1972, 286]). In nonemphatic, intonationally unmarked sentences, the order of the constituents generally represents mounting degree of informativeness. In other words, the most informative constituent is the last one (excluding sentences with emphatic particles such as imenno in, e.g., Imenno on prišel 'it was he who came,' where the most informative element is on 'he').18

${ }^{18}$ In emphatic, intonationally marked sentences, the most informative element can stand anywhere, for it can be marked intonationally. Compare, for instance, (i) and (ii) ((ii) cited in Kovtunova 1969, 62).

(i) Ty dolžen stat' sïl'nym. you must become strong

(ii) Ty süz'nym stat' dolžen. you strong become must

'You must become strong.'

Primary sentence stress (or sentence accent [Bolinger 1952]) is indicated by ". In (i), it is on the last element, which is characteristic of neutral, nonemphatic discourse. In (ii), typical of oral, "expressive" discourse, the primary stress is on the second element. The difference in word order between (i) and (ii) is thus not a difference in message, only a difference in style.

In distinguishing between noninformative and informative elements in sentences, the foremost authorities on word order in Russian, Adamec and Kovtunova (see Adamec 1966 and also 1973, 128-133; Kovtunova 1969, 3-65 and 1973), have used the terms Theme and Rheme. Li and Thompson have recently suggested the terms Presupposition and Focus as most appropriate to "describe the organization of the information transmitted by a subject-predicate construction" ( $\mathrm{Li}$ and Thompson 1975a), distinguishing these terms from Topic and Comment, which have also been used in discussions of word order. Li and Thompson suggest restricting Topic to syntactically independent noun (cont.) 
There are two aspects of the principle of mounting informativeness which are relevant to the grammatical number of prepositive verbal predicates. The first is that of sentences that actually occur with prepositive verbs, a large number are of the type classified as "nerasčlenënnye" (Kovtunova 1969,30 ). These are sentences which contain no Theme, i.e., roughly, no previously mentioned or previously known elements; they are all Rheme, and in most of them, according to Kovtunova (ibid.), "сказуемое выражено глаголами со значением бытия, пвижения, начала, продолжения или окончания действия" (the predicate is expressed by verbs which signify existence, motion, or the beginning, continuation, or end of an action). These are all essentially existential verbs, for verbs which signify motion are only used in such sentences to indicate inchoative, continuous, or ended existence (cf. Nastupaet naša očered' 'our turn is coming,' Padal dozd' 'rain was falling,' and Prošzo desjat' dnej 'ten days passed' [Kovtunova's examples]), and verbs which signify "the beginning, continuation, or end of an action" are also used in this sense (cf. Načalsja gon pjatnistyx olenej '[there] began the pursuit of the spotted deer' [Kovtunova's example]).19

phrases followed by sentential Comments--in certain languages quite regularly, e.g., in Chinese, and in others occasionally, e.g., in English, as in As for John, I don't understand him (cf. also Li and Thompson 1974 and 1975b; Schachter 1975).

Noninformative elements in sentences have also been referred to as "given," or "old" information (dannoe in Russian), in contrast to "new" information (novoe), but, as noted in, e.g., Kovtunova 1969,13 and Halliday 1970, 162 , this dichotomy does not necessarily coincide with the dichotomy Theme/Rheme (or, for that matter, with Pre-supposition/Focus).

${ }^{19}$ The fact that in existential sentences in Russian the verb is preposed (in intonationally unmarked sentences) seems to represent a universal tendency, as indicated in the following statement: "One might set up a universal tendency that where you have a verb of existence and an indefinite subject, the verb of existence will tend to appear at the front of the sentence or tend to move toward the front of the sentence, no matter where verbs normally appear in that language" (Ferguson 1971, 5). In (cont.) 
sentences with prepositive verbs and conjoined subjects, the verbs are thus especially likely to be essentially existential and Regrouping is not likely to have taken place.

The second aspect of the principle of mounting informativeness that is relevant to the grammatical number of prepositive verbal predicates can only be suggested here in general terms, for word order in Russian is to a large extent still an uncharted territory. It seems that sentences with Agent subjects are especially unlikely to have a prepositive predicate, for in such sentences the predicate is usually more central from the communicative standpoint than the identity of the Agents. Consider, for example, the difference noted on pages 234-235 above between (37a) and (37b).

(37) (a) MoZodaja ženščina i maZen'kij mal'čik vošli [p1] $v$ komnatu.

'The young woman and the little boy entered [the/a] room:'

(b) $V$ komnatu vošla[sg] molodaja ženšcina imalen'kij mal'čik.

'Into the room came a young woman and a little boy.'

(c) $V$ komnatu vošzi[p1] moZodaja ženščina imalen'kij mal'čcik.

'Into the room came a young woman and a little boy.'

'Those who entered the room were a young woman and a little boy.'

The focus of (37a) is what the woman and the boy did, and the verb must be postposed. The identity of the Agents in this sentence is assumed by the speaker (or writer) to be known to the hearer (or reader).

In (37b), the focus cannot be what the woman and the boy did but rather their identity (and the room in this sentence represents a location which must have been

English, this tendency is manifested in the preference for sentences introduced by there, e.g., There are three apples on the table rather than Three apples are on the table. Interestingly enough, the verbs in there-sentences tend not to be pluralized when followed by conjoined singular nouns, cf. There was/?were a girl and a boy in the room. 
previously identified in the discourse). The fact that the verb is not pluralized can be taken as evidence that it is used in the sense of "come to be" rather than "walk in" and the subjects are therefore not Agents.

Sentence (37c), where the verb is pluralized, is less typical for two reasons. First, if the verb is used in the sense of "come to be," as in (37b), then its pluralization is less typical. Secondly, if the verb is used in the sense of "walk in"--which is possible in this case, since the verb is pluralized--then the focus of the sentence is the identity of the Agents, which is also less typical than sentences like (37a), where the focus is what Agents do rather than their identity.

These two factors, namely, the predominance of existential verbs in sentences with prepositive predicates and the infrequency of Agent subjects in such sentences, account for Peshkovsky's generalization that prepositive predicates are normally not pluralized. This generalization requires some qualification, however, for sentences with prepositive predicates and Agent subjects do occur and the predicates in such sentences must be pluralized (e.g., (16) and (18)-(19) above). Furthermore, there are sentences such as (20), where the subjects are jointly responsible for the predicates and there is no basis for singular predicates, and there are intonationally marked sentences, where the principle of mounting informativeness does not operate and no generalization can be made with respect to prepositive verbs.

The following section offers a brief sketch of sentences with prepositive verbal predicates associated with two or more nouns or noun phrases linked by conjunctive devices other than $i$ or an intonational signal.

1.2 The discussion in this section opens with a consideration of verbal predicates associated with subject phrases such as otec $s$ synom 'father with son' or god $z a$ godom 'year after year,' which seem to be equivalent to conjoined phrases even though the righthand noun is not in the nominative case. The discussion then turns to verbal predicates associated with subject phrases such as $i$ otec $i$ syn 'both father and son,' already mentioned in Section 1.13 above. After that, subsection 1.23 deals with subject phrases such as kak otec, tak $i$ syn 'father as well as son,' and subsection 1.24--with subject phrases such as ne tol'ko otec, no $i$ syn 'not only father but also son.' The latter subsection also contains a digression on 
sentences of the type Prišël ne otec, a syn '[the one who] came [was] not [the] father but [the] son,' where one of the coordinate nouns or noun phrases associated with the predicate is negated.

1.21 In the following sentences, the prepositive verbs are pluralized despite the fact that each of them appears to be associated with a singular subject noun ( (38d) is cited in Švedova 1970, 555).
(a) Prišli[pl] otec[nom sg] c synom[instr]. came father with son
'Father and son came.'
(b) To že delali[pl] moja mat'[nom sg] s tëtkoj the same did my mother with aunt [instr].
'My mother and aunt did the same thing.'
(c) Proxodjat[p1] god[nom sg] za godom[instr]. 'Year after year goes by.'
(d) Startujut[p1] para[nom sg] za paroj[instr]. start pair after pair
'One pair after the other start off.'

The pluralized verbs in these sentences represent fully normative usage, though singular verbs are also possible in such sentences (cf., e.g., Vinogradov and Istrina 1960, 498-499; Švedova 1970, 555; and Rozental' 1971a, 221-222). The grammatical number assigned to verbal predicates associated with phrases such as otec $s$ synom 'father with son' and god $z \alpha$ godom 'year after year' is essentially independent, however, of the position of the verbal predicates, for postpositive predicates can also be either in the singular or in the plural in association with such phrases, as illustrated in the sentences under (39).

(39) (a) Kurica[nom sg fem] s cypljatomi prjatalas'[sg $\mathrm{fem}]$ pod naves.

'The hen with the chicks hid under the awning.'

(b) Kolja[nom sg] s Petej[instr] postupili[p1]v Kolya with Petya enrolled in odnu $i$ tu ̌̌e školu. the very same school

'Kolya and Petya enrolled in the same school.' 
(c) Tam miska[nom sg] s Zožkoj[instr] ostaZis'[p1] i there bowl with spoon remained and jubka staraja. 20

skirt old

'A bow1 and spoon remained there, and an old skirt.'

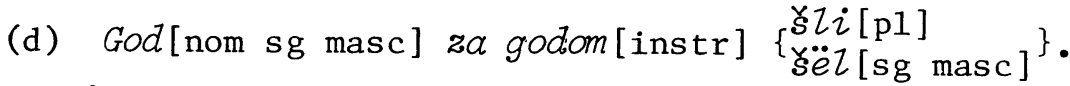
'Year after year went by.'

The grammatical number of verbal predicates in sentences like (38) and (39) is not determined arbitrarily, that is, it is not the case that predicates may be either in the singular or in the plural in every sentence where a singular subject noun or noun phrase (i.e., noun or noun phrase in the nominative case) is followed by a prepositional phrase with $s$ or $z a$ (and, if the preposition is $z a$, the noun or noun phrase it governs are identical to the subject noun or noun phrase). This fact is most aptly demonstrated by the sentences under (40) (from Andreyewsky 1973).

(40) (a) Mat'[nom sg fem] $s$ dočer'ju[instr] \{ nervnicali mother with daughter were nervous $[\mathrm{pl}]$ [sg $\mathrm{fem}]$.

'Mother and daughter were nervous.'

(b) Petja[nom sg masc] s tovariščem[instr] ${ }_{* \text { pogib }}^{\text {pogibli }}$ Petya [p1] with comrade perished

[sg masc] $\}$ na vojne. in war

'Petya and [his] comrade perished in the war.'

Singular verbs are impossible in (40), because they would imply that the daughter in (a) and the comrade in (b) assisted or participated in the mother's being nervous and Petya's perishing, respectively--which is impossible,

${ }^{20}$ The word order in this sentence is representative of oral informal discourse. The sentence is from a recent story (Vladislav Titov, "Razdel," Junost' 1973, No. 12), where it occurs in the speech of a simple peasant. 
since the verbs nemničat' 'be nervous' and pogibnut' 'perish' only allow individual involvement, as pointed out by Andreyewsky (1973).

A singular verb, then, indicates that the role of the entity referred to in the prepositional phrase is distinct from that of the entity referred to in the nominative phrase. This role can be referred to as Comitative. A pluralized verb, in contrast, indicates that the role of the entity referred to in the prepositional phrase is not Comitative but rather identical to the role of the entity referred to in the nominative phrase (cf. Andreyewsky 1973, esp. 164-169).

Consequently, nouns such as Petya and tovarišc in (40b) must be equivalent to one another at some level in the derivation of the sentence and, moreover, must be within a single noun phrase specified [+Plural], for the plural number of the verb must match a [+Plural] specification on a subject NP node and there seems to be no other source for the plural number of the verb. It follows that the underlying structure of $(40 \mathrm{~b})$ must be at some level essentially identical to underlying structures with primary conjunction in the subject phrase, i.e., roughly as in $(41) .21$

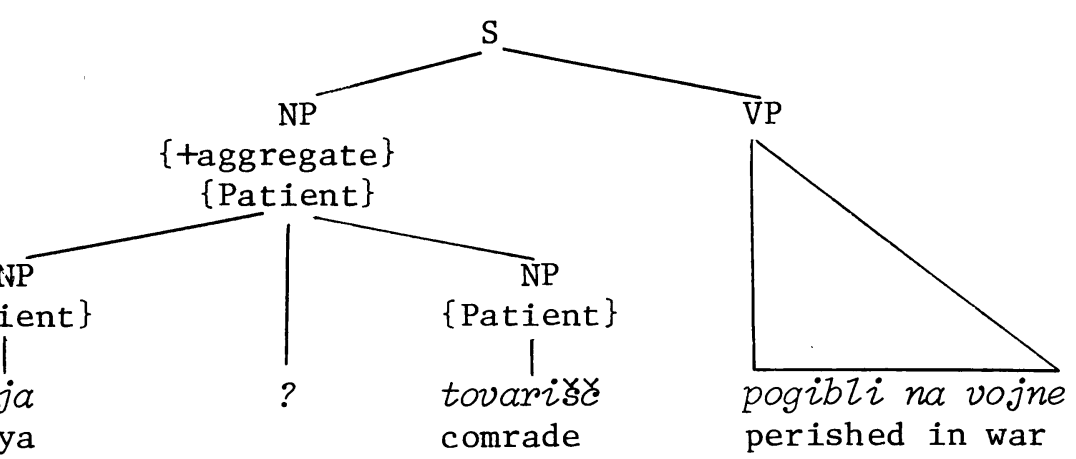

The prepositional phrase $s$ tovariščem 'with [his] comrade' in (40b), accordingly, derives from an underlying coordinate noun phrase, and the preposition as well as the oblique case ending of the noun it governs represent a

${ }^{21}$ It is not clear whether locative phrases such as na vojne 'in [the] war' should be treated as independent sentence constituents or as constituents of verb phrases in a model of Russian grammar. The position of na vojne in (41) therefore represents no more than a working hypothesis. 
relatively superficial level in the derivation (cf. also the similar derivation proposed for certain with-phrases in English in Lakoff and Peters 1969). The preposition may derive as a variant of the connective $i$ (note that $(40 \mathrm{~b})$ is fully synonymous to Petja $i$ tovarišč pogibli na vojne 'Petya and [his] comrade perished in the war'), but a well-motivated account for the derivation of $s$ in such sentences must await further research. 22

As for Comitative phrases--as in (39a), for example, reproduced below as (42)--they apparently also derive as constituents of noun phrases rather than as constituents of verb phrases. More specifically, kurica 'hen' and $s$ cypljatami 'with chicks' are apparently constituents of a single noun phrase in the underlying representation of (42), perhaps as in (43).

(42) Kurica[nom sg fem] s cypljatami[instr] prjatalas' [sg fem] pod naves.

'The hen with the chicks hid under the awning.'

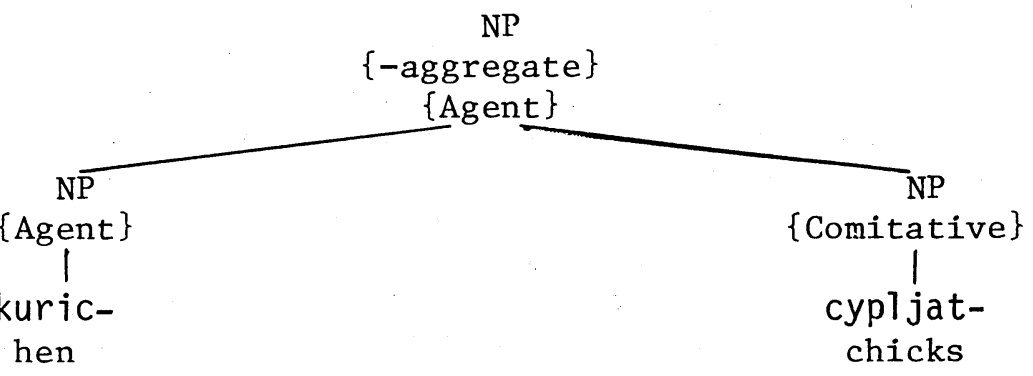

The basis for assuming that Comitative phrases derive from structures as in (43) is data as in (44) (Andreyewsky 1973, 174-175).

${ }^{22}$ Evidence for the underlying coordinate status of $s-$ phrases in sentences like (40) is also provided by the acceptability of pluralized modifiers in phrases such as vyxodjašcie[non pl] iz vorot ded[nom sg] $s$ babuškoj[instr] 'coming out of the gate grandfather with grandmother' = 'grandfather and grandmother, who are coming out of the gate' and moi[nom pl] otec[nom sg] s mater'ju[instr] 'my father with mother' = 'my father and mother' (both cited in Rozental' 1971a, 235, the latter to illustrate stylistically infelicitous [though permissible!] pluralization). Whether the modified nouns are regrouped or represent underlying composites, they are treated as conjuncts. 
(44) (a) *Petja[nom sg masc] s tovariščem[instr] pogib [sg Petya masc] na vojne.

with comrade perished in war

(b) Petja[nom sg masc] pogib [sg masc] $\left\{\begin{array}{ll}s \text { tovarišcem[instr] } & \text { na vojne } \\ \text { with comrade } & \text { in war } \\ \text { na vojne s tovariščem [instr] } & \text { in war with comrade }\end{array}\right\}$.

'Petya perished with [his] comrade in the war.'

The source of $s$ tovarišcem 'with comrade' in (44b) is not clear, but it must be different from that of $s$ tovarišem in (44a), where it is adjacent to the subject noun, because (44a) is not a grammatical sentence and (44b) is. Conversely, the Comitative phrase in (44a), which parallels (42), must be distinguished from the superficially similar phrase which follows the verb in (44b). According to Andreyewsky (1973, 175), there is also a semantic distinction: the phrase in question represents "attendant incident" in (44b), and "comitative" involvement in (44a) and (42). Since superficial adjacency to the subject noun is crucial for the "comitative" interpretation, it seems plausible to assume that Comitative phrases derive within subject phrases--whether distinguished from subject heads by a Comitative specification, as in (43), or by a difference in configurational position (not shown). Be that as it may, the grammatical number of a subject noun phrase which contains a Comitative phrase cannot be affected by the presence of such a phrase; a pluralized verb in (42) would be ungrammatical (the corresponding example in Andreyewsky 1973 [167] is: Maša[nom sg fem] $s$ partizanami[instr] ušla[sg.fem]/*ušli [p1] $v$ les 'Masha with [the] partisans went into the forest' = 'masha led the partisans into the forest').23

${ }^{23}$ The juxtaposition of singular and plural nouns in Andreyewsky's sentence and in (42) apparently excludes the possibility of a non-Comitative source for the plural nouns in the instrumental case, i.e., it excludes the possibility of their representing underlying coordinate Agents (cf. Andreyewsky 1973, 167).

An interesting concomitant phenomenon is the use of first-person and second-person pronouns as subjects with $s$-phrases representing underlying Comitative phrases and with $s$-phrases representing underlying primary (cont.) 
conjunction. In the latter case (signified by pluralized verbs), singular pronouns must be pluralized, as illustrated in (i), whereas with Comitative phrases, as in (ii), there are no restrictions on singular pronouns (cf. Vinogradov and Istrina 1960, 499 and Rozental' 1971a, 221; in Belevickaja-Xalizeva et al. [1973, 35], the rule is said to apply to third-person pronouns as well, but this does not appear to be so, for sentences such as on $s$ ¿enoj rešili[pl] uexat' 'he and [his] wife [1it. he with wife] decided to leave' are not ungrammatical, though they may be stylistically infelicitous [cf. Rozental' 1971a, 221]).

(i) (a) My/*ja s Petej poedem[p1] segodnja za gorod. we/*I with Petya will go today beyond city 'Petya and I will go to the country today.'

(b) Vy/*ty s Natašej dezurite [p1] zavtra. you/*thou with Natasha on duty tomorrow 'You and Natasha are on duty tomorrow.'

(ii) (a) Večerom jas Viktorom pošël[sg] na katok. in evening I with Victor went to skating-rink 'In the evening, I went with Victor to the skating rink.'

(b) Ty s nim budes' [sg] doma? thou with him will be home 'Will you be home with him?'

The restriction illustrated in (i) only applies to subject pronouns linked by $s$. When the connective is $i$, pronouns may remain in the singular even when they derive as primary conjuncts, which seems to be the case in (iii) (cited in Galkina-Fedoruk 1964, 347).

(iii) Ja $i$ mat' podolgu sidim[p1] $v$ temnote $i$ tixo razgovarivaem [p1].

'I and mother sit in the dark for a long time and talk softly.'

Subject phrases as in (iii), however, where a personal pronoun is linked by $i$, are considerably less typical than subject phrases as in (i), where the link is $s$. This is especially true of subject phrases with two personal pronouns--whether singular or plural, e.g., vy $i$ my 'you and we' or on $i j a$ 'he and $I$ ' are stylistically inferior to $v y s$ nami 'you with us' = 'you and we' and $m y$ $s$ nim 'we with him' = 'he and I' (also 'we and (cont.) 
According to this account, $s$-phrases representing Comitative entities derive as underlying noun phrases like $s$-phrases representing primary conjuncts. The source of the preposition $s$ and the instrumental case in surface Comitative phrases can be assumed to be the underlying Comitative specification. In other words, the preposition and the case it governs are manifestations of the role of the noun phrase with respect to the predicate. 24 These prepositional phrases, then, turn out to represent underlying noun phrases rather than underlying prepositional phrases (for some general arguments in support of the treatment of prepositional phrases in Russian as representing underlying noun phrases see Chvany 1975, 211-212).

It seems plausible to assume that subject nouns or noun phrases linked by $z \alpha$ 'after,' as in, e.g., (39d) above, can also have two different underlying sources like $s$-phrases, though $z \alpha$-phrases differ from $s$-phrases in that the constituents linked by $z \alpha$ must be identical to one another. $Z \alpha$-phrases require further investigation.

\subsection{Subject phrases such as $i$ otec $i$ syn 'both} father and son' are apparently always a consequence of the reduction of conjoined sentences with identical verb phrases, for the introductory $i$ is a marker of individual involvement and cannot occur with primary conjuncts (see footnote 13 above). Since there appear to be no

he'), respectively (cf. the comments in Saxmatov 1925, 151).

Pronoun combinations, incidentally, seem to be peculiar not only in Russian, and not only in English (where, e.g., you and me replaces you and I). Compare the following French data (from Dik 1968, 280): J'irai plus tard; Tu iras plus tard; *Je et tu irons plus tard; Moi et to i irons plus tard.

${ }^{24}$ This is only a tentative suggestion, for there is some doubt as to whether there are sufficient grounds to postulate a Comitative role. Arguments against postulating this role include the fact that there do not seem to be verbs which require it or exclude it, and the fact that with-phrases are not subject to reflexivization in English, as in, e.g., He brought her with him/*himself (though the situation is different in Russian, cf. On privël ëes soboj/*nim 'he brought her with himself/*him'). (cont.) 
restrictions at all on the grammatical number of prepositive verbal predicates associated with such subject phrases--they may either manifest the number of the nearest conjunct or be pluralized--it seems that both Identity Deletion and Regrouping are applicable reduction processes when the introductory $i$ is present. Before considering some examples, however, it should be emphasized again that prepositive verbs which manifest the number of the nearest conjunct cannot be accounted for as due to lack of forethought, as due to the fact that speakers may not know how sentences will end when they assign grammatical number to prepositive verbs. Such an account can be challenged by any sentence in which the first conjunct is introduced by $i$ and the prepositive verb is nevertheless not pluralized, and especially instructive are perhaps lines of poetry as in (45), where there can be no question of unawareness (these lines were written by Ivan Nikitin in 1853, but they are not outdated).

(45) I v moroznoj dali / Tixo potonul[sg masc] I napev[nom sg masc] pečali, / I toski razgul[nom $\mathrm{sg} \operatorname{masc}]$.

'And in the frosty distance / Quietly drowned Both the melody of sadness, / And the burst of anguish.'

The absence of restrictions on the grammatical number of prepositive verbal predicates followed by conjoined subjects introduced by $i$ can best be demonstrated by sentences which would not allow alternatives without the introductory $i$. The sentences under (46), for example, have Agent subjects, yet the prepositive verbs do not have to be pluralized, though they could be (these sentences were cited above without the introductory $i$, as (16c) and (18c), to illustrate obligatory pluralization in association with conjoined Agent subjects).

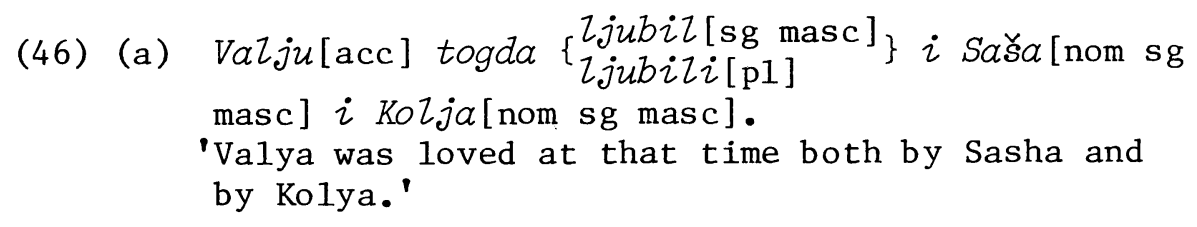

These arguments are presented in Stockwe11 et al. 1973, 744 . 
(b) Ob ètom často $\left\{\begin{array}{l}\text { govorit [sg] } \\ \text { govorjat [p1] }\end{array}\right\}$ i Andrej[nom sg] $i$ Kolja [nom sg].

'This [subject] is often talked about both by Andrey and by Kolya.'

The sentences under (47) correspond to (33)-(35) above.

(47) (a) $V$ boga u nas $\left\{\begin{array}{l}\text { verila[sg fem] } \\ \text { verili [p1] }\end{array}\right.$ i babuška[nom sg in God at home believed both grandmother fem] $i$ tëtja[nom sg fem]. and aunt

(b) Stixi[acc] $\left\{\begin{array}{l}\text { pišet [sg] } \\ \text { pišut [p1] }\}\end{array}\right\}$ i Svetlov[nom sg] $i$ poetry write(s) both Svetlov and Romanov [nom sg].

Romanov

(c) Tebja[acc] $\left\{\begin{array}{l}\check{z} d e t[\mathrm{sg}] \\ \check{z} d u t[\mathrm{p} 1]\end{array}\right\}$ i Kolja[nom sg] i Gena [for] you wait both Kolya and Gena [nom $\mathrm{sg}$ ].

In (48a), where there is no introductory $i$, pluralization is excluded (assuming no pause before the connective). This is because the conjoined subjects are metonymically related--Moscow is part of the Soviet Union-and therefore cannot add up to a plurality. Regrouping is apparently blocked in such cases by an overlap in the semantic features of the subject phrases in the conjoined underlying sentences. 25

(48) (a) Mne očen' \{ ponravilas'[sg fem] Moskva[nom sg fem] $i$ voobšce Sovetskij Sojuz [nom sg masc]. 'I very much liked Moscow and in general the Soviet Union.'

${ }^{25}$ This conjunction is treated as a product of the reduction of conjoined underlying sentences since it could not be accounted for as representing an underlying composite or primary conjunction because of the presence of voob̌če 'in general.' 
(b) Mne očen' \{ponravilas'[sg fem] $\}$ i Moskva[nom sg fem] $i$ voobšce Sovetskij Sojuz[nom sg masc].

'I very much liked both Moscow and the Soviet Union in general.'

(c) Mne očen' \{ponravilas'[sg fem] $\}$ Moskva[nom sg fem], $i$ voob̌še Sovetskij Sojuz[nom sg masc]. 'I very much liked Moscow, and the Soviet Union in general.'

In (48b), which is identical to (48a) except that it excludes the introductory $i$, pluralization is permissible. Regrouping is apparently not excluded when inconjoinable subjects can be marked as discrete--whether by means of the introductory $i$, or by means of an intonational break, as in (48c) (cf. also (33)-(35) above).

The introductory $i$ appears to be a surface particle, because it only occurs with reduced conjuncts (remember that it cannot introduce primary conjuncts). Perhaps the particle can be assumed to be optionally attached to nonidentical parallel constituents in underlying conjoined structures with identical elements before their reduction. It must be attached before reduction, because its presence neutralizes constraints on reduction which might be otherwise applicable, e.g., the restrictions on Identity Deletion when the subjects are Agents and on Regrouping when the subjects are metonymically related.

Quite significantly, the particle even neutralizes the restriction on Identity Deletion when the identical verbal predicates in conjoined sentences are postposed, as illustrated by the sentences under (49) (the author of (49d) is Pushkin; these lines are also cited in Peškovskij $1956,451)$.

(49) (a) I prospect[nom sg masc], i ves' rajon [nom sg masc] očen' izmenilsja[sg masc] $v$ poslednee vremja.

'Both the avenue and the whole neighborhood have changed very much lately.'

(b) I Moskva[nom sg fem], i voobšce Sovetskij Sojuz both Moscow and in general Soviet Union [nom sg masc] mne očen' ponravilsja[sg masc]. to me very appealed

'I very much liked both Moscow and the Soviet Union in general.' 
(c) IVasja[nom sg], i Osja[nom sg] poedet[sg]s nami.

'Both Vasya and Osya will come with us.'

(d) V lesu nočnoj poroj / I dikij zver' [nom sg], $i$ ljutyj čelovek[nom sg], / I lešij[nom sg] brodit [sg] ...

'In the forest at nighttime / Both the wild beast, and the fierce man, / And the wood-goblin wander ...'

Note that in (49b), the verb can have a singular ending even though the gender it manifests must be the gender of the subject noun with which it is associated in the underlying structure, i.e., Sojuz, and this gender conflicts with the gender of the subject noun of the deleted verb-Moskva. This conflict is admissible, though stylistically infelicitous.

In terms of actual usage, postpositive verbal predicates associated with conjoined subjects introduced by $i$ tend to be pluralized, i.e., Regrouping is the regular reduction process in such cases, and prepositive verbal predicates tend to manifest the number of the nearest subject noun, that is, the regular reduction process for identical prepositive predicates is Identity Deletion. (To be precise, only the initial predicate, the "controller" of deletion, must be prepositive--the deleted predicates may also be postpositive.) The presence of the particle $i$ thus has little effect in actual usage and the fact that this particle has the power to neutralize constraints on reduction does not affect the regular patterns of reduction.

Some typical examples from miscellaneous contemporary texts are given under (50) and (51).

(50) (a) I mat'[nom sg], i otec [nom sg] mogut[p1] peredat' svoemu rebënku zadatki odarënnosti.

'Both mother and father can transmit to their child grains of talent.

(b) Eti dve storony svjazany: $i$ ta[nom sg] $i$ drugaja[nom sg] sposobstvujut [p1] bolee proaračnoj členimosti slova $i v$ strukturnom $i v$ semantičeskom otnošenii. 26

${ }^{26}$ Note the deletion of two occurrences of the noun storona 'aspect' from the subject phrase, and the deletion of the first occurrence of the noun otnošenie (cont.) 
'These two aspects are related: both one and the other contribute to the greater transparency of the composition of the word both structurally and semantically.'

(51) (a) $V$ zavisimosti ot $i x$ replik menjaetsja[sg] $i$ Petruškina intonacija[nom sg] i ves' ego vnešnij oblik[nom sg].

'Depending on their responses both Petrushka's intonation changes and his whole external appearance.'

(b) V pamjati ešče zivo to glubokoe volnenie, kotoroe vyzvala[sg fem] i sama povest' [nom sg fem], opublikovannaja $v$ zurnale "Junost", $i$ tonkaja ëe interpretacija[nom sg fem] Ju. Ljubimovym $v$ Teatre na Taganke.

'In my memory still lives the profound emotion aroused both by the story itself, which had been published in the magazine Junost', and by its subtle interpretation by Yu. Lyubimov at the Taganka Theater.'

(c) $V$ ego slovax byla[sg fem] i gorec' [nom sg fem] $z a$ prošloe, $i$ gordost'[nom sg fem] $z a$ podvig $v$ Otecestuennoj vojne.

'In his words [there] was both grief over the past and pride over the heroic deed in the Patriotic War.'

(d) Poskol'ku pri perexodnyx glagolax so značeniem vozbuždenija, pereživanija, čuvstva $v$ ob"ekte-$v$ kačestve sub"ekta možet[sg] vystupat" $i$ oduševlënnyj[nom sg] i neoduševlënnyj predmet [nom sg], postol'ku pri vozvratnyx glagolax vnutrennego pere zivanija, sostojanija $v$ tvoritel'nom padeže sodejstvujuščego ob"ekta vozmožen [sg] $i$ oduševiënnyj [nom sg] $i$ neoduševiënnyj predmet [nom sg].

'Since with transitive verbs signifying the arousal of feeling [or] emotion in an object the subject can be an animate or inanimate entity, with reflexive verbs signifying internal experience [or] state the collaborative object in the

\footnotetext{
'respect' from the conjoined prepositional phrases. Deletions of the latter type, illustrated also in (51d), are discussed in Section 3 below.
} 
instrumental case may be either an animate or an inanimate entity.'

1.23 Subject phrases such as kak otec, tak $i$ syn 'father as well as son' are typical of "bookish" (knižnyj) style and do not normally occur in informal discourse. Perhaps this is why Rozental' asserts flatly that predicates associated with such subject phrases must be pluralized (1968, 271 and 1971a, 227). The examples he gives are reproduced under (52) ((a) from 1968, 271; (b) from 1971a, 227).

(52) (a) Kak srednjaja škola [nom sg], tak $i$ vuz [nom sg] stavjat[pl] svoej zadačej gotovit' molodëz' $k$ praktičeskomu trudu.

'The high school as well as the institution of higher education see as their goal the preparation of young people for practical work.'

(b) Kak nouka[nom sg], tak $i$ iskusstvo [nom sg] $v$ svoëm razvitii otražajut[p1] razvitie obščestva.

'Science as well as art reflect in their development the development of society.'

However, as indicated in Galkina-Fedoruk 1964, 466467 and confirmed by informants, subject phrases as in (52) in fact allow both pluralized and nonpluralized predicates. Subject phrases of this type are apparently generally analogous to phrases such as $i$ otec $i$ syn (possibly also in derivation), but because they are characteristic of formal discourse, verbal predicates associated with them, whether postpositive or prepositive, are usually pluralized, i.e., such subject phrases usually are a consequence of Regrouping rather than Identity Deletion.

It is perhaps worth noting in this connection that phrases such as kak otec, tak $i$ syn are also analogous to phrases such as $i$ otec $i$ syn in that in certain contexts they can only be translated into English as disjunctions. Cf. (51d) above and the sentences under (53) ((53b) is a statement by Karcevski cited in Mučnik 1971, 43). Sentence (54) is provided for contrast with (53a), for its superficial structure parallels that of (53a) but the relationship between the conjuncts is clearly not disjunctive. 
(53) (a) Sub"ekt ètix predloženij [s formoj 2-go lica edinstvennogo čisla] nastol'ko obobščënnyj, čto im možet byt' kak sam govorjašcij, tak $i$ sobesednik ili ljuboj drugoj čelovek.

'The subject of these sentences [with secondperson singular forms] is generalized to such a degree that it can be the speaker himself, the interlocutor, or any other person.'

(b) Net ni odnogo musskogo glagola, kak perexodnogo, tak $i$ neperexodnogo, kotoryj ne mog by byt' upotreblën $v$ bezličnom oborote.

'There is not [even] one Russian verb, whether transitive or intransitive, which could not be used in an impersonal phrase.'

(54) Glubokimi ëe simvolami javljajutsja kak Asuanskij gidrokompleks, tak i Xeluanskij metallurgičeskij kombinat.

'Its significant symbols are both the Aswan hydrocomplex and the Helwan metallurgic complex.'

Finally, note that subject phrases such as otec, kak $i$ syn 'father, like son' belong in a different category. Such phrases are not bookish, and they can apparently represent two different underlying relations. Kcxk $i$ may either indicate a relation of analogy, as in the sentences under (55), or, less typically, a regular conjunctive relationship, as in (56).

(55) (a) Gajda[nom sg], kak $i$ Xort [nom sg], budet [sg] komenščikom.

'Gayda, like Khort, will be a mason.'

(b) Eta povest'[nom sg fem], kak i vse moi knigi [nom $\mathrm{pl}$ ], napisana[sg fem] po zakazu sovetskogo izdatel'stva, i v pervuju očered' dlja sovetskogo čitatelja. (Anatoly Gladilin)

'This story, like all of my books, was written to fulfill an order from a Soviet publishing house and is for the Soviet reader in the first place.'

(c) Ǔ̌e čerez minutu ja[nom sg], kak i vse[nom p1], byz "pogZoščën"[sg masc] ego reč'ju.

'In a minute I, like everyone [else], was "absorbed" by his speech.' 
(56) Zurnalist Sergej Ivanovič [nom sg], kak i drugoj personaž[nom sg], artistka èstrady, ispolnitel'nica rasskazov sobstvennogo sočinenija, sami[pl] po sebe emu ne interesny[p1].

'The journalist Sergey Ivanovich, as well as the other character, the variety performer who reads stories that she herself composes, are in themselves not interesting for him.'

The derivation of sentences like (55), where kak $i$ indicates a relation of analogy, does not and cannot involve Regrouping. In sentences such as (56), on the other hand, $k a k i$ appears to be a variant of the paired connective kak .... tak $i$..., and the grammatical number of verbal predicates in such sentences follows the pattern exhibited in association with subject phrases such as kak otec, tak $i$ syn 'father as well as son.'

1.24 The logical relations within subject phrases such as ne tol'ko otec, no $i$ syn 'not only father but also son' seem quite similar to the relations within subject phrases such as kak otec, tak $i$ syn 'father as well as son,' yet in association with phrases of the former type, according to Rozental' 1971a, 227, verbal predicates usually manifest the number (and gender) of the nearest conjunct. In other words, while Regrouping is the preferred reduction method when subject phrases in conjoined sentences are prefaced by kak and tak $i$, it is generally avoided when the negative particle is present in association with one of the conjuncts. This may be due to analogy with sentences such as (57), where the negative particle completely blocks Regrouping.

$$
\begin{array}{lll}
\begin{array}{ll}
\text { Prił̌ll[sg masc] } \\
\text { *rišli[pl] }
\end{array} & \text { ne otec [nom sg masc], a syn[nom } \\
\text { came } & \text { not father }
\end{array}
$$

sg masc].

'The one who came was not the father but the son.'

It makes sense that pluralization, or Regrouping, is excluded in (57), because only one person came, after all. What is interesting about sentences like (57), where one of the coordinate subject phrases is negated, is that a prepositive verb can only manifest the features of the nearest subject phrase even though it may be the negated one and the verb may turn out to conflict with its 
asserted subject in number, gender, or person, as illustrated in the sentences under (58).27

(a) $\left\{\begin{array}{c}\text { Opasna }[\mathrm{sg}] \\ * \text { Opasny }[\mathrm{p} 1]\end{array}\right\}$ ne sama bolezn'[nom sg], a ëe dangerous not itself disease but its posĩedstvija[nom p1]. consequences

'What is dangerous is not the disease itself but its consequences.'

(b) Indusskie religioznye filosofy prošlogo veka utverždali, čto $\left\{\begin{array}{c}u \check{c} a t[\mathrm{pl}] \\ \text { učit }[\mathrm{sg}]\end{array}\right.$ \} ne knigi[nom p1] teach not books

učitelja i ne živoe ego slovo, a duxovnost' of teacher and not living his word but spiri[nom sg]. tuality

' Indian religious philosophers in the last century asserted that not the teacher's books or his living word taught, but [his] spirituality.'

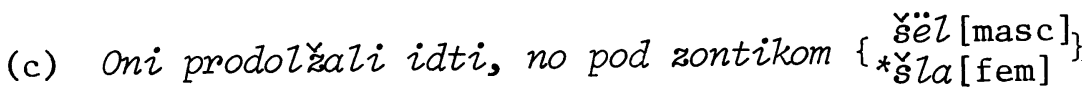
under umbrella walked ne molodoj čelovek[nom masc], a sobaka[nom fem]. not young man but dog

'They continued to walk, but the one who walked under the umbrella was not the young man but the dog.'

(d) Geroja[acc] $\left\{\begin{array}{c}n a \breve{s} \ddot{z}[\text { masc] } \\ \text { našla }_{\text {na }}[\mathrm{fem}]\end{array}\right\}$ ne avtor[nom masc], hero found not author

a sama žizn'[nom fem]. but itself life

'The hero was found not by the author but by life itself.'

${ }^{27}$ Russian appears to differ in this respect from French, where the verb must manifest the features of its asserted subject, according to Blinkenberg 1950, 101. English seems closer to Russian than to French, even in "pseudo-cleft" sentences, as in, e.g., What Nixon would have to sacrifice are [p1!] not lofty principles but hard cash (The New York Review of Books, 1973). 
(e) Ėto $\left\{\begin{array}{c}b y Z a[\mathrm{fem}] \\ * b y Z o[\text { neut }]\end{array}\right\}$ ne kZǐcka[nom fem], a prosto normal'noe $\ddot{e}$ imja[nom neut]. 28

'This was not a nickname but simply her regular name.'

(f) Zamuž $\left\{\begin{array}{c}\text { vyxo zu[1st pers] } \\ * \text { vyxodit[3rd pers] }\end{array}\right\}$ ne ja[nom 1st pers], getting married not $I$ a moja podruga [nom (3rd pers)]. but my friend

'The one who is getting married is not I but my friend.'

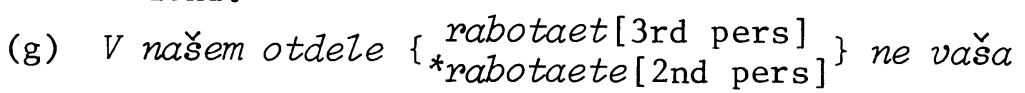
in our department works not your tëtka[nom (3rd pers)], a vy[nom 2nd pers]. 29 aunt but you

'The one who is working in our department is not your aunt but you.'

If the sentences under (58) are viewed as reductions of coordinate sentences, then the fact that the predicates can only manifest the features of the nearest subjects becomes self-evident. The underlying structure of (58a), for example, could also be realized as (59).

(59) Opasna[sg] ne sama bolezn'[nom sg], a ë̈ posledstvija dangerous not itself disease but its conse[nom p1] opasny [p1]. quences dangerous

'Not the disease itself is dangerous but its consequences are dangerous.'

The only difference between (58a) and (59) is that the righthand verb has been deleted in the derivation of (58a). The lefthand verb is only associated with the negated subject in the underlying structure and hence could not possibly manifest the number of the subject in the righthand coordinate sentence--neither in (59) nor in (58a).

${ }^{28} \mathrm{On}$ the number and gender of copulative verbs in sentences introduced by eto see Section 44 in Chapter Five. ${ }^{29}$ On grammatical person see section 5 below. 
There is, however, one problem with this account, which can be illustrated by considering possible alternative reductions of the Russian version of the French proverb Ne gody[nom pl] starjat[p1], a gore [nom sg] 'not years age, but grief.'

If the verb follows the subject in the initial coordinate sentence in the underlying structure, then there are two possible reductions, as shown in (60). If the verb in the initial coordinate underlying sentence is preposed, then the reductions in (61) can be generated (the postposition of the verb in the righthand sentences in (61) is tentative and only represents a working hypothesis; it is not crucial in any case).

(60) (a) Ne gody[nom p1] starjat[p1], a gore [nom sg] not years age but grief stdxpitt [sg]. ages

(b) Ne gody [nom p1] stdx bat [p1], a gore [nom sg] starit [sg].

(61) (a) Starjat[p1] ne gody [nom p1], a gore [nom sg] age not years but grief $\not \operatorname{stdx}\{t t[\mathrm{sg}]$. ages

(b) Stdxpdttp1] ne gody[nom p1], a gore [nom sg] starit $[\mathrm{sg}]$.

In each of the reductions in (60)-(61), the remaining verb manifests the number of the subject within its underlying sentence. The reduction in (61a) is the one illustrated by the sentences under (58).

Now if the underlying coordinate sentences are permuted, not all of the reductions illustrated in (60)-(61) are possible, as shown in (62)-(63).

(62) (a) Gore [nom sg] starit [sg], a he gody [nom p1] grief ages and not years stckrs $d \not t[\mathrm{p} 1]$.

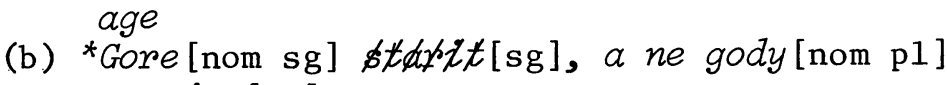
stcrjat $[\mathrm{p} 1]$.

(63) (a) Starit [sg] gore [nom sg], a he gody[nom p1] ages grief and not years stdxbstat $[\mathrm{p} 1]$. age 
(b) * Stdxhtt [sg] gore [nom sg], a ne gody [nom pl] ages grief and not years starjat $[\mathrm{p} 1]$.

age

In general, anaphoric deletion, which is the phenomenon illustrated in (60)-(63), works forward, i.e., when there are identical elements in adjacent constructions, the deleted (or pronominalized) elements are the righthand ones in terms of linear order. Lefthand elements can only be deleted (or pronominalized) under certain conditions. The restriction illustrated by the (b) sentences in (62)(63) is therefore not irregular in any way and can be accounted for by the presence of the negative particle in the righthand sentence. The problem mentioned above is how to account for the derivation of a sentence such as (64), which is a grammatical, normative sentence (cf., e.g., Galkina-Fedoruk 1964, 467 and Rozental' 1971a, 227).

\section{(64) Gore[nom sg], a ne gody[nom p1] starit[sg]. grief and not years \\ ages}

The underlying structure of (64) must be identical to that of the reductions illustrated in (62), and since the verb in (64) manifests the number of the subject of the lefthand sentence, it appears that (64) can be accounted for as a transform of (62a), as a stylistic variant of (62a): after the righthand'verb, or rather verb phrase is deleted, the negated subject phrase of the righthand sentence is transposed into the lefthand sentence to follow the subject phrase as a parenthetic element.

This transposition can apparently only take place in a configuration such as the one represented by (62a), where the lefthand subject phrase is not negated and the righthand one is. A configuration such as the one represented by (60a), for example, could not undergo this transformation to yield *Ne gody[nom p1], a gore[nom sg] starjat[p1] 'not years, but grief age,' nor could any other coordinate configuration in which no negation is involved (or some other special element; see p. 277). The transformation which yields sentences such as (64) is therefore rather special, and indeed informants consider sentences such as (64) awkward. Russian grammarians, however, do not distinguish such sentences from sentences representing deletion with no subsequent transposition. The following are some examples of sentences like (64) 
given by Russian grammarians ((65a) from Šaxmatov 1925, 163; (65b) from Galkina-Fedoruk 1964, 467; (65c) from Senkevič 1964, 9; and (65d) from Rozental' 1971a, 227).

(65) (a) Mat'[nom fem], ne otec[nom masc] posovetovala [fem] mne postupit' $v$ gimnaziju.

'Mother, not father, advised me to enroll in the gymnasium.'

(b) $S y n[$ nom masc], a ne doč'[nom fem] provožal[masc] roditezej.

'The son, not the daughter, accompanied the parents.'

(c) Očerk[nom masc], a ne stat'ja[nom fem] napisan [masc] Smimovym.

'The essay, not the article, was written by Smirnov.'

(d) Roman[nom masc], a ne povest' [nom fem] budet opublikovan [masc] $v$ žurnale.

'A novel, not a novelette, will be published in the journal.'

To return now to sentences with subject phrases such as ne tol'ko otec, no $i$ syn 'not only father but also son,' they do not seem to undergo Regrouping whether their predicates are preposed or postposed, and this fact seems to be due more to the presence of the negative particle than to the nature of the logical relations within such sentences. Regrouping is not excluded, however. The sentence under (66), for example (from a newspaper report), shows evidence of Regrouping.

(66) Zdes' vidny[p1] ne tol'ko rost[nom sg] promyšlennogo potenciala OAR, no $i$ glubokie social'nye processy [nom p1], proisxodjaščie $v$ ¿izni egipetskogo obščestva.

'Here one can see not only the growth of the industrial potential of the UAR but also the profound social processes which are taking place in the life of Egyptian society.'

The verb in (66), however, could also have a singular ending, i.e., it could manifest just the number of the nearest subject noun, for Regrouping is never obligatory when the linking device is ne tol'ko ... no $i$... 'not only ... but also ... .' Some typical examples from 
miscellaneous texts are given under (67) ((d) is from Śvedova 1970, 640; (e) is from Rozental' 1968, 271).

(67) (a) K koncu maja 1831 goda by la gotova[sg fem] ne tol'ko pervaja knizka[nom sg fem] povestej, no $i$ čast'[nom sg fem] vtoroj.

'Toward the end of May, 1831, not only the first book of stories was ready but also part of the second.'

(b) Mimo vnimanija mistera Aksel'banka prošza[sg fem] ne tol'ko naša sovetskaja dejstvitel'nost [nom sg fem], no $i$ te položitel'nye izmenenija [nom pl], kotorye sejčas proisxodjat $v$ soznanii śirokix krugov amerikanskogo naroda.

'Mister Axelbank has been oblivious not only to our Soviet reality but also to the positive changes which are now taking place in the attitude of significant segments of the American people.'

(c) Neobxodima[sg fem] ne tol'ko opredelënnaja posledovatel'nost'[nom sg fem] v vybore sredstv, no $i$ izvestnaja opravdannost' [nom sg fem] konkretnogo vybora.

'Not only a certain consistency is necessary in the choice of means but also some justification for the actual choice.'

(d) Ne tol'ko roditeli[nom pl], no i škola[nom sg] otvečaet[sg] za vospitanie detej.

'Not only the parents but also the school is responsible for the upbringing of children.'

(e) Ne tol'ko soderžanie[nom sg neut] mukopisi, no $i$ sama forma[nom sg fem] podači materiala trebovala[sg fem] special'nogo razgovora.

'Not only the content of the manuscript but also the very form of presentation of the material required special discussion.'

The sentences under (68) illustrate singular predicates in association with other subject phrases introduced by the negative particle ((b) and (c) are from Švedova 1970, 640 [cf. also 554]; (d) is cited from Lev Tolstoy in Galkina-Fedoruk 1964, 467).

(68) (a) K ètomu comerikancev priučila[sg fem] ne stol'ko nabožnost'[nom sg fem], skol'ko kommercija[nom sg fem]. 
'The Americans have been led to this practice [Christmas gift buying] not so much by piety as by the business world.'

(b) Vinovat[sg] ne stol'ko ty[nom sg], skol'ko ja [nom sg].

'The one who is guilty is not so much you but myself.'

(c) Ne otec [nom sg] tak mat'[nom sg] pomožet[sg]. 'If not father, then mother will help.'

(d) Na bol'šej časti ix lic vyražalas'[sg fem] esli ne bojazn'[nom sg fem], to bespokojstvo[nom sg neut].

'On most faces one could see if not fear, then worry.'

Thus in sentences in which coordinate subject phrases contain the negative particle, the subject phrases are rarely truly coordinated, i.e., they are rarely constituents of a single noun phrase in the underlying structure (through Regrouping). Their superficial coordination is due to Identity Deletion, and verbal predicates associated with them normally manifest the features of the nearest noun phrase, which is their only subject in the underlying structure.

2. Postpositive Verbal Predicates Associated with Nouns Linked by $i$ or Asyndetically

2.0 In general, postpositive verbal predicates associated with conjoined subjects must be pluralized. In a sentence such as (69), for example, a singular verb would be out of the question.

(69) Petja[nom sg] $i$ Vanja[nom sg] $\left\{\begin{array}{c}\operatorname{pog} i b l i[\mathrm{pl}] \\ \operatorname{pog} i b[\mathrm{sg}]\end{array}\right\}$ na vojne.

'Petya and Vanya perished in the war.'

This also applies to copulative verbs in sentences with nominal predicates, as in (70) and (71) (compare (71) with (24a) above, where the predicate is preposed and the verb need not be pluralized). 
(70) Petja[nom sg] $i$ Vanja[nom sg] $\left\{\begin{array}{c}b y z i[\mathrm{p} 1] \\ * b y Z[\mathrm{sg}]\end{array}\right\}$ soldatami. 'Petya and Vanya $\left\{\underset{\text { *was }_{\text {was }}}{\text { were }}\right.$ soldiers.'

\section{byzi[p1] \\ (71) Kuxnja[nom sg fem] $i$ obed[nom sg masc] $\left\{{ }^{*} b y z[s g\right.$ masc] $\}$ ë̈ glavnoj zabotoj[instr]. *byZa[sg fem] \\ 'The kitchen and dinner were her main concern.'}

Since pluralization is obligatory in such cases, the subjects must be constituents of a single, [+Plural] noun phrase--either because they represent primary conjunction (cf. the configuration in (41) above), or, if they derive from underlying conjoined sentences, because Regrouping is mandatory when identical verbs or verb phrases in conjoined sentences are postposed.

There do occur, however, sentences with conjoined or coordinate subjects which have singular postpositive predicates. Some sentences within this category have already been discussed in Sections 1.22-1.24 above, where it was pointed out that certain coordinate connectives allow Identity Deletion in underlying coordinate sentences where Regrouping would be obligatory otherwise and the subject phrases linked by such connectives are thus only superficially coordinated. The remainder of the present section is devoted to analyses of other categories of sentences with singular postpositive verbal predicates.

2.1 The first category is illustrated by the sentences under (72), which have already been cited in Chapter Three above under (18).

(72) (a) Takaja semantičeskaja svjazannost' [nom sg] $i$ $v$ zaimoobuslovlennost' [nom sg] $i$ delaet [sg] vozmožnym slijanie ètix dvux rlenov predlozenija $v$ odin komponent.

'Such semantic connection and interdependence make possible the merging of these two sentence constituents into a single component.'

(b) Osnounaja[nom sg fem] cennost'[nom sg fem] $i$ značenie[nom sg neut] recenzimemoj knigi zaključaetsja[sg] ne tol'ko $v$ glubokom $i$ samostojatel'nom videnii mira. 
'The basic value and significance of the book under review lie not only in the profound and original view of the world.'

(c) Naše vospitanie[nom sg neut] i obrazovanie [nom sg neut] dolzno[sg neut] byt' postroeno[sg neut] tak, čtoby ne voznikali tam, gde ne nado, èti ustojcivye svjazi.

'Our upbringing and education must be set up so that these fixed relations would not form at the wrong places.'

(d) E'to novaja arxitektura [nom sg] i planirovka [nom sg] drüno idët[sg] v složivšujusja vekami samuju central'nuju čast' goroda.

'It is the new architecture and planning which are coming in full swing to the very center of the city, formed in the course of centuries.'

As suggested in Chapter Three, the subject nouns in these sentences overlap semantically and apparently derive as single, composite nouns which represent single entities and are grammatically singular (cf. pp. 178-179). Postpositive verbal predicates associated with such composite nouns therefore receive a [-P1ural] specification and the gender of the lefthand component noun, since the gender of composites is the gender of their lefthand component (cf., e.g., the attributive in (72b)). If, however, the predicate's manifestation of the assigned gender conflicts with the gender of the noun nearest the predicate in linear order, then the predicate must be pluralized (this restriction, noted in Skoblikova 1961b, 164, also applies to postpositive attributives; cf. pp. 206-207 above).

In the sentences under (72), the conjoined nouns are of the same gender except in (72b), where the verb does not manifest gender and therefore need not be pluralized. If this sentence were in the past tense, however, the verb would have had to be pluralized, because otherwise it would have had to manifest the feminine gender of the lefthand noun, cennost' 'value,' that is, its form would have been zaključalas', and it would have conflicted with the neuter gender of the righthand noun, znacenie 'significance.' To take another example, the verb in the sentence under (73) could not possibly have a singular ending, even though the subject nouns overlap semantically and seem to represent a composite, because the verb would have had to have a feminine ending and would have 
conflicted with the neuter gender of the righthand subject noun.

(73) Krome ètix ponjatnyx zabot, prežnjaja[nom sg fem] nejasnaja[nom sg fem] trevoga[nom sg fem] $i$ volnenie [nom sg neut], budto pered kakim-to èkamenom $i l i$ pryzkom s vysoty $v$ vodu, kogda éto-to $v$ živote nojušce zamiraet,--ne ostavljali[p1] ego. 'Besides these understandable worries, the former vague agitation and excitement, as in anticipation of some examination or a high dive into water, when something in the stomach painfully freezes,--did not leave him.'

What process can be postulated to account for this phenomenon? It is clearly a phenomenon which represents a "surface" constraint, for pluralization is only mandatory when the verbal predicate actually manifests gender, not when the components of a composite noun do not coincide in gender. Hence Verb Agreement must apparently operate in any case, and pluralization then takes place as a very late adjustment.

In sentences with singular verbal predicates and subjects which can be viewed as constituting composites, these composites commonly denote abstract entities, but composites denoting concrete entities are not excluded, as demonstrated by (74) (cited in Šmelev 1962 from Gorky's Detstuo and approved by informants as fully representative of current usage).

(74) $C_{a j}[$ nom sg masc] $i$ saxar [nom sg masc] xranilsja[sg masc] u každogo otdel'no, no zavarivali čaj $v$ odnom cajnike.

'Tea and sugar were kept by each separately, but [we/they] brewed tea in the same pot.'

If $\nearrow_{a j} i$ saxar 'tea and sugar' did not constitute a composite in the underlying structure, then the verb would have had to be pluralized.

Some further illustrations from miscellaneous texts of sentences with composite subjects denoting abstract entities are given under (75) ( (d-e) cited in Skoblikova 1961b; (f-g) cited in Rozental' 1971a, 227; (g) also cited in Vinogradov and Istrina 1960, 496 [ascribed to Dobrolyubov]). 
(75) (a) Dolgota[nom sg] i kratkost' [nom sg] sogZasnyx sluzit [sg] dlja različenija značenija slov $i$ ix form.

'The length and brevity of consonants serves to distinguish the meaning of words and their forms.'

(b) "Pravil'nost'"[nom sg] i "nepravil'nost'"[nom sg] $v$ vybore variantnyx sredstv opredeljaetsja [sg] tol'ko bol'šej ili men'šej upotrebitel'nost'ju.

"Right" and "wrong" in the choice of a variant in language are determined only by higher or lower frequency of use.'

(c) V naše vremja regulirovanie [nom sg neut] $i$ uporjadočenie[nom sg neut] terminotvorčestva vyzvano[sg neut] terminologičeskim varyvom, nastupivšim $v$ rezul'tate sovremennoj texničeskoj revoljucii.

'The control and regulation of the creation of new terms in our time have been prompted by the terminological boom triggered by the contemporary technological revolution.'

(d) Strax[nom sg masc] i užas[nom sg masc] upaZ[sg masc] na gorod.

'Fear and terror fell on the city.'

(e) Tresk[nom sg masc] i groxot [nom sg masc] metalla razdalsja[sg masc] nad polem.

'The crash and din of metal resounded over the field.'

(f) Avtoritet[nom sg] i prestižr[nom sg] ǔ̈enogo nepreryuno rastët [sg].

'The authority and prestige of the scholar are continuously growing.'

(g) Eta prostota[nom sg] i jasnost'[nom sg] myšrtenija zaključaet [sg] $v$ sebe zadatki novoj žizni.

'This simplicity and lucidity in thinking contains the seeds of a new life.'

The following sentence illustrates singular predicate adjectives in association with conjoined nouns representing an abstract composite.

(76) [Vse suščestuujuščie $v$ nastojašcee vremja tipy složnosokraščënnyx slov složilis' ... v 20-e gody $X X$ v.,] kogda sozdanie [nom sg neut] $i$ vozniknovenie 
[nom sg neut] abbreviatur bylo[sg neut] osobenno intensivnym [sg] i svobodnym [sg].

'[All of the types of word-group abbreviations which exist at present came into being ... in the twenties of the twentieth century,] when the creation and development of abbreviations was especially intensive and unrestrained.'

It should be emphasized that the phenomenon illustrated in (76) is fundamentally different from the phenomenon illustrated in (77) (from (25) in Chapter Three).

...v tot istoričeskij moment, kogda vpervye stalo [sg neut] vozmožnym[sg] ix osvoboždenie[nom sg neut] $i$ sozdanie [nom sg neut] izobilija.

'... at the very historical moment when their liberation and the creation of affluence have for the first time become possible.'

In (77), the predicate constituents manifest the features of the lefthand conjunct; the predicate constituents associated with the righthand conjunct have been deleted. The conjuncts are so dissimilar they could not possibly constitute a composite. In (76), on the other hand, the predicate constituents manifest the features of a union of both conjuncts and no deletion could be postulated, despite the superficial similarity to (77).30 This is also the fundamental difference between the sentences with singular postpositive predicates cited in (72) $-(75)$ and the sentences with singular postpositive predicates cited in Sections 1.22-1.24 above, where the connectives allow deletion of postpositive identical predicates from lefthand coordinate sentences. In the derivation of the sentences under (72)-(75), deletion cannot apply and the singular predicates in these sentences must be accounted for by postulating grammatically singular composites.

2.2 A somewhat different category of sentences with singular postpositive predicates is illustrated in (78).

${ }^{30}$ That is to say, no deletion other than the deletion of sozdanie $i$ vozniknovenie 'creation and development' from the predicate phrase (see Section 10.33 in Chapter One). 
(78) (a) Differenciacija[nom sg] raznyx javlenij $i$ poznonie[nom sg] ix ob"ektivnoj prirody dast [sg] osnovu dlja celesoobraznogo kontrolja mexaniěnosti $i$ štampovannosti gazetnogo jazyka. 'Distinguishing between different phenomena and recognizing their objective nature will provide a basis for expedient control of the mechanical and hackneyed features of newspaper language.'

(b) Otsutstvie [nom sg] ustojěivyx morfologičeskix i sintaksičeskix priznakov u utočnenij $i$ ustojčivaja grammatičeskaja struktura [nom sg] rassmatrivaemyx konstrukcij delaet [sg] odnorodnost' utočnenij i dannyx konstrukcij ves'ma problematičnoj.

'The absence of regular morphological and syntactic features from constructions of specification and the regular grammatical structure of the constructions under consideration render the identification of constructions of specification with constructions of this type quite problematic.'

(c) Mö̈ spokojstvie[nom sg neut] i pokrovitel'stvennoe otnošenie [nom sg neut], mođet byt', bol'še vsego i nravilos'[sg neut] ej vo mne.

'My calmness and [my] protective attitude were perhaps what she liked about me most of all.'

The connective $i$ does not allow deletion of postpositive identical predicates from lefthand sentences in underlying conjunctions, and the conjoined subject phrases in (78) must therefore be viewed as constituents of single noun phrases. Since Regrouping presumably always results in the assignment of a [+Plural] specification to the superordinate NP node, there seems to be only one possible account left for the singular number of the subject phrases in (78), i.e., that they represent grammatically singular primary conjunctions. Such conjunctions are evidently not anomalous only if țhe conjoined phrases refer to abstract entities. 31

${ }^{31}$ The conjunctions accounted for above as representing underlying composites could in some cases be accounted for by postulating primary conjunction, but not in all cases; not in sentences such as (76), for example, and not in (74). In (78), on the other hand, the conjunctions could not possibly represent composites, so that (cont.) 
2.3 In another, third category of sentences with postpositive singular verbal predicates, the subjects are not linked by $i$, only by an intonational signal (the link is asyndetic). Before considering the question of singular predicates in association with such subjects, however, observe that predicates associated with them are in general pluralized, i.e., the derivation of asyndetic subjects is analogous to that of coordinate subjects linked by $i$. They undergo Regrouping and the absence of a lexical link makes no difference. The sentences under (79), drawn from miscellaneous texts, exemplify this fact.

(79) (a) Naša partija[nom sg], Sovetskoe pravitel'stvo [nom sg] budut [p1] emy tvërdo sledovat'. 'Our party, the Soviet government, will follow him steadfastly.'

(b) Svetlye doma[nom p1], zelen'[nom sg] delajut [p1] ulicy narjadnymi i prostomymi.

'The bright houses, the greenery, render the streets elegant and spacious.'

(c) Sem'ja [nom sg], dom[nom sg] zanimajut[p1] ogromnoe mesto $v$ ¿izni každoj ženšciny.

'The family, the home, occupy a very large place in the life of every woman.'

(d) Ličnost'[nom sg], vnutrennij mir [nom sg] čeloveka formimujutsja[p1] pre丸de vsego v gody detstva $i$ junosti.

'The personality, the internal world of a person, are formed primarily in the years of childhood and youth.'

(e) Vremja[nom sg] rosta, sama ego zdorovaja sut' [nom sg] neizbe zno ègoistièny [p1].

'The time of growth, its natural essence, are inevitably self-centered.'

(f) Včera sovetskij narod [nom sg], vsë progressivnoe čelovečestvo [nom sg] toržestuenno otmetili[p1] 105-ju godovšcinu so dnja roždenija Vladimira Il'iěa Lenina--velikogo osnovatelja

Kommunističeskoj partii i sovetskogo gosudarstva, učitelja i druga trudjaščixsja vsego mira.

it is necessary to posit both [-Plural] composites and [-Plural] primary conjunctions to account for postpositive singular predicates. 
'Yesterday the Soviet people [and] all progressive mankind solemnly observed the 105th birthday of Vladimir Ilyich Lenin--the great founder of the Communist Party and the Soviet State, teacher and friend to workers throughout the world.'

(g) Partija zabotitsja o tom, ctoby kazdyj junoša [nom sg], každaja devuška [nom sg] našej strany ime li[p1] zakončennoe srednee obrazovanie.

'The Party sees to it that each youth, each girl in our country have full secondary education.'

(h) Kazdaja professija [nom sg], każdaja naǔnaja disciplina[nom sg] imejut[p1] svoi osobye terminologičeskie sistemy $i$ podsistemy.

'Each profession, each scientific discipline have their own special terminological systems and subsystems.'

(i) Každyj razgovor [nom sg], každaja beseda[nom sg] sil'no trevožili[p1] ego.

'Every conversation, every discussion made him very anxious.'

The last three sentences are especially significant, because each of their coordinate subjects includes the distributive quantifier každyj 'each, every,' which is also characteristic of coordinate asyndetic subject phrases in sentences with singular postpositive verbal predicates, except that the nature of the relationship between the subject phrases is then different. In sentences with singular postpositive verbal predicates, the coordinate subject phrases have closely related, overlapping denotata, and the relationship between the coordinate phrases is such that the phrase closest to the predicate functions as substitute for the preceding phrase or phrases, as a more precise, more adequate definition for the referent intended by the speaker. ${ }^{32}$ Sentences with subject phrases of this type are illustrated under

${ }^{32}$ The internal relationship between the denotata of such phrases is what distinguishes them from appositive constructions (cf. Section 3.4 in Chapter One). Note also that in sentences with coordinate asyndetic subject phrases which have overlapping denotata the predicates are not necessarily associated with just the nearest subject phrase, as demonstrated by a number of sentences under (79). 
(80) ((a) is cited in Rozental' 1968, 272; (b) is cited in Rozental' 1971a, 228; and (c), from a work by Sholokhov, is cited both in Rozental', ibid., and in Galkina-Fedoruk 1964, 466).

(80) (a) Kazdyj novyj šag [nom sg masc], každoe novoe usilie[nom sg neut] približalo[sg neut] nas $k$ zavetnoj celi.

'Every new step, every new effort brought us closer to [our] cherished goal.'

(b) Mne nado, čtoby každoe slovo [nom sg neut], kazdaja fraza [nom sg fem] popadala[sg fem] by $v$ ton, $k$ mestu.

'What I want is that each word, each phrase hit the right tone, the right point.'

(c) ... otobrat' naibolee značitel'noe i političeski dejstvennoe, čtoby každyj èpizod[nom sg masc], kazdaja detal'[nom sg fem] nesla[sg fem] svoju nagruzku.

'... to select what is most significant and politically effective, so that each episode, each detail would carry its own weight.

The verbs in the sentences under (80) manifest the gender of the righthand subject phrases. The lefthand, initial nominative phrases do not control the verbs and are apparently not directly associated with them in the underlying structures. The sentences under (80) must therefore derive from structures like the one shown under (28) in Chapter One, reproduced below as (81).

$(81)$

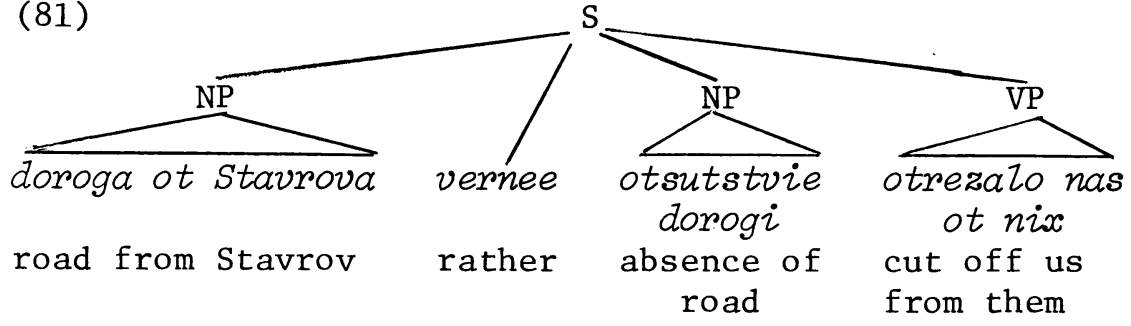

The structure in (81) is apparently basic rather than a consequence of transformations, and the position of the lefthand noun phrase, rejected in favor of a more appropriate phrase, can be referred to as that of a dislocated subject. In (81), this relationship between the two noun phrases is signified lexically by vernee '[or] rather.' 
In (80) there is no lexical marker, but the underlying structure seems to be identical to (81). The sentences under (82) also seem to manifest the same structure ((a) from Krylov's famous "Strekoza i muravej" [The Dragonfly and the Ant]).

(82) (a) Vs̈̈ prošlo: s zimoj xolodno, / Nǔ̃da[nom sg],. golod[nom sg] nastäet [sg]; / Strekoza ǔ ne pö̈t. 'All is over: with the cold winter / Need, hunger comes; / The dragonfly no longer sings.'

(b) Ocenka[nom sg] javlenij v nerazryvnoj svjazis razvitiem obšcestvennogo soznanija, istoričeskij podxod[nom sg] $k$ xarakteristike značenija sintaksiéeskix konstrukcij otkryvaet [sg] vozmožnosti $i x$ vsestoronnego istolkovanija.

'The evaluation of phenomena in close relation to the development of social consciousness, the historical approach to the characterization of the meaning of syntactic constructions, opens up the possibility of an overall interpretation.'

(c) Rasširenie[nom sg neut] sostava nositelej musskogo literaturnogo jazyka, vadimodejstvie [nom sg neut] ix razliěnyx rečevyx navykov podgotovilo[sg neut] počvu dlja novoobrazovanij. 'The wider range of speakers of Russian, the interaction among their different speech habits, prepared the ground for innovations.'

One could suggest that the singular number of the verbs in (82) matches the singular number of NP nodes dominating primary coordinations of phrases referring to abstract entities, as in (78) above, for there is no morphological evidence in these sentences that the features manifested by the verbs are those of the subject phrases nearest to them. ${ }^{3}$ What supports the analysis of these sentences as nevertheless analogous to (80) is, first, the absence of an overt lexical connective, and, secondly, the semantic relationship between the coordinate

${ }^{33}$ Unfortunately, I cannot supply sentences of this type with a predicate manifesting the features of the nearest subject unambiguously, I have not encountered such sentences in texts, and interrogation of informants with regard to such questions is not productive, for these questions involve the perception of logical relations between coordinate subjects and informant responses vary. 
subject phrases (and note also that the semantic relationship is such that it excludes the interpretation of the coordinate phrases as being in apposition). 34

2.4 Finally, as a postscript to the discussion above, consider the following sentences ( $(c-d)$ cited in Rozental' 1971a, 219; (f) cited in Skoblikova 1959b).

(83) (a) Celyj otrjad[nom sg masc] fauny ( $i$ osobenno ta dič'[nom sg fem], za kotoroj oxotilis' orly) pogloščl [sg masc] nenormal'no vysokoe količestvo rtuti.

'A whole array of animals (and especially the birds hunted by eagles) have ingested an inordinate amount of mercury.'

(b) Mysl'[nom sg fem] o nezavisimosti formy ot substancii $i$ osobenno vytekajušcee iz nëe položenie [nom sg neut] o tom, čto čelovečeskij jazyk moðet byt' ne zvukovym, kazalas'[sg fem] fantastičeskoj[sg fem].

'The notion of the independence of form from substance and especially the proposition it entails to the effect that human language does not necessarily have to be vocal seemed fantastic.'

(c) Koe-kto [nom] na Zapade, i $v$ osobennosti nekotorye amerikanskie generaly [nom $\mathrm{pl}]$, rassmatrival[sg] Berlin kak ostrië dlja napadenija na Sovetskij Sojuz.

'Some people in the West, and especially certain American generals, considered Berlin a spearhead for an attack on the Soviet Union.'

${ }^{34}$ Another type of sentences which may belong in this category is illustrated by the following: Nikto[nom] $i$ ničto [nom] ne narušal.o[sg neut]/*narušali[p1] tišiny 'no one and nothing disturbed the silence.' Although the subjects are linked by $i$, the verb in this sentence cannot be pluralized. The fact that it must have a neuter ending seems to indicate that it is only associated with ničto 'nothing,' for if it were associated with nikto 'no one,' the [tanimate] feature of nikto would be manifested through a masculine ending. Perhaps, then, nikto represents a displaced subject when conjoined with another pronoun. (This also applies to kto 'who' in the conjunction kto $i$ éto 'who and what.') 
(d) Amerikanskaja tvorčeskaja intelzigencija[nom sg], $v$ častnosti amerikanskie kinorabotniki [nom p1], pereživaet [sg] sejěas èpoxu povyšennogo interesa $k$ sovetskomu kinoiskusstvu.

'The American creative artistic elite, in particular that part of it which is associated with movie-making, is now going through a period of intensified interest in Soviet movie-making.'

(e) Antivoennaja koalicija[nom sg], i $v$ tom čisie "Nacional'noe sobranie[nom sg] juristov za prekraščenie vojny", vidit [sg] svoju pervejšuju zadaču $v$ tom, čtoby ubedit' kak mozno bol'še senatorov podderzat' ètu popravku.

'The anti-war coalition, including the "National Conference of Lawyers to End the War," views as its primary task the persuasion of as many senators as possible to support this amendment.'

(f) Počemu iskusstvo[nom sg neut], naprimer, muzyka [nom sg fem], tak živuče[sg neut], tak populjarno [sg neut] i tak sil'no[sg neut]?

'Why is art--for example, music--so vital, so popular, and so potent?'

In distinction from the singular predicates in the sentences discussed in 2.1-2.3, the singular predicates in the sentences under (83) do not call for a special account, for the righthand nominative noun phrases are lexically marked as parenthetic--by osobenno 'especially' in (a) and (b), $v$ osobennosti 'especially' in (c), $v$ častnosti 'in particular' in (d), $v$ tom čisle 'including' in (e), and naprimer 'for example' in (f) (in (a) there are also parentheses to mark the parenthetic status of the righthand noun phrase). The predicates in these sentences are therefore only associated with the initial nominative noun phrases as subjects (note also that the predicate adjective in (b) manifests the features of the head noun in the lefthand phrase, presumably through its association with a deleted predicate noun identical to the head subject noun).

The derivation of the sentences under (83) seems to resemble the derivation suggested above for (65) (p. 262), for these sentences appear to derive from coordinate sentences identical in all but their subject phrases. For example, (83a) would derive, accordingly, from Celyj otrjad fauny poglošcal nenormal'no vysokoe količestvo rtuti; (i) osobenno ta dič', za kotoroj oxotilis' orly, poglošcala nenormal'no vysokoe količestvo rtuti 'a whole 
array of animals have ingested an inordinate amount of mercury; (and) especially the birds hunted by eagles have ingested an inordinate amount of mercury.' The righthand sentence would be reduced by Identity Deletion--to yield Celyj otrjad fauny pogloščal nenormal'no vysokoe količestvo rtuti; (i) osobenno ta dič', za kotoroj oxotilis' orly 'a whole array of animals have ingested an inordinate amount of mercury; (and) especially the birds hunted by eagles'-and the subject phrase in the righthand sentence would then be transposed into the lefthand sentence.

This transposition is conditioned by the presence of either a negative particle or an element such as osobenno 'especially,' for otherwise the transposed phrase would not be set off as parenthetic within the lefthand sentence and the sentence would be ungrammatical (cf., e.g., *Celyj otrjad [nom sg] fauny $i$ diě' [nom sg] pogZołral [sg] nenormal'no vysokoe količestvo rtuti 'a whole array of animals and birds has ingested an inordinate amount of mercury').

The source of elements such as osobenno 'especially' is problematic, and especially problematic is the source of $v$ tom éisle 'including' in sentences such as (83e), for example, for this element defines a relation of inclusion which only holds between noun phrases, not between sentences. If indeed sentences such as (83e) are accounted for as reductions of coordinate sentences, then either an element signifying a relation of inclusion must be attached to the righthand subject in the ultimate underlying structure and reduction of the righthand underlying sentence and transposition of its subject are then obligatory, or, alternatively, such an element can be optionally attached to the righthand subject phrase at a shallow level in the derivation, and only then do reduction and transposition become obligatory.

Whatever derivation is postulated to account for the sentences under (83), their structure is clearly conditioned by definitions of logical relations (whether real or imagined), which is perhaps one reason for the fact that such sentences do not normally occur in casual discourse. They are thus analogous in this respect too to sentences of the type illustrated by (64), where a negated subject occurs in parenthetic position. 35

${ }^{35}$ According to Rozental' 1971a, 219-220, sentences which resemble the sentences under (83) may also occur with a verbal predicate which manifests the features of the righthand nominative noun phrase. The examples (cont.) 
3. Verbal Predicates Associated with Reductions of Conjoined Noun Phrases with Identical Nouns

\subsection{Postpositive Verbal Predicates}

Sentence (84a) below illustrates conjoined noun phrases with an identical noun, kotèl 'boiler.' Sentences (84b) and (84c) illustrate two possible reductions through Identity Deletion. In (b), the righthand occurrence of the noun is deleted, and in (c)--its lefthand occurrence. ${ }^{36}$

he gives, however, seem to indicate a different underlying source. The connectives in his examples are vernee '[or] rather,' imenno 'that is,' and to est' 'that is,' and his sentences apparently do not represent two underlying sentences but rather one, with the lefthand phrase representing either a basic dislocated phrase, as in (81), or an appositive phrase dislocated at a later stage in the derivation (see Section 3.4 in Chapter One).

Another point worth mentioning is that $v$ osobennosti 'especially' and osobenno 'especially' do not necessarily always signify a relation of inclusion as they do in $(84 a-c)$, where they introduce parenthetic phrases. In the following sentence, for example, the noun phrase introduced by $v$ osobennost $i$ is not parenthetic and does not refer to an entity included in the referent of the initial noun phrase: Ego p'esa[nom sg] "Na dne" $i v$ osobennosti povest'[nom sg] "Mat'" proizvodjat[p1] vpečatlenie neobyknovennoj novizny $i$ svezesti 'his play "The Lower Depths" and especially the novelette "Mother" give the impression of unusual novelty and freshness.'

${ }^{36}$ There have been suggestions that deletions as in (84b) follow pronominalization as an intermediate stage in English (cf. Stockwell et al. 1973, $166 \mathrm{ff}$. [for alternative approaches see Jackendoff 1971a and Sommerstein 1972]) as well as in Slovenian and other languages (Per1mutter 1973), but there is no evidence to support such an account for Russian. It has also been suggested that sentences such as (84c) do not involve "backward" deletion but rather a rearrangement of the constituents referred to as Right-Node Raising (argued for in, e.g., Perlmutter 1973, 442-445). Again, there is no evidence for (cont.) 
such a transformation in Russian, and there is fairly strong evidence for backward deletion. Consider, for example, (i).

(i) Kvartira sostoit iz trëx svetlyx[p1] i odnoj tëmnoj apartment consists of 3 bright and one dark komnaty [sg].

room

'The apartment consists of three bright rooms and one dark one.'

The plural number manifested by svetlyx 'bright' must be that of a deleted noun, for this attributive clearly modifies a noun denoting rooms, and the only occurrence of such a noun in this sentence is in the singular.

Note also that backward deletion of identical nouns is not restricted to conjoined noun phrases, as illustrated by the sentences under (ii), where the deletion sites are indicated by $\emptyset$ ((b) and (c) are cited in Padučeva 1971 and 1969, respectively, and (d) was provided by Padučeva in a personal communication).

(ii). (a) Ni materialy [nom] Klassičeskoj[gen fem] $\emptyset$, neither materials of classical [1iterature] ni ( $\emptyset$ ) sovetskoj[gen fem] Ziteratury[gen nor [materials] of Soviet literature fem] ne podtverz̃dajut ètix predpisanij.

'Neither data from classical literature nor data from Soviet literature support these prescriptions.'

(b) Otremontirovany dejstuujušcie [p1] $\emptyset$ have been repaired operative [dining rooms] $i$ postroeny novye $[\mathrm{pl}]$ stolovye [p1]. and have been built new dining rooms

'Operative dining rooms have been repaired and new ones have been built.'

(c) Sleduet rešit' esli ne vse $\emptyset$, to po krajnej mere bol'śinstvo zadac.

'One has to solve if not all, then at least most of the problems.'

(d) Ja pereš̈l iz xvojnogo[gen sg] $\emptyset v$ smešannyj[acc $\mathrm{sg}$ ] Zes[acc sg].

'I crossed from a pine forest to a mixed one.' 
Sentence (84d) illustrates reduction through Regrouping. The conjoined noun phrases have been regrouped so that the attributive modifiers are sister constituents dominated by an Attributive node, and the two occurrences of kotël have been regrouped and collapsed into a single plural form (the plural number of the noun is manifested through the connective linking the attributives rather than by their endings in this case).

The verb must be pluralized no matter how the conjoined subject phrases are reduced, because the conjoined phrases must be dominated by an NP node marked [+Plural], most likely as a consequence of the regrouping of underlying conjoined sentences which could also be realized as (85). The reduction processes cannot affect the position of this NP node in the sentence structure nor its grammatical number.

(84) (a) Pjatyj[sg] kotël[sg] i šestoj[sg] kotëz[sg] fifth boiler and sixth boiler naxodilis' [p1] $v$ novom korpuse. were located in new building

'The fifth boiler and the sixth boiler were located in the new building.'

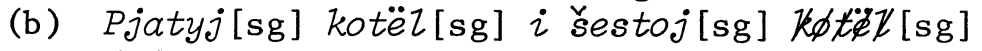
fifth boiler and sixth naxodilis'[p1] $v$ novom korpuse. were located in new building

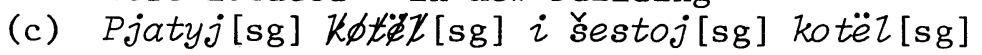
fifth and sixth boiler naxodilis'[p1] $v$ novom korpuse. were located in new building

(d) Pjatyj[sg] $i$ šestoj[sg] kotly[p1] naxodilis' [p1] fifth and sixth boilers were located $v$ novom korpuse. in new building

(85) Pjatyj kotël naxodilsja $v$ novom korpuse $i$ šestoj kotël naxodilsja $v$ novom korpuse.

'The fifth boiler was located in the new building and the sixth boiler was located in the new building.'

Compare also nad $\emptyset i$ pod vodoj 'over and under water,' vdol' $\emptyset$ i poperëk komnaty 'along and across the room' (Leont'eva 1967). 
3.11 As in other constructions, the regular reduction process in formal discourse is Regrouping, yielding sentences like (84d). Some typical examples from miscellaneous texts are given under (86).

(86) (a) Lomonosovskaja[nom sg] i karamzinskaja[nom sg] xudožestvennye [nom $\mathrm{p} 1]$ sistemy [nom $\mathrm{p} 1]$ by $i$ [p1] vraždebny [p1] novomu realističeskomu iskusstvu Pǔskina. 3

'The Lomonosovian and Karamzinian literary systems were not receptive to Pushkin's new realistic art.'

(b) Ustnaja[nom sg] i pis'mennaja[nom sg] formy [nom p1] Ziteraturnogo jazyka sušestvujut[p1]

scomostojatel'no $i$ vnešne nezavisimo.

'The oral and written forms of the 1iterary language exist independently and appear to be selfsufficient.'

(c) Glavnyj[nom sg] i pođêinënnyj [nom sg] èlementy [nom $\mathrm{pl}$ ] každoj sintagmy svjazany [p1]

numerovannoj strelkoj.

'The head and dependent elements of each syntagma are connected by a numbered arrow.'

(d) $V$ nastojašcix kollektivax "formal 'nyj"[nom sg] i "neformal'nyj"[nom sg] Zidery[nom p1] čašče vsego soedinjajutsja[p1] $v$ odnom Zice.

'In present-day collectives, the "formal" and "informal" leaders are more often than not united in the same person.'

(e) Sovetskij[nom sg] i v'etnamskij[nom sg] inžnery [nom p1] obmenivajutsja[p1] družeskim mikopozatiem.

'The Soviet engineer and the Vietnamese engineer exchange a friendly handshake.'

${ }^{37}$ Regrouping has also applied in the derivation of this sentence to the modifier associated with the identical noun in each of the underlying conjuncts. Analogous reductions are illustrated in (i) and (ii).

(i) Ešëe niðe raspolagajutsja[p1] 5-ja[nom sg] i 1-ja [nom sg] gorodskie[nom p1] bol'nicy [nom p1].

'Still lower are the Fifth and First City Hospitals.' (cont.) 
Note the lack of ambiguity in Russian with regard to the number of referents in comparison with English. In (86e), for example, the singular attributives in Russian signify reference to one Soviet engineer and one Vietnamese engineer, whereas English does not possess this device and a phrase equivalent to the Russian, viz., the Soviet and Vietnamese engineers, would tend to be interpreted as referring to more than a total of two (the degree of actual ambiguity in English apparent1y depends on the nature of the attributives; cf. the other examples under (86)).

3.12 The derivational history of conjoined underlying noun phrases with identical nouns does not seem to bear on the process of reduction applied to them. In the sentences under (86), the reduced noun phrases represent both primary conjunction $((c-e))$ and Regrouping $((a-b))$, and all undergo Regrouping. In the sentences under (87),

(a) represents primary conjunction and (b-c) seem to represent regrouped sentences, yet all three are reduced by Identity Deletion ( (a-b) are cited in Rozental' 1971a, 232).

(87) (a) Revoljucionnoe [nom sg] i opportunističeskoe [nom sg] krylo[nom sg] partii ne mogli[p1] prijti $k$ sogZašeniju.

'The revolutionary and opportunistic wings of the party could not come to an agreement.'

(b) Pravaja[nom sg] i Zevaja[nom sg] polovina[nom sg] doma byZi[p1] osveščeny [p1].

'The right and left halves of the house were illuminated.'

(c) Pervyj[nom sg] $i$ vtoroj[nom sg] kurs[nom sg] first and second course poexali[p1] $v$ kolxoz. have gone to kolkhoz

'The first-year and second-year students have gone to a kolkhoz.'

(ii) On prinimal učastie $v$ soomǔenii Kuzneckogo[gen sg] $i$ Zapadno-Sibirskogo[gen sg] metalZurgičeskix[gen p1] predprijatij[gen p1].

'He took part in the construction of the Kuznetsk and West-Siberian metallurgical plants.' 
Reduction by Identity Deletion where Regrouping is also applicable, as in the derivation of (87), is generally typical of informal, casual discourse, though it is by no means restricted to casual discourse in such structures, just as reduction by Regrouping is not restricted to formal discourse. 38

${ }^{38}$ It seems instructive to cite in this connection a comment made by Peshkovsky in reference to the singular noun in the title of his articel "Ob"ektivnaja $i$ normativnaja točka[sg] zrenija na jazyk" (The Objective and Normative Point[s] of View on Language). He says (Peškovskij 1956, 453): "1ы сознательно и после догого обдумывания остановились на единственном [Р.'s emphasis] числе, так как множественное казалось нам слинком книхным и мертвенғым (we have consciously and after long consideration selected the singular number, since the plural seemed to us too bookish and vapid).

Rozental' suggests that the grammatical number of nouns in such phrases depends on whether the phrases are in the nominative case or not, proposing that in oblique cases the noun is not pluralized if the attributives are "ordinal numerals or pronominal adjectives" (Rozental' 1971a, 233). The following are some random sentences from various sources which seem to indicate that grammatical case is not a factor.

(i) Lučšie orkestry igrajut pjatuju[acc sg fem] i šestuju[acc sg fem] simfonii[acc pl].

'The best orchestras play the fifth and sixth symphonies.'

(ii) Ja zdes' progulivaju tretij[acc sg masc] i četvërtyj [acc sg masc] uroki[acc p1]. [U nas kontrol'naja po arifmetike.]

'I am whiling away here the third and fourth periods. [We have a test in arithmetic.]'

(iii) Raznica mezdu pervym[instr sg] i vtorym[instr sg] oborotami[instr p1] zakljucaetsja $v$ stepeni rasčlenënnosti predstavlenij sub"ekta i ob"ekta dejstvij.

'The difference between the first and the second phrase is in the degree of discreteness of the representations of agent and patient.'

(iv) Po otnošeniju $k$ nim modeli vtorogo[gen sg] $i$ tret'ego[gen sg] tipov[gen pl] vypolnjajut vspomogatel'nuju rol'. 
'In relation to them models of the second and third types have an auxiliary role.'

(v) $K$ pervomu sprjaðeniju otnosjatsja glagoly, imejušcie vo 2-m[1oc sg] $i v 3-m[10 c \mathrm{sg}] \mathrm{Z} i \mathrm{cax}[1 \mathrm{oc} \mathrm{p} 1]$ edinstuennogo čisla tematičeskij glasnyj -e-.

'The first conjugation subsumes verbs which have the thematic vowel $e$ in the second and third persons singular.'

The nouns could also be in the singular, of course, in all five sentences. Regrouping in (v) is especially interesting, because the regrouped nonidentical attributives include prepositions. Such reductions also occur with the introductory $i$ and with other conjunctive connectives, as illustrated by (vi)-(viii) (informants confirm the acceptability of these sentences, though there are grammarians who prescribe singular nouns with connectives as in (viii), whether with or without prepositions [cf. Galkina-Fedoruk 1964, 478; Senkevič 1964, 13; and Rozental' 1971a, 232]).

(vi) Sovetskaja strana zanimaet odno iz veduščix mest $v$ mire kak samoe mogušcestvennoe gosudarstvo is èkonomičeskoj[gen sg], is voennoj[gen sg] toček [gen p1] zrenija.

'The Soviet country occupies one of the leading positions in the world as the most powerful state both from the economic [point of view] and from the military point of view.'

(vii) Vyxodnye tufli nel'zja nadet' $n i k$ golubomu[dat $\mathrm{sg}$ ], $n i k$ sinemu[dat sg] plat'jam [dat pl].

'One cannot wear the good shoes with the light blue [dress] nor with the dark blue dress.'

(a) Sud'by nekotoryx żitelej doma na llal'cgasse xorošo nam znakomy--kak po prošlogodnej[dat sg], tak $i$ po nynešnej[dat sg] poezdkam[dat pl] $v$ Venu.

'We know the fates of certain residents of the house on Maltzgasse [quite] we11--from last year's as well as from the present trip to Vienna.'

(b) My pobyvali ne tol'ko $v$ literatumom [loc sg], no i $v$ istoriceskom[1oc sg] muzejax[1oc pl].

'We visited not only the 1iterary but also the historical museum.' 
3.13 The following sentences differ from (87) in that reduction of the subject phrases by Identity Deletion is not an alternative to Regrouping but rather the only applicable reduction process. This is because the nouns denote homogeneous entities $((a-c)$ are cited in Rozental' $1971 \mathrm{a}, 232$ [(a) has already been cited above as (6)]; (d) is from a lecture at MGU).

(88) (a) Tjað̈ëlaja[nom sg] i lëgkaja[nom sg] promyšlennost' [nom sg] perevypolnili[p1] svoi plany. 39

'The heavy [industry] and light industry have overfulfilled their plans.'

(b) Opisatel'naja[nom sg] i istoričeskaja[nom sg] fonetika[nom sg] imejut[p1] svoim ob"ektom otdel'nyj konkretnyj jazyk.

'Descriptive [phonetics] and historical phonetics focus on individual concrete languages.'

(c) Amerikanskaja[nom sg] i anglijskaja[nom sg] pressa[nom sg] ne mogut[p1] skryt' bespokojstva $v$ svjazi s novoj situaciej.

'The singular [number] and plural number are viewed as different words.'

I am not sure about the derivation of phrases as in (v)-(viii) and will not consider possible underlying configurations here. This question is not directly related to the subject matter of the present chapter, but I would like to suggest that perhaps such phrases can be used as evidence that prepositions do not represent independent syntactic constituents in Russian grammar but rather realize features of noun phrases (which may have other ultimate sources) and are attached to the leftmost constituents of noun phrases.

${ }^{39}$ Compare also Mašinostroitel'naja[nom sg] $i$ metalZoobrabatyvajuščaja [nom sg] promyšlennost' [nom sg], zanimajuščie [nom pl] po čislu rabočix pervoe mesto sredi drugix otraslej promyšlennosti, ...' the machine-construction [industry] and the metal-processing industry, which in the number of workers occupy the first place amoung other branches of industry ...' (Rozental' 1971a, 234). 
(d) Edinstvennoe [nom sg] i množestvennoe [nom sg] čislo[nom sg] rassmatrivajutsja[p1] kak raznye slova.

'The singular [number] and plural number are viewed as different words.'

If the subject nouns in these sentences were pluralized, the sentences would be ungrammatical, or only marginally so (Rozental' 1971a cites as stylistically inferior a phrase analogous to the subject phrase in (88a) in which the noun promyszlennost' 'industry' is pluralized [p. 232], and Skoblikova 1963 mentions that the noun čislo 'number' as used in (88d) could conceivably be pluralized [p. 146]). Perhaps a distinction should be drawn with respect to such constructions between nouns which can only denote homogeneous entities and can be assumed to be specified <+homogeneous> and nouns which can also denote heterogeneous entities and can be assumed to be marked $<$ homogeneous>, with only nouns of the latter category allowing Regrouping. (An interesting case in point is the noun maslo 'fat; oil,' which is apparently a <thomogeneous> noun in its first sense and a <homogeneous > noun in the second, for in the phrase slivočnoe $i$ smetannoe maslo 'butter and cream,' where maslo is used in the sense of "fat," it could not possibly be pluralized [cf. Peškovskij $1956,453]$, but in the phrase konopljanoe $i$ podsolnečnoe maslo 'hempseed and sunflower oil' it could be (cf. Avanesov and Sidorov 1945, 90].) In any case, the distinction is of minor significance and the standard reduction process is Identity Deletion whether the identical nouns are marked <thomogeneous> or just <homogeneous>.

One could suggest that perhaps Regrouping does take place in the derivation of sentences such as (88) and when the identical nouns are regrouped under a single $\mathrm{N}$ node and collapsed to a single form, it is in the singular because of the homegeneity feature. This would be a plausible account were it not for the parallelism with the phenomenon described in Section 2 of the preceding chapter, which is, briefly, that an attributive modifier associated with conjoined nouns denoting homogeneous entities generally cannot be pluralized. Given, then, an underlying structure as in (89), a rule which blocks Regrouping due to the homogeneity of the nouns can account both for the fact that a single attributive in surface structures cannot be pluralized and for the fact that a single noun cannot be pluralized. In other words, the rule applies both 
when identity holds between attributives and when it holds between nouns. Otherwise, i.e., if we were to assume that Regrouping could operate when the nouns were identical and their singular number could be accounted for in a different way, then the two phenomena would appear to represent different principles and the relationship between them would not be captured.

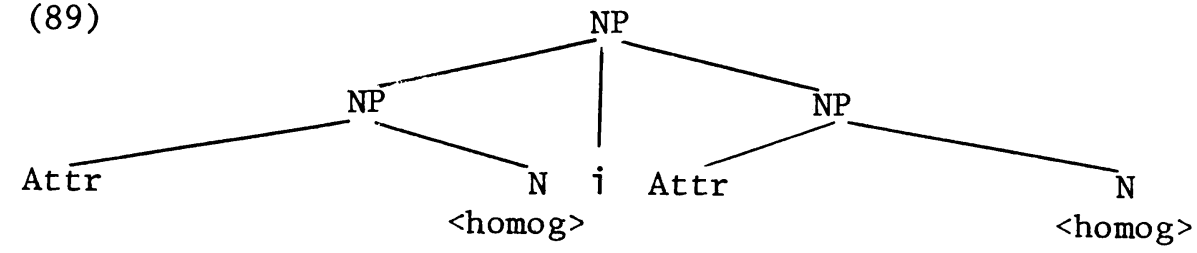

Note that the two phenomena are also similar in that violations do occur. This fact too can be handled by a single account.

3.14 While in (88) the verbal predicates have plural endings, presumably manifesting the grammatical number of the underlying NP nodes which dominate the conjoined noun phrases with identical nouns, in (9) the situation is different (cited in Rozental' 1971a, 232).

(90) Atomnoe [nom sg] i vodorodnoe [nom sg] oružie[nom sg] doľ̌no[sg] byt' uničtoženo [sg].

'Nuclear and hydrogen weapons must be abolished.'

The grammatical number manifested by the predicate constituents in this sentence is singular. Apparently the subject phrase in this sentence is analogous to the subject phrases in (78) above (Section 2.2), where an under1ying grammatically singular primary conjunction was proposed to account for the singular number of the predicates. That account seems applicable also to (90) and other possible accounts will therefore not be explored here. Sentence (90) may possibly represent a different phenomenon, but I do not have conclusive data to support an alternative account.

3.15 Regrouping is apparently blocked by nouns which denote homogeneous entities not only in conjoined noun phrases which contain attributive modifiers but also in conjoined noun phrases with other constituents. 
Consider (91) (from Iu. M. Lotman, Lekcii po struktural'noj poètike [Providence, R.I.: Brown University Press, 1968], 162-163).

(91) Poèzija[nom sg] Batjuškova[gen] i Katenina[gen] prinadlezali[p1] odnoj èpoxe $i$ vosprinimalis' [p1] $v$ proekcii na odni $i$ te Æe stilističeskie struktury. 'The poetry of Batyushkov and [the poetry] of Katenin belonged to the same period and were received with reference to the same stylistic structures.'

The pluralized verbs in (91) apparently manifest the number of the conjoined underlying subject phrases poèzija Batjuškova 'the poetry of Batyushkov' and poèzija Katenina 'the poetry of Katenin' (which, incidentally, represent primary conjunction, for the predicate asserts their belonging to the same period), and the singular noun in the surface subject phrase is thus not the only subject noun with which the verbs are associated.

Sentence (91), which is rather unusual, contains evidence for the existence of a deleted noun in the form of plural verb endings. There are sentences in which there is no such evidence, yet deletion of an identical noun from underlying conjoined phrases may nevertheless have taken place, even when the nouns are not ones marked as homogeneous. Compare, for example, (92) ((a) occurs in Kondrašov 1962, 114; (b) occurs in Svedova 1970, 536).

(92) (a) Imja suščestvitel'noe obladaet kategoriej[sg] roda[gen], čisla[gen] i padě̌a[gen].

'The noun possesses the category of gender, [the category] of number, and [the category] of case.'

(b) $V$ slovosočetanijax, obrazovannyx na osnove svjazi[sg] upravlenija[gen] i primykanija[gen], zavisimyj komponent ostä̈tsja neizmennym.

' In phrases formed on the basis of the relation of government and [the relation] of parataxis, the dependent component remains unchanged.'

When identical nouns in underlying configurations which can yield reductions as in (91) or (92) are not marked as homogeneous, the regular reduction process is Regrouping, as in (93). 
(93) (a) Poroždajuščaja grammatika ne stavit pered soboj zadaču modelirovanija real'nyx processov [gen] poroždenija[gen] $i$ vosprijatija[gen] reči, kak oni protekajut $v$ golove govorjaščego $i$ slušatelja. ${ }^{40}$

'Generative grammar does not see as its goal the development of a model of the actual processes of production and perception of speech as they take place in the speaker's and hearer's heads.'

(b) Stancija "Oktjabr'skoe pole" budet na perekrëstke ulic [p1] Maršala Birjuzova[gen] i AZabjana [gen].

'The Oktyabrskoe Pole station will be at the intersection of Marshal Biryuzov Street and Alabyan Street.'

Identity Deletion is apparently completely excluded in such constructions when the identical nouns are neither marked as homogeneous nor abstract, whether the existence of a deleted noun can be signified by a plural predicate or not, as illustrated under (94).
(94)

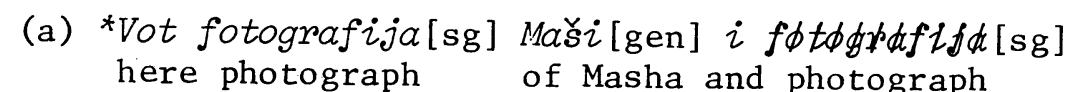 Saši [gen]. of Sasha
(b) Vot fotografii[p1] Maši[gen] i Saši[gen]. here photographs of Masha and of Sasha
'Here [are] photographs of Masha and of Sasha.'
(c) *Fotografija[sg] Maši[gen] i fotografija[sg] Saši [gen] stojali[pl] na rojale.
'The photograph of liasha and [the photograph] of Sasha stood on the piano.'
(d) Fotografii[p1] Maši[gen] i Saši[gen] stojaZi[p1] na rojale.
'The photographs of Masha and of Sasha stood on the piano.'

3.16 Finally, note that when identical nouns do denote homogeneous or abstract entities in conjoined noun phrases with nonidentical constituents other than

${ }^{40}$ Note also the singular number of golove 'head' in the last phrase. The NP node dominating this noun is apparently specified \{thomogeneous\} in the underlying representation; cf. Section 2.4 in Chapter Two. 
attributive modifiers and Identity Deletion is in principle applicable, it often in fact is not, because the deleted noun can leave no trace behind within its phrase, in contrast to deleted nouns in phrases with attributive modifiers, where the attributive modifiers manifest the features of the deleted nouns. In the following sentences, for instance, the repeated nouns cannot be deleted (the prepositive position of the verbs has no significance here).

(95) (a) S rassvetom nastupaet udivitel'naja lëgkost', prixodit radost' sdelannogo[gen] i radost' novogo dnja[gen].

'With dawn comes a wonderful lightness, the happiness of what has been accomplished and the happiness of the new day.'

(b) Dlja čeloveka suščesturet mir udovol'stvij[gen] $i$ mir radostej [gen].

'For man [there] exist a world of pleasures and a world of joys.'

The deletability of identical nouns in such constructions is apparently conditioned by the relationship between the semantic features of the nonidentical constituents in the conjoined phrases. More specifically, deletion is apparently only applicable when the nonidentical constituents belong to the same semantic category but do not intersect, at least not from the speaker's point of view. An example of the subjectivity of such judgments is the following. At a lecture $I$ attended at Moscow University the speaker referred to process[sg] integracii[gen] $i$ differenciacii[gen] 'process of integration and [process] of differentiation,' viewing integration and differentiation as nonintersecting concepts, i.e., as incompatible with one another and hence obviously occurring in separate processes. One of the listeners, however, understood the phrase as referring to a single process and questioned it. At any rate, the

- formalization of such semantic relations is a matter beyond the scope of the present monograph. 41

${ }^{41}$ Another interesting question which must remain outside the scope of the present monograph is the reduction of proper names, some of which cannot be pluralized while others can. Compare, for example, na territorii Vostocnoj $i$ Južnoj Evropy[sg]/*Evrop[p1] 'in the territory of (cont.) 


\subsection{Prepositive Verbal Predicates}

Sentences with prepositive verbal predicates require special attention because prepositive verbal predicates associated with conjoined subject phrases are not necessarily pluralized; they may be associated just with the nearest conjunct. This fact has bearing on the reduction processes applicable to identical nouns. Consider (96) and (97) (which are variants of (84)).

(96) (a) $V$ novom korpuse naxodilsja[sg] pjatyj[sg] kotël in new building was located fifth boiler [sg] i seštoj[sg] kotël[sg]. and sixth boiler

'In the new building were located the fifth boiler and the sixth boiler.'

(b) V novom korpuse naxodilsja[sg] pjatyj[sg] kotël

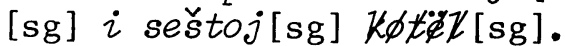

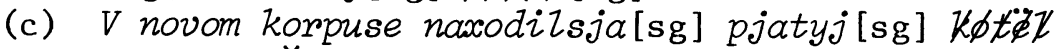
[sg] i seštoj[sg] kotër[sg].

(d) $* V$ novom korpuse naxodilsja[sg] pjatyj[sg] $i$ in new building was located fifth and seštoj[sg] kotly[p1]. sixth boilers

(97) (a) V novom korpuse naxodilis'[p1] pjatyj[sg] kotël in new building were located fifth boiler [sg] i seštoj[sg] kotëZ[sg].

$$
\text { and sixth boiler }
$$

(b) V novom korpuse naxodilis'[p1] pjatyj[sg] kotël

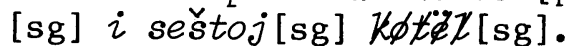

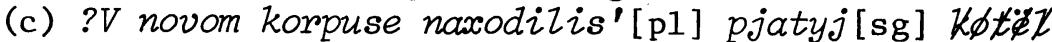
[sg] $i$ seštoj[sg] kotëZ[sg].

(d) $V$ novom korpuse naxodilis' [p1] pjatyj[sg] $i$ in new building were located fifth and šestoj[sg] kotly[pl]. sixth boilers

The reductions which yield the (a) sentences presumably precede the reductions illustrated in the remaining

Eastern [Europe] and Southern Europe'; brat'ja Kennet $i$ Kejt Littldzony[p1] 'the brothers Kenneth and Keith Littlejohn [lit. Littlejohns]'; and $s$ Ol'goj $i$ Veroj PavZounami[p1] 'with 01ga Pavlovna and Vera Pavlovna' (the last example from Rozental' 1971a, 171). 
sentences, so that what we are dealing with here are possible reductions of subject noun phrases in sentences with prepositive verbal predicates rather than the grammatical number of the predicates, for that seems to be independent of what happens within the noun phrases, assuming that sentences such as (b)-(d) are the consequence of reductions.

In (96a), the verb manifests the number of the nearest conjunct, and an identical verb associated with the righthand conjunct has presumably been deleted. The constituent structure of this sentence is hence as in (98).

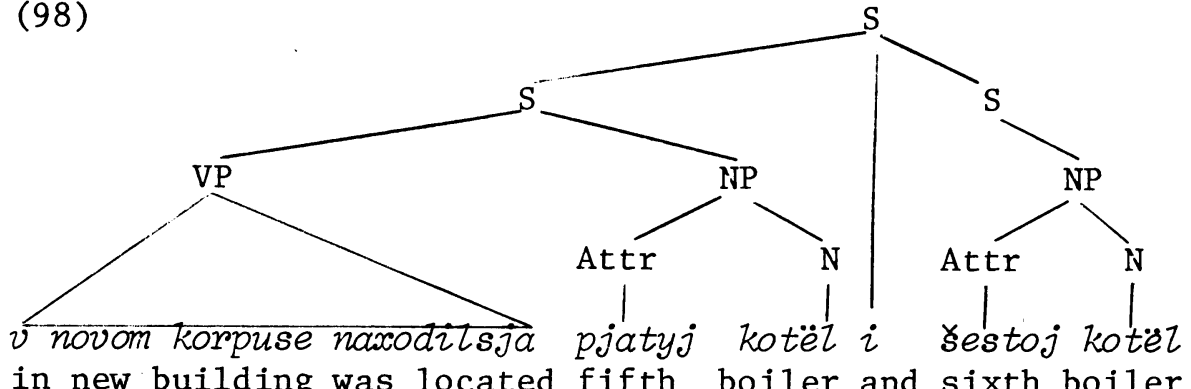

As demonstrated by the acceptability of (96b) and (96c), the identical nouns in this configuration can be deleted both by "forward" deletion and by "backward" deletion. They cannot undergo Regrouping, however, because the noun phrases containing them are not sister constituents within the same noun phrase. Sentence (96d), which would be the consequence of Regrouping, is indeed ungrammatical. 42

${ }^{42}$ Sentences such as the following would be classified as errors by most speakers of standard Russian ( $i$ ) occurs in Kondrašov 1962, 138, and (ii) in Junost' 1970, No. 6, 108).

(i) $V$ pervyx dvux tipax sklonenija vaznoe značenie imeet [sg] tvërdaja[nom sg] i mjagkaja[nom sg] raznovidnosti[nom $\mathrm{pl}$ ].

' In the first two types of declension, the hard and soft variants are very important.'

(ii) Cto soboj predstavljaet[sg] pervaja[nom sg] $i$ vtoraja[nom sg] časti[nom pl] proizvedenija?

'What do the first and second parts of the work represent?' 
The pluralized verb in (97a) indicates that the sentence has undergone Regrouping. The conjoined subject phrases are then constituents of a single noun phrase and can be reduced by Regrouping, which is indeed demonstrated by the acceptability of (97d). The interesting case in (97) is (c), where reduction of the subject phrase by backward deletion is of questionable acceptability. The acceptability of (97b) is not incongruous, for forward deletion is generally applicable in almost any configuration and is not constrained by conditions of structural identity like backward deletion (cf., e.g., Srok obučenija na fakul'tete[sg] Zurnalistiki i juridičeskom $\emptyset 4$ goda 'the period of study at the School of Journalism and [the] Law [School] is four years,' but not *'Srok obučenija na juridičeskom $\emptyset i$ fakul'tete zurnalistiki 4 goda 'the period of study at the Law [School] and [the] School of Journalism is four years'). The question why backward deletion is not applicable is puzzling, however, since the conditions for its application do seem to exist.

Sentences like (97c) are in fact not completely ungrammatical, and their marginality may be simply due to the inconsistency they manifest in the choice of reduction

The restriction violated by these sentences, however, may be different from the one discussed in the text. The conjoined underlying subject phrases in these sentences may represent grammatically singular primary conjunctions, as in (iii) (cf. Section 2.2 above).

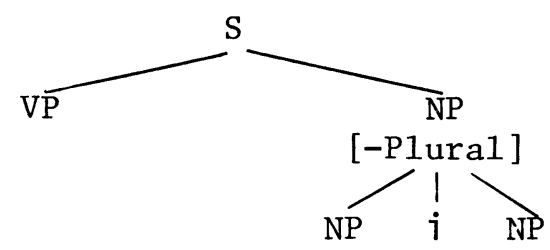

The identical nouns are thus within noun phrases which are sister constituents within the same noun phrase and are eligible for Regrouping. Perhaps the restriction violated by (i) and (ii) is that Regrouping should not take place when conjoined noun phrases with identical constituents are dominated by an NP node marked [-Plural], and this may very well be no more than a stylistic constraint, which makes sentences like (i) and (ii) stylistically infelicitous but not ungrammatical, in distinction from the unquestionably ungrammatical (96d). 
process: the subject phrase reduced by Identity Deletion after the sentence has undergone Regrouping. The fact that when Regrouping is applied as an optional alternative to Identity Deletion it tends to be followed by another Regrouping rather than by Identity Deletion has already been noted above in connection with the reduction of phrases with identical attributives (p. 186), and the tendency to follow optional Regrouping with Regrouping may be especially dominant in the reduction of conjoined noun phrases with identical nouns because Regrouping is a regular reduction process for this construction in any case (unless the nouns denote homogeneous entities), in distinction from its marginality in the reduction of conjoined noun phrases with identical attributives. ${ }^{3}$

A fact which may support this analysis is that in several years of research the only sentence I have encountered with a plural prepositive verb and a singular subject noun following conjoined attributives does not involve Regrouping. The sentence is the following (from Suprun 1969, 30).

$V$ period takogo postepennogo vključenija [novyx èlementov] $v$ jazyke sosušcestvujut [p1] staryj[nom $\mathrm{sg}$ ] $i$ novyj [nom sg] èlement [nom sg] sistemy.

'In a period of such gradual inclusion [of new elements], the old [element] and the new element of the system coexist in the language.'

This sentence must have primary conjunction in its underlying structure, for the predicate is sosušcestoujut 'coexist,' and the reduction process for the subject phrase can therefore be determined independently.

It is noteworthy that when the first conjunct is introduced by $i$ or by kak (as initial element of the paired connective kak ... tak $i$...) in a structure such as $(97 a)$, the reduction process within the subject phrase is independent of the earlier Regrouping. The sentences under (100) are fully acceptable.

${ }^{43}$ Nouns which denote homogeneous entities apparently cannot be regrouped whether the verb phrase has been reduced by Identity Deletion or by Regrouping. In practice, it seems that either identical verb phrases associated with such subject nouns are reduced by Identity Deletion or, if not, the subject nouns are not reduced (despite their identity). 
(100) (a) $V$ novom korpuse naxodilis'[p1] i pjatyj, $i$ seštoj kotëz[sg].

'In the new building were located both the fifth and the sixth boiler.'

(b) $V$ novom korpuse naxodilis'[p1] kak pjatyj, tak $i$ šestoj kotël[sg].

'In the new building were located the fifth as well as the sixth boiler.'

Noun phrases linked by kak ... tak $i$... are regularly reduced by deletion rather than by Regrouping and the acceptability of (100b) may be ascribed to this fact. Conjunctions introduced by $i$, on the other hand, undergo Regrouping quite regularly. Some examples of such reduction in sentences with prepositive and postpositive predicates are given under (101).

(101) (a) Vskore za pervoj povest'ju sledujut [p1] $i$ vtoroe[nom sg], i tret'e[nom sg] proizvedenija [nom p1].

'Soon after the first novelette follow both the second [work] and the third work.'

(b) Na literaturnyj pol'skij jazyk okazali[p1] viijanie $i$ velikopol'skij[nom sg], $i$ malopol'skij[nom sg] dialekty[nom p1].

'The literary Polish language was influenced both by the Great Polish [dialect] and by the Little Polish dialect.'

(c) I demokratičeskaja[nom sg], i respublikanskaja [nom sg] administracii[nom p1] vovse ne pomyšljali[p1] o mimom uregulirovanii $v$ Indokitae.

'Both the Democratic [administration] and the Republican administration did not contemplate a peaceful settlement in Indochina.'

(d) I tot [nom sg] $i$ drugoj[nom sg] glagoly [nom p1] oboznačajut [p1] moment otpravlenija, t.e. načalo dviženija.

'Both this [verb] and the other verb denote the moment of departure, that is, the beginning of the motion.'

It appears, then, that the reduction process within noun phrases is indeed independent of earlier processes when the lefthand conjunct is introduced by some conjunction marker. 
4. Verbal Predicates Associated with Nouns linked by $i Z_{i}$ and Other Disjunctive Connectives.

4.0 Number manifestations in association with nouns or noun phrases linked by $i l i$ 'or' seem erratic, and not only in Russian (for instructive observations on the situation in English see Langendoen 1970, 24-26 and Morgan 1972, 281). One fundamental reason for this is that $i$ in, like or in English, has an ambiguous role. It signifies exclusive disjunction, as in (102), where the assertion only applies to one of the disjuncts, as well as inclusive disjunction, as in (103), where the assertion applies to both disjuncts.

(102) Metrax $v$ dvadeati ot našego doma byla[sg] rečuška ili kanava, kak ëe[sg] dostatočno spravedlivo togda nazyvali.

'About twenty meters from our house there was a rivulet or ditch, as it was appropriately enough called then.'

(103) Maleǰ̌aja iskra ili peregrev vlekut[p1] za soboj katastrofu, $i$ togda more pylaet vmeste s korablëm.

'The slightest spark or overheating lead to a catastrophe, and then the sea is in flames together with the ship.'

Furthermore, $i Z_{i}$ can often be considered a superficial substitute for an underlying conjunctive connective, conditioned by the presence of a modal element. Consider, for example, (104).

(104) (a) Ne každaja provincija ili gorod privodjat [p1] dannye o tom, skol'ko molodëži napravleno $v$ derevni.

'Not every province or city provide data on the number of young people sent to villages.'

(b) Posmotrite xotja by, kak tesno i melko pečatajutsja[p1] teper' "Nedelja" ili "Filosofskij slovar" izdanija 1972 goda. 'Just look how close and small Nedelja or the Dictionary of Philosophy of 1972 are printed now.'

In (104a) the disjunctive phrase is a paraphrase of the conjunction ne kazdaja provincija $i$ ne každyj gorod 
'not every province and not every city,' conditioned by the presence of the negative particle. In (104b), the disjunction is conditioned by the imperative, for in the indicative mood this disjunction would not make any sense (cf. "Nedelja" ili "Filosofskij slovar" pečatajutsja teper' tesno $i$ melko 'Nedelja or the Dictionary of PhiZosophy are printed now in close and small print'). Only a conjunction would make sense in the indicative mood; cf. "Nedelja" i "Filosofskij slovar"" pečatajutsja teper' tesno $i$ melko 'Nedelja and the Dictionary of Philosophy are printed now in close and small print.'

A second fundamental reason for the inconsistency of number manifestations in association with nouns or noun phrases linked by $i i_{i}$ is that when such nouns or noun phrases conflict in gender or number, postpositive constituents which manifest these features must be pluralized (cf., e.g., Galkina-Fedoruk 1964, 467 and Rozental' 1971a, 226-227). Consider (105).

\section{(105) Ručë̈k[nom masc] ili kanava[nom fem] \\ stream or ditch \\ $\left\{\begin{array}{c}\text { ispol'zovalis'[p1] } \\ \text { *ispol'zovalsja[masc] } \\ \text { *ispol'zovalas'[fem] }\end{array}\right\} d l j a$ čego-nibud'? \\ were used \\ 'Was the stream or ditch used for anything?'}

If taken as a response to (102), the subject phrase in (105) has one referent and represents an exclusive disjunction. Since the disjuncts conflict in gender, however, the verb must be pluralized (unless the lefthand disjunct is dislocated, in which case it would be intonationally set off from the rest of the sentence, and unless the righthand disjunct is in a parenthetic position, which would also be indicated by intonational signals). The number manifested by the verb in this sentence thus does not correspond to the number of referents and is independent of the role of the connective.

What follows is an attempt to elucidate the facts and to relate them to the processes postulated so far to account for number manifestations in association with nouns and noun phrases linked by conjunctive connectives. Sentences in which $i i_{i}$ or some other disjunctive connective represent exclusive disjunction are discussed in 4.1, and all other cases are discussed in 4.2. 
4.1 Exclusive disjunction in natural language cannot be defined as rigorously as in logic; in language it is more a question of subjective perception in many cases. Roughly, a noun phrase can be said to represent exclusive disjunction if it refers to a single entity and contains two or more alternative references to that entity.

In (102), for example, the speaker refers to a single, specific body of water and offers two alternative names for it. In the underlying representation of the sentence, the disjunctive phrase must therefore be specified $\{-a g-$ gregate\}, and the disjunction is apparently primary, i.e., not a consequence of reduction or some other syntactic transformation. The putative underlying representation of the phrase is thus as shown in (106).

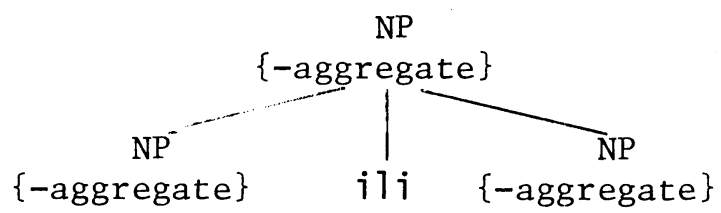

The verb in (102) indeed cannot be pluralized--and not merely because it is associated with disjuncts, for in (103) the verb does have a plural ending. The fact that the verb cannot be pluralized must be due to the fact that the disjuncts have a single referent and the phrase is therefore grammatically singular.

This also applies to (105), assuming the disjuncts in that sentence refer to a single body of water. Had the verb associated with them been in the present tense, where it would not have manifested gender, it would have had to have a singular ending. The verb is only pluralized because it has to manifest gender and the gender of the disjuncts does not coincide (cf. Section 2.1 in the present chapter).

Some additional examples of sentences with subject phrases representing exclusive disjunction are given under (107) ( (a) and (e) are cited in Rozental' 1971a, 226; (b) and (c) are cited in Skoblikova 1959b, 200; (f) is cited in Padučeva 1969, 33).

(107) (a) Sobaku[acc] [seǰ̌as] $\left.\begin{array}{c}\text { oxvatyvaet }[\mathrm{sg}] \\ \text { oxvatyvajut }[\mathrm{p} 1]\end{array}\right\}$ sonlivost'[nom sg], son[nom sg] ili gipnoz [nom sg]. 
'The dog is [now] overcome by drowsiness, sleep, or hypnosis.'

(b) Spinoj ko mne ... $\left\{\begin{array}{c}\text { sidit }[\mathrm{sg}] \\ \text { sidjat }[\mathrm{p} 1]\end{array}\right\}$ zenščina [nom sg fem] molodaja ili devica[nom sg fem], na muku $\left\{\begin{array}{l}\text { oblokotilas'[sg fem] } \\ \text { *oblokotilis' [p1] }\end{array}\right.$

'With [her] back towards me sits a young woman or a girl, leaning on [her] elbow.'

(c) Za gorodom do samogo gorizonta tjarallas'[sg 'tjanulis'[p1] fem] he to step'[nom sg fem], ne to pustynja [nom sg fem].

'Beyond the city all the way to the horizon [there] stretched [something which was] either a steppe or a desert.'

(d) Opjat' $\left\{\begin{array}{r}\text { idët }[\mathrm{sg}] \\ \text { idut }[\mathrm{p} 1]\end{array}\right\}$ ne to dożd'[nom sg], ne to sneg [nom sg].

'Again [there] falls [something which is] either rain or snow.'

(e) Ne to tuman[nom sg masc], ne to dym[nom sg masc] okutyvaZ[sg masc]
*okutyvali[p1] vsju rošcu.

'[Something which was] either mist or smoke enveloped the whole grove.'

(f) Libo ugol[nom sg] $A$, Zibo ugol[nom sg] $B$ ne $\left\{\begin{array}{cl}\text { javijaetsja[sg] } & \text { prjamym }[\mathrm{sg}] \\ \text { *javijajutsja[p1] } & \text { prjamymi [p1] }\end{array}\right\}$.

'Either angle $\mathrm{A}$ or angle $\mathrm{B}$ is not [a] right [angle].'

It seems that exclusive disjuncts tend to follow predicates rather than precede them (in unmarked word order), because sentences usually begin with given, known information, and exclusive disjuncts essentially signify uncertain, indefinite indentity. Sentences (e-f) under (107) are thus less typical than (a-d) (cf. also the observations in Skoblikova 1959b, 201).

While in the sentences under (107) it is fairly obvious that the disjunctive connectives represent exclusive disjunction, for the disjunctive phrases can be said to refer, ultimately, to single entities, there are sentences in which exclusive disjunctions are not as obvious and are only motivated by speakers' subjective perceptions. 
Such sentences are analyzed in the following subsection, after non-exclusive disjunctions.

4.2 When disjunctive connectives do not represent exclusive disjunction, they are apparently indistinguishable syntactically from conjunctive connectives, which means that coordinate constituents linked by a disjunctive connective can undergo Regrouping just like conjoined constituents if they contain identical elements. This applies to noun-phrase reductions as well as to sentential reductions, discussed in this order in what follows.

4.21 Reductions of disjunctive noun phrases with identical attributives by Regrouping were already illustrated and discussed in Chapter Three (pp. 200-203). Reductions of disjunctive noun phrases with identical nouns by Regrouping are illustrated in the sentences under (108) below.

(108) (a) Yto ¿̌e kasaetsja delovogo[sg] ili naurnogo[sg] stilej[p1], to metaforiceskoe slovoupotreblenie dlja nix nexarakterno.

'As for the business [style] or the scientific style, the metaphoric use of words is not characteristic for them.'

(b) Fomilii inojazyčnogo proisxoždenija s konečnym tvërdym soglasnym $v$ primenenii $k$ licam Æenskogo pola sočetajutsja $v$ russkom jazyke $s$ pojasnitel'nymi slovami $v$ formax 丸en. r., ne izmenjaja svoego morfologičeskogo oblika, kak èto proisxodit $v$ Cesskom[sg] ili pol'skom[sg] jazykax [p1].

'Non-Russian surnames which end in a hard consonant and apply to female persons are combined in Russian with elucidatory feminine words without changing their morphological form as in the Czech [language] or the Polish language.'

(c) Dejstvitel'naja[sg] ili stradatel'naja[sg] konstrukcii[p1]--èto toæe duusostavnye ličnye predlozenija aktivnogo ili passivnogo postroenija. [Odnako ... oni ne mogut byt' obratimymi.]

'The active [construction] or the passive construction are also active or passive binomial personal sentences. [However,... they are not reversible.]' 
(d) Podležaščee v nëm obyčno vyraženo oduševlënnym suščestvitel'nym, ... a skazuemoe--perexodnym glagolom iz"javitel'nogo naklonenija soveršennogo [sg] ili nesoveršennogo[sg] vidov [p1] $v$ forme vsex trëx lic.

'The subject in it is expressed by an animate noun, ... and the predicate--by a transitive verb in the indicative mood of either the perfective [aspect] or the imperfective aspect in all three persons.'

(e) Odnorodnye Členy predloženija rassmatrivajutsja, naprimer, kak sxodnye $v$ morfologičeskom [sg], leksičeskom[sg] ili logičeskom[sg] otnošenijax [p1].

'Coordinate sentence constituents are viewed, for example, as similar in the morphological, lexical, or logical respects.'

Reductions as in (108) are supposed to be incorrect, because the connective is not conjunctive (cf., e.g., Rozental' 1971a, 232). However, the nature of the connective is evidently insignificant in fact. The sentences above were selected to demonstrate this despite their relative complexity because all five occur in carefully written and edited texts and the "incorrect" reductions cannot be accounted for as slips ((a) occurs in Efimov 1969, 135; (b) occurs in Panov 1968, 33; (c-d) occur in Kočetkova and Matveeva 1970, 5 and 7; and (e) occurs in the abstract of a dissertation in philology).

Reduction by Regrouping is blocked only when the coordinate phrases derive from a structure as in (106) above, i.e., when the connective represents exclusive disjunction. In the underlying structures of the sentences under (109), for example, Regrouping is excluded.

(109) (a) Vy govorili na češskom[sg] ili pol'skom[sg]

Czech or Polish

$\left\{\begin{array}{c}\text { jazyke }[\mathrm{sg}] \\ \text { *jazykax }[\mathrm{p} 1]\end{array}\right\}$ ?

language

'Did you speak Czech or Polish?'

(b) Vy kupili letnij[sg] ili zimnij[sg] $\left\{\begin{array}{l}\text { kostjum }[\mathrm{sg}] \\ * \text { kostjumy }[\mathrm{p} 1]\end{array}\right\}$ ?

'Did you buy a summer [suit] or a winter suit?' 
In actual usage, nouns modified by disjoined attributives in reduced phrases are usually not pluralized for the same reasons that nouns modified by conjoined attributives are not pluralized, that is, either because the nouns denote homogeneous entities, or because Identity Deletion is the favored reduction process in such configurations regardless of the nature of the connective. 44

4.22 When coordinate sentences have identical postpositive verb phrases, the regular reduction process is Regrouping whether the sentences are linked by an element realized as a conjunctive connective or by an element realized as a disjunctive connective. Consider, for example, the sentences under (110), which have already been cited in Chapter Three under (47).

\section{(110) (a) V ètom slučae professional'noe slovo[nom sg] ili oborot [nom sg] priobretajut [p1] osobuju stilističeskuju okrasku. \\ 'In this case a technical word or expression acquire a special stylistic coloring.'}

${ }^{44}$ The fact that non-exclusive disjunctive connectives are not distinguished from conjunctive connectives when it comes to reduction is also evident in the reduction of noun phrases with identical nouns and nonidentical constituents other than attributive modifiers. Sentence (i), for example, shows evidence of Identity Deletion, whereas (ii) shows evidence of Regrouping.

(i) Ponjatie transformacii javljaetsja bolee slołnym, čem ponjatie [sg] dobavienija, opuščenija, substitucii ili perestanovki.

'The notion of transformation is more complex than the notion of addition, [the notion] of deletion, [the notion] of substitution, or [the notion] of transposition.'

(ii) Ponjatija[p1] "puškinskij jazyk" ili "jazyk turgenevskij", razumeetsja, uslovny.

'The notion "Pushkin's language" or [the notion] "Turgenev's language" are, of course, conventional.'

In (i), the disjuncts could have been regrouped and ponjatie 'notion' would then have been pluralized, and in (ii) the same noun could be in the singular as a consequence of Identity Deletion. 
(b) Malejšaja iskra[nom sg] ili peregrev [nom sg] vlekut[p1] za soboj katastrofu, $i$ togda more pylaet vmeste $s$ korablëm.

'The slightest spark or overheating lead to a catastrophe, and then the sea is in flames together with the ship.'

The predicates in these sentences apply to each of the disjuncts independently and the sentences are true for both disjuncts, in distinction from, e.g., (107), where the sentences are true for only one of the disjuncts. The disjuncts in (110) thus appear to represent independent subjects in underlying coordinate sentences, e.g., for (a)--Professional'noe slovo priobretaet osobuju okrasku 'a technical word acquires a special coloring' and Professional'nyj oborot priobretaet osobuju okrasku 'a technical expression acquires a special coloring'; for (b)-MaZejšaja iskra vlěeèt za soboj katastrofu'the slightest spark leads to a catastrophe' and Malejšij peregrev vlečet $z \alpha$ soboj katastrofu 'the slightest overheating leads to a catastrophe.'

The source of $i l i$ in the surface sentences is obscure. Perhaps it realizes a certain set of features which links the underlying sentences, and perhaps the realization of such features as $i l i$ hinges on reduction. Whatever the source of this connective, the noun phrases it links must be dominated by a single NP node marked [+P1ural], because the verbal predicates associated with the disjuncts are pluralized. The most plausible source for the grammatically plural subject node seems Regrouping, for this is the process which accounts for the plurality of subject phrases containing conjuncts.

The pluralized predicates in (110) and also in other sentences with disjunctive subjects can thus be accounted for by postulating underlying coordinate sentences which undergo Regrouping, in contrast to sentences in which the disjunctive phrases are grammatically singular because they represent primary disjunction and are not a consequence of reduction (reduction by Identity Deletion is considered later on). This account is fairly adequate as far as it goes, for it explains different number manifestations in association with nouns or noun phrases linked by disjunctive connectives, but note that it does not go very far, because sentences such as the following are also possible. 
(111) Muykant[nom sg] ili pevec [nom sg] dejstvuet[sg] srazu na tysjači.

'A musician or a singer affects thousands at a time.'

In this sentence (cited in Skoblikova 1959b from Chekhov), the predicate seems to apply to both disjuncts and yet the verb is not pluralized. But this sentence does not invalidate the account given above, for, as noted earlier, primary disjunction in underlying representations is not restricted to situations which call for exclusive disjunction by objective or logical standards. Chekhov in this case evidently had a single entity in mind and his conception of the situation called for an exclusive disjunction. The account is thus restricted to strictly linguistic facts and does not extend beyond them. What can be suggested, however, is that when a speaker ultimately has a single entity in mind, primary disjunction is the only possible underlying representation, and hence sentences with disjunctive subject phrases which have pluralized predicates associated with them must always be interpreted as containing a non-exclusive disjunction from the speaker's point of view and can be related to underlying coordinate sentences (unless the plural number is due to gender or number conflicts [see pp. 298-299 above]). Consider, for example, the sentences under (112).

\section{(112) (a) [On stučal $v$ dver' ...., prislušivalsja i slyšal} maminy lëgkie šagi.] No otkryvali[p1] dver' sosed[nom $\mathrm{sg}$ ] $i i_{i}$ sosedka[nom $\mathrm{sg}$ ].

'[He would knock at the door ..., listen, and hear [his] mother's 1ight footsteps.] But the door would be opened by the male-neighbor or by the female-neighbor.'

(b) $V$ každoj kvartire predusmatrivajutsja[p1] kladovaja[nom sg] ili mesta[nom p1] dija vstroennyx stennyx škafov.

'Each apartment is going to have a storeroom or closet space.'

(c) [Nynešnij Romeo ispolnjaet $v$ žizni daleko ne edinstvennuju rol'vljublënnogo. Krome vsego pročego,] on rabotaet ili učitsja, i rabota[nom $\mathrm{sg}$ ] ili učëba[nom sg] trebujut [p1] ot nego často ogromnogo vnimanija $i$ umstvennogo naprjaženija.

'[The present-day Romeo certainly does not play just the role of lover in life. In addition to 
everything else,] he works or studies, and the work or study often demand a great deal of attention and mental effort.'

(d) $K$ nom doľ̌ny[p1] byli[p1] priexat' Viktor [nom sg] ili Vanja[nom sg].

'Victor or Vanya were supposed to come to see us.'

A11 four sentences are especially interesting because their subject phrases border on exclusive disjunction.

In (a), the speaker refers to multiple door-openings, each of which involved either the male neighbor or the female neighbor but not both. In reference to a single door opening the verb indeed would have had to have a singular ending, but the repeated openings involved both neighbors and the disjunction is thus not exclusive.

Sentence (b) is similar in that each apartment is going to have either a storeroom or closet space but not both, and in reference to a single apartment the verb would have had to be singular (a prepositive verb is not sensitive to number or gender conflicts). As it is, the sentence refers to multiple apartments and applies to both disjuncts (its underlying representation is an interesting question I will not go into here).

In (c), the NP node dominating nynešnij Romeo 'the present-day Romeo' must be specified \{taggregate, thomogeneous\} (see Section 2.4 in Chapter Two), and the pronoun on 'he' thus does not have a single specific referent. It refers to a class of individuals (young men in love), some of whom may be working while others may be studying.

As for (d), the modality represented by dolzhy 'supposed to' apparently affects the perception of the situation: even though perhaps only one person was supposed to come, the possibility of coming was true for both.

The sentences under (112) thus illustrate the correlation between pluralized predicates and non-exclusive disjunction. A corresponding correlation between singular predicates and exclusive disjunction cannot be established not only because primary disjunctions are not always truly exclusive but also because singular predicates may be a consequence of the reduction of underlying coordinate sentences by Identity Deletion. A sentence such as (113), for example, may be a reduction of an underlying structure which could also be realized as (114), though brat ili sestra 'brother or sister' may also represent primary disjunction. The sentence is ambiguous in this respect. 
(113) Priedet[sg] brat [nom sg] iZi sestra[nom sg]. will come brother or sister

'Either [my] brother or [my] sister will come.'

(114) Priedet brat, ili $\left\{\begin{array}{l}\text { priedet sestra } \\ \text { sestra priedet }\end{array}\right.$.

will come brother or $\left\{\begin{array}{l}\text { will come sister } \\ \text { sister will come }\end{array}\right\}$

The restrictions on Identity Deletion appear to be the same as when the connectives are conjunctive. More specifically, $i \tau_{i}$ appears to be equivalent to $i$, and the effect of an introductory $i l_{i}$ or $l_{i b o}$, as in (115), for example, is equivalent to the effect of the introductory $i$.

$$
\begin{aligned}
& \left\{\begin{array}{l}
I Z_{i} \\
L i b o
\end{array}\right\} \text { on, }\left\{\begin{array}{l}
i Z_{i} \\
l i b o
\end{array}\right\} \text { ona priedet }[\mathrm{sg}] . \\
& \text { either he or she will come }
\end{aligned}
$$

The underlying structure of (114) can thus undergo Identity Deletion because the verb is preposed and is essentially existential, and (115) could be a consequence of Identity Deletion because of the presence of an introductory particle, which, like the introductory $i$, neutralizes all restrictions on Identity Deletion (in reducible coordinate structures).

The paired disjunctive connectives ne to ... ne to ... , to $l_{i} \ldots$ to $l_{i} \ldots$, and to ... to ... are generally equivalent to paired conjunctive connectives such as kak ... tak $i \ldots$ and ne tor'ko ... no $i$... in allowing Identity Deletion in any context.

Singular predicates in sentences with disjunctive subjects can hence be accounted for by postulating primary disjunction only if Identity Deletion would have been inapplicable to an underlying coordination--as in (111), for example, or if the context indicates that the disjunction is unquestionably exclusive--as in (107) or (102) above. 45

Finally, noun phrases linked by the particles $n i \ldots$ ni ...' 'neither ... nor ...' in negative sentences correspond to disjunctive phrases (as in, e.g., (116a), also

${ }^{45}$ To find out what the Academy grammars have to say about number manifestations in association with disjunctive subjects see Vinogradov and Istrina 1960, 497 and Švedova 1970, 554. 
cited under (51) in Chapter Three), to conjunctive phrases linked by $i$... $i$...' 'both ... and ...' (as in (116b)), or to asyndetic phrases with dislocated constituents as in $(116 c)$.

(116) (a) $V$ naš vek ǔ̃e ne možet [sg] udov Zetvorit' molodogo čeloveka ili devušku ni rabota[nom] na primitivnoj životnovoďeskoj ferme, ni rol'[nom] raznorabočego $v$ polevodstve, ni dolžnost' [nom] patuxa.

'In our age, a young man or a girl can no longer be satisfied with work on a primitive stockbreeding farm, with the role of an unskilled laborer in the fields, or with the duties of a shepherd.'

(b) $N i$ slovo[nom] zalovan'e, ni slovo[nom] polučka ne upotrebljajutsja[p1] sejčas $v$ nejtral'nom stile musskogo literaturnogo jazyka.

'Neither the word ¿alovan'e nor the word polucka are used now in the neutral style of the Russian literary language.'

(c) Ja ne našla v ètom fil'me ni odnogo kadra[gen masc], ni odnogo xoda[gen masc], ni odnoj montaknoj frazy[gen fem], pro kotomiju[fem] možno bylo by skazat': "A! Bylo!"

'I did not find in this film [even] one frame, one action, [or] one phrase about which one could say: "Yes! That's how it was!"'

Number manifestations in sentences with such subject phrases therefore require no special comment.

\section{Grammatical Person}

There are three grammatical persons in Russian: first, second, and third. The third person can be defined negatively as neither first nor second ([-I, $-I I])$, for it is the person manifested by non-past finite verb forms (attributive modifiers and short-form adjectives and participles do not manifest person) whenever the subject phrase with which they are associated does not contain a first-person or second-person pronoun in the nominative case. We can assume that NP and VP nodes bear not only negative gender and number features but also the negative person features $[-I,-I I]$, and these negative person 
features are manifested by third-person endings unless different specifications are assigned through Verb Agreement. When a subject phrase contains a first-person or second-person pronoun in the nominative case, the verb associated with it must have a matching ending in any word order. In (117), for example, the first-person subject represents new information from the communicative standpoint and follows the verb, which represents presupposed information, but the verb cannot have a third-person ending and must manifest the person of the subject.

$$
\begin{aligned}
& \text { (117) Čaj[acc] }\left\{\begin{array}{c}
p_{*}^{\prime} j u[1 s t \text { pers }] \\
x^{\prime} \ddot{e t}[3 r d \text { pers] }
\end{array}\right\} \quad j a[\text { nom] } \\
& \text { tea drinks I } \\
& \text { 'The one who drinks tea is I.' }
\end{aligned}
$$

In sentences which have regrouped coordinate subject phrases and the head of one of the coordinates is a firstperson or second-person pronoun, the person manifested by the verb must match that of the pronoun in the subject phrase even though the number manifested by the verb may differ from that of the pronoun. This is illustrated by the sentences under (118) (from Galkina-Fedoruk 1964, 467 and 347 [(b) is also cited in footnote 23 for this chapter]).

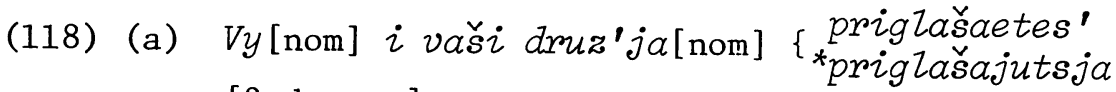 [2nd pers] $\}$ na vypusknoj večer.
'You and your friends are invited to the gradu- ation party.'
(b) $J a[n o m] ~ i m a t '[n o m]$ podolgu $\left\{\begin{array}{c}\text { sidim[1st pers } \\ \text { sidjat[3rd pers }\end{array}\right.$ $\left.\begin{array}{l}\mathrm{p} 1] \\ \mathrm{p} 1]\end{array}\right\} \mathrm{v}$ temnote $\mathrm{i}$ tixo $\begin{gathered}\text { razgovarivaem [1st pers } \\ \text { *azgovarivajut [3rd pers }\end{gathered}$ p1] p1].
'I and mother sit in the dark for a long time and talk softly.'

The following examples (from Švedova 1970, 554-555) illustrate the same priniciple in sentences in which first-person pronouns are coordinated with third-person pronouns (on pronoun combinations as in (119b) see footnote 23 above). 
(119) (a) $\left.\begin{array}{c}\text { Rabotaem [1st pers] } \\ \text { Rabotajut [3rd pers] }\end{array}\right\}$ i my $i$ on.

'[Those who] work [are] both we and he.'

(b) Ja $i$ on $\left\{\begin{array}{c}\text { pridem [1st pers p1] } \\ \text { pridut [3rd pers p1] }\end{array}\right.$.

'I and he will come.'

Now consider (120), where there are no other verb endings possible ((a), (b), and (e) from Švedova 1970, 555 and Rozental' 1971a, 228).

(120) (a) I ja, $i\left\{\begin{array}{c}\text { on } \\ \text { oni }\end{array}\right\}$ ostaëmsja[1st pers p1].

'Both I and $\left\{\begin{array}{l}\text { he } \\ \text { they }\end{array}\right\}$ are staying.'

(b) I ty $i\left\{\begin{array}{c}o n \\ \text { on }\end{array}\right\}$ mozete [2nd pers p1] pristupit' $k$ rabote zavtra.

'Both you and $\left\{\begin{array}{l}\text { he } \\ \text { they }\end{array}\right\}$ can start working tomorrow.'

(c) Otvečat' budem[1st pers p1] za vse raboty responsible will be for all works tol'ko vy $i j a$. only you and $I$

'Only you and I will be responsible for all the work.'

(d) $\left\{\begin{array}{l}O n \\ T y \\ V y\end{array}\right\}$ ili ja sdelaem[1st pers p1] ètu rabotu. ' $\left\{\begin{array}{l}\text { He } \\ \text { Thou } \\ \text { You }\end{array}\right\}$ or I will do this work.'

(e) $N i j a, n i\left\{\begin{array}{l}o n \\ t y \\ v y\end{array}\right\}$ ne edem[1st pers p1]. 'Neither I nor $\left\{\begin{array}{l}\text { he } \\ \text { thou } \\ \text { you }\end{array}\right\}$ are going.'

The coordinate subjects in these sentences are not necessarily regrouped. What these sentences illustrate is that when a verb follows coordinate subjects which do not coincide in person (more precisely, one of the subjects is a first-person or second-person pronoun and the other neither, or one is a first-person pronoun and the other a second-person pronoun)--whether the subjects have 
undergone Regrouping or not--the verb must be pluralized, and it must have a first-person ending if the coordination contains a first-person pronoun, a second-person ending otherwise. In other words, a verb which follows coordinate subjects which have not undergone Regrouping and do not coincide in person cannot simply manifest the person and number of the nearest subject in the coordination--its underlying subject. By what must be considered a "surface constraint" (cf. Section 2.1 in this chapter), its number should be plural and its person should be adjusted in accordance with the principle that first person supersedes second and both supersede third. (This hierarchy of grammatical persons is not uniquely Russian; cf., e.g., Blinkenberg $1950,87$. )

Finally, a prepositive verb associated with coordinate nouns one of which is a personal pronoun must manifest the person of the pronoun only if it is the nearest coordinate. Consider (121).

(121) Kto rabotaet na sledujuščej smene? who works on next shift

(a) $\left\{\begin{array}{l}\text { Rabotaju [lst pers sg] } \\ \text { Rabotaem [1st pers p1] } \\ \text { *Rabotajut [3rd pers p1] }\end{array}\right\} \begin{aligned} & j a \text { Vanja. } \\ & \text { work }\end{aligned}$

(b) $\left\{\begin{array}{l}\text { Rabotaes' [2nd pers sg] } \\ \text { Rabotaete [2nd pers p1] }\end{array}\right\}$ ty i Vanja. *Rabotajut [3rd pers pl] work

(c) $\left\{\begin{array}{l}\text { Rabotaet [3rd pers sg] } \\ \text { Rabotaem [1st pers p1] } \\ \text { Rabotajut [3rd pers p1] }\end{array}\right\}$ Vanja $i j a$.

(d) $\left\{\begin{array}{l}\text { Rabotaet [3rd pers sg] } \\ \text { Rabotaete[2nd pers p1] } \\ \text { Rabotajut [3rd pers p1] }\end{array}\right\}$ Vanja i ty. work Vanya and you

Since nouns and pronouns belong to different categories, they are evidently separated by a pause in coordinations as in (121) and Identity Deletion is app1icable in the derivation of the sentences under (121) despite the fact that the subjects seem to be Agents (see Section 1.16 in the present chapter). This accounts for the singular endings in (121), each of which manifests the features of the nearest coordinate. 
The first-person plural forms in (a) and (c) and the second-person plural forms in (b) and (d) must be a consequence of Regrouping and exhibit the regular hierarchy of grammatical persons. Third-person forms would violate this hierarchy and are predictably excluded in (a) and (b). Why they are not excluded in (c) and (d) is an interesting question for which I can offer no satisfactory answer at the moment. I can only suggest that this phenomenon is related to the idiosyncrasies in the use of pronouns mentioned in footnote 23 for this chapter.

\section{Summary}

The purpose of this chapter was to provide an outline of possible syntactic relations in sentences with verbal predicates associated with two or more nouns or noun phrases and thereby to account for the occurrence of nonpluralized verbs in such sentences.

Nonpluralized verbs turned out to occur in the following circumstances: (1) in the sentences which can be assumed to derive through the reduction of underlying conjoined sentences with identical verbs or verb phrases by deletion; verbal predicates in such sentences are associated with their prereduction subject and are not pluralized if it is grammatically singular; (2) in sentences in which conjoined nouns in the subject phrases can be assumed to derive as composites which refer to single entities and are grammatically singular; (3) in sentences in which verbal predicates are associated with conjoined noun phrases which denote abstract entities and can be assumed to represent grammatically singular primary conjunctions, i.e., they can be assumed to be conjoined in ultimate underlying representations and to have single referents; (4) in sentences in which nouns or noun phrases in the nominative case which appear to be subjects are not within the sentences which contain the verbal predicates; such nouns or noun phrases can be viewed as "dislocated" subjects; and (5) in sentences in which the nouns or noun phrases in the subject phrase are linked by a disjunctive connective and can be assumed to represent primary disjunction, i.e., they can be assumed to be disjoined in ultimate underlying representations.

Whether a verbal predicate precedes or follows the nouns or noun phrases with which it is associated is only significant for sentences of the first category, and only with certain connectives. More specifically, it is only 
significant when the subject nouns or noun phrases are linked by $i$ 'and' or $i l i$ 'or' and the connective is not preceded by an intonational break. Sentences of the first category are then impossible if the verbal predicate is postpositive or, when it is prepositive, if the subject nouns or noun phrases refer to animate beings which function as Agents with respect to the predicate. In these cases the sentences represent underlying conjoined sentences with identical verbs or verb phrases which cannot be reduced by deletion but only through a rearrangement of the constituents, their "regrouping," a process which invariably yields grammatically plural subject phrases and hence pluralized verbs. 


\section{ALTERNATIVE NUMBER MANIFESTATIONS IN ASSOCIATION WITH NOUN PHRASES INVOLVING PARTITIVE QUANTIFIERS}

0. "Partitive" quantifiers can be defined as lexical items which can both (1) signify quantity within noun phrases and (2) impose the genitive case on associated nouns or noun phrases which would otherwise be in the nominative case. "Basic" quantifiers, in distinction from "partitive" quantifiers, always coincide in case with associated nouns or noun phrases. The quantifiers in (1), for example, are "basic," whereas the ones in (2) are "partitive."

(1) (a) Tak rabotaet[sg] každyj[nom sg] francuz[nom sg]. so works every Frenchman

'Every Frenchman works like this.'

(b) Tak rabotajut[p1] vse[nom p1] francuzy [nom $\mathrm{p} 1]$. so work a11

Frenchmen

(a) Tak $\left\{\begin{array}{l}\text { rabotaet }[\mathrm{sg}] \\ \text { rabotajut [p1] }\end{array}\right\}$ pjat'[nom] francuzov[gen]. so work five Frenchmen

(b) Tak $\left\{\begin{array}{l}\text { rabotaet }[\mathrm{sg}] \\ \text { rabotajut }[\mathrm{p} 1]\end{array}\right\}$ neskol'ko francuzov[gen]. so work several Frenchmen

Number manifestations in sentences with "basic" quantifiers in the subject phrases do not vary. In (1a), for example, the verb can only have a singular ending, and in (1b) it can only have a plural ending. Number manifestations in sentences with "partitive" quantifiers, on the other hand, do vary, as illustrated in (2). This is why the discussion in the present chapter is restricted to number manifestations in association with noun phrases involving "partitive" quantifiers.

Alternatives in sentences with numerical quantifiers are discussed in Section 1, in sentences with adverbial quantifiers in Section 2, and in sentences with nominal quantifiers in Section 3. The last section, Section 4, is devoted to alternative number manifestations by copulative verbs and includes a disgression on copulative verbs in sentences with èto 'this' and kto 'who.' 
1. Alternatives in Sentences with Numerical Quantifiers

In order to account for the fact that certain sentences with numerical quantifiers allow alternative number manifestations as in (2a), it will be instructive to consider first sentences which unquestionably do not allow alternative number manifestations. Four types of sentences of this kind will be considered--first, sentences like (3a), where pluralization is excluded; then sentences like ( $3 b)$, where pluralization is mandatory; then sentences like (3c), where again pluralization is excluded; and finally sentences like (3d), where pluralization is mandatory.

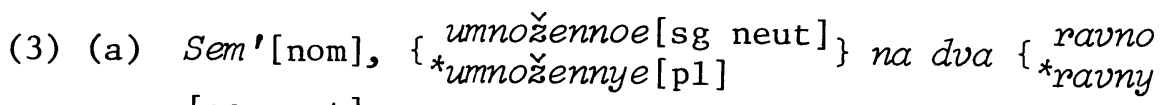
[sg neut] $\}$ četyrnadcati.

'Seven multiplied by two equals fourteen.'

(b) $S e m '$ [nom] mal'čikov[gen] \{vesëlye[nom pl] vesëloe[nom sg neut] $^{2}$. 'Seven boys are cheerful[ones].'

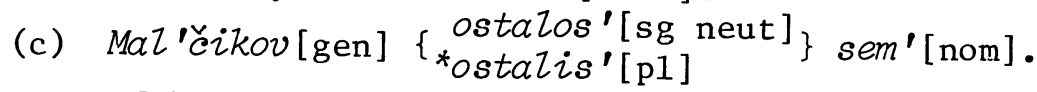
of boys remained seven

'[There] remained seven boys.'

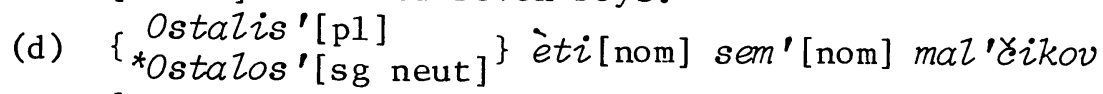
[gen].

'These seven boys remained.'

1.1 Sentences like ( $3 a$ ), where the numeral has no noun associated with it, should be distinguished from sentences such as (4).

(4) Sem'[nom] nužny[p1] sejěas že.
'Seven are needed right away.'

In this sentence too the numeral does not have a noun associated with it, but this sentence is elliptic, which can be demonstrated by the fact that it could not initiate a discourse. The numeral can be assumed to have a noun associated with it in the underlying representation of this sentence. In (3a), in contrast, no quantified noun can be assumed to exist in the underlying representation, for the numeral signifies number in the abstract. What 
(3a) illustrates is that whenever a numeral signifies number in the abstract, the number manifested in association with it can only be singular.

This singular number is analogous to the neuter gender manifested in association with numerals in such contexts (cf. (31a) in Chapter One [Section 4.1]) in that it can be assumed to represent the "provisional" specifications. Numerals have no inherent grammatical number, and their reference evidently cannot be defined in terms of the opposition \{taggregate\}/\{-aggregate\}. Alternative number manifestations in sentences with numerals are only possible, then, when there are nouns or noun phrases associated with the numerals.

1.2 In (3b) (reproduced below), the plural number of the predicate adjective must be the number of the quantified noun, in light of the preceding discussion. More precisely, it is the number of a predicate noun deleted under identity to the quantified noun (see Section 10.33 in Chapter One).

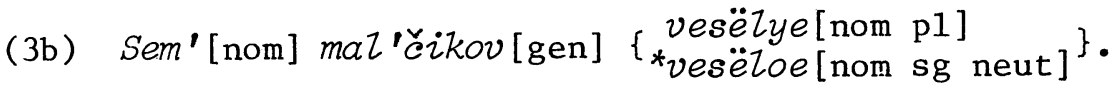
'Seven boys are cheerful [ones].'

Now compare (3b) to (5).

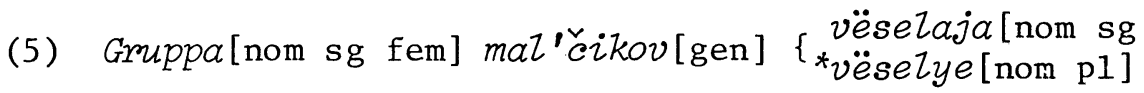
fem] $\}$.

'[The] group of boys $\left\{\begin{array}{l}\text { is [a] cheerful [one] } \\ \text { are cheerful [ones] }\end{array}\right.$.

Sentence (5) demonstrates, first, that the adjective vesëlyj 'cheerful' is not necessarily pluralized when applied to a plurality of individuals. Secondly, (5)

demonstrates that a predicate adjective cannot always manifest the number of a noun in the genitive case within the subject phrase. It is in fact only in sentences which have a quantifier in the subject phrase that a predicate adjective can manifest the number of a noun in the genitive case. This applies not only to sentences with numerical quantifiers but also to sentences with adverbial and nominal quantifiers, and not only to predicate adjectives modifying animate nouns, as illustrated in (6) (cf. also Skoblikova 1959a, 107-108). 
(6) (a) $\left\{\begin{array}{l}\text { Sem'[nom] } \\ \text { Neskol'ko } \\ \text { Bol's'instvo[nom] }\end{array}\right\}$ mal'čikov [gen] vesëlye [nom p1]. ' $\left\{\begin{array}{l}\text { Seven } \\ \text { Several } \\ \text { [A] majority [of the] } \\ {[\text { The] group [of] }}\end{array}\right\}$ boys are cheerful [ones].'

(b) $\left\{\begin{array}{l}\text { Sem'[nom } \\ \text { Neskol'ko } \\ \text { Boz'šinstvo[nom] } \\ * \text { Pačka }\end{array}\right\}$ pisem[gen] serditye [nom p1]. ' $\left\{\begin{array}{l}\text { Seven } \\ \text { Several } \\ \text { [A] majority [of the] } \\ \text { [The] pack [of] }\end{array}\right\}$ letters are angry [ones].'

The predicate adjectives in (6) not only can be pluralized when the noun in the genitive case is associated with a quantifier, but must be (cf., e.g., *Bol'šinstvo[nom sg neut] mal'čikov[gen] vesëloe [nom sg neut] 'a majority of the boys is [a] cheerful [one]'; *Bol'šinstvo[nom sg neut] pisem[gen] serditoe [nom sg neut] 'a majority of the letters is [an] angry [one]').

One might suggest that this phenomenon is due to the fact that the predicate adjectives apply to the referents of the quantified nouns rather than to their quantity. This is indeed the case, but then why can predicate adjectives not be pluralized when they apply, or seem to apply, to the referents of genitive nouns in subject phrases with nouns such as gruppa 'group' or pačka 'pack'?

The data in (6) indicate that qunatifiers differ from nouns such as gruppa or pačka not only superficially-e.g., in morphological properties or by some semantic or grammatical feature--but fundamentally, in their position in underlying structures. They appear to derive from embedded sentences. The matrix sentence underlying a sentence such as (3b) would be, accordingly, Mal'čiki-vesëlye mal'čiki 'the boys are cheerful boys.' The fact that a pluralized predicate adjective is unacceptable unless the subject phrase contains a qunatifier supports this hypothesis. The syntactic position of quantifiers in subject phrases is thus only superficially similar to that of nouns such as gruppa or pačka. Such nouns are heads of the subject phrases in underlying structures, whereas quantifiers are raised from embedded sentences in 
underlying structures. The position and internal structure of these embedded sentences are explored in subsequent sections.

1.3 In (3c) (reproduced below as (7)), where the verb stands between a quantified noun and a numerical quantifier, it cannot be pluralized. In light of the discussion so far, this fact can be interpreted as an indication that the verb in this section cannot be associated with the quantified noun, i.e., there can be no subject-verb relationship between the quantified noun and the verb--in distinction from a sentence such as (2a), for example (reproduced below as (8)), where the verb can be pluralized and therefore must be somehow associated with the quantified noun.

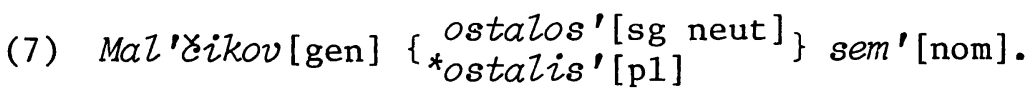
of boys remained seven

'[There] remained seven boys.'

(8) Tak rabotajut[p1] pjat'[nom] francuzov[gen]. so work five Frenchmen

Note that the fact that pluralization is excluded in (7) cannot be ascribed to the fact that there is no noun in the nominative case in the sentence, for in sentences such as (8) there is no noun in the nominative case either and yet pluralization is fully acceptable.

Another possible account for the fact that pluralization is excluded in (7) merits more serious attention. Briefly, it can be suggested that word order has something to do with the number of the verb. More specifically, it can be suggested that the fact that the verb cannot be pluralized is a function of the fact that the quantifier is separated from the quantified noun and constitutes the focus of the sentence from the communicative standpoint. In what follows I will argue that it is not merely a question of word order, that pluralization is excluded in (7) because the configuration underlying this sentence does not provide a basis for it, regardless of surface word order.

As a first step I will try to show that the syntactic relationship between the numeral and the quantified noun in (7) is fundamentally different from the relationship between an attributive numeral and the noun it modifies, 
that is, that the numeral in (7) cannot be viewed as transposed from a position within the same phrase as the quantified noun. (The conventional view is that it is. Cf., e.g., Švedova 1970, 561-562, 590, and 601-602.) Morphological differences between sentences such as (7) (hereafter Type (7)) and corresponding sentences with the numerals in attributive position will be pointed out first, and then syntactic differences.

One morphological difference is illustrated in (9) and (10) (the phenomenon illustrated in (10) is noted in Šcerbakov 1969, 20).

(9) (a) V vagone ostaZos' pjat' $\left\{\begin{array}{c}\text { čeZovek[gen pl] } \\ \text { * Zjudej[gen pl] }\end{array}\right.$. in car remained five people

'Five people remained in the car.'

(b) $\left\{\begin{array}{c}\text { Ljudej[gen p1] } \\ \text { ?Celovek[gen p1] }\end{array}\right\}$ vagone ostalos' pjat'. of people in car remained five

(10) (a) $V$ vagone ostaZos' troe $\left\{\begin{array}{l}\text { čelovek[gen p1] } \\ Z j u d e j[\text { gen p1] }\end{array}\right\}$. in car remained three people

(b) $\left\{\begin{array}{c}\text { Ljudej[gen } \mathrm{p} 1] \\ * \text { Celovek[gen } \mathrm{p} 1]\end{array}\right\}$ vagone ostaZos' troe. of people in car remained three

The noun čelovek 'person' has two genitive plural forms: čelovek and Zjudej. In the nineteenth century the former was used only when the noun was modified by numerals (Ščerbakov 1969, 12-13). In current usage, čelovek is also the preferred form when the noun is modified by a "collective" numeral (Ščerbakov, ibid.) or by skol'ko 'how many' or neskol'ko 'several' (cf., e.g., Lobanova 1966, 37).1

In (9a) the noun is modified by pjat' 'five' and Zjudej is excluded. In (9b), however, this form is not only not excluded, it is the preferred form. In (10a), the form modified by the collective numeral troe 'three' may be either čelovek or Zjudej, but in (10b) čelovek is excluded. In the (b) sentences, then, which illustrate Type (7), the choice of genitive plural form is not

${ }^{l}$ But note that the genitive form is $2 j u d e j$ when the noun has an attributive modifier associated with it. Cf., e.g., (45g) below. 
governed by the principles which govern the choice in the (a) sentences, where the numerals are in attributive position. (11).

Another morphological difference is illustrated in

(11) (a) $V$ banke ostalos' dve $\left\{\begin{array}{c}\text { sardinki[gen sg] } \\ \text { sardinok [gen } \mathrm{p} 1]\end{array}\right\}$. in can remained two sardines

'There are two sardines left in the can.'

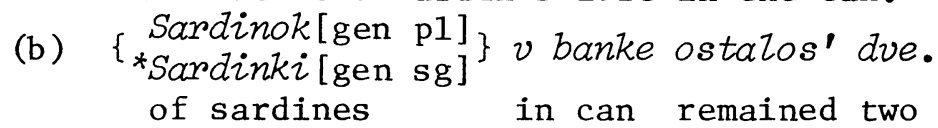

What these sentences illustrate is that while a noun modified by the numeral $d v a / d v e$ 'two' must have a singular ending, as in (11a), in a corresponding Type (7) sentence the noun cannot have a singular ending (this phenomenon is also noted in Skoblikova 1959a, 93 and in Kamynina 1961, 21-22). ${ }^{2}$ This difference is demonstrated in greater relief in the sentences under (12) and (13).

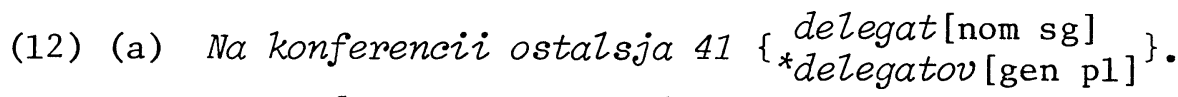
at conference remained delegates

'Forty-one delegates remained at the conference.'
(b) $\left\{\begin{array}{c}\text { DeZegatov [gen pl] } \\ * \text { Delegat [nom sg] }\end{array}\right\}$ na konferencii ostalos' 41. of delegates at conference remained

(13) (a) U menja $v$ to vremja ostalsja vsego odin by me at that time remained only one $\left\{\begin{array}{l}\text { drug [nom sg] } \\ \text { druzej[gen p1] }\end{array}\right\}$. friend

'I only had one friend left at that time.'

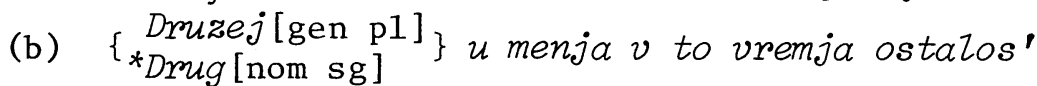
of friends by me at that time remained vsego odin. only one

2 The source of the grammatical number manifested by the quantified noun in (11a) is discussed later on. 
A noun modified by odin 'one' or by a compound which ends in odin must have a singular ending (unless it is a noun which has no singular forms, in which case odin has a plural ending, e.g., odni nosilki 'one stretcher') and does not go into the genitive case if it should be in the nominative, as illustrated in the (a) sentences under (12) and (13). In the (b) versions, which are Type (7) sentences, the nouns representing the quantified entities must be both pluralized and in the genitive case.

The last noteworthy morphological difference is illustrated in (14).

\author{
(14) (a) My[nom] troe $v$ otpuske. \\ we three on vacation \\ 'The three of us are on vacation.' \\ (b) $\left\{\begin{array}{c}\text { Nas [gen }] \\ * \text { My }[\text { nom }]\end{array}\right\}$ otpuske troe. \\ of us on vacation three \\ 'There are three of us on vacation.'
}

When a pronoun in a subject phrase is modified by a numeral, the numeral must have a "collective" form and it does not impose the genitive on the modified pronoun if it is within the same noun phrase as the pronoun, as illustrated in (14a). In (14b), a Type (7) sentence, the pronoun must be in the genitive. ${ }^{3}$

In sentences of Type (7), then, the nouns which signify the quantified entities are always in the genitive case and always pluralized and do not exhibit the idiosyncrasies which nouns modified by attributive numerals do. The purpose of what follows is to show that this formal difference is a consequence of the fact that sentences of Type (7) and sentences with numerals in attributive position differ in their constituent structure:

\title{
${ }^{3}$ There is no asterisked genitive form in (14a)
}

because the sentence Nas[gen] troe $v$ otpuske would not be ungrammatical. On the other hand, the genitive form is not included in (14a) as an alternative because the sentence Nas[gen] troe $v$ otpuske is not a variant of (14a) but rather of (14b), which can be demonstrated by the fact that it can only mean "there are three of us on vacation" and it does not allow the reading "the three of us are on vacation" (cf. also the comments in Dobromyslov and Rozental' 1960, 183). 
in sentence of Type (7) the quantified noun and the numeral are not constituents of the same noun phrase.

All of the sentences of Type (7) cited so far include an overt verb or some other element between the quantified noun and the numeral. Sentences of Type (7) may also occur without an overt verb or any other element between the quantified noun and the numeral, as illustrated in $(15 b)$.

\section{(15) (a) Mal'čikov[gen p1] sem' [nom] ... of boys seven \\ 'About seven boys...' \\ (b) Mal'čikov [gen p1]--sem' [nom]. of boys seven \\ 'There are seven boys.'}

Although (15b) has no verb, it is a complete sentence, with sentential intonation and a major-constituent break between the noun and the numeral. Its being a complete sentence is not merely a function of word order, as demonstrated by (15a); (15a) has the same elements and the same word order, but without sentential intonation and a majorconstituent break it can only be interpreted as a noun phrase, with the inverted word order signifying that the number is approximate.

The examples under (16)-(19) (based on Ščerbakov 1969) illustrate additional properties (other than intonation) which indicate that strings such as (15b) cannot be accounted for as noun phrases with inverted word order.

(16) (a) Kopeek[gen p1], Vitja, tri[nom]. 'Of kopecks, Vitya, [there are] three.'

(b) Kopejki[gen sg] tri[nom] ... 'Some three kopecks ...'

(c) *Kopejki[gen sg], Vitja, tri[nom] ...

The numeral in (16b) follows the noun, but this is still a noun phrase, as the noun has a singular ending, and the postposition of the numeral only indicates that the number is approximate. What (16c) illustrates is that the quantified noun and the numeral in such a phrase cannot be separated by a vocative noun, in contrast with (16a), representing Type (7), where the quantified noun can be separated from the numeral by a vocative noun. 
(17) (a) Kopeek[gen p1] ne tri[nom]. of kopecks not three 'The number of kopecks is not three.'

(b) *Kopejki[gen sg] ne tri[nom] ...

The numeral in the noun phrase illustrated in (16b) cannot be negated, as shown in (17b), but in a Type (7) string it can, as shown in (17a).
(a) Grozdej[gen p1] trideat'[nom], a Šumupov[gen p1] of nails thirty but screws ne xvataet. not enough
'There are thirty nails but there are not enough screws.'
(b) *Tridcat'[nom] gvozdej[gen p1], a $\left\{\begin{array}{l}\text { šumpov [gen } \\ \text { screws } \\ n e x v a t a e t \\ \text { not enough }\end{array}\right.$ $\left.\begin{array}{l}\text { p1] ne xvataet } \\ \text { not enough } \\ \text { šumpov [gen p1] } \\ \text { screws }\end{array}\right\}$.

The acceptability of (18a) indicates that gvozdej tridcat' 'of nails [there are] thirty' is a complete sentence rather than a noun phrase, for the string which follows $a$ 'but' is a sentence and its coordinate must be a sentence as well. This is demonstrated by the unacceptability of (18b), where the noun phrase tridcat' gvozdej 'thirty nails' cannot be coordinated with the sentence following the connective, whatever the order of constituents within it.

The "sentencehood" of strings like (15b) and their distinctness from noun phrases with the same lexical elements is also demonstrated in (19). In (19a), kogda 'when' introduces a complete clause, whereas in the illformed (19b) it introduces a noun phrase.

(19) (a) Teper', kogda nas [gen] troe [nom], mołno pristupit' $k$ rabote.

'Now, when there are three of us, we can get down to work.' 
(b) 'Teper', kogda my [nom] troe[nom], mołno pristupit' $\mathrm{k}$ rabote.

'Now, when the three of us, we can get down to work.'

The question, then, is what is the constituent structure of sentences of Type (7)--including sentences like (15b)--and how it accounts for the fact that a verb in such sentences cannot be pluralized.

Answers given by grammarians who have considered this question represent two seemingly opposite points of view. According to one, the quantifier in such sentences (which, incidentally, may also be an adverbial or nominal quantifier; see below) is a kind of grammatical subject, and the quantified noun is either part of the subject or some kind of complement (see, e.g., Šaxmatov 1925, 128-131 [interpreted in Dobromyslov and Rozental' 1960, 183]; GalkinaFedoruk 1958, 121; and Peškovskij 1956, 368-369). According to the other point of view, the quantifier represents a kind of predicate and the quantified noun is its subject in a certain sense (Kostinskij 1969; Ščerbakov 1969; Adamec 1973, 51; and Zolotova 1973, 133-134). In the analysis that follows I will try to show that the two views of the role of the quantifier are both valid and, furthermore, are not incompatible with one another. I will propose that in sentences of Type (7) the quantifiers represent underlying predicates but in the surface structure they can be considered grammatical subjects.

The "subjecthood" of quantifiers in sentences of Type (7) can be demonstrated through the contrast with sentences such as (20) and (21), which are analogous to Type (7) except that the numerals are in the accusative case and function as direct objects.
(20) (a) $\left.\begin{array}{c}\text { Pisem[gen } \mathrm{p} 1] \\ \text { *Pis'ma[gen sg] }\end{array}\right\}$ Vanja[nom] napisal četyre[acc]. of letters Vanya wrote four
'Vanya wrote four letters.'
(b) $\left\{\begin{array}{l}\text { Zurnalov [gen p1] } \\ \text { Zurnala[gen sg] }\end{array}\right.$ prines $2 i$ tri $[$ acc]. of journals [they] brought three 'There were three journals brought in.' 
(21) Devoček[gen p1] ja[nom] videl $\left\{\begin{array}{r}\text { odra [acc] } \\ \text { odna [nom] }\end{array}\right\}, a$ of girls I c saw one
maZ'cikov[gen pl] $--\left\{\begin{array}{c}\text { troix [acc anim] } \\ \text { troe [inanim] }\end{array}\right\}$.
of boys three
'I saw one girl and three boys.'

That the sentences under (20) are analogous to Type (7) is evident from the fact that the quantified nouns cannot have the singular endings they would have as constituents of the object phrases. While the case of the numerals in these two sentences can only be established by syntactic criteria, in (21) there is also morphological evidence. Odnu 'one' can only be an accusative form, and troix 'three,' which manifests animacy, is distinct from the nominative form troe.

Note also that the ending of odnu 'one' is a feminine one, and this can be accounted for, as suggested in Section 10.34 in Chapter One, by postulating a deleted quantified noun identical to the noun which signifies the quantified entity in the surface structure. The animacy of troix 'three' can be accounted for in the same way.

Evidence for the existence of an additional noun within the same phrase as the numeral in the underlying structures of sentences such as (20)-(21) and sentences of Type (7) can also be provided by sentences such as (22).

(22) (a) Druzej[gen p1] u menja $v$ to vremja byZo[neut] of friends by me at that time was vsego odna[nom] podruga[nom]. only one girlfriend

'As for friends, I only had one girlfriend at that time.'

(b) Nas[gen] byzo[neut] $v$ sem'e četvero[nom] detej of us was in family four children [gen].

'We were four children in our family.'

(c) [V 1914/1915 ucebnom godu na territorii Belorussii bylo 7682 školy.] Učitelej [gen p1] of teachers

$v$ nix rabotalo[neut] nemnogim bolee 12,4 in them worked little over tysjač čelovek. thousand people 
'[In the 1914-1915 school year there were 7682 schools in the territory of Belorussia.] The number of teachers employed in them was a little over $12,700 . '$

(d) Ljudej[gen p1] bylo[neut] devjat'[nom] čelovek of people were nine people [gen].

'The number of people was nine.'

(e) Vremeni[gen] prošZo[neut] dve[nom] nedeZi[gen]. of time passed two weeks

'Two weeks went by.'

(f) Vremeni[gen] do okončanija suda ostavalos'[neut] of time to end of trial remained $d v a[$ nom] $d n j a[$ gen]. two days

'There remained two days to the end of the trial.'

The initial nouns in the sentences under (22) identify the quantified entities in general (note that the noun vremeni 'of time' in (e-f) is not pluralized because it denotes a homogeneous entity), while the overt nouns directly associated with the quantifiers can be said to identify the actual count units. These nouns can be referred to as "classifiers" (cf. Greenberg 1972), and it can be assumed that all numerals have classifiers associated with them in underlying structures (unless they signify number in the abstract; see Section 1.1 above). ${ }^{4}$ The conditions under which they can be deleted are discussed further on.

${ }^{4}$ Shakhmatov must have had something like this in mind when he suggested that Korov [gen p1] dve [nom fem] 'of cows [there are] two' can be considered a reduction of Korov [gen p1] dve[nom fem] צtuki[gen sg] 'of cows [there are] two pieces' (Šaxmatov 1925, 131). He was on the wrong track, however, since štuka 'piece, item' cannot be deleted from an underlying predicate quantifier phrase unless it is identical to the noun denoting the quantified entity. Consider, for example, Jablok [gen p1] dve [nom fem] కtuki[gen sg] 'of apples [there are] two items.' Stuka here is not deletable; cf. *Jablok[gen pl] dve [nom fem] 'of apples [there are] two.' The inherent gender of jabloko 'apple' is neuter and the numeral cannot manifest a different gender. (The underlying representation of Korov [gen pl] dve [nom fem] 'of cows [there are] two' is explored in footnote 7 below). 
The most interesting sentence under (22) is (a), for the classifier noun in this sentence is in the nominative case, it has a singular ending and is inherently feminine, yet the verb cannot manifest its gender: the feminine form byla would be unacceptable in this sentence. It seems that odna podruga 'one girlfriend' is indeed associated with the verb as grammatical subject, but it is apparently not a noun phrase but rather a quantifier phrase (QP) and therefore has no features which can be copied onto the verb.

In order to understand the structure of this sentence, it will be useful to consider first the structure of (21), whose first part is reproduced below as (23).

(23) Devoček[gen p1] ja[nom] videl odnu[acc fem]. of girls I saw one

The underlying structure of (23) can be assumed to be at some point in the derivation roughly as in (24).

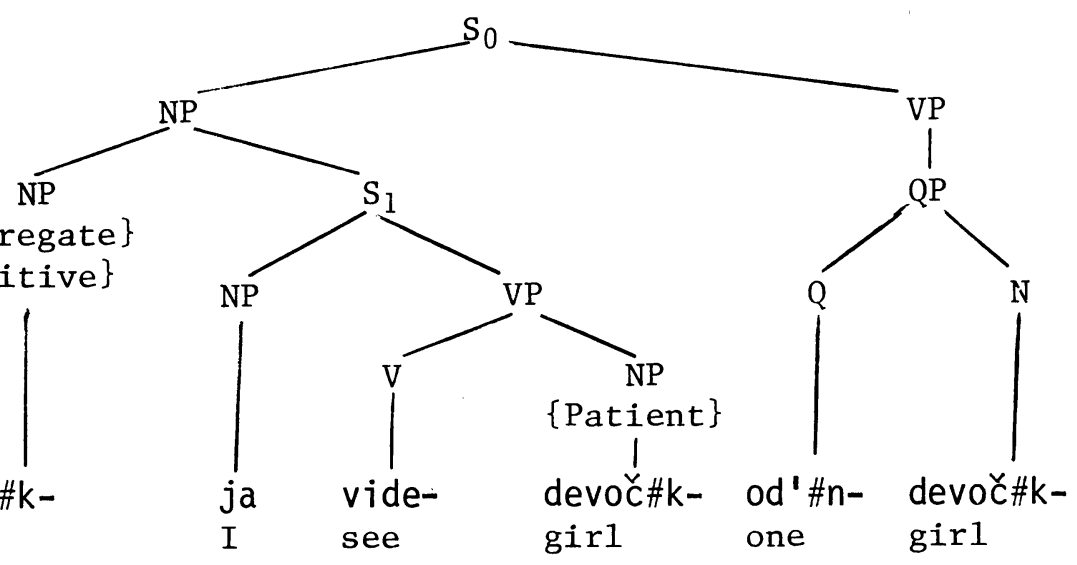

The \{Partitive\} feature defines the role of the entity represented by the noun phrase in relation to the predicate of the sentence, which in this case is a quantifier phrase. A noun representing the same role in association with a verb was illustrated above in (18) (Sumpov [gen] ne xvataet 'of screws [there is] not enough').

The grammatical case of noun phrases associated with QP predicates or with the verbs xvatat' 'be sufficient' and dostavat' 'be sufficient' is always genitive and it is therefore also possible to argue that the case of such noun phrases is determined by the predicates rather than 
by the underlying role definition. There are predicates, however, in association with which a noun phrase may be either in the genitive or in the nominative case, as in, e.g., (25) (for additional examples see Kostinskij 1969, 52).

(25) (a) Vody[gen] pribavilos'[neut]. of water became more

(b) Voda[nom] pribavilas'[fem]. water became more 'The water rose.'

The sentences under (25) can be assumed to derive from the same underlying configuration [NP VP], except that the role of the noun phrase in the underlying representation of (a) is defined as Partitive and the role of the corresponding phrase in the underlying representation of (b) is defined as Patient. One could, of course, account for the morphological differences between (a) and (b) by postulating different underlying configurations, e.g., by viewing the noun in (a) as representing an underlying complement within the verb phrase, but such an account would not capture the fact that the genitive ending in (25a) has the same interpretation as the genitive ending in (23) and the one in (18) (Sumpov[gen] ne xvataet 'of screws [there is] not enough'), that the role of the genitive noun in all three contexts is the same-a fact which can be captured by an account according to which the source of the genitive in all three sentences is an underlying \{Partitive\} specification. 5

${ }^{5}$ An underlying Partitive role is also postulated in Chafe 1970 (see p. 207) and Langendoen 1970 (p. 104). Note that genitive endings representing this role are by no means limited to sentences such as the ones discussed in the text. They are especially characteristic of directobject nouns, as in (i), but also occur with miscellaneous predicates on nouns or noun phrases which can be considered grammatical subjects at least in some sense, cf., e.g., (ii) (and cf. also Muxin 1968, 135-139, Kostinskij 1969, and Mrazek 1973 for arguments in favor of the proposition that such nouns can be viewed as grammatical subjects).

(i) (a) Cvetov [gen] namali. of flowers [we] picked 
To return to the derivation of (23) from (24), what it involves essentially is deletion of the object noun from the embedded sentence under identity to the head noun in the higher noun phrase--by a rule similar or partially identical to the rule which operates in the derivation and reduction of relative clauses (cf. Devoček, kotoryx ja videl 'the girls whom I saw' and Devoček, vidennyx moju 'the girls seen by me')--and the replacement of the deleted noun by the QP node from the higher sentence (with all that it dominates), by a rule which can be referred to as QP Lowering (the uniqueness of this rule is discussed later on).

Deletion of the object noun and its replacement by the QP node yield the structure under (26).

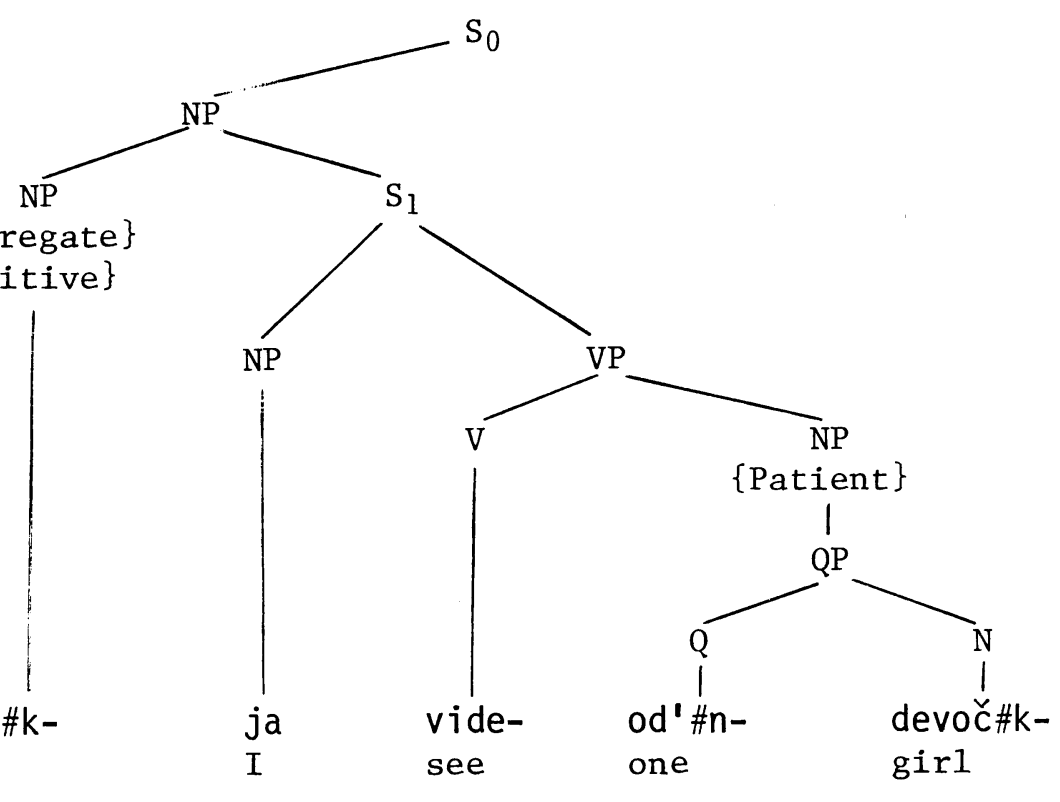

devoð\#kgir1

(b) Plesni-ka eščë kofejku[gen]. do pour more of coffee

(ii) (a) Kaši[gen] eščë ostaZos' [neut]. of kasha still remained

(b) Na okne naledi [gen] nometano [neut]. on window of ice piled up

(c) Narodu[gen] prišo[neut]! of people came

(d) Xoxotu[gen] bylo[neut]! of laughter was 
The embedded sentence again contains a noun identical to the head noun in the higher noun phrase and this noun also undergoes deletion, but only after the quantifier phrase undergoes Attributive Agreement, as a consequence of which the $Q$ node receives feminine specifications (cf. Section 10.1 in Chapter One).

As shown in (26), the Q node is now under an NP node which must be assigned the accusative case (for it is marked \{Patient\}, dominated by a VP node, and the verb with which it is associated has no special government features). The case specification is lowered to the numeral, and the end result is thus (23) (Devoček [gen p1] ja[nom] videl odra [acc fem] 'of girls I saw one').6

The putative underlying structure of (22a), reproduced in a somewhat abbreviated form as (27), is shown under (28). (Following Chvany 1975, the verb bylo 'was' in (27) is represented in (28) by the existential symbol $\exists$, to distinguish it from the homonymous copulative verb, and the role of the pronoun in $u$ menja 'by me' is defined as Locative, though the framework of the present analysis differs from Chvany's in many respects [on $\exists$ in Chvany's theory see footnote 7 below]. A node label Det to dominate elements such as vsego 'only' within QPs is postulated in Bresnan 1973. Its special significance for Russian is pointed out at the end of Section 1.4 below.)

$$
\begin{aligned}
& \text { Druzej[gen p1] u menja } \left.\begin{array}{c}
\text { byzo[neut] } \\
* b y Z a[\text { fem] }
\end{array}\right\} \text { sego odna[nom } \\
& \text { of friends by me was only one } \\
& \text { fem] podruga[nom]. } \\
& \text { girlfriend }
\end{aligned}
$$

The structure under (28) is essentially the same as (24). The only significant differences are that, first, the classifier noun is not identical to the Partitive noun, and, secondly, the noun in the embedded sentence which is identical to the higher, Partitive noun is in a subject phrase, not in a direct-object phrase (on the relationship between tree positions and grammatical functions see Chomsky 1965, 68-74; for more extensive explorations of

${ }^{6}$ The derivation can be assumed to include a lowering of the Partitive NP, as the only constituent left in $\mathrm{S}_{0}$, into $S_{1}$. This operation makes no difference in the sur-face structure, however. 
the notion of grammatical subject see esp. Keenan 1974 a and 1974b, Anderson 1975, and Chvany 1975, 15-41.

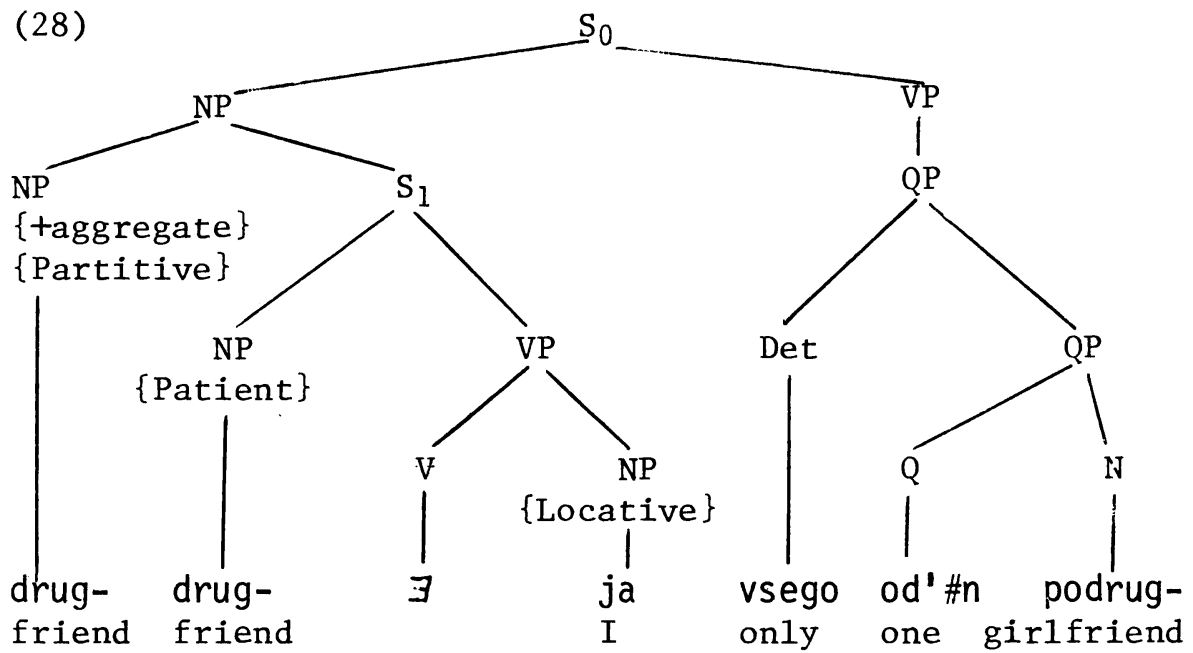

Deletion of the noun from the embedded sentence and its replacement by the QP node thus yields (29).

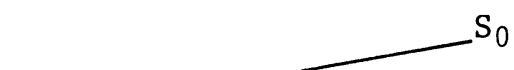

\{taggregate\}

\{Partitive\}
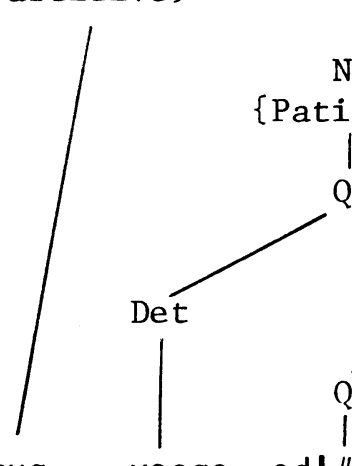

drug- vsego od'\#n- podrug-

friend only one girlfriend

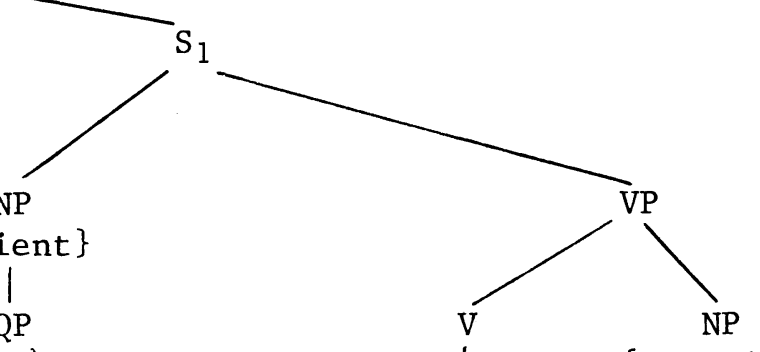

\{Locative\}

The NP node which dominates the quantifier phrase is assigned the nominative case, and the case specification 
is then lowered to the constituents of the quantifier phrase. The NP node has only the "provisional" gender specifications (not shown), for it dominates a QP node and $Q P$ nodes have no gender (the inherent gender of classifier nouns is not copied onto the QP nodes which dominate them). The verb thus cannot possibly have a feminine ending and can only have a neuter ending, manifesting the "provisional" specifications of the NP node.

The grammatical number of the verb is also determined by the "provisional" [-Plural] specification on the NP node, for QP nodes have no number. As for "contextual" number on the NP node, the number of intended referents (symbolized by \{taggregate\} or \{-aggregate\}), either it is cancelled out due to the fact that the node only dominates a $Q P$, or one can assume that contextual number is not specified for an NP which corresponds to a Partitive NP in the next higher sentence. (The latter assumption seems more plausible from the conceptual standpoint but is less amenable to formalization. It would have to be stated in terms of conditions on the well-formedness of semantic representations.)

As for the order of the constituents in the surface sentence, it is determined by their relative communicative weight. The quantifier phrase is the most informative element in the sentence and it must therefore be the rightmost in linear order ( $I$ have no concrete suggestions for the mechanism by which this is accomplished). Any other word order would be quite awkward for this particular sentence, but in general Type (7) sentences do not necessarily have the word order exhibited by the examples given so far in the present section. The sentences under (30), for instance, also represent Type (7) although their word order is not Partitive NP--Verb--Quantifier (Phrase). Sentence (30a) is cited in Skoblikova 1959a, 92, where she points out that the verb could not possibly have a feminine ending; (30b), which occurs in Galkina-Fedoruk 1958, 250 , exhibits the same word order and can only be interpreted as a Type (7) sentence because of the determiner associated with the quantified noun; in (30c), which represents oral discourse, the quantifier phrase čelovek dvadcat' 'about twenty people' is the focus of the sentence from the communicative standpoint but it is marked as such by emphatic intonation and therefore need not be sentence-final. Note that since pronouns cannot be modified by attributive quantifiers (except as in (14a) above), the pronoun $i x$ 'of them' in this sentence can 
only represent a Partitive NP, like druzej 'of friends' in (27), for example, despite the fact that it follows the quantifier phrase.
(30) (a) ZagotovZeno[neut] silosa[gen] odna[nom fem] [is] ready of silage one tonna [nom]. ton
'There is one ton of silage ready.'
(b) U Śxmatova otmečeno [neut] ètix značenij[gen] in Shakhmatov [is] noted of these meanings dvenadcat' [nom]. twelve
'There are twelve of these meanings noted in Shakhmatov.'
(c) [Ne odna ved'.] Čelovek [gen] dvadcat'[nom] ix not alone after all people twenty of them [gen] sobralos'[neut]. [has] gathered
' [After all, (she) is not alone.] There are about twenty of them gathered.'

In $(30 a-b)$, then, the word order is Verb--Partitive NP--Quantifier Phrase, and in (30c) it is Quantifier Phrase--Partitive NP--Verb. The order illustrated in (31) below, where the quantifier is mnogo 'many,' is similar to the latter in that the verb comes last, but in these sentences the Partitive phrase precedes the quantifier ((31a) is cited by Gorelova [1969], who points out the prevalence of such sentences in colloquial usage). In (32), where the quantifier is also mnogo 'many,' the verb stands between the quantifier and the Partitive phrase, but in distinction from the order that is typical for Type (7), the quantifier precedes the verb and the Partitive noun follows it $((32 a)$ is cited in Kamynina 1961 with the comment that the verb cannot be pluralized in sentences with such word order, in distinction from sentences with the same units arranged differently [pp. 21-22]).

(31) (a) Da tut $i$ televizorov[gen] mnogo stalo[neut]. here also television-sets many has become

'There are now also many television sets here.'

(b) tto-to $i x[g e n] v$ poslednee vremja mnogo pojavilos' for some reason of them lately many has ap[neut] $v$ pečati. peared in print 
'For some reason quite a few of them have appeared in print lately.

(c) Gadov [gen] mnogo $v$ Ziteratum napolzZo[neut]. of creeps many into literature has crawed in 'Quite a few creeps have [recently] become writers.'

(32) (a) Mnogo byzo kupleno[neut] knig[gen]. many was bought of books

'There were many books bought.'

(b) Osobenno mnogo byzo[neut] min-sjurprizov[gen]: especially many was of mine-surprises vsjakie tam avtomički, zažigalki, portsigary. 'There were especially many "surprise mines": various pens, lighters, cigarette cases.'

The sentences in (30)-(32) demonstrate not only that the surface order of constituents in sentences of Type (7) is not fixed but also, more significantly, that the fact that a verb in such sentences cannot be pluralized is not a function of word order but of syntactic relations: the verb is not associated with the noun which denotes the quantified entity. The verb is only associated with the quantifier, or quantifier phrase, and there is thus no basis for its pluralization whatever the order of constituents when Verb Agreement operates.

The derivation proposed here for sentences of Type (7) generally involves grammatical processes which have independent justification. The only exception is QP Lowering. Arguments in favor of such a rule despite its uniqueness, or rather arguments in favor of underlying structures such as (24) and (28) which render such a rule necessary, are given in Carden 1968 and 1970a and in Lakoff 1970a, 173-183 and 1970b (see also Lakoff 1969), and cf. also McCawley 1972, $509 \mathrm{ff}$. (for counter-arguments see Partee 1970 and Jackendoff 1971b). The nature of the rule has remained rather obscure in all of these discussions (Carden called it Q-Magic in 1968), perhaps because English can provide little inflectional evidence to support any specific account. Russian, of course, is very different in this respect, and the Russian data indeed fall into place with a QP Lowering rule--not only in 
sentences of Type (7) but also in sentences of other types, as the analyses that follow will show. ${ }^{7}$

1.4 The last sentence cited under (3) to illustrate contexts which do not allow alternative number manifestations is reproduced below as (33).

$$
\begin{aligned}
& \left.\begin{array}{l}
\text { Ostalis'[p1] } \\
\text { * OstaZos'[sg neut] }
\end{array}\right\} \text { èti[nom] sem'[nom] mal'čikov } \\
& \text { remained these seven boys } \\
& \text { [gen]. } \\
& \text { 'These seven boys remained.' }
\end{aligned}
$$

As noted by several Russian grammarians (though somewhat ambiguously), when a phrase which contains a numeral in the nominative case also contains a pluralized attributive in the nominative case, then a verb associated with it must be pluralized (cf., e.g., Skoblikova 1959a, 108109; Svedova 1970, 554; and Rozental' 1971a, 217).

In order to account for the mandatory plural number of the verb in such sentences, it will be necessary to account first for the plural number and nominative case of the attributives which appear to determine it. Consider the sentences under (34).
(34) (a) Èti[nom] tri[nom] studenta[gen sg] priexali these three students arrived věera. yesterday
(b) Vse[nom p1] 51 [nom] student [nom sg] učastvovali al1 students
[p1] $v$ sorevnovanijax. in competitions

The quantified nouns in (34) have singular endings and yet the attributives associated with them are pluralized--and must be pluralized. It should perhaps be emphasized again that the number manifested in association with phrases such as the ones modified by these attributives is not necessarily plural, as illustrated in (35).

${ }^{7}$ In the discussion in the present section I concentrated on sentences which involve agreement, but a few words are also in order on sentences such as (i), which do not involve agreement but represent Type (7) as well. 
(i) Korov [gen p1] dve[nom fem]. of cows two

'There are two cows.'

Such sentences can be assumed to derive from an underlying simplex sentence, i.e., a sentence which does not contain another sentence. The sentence under (ii) would then be roughly analogous in its derivation to, e.g., (iii), where the verb is merely a copula to carry tense and mood.

(ii) Korov[gen p1] bylo[neut] dve[nom fem] of cows was two

'There were two cows.'

(iii) Boris byl sportsmenom.

Boris was sportsman

'Boris used to be a sportsman.'

Another possible analysis, which seems more plausible, is that the underlying representation of ( $i$ ) is something like (iv).

(iv)

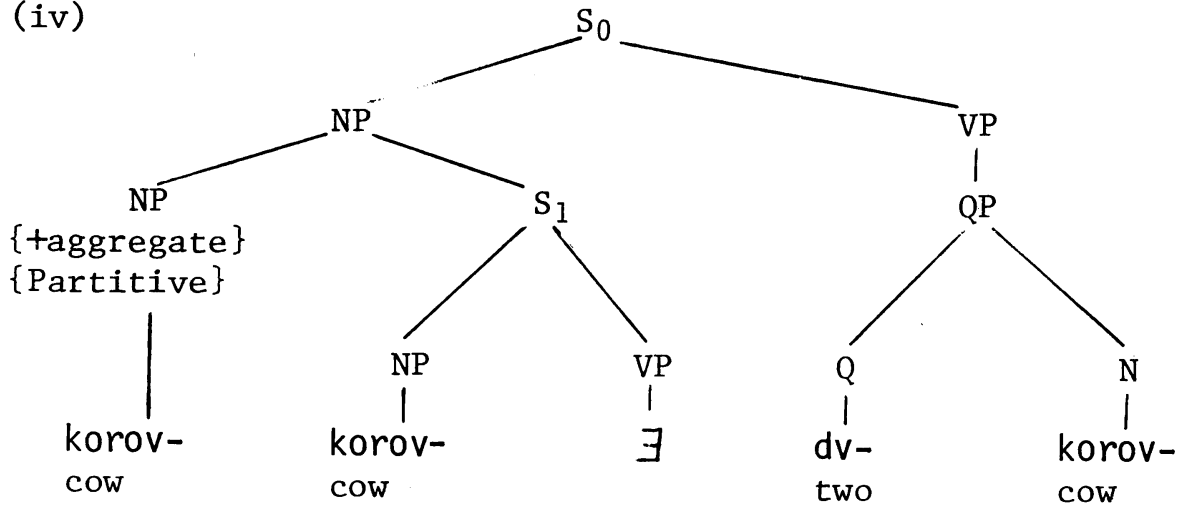

The absence of an overt est' in (i) (and the unacceptability of sentences such as (v)) can be attributed to a rule which deletes the verb $\exists$ in certain environments.

(v) *Korov[gen $\mathrm{pl}]$ est' dve[nom fem].
of cows there are two of cows there are two (cont.) 
(35) (a) Včera priexalo[sg] tri[nom] studenta[gen sg]. yesterday arrived three students

(b) $V$ sorevnovanijax učastvoval [sg] 51 [nom] student in competitions participated students [nom $\mathrm{sg}$ ].

The plural number manifested by the attributives in (34) apparently matches the "real" number of the quantified nouns, and the singular endings of these nouns are only a consequence of their association with the numerals at a relatively superficial level in the derivation of these sentences. The numerals in (34) can be assumed to derive from embedded (not higher!) sentences. Compare, for example, the sentences under (36).

(36) (a) $T e[$ nom p1] mižciny[nom p1], kotoryx[gen p1] bylo [sg neut] desjat'[nom], igrali[p1] $v$ karty.

'Those men, of whom [there] were ten, played cards.'

(b) Te[nom p1] desjat'[nom] mužcin[gen pl] igrali [p1] $v$ karty.

'Those ten men played cards.'

I would like to suggest that (36b) derives from the structure underlying (36a), i.e., from a configuration as in (37). The putative process which yields (36b) from (37), which will hereafter be referred to for mnemonic purposes as QP Raising, appears to be as idiosyncratic as QP Lowering, but it does seem to account for a number of phenomena (arguments for postulating such a process in English grammar, to account for properties of sentences with post-determiner quantifiers, are presented in Carden 1970b). Before considering the advantages of postulating QP Raising, however, note that it is not completely

The deletion of $\exists$ from structures such as (iv) (or from their derivatives) can be assumed to take place only when grammatical tense and mood are unmarked, and then bylo in sentences like (ii) can be analyzed as a pasttense form of $\exists$. (Another possible account is that $\exists$ is deleted regardless of tense specifications, and by $7_{0}$ in sentences like (ii) is then a copula after all. This is essentially the approach advocated in Chvany 1975, though the structures from which $\exists$ is deleted according to Chvany's theory are different from the ones postulated here.) 
idiosyncratic. It involves deletion of a noun or noun phrase from an embedded sentence under identity to a higher noun or noun phrase, which is a regular phenomenon, and, depending on the derivation postulated for $S_{1}$, it involves either deletion of a copulative verb, which also takes place in Relative Clause Reduction, or deletion of the verb $j$, which would take place anyway (cf. footnote 7).

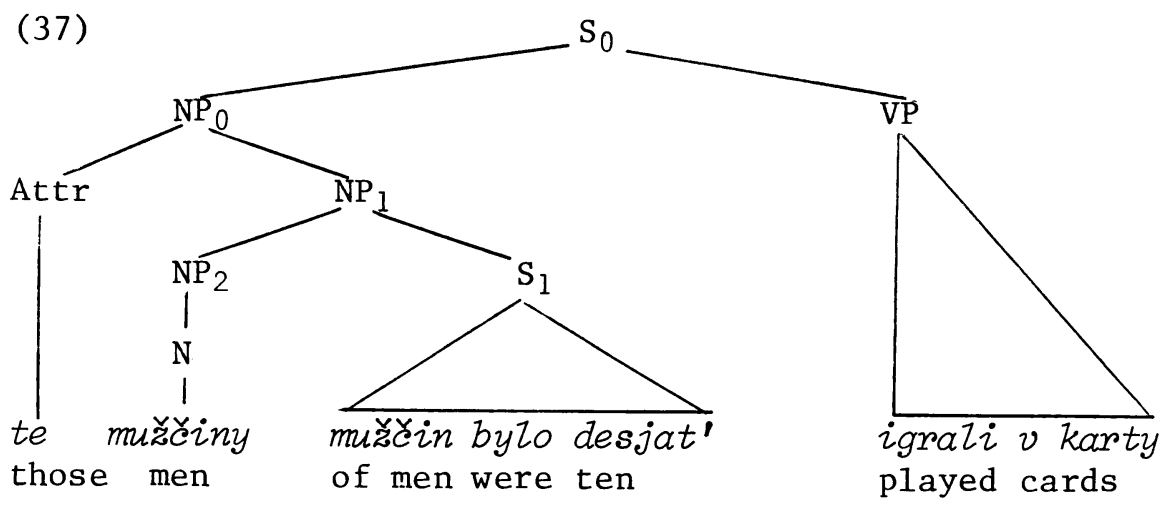

How does (37) account for (36b)? The grammatical case assigned to $\mathrm{NP}_{0}$ must be nominative, since there is no basis for any other case. The grammatical number of this node must be plural, because its head, $\mathrm{NP}_{2}$, is presumably marked \{taggregate\}. The verb associated with $\mathrm{NP}_{0}$ thus can only have a plural ending regardless of whether the phrase contains a plural attributive in the nominative case or not. As for the attributive, it must manifest the number of the NP with which it is associated, $\mathrm{NP}_{1}$, whose number is the number of $\mathrm{NP}_{2}$. The attributive, then, can also only have a nominative plural ending.

After QP Raising, the internal structure of $\mathrm{NP}_{2}$ can be assumed to be as in (38).

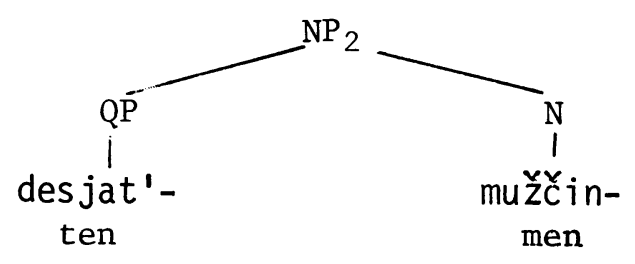

The $\mathrm{NP}_{2}$ node is marked for the nominative case--a marking presumably lowered at some point from the superordinate $\mathrm{NP}$ node, $\mathrm{NP}_{0}$, and this marking is now lowered to 
the QP node, which by a special government feature imposes the genitive case on the $\mathrm{N}$ node associated with it. The result is (36b). (Note that although the quantifier phrase can be assumed to have contained a classifier noun in the ultimate underlying representation, that noun must have been deleted in the "processing" of $\mathrm{S}_{1}$.)

The derivation of (34a) would be identical, except that the numeral is tri 'three,' and it is one of the numerals which impose on an associated noun not only the genitive case but also a special grammatical number which can be referred to as "paucal" (cf. Hockett 1958, 234), for it is a grammatical number only imposed by the numerals poltora 'one and a half,' dva 'two,' tri 'three,' and četyre 'four,' i.e., it represents small qunatities. 8 Thus when the numeral is moved to the position of attributive modifier in the derivation of (34a), the $\mathrm{N}$ node dominating student- receives genitive as well as "paucal"

${ }^{8} \mathrm{Oba}$ 'both' is also sometimes listed with these numerals in this connection (see, e.g., Zaliznjak 1967a, 47). It is not a pure numeral, however, but apparently a lexical unit which combines vse 'all' and dva 'two.' One could say, for example, vse tri studenta 'all three students,' but not *vse dva studenta 'all two students,' only oba studenta 'both students.' (This account of oba is suggested in Suprun 1969, 37-38 and mentioned in Padučeva 1974, 112 as a well-known fact. Padučeva [ibid.] also mentions that $o b a$ is a substitute for èti $d v a$ 'these two' in certain contexts, but she does not substantiate this claim. On the idiosyncracies of $o b a$ as a determinernumeral combination see also Worth 1959, 126-127.) Predicates associated with subject phrases containing oba indeed must always be pluralized (cf., e.g., Skoblikova 1959a, 108-109), and oba cannot function as quantifier in Type (7) sentences just as vse 'all' or vse tri 'all three' cannot; cf. 'Studentov[gen p1]--oba[nom] 'of students [there are] both'; *Studentov[gen p1]--vse [nom] (tri [nom]) 'of students [there are] al1 (three).' On1y pure partitive quantifiers can function as quantifiers in Type (7) sentences and none of the "basic" quantifiers can-this is one of the fundamental differences between the two categories of quantifiers. 
specifications, and the latter specifications are realized by a singular ending in this instance. 9

9"Paucal" specifications are realized by plural endings when they are manifested by nouns which follow the adjectival declension, e.g., tri[nom] podležaščix[gen pl] 'three subjects,' or četyre [nom] prilagatel'nyx [gen p1] 'four adjectives,' and by special endings which are neither singular nor plural when the nouns are čas 'hour,' Sar 'ball,' '̌ag 'step,' or rjad 'row.' Cf., e.g., poltora [nom] časáa [gen pauc] 'one and a half hours' and oḱolo čása [gen sg] 'around an hour'; tri[nom] šagá [gen pauc] 'three steps' and $n i$ odnogo [gen sg] šága[gen sg] 'not one step.'

Somewhat difficult to account for is the fact that nouns which follow the adjectival declension and are inherently feminine may have nominative instead of genitive endings when associated with one of the "paucal" numerals through QP Raising, e.g., tri[nom] vannye [nom p1] 'three bathrooms,' and some speakers even consider genitive endings unacceptable then (these statements are based on informant responses as we11 as on comments in Rozental' 1968, 281 and 1971a, 231; Senkevič 1964, 12; and Kozyreva and Xmelevskaja 1972,60). The "paucal" specifications (perhaps [+Plural, +Sing]) can apparently neutralize genitive specifications under certain conditions. This also happens when "paucal" specifications are attached to Attributive nodes as a consequence of QP Raising, i.e., when a noun such as studenta in (34a) has an attributive associated with it and the configuration following QP Raising is as in ( $i$ ).

(i)

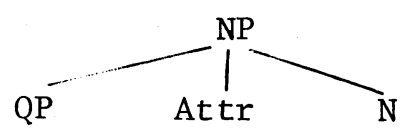

Attributives always manifest "paucal" number by plural endings and should be in the genitive, as in (ii). (The numeral in (ii) is actually in the accusative rather than the nominative case, but when a "paucal" numeral in the accusative case does not manifest animacy, it imposes the genitive just as when it is in the nominative case.)

(ii) My s tovarišcem vajali poltora bol'šix [gen p1] arbuza [gen sg].

'My friend and I took one and a half large watermelons.' 
The case manifested by attributives in phrases representing structures such as (i) may be nominative when the quantifier is a "paucal" numeral if the modified noun is inherently feminine, and sometimes, or for some speakers, also when the modified noun is inherently masculine or neuter (cf., e.g., Okon' and Polovnikova 1964, 14; Lebedeva 1968, 64; Rozental' 1968, 279-280; Gorbačevič 1971, 259; and Kozyreva and Xmelevskaja 1972, 61-62). This phenomenon is exemplified by the sentences under (iii) ( (a) was printed in Literaturnaja gazeta, the remaining two in Voprosy jazykoznanija).

(iii) (a) Ja verju, čto pridët den', kogda dve [nom] naši [nom p1] velikie [nom p1] straný[gen sg] budut great countries doverjat' drug drugu.

'I believe that the day will come when our two great countries will trust one another.'

(b) Po smyslovomu soderžaniju vydeljajutsja četyre by semantic content are distinguished four [nom] osnovnye [nom p1] klassa[gen sg] slovesnyx znakov. basic classes of verbal signs

(c) Pri ètom zabyvajutsja dva[nom] važnye [nom p1] thereby are forgotten two important obstojatel'stua[gen sg]. circumstances

The quantified noun in (a) is feminine, in (b)--masculine, and in (c)--neuter. It should be added that sentence (a) is not a typical example, because nominative attributives are more typical in association with feminine nouns whose genitive singular and nominative plural forms are completely identical rather than in association with nouns like strana 'country,' whose genitive singular form is straný and the nominative plural form is strány (cf., e.g., Galkina-Fedoruk 1964, 365 and Kozyreva and Xmelevskaja 1972, 62).

The syntax of "paucal" numerals is thus quite complex and any formal statement of the rules involved would have to be fairly elaborate (see, e.g., Dingwall 1969 for an attempt to deal with some of the data presented here). There is little to be gained from such a formal (cont.) 
As for the derivation of (34b) (reproduced below), the only difference is that the quantified noun has a nominative singular ending.

(34b) Vse[nom p1] pjat'desjat odin[nom sg masc] student al1 fifty one students

[nom sg] učastvovali[p1] $v$ sorevnovanijax. participated in competitions

In distinction from other quantifiers, the numeral odin 'one' does not impose the genitive case--whether it occurs independently or as the righthand component in compound numerals--and it can be assumed to impose singular specifications just as dva 'two,' tri 'three,' etc. impose paucal specifications. This also applies to attributives associated with the quantified noun; cf., e.g., tridcat' odna[nom fem] inostrannaja[nom sg fem] studentka[nom sg fem] 'thirty-one foreign female-students.' The numeral in (34b) also manifests the gender of the quantified noun, but is apparently acquires gender not by Attributive Agreement after QP Raising but rather by Attributive Agreement prior to QP Raising and prior to the deletion of the classifier noun, at a stage where the underlying representation is roughly as in (39).

statement at the moment and I will therefore not try to make any specific suggestions now.

Finally, note that according to the approach advocated here, the "paucal" numerals impose the genitive case like all other numerals (except for odin 'one') and impose a special grammatical number besides. According to a different approach, proposed by Zaliznyak, these numerals can be assumed not to impose any number at all but only a special case; Zaliznyak calls it "scëtnaja forma" (Zaliznjak 1967a, 46-48, and cf. also Naylor 1974). 


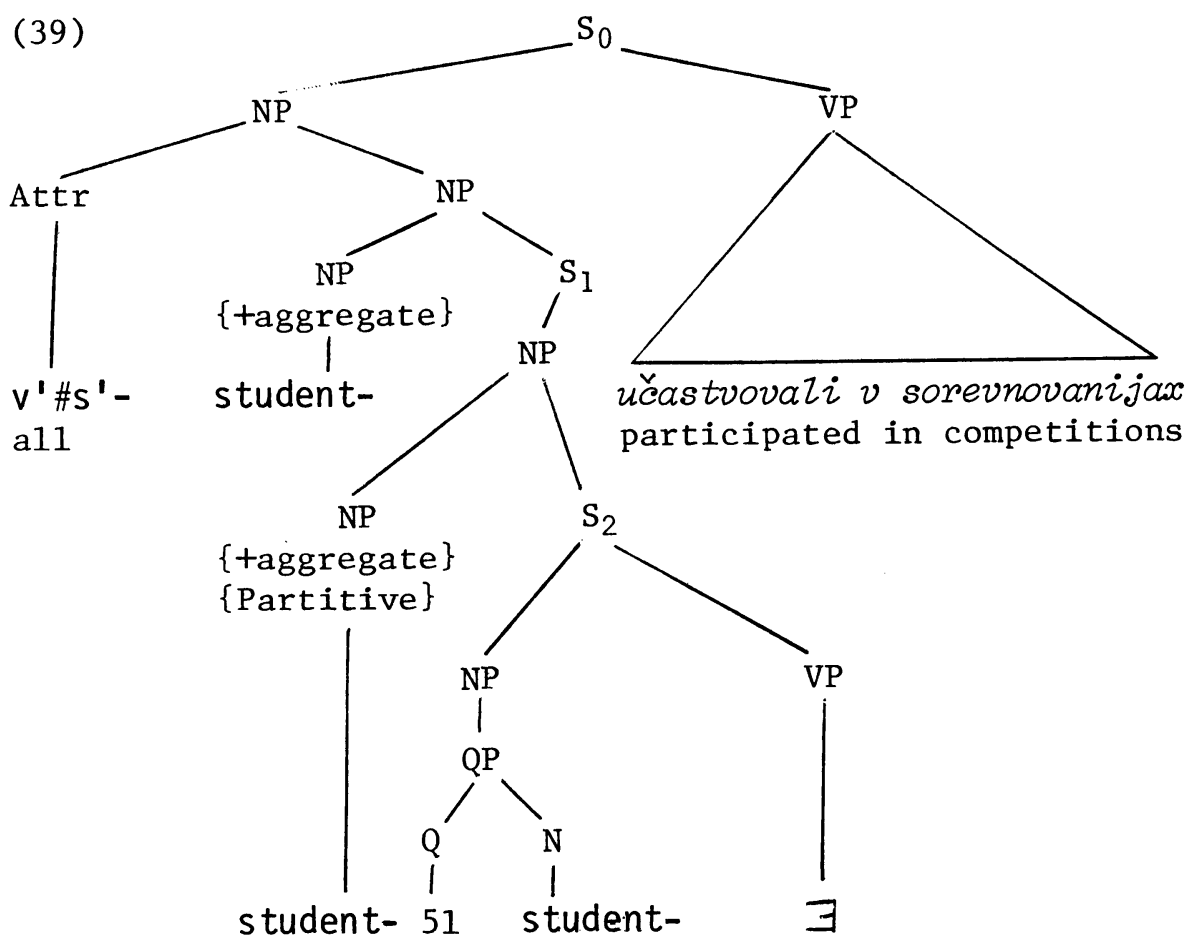

Attributive Agreement must take place within the QP before the classifier noun is deleted, so that the masculine gender manifested by the numeral in (34b) is actually not the gender of the noun it modifies in the surface structure but rather the gender of a noun identical to it. This account also applies to other numerals which manifest gender (poltora 'one and a half' and $d v a$ 'two') as well as to "collective" forms (dvoe, etc.).10

10 The assumption that the numeral is assigned gender at an earlier stage in the derivation raises the question of the cyclicity of the rules of Agreement (on the cyclical application of rules in transformational-generative grammars see, e.g., Bach $1974,110-129)$. I would say that Attributive Agreement within QPs is cyclic and perhaps also within PredPs, but there is insufficient evidence for the assumption that the rules of Agreement apply cyclically in Russian otherwise (for some discussion of the problem with reference to Czech see Vanek 1970; with reference to English see Borkin and Peterson 1972, 70-72; and with reference to Russian see Babby 1973b). 
The attributives illustrated in (34), vse 'all' and èti 'these,' are both determiner-type attributives, and indeed such attributives are the typical ones for such constructions, i.e., constructions in which the attributive is external to the quantifier and quantified noun. The phrases under (40) illustrate determiner-type attributives other than vse and èti in such constructions.

(40) (a) každye [nom p1] dve [nom] nede $i$ [gen sg] 'every
two weeks';

(b) kakie-to[nom p1] dve[nom] korobki[gen sg] 'some two boxes';

(c) te [nom p1] samye [nom p1] četyre [nom] mublja[gen $\mathrm{sg}]$ 'those very same 4 rubles';

(d) poslednie [nom pl] poltora[nom] goda[gen sg] '[the] last one and a half years';

(e) pervye[nom p1] tri[nom] desjatiZetija[gen sg] 'the first three decades';

(f) ostal'nye [nom p1] tri[nom] Zošadi[gen sg] '[the] remaining three horses.'

Non-determiners are less typical but are not excluded from such constructions. A phrase such as, e.g., novye [nom p1] dva[nom] zavoda[gen sg] '[the] new two plants' is also acceptable (Skoblikova 1967), and participles, which may also be postposed, are especially common (as formulated by Senkevic [1964, 12], a participle which precedes a numeral and a noun phrase must always have a nominative plural ending). Prepositive participles are illustrated in $(41 a-b)$, and postpositive ones in (41c-d) (note that (41d) illustrates an "external" determiner as well as a determiner which only modifies the quantified noun).

(41) (a) Ostavšiesja [nom pl] na vaxte desjat' [nom] remained on guard ten

členov[gen p1] èkipała v tečenie 8 minut vyveli members of crew

[p1] tanker iz zony pozara.

'The ten members of the crew who remained on guard brought the tanker out of the fire area in 8 minutes.'

(b) Priexavšie[nom p1] noč'ju tri[nom] tovarišča arrived at night three comrades [gen sg] rano utrom prišli[pl] na rabotu.

'The three comrades who had arrived at night came to work early in the morning.' 
(c) V tot den' byli arestovany [p1] dva[nom] čeloveka that day were arrested two persons [gen sg], imevšie[nom $\mathrm{pl}$ ] pri sebe zarjǎ̈ënnye had pistolety.

'That day two persons who had loaded pistols on them were arrested.'

(d) Vse[nom p1] četyre [nom] našix[gen p1] skripača al1 four our violinists [gen sg], prinimavšie[nom p1] $v$ ètom godu took this year učastie $v$ konkurse, polučili prenii. part

'Al1 four of our violinists who took part in the competition this year won prizes.'

Postpositive participles may also be associated just with the quantified noun and governed by the quantifier, and then they have a genitive ending.

Finally, Russian grammarians note that not all attributives which precede quantifiers have nominative endings. Galkina-Fedoruk [1964, 365] lists four adjectives which get genitive endings: celyj 'whole,' polnyj 'full,' dobryj 'good,' and Zǐ̌nij 'extra'; Rozental' lists the first three and mentions that there are a few others (Rozental' 1971a, 231). Consider the examples under (42).

(42) (a) U koški pojavilis'[p1] kotjata, celyx[gen p1] by cat appeared kittens whole četyre [nom] štuki [gen sg]. four pieces

'The cat had kittens, a whole four of them.'

(b) Emu bylo[sg] nepolnyx [gen p1] dvadcat' dva[nom] to him was not full twenty one goda[gen sg]. years

'He was almost twenty-two years old.'

(c) Do goroda ostalos'[sg] dobryx [gen p1] poltora to city remained good one-and-a[nom] kilometra[gen sg]. half kilometers

'To the city [there] remained a good one and a half kilometers.' 
(d) Kakix-nibud'[gen p1] dvadeat'[acc] Zet[gen p1] some twenty years nazad bylo trudno predstavljat' takoe naučnoe ago was difficult ucrezdenie.

'Some twenty years ago it was difficult to imagine such a scientific institution.'

The genitive attributives only modify the numerals-they are QP modifiers rather than NP modifiers. They have a special reading in these sentences which depends on their association with the numerals and they would not make any sense in these sentences if the quantifiers were deleted or even if the quantifiers were to precede rather than follow them (the only exception is $(42 \mathrm{~b})$, where the numeral could also precede the genitive attributive; I am not sure how to explain this difference). In (42a), for example, if the quantifier were to precede the genitive attributive (četyre celyx štuki 'four whole pieces'), then the attributive could only be interpreted as modifying the noun and hence as qualifying the kittens as whole ones, which would make the sentence rather strange. Genitive attributives in pre-quantifier position are thus not analogous to nominative attributives in the same position, for the latter are independent of the presence of the quantifier. Compare, for example, èti[nom] tri studenta 'these three students' and èti studenty 'these students,' poslednie[nom] poltora goda 'the last one and a half years' and poslednie gody 'the last years,' versus dobryx [gen] poltora kilometra 'a good one and a half kilometers' and ?dobrye kilometry 'good kilometers,' kakix-nibud'[gen] dvadcat' let 'some twenty years' and kakie-nibud' gody 'any years.'

The underlying structure of the subject phrase in (42a) is then perhaps as in (43).

Declinable QP determiners can be assumed to be always assigned the genitive case and plural number (indeclinable QP determiners are, e.g., elements such as vsego 'only' [cf. (28) above], Ziš' 'only,' or rovno 'exactly'). Otherwise the operations which yield the subject phrase in (42a) are not new. The only difference in this instance is that the quantifier phrase is not preposed to the noun, it is not "raised." The position of the quantifier phrase in (42a) can be compared to that of dvoe 'two' in (44a), where the numeral is not "raised," in contrast with (44b), where it is. 


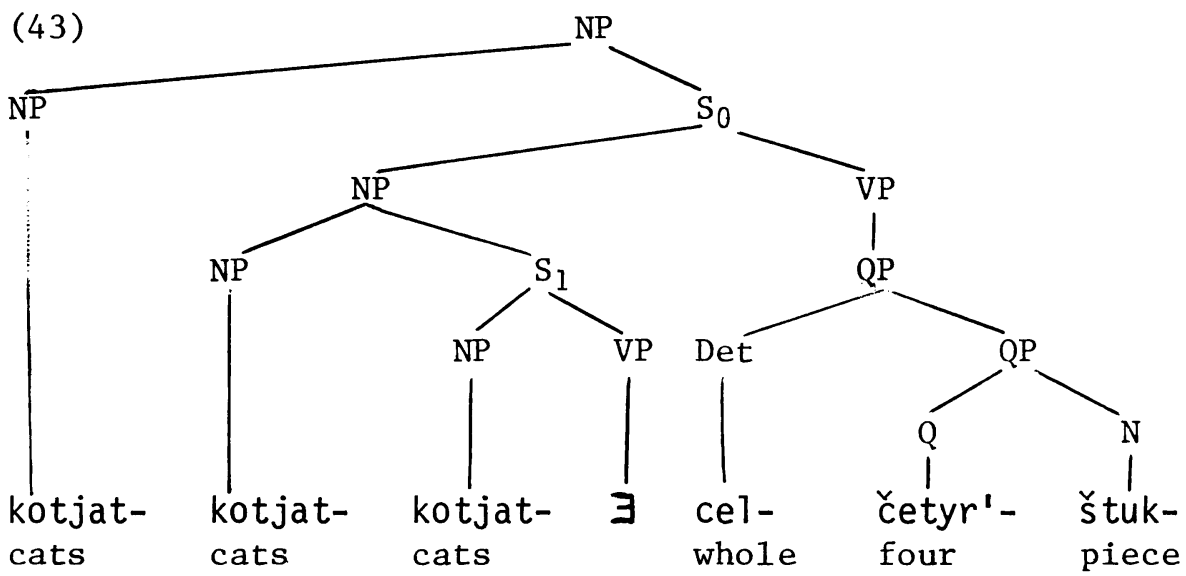

(44) (a) U koški pojavilis' kotjata[nom], dvoe[nom]. by cat appeared kittens two

'The cat had kittens, two of them.'

(b) U koški pojavilis' dvoe[nom] kotjat[gen]. by cat appeared two kittens

'The cat had two kittens.'

A quantifier phrase which contains a single numeral is considerably more likely to be "raised" than a quantifier phrase which also contains a determiner and a classifier noun. Quantifier phrases of the latter type are in any case not likely to be candidates for "raising," for in most cases they seem to derive from higher sentences rather than from embedded sentences, as in $(42 b-c)$, whose derivation is analyzed in the next section.

1.5 Sections 1.1 through 1.4 focused on sentences which have numerals in the nominative case and do not allow alternative number manifestations. Section 1.1 dealt with sentences in which the numerals were not associated with any noun. The grammatical number manifested in association with such numerals can only be singular.ll Section

${ }^{11}$ An interesting phenomenon worth mentioning in this connection is the tendency to signify number in such contexts by nouns instead of numerals whenever possible, i.e., by lexical units which do have inherent gender. The noun dvojka 'two,' for example, is used instead of the numeral $d v a$, the noun desjatok 'ten' is used instead of desjat', and the noun edinica 'one' is used for odin, as in, e.g., Xislo korreljacij kolebletsja $v$ predelax (cont.) 
1.2 dealt with sentences in which the predicates were long-form adjectives. Such predicates must be pluralized, a fact accounted for by assuming that the underlying subjects in sentences with predicate adjectives (and, for that matter, predicate nouns) are the quantified nouns, and the numerals derive from embedded sentences. Section 1.3 dealt with sentences in which the numerals were separated from the quantified nouns and the verbs could not be pluralized. The verbs in such sentences were shown not to be associated with the quantified nouns; they are only associated with the numerals. Section 1.4 dealt with sentences with nominative attributives in the subject phrases and mandatorily pluralized verbs. As in Section 1.2, the quantified nouns in such sentences were shown to represent underlying subjects, with the numerals derived from embedded sentences.

The present section focuses on sentences not distinguished by any of the formal features distinguishing the sentences discussed so far. Its central thesis is that pluralized verbs in sentences with numerals in the subject phrase can be accounted for as associated with the quantified nouns, and the numerals in such cases derive from embedded sentences. Nonpluralized verbs in most cases indicate a different derivation.

1.51 Several Russian grammarians have observed that what determines the choice between singular and plural verbs in association with subjects with numerical quantifiers is whether the focus of the sentence from the communicative standpoint is the quantity signified by the numeral, or some other element or elements in the content of the sentence. When the focus of the sentence is quantity, then the verb is in the singular; otherwise it is pluralized (see, e.g., Skoblikova 1959a; Lobanova 1966, 32-33; and Gorelova 1969).

One corollary of this principle is a correlation (noted in, e.g., Svedova 1970, 554 and in other sources as well) between the number manifested by a verb and its position with respect to the subject phrase in terms of linear order, for in sentences in which the quantity is in focus, the subject phrase with the quantifier necessarily follows the verb (in intonationally unmarked discourse). Another, more interesting corollary is that in sentences

ot edinicy do 245 ' the number of correlations varies within the range of one to $245 . '$ 
in which the quantity is in focus all of the other constituents must carry relatively little communicative weight. The verbs in such sentences are therefore essentially existential, or verbs used in an existential sense, unless they are verbs which cannot possibly provide any new information in the given context (the correlation between existential verbs and singular number in sentences with quantifiers is noted in, e.g., Vinogradov and Istrina 1960, 502; Akopdžanjan 1964 and 1965; Galkina-Fedoruk 1964, 348; and Rozental' 1971a, 216; cf. also Šaxmatov 1925, 128). 12

The following are some typical examples.

(45) (a) V 1965 godu zdes' bylo[sg] vsego dva[nom] čZena [gen] Sojuza pisatelej.

'In 1965 [there] were only two members of the Writers' Union here.'

(b) Segodnja v klasse prisutstvovalo[sg] tol'ko dvenadcat'[nom] mal'čikov[gen].

'Today in class [there] were present only twelve boys.'

(c) Itak, do Berlina ostalos'[sg] tol'ko 896 [nom] kilometrov[gen].

'And so, to Berlin [there] remained only 896 kilometers.'

(d) Po ètomu voprosu suscestvuet [sg] dva[nom] menija [gen].

'On this question [there] exist two opinions.'

12 But note that an existential verb does not necessarily carry less weight than the quantifier, as demonstrated, for example, by the following sentence:

Odinnadcat'[nom] s poltinoj na ulice ne eleven with fifty-kopecks in street not valjajutsja[p1], tem bolee kogda do stipendii celyx sem' lie-around especially when until stipend whole seven dnej. days

'Eleven rubles and fifty kopecks do not lie around in the street, especially when there are seven whole days left until the stipend is given.'

For a corresponding caveat with respect to word order see the text below. 
(e) V oblasti za poslednie gody vystroeno[sg] 280 [nom] domov[gen] kul'tury, otkryto [sg] 237 [nom] bibliotek[gen].

'In the district in the last [few] years [there] have been built 280 cultural centers, [there] have been opened 237 libraries.'

(f) $V$ sadu roslo[sg] 15 [nom] jablon'[gen]. 'In the garden [there] grew 15 apple trees.'

(g) V našej kvartire živët[sg] 7 [sg] odinokix ljudej [gen], iz nix 5 celovek $v$ vozraste ot 67 do 80 let.

'In our apartment [there] live 7 single persons, of them 5 persons aged 67 to $80 . '$

(h) Itak, za dva goda, obratite vnimanie na cifm, $v$ kolxoz vernulos'[sg] 104 [nom] molodyx čeloveka [gen].

'And so, in two years, pay attention to the figure, [there] have returned to the kolkhoz 104 young men.'

(i) [U sosedej ǔ̌in.] Uzinaet[sg] 16 [nom]čelovek. have supper persons

'[The neighbors are having supper.] The number of those having supper is 16.'

(j) Na ostrove Cejlon za 6 mesjacev maljariej zabolezo[sg] 4[nom] milliona[gen] čelovek[gen]; caught million persons 60 [nom] tysjač [gen] $i z n i x$ pogibzi $i$ [p1].

'On the island of Ceylon, four million people caught malaria in six months; six thousand of them died.'

(k) Ved' na territorii Zapadnoj Germanii dejstvuet [sg] 15 [nom] peredatěikov[gen] "Svobodnoj Evropy".

'After all, in the territory of West Germany [there] are operating fifteen transmitters of [Radio] Free Europe.'

In $(45 a-c)$, the numerals are qualified by vsego 'only' and tol'ko 'only,' elements which serve to foreground the quantities. Some Russian grammarians have even claimed that verbs associated with subject phrases which contain such elements are "usually" in the singular (e.g., Vinogradov and Istrina 1960, 504; Rozental' 1971a, 217) or "must be" in the singular (Valgina 1973, 102). These claims, however, cannot be substantiated (cf. the 
observations in Skoblikova 1959a, 114). Consider, for example, (46).

(46) Na sentjabr' 2973 goda sredi vsej prozivajuščej v for September of 1973 among all living in obščezitijax predprijatija molodëži--a èto okolo dormitories of plant youth and that around desjati tysjač čelovek--liš' poltory[nom] tysjači ten thousand persons only one-and-a-half thou[gen] imeli[p1] professional'nuju podgotovku, a sand had professional preparation and okolo vos'mi[gen] tysjač[gen]--ne imeli[p1]. around eight thousand not had 'For September 1973, of all the young people living in the dormitories of the plant--and that comes to around ten thousand people--only 1,500 had professional preparation and around 8,000 had none.'

This sentence is interesting in several respects. First, it demonstrates that the presence of a $Q P$ modifier such as Ziš' 'only' does not necessarily affect the grammatical number of the verb. ${ }^{3} L i{ }^{\prime}$ ' does serve to foreground the quantity, but the informative weight of the remaining constituents in this particular sentence is too high for them to be relegated to a secondary position and quantity is thus not focal in this sentence despite its significance. Secondly, this sentence demonstrates that a verb associated with a subject phrase containing a numeral may manifest the number of the quantified noun even if the noun is absent from the surface subject phrase. In poltory tysjači imeli[p1] ... 'one and a half thousand had ...' the verb manifests the number of the deleted noun čelovek 'people' (cf. also ( $45 j)$ ). Thirdly, the last verb in (46) is associated with a phrase which does not contain any constituent in the nominative case. The verb apparently manifests the number of a deleted quantified noun with which it is associated in the underlying structure, and the surface subject okolo vos'mi tysjac 'around eight thousands' must be a quantifier phrase "raised" from an embedded sentence.

${ }^{13}$ According to Valgina $(1973,102)$, a pluralized verb is excluded in the sentence Vystupilo[sg] to l'ko tri[nom] oratora[gen] 'only three speakers spoke' because of the presence of tol'ko 'only,' but there must obviously be other factors involved. 
This point calls for a brief digression on number manifestations in association with quantifier phrases signifying approximate quantities. In such phrases there is often no constituent in the nominative case, as in (46) (and cf. also the illustrative sentences in $(47)-(48)$ ), and such phrases are thus not subjects by morphological criteria. Nevertheless, they are classified as subject phrases in Russian school grammars despite the inconsistency this represents, and plural number manifestations in association with such phrases--whether with or without an overt quantified noun--are not considered substandard, though the singular is viewed as preferable (cf., e.g., Vinogradov and Istrina 1960, 503 and Svedova 1970, 554; cf. also the critical comments on such judgments in Skoblikova 1959a, 112-114, and the statistical data in Patton 1969, showing that plural verbs in association with such phrases are in fact more frequent in printed texts than singular verbs).

Approximate quantities are perhaps more likely to be focal in sentences than precise quantities. In other words, they are less likely to be marginal from the communicative standpoint, but they can be, as illustrated in (47), where the verbs manifest the number of the quantified nouns. In the sentences under (48), on the other hand, the verbs do not manifest the number of the quantified nouns and the quantifier phrases appear to be
focal. 14

${ }^{14}$ The comments on quantifier phrases signifying approximate quantities also apply to quantifier phrases in which the numeral is introduced by the distributive po, as in (i).

\section{(i) Na kaðdom okne stojalo[sg] po odnomu cvetku[dat]. 'On each window [there] stood one flower.'}

Such phrases are not subjects by morphological criteria but they are otherwise indistinguishable from quantifier phrases which are considered subjects in Russian school grammars. Like phrases signifying approximate quantity, they apparently tend to be focal in sentences (cf. Lobanova 1966, 33-34, where verbs associated with such phrases are said to be usually in the singular), but they can also evidently derive from embedded sentences, for verbs associated with them may also manifest (cont.) 
(47) (a) Tislo členov gmuppy ne prevysaet pjati tysjac čelovek, prï̌èm svyše trëx[gen] tysjar[gen] iz nix prozivajut[p1] $v$ provincii.

'The members of this group number no more than five thousand, and over three thousand of them live in the provinces.'

(b) Po podš̈ëtom amerikancev, nas sejeas okmizajut [p1] do 80[gen] procentov [gen] takix predmetov [gen], kotoryx ne znali ljudi prołlogo veka.

'According to calculations made by Americans, up to eighty percent of the objects surrounding us now were unkown in the last century.'

(c) [Semidesjatipjatiletie MXAT vstretit $v$ novom zdanii na Tverskom bul'vare.] Na dnjax bolee 1400 [gen] zritelej[gen] vpervye zapolnjat[p1] prekrasnyj sovremennyj zal.

' [The Moscow Art Theater will celebrate its seventy-fifth anniversary in a new building on the Tverskoy Boulevard.] In a few more days, more than 1,400 spectators will fill its beautiful modern auditorium for the first time.'

(48) (a) V institute obučaetsja[sg] okolo desjati[gen] at institute study around ten tysjač [gen] studentov[gen]. thousand students

the number of the quantified nouns, as in the sentences under (ii) (cf. also Švedova 1970, 554).

(ii) (a) Po dvadcat' relovek priezzali[pl] s nim. 'Twenty people came with him [each time].'

(b) Yivut $[\mathrm{p} 1], v$ osnovnom, po retyre celoveka $v$ komnate.

'They live mostly four in a room.'

Note that quantifier phrases introduced by the distributive po can also occur in Type (7) sentences, as in (iii), though sentences such as (iiib) are generally avoided. (See Crockett 1976 for further discussion and bibliograhy.)

(iii) (a) Ix[gen pl] bylo[sg] po desjat' na kǎ̌doj of them was ten on each storone. side 
'There are around ten thousand students studying at the institute.'

(b) O populjarnosti boksa $v$ našej strane govorit tot fakt, čto im uvlekaetsja[sg] bolee 300 [gen] tysjač [gen] sportsmenov[gen].

'The popularity of boxing in our country is testified to by the fact that it attracts more than 300,000 sportsmen.'

(c) Za pjatiletku budet vvedeno[sg] $v$ stroj ne menee 1600 [gen] avtomatizirovannyx sistem[gen] upravlenija.

'During the five-year plan period no less than 1,600 automatic control systems will be put into operation.'

1.52 To return to the central topic of discussion, there is a close correlation between the grammatical number of a verb in a sentence with a numeral in the subject phrase and the relative significance of the numeral from the communicative standpoint. It is not only a question of rhetorical emphasis or subjective judgment, however, for there are sentences in which singular endings for the verbs are not acceptable, as in, e.g., (49).
(a) $\operatorname{Spor}[\mathrm{acc}]\left\{\begin{array}{c}z a v j a z a Z i[\mathrm{p} 1] \\ * z a v j a z a Z o[\mathrm{sg}]\end{array}\right\} d v a[\mathrm{nom}]$ novyx[gen] argument started two new mal'čika[gen].
boys
'The argument was started by the two new boys.'

(b) Na sobranii $\left\{\begin{array}{c}\text { zasumeli }[\mathrm{p} 1] \\ { }_{\text {zasumelo[sg] }}\end{array}\right\}$ dve[nom] zenšiny at meeting started-to-wrangle two women [gen].

'Two women started to wrangle at the meeting.'

Singular verbs are inappropriate for these sentences despite the fact that the order of their constituents is as in sentences in which the verbs are not pluralized, e.g., (45). The verbs in these sentences must manifest

'There were ten of them on each side.'

(b) ?Cvetov[gen p1] na kazdom okne stojalo[sg] po of flowers on each window stood odnomu. one 
the number of the quantified nouns, like verbs in sentences in which the subject phrases contain nominative attributives. The numerals in (49) can therefore be assumed to derive from embedded sentences, like the numerals in sentences with nominative attributives. The question this account raises is the following: what underlying configuration is excluded for (49)? What would be the configuration which would yield a sentence in which the subject phrase contains a numeral and the verb has a singular ending? A possible answer is that this would be a configuration like the one underlying Type (7) sentences, i.e., a configuration as in (50).

(50)

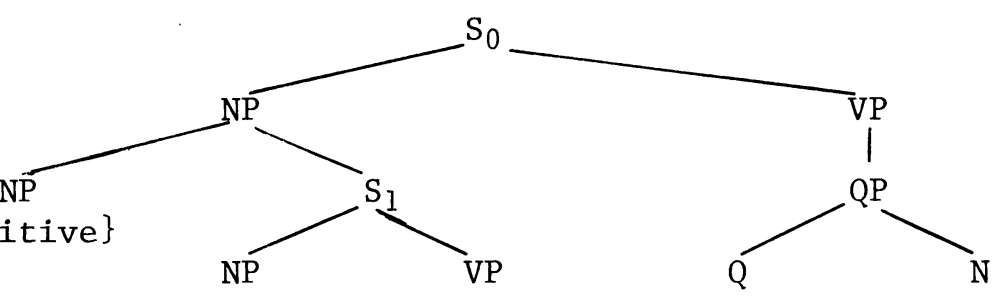

After QP Lowering, this configuration yields (51).

(51)

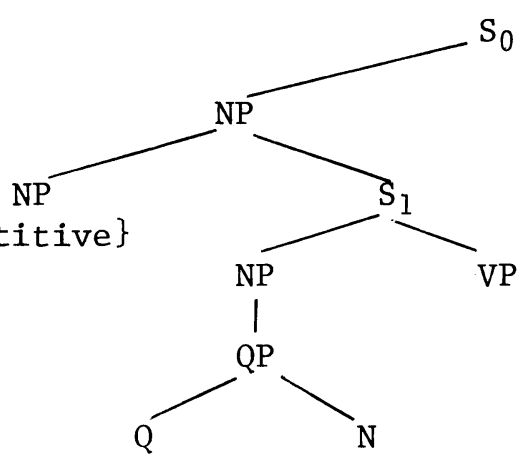

The embedded sentence, $S_{1}$, would be a plausible underlying structure for any sentence in which a subject phrase containing a numerical quantifier has a singular verb associated with it. One could propose, then, that $S_{1}$ represents a basic, independent underlying configuration and there are altogether three possible underlying configurations for surface sentences which include quantifiers in the nominative case: configurations like (50), configurations like (37), where the quantifier appears in an 
embedded sentence which also represents (50), and configurations like $S_{1}$ in (51). $S_{1}$ would then be the only configuration in which the quantifier would not represent an underlying predicate.

The semantic and syntactic similarity between sentences which can be analyzed as representing $\mathrm{S}_{1}$ and sentences of Type (7) indicates that this would be an incorrect assumption and that sentences whose constituent structure in $S_{l}$ should be related to (50) as $S_{l}$ in (51) is. The only "cost" of this assumption would be a rule which would allow deletion of the Partitive noun rather than the classifier noun under identity between them. Pairs of sentences such as (52) can then be assumed to have the same underlying structure. The (a) sentence can be accounted for as a consequence of the deletion of the classifier noun, and the (b) sentence can be accounted for as a consequence of the deletion of the Partitive noun.

(52) (a) Mal'čikov[gen] ostalos'[sg] sem'[nom]. of boys remained seven

(b) Ostalos'[sg] sem' [nom] mal'čikov[gen]. remained seven boys

Now consider (53) and (54).

(53) (a) Tkani[gen] ostalos'[sg] dva[nom] metra[gen]. of fabric remained two meters

(b) OstaZos'[sg] dva[nom] metra[gen] tkani[gen]. remained two meters of fabric

(54) (a) Rabočix[gen] na zavodskom dvore stojalo[sg] of workers in factory yard stood čelovek[gen] vosem'[nom]. people eight

'In the factory yard [there] stood about eight workers.'

(b) Na zovodskom dvore stojalo [sg] čelovek [gen] in factory yard stood people vosem' [nom] rabočix [gen]. eight of workers

'In the factory yard [there] stood about eight workers.'

These sentences differ from (52) in that they contain classifier nouns (metr 'meter' and celovek 'person') as well as nouns identifying the quantified entities (tkani 
'fabric' and rabočix 'workers'). These sentences do not involve the deletions postulated for (52) and the relationship between the (a) and (b) sentences is therefore more obvious; both can be traced back to (51) and ultimately to $(50) .15$

Returning now to the sentences in (49) (reproduced below), it can be asserted that singular verbs are unacceptable in them because they could not possibly derive from underlying configurations like (50). This assertion can be supported by the unacceptability of the sentences under (55), which would be the Type (7) versions of (49).

${ }^{15}$ The most typical classifiers in surface sentences are the nouns čelovek 'person' and štuka 'piece,' especially in phrases signifying approximate quantities (cf. (54b) in the text and (iia) below), and also nouns denoting measure units (cf. the comment in Galkina-Fedoruk 1964, 364, and on measure nouns and measure phrases in general see Klooster 1972). The noun procent 'percent,' as in (i), should apparently also be classified as a measure unit.

(i) 34 [nom] procenta[gen] ¿il'cov[gen] pokidaet [sg] ob ščežitie ǔ̃e čerez god.

'Thirty-four percent of the residents leave the dormitory after just one year.'

Note that the verbs in surface sentences which contain both classifiers and nouns identifying the quantified entities may be pluralized, as in (ii). The quantifier phrases (i.e., numerals and classifiers) in these sentences can be assumed to derive from embedded sentences.

(ii) (a) Za ego manipuljacijami s interesom sledjat[p1] after his manipulations with interest follow čelovek [gen] pjat'[nom] sosedej[gen] szadi, persons five of neighbors in rear sprava $i$ sleva. on right and on left

'His manipulations are followed with interest by some five of his neighbors in the rear, on the right, and on the left.'

(b) Vyjasnilos', čto 82 [nom] procenta[gen] molodyx $i_{j u d e j[g e n]}$ vpervye vypi $i[\mathrm{p} 1]$ doma.

'It was found that eighty-two percent of the young had their first drink at home.' 
(49) (a) Spor[acc] $\left\{\begin{array}{c}z a v j a z a Z i[p 1] \\ * z a v j a z a Z o[s g]\end{array}\right\} d v a[$ nom] novyx[gen] argument started two new mal'čika

boys

'The argument was started by the two new boys.'

(b) Na sobranii $\left\{\begin{array}{r}\text { zašumeli }[\mathrm{p} 1] \\ \text { zašumelo[sg] }\end{array}\right\}$ dve[nom] zenščiny at meeting started-to-wrangle two women [gen].

'Two women started to wrangle at the meeting.'

(55) (a) *Novyx mal'čikov zavjazalo spor dvoe. 'Of the new boys started an argument two.'

(b) *Ženščin zašumelo dve. 'Of women started to wrangle two.'

The explanation for the fact that the sentences under (49) could not possibly derive from a structure like (50) must be given on semantic grounds. It apparently has to do with the fact that animate beings associated with verbs as in these sentences cannot be assigned any role other than Agent, and NP nodes marked \{Agent\} are incompatible with QP predicates, but I cannot offer any definitive explanation because the facts are extremely elusive in this area. 16

The significance of the statement that the unacceptability of singular verbs in (49) is due to the fact that (50) is an impossible underlying representation for these sentences is that it establishes that whatever the restrictions are that account for the unacceptability of singular verbs in (49), they also account for the unacceptability of (55).

${ }^{16}$ For example, not all inchoative perfective verbs with the prefix $z \alpha$ - would be completely unacceptable in sentences derived from (50). The sentences in (i) are not so bad. Also not all transitive perfective verbs would be completely unacceptable in such sentences; sentences as in (ii) do occur. Furthermore, animate beings associated with verbs as in (i)-(iii) should presumably be viewed as Agents. Perhaps the verbs in these sentences do not necessarily require Agents, or, alternatively, perhaps the Agents in (49) and (55) have some additional role or property. The situation is by no means clear. (Ivanova [1973, 98] observes that verbs of "active concrete (cont.) 
1.53 A few more words are perhaps in order on the relationship between sentences like (52a) and (52b) (reproduced below). Consider (56).

(52) (a) Mal'čikov[gen] ostalos'[sg] sem'[nom]. of boys remained seven

(b) Ostalos'[sg] sem' [nom] mal'čikov [gen]. remained seven boys

(56) (a) Devušek[gen p1] ostaZos'[sg] dve[nom] . of girls remained two

(b) OstaZos'[sg] dve[nom] devuški[gen sg]. remained two girls

'[There] remained two girls.'

In Section 1.3 it was argued that morphological differences were among the reasons sentences like (56a) could not be viewed as simply "rearrangements" of sentences like (56b). The relationship between these two sentences that I am now proposing is not a contradiction and in fact accounts for the morphological differences, for devušek [gen p1] in (56a) and devuški[gen sg] in (56b) are assumed to represent different underlying nouns. The former is assumed to derive from a noun phrase which has a Partitive

action" are not used in Type (7) sentences, but as (55) and (i)-(iii) demonstrate, there are additional factors involved.)

(i) (a) ?Na sobranii zagovorizo[sg] dve [nom] ženščiny at meeting spoke up two women $\begin{array}{lll}\text { (b) ?Zenščin [gen p1] } & \text { zagovorizo [sg] } & \text { dve [nom] } \\ \text { of women } & \text { spoke up } & \text { two }\end{array}$

(ii) (a) Šuby [acc] kupilo[sg] pjat'[nom] turistov[gen]. furs bought five tourists

(b) ?Turistov[gen] kupilo[sg] šuby [acc] pjat'[nom]. of tourists bought furs five

(iii) (a) Na večere igralo[sg] pjat' [nom] garmonistov at party played five accordionists [gen].

(b) Garmonistov [gen] na večere igralo[sg] pjat' of accordionists at party played five [nom]. 
role, and the latter--as a classifier within the quantifier phrase. 17

1.54 The different constituent structure of sentences such as (56a) and sentences such as (56b) was also demonstrated by juxtaposing sentences such as (57a), with no overt verb, and phrases like (57b).

(a) Devušek[gen p1]--dve[nom]. 'Of girls [there are] two.'

(b) Dve[nom] devuški[gen sg] ... 'Two girls ...'

A valid question to ask now would be whether the underlying structures of sentences like (57a) allow deletion of the Partitive noun rather than the classifier noun and, if so, how such sentences would be realized and how they would differ from (57b).

If sentences like (57a) are assumed to derive from structures with no embedded sentences, then there is only one possible derivation--the one which yields (57a): the QP node cannot be lowered (for there is no embedded sentence), and the classifier noun is deleted by the rule which deletes predicate nouns when they are identical to subject nouns and have attributives associated with them, as in, e.g., (58).

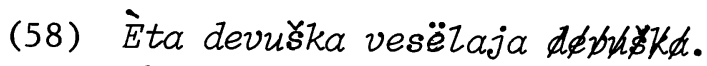
this girl cheerful girl

'This girl is a cheerful one.'

${ }^{17}$ The principles which govern the choice between the derivational path which leads to sentences like (56a) and the one which leads to sentences like (56b), if there are any, are not clear. According to Akopdžanjan 1964 (p. $124)$, any sentence like (56b) can be paraphrased as (56a), i.e., any sentence in which the subject phrase contains a numeral and the verb is not pluralized has a Type (7) variant. However, when a sentence like (56b) contains additional constituents, it can be stylistically quite infelicitous as a Type ( 7 ) sentence. Hence the complexity of the underlying structure apparently has some effect on the choice between the two alternatives. Whether there are other factors involved is uncertain. 
In (58), the subject noun could be deleted instead of the predicate noun because the subject phrase also contains an attributive (cf. Èta--vesëlaja devuška 'this [one] is a cheerful girl'). Deletion of the Partitive noun in the underlying structure of (57a), on the other hand, would leave nothing behind and the consequence would indeed by a phrase as in (57b). There is thus only one possible derivation if the underlying representation of (57a) is assumed to contain no embedded sentence. But the sentence in (57a) can also be assumed to derive from a structure as in (59) (cf. footnote 7).

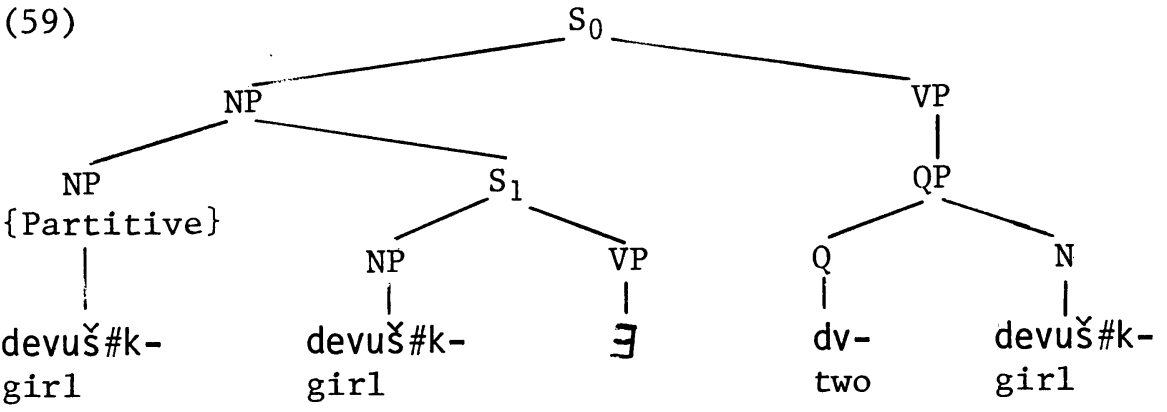

The $\mathrm{QP}$ in this structure can be lowered into the embedded sentence, and in this case there are indeed two possibilities: either deletion of the classifier and of $\exists$, yielding (57a), or deletion of the Partitive noun, in which case $\exists$ cannot be deleted, for its deletion would leave behind just a noun phrase (but note that had there been an additional constituent in the sentence, the verb could have been deleted; cf., e.g., Tom dve[nom] devuški [gen sg] '[there are] two girls there'). The output of the latter procedure would be $(60)$.

(60) Est' dve[nom] devuški[gen sg]. there-are two girls

Sentence (60) is ambiguous in that its underlying representation can be either (59) or (61). If its underlying structure is (59), then it asserts the number of girls whose existence is known and it is synonymous with (57a). If its underlying structure is (61), then it asserts the existence of the girls as well as their number. This ambiguity is unique, for in all other sentences with subject phrases containing numerals the verbal predicates manifest number and their number can be taken as an index 
of the underlying structure (and in sentences with nominal predicates the numerals derive from embedded sentences [see Section 1.2 in this chapter]).

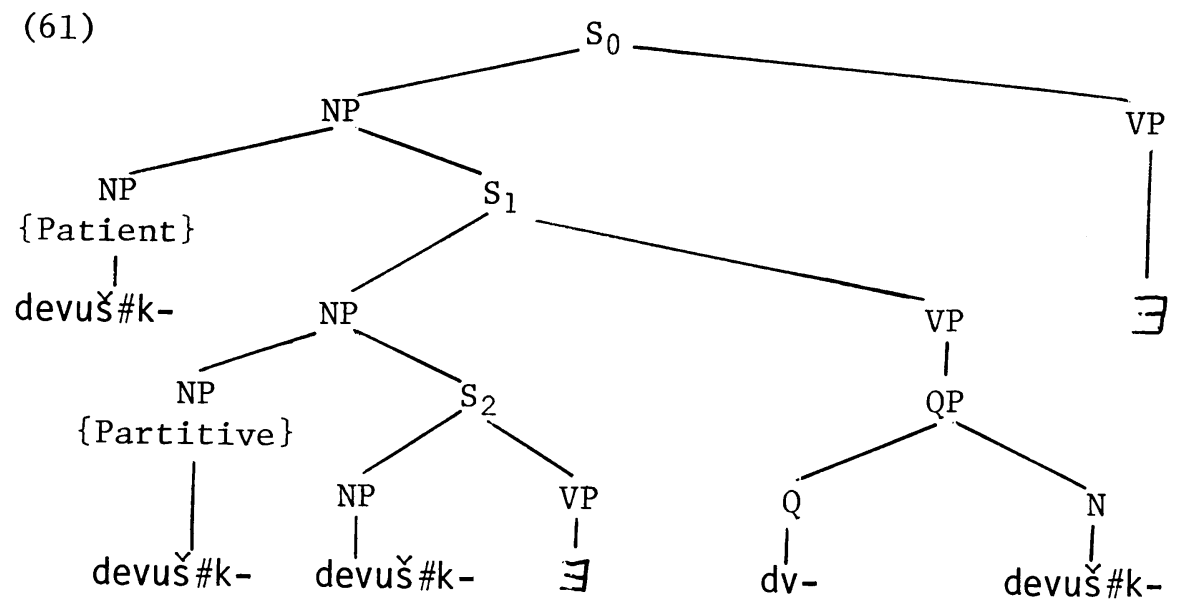

1.55 The sentences under (62) illustrate an additional morphological difference between sentences in which the numerals can be assumed to derive from higher predicates and sentences in which they can be assumed to derive as predicates of embedded sentences.
(a) Na polke ZezaZi[p1] dve[nom] $\left\{\begin{array}{l}k r a s n y x[\text { gen } p 1] \\ k r a s n y e[\text { nom } 1]\end{array}\right\}$ on shelf lay šapki [gen sg]. caps

'There were two red caps lying on the shelf.'

(b) Na polke lě̌alo[sg] dve[nom] $\left\{\begin{array}{c}\text { krasnyx [gen p1] } \\ * k r a s n y e[\text { nom p1] }\end{array}\right\}$ on shelf lay šapki [gen sg]. two red caps

'There were two red caps lying on the shelf.'

In (62b), where the whole subject phrase is a lowered quantifier phrase according to the account proposed above, the attributive modifier can only have a genitive ending. This fact supports the assumption that it modifies a classifier noun within a quantifier phrase. In (62a), where the numeral has presumably been "raised" from an 
embedded sentence and where it imposes the genitive case on an independent subject noun phrase, the attributive does not have to assume a genitive ending. (This phenomenon is not mentioned explicitly in any of the sources; it is referred to in vague terms in Rozental' 1968, 250-251 and 1971a, 230. The data in (62) are based on informant responses.)

1.56 Sentence (62a) illustrates another fact: a prepositive existential verb does not necessarily have a singular ending in association with a subject phrase which contains a numeral. Though in sentences in which there are quantifiers derived as higher predicates the verbs are typically existential, existential verbs may also derive as higher predicates (cf. (61) above). Some illustrations are given in (63).

(a) Navstreču po mostovoj exal gruzovik, v kotorom stojali[p1] 4 [nom] korovy[gen].

'Towards us along the road came a truck in which [there] stood four cows.'

(b) Von tri[nom] kuricy[gen] ostalis'[p1].

'Three hens remained here.'

(c) Nyne ot mnogočislennoj kogda-to sem'i ostalis' [p1] $v$ ¿̌ivyx dvoe[nom]: Aleksandr Isaevič Solženicyn $i$ ego dvojurodnaja sestra Ksenija Vasil'evna Zagorina, $v$ devičestve Solženicyna.

'Now from the once large family [there] have remained alive two: Alexander Isaevich Solzhenitsyn and his cousin Xenia Vasilievna Zagorina, née Solzhenitsyna.'

The information provided by (63a) is that there were cows standing in the truck and not only that there were four of them, and the information provided by (63b) is that there remained hens and not only that there were three of them. In (63c), the subject noun celovek 'person' has been deleted, apparently by a rule which optionally deletes this noun when it is associated with numerals for which there is a "collective" form, and when it is deleted the numerals assume their "collective" form (this form is apparently mandatory unless the deleted noun is anaphoric, i.e., identical to another noun in the discourse; cf. Zaliznjak 1967, 87). Sentence (63c) provides information about the members of the family who have stayed alive, and their number again evidently does not 
represent the main predicate in the underlying structure. 18

1.57 The fact that existential verbs do not necessarily have singular endings should be especially emphasized with respect to sentences which assert the passage of a certain period of time, since such sentences are often cited as sentences where the verb should not be pluralized (cf., e.g., Vinogradov and Istrina 1960, 503 and Svedova 1970, 554). Sentences such as (64), where the verbs signifying the passage of time are pluralized, are fully grammatical.

(64) (a) Ne prošzi[p1] darom dZja Andreja Evgen'eviěa not passed without-payment for Andrey četyre [nom] goda[gen] fronta. Evgenievich four years of front

'Andrey Evgenievich's four years at the front took their toll.'

(b) [--Etot vaš Medved' ... čempion na desjat' buduščix let.] ... I vot proneslis'[p1] èti and here went-by these [nom] desjat'[nom] let[gen]. ten years

'[--This Bear of yours ... will be champion for the next ten years.] ... And these ten years have gone by.'

The quantifiers are not focal in these sentences and evidently derive from embedded sentences.

Sentences such as (65) below are more typical, however, and this is apparently because time periods are essentially measure units and nouns denoting time periods are especially likely to occur as classifiers whenever there is reference to the passage of time. Consider (66).

${ }^{18}$ According to the Academy grammars, the preferable number for prepositive verbs associated with "collective" numerals when there is no overt quantified noun is singular (Vinogradov and Istrina 1960, 494 and Švedova 1970, 554). What this apparently means is that singular verbs seem to occur more frequently than plural verbs in association with "collective" numerals. My research indicates otherwise, but I have not investigated this question systematically. 

(a) Prošlo[sg] nedeli[gen sg] poltory [nom fem]. passed weeks one-and-a-half
'About a week and a half passed.'
(b) Dva[nom] goda[gen] proletelo[sg]. two years flew by

(66) Vremeni[gen] prošlo[sg] dve[nom] nedeli[gen]. of time passed two weeks

'Two weeks passed.'

In (66), time is signified overtly as the quantified entity and nedeli 'weeks' is clearly a classifier. Since nedelja 'week' can only measure time, the noun vremeni 'of time' is redundant in this sentence and could be deleted to yield Prošlo[sg] dve[nom] nedeli[gen] 'two weeks passed.' Any sentence in which a singular verb signifying the passage of time is associated with a subject phrase which consists of a quantifier and a noun denoting a time period may thus be related to an underlying structure such as the one underlying (66) (cf. Kostinskij 1969, 54), though the underlying Partitive noun could also be identical to the classifiers in such sentences. The fact that speakers are warned against using expressions such as čas vremeni 'an hour of time' and mesjac vremeni 'a month of time' (Lebedeva 1968, 137 and 258) seems to support the assumption that quantified time periods are associated with vremja 'time' as underlying Partitive noun. 19

Note that such an assumption may also app1y to sentences such as, e.g., (45c) above, where the classifier noun is kilometr: the quantified entity in the underlying structure of that sentence may possibly be identified by rasstojanija 'of distance' rather than by kilometrov 'of kilometers.'

1.58 The last topic for the present section is the number and gender of verbal predicates associated with phrases which include compound numerals ending in odin 'one.' Such phrases differ from all other phrases with numerals in that the noun modified by the numeral is in

19 The sentence with čas vremeni 'an hour of time' cited in Lebedeva 1968, 258 apparently does not involve a "partitive" quantifier. It is possible, then, that the association of nouns which denote time periods with vremja 'time' is not restricted to sentences in which such nouns occur within quantifier phrases. 
the nominative rather than the genitive case, as in (34b) above, reproduced below as (67).

(67) Vse[nom p1] 51 [nom] student [nom sg] věastvovali[p1] al1 $v$ sorevnovanijax. students participated in competitions

In this sentence, the fact that the subject noun has a nominative ending makes no difference: the verb manifests the number of the subject noun prior to QP Raising as in sentences with other numerals. This is also the case in the sentences under (68), where the subject phrases do not contain nominative attributives.

(68) (a) Dvadcat' odin[nom] student [nom sg] javilis'[p1] na ěkzamen.

'[The] twenty-one students came for the examination.'

(b) V simpoziume učastvovali[p1] 101 [nom] delegat [nom sg] iz 31 zambe žnoj strany.

'In the symposium participated 101 delegates from 31 foreign countries.'

In formal discourse, pluralized verbs in sentences like (68) must be avoided. The verbs should manifest the singular number manifested by the nouns in the nominative case (and their gender), as illustrated in (69) (from Okon' and Polovnikova 1964, 8).

(69) (a) $V$ auditorii sidel [sg masc] 31 [nom] student [nom in classroom sat sg masc].

'There were 31 students sitting in the classroom.'

(b) Za poslednie gody $v$ našem gorode postroena [sg] in last years in our city has been built 31 [nom] novaja škola [nom sg fem]. new school

'Thirty-one new schools have been built in our city in the last few years.'

(c) Za mesjac studentami by [sg masc] provedën[sg in month by students was conducted masc] $71[\mathrm{nom}]$ ximičeskij opyt [nom sg masc]. chemistry experiment 
'In the course of one month there were seventyone chemistry experiments conducted by the students.'

The pattern illustrated by (69) is the one recommended in all textbooks and handbooks (cf., e.g., Dobromyslov and Rozental' 1960, 198; Senkevič 1964, 5; Lebedeva 1968, 163; Okon' and Polovnikova 1964, 8; and Rozental' 1971a, 216). Curiously enough, in the 1960 Academy grammar it is not. The Academy grammar (Vinogradov and Istrina 1960, 502-503) recommends pluralized verbs and allows singular neuter endings colloquially, and it makes no mention of any other alternative (a fact which Dobromyslov and Rozental' find quite perplexing [1960, 198]).

The two alternatives mentioned in the Academy grammar are indeed the two predictable ones: a pluralized verb when the numeral derives as predicate of an embedded sentence, and a singular neuter ending for the verb when the numeral derives as higher predicate. The latter alternative is illustrated under (70) ((a) is cited in Vinogradov and Istrina 1960, 503; (b) is cited in Rozental' 1971a, 216; and (c) is cited in Lebedeva 1968, 163 to illustrate "incorrect" usage).

(70) (a) Na sobranii prisutstvovalo[sg neut] dvadeat' odin[nom] čelovek[nom sg masc].

'The meeting was attended by twenty-one persons.'

(b) Za vsë uplaceno [sg neut] 231 [nom] rubl' [nom sg masc].

' 231 rubles have been paid for everything.'

(c) V kanun prazdnika raportujut Rodine: vmesto obeřčannyx pjati tysjač tonn sverxplanovogo uglja ... vydano[sg neut] 19391 [nom] tonna[nom sg fem] uglja[gen].

' On the eve of the celebration the Motherland receives the [following] report: instead of the five thousand tons of coal promised over and above the plan ... there have been produced 19,391 tons of coal.'

The subject phrases in these sentences are in effect quantifier phrases, and the nominative nouns--classifiers (note that (c) also contains a noun which identifies the quantified entity: uglja 'of coal'). This account also applies to sentences with age expressions like (71a) (cf. 
also Rozental' 1971a, 216) and to sentences such as $(71 b-c)$, in which the numeral in the subject phrases is odin (in (c), a Shakhmatov example cited in Sapiro 1953, 149, the phrase ot trëx kopeek 'of three kopecks' seems to represent a Partitive noun phrase, and this sentence is therefore especially interesting in that despite the identity of the classifier noun with the noun in the Partitive phrase, neither noun is deleted; most informants find this sentence fully acceptable [cf. also (27) above and the subsequent analysis]).

\section{(71) (a) Emu[dat] bylo[sg neut] 51 [nom] god[nom sg masc]. 'He was fifty-one years old.' \\ (b) Ostalos'[sg neut] tol'ko odin[nom] kilometr[nom sg masc]. \\ '[There] remained only one kilometer.' \\ (c) U menja ostalos' [sg neut] ot trëx kopeek odna [nom] kopejka[nom sg fem]. \\ 'Of three kopecks I have one kopeck left.'}

The sentences under (69), then, although they exhibit a more regular pattern in that the verbs manifest the number and gender of the subject nouns, are in fact irregular in comparison with other sentences with subject phrases which contain numerals. The numerals in (69) can be assumed to derive from embedded sentences by QP Raising. They impose the singular number on the subject nouns or noun phrases, and since they do not impose the genitive case, the singular number is then copied from the quantified nouns (with their gender) onto the superordinate NP node, where it supersedes the [+Plural] specification which must have been assigned to that node prior to $Q P$ Raising on the basis of its taggregate\} specification (cf. (37) above and the subsequent analysis). This special process, triggered by the consequences of QP Raising when the quantifier is a compound which ends in odin, apparently only takes place in nonspontaneous discourse.

\section{Alternatives in Sentences with Adverbial Quantifiers}

Adverbial quantifiers can be defined negatively as "partitive" quantifiers which are neither numerals (for they cannot be represented by digits), nor nouns (for they have no inherent gender). A positive property which distinguishes adverbial quantifiers from numerical and nominal quantifiers is their applicability to verbs as well. 
2.1 Like all "partitive" quantifiers, adverbial quantifiers can function as quantifiers in Type (7) sentences, as illustrated under (72).

(72) (a) Povozok[gen p1] v"exalo [sg neut] vo dvor of carriages drove-in into yard neskol'ko. several

'Several carriages drove into the yard.'

(b) Pretendentov [gen p1] na novuju dolžnost' bylo of candidates for new position was [sg] mogo. many

'There were many candidates for the new position.'

(c) Narodu[gen sg] prišzo[sg] mnogo. of people came many

'Many people came.'

(d) Domašnej mebeli[gen sg] byZo[sg] malo. of home furnishings was little

'There was little furniture.'

(e) Rabotnikov[gen pl] stalo[sg] men'še, produkcii of workers [gen sg]--bol'še. tion more

'There are now less workers and production is up.'

(f) Problem[gen p1] u menja predostatočno. of problems by me quite enough

'I have quite enough problems.'

Sentences (72c-e) illustrate the fact that adverbial quantifiers in Type (7) sentences are applicable to nouns which denote homogeneous entities without the mediation of measure units, in distinction from numerical quantifiers (cf. Silosa sto tonn 'of silage there are a hundred tons,' *Silosa sto 'of silage there are one hundred,' and Silosa mnogo 'of silage there is much'). ${ }^{20}$ Neskol 'ko 'several' is the only adverbial quantifier not directly applicable

${ }^{20}$ The noun narodu 'of people' in (c) represents a bona fide collective noun and cannot be pluralized. It should be distinguished from the homonymous narod 'people, nation,' which is a pseudocollective noun, can be pluralized, and could not be used in the singular in such a sentence (on the distinction between bona fide collectives and pseudocollectives see Section 2.3 in Chapter Two). 
to nouns denoting homogeneous entities (cf. Silosa neskol'ko tonn 'of silage there are several tons' and * Silosa neskol'ko 'of silage there are several').

2.2 The nouns which identify the quantified entities in Type (7) sentences with adverbial quantifiers can have singular endings only if they denote homogeneous entities. The sentences under (73) may seem to be counterexamples at first glance, but they are not Type (7) sentences.

(73) (a) Korovy[gen sg] im za izbu mazo! cow for-them for hut little

'A cow [in exchange] for a hut is [too] little for them!'

(b) A razue ètogo [gen sg] malo?

'And is this [too] little?'

(c) Odnogo slova[gen sg] dostatočno.

'One word is enough.'

(d) Privedënnogo spiska[gen sg] slov javno nedostatočno dlja širokix obobščenij.

'The given list of words is clearly not enough for broad generalizations.'

The adverbials in (73) do not provide information on the quantity of the entities signified by the genitive nouns or noun phrases; these adverbials do not function as quantifiers. In all four sentences, the quantity of the entities signified by the genitive phrases is known (in (c) it is overtly specified), and the adverbials provide an evaluation of its adequacy for some specific purpose. In (a) and (d) the purpose is specified, in the remaining sentences it is not. Consider also (74).

(74) Četyrëx mik[gen p1] maZo. four hands little

'Four hands are not enough.'

The adverbial evaluates the adequacy of a given quantity of hands for some particular task. (For an analysis of the meaning of little and enough when used as quantifiers in English see Bresnan 1973.) ${ }^{21}$

${ }^{21}$ The numeral in (74) can be assumed to derive from an embedded sentence. 
The genitive case of the evaluated phrases in (73)(74) cannot be attributed to a Partitive role. It is apparently imposed by the government features of malo and dostatocno, for the role of the evaluated phrases seems to be that of Patient. There is a1so no basis for assuming that the adverbials in (73)-(74) derive as predicates of higher sentences; these sentences seem to represent simplex underlying structures. They clearly merit further attention, but since they do not involve quantifiers nor do they allow alternative number manifestations--only singular verbs can occur in such sentences (cf., e.g., Cetyrex ruk $\left\{\begin{array}{c}\text { bylo[sg]/okazalos'[sg] } \\ * \text { byli[p1]/okazalis' }[\mathrm{p} 1]\end{array}\right\}$ maZo 'four hands was/turned out to be not enough')--no more will be said about them in the present chapter.

2.3 Returning now to bona fide adverbial quantifiers, they differ from numerical quantifiers not only in that they are directly applicable to nouns which denote homogeneous entities but also in that nouns associated with them in any sentence type are always pluralized unless they denote homogeneous entities, i.e., no adverbial quantifier can impose "paucal" number specifications (like tri, for example, in tri stranýy [sg] 'three countries') or singular number specifications (like dvadcat' odna in dvadcat' odna strana[sg] 'twenty-one countries'), and adverbial quantifiers also can never manifest the gender of the nouns associated with them, in distinction from certain numerical quantifiers. There are thus no morphological differences between Type (7) sentences with adverbial quantifiers as in (72) and corresponding sentences in which the adverbial quantifiers are in attributive position, as in (75).

(75) (a) Vo dvor v"exalo[sg neut] neskol'ko povozok into yard drove-in several carriages [gen $\mathrm{p} 1$ ].

'Several carriages drove into the yard.'

(b) Na novuju dolžnost' bylo[sg neut] mnogo for new position was many pretendentov [gen $\mathrm{p} 1$ ]. canditates

'There were many candidates for the new position.'

(c) Prišlo[sg neut] mnogo narodu[gen sg]. came

'Many people came.' many poeple 
(d) Bylo[sg neut] malo domašnej mebeli [gen sg]. was little home furnishings

'There was little furniture.'

(e) Stalo [sg neut] men'še rabotnikov[gen p1], has become less of workers bol'še produkcii[gen sg]. more of production

'There are now less workers and production is up.'

(f) U menja predostatočno problem[gen p1]. by me quite enough problems.

'I have quite enough problems.'

In the section on sentences with numerical quantifiers it was suggested that in sentences in which the verbs were not pluralized and the numerals were in attributive position, i.e., in sentences analogous to (75) (like (76a)), the nouns associated with the numerals represented underlying classifier nouns, in distinction from corresponding Type (7) sentences (like (76b)), in which the nouns associated with the numerals represented independent, Partitive noun phrases.
(76) (a) ByZo[sg neut] dve[nom fem] devuški[gen sg]. was two girl
'There were two girls.'
(b) Devušek[gen p1] bylo[sg neut] dve [nom fem]. of girls was two
'There were two girls.'

One could assume that adverbial quantifiers are also generated in quantifier phrases with classifier nouns or noun phrases identical to the nouns or noun phrases which identify the quantified entities, but there is no morphological evidence for such an assumption and little syntactic evidence. Classifier nouns can therefore be considered optional in quantifier phrases with adverbial quantifiers (they should be allowed in order to account for sentences such as, e.g., Silosa bylo neskol'ko tonn 'of silage there were several tons').

The underlying structure of a sentence such as, e.g., (77), can then be assumed to be roughly as in (78), and after QP Lowering (78) has the structure shown in (79).

(77) Devušek[gen p1] byZo[sg neut] mnogo. of girls was many

'There were many girls.' 
(78)

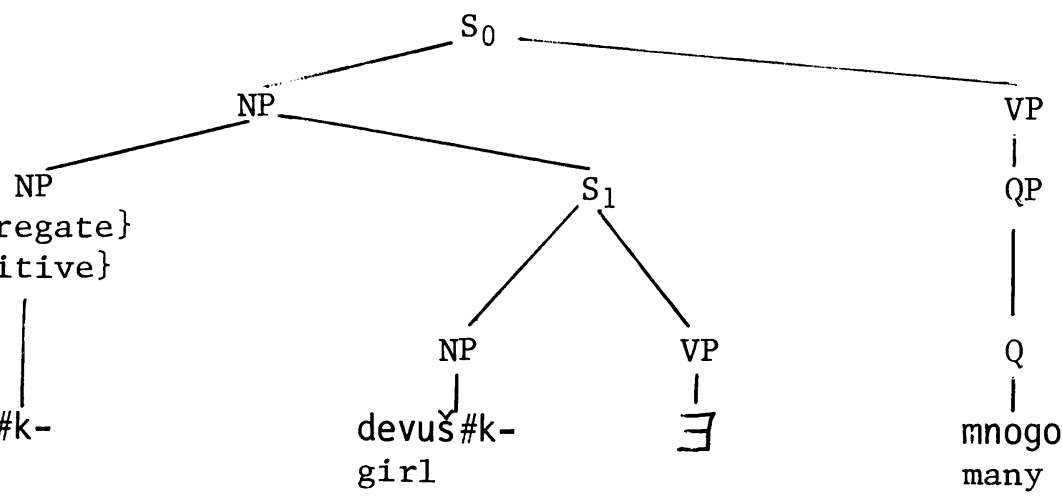

(79)

$\mathrm{S}_{0}$

devuš\#k-

gir1

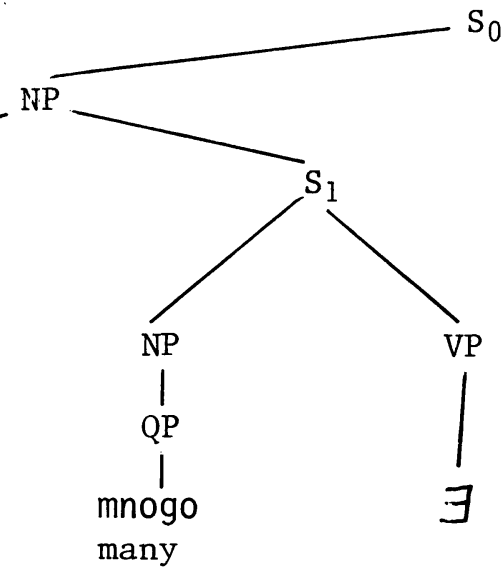

As mentioned in footnote 6 for this chapter, the Partitive NP can be assumed to be also lowered into $S_{l}$, as the only constituent left in $\mathrm{S}_{0}$.

2.4 The resultant structure can be realized not only by (77), which can be considered its most felicitous realization from the stylistic standpoint, but also by any of the sentences under $(80)$.

(80) (a) ByZo[sg neut] mnogo devušek[gen p1].

was many of girls

(b) Mnogo byZo[sg neut] devušek[gen p1]. many was of girls

(c) Devušek[gen p1] mnogo byZo[sg neut]. ${ }^{22}$ of girls many was

${ }^{22}$ Note that the same word order with a numeral in place of the adverbial quantifier would be (cont.) 
It seems, then, that the constituent structure of (80a) is identical to that of (77) and only the order of the constituents is different. In other words, it seems that mnogo 'many' and devušek 'girls' in (80a) are not constituents of the same noun phrase and mnogo is thus not an attributive modifier to the noun. However, there is some evidence which indicates that while this may be a valid analysis for $(80 b-c)$, the quantifier and quantified noun in ( $80 \mathrm{a}$ ) do constitute a single noun phrase, or at least may constitute one.

The evidence is twofold. First, there are sentences in which the order of QP-NP gen seems considerably more natural than the order $\mathrm{NP}$ gen $-\mathrm{QP}$, which may even be excluded. Consider, for example, (81).

(81) (a) Prislalo[sg neut] otzyv $\left.\begin{array}{l}\text { mnogo čitatelej[gen] } \\ \text { sent }\end{array}\right\}$ response $\left.\begin{array}{l}\text { many readers } \\ \text { čitatelej[gen] mnogo }\end{array}\right\}$ 'Many readers have responded.'

(b) Ne o vsjakom čeloveke soxranilos' [sg neut] not about every person has-been-preserved $\left\{\begin{array}{c}\text { dostatǒ̌no svedenij[gen] } \\ \text { sufficient data } \\ \text { ?svedenij[gen] dostatǒnno }\end{array}\right\}$.

Secondly, consider (82).

(82) (a) Devušek[gen] mnogo. of girls many

'There are many girls.'

(b) Est' mnogo devušek[gen].

'There are many girls.'

(c) *Devušek[gen] est' mnogo. of girls there are many

ambiguous. Devušek pjat' bylo, for example, can mean either "of girls there were five" or "there were approximately five girls," because devušek pjat' can be interpreted as a quantifier phrase with inverted word order signifying that the number is approximate. The quantities signified by adverbial quantifiers cannot be approximate, and a sequence such as devušek mnogo can therefore only be interpreted as consisting of a Partitive noun and a lowered quantifier. 
The sentences under (81) may demonstrate constraints on word order rather than differences in constituent structure, but the sentences under (82) seem to indicate that there are differences in constituent structure, for only one word order allows est' 'there are.'

Sentence (82b) is ambiguous in that it represents two possible underlying structures (like (60) above). One of the two is (78), which yields (79) (reproduced below) after QP Lowering.

(79)

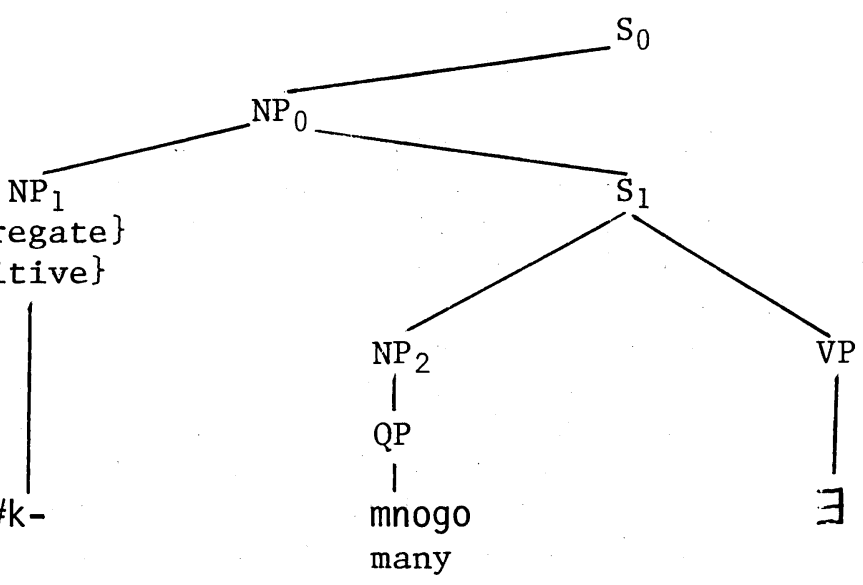

The verb in (79) must be deleted, as indicated by the ungrammaticality of ( $82 \mathrm{c}$ ) (cf. footnote 7 ). The acceptability of (82b) can be accounted for by assuming that the Partitive $\mathrm{NP}$ can be lowered into $\mathrm{NP}_{2}$ in $\mathrm{S}_{1}$, to yield a structure like (83).

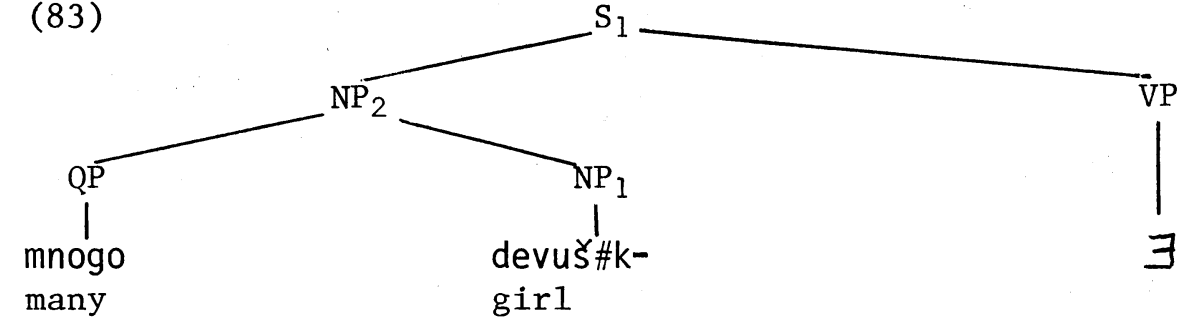

The internal structure of $\mathrm{NP}_{2}$ now resembles the structure of NPs which contain "raised" QPs (as in (38) on p. 338), so that this is not an implausible position for $\mathrm{NP}_{1}$ to occupy. The verb cannot be deleted from this structure, for it would leave behind just a noun phrase (cf. p. 361 above), whereas if it is deleted from (79) (or 
from (84), if $\mathrm{NP}_{1}$ is assumed to be lowered into $\mathrm{S}_{1}$ [but not into $\left.\mathrm{NP}_{2}\right]$ ), its deletion leaves behind two independent noun phrases.

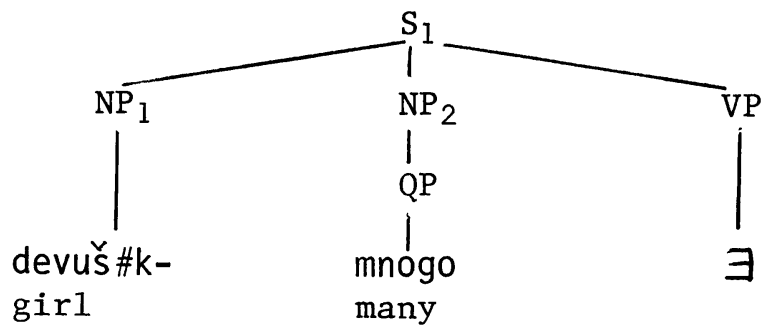

The process which yields structures like (83) can account not only for the data in (82) but also for the fact that in (81) the quantifiers and the quantified nouns seem to constitute single noun phrases. Note, however, that such a process must be postulated only if adverbial quantifiers are assumed to derive without classifier nouns or noun phrases, for if adverbial quantifiers are assumed to be associated with classifiers in underlying quantifier phrases, then the derivation of sentences like (81) and (82) can be accounted for without any additional postulates (the comments in footnote 17 above apply in either case).

2.5 Whatever derivational process is postulated for underlying representations with adverbial quantifiers as higher predicates and whatever the internal structure of the quantifier phrases in such structures, the verbs in the surface sentences cannot be pluralized. As in sentences with numerical quantifiers, pluralization is only possible when the quantifiers can be assumed to derive from embedded sentences. Consider the sentences under (85) ((a) cited in Svedova 1970, 549; (b) cited in Skoblikova 1959a, 111; (c) is from Literaturnaja gazeta; and (d) is cited in Rozental' 1968, 256).

(85) (a) Neskol'ko begunov[gen p1] otstali[p1].

'Several runners fell behind.'

(b) Mnogo vozdušnyx šarov [gen p1] letjat [p1] na tex vysotax, gde letajut transportnye $i$ passažirskie samolëty.

'Many balloons fly as high as cargo and passenger airplanes.' 
(c) NemaZo učaščixsja[gen p1] Donecka obučajutsja [p1] $v$ poslednie gody po èksperimental'noj metodike, osnovnaja cel' kotoroj--sokraščenie učebnoj nagruzki škol'nikov.

'Quite a few students in Donetsk have been studying in recent years according to an experimental program whose chief aim is to cut the amount of work required from schoolchildren.'

(d) Pust' bol'še Zjudej[gen p1] polučajut[p1] svežij vozdux: oni budut bodree $i$ zdorovee.

'Let more people get fresh air; they will be more energetic and healthier.'

Like sentences with numerical quantifiers in which the verbs are pluralized, the sentences under (85) would not be appropriate answers to questions with the interrogative skol'ko 'how many/much': the quantifiers are secondary in the semantic structure of these sentences and can be assumed to derive from embedded sentences, like numerical quantifiers in analogous sentences.

The sentences under (86) illustrate determiners which manifest the putative case of the underlying subject phrases in the matrix sentences prior to QP Raising.
(a) Ėti[nom p1] neskol'ko dnej[gen p1] byli[p1] očen' prijatny[p1].
'These several days were very pleasant.' (b) Eti[nom $\mathrm{p} 1]$ neskol'ko praktikantov [gen $\mathrm{p} 1]$
priexali[p1] včera s vecernim poezdom.
'These several trainees arrived yesterday with the evening train.'

2.6 Different number manifestations in sentences in which the verbs are associated with phrases containing adverbial quantifiers can thus be related to the semantic structure of the sentences and can be accounted for by postulating different underlying sources for the quantifiers. However, the situation is complicated by the fact that nonpluralized verbs also occur in sentences in which adverbial quantifiers can be assumed to derive from embedded sentences. In sentences like (87) this is predictable, but in other cases the singular verbs require a special account.

(87) Nedavno $v$ gorode postroili zavod, na kotoryj iz dereven' ${ }_{* \text { naexalo }}^{\text {naexali }[\mathrm{p} 1]}$ neut] $\}$ mnogo molodëżi[gen sg]. 
'Recently a plant has been built in town to which
many young people have come from the villages.'

The quantified noun in (87) is a collective noun. A verb associated with it can only have a singular ending in standard Russian (cf. Section 2.3 in Chapter Two), and this is why a pluralized verb is excluded in this sentence despite the fact that the quantifier seems to derive from an embedded sentence. (Only in dialects which allow pluralized verbs in association with collective nouns can verbs in sentences like (87) be pluralized; e.g., Mnogo narodu[gen sg] sidjat[p1] 'many people are sitting' [Gorelova 1969].) 23

A special account is needed for sentences such as the following ( $(a)$ is cited in Vinogradov and Istrina 1960, 504 from Gorky; (b) is from a Novyj mir story by a beginning writer).

(88) (a) Neskol'ko čelovek[gen p1] ogljanulos'[sg neut]-pozadi ix stojala plotnaja massa tel.

'Several people looked back--behind them [there] stood a thick mass of bodies.'

(b) Ja ne obernulsja i ne pribavil šaga i togda, kogda tri[nom] snežka[gen sg] udarizi[p1] mne v spinu $i$ neskol'ko proletelo[sg neut] mimo.

'I did not turn around and did not quicken my pace even when three snowballs hit my back and several flew past me.'

These sentences do not lend themselves to a reading whereby the quantities signified by the quantifiers are focal. Both sentences provide information about what events took place, and the number of entities involved is secondary. Sentence ( $88 \mathrm{~b})$ is especially revealing, because it demonstrates the contrast between the number of a verb associated with a phrase containing a numerical quantifier and the number of a verb associated with a phrase containing an adverbial quantifier (the fact that

${ }^{23}$ While the verb in (87) can be assumed to manifest the grammatical number of the NP node dominating the quantified noun prior to QP Raising, it cannot manifest the gender of the quantified noun. This fact can be accounted for by assuming that once the genitive case is imposed on a noun by a quantifier, the gender specifications copied onto the NP node from this noun must be deleted. 
the quantified noun has been deleted from this phrase is of no significance).

The singular number of the verbs in (88) can be accounted for by a process similar to the one posited above to account for the number and gender manifested by verbs in sentences such as (89) (identical to (69a) above).

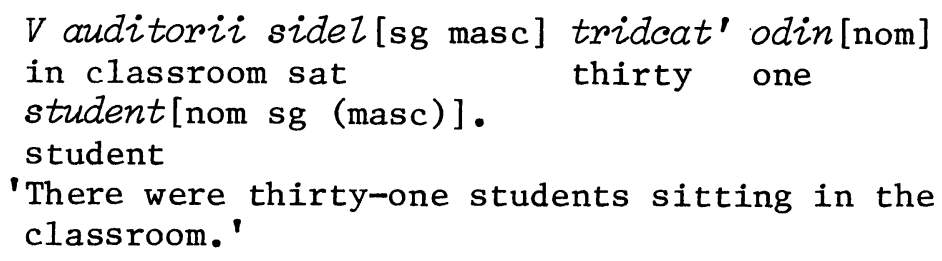

'There were thirty-one students sitting in the classroom.'

In the derivation of (89), QP Raising is assumed to be followed by an adjustment of the number specifications on the subject NP node that hinges on the identity of the quantifier, for this particular quantifier does not impose the genitive case and does impose singular on the head noun, and the specifications of the noun after QP Raising supersede the earlier NP specifications. As noted above (p. 368), this adjustment apparently takes place only in nonspontaneous discourse.

A similar adjustment can be posited for the derivation of sentences such as the ones under (88), triggered by the fact that the nominative specifications of the subject NP node cannot be manifested by any of the constituents it dominates. ${ }^{24}$ This fact and the fact that the only constituent within the node which could manifest its case is dominated by $Q P$ must trigger a neutralization or cancellation of the nominative specification of the NP

${ }^{24}$ The final -o in neskol'ko cannot be considered a nominative ending even though neskol'ko has corresponding oblique forms (as in, e.g., s neskol'kimi[instr] studentami [instr] 'with several students'), for the form neskol'ko is also used adverbially, in which case it indisputably does not manifest case. None of the adverbial quantifiers can be said to have an ending which manifests the nominative case (or the accusative case in sentences such as, e.g., Ja vstretil neskol'ko studentov 'I met several students'). (On the use of the form neskol'ko in accusative phrases with animate nouns see Lebedeva 1968, 151, and cf. also Zaliznjak 1967a, 88. On the oblique forms which correspond to adverbial quantifiers in general see the discussion in Vinogradov 1947, 311-315.) 
node, which can be thought of as a negative specification, that is to say, [-Nominative] (the case specification cannot be deleted because every NP requires a case specification, whether it can be realized or not). As a consequence, the NP node no longer qualifies as grammatical subject and its specifications cannot be copied onto the $\mathrm{V}$ node by Verb Agreement. The endings of the verbs in (88) thus manifest the "provisional" specifications of the VP nodes which dominate them.

This process characterizes nonspontaneous discourse, like the adjustment process which follows QP Raising when the quantifier is a compound numeral which ends in odin (note that (88b) comes from the pen of a beginning, conscientious writer). In informal, spontaneous discourse, the consequences of QP Raising can be disregarded and Verb Agreement does apply, resulting in sentences with pluralized verbal predicates, as in (85) above.

2.7 In actual usage, the quantifier in sentences which have pluralized verbal predicates is most commonly neskol'ko 'several' (cf. the comments in Skoblikova 1959a, 112; Vinogradov and Istrina 1960, 504; and Lobanova 1966, 38). Sentences such as the following are thus especially typical ( (a) was cited in Chapter Three as $(22 a)$; (b) is cited in Lebedeva 1968, 152; (c) in Lobanova 1966, 38).

(90) (a) Neskol'ko glotkov[gen p1] ukrepili[p1] naš dux $i$ tezo.

'A few gulps fortified our spirit and body.'

(b) Neskol'ko komnej[gen p1] udarili[p1] $v$ zabor.

'Several rocks hit the fence.'

(c) Neskol'ko studentov[gen p1] spomili[p1]s dokladěikom, ěto-to dokazyvali[p1] emu.

'Several students were arguing with the speaker, trying to prove something to him.'

2.71 One reason for the predominance of neskol'ko in such sentences is that mnogo 'many' and its negative counterpart malo 'few' tend to be realized by adjectival forms (mnogie and nemnogie, respectively) when "raised" from embedded sentences, especially in formal discourse. In the sentences under (91), for example, the adjectival form mnogie 'many' can be assumed to represent an underlying quantifier in an embedded sentence which could also be realized as mnogo. 
(91) (a) Mnogie[nom] podpol'nye fil'my[nom p1]--ð̌istejšij frejdizm.

'Many underground films are pure Freudianism.'

(b) Mnogie [nom] dannye [nom pl] pokazyvajut [p1], čto čislennost' naselenija bol'six gorodov budet $i$ vpred' rasti.

'Many data indicate that the population in large cities will keep on growing.'

(c) Mnogie [nom] čitateli[nom pl] dosadujut[p1] na to, čto počta medlenno iskorenjaet nedostatki, o kotoryx pisala gazeta.

'Many readers are indignant because the postal service has been slow in eradicating the shortcomings pointed out in the newspaper.'

The adjectival form is mandatory in the standard language when the quantified noun has been deleted. Consider (92).

(a) $\left\{\begin{array}{l}\text { Mnogie }[\mathrm{nom}] \\ \text { *nogo }\end{array}\right\}$ stremjatsja[p1] poslušat' operu
$v$ teatre.

'Many [people] would very much like to hear an opera in the theater.'

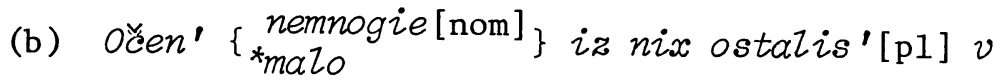
slovarjax kak istorizmy.

'Very few of them have remained in dictionaries as historicisms.'

In (92a) there is no noun associated with the quantifier, presumably as a consequence of the deletion of a noun denoting "people." Such deletion must evidently be accompanied by the assignment of an adjectival ending to the quantifier, through a mechanism which may be analogous to the one which assigns "collective" endings to numerals under the same conditions (p. 363).

Sentence (92b) indicates that the deletion of any noun associated with mnogo or its negation must be accompanied by the assignment of an adjectival ending to the quantifier (on the derivation of partitive constructions as in (92b) see Section 10.2 in Chapter One).25

${ }^{25}$ There have been suggestions, apparently based on Vinogradov 1947, 313-314, that the adjectival form mnogie applies to entities which constitute part of a (cont.) 
2.72 Another reason for the predominance of neskol'ko in sentences with pluralized verbal predicates in comparison with other adverbial quantifiers is that other adverbial quantifiers rarely seem to occur in embedded sentences, i.e., they are usually focal in sentences. This applies in the first place to questions in which the interrogative is skol'ko 'how many/much,' where quantity is clearly the focus, as in, e.g., (93) (cited in Skoblikova 1959a, 111, to illustrate a similar observation). ${ }^{26}$

larger aggregate (Okon' and Polovnikova 1964, 37), that it is always interpreted as applying to a subset of "an identifiable set" (Chvany 1973, 74). If this is so, then either this interpretation is due to the association of the adjectival form with a quantifier in an embedded sentence (for it could not possibly represent a higher predicate), or, alternatively, the adjectival form represents an underlying quantifier with some special feature, a quantifier which could not be realized as mnogo. The latter assumption seems implausible, however, because of sentences such as (92), where mnogo is excluded for no obvious semantic reasons and only mnogie is acceptable, and also because mnogie can apparently substitute for mnogo in any sentence in which the verb is pluralized. The only exception I have found so far is the book title Mnogo Amerik snova stanut edinoj '[the] many Americas shall again become one' (The Many Americas Shall Be One; see p. 125), where mnogo could not be replaced by mnogie, but this may have something to do with the fact that the quantified noun is a proper name, though the whole problem clearly merits further investigation.

${ }^{26}$ Skoblikova notes that in exclamations, in distinction from questions, skol'ko is not necessarily focal (Skoblikova 1959a, 111). She cites the sentence under (i) to illustrate.

(i) A skol'ko pisatelej[gen p1] bratskix literatur narodov SSSR tvorčeski sozreli[p1] $v$ sovetskie gody! 'And how many writers from the fraternal literatures of the nationalities in the USSR have matured in their creative work during the Soviet years!'

In exclamations too, however, skol'ko seems focal more often than not, as in, e.g., (ii), though (cont.) 
(93) Skol'ko ucenikov[gen p1] otpravilos'[sg neut] $v$ èkskursiju?

'How many students set off on an excursion?'

Sentences with other adverbial quantifiers as foci (in attributive position) are illustrated under (94).

singular verbs in such sentences generally cannot be taken as evidence that skol'ko derives as higher predicate, for singular verbs may also be due to the "late adjustment" described above, which may perhaps be the case in (iii).

(ii) (a) Esli by vy znali, skol'ko na èto uxodit [sg] how much for this goes

vremeni[gen sg] $i$ siz[gen $\mathrm{pl}$ ]!

time and physical-resources

'If only you knew how much time and energy is spent on this!'

(b) Skol'ko interesnyx vstreč [gen pl] bylo [sg neut] $u$ nas ètim letom!

'How many interesting meetings we had this summer!'

(iii) Skol'ko Zjudej[gen pl] pisalo[sg neut] mne, čto sonety pomogli im perenosit' tjaž̈luju xroničeskuju bolezn'... (Samuil Marshak)

'How many people have written to [te11] me that the sonnets helped them endure a serious chronic disease ...'

Note that (iia) may be a consequence of the reduction of conjoined sentences by Identity Deletion. In general, coordinate sentences which have Type (7) underlying representations cannot be reduced by Regrouping. In other words, verbal predicates associated with conjoined phrases which contain qunatifiers derived as higher predicates can never be pluralized; cf. (iv).

(iv) Skol'ko syra $i$ skol'ko xleba $\left\{\begin{array}{c}b y z o[s g \text { neut] } \\ * b y z i[\mathrm{p} 1]\end{array}\right\}$ kuxne?

'How much cheese and how much bread was there in the kitchen?' 
(94) (a) $V$ našem gorode ¿̌ivët[sg] nemalo byvšix pilotov [gen $\mathrm{p} 1$ ] polka.

'Quite a few pilots from [our] group live in our town.'.

(b) Vsë boi'še vuzov[gen p1] organizuet [sg] olimpiady dlja škol'nikov.

'More and more institutions of higher education are organizing competitions for schoolchildren.'

(c) Čem temnee stanovitsja vokmig, tem men'še proxožix[gen pl] dvižetsja[sg] po bul'varu. 'The darker it gets outside, the less passers-by walk along the boulevard.'

2.8 Finally, there are miscellaneous colloquial expressions which serve to signify quantity in Type (7) sentences. They rarely if ever occur in attributive position and can never be associated with pluralized verbs. Such expressions cannot be classified as numerical or nominal quantifiers, and perhaps they can be considered a subclass of adverbial quantifiers--even though they generally do not modify verbs. Some examples from various sources are given under (95).

(95) (a) Kul'turnosti[gen sg] $v$ tebe, F̈ëdor, nu ni na of culture in you Fyodor not for kapel'ku. drop

'There is not a bit of culture in you, Fyodor.'

(b) Ljudej[gen p1] ostä̈tsja[sg] kot naplakal. of people remains cat cried 'There are practically no people left.'

(c) Moloka[gen sg] xot' zalejsja. of milk even flood yourself 'There is plenty of milk.'

(d) A deneg[gen p1] u menja bylo [sg neut] do čërta. and of money by me was up to devil 'And I had a great deal of money.'

(e) Vremeni[gen sg] u nego ostavalos'[sg neut] $v$ of time by him remained to obrez. edge

'He had just enough time 1eft.'

(f) U menja $i x$ [gen] negusto. by me of them not dense 'I do not have too many of them.' 
(g) BeZiZ[gen p1] ostavaZos'[sg neut] tam e $\check{s} \dddot{e} \ddot{e}$ of whitewash remained

there still porjadorno. decently

'There remained a good amount of whitewash there.'

(h) Takix devoček [gen p1] na našej ulice bylo [sg of such girls neut] polnym-polno.

\section{full}

'There were a great many girls like this on our street.'

The pattern illustrated by these sentences is the typical one for Type (7) sentences: a genitive noun or noun phrase, an existential-type verb, and an expression indicating how much is available of the entity or entities signified by the genitive noun or noun phrase. These quantifying expressions can be assumed to be dominated by a QP node like regular adverbial quantifiers.

\section{Alternatives in Sentences with Nominal Quantifiers}

There are three major classes of nominal quantifiers: numeral-like, adverbial-1ike, and fractional.

Numeral-1ike nominal quantifiers divide into two subclasses. The first subsumes essentially nol' 'null, zero,' tysjača 'thousand,' million, billion, and milliard. The second subsumes nouns such as dvojka 'two,' trojka 'three,' pjatërka 'five,' desjatok 'ten,' djüina 'dozen,' and sotnja 'one hundred,' nouns for which there are corresponding numerical quantifiers (see footnote 11 for this chapter). Nouns of the second subclass will be referred to as "nondigital," to distinguish them from the "digital" nouns of the first subclass.

Adverbial-1ike quantifiers also divide into two subclasses, which will be referred to as "regular" and 'hyperbolic." "Regular" quantifiers within this class are, e.g., množestvo 'multitude, many,' značitel'noe čislo 'significant number, quite a few,' and rjad 'several.' The "hyperbolic" quantifiers, all of which are colloquial, are, e.g., massa, bezdna, propast', t'ma, and ujma, all of which signify vast quantities, and, on the other hand, nouns such as kapel'ka 'little drop,' gorstka 'handful,' and pustjaki 'trifles,' which signify miniscule quantities.

Fractional quantifiers divide into "definite" and "indefinite." The "definite" ones are tret' 'third,' 
četvert' 'quarter,' and polovina 'half,' and the "indefinite" ones are bol'šinstuo 'majority,' men'šistvo 'minority, ' čast 'part, some of,' ból'šaja čast' 'the greater part, majority,' and a few others. On1y "fractional" quantifiers can have singular count nouns associated with them.

What distinguishes all of these quantifiers from numerical and adverbial quantifiers is the fact that they have inherent gender. What distinguishes them from other nouns is the fact that their inherent gender is not always manifested in association with them, and, furthermore, the number manifested in association with them does not always match the number manifested by their endings. 27

3.1 It seems that in sentences in which the gender manifested in association with nominal quantifiers is not their inherent gender but neuter, they derive as quantifiers within quantifier phrases: $Q$ and $Q P$ nodes do not bear gender specifications, and the inherent gender of the nouns cannot be manifested by other constituents. This applies especially to sentences with the colloquial

${ }^{27}$ The only other nouns which appear to resemble nominal quantifiers in this respect are nouns such as pora 'time,' Zen' 'laziness,' and neoxota 'reluctance' in sentences like (i)-(iii), where the verbs do not manifest their gender.

(i) Pora[nom fem] bylo[neut] vozvrašcat'sja na korabl'. time was to return to ship

'It was time to return to the ship.'

(ii) Vstat' i brat' druguju knigu Zen'[nom fem] bylo to get up and take another book laziness was [neut].

'[I] was too lazy to get up and take another book.'

(iii) Neoxota[nom fem] byzo[neut] razgovarivat'. reluctance was to talk

'[I] did not feel like talking.'

The nouns illustrated in these sentences in fact represent predicates rather than grammatical subjects; they cannot be involved in Verb Agreement. (In usage, though, such predicates are occasionally treated as subjects; see, e.g., Svedova 1970, 555.) 
"hyperbolic" quantifiers, as in (96), and to sentences with "digital" or "definite" fractional nominal quantifiers, as in (97) and (98), respectively ((96a), (96c), and (97) cited in Vinogradov and Istrina 1960, 505-506; (96d) cited in Senkevič 1964, 5).

(96) (a) Vremeni[gen sg] prošZo[neut] ujma[nom sg fem], of time passed a great deal a ty ničego ne sdelal.

'So much time has gone by and you have done nothing.'

(b) Narodu[gen sg] s"exalos'[neut] bezdna[nom sg of people gathered an infinite fem]. number

'An infinite number of people have gathered.'

(c) Gostej[gen pl] bylo[neut] propast'[nom sg fem]. of guests was multitude

'There was a multitude of guests.'

(d) SobraZos'[neut] ujma[nom sg fem] žeZajuščix[gen gathered multitude of wishers p1] popast' na koncert. to get to concert

'A multitude of people wishing to get in to [hear] the concert have gathered.'

(97) Segodnja na zanjatija prišlo[neut] tysjača[nom sg fem] novyx studentov [gen $\mathrm{p} 1$ ].

'Today one thousand new students have come to classes.'

(98) (a) Mne raižno[neut] četvert' [nom sg fem] časa[gen to me needed quarter of hour $\mathrm{sg}$.

'I need a quarter of an hour.'

(b) Prošzo[neut] tret'[nom sg fem] semestra[gen sg]. 'One third of the semester has gone by.'

The first three sentences under (96) are Type (7) sentences. In (96d) the quantifier is in attributive position, but this sentence must also have a Type (7) underlying representation and its derivation can be assumed to follow the procedure posited above for sentences with adverbial quantifiers.

In (98), both sentences can be assumed to derive from Type (7) underlying representations with vremja 'time' as 
the Partitive noun and čas 'hour' and semestr 'semester' as classifiers. The underlying Partitive noun could be realized in the genitive as vremeni 'of time,' but it has been deleted. Četvert' ̌̌asa 'quarter of an hour' and tret' semestra 'third of a semester' are thus quantifier phrases. Note that the classifier nouns have singular endings. This is the number of all classifiers associated with "definite" fractionals (when such fractionals are associated with plural nouns, e.g., četvert' studentov[gen p1] 'a quarter of the students,' the nouns do not derive as classifiers).28

When the fractional quantifier in such phrases with classifiers is $1 / 2$, it is realized by the truncated form pol-, unless the classifier is a regular measure noun. Then the truncated form is not mandatory, as illustrated in (99), where the putative Partitive noun in the underlying representation is again vremja 'time' (there are speakers, however, for whom only the truncated variant is acceptable).

(99) Proß̌Zo[neut] $\left\{\begin{array}{l}\text { polovina[nom sg fem] mesjaca[gen sg] } \\ \text { polmesjaca }\end{array}\right.$. 'Half a month passed.'

The truncated form is mandatory when the classifier is not a measure noun, as illustrated under (100), where the Partitive noun in the underlying representations may be Zjudi 'people,' or narod 'people' ((a) cited in Lebedeva 1968, 190; (b) cited in Rozental' 1971a, 218).

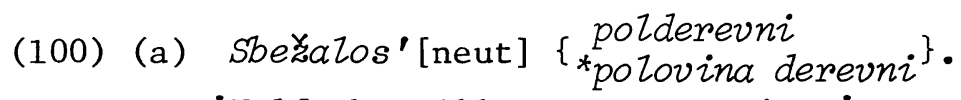
'Half the village came running.'
(b) $\left\{\begin{array}{l}\text { Polgoroda } \\ \text { Polovina goroda }\end{array}\right\}$ učastvovalo [neut] $v$ demonstracii.

'Half the town participated in the demonstration.'

${ }^{28}$ The "definite" fractionals, and also other nominal quantifiers, especially the numeral-like ones, are often themselves classifiers to numerical quantifiers, as in, e.g., Prošlo tri četverti časa 'three quarters of an hour have passed,' Rublej ostalos' dve tysjači 'of rubles there are two thousand left.' 


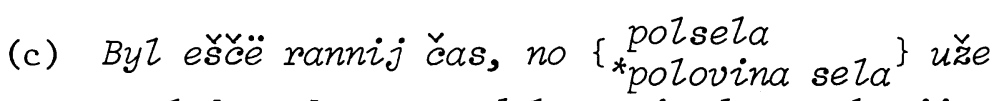
znalo[neut] o zapozdalom priezde Praskov'inyx detej.

'It was still an early hour, but half the village already knew about the belated arrival of Praskovya's children.'

Though "definite" fractionals typically derive with classifier nouns, they may also derive as independent quantifiers, as demonstrated by (101), where the quantified entity is signified by the Partitive phrase takix slov 'of such words' and the quantifier is dobraja polovina 'a good half.'

(101) Takix slov[gen p1] u nas dobraja polovina [nom sg of such words by us good half fem].

'A good half of the words we have are of this type.'

The quantifier could not possibly have a singular classifier noun associated with it in the underlying representation of this sentence, and there is no evidence for the occurrence of plural classifier nouns with fractional quantifiers. 29

The nominal quantifiers most likely to be treated as bona fide quantifiers in derivations from Type (7) underlying representations are thus the "hyperbolic" ones, which are typical of informal discourse, numeral-like "digital" quantifiers, whose affinity with numerals is unquestionable, and "definite" fractionals, which are also essentially numerical. The identity of other nominal quantifiers as nouns is apparently too strong to allow their use as bona fide quantifiers, and though they may derive as Qs, their presence in quantifier phrases can be assumed to trigger an adjustment as a result of which

${ }^{29}$ The attributive dobraja 'good' in (101) is apparently not a QP determiner but rather a $Q$ determiner and is directly associated with polovina, perhaps in a structure such as the following.

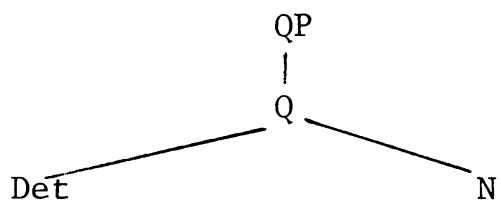


their gender is manifested by associated constituents. This adjustment is analogous to the ones which may take place after QP Raising when the quantifier is a compound numeral which ends in odin 'one' or when the quantifier is an adverbial one (pp. 379-380).30

3.2 Since the putative adjustment triggered by nominal quantifiers may follow not only QP Lowering but also QP Raising, it will be instructive to consider first the consequences of QP Raising when it does not take place. The following sentences, drawn from various texts, illustrate pluralized verbal predicates in association with

${ }^{30}$ There do occur, however, sentences with neuter verbal predicates in association with nominal quantifiers other than the ones illustrated in the sentences cited in the text, and the fact that such sentences do not represent isolated instances is indicated by their mention in the 1960 Academy grammar, though as "incorrect" (Vinogradov and Istrina 1960, 518). The illustrations given in the Academy grammar are the following.

(i) Cast'[nom sg fem] rabotnikov[gen p1] perevedeno [neut].

'Part of the workers have been transferred.'

(ii) Komissiej otmečeno[neut] rjad[nom sg masc] by commission noted several nedostatkov [gen $\mathrm{p} 1$ ]. deficiencies

'A number of deficiencies have been noted by the commission.'

Sentence (iii) illustrates the same phenomenon in association with a plural nominal quantifier. (This sentence is cited in Vinogradov 1950, 95, in a criticism of the analysis offered by Shakhmatov for Pustjaki[nom pl] ostalos'[sg neut] 'there's [only] a trifle left' [Šaxmatov 1925, 125]; cf. also the analysis of the sentence cited by Shakhmatov in Peškovskij 1956, 368.)

(iii) $V$ košel'ke ostalos'[sg neut] pustjaki[nom p1]. in purse remained trifles

'There is practically nothing left in the purse.' 
subject phrases which contain singular nominal quantifiers and plural quantified nouns in the genitive case. The verbs manifest the number of the quantified nouns.

The sentences under (102) illustrate "digital" and "nondigital" numeral-like quantifiers ( (a) cited in Rozental' 1971a, 217; (b) cited in Švedova 1970, 554). Sentence (d) is especially interesting, because the verb is associated with a prepositional phrase which has no noun in the nominative case and it nevertheless manifests the number of the quantified noun (cf. pp. 352-354 above).

(102) (a) Tysjača [nom sg] soldat[gen p1] brosilis'[p1] na pravyj flang.

'A thousand soldiers rushed to the right flank.'

(b) Razygryvajutsja[p1] million[nom sg] vyigryšej [gen p1].

'A million prizes are being drawn.'

(c) Desjatok[gen p1] jabZok[gen p1] Zě̌aZi[p1]v škafu.

'Ten apples lay in the cupboard.'

(d) $S$ desjatok[acc sg] ucenikov [gen p1] bol'ny[p1]. 'About ten students are sick.'

The sentences under (103) illustrate adverbial-like quantifiers, all of which are of the "regular" type. Hyperbolic quantifiers do not seem to occur much within subject phrases in sentences with pluralized verbs, apparently because these quantifiers tend to be focal in sentences and thus tend to derive as higher predicates. In (b) and (c), the modifiers bol'soe 'large' and značitel'noe 'significant' can be assumed to derive as Q determiners, like dobraja in dobraja polovina 'a good half' (see footnote 29). (Sentences (c) and (d) both occur in Mučnik 1971, 62.)

(103) (a) Pered zdaniem zavodoupravlenija množestvo[nom $\mathrm{sg}$ ] motociklov[gen pl], slovno gustoj pčelinyj roj, oblepili[p1] plotnym kol'com monument rabočemu-sudoremontniku.

The quantified entity in (iii) is apparently money, and the noun signifying it has been deleted. 
'In front of the plant's administration building, many motorcycles, like a dense swarm of bees, have formed a tight ring around the monument for the ship-repair workers.'

(b) Bol'šoe čislo[nom sg] żitelej[gen p1] goroda Soronga bezali[p1] $v$ džngli $i$ prisoedinilis' [p1] $k$ partizanam.

'A large number of the residents of the city of Sorong fled into the jungle and joined the partisans.'

(c) Sredi privedënnyx $v$ nastojaščem razdele glagol'nyx obrazovanij s -sia značitel'noe količestvo[nom sg] ne mogut[p1] upotrebljat'sja $v$ značenii "izmenenie $v$ sostojanii sub"ekta".

'Of the verbs with -sja cited in the present section, a significant number [1it. quantity] cannot be used in the sense of "change in the state of the subject."'

(d) Rjad[nom sg] glagolov[gen $\mathrm{pl}$ ] $v$ silu svoego real'nogo značenija ne mogut [p1] $v$ formax $s$ -sja priobretat' značenija izmenenija $v$ sostojanii sub"ekta.

'A number of verbs, because of their basic meaning, cannot acquire the meaning of change in the state of the subject in their forms with -sja.

(e) Rjad[nom sg] vystupavšix [gen p1] vyskazali[p1] menie, čto kauzativ sledovalo by sčitat' zalogom.

'Several speakers expressed the opinion that the causative should be considered a grammatical voice.'

The sentences under (104) illustrate definite fractionals as "raised" quantifiers $((a)-(b)$ cited in Gorelova 1969, 13; (c) cited in Akopdžanjan 1962a, 52). Note that if grammatical subjects are defined as nouns in the nominative case, then (c)-(e) have no grammatical subjects.

(104) (a) Polovina[nom sg] studentov[gen p1] s pervogo kursa uexali [p1].

'Half of the first-year students have gone away.'

(b) [Imel Zi pravo Barnard peresażivat' serdce?] Polovina[nom sg] vračej[gen pl] otvečajut[p1], čto ne imel. 
'[Did Barnard have the right to transplant a heart?] Half of the doctors answer that he did not.'

(c) Bol'še poloviny [gen sg] ranenyx matrosov [gen p1] vernulis'[p1] v stroj.

'Over half of the wounded sailors have returned to their posts.'

(d) $V$ Kostrome bol'še poloviny [gen sg] vsex mal'čikov[gen p1], roždënnyx v 1961 godu, polučili[p1] tol'ko 4 imeni: Sergej, Aleksandr, Andrej, Vladimir.

' In Kostroma, over half of all the boys born in 1961 received only four names: Sergey, Alexandr, Andrey, Vladimir.'

(e) Bolee treti[gen sg] policejskix [gen p1] $v$ rabočee vremja p'janstvovali $[\mathrm{p} 1]$ ili spali[p1]. 'Over one third of the policemen drank or slept while on duty.'

The sentences under (105) illustrate indefinite fractionals, of which bol'šinstuo 'majority' is especially typical as a bona fide quantifier. (Sentence (a) is cited in Rozental' 1971a, 214; (c) occurs in Lobanova 1966, 30; (d) occurs in Švedova 1970, 350; (f) is cited in Rozental' 1968, 244; (g) in Rozental' and Telenkova 1973a, 284; and (h) in Vagner and Ovsienko 1967, 538.)

(105) (a) Čast'[nom sg] Zunnyx obrazcov [gen p1] napominajut [p1] po svoemu sostavu kamni, obnamizennye na Zemle bliz staryx vulkanov.

'Some [1it. part] of the moon samples resemble in their composition stones which were found on earth near old volcanos.'

(b) Bol'šinstvo[nom sg] Zjudej[gen p1] upotrebljajut[pl] pišci primerno $v$ poltora raza bol'še, čem nado.

'Most people consume about one and a half times more food than is necessary.'

(c) Bol'sinstvo[nom sg] sobiratel'nyx sušcestvitel'nyx [gen pl] upotrebljajutsja[p1] tol'ko $v$ edinstvennom čisle.

'Most collective nouns are only used in the singular.'

(d) Bol'šinstvo[nom sg] perexodnyx glagolov[gen p1] prisoedinjajut [p1] $k$ sebe $v$ kačestve prjamogo ob"ekta imja v vinitel'nom pade‡e. 
'Most transitive verbs take as direct object a noun in the accusative case.'

(e) Esli sprosit' u kogo-nibud' (nu xotja by u devoček iz našego klassa), kak oni otnosjatsja $k$ svoim mamam, to bol'šinstvo [nom sg] otvetjat [p1], čto ljubjat i uvažajut svoju mamu.

'If you ask someone (let's say the girls of our class, for example) what their attitude is to their mother, then most will answer that they love and respect their mother.'

(f) $V$ zale bylo mnogo delegatov; bol'šinstvo[nom $\mathrm{sg}]$ üe zanjali[p1] predostavlennye im mesta.

'There were many delegates in the hall; most had already taken the seats assigned to them.'

(g) Ogromnoe bol'šinstvo[nom sg] dejstvitel'no Zučsix artistov[gen $\mathrm{p} 1]$ otvetili[p1], eto $v$ samye siz'nye momenty pod'rema oni osobenno sil'no oščuščajut svjaz's čelovečeskoj massoj, so zriteljami.

'A large majority of the very best artists answered that at the moments of most intense elation they were especially aware of the contact with the human mass, the spectators.'

(h) Podavljajuščee bol'šinstvo[nom sg] prisutstvujušcix [gen p1] prinjali[p1] predloženie.

'The overwhelming majority of those present accepted the proposal.'

Sentence (c) is especially interesting, because it comes from the text of a book (Lobanova 1966) which explicitly rules out such sentences, stating that when "nouns of indefinite quantity" like mnozestvo 'many' or bol'šinstvo 'majority' occur with a noun in the genitive case, a verbal predicate associated with them must always [sic!] be in the singular (p. 38).

Sentence (d), which comes from the text of the 1970 Academy grammar, is interesting for the same reason, though the statement it contradicts does not appear in the same volume but rather in the 1960 Academy grammar. The 1960 Academy grammar states that in association with a subject phrase which contains a collective noun which signifies quantity, like bol'šinstvo 'majority,' mozestvo 'many, ' rjad 'several,' or čast' 'part,' a verbal predicate must be in the singular, and it may only be in the plural 
if there is a genitive noun which denotes human beings (Vinogradov and Istrina 1960, 501).

What (c) and (d) demonstrate, then, is that nominal quantifiers can function like numerical and adverbial quantifiers even in the speech of grammarians who are well versed in the rules of school grammar. On the other hand, these sentences indicate that what Russian grammars and style manuals say about agreement with nominal quantifiers should not be taken at face value (for a survey of representative statements see Mullen 1967).

Sentences (e) and ( $f$ ) demonstrate that a verb may be pluralized in association with a subject phrase which contains a nominal quantifier even when the subject phrase does not contain a plural noun in the genitive case (cf. also (103c) above, where značitel'noe količestvo 'significant quantity' has no noun in the genitive associated with it and the verb is pluralized). The number manifested by the verbs in such sentences must be the number of deleted underlying nouns with which they are associated. In (e), the deleted noun is evidently devočki 'girls,' and in ( $f$ ) it must be delegaty 'delegates.'

The last comment with respect to the sentences under (105) relates to the modifiers ogromnoe 'vast' and podavljajuščee 'overwhelming' in $(\mathrm{g})$ and $(\mathrm{h})$ : both can be accounted for as $Q$ determiners (cf. footnote 29 above). (For some further data on čislo 'number' and bol'šinstvo 'majority' as quantifiers see Akopdžanjan 1962c and 1962d.)

3.3 One might suggest that the number manifested by the verbs in sentences such as (102)-(105) is not the number of nouns associated with the nominal quantifiers but rather a manifestation of the lexical plurality of the alleged quantifiers. There are three arguments against such an account. First, there is the fact that such nouns can function as quantifiers in Type (7) sentences and the verbs then do not necessarily manifest their gender. 31 They are analogous to numerical and adverbial quantifiers in these sentences and there is no reason to

${ }^{31}$ This cautious formulation is meant to accomodate sentences in which the nominal quantifiers can be assumed to have triggered an adjustment (see Section 3.5 below) and sentences such as the following, where the nominal quantifiers are inherently neuter and the gender manifested by the verbs appears to be their inherent gender. 
believe that they are not analogous to numerical and adverbial quantifiers also in sentences in which the verbs are pluralized. In other words, nominal quantifiers can be assumed to derive as Qs to account for their occurrence in Type (7) sentences, and it should therefore be possible for them to derive also as Qs in embedded sentences, especially since there is evidence for it in the form of pluralized verbs.

The second argument is based on sentences such as (106), where the verbs cannot possibly be pluralized (except in substandard discourse) because the nouns associated with bol'sinstvo are in the singular.

(106) (a) Vo vremena Puškina ... podavijajušcee bol'šinstvo[nom sg] naroda[gen sg] $\begin{gathered}\text { govorilo } \\ \text { govorili }\end{gathered}$ [sg] \} na dialektax.

'In Pushkin's time ... the overwhelming majority of the people spoke dialects.'

(b) Bol'šinstvo[nom sg] gruppy [gen sg] \{ vypolnilo $[\mathrm{sg}]\}$ zadanie dosročno.

'The majority of the group fulfilled the assignment ahead of time.'

(i) Narodu[gen sg] bylo[sg neut] mnoæestvo[nom sg neut]. of people was multitude

'There were a great many people.'

(ii) Ix[gen p1] skopilos'[sg neut] u nego velikoe of them accumulated by him great mnoð̌stvo [nom sg neut]. many

'He had a great many of them accumulated.'

(iii) Kolebanij[gen p1] v rečevoj praktike bylo[sg neut] of variations in speech practice was značitel'noe čislo[nom sg neut]. significant number

'There was a significant number of variations in usage.' 
These sentences demonstrate that number manifestations in association with bol'sinstvo are not independent of the noun associated with the nominal quantifier. If the plural number of verbal predicates associated with bol'šinstvo and similar nouns were only determined by their lexical plurality, sentences such as (106) should not have been any different. Furthermore, in substandard Russian, where collective nouns such as narod 'people' and gruppa 'group' may have pluralized verbs associated with them, pluralization is also acceptable in (106).

The third argument is based on the fact that number manifestations in standard Russian cannot be determined by lexical or contextual plurality (see Section 2.3 in Chapter Two). Compare, for instance, the sentences under (107) ((a) was cited above as (103b)).

(107) (a) Bol'šoe čislo[nom sg] žitelej[gen p1] goroda Soronga bežli[p1] $v$ džungli.

'A large number of the residents of the city of Sorong fled into the jungle.'

(b) *Bol'šaja gruppa [nom sg] zitelej [gen p1] goroda Soronga bezali[p1] $v$ dzungli.

'A large group of the residents of the city of Sorong fled into the jungle.'

Only in substandard discourse can a sentence such as (107b) be acceptable. The acceptability of a plural verb in (107a) in standard discourse must thus be due to some special property of bol'šoe čislo 'large number' which distinguishes it from bol'šaja gruppa 'large group.' That property seems to be its susceptibility to derivation as Q.

3.4 There do occur plural endings in association with nominal quantifiers which have singular nouns associated with them, and they are indeed difficult to account for. Such plural endings occur in association with the definite fractionals četvert' 'quarter' and pol- 'half.' Consider the sentences under (108)-(109) ((109a) cited in Švedova 1970, 554; (109b-d) cited as model sentences in Lebedeva

(iv) Takix slov[gen p1] okazalos'[sg neut] ogromnoe of such words turned out vast količestuo[nom sg neut]. quantity

'There turned out to be a great many words of this type.' 
1968, 190, Vinogradov and Istrina 1960, 505, and Rozental' 1971a, 218, respective1y).

(108) (a) $V$ èti[nom pl] četvert' [nom sg] goda[gen sg] my sobiraemsja postroit' pjat' novyx zavodov.

'During this quarter of the year we are planning to build five new plants.'

(b) Ja tuda xő̌u ka̋̌dye [acc p1] četvert' [acc sg] časa[gen sg].

'I go there every quarter of an hour.'

(109) (a) PolkZassa ne vyučili[p1] urokov.

'Half of the class have not studied their lessons.'

(b) Gnilye[nom p1] pol-arbuza valjalis'[p1] pod Zavkoj.

'A rotten half watermelon lay under the bench.'

(c) Ėti[nom p1] pol-jabloka lezali[p1] na stole.

'This half apple was lying on the table.'

(d) Ostal'nye[nom p1] poldoma uceleli[p1] ot požara.

'The remaining half of the house did not burn down in the fire.'

(e) Lǐs' teper' zametila Saša, čto dobrye [nom p1] polneba vsë ešc̈e sijajut [p1] bezoblačnoj jasnost'ju.

'Only now did Sasha notice that a good half of the sky was still shining with cloudless brightness.'

(f) Polżizni, provedënnyx [gen p1] tom, otdalis'[p1] emu preždevremennym paraličom.

'The half of [his] life which he had spent there resulted in premature paralysis.'

(g) Ćto izmenilos' $v$ sud'be poèzii Bloka za polveka, prošeď̌ie[acc pl] so dnja ego smerti?

'What has changed in the fate of Blok's poetry in the course of the half century which has passed since his death?'

(h) Prošli[pl] celyx [gen p1] polnedeli. 'A whole half week has passed.'

To take one sentence, (109a), pol-can be assumed to represent the underlying quantifier $1 / 2$ in an embedded sentence, and the verb should manifest the number of the NP node dominating klass in the underlying matrix sentence. The subject phrase in (109a) refers to one half 
of one class, so that the NP node cannot be assumed to be specified \{taggregate\} (that would yield polovina klassov 'half of the classes'). The contextual number specification of the NP node must be \{-aggregate\}.

A possible account for the plural number of the verb is the following. The NP node can be assumed to have an additional contextual number specification, perhaps $\{+$ fraction\}, and the grammatical number of the node is then defined on the basis of the feature combination \{-aggregate, +fraction\}. It is defined as "paucal," possibly specified as [+Plural, +Sing] (cf. pp. 339-342 and footnote 9 for this chapter). When the paucal specifications are lowered to the noun stem, they are realized by singular endings. When they are copied onto Attributive and $\mathrm{V}$ nodes and lowered to the respective stems, they are realized by plural endings ( $c f$. the remaining sentences in (108) and (109)). After QP Raising, the fractional quantifiers only impose the genitive case on the nouns they modify and do not affect their grammatical number. 32

Some supportive evidence for this account is provided by the fact that nouns which have special paucal forms (cf. footnote 9) may also assume them in association with četvert' and pol-. Compare dva časá 'two hours, 'okolo čása 'around an hour,' and polčaśa 'half an hour, ' četvert' časá/čása 'quarter of an hour'; dva sagáa 'two steps,' ni odnogo šága 'not one step,' and polšagá/polšága 'half a step.' (Pol- is also accounted for as a paucal numeral in Zaliznjak 1964, 38-39 and 1967a, 78.)

The difference in the case of the postpositive attributives in (109f) and $(109 \mathrm{~g})$ can be accounted for by postulating different underlying configurations. In $(\mathrm{g})$, the attributive can be assumed to be external to the noun phrase which contains the embedded sentence with the quantifier and its case is therefore not affected by QP Raising. In (f), on the other hand, the attributive is apparently directly associated with ¿izn' '1ife' in the

${ }^{32}$ This distinguishes fractional quantifiers from the numerals which impose paucal specifications. This distinction accounts for the fact that while nouns which follow the adjectival paradigm have plural endings when modified by paucal numerals, they have singular endings when modified by fractionals (cf., e.g., dve vannye [p1] 'two bathrooms' and polvannoj[sg] 'half a bathroom'). 
underlying structure and after QP Raising it is assigned the genitive case along with the noun.

In $(109 \mathrm{~h})$, the attributive appears to represent an underlying QP modifier, and like all QP modifiers it must be pluralized and must be in the genitive case (see pp. 345-347 above).

If it were not for sentences like (108), where there are plural endings in association with četvert' 'quarter,' the pluralized forms in association with pol- could perhaps be accounted for by viewing pol- as inherently plural (this would not be implausible, since singular endings in association with pol- are invariably neuter and only occur in sentences which have Type (7) underlying representations, i.e., when Verb Agreement cannot apply). 33 However, plural number is also manifested in association with subject phrases containing četvert' and no plural noun, and this indicates a more general phenomenon, though it apparently only involves pol- and četvert', and the latter only in association with čas 'hour' and god 'year.' Plural endings do not occur in association with subject phrases in which cetvert' is associated with other nouns or in which the heads are tret' 'third' or the full form polovina 'half.' This can be accounted for either by assuming the operation of an adjustment which fails to be triggered in the environments illustrated in (108) and (109), or by assuming the absence of a $\{$ fraction $\}$ specification. 34

3.5 The adjustment referred to in the preceding paragraph and also earlier in the present discussion ( .390$)$ is apparently triggered by nominal quantifiers which derive

${ }^{33}$ Combinations with pol- are labelled in dictionaries as regular nouns with inherent gender (i.e., not as pluralia tantum nouns). Poľcasa 'half an hour,' for example, is labelled masculine, polslova 'half a word' is labelled neuter, and polsotni 'half a hundred' (='fifty') is labelled feminine. But these genders can only be manifested in association with the pol-combinations when they are in oblique cases, and the oblique case forms may represent different lexical units, as proposed in Zaliznjak 1964, 38-39 and 1967a, 78.

${ }^{34}$ There is also no evidence for postulating a f+fraction $\}$ specification in association with indefinite fractionals. 
as Qs when the QP node which dominates them comes to be dominated by an NP node (whether through QP Lowering or QP Raising). The adjustment presumably involves the deletion of any number or gender specifications on the superordinate NP node (other than the "provisional" ones) and their replacement with the specifications of the $Q$ noun, which are usually only gender specifications. (A noun which functions as a quantifier can only have number specifications if it is an inherently plural noun. Pustjaki 'trifles,' for example, illustrated in footnote 30 for this chapter, can apparently be considered inherently plural as a quantifier.)

This adjustment is generally more typical of formal, nonspontaneous discourse, but it is not limited to such discourse. The evidence for such an adjustment is clearest in sentences which represent Type (7), like the sentences under (110) ((b) cited in Kamynina 1961, 25 and Ivanova 1973, 101 from a work by Konstantin Simonov; (c) cited in Švedova 1970, 555).

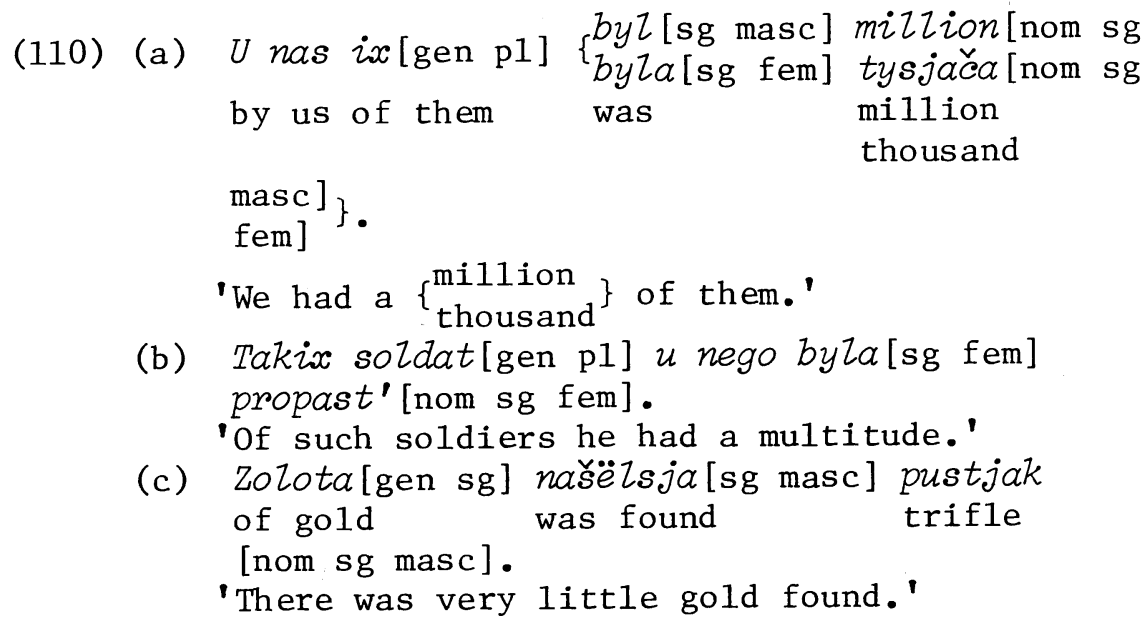

Without the adjustment, the verbs in (110) would have neuter endings. In most sentences in which constituents associated with nominal quantifiers manifest their gender, however, the nominal quantifiers can be assumed to derive either as Qs or as regular nouns. The underlying representations cannot be determined by the grammatical endings in the surface sentences (though there may be other indicators). The following are examples of such sentences with various quantifiers ((a) cited in Senkevič 1964, 5; (b)-(d) cited in Rozental' 1971a, 216 and 218; (j) cited 
in Patton 1969, 113; and (n) cited in Akopdžanjan 1962b, 163).

(111) (a) Million[nom sg masc] posetitelej[gen p1] proš̈l[sg masc] po pavil'onom vystavki za odin mesjac.

'A million visitors have gone through the pavilions of the exhibition in one month.'

(b) Tysjača[nom sg fem] knig[gen pl] postupila[sg fem] $v$ škol'nuju biblioteku. ${ }^{35}$

'A thousand books ahve been added to the school library.'

(c) Semërka[nom sg fem] samolëtov[gen p1] ustremilas'[sg fem] vperëd.

'Seven airplanes headed forward.'

(d) Sotnja[nom sg fem] rebjat [gen p1]razbezalas' [sg fem] vo vse storony.

'A hundred kids ran in all directions.'

(e) Na ulicax švedskix gorodov rasstavleno [sg neut] neverojatnoe možestvo[nom sg neut] korzin[gen p1] dija brosovoj bumagi.

'In the streets of Swedish cities there are incredibly many trash baskets all over.'

${ }^{35}$ Tysjaca 'thousand' resembles numerical quantifiers more than any other nominal quantifier, not only because it regularly occurs with neuter or pluralized verbs but also because, colloquially, when it occurs in oblique cases the quantified nouns may coincide with it in case, as with a bona fide numeral; e.g., Reč' idët o tysjače [1oc] mbljax[1oc] '[we are] speaking of a thousand rubles,' rather than 0 tysjace [1oc] mblej[gen], with the quantified noun in the genitive, as it should be with all nominal quantifiers regardless of their case. (Unless it is a noncount noun, the quantified noun should also be in the plural with all but the fractional nominal quantifiers, where it may also be in the singular. Note that this also applies to nol'/mul' 'zero,' e.g., nol' gradusov [gen pl] 'zero degrees,' $k$ nulju[dat] gradusov[gen pl] 'to zero degrees')

Tysjača also has a Third-Declension instrumental form --tysjac'ju--which underscores its resemblance to bona fide numerals (most of which follow the Third Declension). Tysjac'ju is used as a variant of the regular, Second-Declension form tysjačej. There is a tendency to use tysjač'ju with a quantified noun in the instrumental (cont.) 
(f) V 1913 godu v promyšlennoj strukture goroda naibol'šee čislo[nom sg neut] rabočix[gen p1] (38\%) bylo zanjato [sg neut] $v$ tekstil'noj promy šlennosti, a sejčas--menee $10 \%$.

'In 1913, the greatest number of workers (38\%) in the industrial structure of the city were employed in the textile industry, and now--less than $10 \%$.'

(g) Za poslednee vremja pojavilsja[sg masc] rjad [nom sg masc] novyx proizvedenij[gen p1] 0 vračax.

'A number of new literary works about doctors have appeared lately.'

(h) Teper' na nee obmišilas'[sg fem] takaja bezdna [nom sg fem] nenužnogo vremeni[gen sg], čto ne znala kuda ot nego i det'sja.

'Now she was suddenly flooded with so much unnecessary time that she did not know where to get away from it.'

(i) Ujma[nom sg fem] gostej[gen p1] nagrjanula[sg fem].

'A multitude of guests showed up.'

(j) Polovina[nom sg fem] magazinov[gen p1] ne rabotala[sg fem] po subbotam.

'Half of the stores were not open on Saturdays.'

(k) Bol'šinstvo[nom sg neut] takix pisem[gen pl] anonimno [sg neut].

'Most letters of this kind are anonymous.'

(1) Bol'šinstvo[nom sg neut] Zjudej[gen p1] ravnodušno [sg neut] $k$ pesne.

'Most people are indifferent to songs [1it. the song].'

(m) Bol'šaja čast'[nom sg fem] ¿̌itelej[gen p1] goroda svjazana[sg fem] s flotom.

'Most [1it. the greater part] of the residents of the city are connected with the navy.'

(n) Bol'šaja čast' [nom sg fem] ruček [gen p1] Zě̌ala [sg fem] na stole.

'Most [1it. the greater part] of the pens lay on the table.'

rather than the genitive, but there is no consistent correlation (see Ivanova 1969 and also Rozental' 1971a, 187). 
3.6 To recapitulate, nominal quantifiers are nouns which may function as numerical or adverbial quantifiers in underlying representations. Since they possess inherent gender, their presence in quantifier phrases may trigger an adjustment as a result of which associated constituents manifest their gender despite the fact that they are within quantifier phrases. ${ }^{36}$ When such an adjustment does not take place, associated constituents may either have singular neuter endings, in which case the nominal quantifiers can be assumed to derive as higher predicates, or plural endings, in which case they can be assumed to derive as predicates of embedded sentences.

\section{Copulative Verbs}

\subsection{Introduction}

The term "copulative verb" as used in the present section applies to any verb which co-occurs with a verbal or nominal predicate. When a copulative verb co-occurs with a verbal predicate, i.e., a short-form adjective or participle, there are no possible alternatives in the number and gender it manifests: its ending always matches the ending of the verbal predicate. This is predictable, for Verb Agreement applies to copulative verbs as it applies to main verbs (i.e., verbal predicates). The sentences under (112) illustrate singular copulative verbs and verbal predicates in association with subject phrases containing quantifiers, and the sentences under (113) illustrate plural copulative verbs and verbal predicates in association with such subjects $((112 a)$ is essentially

${ }^{36}$ This applies chiefly to verbs, because when nouns which function as quantifiers are modified by attributives, the attributives are usually directly associated with them as $Q$ determiners, e.g., dobraja[nom sg fem] polovina[nom sg fem] 'a good half,' though there also occur QP modifiers, e.g., celyx [gen pl] polčasa 'a whole half hour' or modifiers external to noun phrases with embedded sentences containing quantifiers, e.g., každye [acc pl] četvert'[acc $\mathrm{sg}$ ] časa[gen sg] 'every quarter hour.' An interesting phrase in this connection is $v$ sledujušcie[acc pl] paru [acc sg] nedel'[gen pl] 'in the next couple of weeks,' where the noun para is used as quantifier (cf. the data and comments on the use of para as quantifier in Lebedeva $1968,176-177)$. 
identical to (111m) above; (112b) cited in Lobanova 1966, 38; and (113b) is cited in Rozental' 1971a, 215) ${ }^{37}$

(112) (a) Ból'šaja čast'[nom sg fem] žitelej[gen p1] goroda $\left\{\begin{array}{c}\text { byla[sg fem] } \\ * b y l i[\mathrm{pl}]\end{array}\right.$ svjazana[sg fem] s flotom. 'Most [1it. the greater part] of the residents of the city were connected with the navy.'

(b) Bol'šinstvo[nom sg neut] specialistov

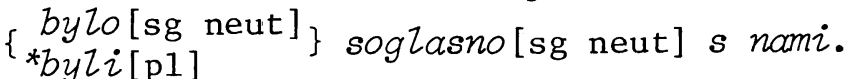
'Most of the specialists were in agreement with us.'

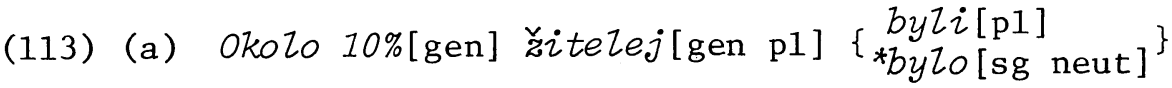
negramotny $[\mathrm{p} 1]$.

'Around $10 \%$ of the residents were illiterate.'

${ }^{37}$ These sentences call for a comment on the fact that short-form adjectives in sentences with quantifiers in the subject phrase are generally pluralized (cf. also the observation in Rozental' 1971a, 215). Consider, for example, the following sentence.

Bol'šinstvo[nom sg neut] studentov[gen p1] $\begin{gathered}\text { bol'ny[p1] } \\ \text { ?*bol'no[sg }\end{gathered}$ neut] . $^{\text {. }}$

'Most of the students are sick.'

The neuter form is awkward even though it represents the standard pattern of agreement. I am not sure how to account for this fact, but I can suggest that perhaps the putative adjustment of the NP node specifications after $Q P$ Lowering and QP Raising is sensitive to the role of the NP with respect to the predicate. The role of the NP associated with short-form adjectives in most cases can be defined as Essive (cf. p. 227), and perhaps this role specification on the NP node can be assumed to discourage any adjustment of the number and gender specifications (this would also apply to adjustments triggered by adverbial quantifiers and by compound numerals which end in odin). According to Peškovskij 1956, 357, neuter short forms are avoided in general, but this does not seem to (cont.) 
(b) Bol'šinstvo[nom sg neut] dverej[gen pl] $\left.\begin{array}{l}\text { byli[p1] } \\ \text { *bylo[sg neut] }\end{array}\right\}$ nizki[p1] dlja ego rosta.

'Most of the doors were [too] low for his height.'

Sentences with nominal predicates are considerably more interesting with respect to copulative verbs, because the gender and grammatical number of the nominal predicates are independent of the gender and number of the subject phrases. Thus copulative verbs, which assume the specifications of subject phrases by Verb Agreement, may conflict in number or gender with the nominal predicates with which they co-occur, as in, e.g., (114).

\section{(114) Pervoj ëereakciej[instr sg fem] byzo[sg neut]}

first her reaction was razočarovanie [nom sg neut]. disappointment

'Her first reaction was disappointment.'

The predicate phrase is marked by the instrumental case in this sentence. In the following sentence, which has the same constituent order, i.e., PredP--Verb--Subject, the predicate phrase is not marked by the instrumental and the copulative verb may appear to agree with the nominal predicate, i.e., it might appear to exhibit "backward agreement."

(115) Kabinet[nom sg masc] byla[sg fem] bol'šaja komnata study [nom sg fem]. large room

'The large room was the study.'

The fact that kabinet 'study' is not subject in (115) can be demonstrated by the unacceptability of (116).

(116) *Ettot kabinet[nom sg masc] byza[sg fem] bol'saja this study komnata[nom sg fem]. large room

be an adequate account for the plural number of shortform adjectives in sentences with quantifiers. 
What renders (116) unacceptable is the determiner ètot 'this,' because a nominal predicate cannot take this determiner (for an elaboration of this argument and a detailed analysis of (115) and the other sentences which have been traditionally viewed as exhibiting "backward agreement" see Revzin 1973, esp. $129 \mathrm{ff} . ;$ sentences such as (115) are viewed as exhibiting "backward agreement" in, e.g., Vinogradov and Istrina 1960, 519; Svedova 1970, 555; and Rozental' 1971a, 225). Now consider (117).
(117) (a) Kabinet[nom sg masc] byz[sg masc] bol'šaja study was large komnata[nom sg fem]. room
'The study was a large room.'
(b) Etot kabinet [nom sg masc] byz [sg masc] bol'šaja this study komnata[nom sg fem]. room
'That study was a large room.'

In (117a) the copulative verb manifests the gender of kabinet, and the acceptability of (117b) demonstrates that this is indeed the subject in this case. Sentence (117a) and sentence (115) thus do not represent variants of the same underlying structure with different patterns of agreement but rather two different sentences. It is noteworthy, though, that such sentences are quite uncommon in usage in comparison with sentences such as (114), where the predicate is marked by the instrumental case (cf. the footnote in Revzin 1973, 129). They were analyzed here primarily by way of introduction to the discussion that follows.

Section 4.2 deals with sentences in which the subject phrases contain quantifiers. In Section 4.3 the discussion turns to sentences with the pronominal form kto 'who' or one of its derivatives (e.g., nekto 'someone,' kto-to 'someone,' koe-kto 'some people'), and Section 4.4 contains some observations on sentences with èto 'this, that.'

\subsection{Sentences with Quantified Subjects}

Most interesting in the category of sentences with quantified subjects are sentences with quantifiers which can trigger an adjustment in the specifications of the subject NP node, and especially nominal quantifiers. Since quantifiers in sentences with nominal predicates 
always derive from embedded sentences (see Section 1.2 in this chapter), a copulative verb in a sentence in which the specifications of the subject NP node have not been adjusted would manifest the number of the quantified noun (the noun in the genitive), and a copulative verb in a sentence in which the specifications of the NP node have been adjusted would manifest the number and gender of the quantifier (assuming it is a nominal quantifier). The sentences under (118) illustrate the latter alternative.

(118) (a) Bol'šinstvo [nom sg] ètix universalij [gen pl] predstavljaet [sg] soboj sušcestvennye, $v$ izvestnoj stepeni osnovnye ponjatijnye kategorii [nom p1].

'The majority of these universals are substantive, to a certain extent fundamental conceptual categories.'

(b) Bol'šinstvo[nom sg] načinajuščix pisatelej [nom p1] ètoj gmuppy javijaetsja[sg] aktivnymi rabkorami[instr p1] gazety.

'Most of the beginning writers in this group are active volunteer correspondents of the newspaper.'

(c) Podavijajuščee bol'šinstvo [nom sg] oduševlënnyx suščestvitel'nyx [gen pl] javZjaetsja[sg] slovami[instr pl] mižskogo i ženskogo roda.

'The overwhelming majority of animate nouns are words of masculine and feminine gender.'

(d) Nadejus', ¿̌to ból'šaja čast'[nom sg] studentov [gen p1] ètogo kursa stanet[sg] specialistami [instr pl] po russkomu jazyku.

'I hope that most [1it. the greater part] of the students of this course will become specialists in the Russian language.'

(e) Ból'šaja čast'[nom sg] soglasnyx[gen p1] mozet [sg] byt' tvërdymi[instr pl] i mjagkimi[instr p1].

'Most [1it. the greater part] consonants can be hard and [can be] soft.'

Note that in (118a) the predicate phrase is in the nominative case, and in the remaining sentences it is in the instrumental. In the last sentence, (e), the predicate phrase only contains adjectives.

Sentence (118b) is a model sentence in Lebedeva 1968, 29 , where the singular verb is said to be the only proper 
form and a plural verb in its place would be inappropriate. Curiously enough, other style manuals consider a singular verb in such sentences inappropriate and recommend a plural verb whenever the predicate phrase is in the plural and the subject contains a nominal quantifier, by "backward agreement" (see, e.g., Senkevič 1964, 3-5; Senkevič and Feller 1968, 152; and Rozental' 1971a, 215 [giving (119c) below as a model sentence]; and cf. also Vinogradov and Istrina 1960, 520). Sentences such as the following thus represent the norm according to these sources.

(119) (a) Bol'šinstvo[nom sg] moix druzej[gen pl] byli [p1] studenty[nom p1] staršix kursov.

'Most of my friends were upperclassmen.'

(b) Polovina[nom sg] domov[gen p1] byli[p1] derevjannye [nom $\mathrm{p} 1]$.

'Half of the houses were wooden [ones].'

(c) Ešc̈ë nedavno bol'šinstvo [nom sg] predstavlennyx na konferencii stran [gen $\mathrm{p} 1]$ byli[p1] bespravnymi kolonijami[instr p1].

'Only recently most of the countries represented at the conference were colonies without any rights.'

(d) [Lučšie teatral'nye sceny i koncertnye zaly budut otdany molodym masteram iskusstv ....] Bol'šinstvo[nom sg] iz nix [gen pl] za èti gody stali[p1] artistomi[instr p1] s mirovymi imenami.

'[The best theater stages and concert halls will be offered to the young artists ...] Most of them have become artists with worldwide fame in the course of these years.'

(e) Zanačitel'naja čast'[nom sg] delegatov[gen p1], pribyvšix na konferenciju, javljajutsja[p1] deputatami[instr p1] pariamentov.

'A significant number [1it. part] of the delegates who have come for the conference are members of parliaments.'

(f) Ved' my znaem, skol'ko molodyx mužcin[gen p1] stali[p1] svoego roda moral'nymi zertvami [instr p1] ...

'Well do we know how many young men have become emotional victims ...' 
(g) Množestvo[nom sg] naučynx problem [gen p1], kotorye vydvigajutsja samoj ¿izn'ju, ostajutsja [p1] ešc̈e nerešënnymi [instr p1].

'Many scientific problems which life itself raises remain still unresolved.'

(h) Po dannym JUNESKO, ogromnoe količestvo [nom sg] Zjudej[gen pl] $v$ razvivajuščixsja stranax ostanutsja[p1] negromotnymi[instr p1], esli ne bydet raš̌irena set' obščeobrazovatel 'nyx škol.

'According to data from UNESCO, a vast number [1it. quantity] of people in the developing countries will remain illiterate if the network of general schools is not expanded.

(i) $V$ štate IIZinojs bolee milliona[gen sg] čelovek [gen p1] Zozatsja[p1] spat' golodnymi[instr p1]. 'In the state of Illinois, over a million people go to bed hungry.'

(j) Mnogo sočinenij[gen p1] okazalis'[p1] neproverennymi[instr $\mathrm{pl}$ ].

'Many compositions turned out to have been uncorrected.'

The quantifiers illustrated in these sentences are nominal (bol'šinstvo 'majority,' polovina 'half,' značitel'naja čast' 'significant part,' množestuo 'many, multitude,' ogromnoe količestvo 'vast amount,' and bolee milliona 'over a million') and adverbial (skol'ko 'how many' and mnogo 'many'), and the predicate phrases are in the nominative case in the first two sentences ((b) only has a predicate adjective), and in the instrumental case in the rest (with $(g)-(j)$ only having predicate adjectives). The copulative verbs are varied and all are pluralized. Is this "backward agreement"? Consider also (120).

(120) (a) Šest'desjat [nom] procentov [gen p1] mal'čikov [gen p1] stanovjatsja[p1] Aleksandrami [instr p1], AZeksejami[instr p1], Andrejami[instr p1],

'Sixty percent of the boys become Alexandrs, Alekseys, Andreys ...'

(b) Mnogo Amerik[gen p1] snova stanut[p1] edinoj [instr sg].

'[The] many Americas shall again become one.'

Does (120a) represent "backward agreement"? According to school grammars it does not. And how does (120b) 
differ from (119j) above? In both sentences the copulative verbs are pluralized, but in $(119 j)$ the predicate phrase is in the plural, while in (120b) it is in the singular. Do these two sentences represent different patterns of agreement? ( $(120 \mathrm{~b})$ was also discussed above on p. 125, in footnote 48 for Chapter One, and in footnote 25 for the present chapter.)

The obvious answer, in light of the exposition throughout the present chapter, is that there is no "backward agreement" and that the fact that the copulative verbs and the predicate phrases in sentences like (119) manifest the same number is only a coincidence, though perhaps a happy one from the stylistic standpoint. Only "perhaps," because informants questioned about the sentences under (119), where there are singular copulative verbs with plural predicate phrases, all found them flawless, and indeed such sentences are recommended in at least one style manual (Lebedeva 1968).

Still, it is significant that plural verbs in association with subject phrases which contain nominal or adverbial quantifiers are considered admissible in sentences with plural nominal predicates by grammarians who frown upon pluralized verbs in association with such subject phrases in other contexts. "Backward agreement" thus cannot be dismissed offhand.

Perhaps it can be assumed that the putative adjustment of the specifications on subject NP nodes after QP Raising is sensitive to the presence of a predicate phrase and does not take place in spontaneous discourse when there is one. This would not be an implausible assumption, for nominal predicates modify their subjects and the relationship might be obscured by feature adjustments. Such an assumption would also account for the full acceptability of $(120 \mathrm{~b})$, where the predicate phrase is in the singular. Sentences as in (119) can then be considered a consequence of nonspontaneous, more or less conscious adjustment. They are indeed more typical of formal discourse. 38

${ }^{38} \mathrm{An}$ account in line with the one suggested in the preceding footnote is also perhaps possible, except that it would have to be modified to accomodate sentences such as (119i) or the one below, where the surface subjects do not represent an Essive role and the pluralized verbs are nevertheless fully acceptable. (cont.) 
Whatever accounts for the greater acceptability of pluralized verbs in sentences with nominal predicates, there is no evidence that plural verbs in such sentences are the consequence of a process different from the one which results in pluralized verbal predicates, or in pluralized copulative verbs in sentences with numerical quantifiers in the subject phrases (as in (120a)), which Russian grammarians do not view as manifestations of "backward agreement." "Backward agreement" would only be a justified postulate if plural verbs in association with nominal or adverbial quantifiers were unique to sentences with nominal predicates.

There is only one case where plural verbs do seem unique to sentences with nominal quantifiers: in sentences in which the subject phrase does not contain a plural noun. Consider (121) ( (a) cited in Valgina 1973, 105; (b) cited in Rozental' 1971a, 214).

\section{(121) (a) Bol'šinstvo[nom sg] truppy[gen sg] byZi [p1] akrobatami[instr p1]. \\ 'The majority of the troupe were acrobats.' \\ (b) Bol'šinstvo[nom sg] gruppy [gen sg] by Zi [p1] priezžie[nom $\mathrm{pl}$ ]. \\ 'The majority of the group were newcomers.'}

What is the source of the plural number manifested by the verbs in (121)? In (b), perhaps the subject is priez:ie 'newcomers' rather than bol'śinstvo gruppy 'the majority of the group' and the verb simply manifests the number of its subject (cf. the discussion in Section 4.1). In (a), however, the plural noun is in the instrumental and the phrase with which the verb is associated must be bol'sinstvo truppy 'the majority of the troupe,' where there is no plural noun. This sentence nevertheless does not seem to represent "backward agreement" because of two facts. First, informants questioned about it did not find it stylistically felicitous. Secondly, sentence (b), which illustrates "backward agreement" in Rozental' 1971a, has been changed in the corresponding passage in Rozental' and Telenkova 1973a (p. 283) to (122), where the subject phrase does contain a plural noun.

Bol'šinstvo[nom sg] ètix slov[gen p1] v tolkovyx slovarjax pomečeny[p1] kak ustarevšie[nom pl]. 'Most of these words are labelled in monolingual diction-
aries as obsolete.' 
(122) Bol'šinstvo[nom sg] studentov[gen p1] nasej gruppy [gen sg] by $i$ [p1] priezఓie[nom p1].

'The majority of the students of our group were newcomers.'

The change made in (121b) indicates a possible account for the plural number of the verbs in sentences like (121a): in their underlying representations, the predicate phrases may be associated with nouns which do not appear in the surface sentences, nouns which, if not deleted, would be realized as plural nouns, like studentov in (122). Now consider (123).

(123) ?Bol'šinstvo[nom sg] gruppy[gen sg] ne vyučili[p1] urokov.

'The majority of the group did not study their lessons.'

An underlying noun like studentov 'of students' could also be postulated for (123), yet it is worse than (121a). Perhaps, then, such an underlying noun, i.e., a noun signifying the members of an identified collective, can only be deleted in sentences which have nominal predicates. This is admittedly not a very satisfactory solution, but sentences such as (121) do not seem to constitute strong enough evidence for postulating "backward agreement."

\subsection{Sentences with kto}

What follows are some observations on number and gender manifestations in association with kto 'who' as an interrogative and as relative pronoun (as in (124a) and (124b), respectively) and in association with indefinite pronouns which have kto as their core component, as in $(124 \mathrm{c})$. These observations are relevant in the present context because "backward agreement" has also been claimed for copulative verbs associated with $k$ to (see, e.g., Rozental' 1971a, 222).

(124) (a) Kto [nom] včera byz [sg masc] $v$ teatre?

'Who was at the theater yesterday?'

(b) $\mathrm{Te}[\mathrm{nom} \mathrm{p} 1]$, kto [nom] včera byl[sg masc] $v$ teatre, segodnja opozdali[p1].

' Those who were at the theater yesterday were late today.' 
(c) Koe-kto [nom] byz [sg masc] včera $v$ teatre. 'Some people were at the theater yesterday.'

Sentences such as (124a) and (124c) are discussed in 4.3., and sentences such as $(124 \mathrm{~b})$ in 4.32 .

4.31 In standard Russian, a verbal predicate associated with the interrogative $k$ to or with an indefinite pronoun formed of kto can only be in the singular and its gender must be masculine. Sentences such as the ones under (125), where the verbs are pluralized, are considered substandard, and so are sentences such as (126), where the verb has a feminine ending $((125)$ cited in skoblikova 1967,46 to illustrate substandard usage; (126) cited in Nikitevič 1963 , 48 with the comment that Shakhmatov found no fault with such sentences).

(125) (a) Kto [nom] èto $k$ vam věera prixodizi [p1]?

'Who was it who came to see you yesterday?'

(b) U nas ü nikto[nom] teper' ne prjadut[p1]. 'There is no one here who still weaves.'

(126) Nikto[nom] iz nas ne uspela[sg fem] $s$ neju prostit'sja.

'None of us has had a chance to say good-bye to her.'

In standard colloquial usage, pluralization of a verbal predicate may be acceptable with certain indefinite forms, e.g., koe-kto 'some people,' or kto ugodno 'anyone, whoever you like,' as illustrated under (127) (cited in Rozental' 1971a, 223 to illustrate colloquial usage).

\section{(127) Prixodili[p1] kto[nom] ugodno.}

Feminine endings, however, are not admissible, even when the potential referents of the pronoun are all of the female sex (they must be human, incidentally, for $k$ to is not used for animals unless they are personified; cf. Galkina-Fedoruk 1964, 124). In the following sentences, for example, the standard language does not allow feminine verbs (these sentences are cited as models in Senkevič 1964, 7, Valgina et al. 1971, 209, and Rozental' 1968, 264, respectively, and have been confirmed by native informants as good sentences, considerably better than 
they would have been with feminine verbs; cf. also Vinogradov et al. 1960, 393, and Švedova 1970, 331-332).

(128) (a) Kto[nom] iz sportsmenok[gen p1 (fem)] polučil [sg masc] zolotuju medal'?

'Which of the sportswomen received a gold medal?'

(b) Kto [nom] iz vas, devuški, byl [sg masc] $v$ teatre?

'Which of you girls was at the theater?'

(c) Kto-to [nom] iz delegatok[gen pl (fem)] proprosiz[sg masc] slova.

'One [1it. someone] of the women-delegates asked to speak.'

The difference between standard and nonstandard usage in these cases seems analogous to the difference exhibited in association with collective nouns in that in standard usage contextual specifications can have no effect, but in substandard usage they do play a role in Verb Agreement (cf. Section 2.3 in Chapter Two). In association with kto, which presumably has no inherent gender or number specifications, substandard usage allows contextual specifications to determine the number and gender for verbal predicates, whereas in standard usage this is generally avoided: the number and gender manifested in association with kto or its derivatives must be determined on the basis of the "provisional" specifications on the NP node which dominates the pronominal form (see esp. Section 7.122 in Chapter One). Now consider the following sentences.
(a) Kto [nom] $\left.\begin{array}{r}\text { by } 2 a[\mathrm{fem}] \\ * b y Z[\mathrm{masc}]\end{array}\right\}$ vaša prodruga[nom fem]? 'Who was your friend?'
(b) Kto[nom] $\left.\begin{array}{c}\text { byzi }[\mathrm{p} 1] \\ * b y z[\mathrm{sg} \operatorname{masc}]\end{array}\right\}$ vasi pomošniki[nom p1]?
'Who were your assistants?'

At first glance the sentences under (129) seem to represent "backward agreement," but in fact kto is predicate in these sentences, which can be demonstrated by comparison with sentences as in (130). 


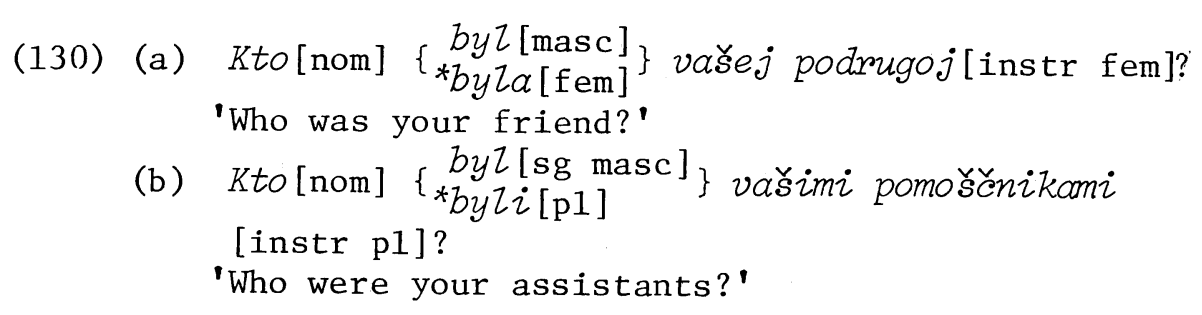

In these sentences (which, though somewhat awkward, are fully grammatical), kto cannot be predicate, for the instrumental case marks the phrases to the right of the verbs as predicates. It must be subject, and the verbs indeed must have singular masculine endings. Only in substandard discourse, where contextual specifications may play a role in Verb Agreement, can copulative verbs in such sentences have other endings. Hence in (129) kto is not subject, and there is no basis for viewing the sentences as representing "backward agreement." This account can also be substantiated by sentences as in (131).

(131) Kto-to vošel v komnatu.

'Someone entered the room.'

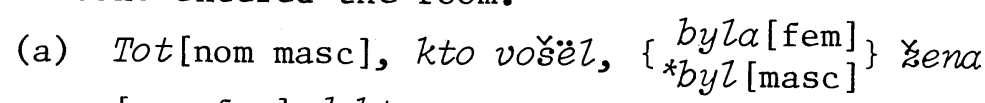
[nom fem] doktora.

(b) Tot [nom masc], kto vošër, $\left\{\begin{array}{c}\text { by }[\text { [masc }] \\ \text { by }\{a[\mathrm{fem}]\end{array}\right.$ ženoj [instr fem] doktora.

'The one who entered was the doctor's wife [1it. wife of doctor].'

The sentences under (131) demonstrate that the phenomenon illustrated in $(129)-(130)$ is not restricted to sentences in which the head of the phrase to the left of the verb is kto; in (131a-b) the head is tot. Sentence (131a) has the same structure as (129a), and (131b) has the structure of (130a). The question why in sentences like (131a) or (129a) kto cannot represent an underlying subject is beyond the scope of the present discussion, but this fact is no doubt related to the phenomenon illustrated by (116) on page 406 above (for some pertinent observations see Lobanova 1966, 16-21 and Revzin 1973). The difference in meaning between (129a) and (130a) is that in (129a) the speaker is seeking information about a person identified as the addressee's friend, while in (130a) the speaker is inquiring about the identity of the addressee's 
friend (who may be no one). This also applies to the (b) sentences under (129) and (130).

In (129)-(130), the phrases to the right of the copulative verbs contain nouns. When there are only adjectives, the picture changes somewhat, as illustrated in (132) (the initial sentence should be taken as introductory to $(a)-(c))$.

(132) Ona byza $\left\{\begin{array}{l}\text { krasivaja[nom fem] } \\ \text { krasivoj[instr fem] }\end{array}\right\}$.

'She was [a] beautiful [one].'

(a) Kto $[\mathrm{nom}]\left\{\begin{array}{c}b y Z a[\mathrm{fem}] \\ * b y z[\mathrm{masc}]\end{array}\right\}$ krasivaja[nom fem]?

(b) ?Kto[nom] $\left\{\begin{array}{l}b y Z[\mathrm{masc}] \\ b y Z a[\mathrm{fem}]\end{array}\right\}$ krasivoj[instr fem]?

(c) Kto [nom] by [masc] krasivym[instr masc]? 'Who was [a] beautiful [one]?'

Briefly, (132a) corresponds to (129a) and no comment is necessary. Sentence (132b) differs from the corresponding (130a) in that it is unacceptable in standard discourse with either verb form. Rozental' recommends what he calls "backward agreement" in similar cases, citing the sentence under (133) (Rozental' 1971a, 222).

(133) Kto[nom] iz Zyznic[gen p1 (fem)] prišla[fem] pervoj [instr fem]?

'Which of the lady-skiers arrived first?'

Informants questioned about (133) did not consider it fully acceptable in standard discourse, however, apparently because the feminine ending of the verb is indeed perceived as representing contextual sex and the sentence is essentially analogous to the substandard (126) above and does not differ substantially from (132b). There are two questions, then. First, why do speakers reject (132b), and secondly, why does Rozental' approve of (133).

The answer to the first question can be gathered by returning to (130a), reproduced below.

(130a) Kto[nom] byZ[masc] vasej podrugoj[instr fem]? 'Who was your friend?'

The predicate noun could not be deleted in this sentence, because there is no noun identical to it in the subject phrase. Sentence (132b) thus represents an 
impossible derivation: kto could not be associated with a feminine predicate adjective. In the grammatical (132c), where the predicate adjective has a masculine ending, it cannot be assumed to manifest the inherent gender of a deleted predicate noun. Rather, this predicate adjective is evidently associated in the underlying structure of the sentence with a "dummy" noun marked as identical to the subject by the specification \{tpro\} (see Section 10.35 in Chapter One). Since kto has no pertinent inherent specifications other than <+human>, the predicate adjective receives a singular ending and manifests the unmarked animate gender--masculine.

The second question is more difficult to answer, because (133) may derive from a complex structure and it is not clear why the predicate adjective has a feminine ending (cf. footnote 48 in Chapter One.) It could be the gender of Zyžnica 'lady skier,' but it could also be determined by the contextual sex specification of kto, whether in an embedded sentence or in the matrix sentence-which would explain the fact that not all native speakers find this sentence acceptable. At any rate, the fact that Rozental' approves of this sentence indicates that perhaps the determination of the gender assigned to a copulative verb is indeed sensitive to the gender of a predicate adjective when a sentence contains one. More specifically, if there is a predicate adjective marked as feminine, the gender assigned in Verb Agreement may be determined by the contextual sex specification on the subject NP node, as in substandard usage in other contexts. Thus there is no actual "backward agreement," i.e., the copulative verb does not ever receive its gender from a predicate adjective, but the gender of a predicate adjective may affect the choice of gender for the copulative verb.

The observations in the preceding paragraph also apply to number, and since there are no differences between gender and number in this respect, there is no need to elaborate. 39

${ }^{39}$ The sentences under (i) below require no special comment, because they seem to involve dislocation, which has already been discussed above in Chapter One (pp. 2931) and Chapter Four (pp. 273-276). The sentences under (ii) represent the phenomenon discussed in Section 1.24 of Chapter Four, and (iii) represents a combination of the type discussed in Section 9.3 of Chapter One. (cont.) 
(Sentences $(a-c)$ under ( $i$ ) are cited in Rozental' 1971a, 222-223; (ii) in Rozental' 1968, 265; and (iii) in Nikitevič 1963, 48.)

(i) (a) Kto [nom], kak ne sem'ja[nom fem], vospitala [fem] junošu barčukom ...

'Who if not the family raised the boy as a young gentleman ...'

(b) Nikto[nom] iz devušsk, dǎe Zoja[nom fem], ne našlas'[fem] čto skazat'.

'None of the girls, even Zoya, knew what to say.'

(c) Nekto[nom] $v$ čërnom, po-vidimomu inostranka[nom fem], vošla [fem] $v$ loæu teatra.

'Someone in black, evidently a foreign woman, entered the theater box.'

(d) Vdmug kto-to[nom], a imenno Katja[nom fem] ko me szadi podkralas'[fem].

'Suddenly someone, namely Katya, stole up to me from behind.'

(ii) (a) Èto sdelaZ[masc] ne kto[nom] inoj, kak olja[nom this did no one else but 0lya fem].

'This was done by no other than 0lya.'

(b) Ne kto[nom] inoj, kak olja[nom fem], sdelala no one else but 01ya [fem] èto. this

'No other than 01ya did this.'

(c) Eto sdelaZ[sg masc] ne kto[nom] inoj, kak deti this did no one else but chil[nom pl]. dren

'This was done by no other than the children.'

(d) Ne kto[nom] inoj, kak deti[nom p1], sdelali[p1] no one else but children did èto. this

'No other than the children did this.'

(iii) Prišla[fem] nekto[nom] Nikolaeva[nom fem].

'Some Nikolaeva has come.' 
4.32 Kto as relative pronoun is most typical in clauses associated with pronouns or determiner-type attributives. It is less typical in clauses associated with singular or plural masculine nouns, and is apparently generally avoided in clauses associated with feminine nouns.

In clauses associated with plural forms of nouns, of personal pronouns, or of determiner-type attributives, the verb associated with $k$ to in the relative clause can either have a singular (masculine) ending or a plural ending. In formal discourse, singular endings predominate, in informal discourse--plural endings (see Malovickij 1971, 97 , and cf. also Vinogradov and Istrina 1960, 492, and Švedova 1970, 555; the latter source does not seem to allow pluralization unless the relative clause is associated with a personal pronoun or a determiner-type attributive, but the former makes no distinctions and illustrates pluralization with the sentence cited under (135a) below, where the relative clause is associated with a lexical noun). The sentences under (134) illustrate singular verbs, and the sentences under (135) illustrate plural verbs ((134c) cited in Senkevič 1964, 7; (134d) in Švedova 1970, 555; (135a) in Vinogradov and Istrina 1960, 492; (135c) in Malovickij 1971, 97; and (135d) in Senkevič $1964,7)$.

(134) (a) Est' Zjudi[nom p1], $k$ sozaleniju, ix nemaZo, $k$ to [nom] gotov [sg masc] ustupit' pervoj trudnosti, pri pervom soprotivlenii sčitaet [sg] svoju missiju zakončennoj.

'There are people--unfortunately, there are quite a few of them--who are ready to give up at the first [sign of] difficulty, [who] consider their mission completed at the first [sign of] opposition.'

(b) Pravy $Z_{i}$ te [nom p1], kto[nom] izgnal[sg masc] Valju s raboty?

'Are those who have dismissed Valya from her job right?'

(c) Tut vse [nom p1], kto[nom] šël[sg masc] pełkom, brosilis'[p1] bežat'.

'At this point all [those] who were walking on foot started to run.'

(d) Vse [nom p1], kto [nom] opozdal [sg masc], ostalis'[p1] bez biletov.

'A11 [those] who came late remained without tickets.' 
(135) (a) Vse moi dmz'ja[nom p1], kto[nom] ego xoroš zhali[p1], byli[p1] o nëm xorošego mnenija.

'All of my friends who knew him well had a good opinion of him.'

(b) Krome somix manekenščic, zdes' byzi[p1] te [nom p1], kto[nom] pomogali[p1] im odet'sja.

'Besides the mannequins themselves, there were here $[$ also] those who helped them dress.'

(c) Ja ǔe otmetila vsex[acc p1], kto[nom] opozdali [p1] segodnja.

'I have already noted all [those] who came late today.'

(d) Pervye [nom p1], kto[nom] prišli[pl] na èkzamen, first who came to examination uže sdali[p1] ego. already passed it

'Those who came first for the examination have already passed it.'

In sentences such as (135d), where the relative clause modifies a plural adjectival form, according to Senkevic 1964, 7 and Rozental' 1971a, 222, the verb in the relative clause should be pluralized, but native informants do not confirm this. The only environment in which a plural verb associated with $k$ to in a relative clause must be pluralized and cannot be in the singular is apparently in association with the polite vy 'you,' i.e., in association with the plural pronoun $v y$ when it has a single referent (Svedova 1970, 555). The presence of a plural nominal predicate in the relative clause makes no difference, just as it makes no difference in association with $k$ to as interrogative or indefinite pronoun (and a plural predicate adjective would have no basis in standard discourse). The following is an interesting example (from Literaturnaja gazeta).

(136) Severnaja Amerika, severnoamerikancy--tak govorjat [p1] te [nom pl], kto[nom] ¿ivët[sg] v Latinskoj Amerike $i$ imeet[sg] takoe ¿e pravo nazyvat'sja amerikancami[p1], kak i naselenie SSA.

'Northern America, Northern Americans--these are the terms used by those who live in Latin America and have the same right to be called Americans as the population of the USA." 
This sentence is interesting because the verbs živët 'lives' and imeet 'has' are in the singular, yet the appellation applicable to the subject of these verbs, kto, is in the plural--amerikancami 'Americans.'

$K$ to is generally avoided in relative clauses modifying feminine nouns, as noted above, but in principle the verb in a relative $k$ to-clause modifying a feminine noun would have to have a feminine ending, as illustrated under (137).

(137) Gde ta parikmaxeř̌a [nom sg fem], kto[nom] menja podstrigla [sg fem]
* podstrig [sg masc]

'Where is the hairdresser who cut my hair?'

These are the facts concerning relative kto-clauses, but they cannot be accounted for without first looking at relative clauses in which the relative pronoun is kotoryj, as in (138), or čto, as in (139) ((139b) cited in Malovickij 1971, 98).

(138) (a) Esli každyj[nom sg masc], kotoryj[nom sg masc] xočet [sg] dumat', načnët bočki ukatyvat', $v$ čëm my kapustu budem xranit'?

'If every [person] who wants to meditate will start rolling barrels away, what are we going to keep cabbage in?'

(b) $\mathrm{Te}[$ nom $\mathrm{p} 1]$, kotorye [nom $\mathrm{p} 1]$ ej sočuvstvovali [p1] i udivljalis'[p1], sami byli ne bog znaet kak sčastlivy.

'Those who sympathized with her and were amazed at her were not too happy themselves.'

(139) (a) $T e[$ nom $\mathrm{p} 1]$, čto byZi[p1] togda 9-10-Zetnimi det'mi[instr $\mathrm{p} 1]$, stali[p1] teper' 14 - 15letnimi mal'čiškami $i$ devčonkami.

'Those who were then nine- or ten-year-old children have now become fourteen- or fifteenyear-old boys and girls.'

(b) Ta[nom sg fem], čto prišla[sg fem] $k$ dveri, by Za [fem] uporna [fem].

'The one who came to the door was insistent.'

The relative kotoryj always manifests the number and gender of its antecedent and the verb in the relative clause must manifest the same number and gender (provided 
kotoryj is subject of the clause). The relative čto never manifests number or gender and the verb in the relative clause must always manifest the number and gender of the antecedent. There is no other alternative. (On the growing use of the relative čto in the standard language see Akimova 1970 and Malovickij 1971; the 1atter also discusses the use of kotoryj versus $k$ to in sentences such as (138) and points out that the čto illustrated in (139) is excluded when the relative must be in an oblique case.) $K$ to, then, is roughly analogous to čto when the verb associated with it manifests the number or gender of the antecedent. In sentences in which the verb in a ktoclause has a singular masculine ending and does not agree with the antecedent of kto, kto seems closer to kotoryj in that the verb appears to be directly associated with it.

The following is a tentative account. Assuming that relative pronouns are substitutes for nouns, 40 it can be further assumed that when the replaceable nouns are inherently feminine, they are replaced either by kotoryj, which can manifest gender, or by čto, which is a completely neutral connective and has no inherent features at all. For the operation of Verb Agreement it makes no difference which relative pronoun is chosen, for the NP node which dominates the relative pronoun bears the specifications of the deleted noun anyway. When kto is chosen in such contexts (and the language does offer this option), Verb Agreement operates as it does when the relative is kotoryj or cto.

When $k$ to is chosen to replace a noun dominated by a node specified [+Plural], Verb Agreement can again operate as it would if the relative had been kotoryj or čto (to yield sentences like (135)), but here there is yet another alternative. The fact that kto cannot manifest the plural specification of the node can be assumed to trigger deletion of the plural specification. The verb in the relative clause must then receive an ending based on the "provisional" number and gender of the node and its [+Animate] specification (see Section 7.122 in Chapter One; on the process by which kotoryj assumes the number and gender of the noun it replaces see footnote 52 in Chapter One). Only when the plural specification represents a "polite" plural can it not be deleted; cf. Vy[p1], Saša

${ }^{40}$ Relative pronouns substitute not only for nouns but also for noun phrases. For the sake of simplicity I only refer to nouns in this discussion. 
[sg], kto rabotali[p1]/*rabotal[sg] tom ... 'you, Sasha, who have worked there ...' (the idiosyncracy of patterns of agreement with the polite $v y$ is also pointed out in Section 10.35 in Chapter One).

Kto does not trigger the deletion of feminine specifications because they represent inherent features of the deleted noun, unlike number. As for why čto does not trigger the deletion of plural specifications--perhaps because it is a completely neutral connective and has no inherent features at all.

\subsection{Sentences with èto}

Patterns of agreement in sentences with the nominative form èto 'this' as attributive modifier present no problem, for gender and number manifestations in association with an attributive èto are determined by the noun it modifies in the underlying structure and cannot vary. Compare, for example, the sentences under (140).

(140) (a) Krasnoe [nom sg neut] vedërko[nom sg neut] red bucket stojalo[sg neut] na okne, a èto[nom sg neut] stood on window and this

stojalo[sg neut] u krovati. stood by bed

'The red bucket stood on the window, and this [one] stood by the bed.'

(b) Krasnaja[nom sg fem] čałka[nom sg fem] stojala red cup stood [sg fem] na okne, a èta[nom sg fem] stojala[sg on window and this stood

fem] u krovati.

by bed

'The red cup stood on the window, and this [one] stood by the bed.'

(c) Krasnye [nom p1] vedërki[nom p1] stojali[p1] na red buckets stood on okne, a èti[nom p1] stojali[p1] u krovati. window and these stood by bed

'The red buckets stood on the window, and these stood by the bed.'

Èto in (140a) represents an underlying attributive modifier to the noun vedërko 'bucket.' It manifests the number and gender of this noun, and so does the verb which 
follow it. This is demonstrated by the contrast with $(140 \mathrm{~b})$, where the pronoun and the verb associated with it manifest the gender of časka 'cup,' and also by the conrast with $(140 \mathrm{c})$, where the pronoun and the verb associated with it are pluralized, manifesting the number of an underlying modificand which could be realized as vedërki 'buckets.'

Sentences with the nominative form èto are of interest when èto does not represent an underlying attributive, when it is head of its phrase. In such sentences there are two possible patterns of agreement, as illustrated under (141).

$$
\begin{aligned}
& \text { (141) (a) Éto[nom] }\left\{\begin{array}{c}
b y Z_{a}[\mathrm{fem}] \\
* b y Z_{0}[\mathrm{neut}]
\end{array}\right\} \text { novost'[nom fem] dlja } \\
& \text { menja. } \\
& \text { 'That was news for me.' } \\
& \text { (b) Ėto [nom] }\left\{\begin{array}{c}
b y Z_{0}[\text { neut }] \\
* b y L_{a}[\mathrm{fem}]
\end{array}\right\} \text { novost'ju[instr fem] } \\
& \text { dlja menja. } \\
& \text { 'That was news for me.' }
\end{aligned}
$$

These sentences seem analogous to the sentences under (129) and (130) with kto: in (141a) èto is not subject, and in (141b) it is. The fundamental difference between (141a) and (141b) can be perceived by comparing them to sentences such as the following, where èto can only be treated as non-subject and there are no alternatives (note that (142a) corresponds to (131a) above).41

${ }^{41}$ Sentence (142a) is cited in Borras and Christian 1971, 16 to illustrate the statement that "in combinations involving èto, agreement is always with the noun." In the 1961 edition, Borras and Christian identified èto explicitly as predicate in this sentence, but in the 1971 edition there is no mention of its syntactic function. Such wavering is not atypical. I myself argued several years ago (in a paper read at the 1970 summer meeting of the Linguistic Society of America) that èto was subject in sentences like (142a), but after further research I have come to a different conclusion. The conventional approach in Russian school grammars has been that èto is grammatical subject and the copulative verb agrees with the predicate by "backward agreement" (see, e.g., Vinogradov and Istrina 1960, 519; Dobromyslov and Rozental' 1960, 149150; and Valgina 1973, 105). Peshkovsky, however, (cont.) 
(142) Kto-to vošël v komnatu.

'Someone entered the room.'

(a) Ėto [nom] byla[fem] そena[nom fem] doktora.

(b) *Eto[nom] bylo[neut] Zenoj[instr fem] doktora. 'It was the doctor's wife [lit. wife of doctor].$^{\prime}$

(143) S Nelej oni prozili dva goda.

'He and Nelya lived together for two years.'

(a) Ėto[nom] byli[pl] očen' sčastlivye gody[nom

(b) * $\mathrm{p}$ to by bo [neut] očen' sčastzivymi godomi [instr p1].

'Those were very happy years.'

The (b) sentences would be ungrammatical in any context. This is because éto can only serve as subject when it substitutes for a sentence, and phrases such as žna doktora 'doctor's wife' and sčastlivye gody 'happy years' would be meaningless as predicate modifiers to a sentential constituent, i.e., a constituent representing an underlying structure with a verb phrase. Sentence (144), for example, provides a context for (141b) above, where eto is indeed subject. In (144), èto can be assumed to represent the underlying sentence čto ona ¿ena doktora 'that she is a doctor's wife.'

(144) Mne skazali, čto ona ¿ena doktora. Ėto [nom] bylo [neut] novost'ju[instr fem] dlja menja.

'I was told that she was a doctor's wife. That was news for me.'

Ėto as subject in sentences which have nominal predicates can always be assumed to derive as substitute for an underlying sentence--or, if not as substitute, then at any rate as a constituent dominated by a node labelled $\mathrm{s.42}$

${ }^{42}$ In Adamec 1973, 49, the pro-sentential èto is described as "a pronominalized designation for some event, action, or fact," in distinction from èto in sentences like (142a) and (143a), where it "indicates some substance."

When èto is associated with verbal predicates, it is a pro-sentence as a rule, but note that this morpheme has several functions in Russian (for some data and discussion of èto in various contexts see Dobromyslov and Rozental' 1960, 151-152 and 171-172; Molotkov 1960; and Lobanova 1966, 65-66). 
The number and gender manifested in association with the prosentential èto can be assumed to be determined by the "provisional" specifications on the NP node which dominates the $\mathrm{S}$ node over èto. As for èto itself, the neuter gender it manifests may also be determined by the NP specifications; or, alternatively, this èto may be viewed as having an inherent declension paradigm but no gender, like ¿to 'what' and like numerals. (The conventional view of èto as inherently singular and neuter seems implausible for a number of reasons, but this question does not merit an extended discussion in the present context.)

To return to the (a) sentences under (141)-(143), where èto cannot be considered subject, perhaps it is not predicate either, at least not a predicate dominated by a PredP node, for such sentences do not allow any copulative verb other than byt' 'be,' èto cannot be in the instrumental case (unlike kto in (129), for example), èto cannot follow the copulative verb, and it cannot be conjoined with any other nominal (unlike regular predicates). Such sentences appear to be purely equational, and èto is perhaps not even dominated by a VP node. The constituent structure of these sentences may be as in (145).

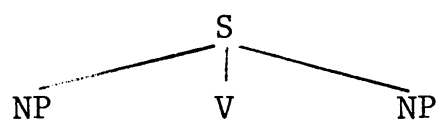

The two NPs in (145) are both subjects by structural criteria, but for the purposes of Verb Agreement the subject NP will be the one which has gender and number specifications other than the "provisional" ones--or, more generally, the one which has the greater number of specifications.

\subsection{Summary}

The number and gender manifested by copulative verbs turn out to be inconsistent for a number of reasons. First, there are sentences in which both subject and predicate are in the nominative case, and when the predicate precedes the verb and the subject follows it the pattern of agreement may seem "backward." This may happen not only when the head of the subject phrase and the head of the predicate phrase are both lexical nouns, but also when the head of the predicate phrase is a 
pronominal form, most typically kto 'who' or èto 'this, that.' In the latter case, the predicate phrase may represent a special kind of predicate, not a verb-phrase predicate.

In sentences in which the predicate phrase is marked by the instrumental case, a copulative verb may seem to manifest "backward agreement" when the head of the subject phrase is a nominal or adverbial quantifier, and also when the head of the subject phrase is kto 'who' or one of its derivatives. Copulative verbs do not receive the features of predicate phrases in such sentences, but the choice between potential alternatives in the operation of Verb Agreement in these sentences does seem to be sensitive to the fact that they contain predicate phrases.

argued for the position advocated in the present exposition, i.e., that there is no "backward agreement" and èto is not grammatical subject in sentences like (142a) (Peškovskij $1956,242-243)$. 
The most salient facts about agreement in Russian can be summarized as follows.

There are two basic processes which assign the features of nouns and noun phrases to constituents associated with them: Attributive Agreement and Verb Agreement. The former process accounts for the endings of attributive modifiers as well as predicate adjectives, and the latter accounts for the endings of verbal predicates as well as copulative verbs. The features assigned by these processes are inherent features of the head noun stems whenever the stems possess inherent gender, number, person, or animacy.

When noun stems do not possess inherent person (the only stems which can be assumed to possess inherent person are first-person and second-person pronouns), then the person manifested in association with them is always the third person. When stems do not possess inherent gender or number, then the gender and number manifested in association with them may be determined by other inherent features, or by the sex and/or number of the referents. When there is no basis at all for determining the gender and number to be manifested in association with such noun stems, then the manifested gender is masculine in association with inherently animate nouns, neuter otherwise, and the manifested number is singular. These are the basic principles.

Structure-related alternatives may occur in association with two or more nouns or noun phrases, for the grammatical endings of associated constituents depend then on the syntactic relationship between the coordinate nouns or noun phrases. If they are only superficially coordinated--as a consequence of the reduction of coordinate structures with identical constituents through deletion-then associated constituents generally manifest the features of the nearest noun or noun phrase. If they are coordinated as a consequence of the reduction of coordinate structures by a process of regrouping, then associated constituents are pluralized. These are the two major sources of variation in patterns of agreement in association with two or more nouns or noun phrases.

Structure-related alternatives also occur in association with noun phrases involving numerical, adverbial, 
or nominal quantifiers, for grammatical endings may then be determined either by association with the quantifiers, or by association with the quantified nouns or noun phrases, depending on the underlying syntactic relations. Grammatical endings may also be determined in such sentences, however, on the basis of the position of the quantifiers in the surface structure, through a process of adjustment.

Numerous special cases and apparent deviations from the general principles of agreement are described and analyzed in the five chapters of the monograph in an attempt to show how they fit into the basic patterns. The monograph contains data on hitherto unnoted phenomena in the area of agreement, especially in sentences with coordinate structures, and it offers coherent descriptions of phenomena which hitherto have not been treated systematically from the point of view of agreement, especially noun combinations, abbreviations, and First-Declension nouns in reference to females.

The monograph constitutes neither a general treatise on Russian grammar nor an essay in syntactic theory. It's aim has been to illuminate one facet of Russian grammar, and it is my hope that this has been accomplished. 


\section{B IBL IOGRAPHY}

Adamec, Přemys1 (1966) Porjadok slov v sovremennom musskom jazyke, Prague.

(1973) Očerk funkcional'no-

transformacionnogo sintaksisa sovremennogo russkogo jazyka, I: Odnobazovye predlołenija, Prague: Státní pedagogické nakladetelství.

Akimova, G.N. (1970) "Konstrukcii tipa 'Dom, čto stoit naprotiv," Russkij jazyk $v$ škole 6, 89-93.

Akopď̌anjan, A.A. (1962a) "Soglasovanie skazuemogo s podležaščim, vyražennym neopredelenno-količestvennym sušcestvitel'nym v sočetanii s suščestvitel'nym v roditel'nom padeže," Učenye zapiski Elabužskogo pedagogičeskogo instituta 13, 32-84.

(1962b) "Soglasovanie skazuemogo s podležaščim, vyražennym suščestvitel'nym 'čast'' v sočetanii s suščestvitel'nym $v$ roditel'nom padeže množestvennogo čisla," in Voprosy teorii $i$ metodiki izucenija russkogo jazyka, Ceboksary, vyp. 2, 150165 .

(1962c) "Značenie predikativnogo glagola v predloženijax s podležaščim tipa 'bol'šinstvo zritelej., " Učenye zapiski Elabužskogo pedagogiceskogo instituta 13, 85-96.

(1962d) "Soglasovanie skazuemogo s podležaščim, vyražennym suščestvitel'nym čislo v sočetanii s roditel'nym padežom množestvennogo čisla," Učenye zapiski Elabužskogo pedagogičeskogo instituta $13,332-336$.

(1964) "O vidax svjazi glagola-skazuemogo s podležasčim-količestvenno-imennym sočetaniem," Učenye zapiski Elabužskogo pedagogičeskogo instituta $15,122-132$. 
Akopdžanjan, A.A. (1965) "O forme čisla glagola-skazuemogo $\mathrm{v}$ predloそ̌enijax s količestvennym podleそ̌ǎ̌im," in Voprosy teorii $i$ metodiki izucenija msskogo jazyka, Iževsk, vyp. 4, 104-113.

Alekseev, D.I. (1963a) Slovar' sokrasłenij musskogo jazyka, Moscow.

(1963b) "Grafiと̌eskie sokraščenija i slovaabbreviatury," in Razvitie sovremennogo russkogo jazyka, ed. by S.I. Ožegov and M.V. Panov, Moscow: AN, 145-160.

(1966) "Abbreviatury kak novyj tip slov," in Razvitie slovoobrazovanija sovremennogo musskogo jazyka, ed. by E.A. Zemskaja and D.N. Šmelev, Moscow: Nauka, 13-37.

Anderson, John M. (1971) The Grammar of Case, Cambridge: University Press.

Anderson, Stephen R. (1975) "On the Notion of Subject in Ergative Languages," paper presented at the Symposium on Subject and Topic, Santa Barbara.

Andrews, Avery D. (1971) "Case Agreement of Predicate Modifiers in Ancient Greek," Linguistic Inquiry 2, 127-151.

Andreyewsky, Alexander (1973) The $\underline{i}$ structures of Modern Russian: A Study in the Gramar of Conjunction, unpublished $\mathrm{Ph} . \mathrm{D}$. dissertation, New York University.

Anpilogova, B.G. et al. (1968) Posobie po razvitiju reči, Moscow: MGU.

Arbatskij, D.I. (1972) "Množestvennoe čislo giperboličeskoe," Russkij jazyk v łkole 5, 91-96.

Avanesov, R.I. and V.N. Sidorov (1945) Orerk grommatiki musskogo Ziteraturnogo jazyka, Moscow: Učedgiz.

Axmanova, O.S. (1966) Slovar' Zingvistiěeskix terminov, Moscow. 
Babajceva, V.V. (1968) Odnosostavnye predložnija v sovremennom musskom jazyke, Moscow: Prosveščenie.

Babby, Leonard H. (1973a) "The Deep Structure of Adjectives and Participles in Russian," Language 49, 349-360.

(1973b) "A Note on Agreement in Russian," GZossa 7:2, 253-264.

(1975) A Transformational Grommar of Russian Adjectives, The Hague: Mouton.

(1976) "Morphology in a Transformational Grammar of Russian," Folia Slavica 1.

Babcock, Sandra Scharff (1972) "Paraphrastic Causatives," Foundations of Language 8, 30-43.

Bach, Emmon (1974) Syntactic Theory, New York: Holt, Rinehart \& Winston.

$$
\text { et al. (1974) "'Sloppy Idnetity': An }
$$

Unnecessary and Insufficient Criterion for Deletion Rules," Linguistic Inquiry 5, 609-614.

Barsov, A.A. (forthcoming) The Detailed Grommar of Russian, ed. by Lawrence W. Newman, Cambridge, Mass.: Slavica Publishers.

Belevickaja-Xalizeva, V.S. et al. [1973] Sbornik upražnenij po sintaksisu musskogo jazyka s kommentarijami: Prostoe predložnie, 3rd ed., Moscow: Progress.

Bierwisch, Manfred (1967) "Syntactic Features in Morphology: General Problems of So-Called Pronominal Inflection in German," in To Honor Roman Jakobson, The Hague: Mouton, I, 239-270.

(1971) "On Classifying Semantic Features," in Semantics: An Interdisciplinary Reader in Philosophy, Linguistics and Psychology, ed. by Danny D. Steinberg and Leon A. Jakobovits, Cambridge: University Press, 410-435. 
Blinkenberg, A. (1950) Le problème de l'accord en français moderne, Copenhagen.

Bogdanov, V.N. (1968) "Osobyj slučaj dialektnogo soglasovanija skazuemogo s podležaščim po smyslu i kategorija predstavitel'nosti," Filologičeskie nouki $11: 4,68-75$.

Bolinger, Dwight L. (1952) "Linear Modification," PMLA 1117-1147.

(1967) "Adjectives in English: Attribution and Predication," Lingua 18, 1-34.

Bondaletov, V.D. (1970) "Dinamika ličnyx imen v XX v.," in Lǐ̌nye imena $v$ prošlom, nastojaščem, buduščem, Moscow: AN, 91-105.

Borisov, V.V. (1972) Abbreviacija i akronimija, Moscow.

Borkin, Ann and David Peterson, eds. (1972) "Where the Rules Fail: A Student's Guide," manuscript distributed by the Indiana University Linguistics Club.

Borkovskij, V.I. and P.S. Kuznecov (1965) Istoričeskaja grammatika musskogo jazyka, Moscow: AN.

Borras, F.M. and R.F. Christian (1971) Russian Syntax, 2nd ed., Oxford: Clarendon Press.

Bragina, A.A. (1973) Neologizmy $v$ musskom jazyke, Moscow: Prosveščenie.

Bresnan, Joan W. (1973) "Syntax of the Comparative Clause Construction in English," Linguistic Inquiry 4, 275-343.

Bukčina, B.Z. and L.P. Kalakuckaja (1974) Složnye slova, Moscow: Nauka.

Butorin, D.I. (1968) "Sočetanie suščestvitel'nyx s čislitel'nym poltora," Russkaja reč' 6, 44-47.

Carden, Guy (1968) "English Quantifiers," Mathematical Linguistics and Automatic Translation, Report NSF20, Cambridge, Mass.: The Computation Laboratory of Harvard University. 
Carden, Guy (1970a) "Logical Predicates and Idiolect Variation in English," Mathematical Linguistics and Automatic Translation, Report NSF-25, Cambridge, Mass.: The Computation Laboratory of Harvard University.

(1970b) "On Post-Determiner Quantifiers," Linguistic Inquiry 1, 415-427.

Chafe, Wallace L. (1970) Meaning and the Structure of Language, Chicago and London: University of Chicago Press.

Channon, R. (1975) "The NAC and How Not to Get It," in Papers from the Fifth Annual Meeting of the North Eastern Linguistic Saciety, ed. by E. Kaisse and J. Hankamer, Cambridge, Mass., 276-298.

Chomsky, Noam (1965) Aspects of the Theory of Syntax, Cambridge, Mass.: MIT Press.

Chvany, Catherine V. (1973) "On the Role of Presuppositions in Russian Existential Sentneces," in Papers from the Ninth Regional Meeting, Chicago: Chicago Linguistic Society, 68-77.

(1974) "The Grammar of Dolðen:

Lexical Entries as a Function of Theory," in Slavic Transformational Syntax, ed. by Richard D. Brecht and Catherine V. Chvany, Ann Arbor: Michigan Slavic Publications, 78-122.

(1975) On the Syntax of BE-Sentences in Russian, Cambridge, Mass.: Slavica Publishers.

Comrie, Bernard (1974) "Impersonal Subjects in Russian," Foundations of Language 12, 103-115.

(1975) "Polite Plurals and Predicate Agreement," Language 51, 406-418.

Crockett, Dina B. (1972) "More on Coordination Reduction," in Papers from the Eighth Regional Meeting, Chicago: Chicago Linguistic Society, 52-61. 
Crockett, Dina B。 (1976) "The Distributive po in Contemporary Russian," in Russian Linguistics, ed. by Thomas Magner, Cambridge, Mass.: Slavica Publishers.

Cruse, D.A. (1973) "Some Thoughts on Agentivity," Joumal of Linguistics 9, 11-23.

Černov, V.I. (1971) "O klassifikacii svjazočnyx glagolov sovremennogo russkogo literaturnogo jazyka," Russkij jazyk $v$ škole 2, 83-88.

Česnokova, L.D. (1972) "Konstrukcii s predikativnym opredelitelem," Russkij jazyk $v$ škole 1, 80-82.

Degtjarev, V.I. (1966) "Osobennosti soglasovanija skazuemogo s podležaščim-imenem sobiratel'nym $v$ drevnerusskom jazyke," Filologičeskie nauki 9:3, 138-146.

Delorme, Evelyne and Ray C. Dougherty (1972) "Appositive NP Constructions: we, the men; we men; I, a man; Etc.," Foundations of Language 8, 2-29.

Dik, S.D. (1968) Coordination, Amsterdam: North-Holland Publishing Co.

Dingwall, William Orr (1969) "Government, Concord and Feature-Change Rules," Glossa 3:2, 210-240.

Dobromyslov, V.A. and D.̇̀. Rozental' (1960) Trudnye voprosy gramatiki i pravopisanija, Moscow: Učpedgiz.

Drejzin, F.A. (1966) Sintaksičeskaja omonimija $v$ musskom jazyke s točki zrenija avtomatičeskogo analiza, unpublished Kandidat dissertation, Moscow University.

Efimov, A.I. (1969) Stilistika russkogo jazyka, Moscow: Prosveščnie.

Evgen'eva, A.P., ed. (1971) Slovar' sinonimov russkogo jazyka, Vol. II, Leningrad: Nauka.

Ferguson, Charles A. (1971) "A Sample Research Strategy in Language Universals," Working Papers on Language Universals $6,1-22$. 
Fillmore, Charles J. (1968) "The Case for Case," in Universals in Linguistic Theory, ed. by Emmon Bach and Robert T. Harms, New York: Holt, Rinehart and Winston, 1-88.

(1971a) "Types of Lexical Information," in Semantics: An Interdisciplinary Reader in Philosophy, Linguistics and Psychology, ed. by Danny D. Steinberg and Leon A. Jakobovits, Cambridge: University Press, 370-392.

(1971b) "Some Problems for Case Grammar," Georgetown University Monograph Series on Languages and Linguistics 24, 35-56.

Finke1', A.M. and N.M. Baženov (1965) Kurs sovremennogo misskogo literatumogo jazyka, Kiev.

Galkina-Fedoruk, E.M. (1958) Bezlǐ̌nye predloženija v sovremennom misskom jazyke, Moscow: MGU.

, ed. (1964) Sovremenny musskij jazyk:

East' II, Moscow: MGU.

Geach, P.T. (1972) "A Program for Syntax," in Semanatics of Natural Language, ed. by Donald Davidson and Gilbert Harman, Dordrecht-Holland: Reide1, 483497.

Gogol', N.V. (1959) Sobranie sočinenij, Vo1. I: Vě̌era na xutore bliz Dikan'ki, Moscow.

Gorbačevič, K.S. (1971) Izmenenie norm musskogo literatumogo jazyka, Leningrad: Prosveščenie.

, ed. (1973) Tmudnosti slovoupotreblenija $i$ varianty norm muskogo literaturnogo jazyka: Slovar'-spravočnik, Leningrad: Nauka.

Gorelova, L.N. (1969) Sintaksičeskie konstrukciis roditel'nym količestvennym $v$ sovremennom russkom jazyke (na materiale različnyx vidov ustnoj reči), abstract of Kandidat dissertation, Voronež. 
Greenberg, Joseph H. (1972) "Numeral Classifiers and Substantival Number: Problems in the Genesis of a Linguistic Type," Working Papers on Language Universals $9,1-39$.

Halliday, M.A.K. (1970) "Language Structure and Language Function," in New Horizons in Linguistics, ed. by John Lyons, Penguin, 140-165.

Hankamer, Jorge (1973) "Unacceptable Ambiguity," Linguistic Inquiry 4, 17-68.

Hockett, Charles F. (1958) A Course in Modern Linguistics, Macmillan.

Isačenko, A.V. (1963) "Transformacionnyj analiz kratkix i polnyx prilagatel'nyx," in Issledovanija po strukturnoj tipologii, ed. by T.N. Mološnaja, Moscow: AN, 61-93.

(1965) Grommatičeskij stroj musskogo jazyka $v$ sopostavlenii s slovackim: Morfologija, I, 2nd ed., Bratislava: AN.

Ivanova, V.F. (1969) "Celovek s tysjač'ju lic ili čelovek s tysjač'ju licami?" Russkij jazyk $v$ škole 2, 66-73..

(1973) "Modeli količestvennyx predloženij," Russkij jazyk $v$ škole 3, 96-101.

Jackendoff, Ray S. (1971a) "Gapping and Related Rules," Linguistic Inquiry 2, 21-35.

(1971b) "On Some Questionable Arguments About Quantifiers and Negation," Language 47, 282297.

(1972) Semantic Interpretation in Generative Grommar, Cambridge, Mass.: MIT Press.

Jakobson, R.0. (1958) "Morfologičeskie nabljudenija nad slavjanskim skloneniem," in American Contributions to the Fourth International Congress of Slavicists, 127-156. 
Jakobson, R.0. (1960) "Linguistics and Poetics," in Style in Language, ed. by Thomas A. Sebeok, Cambridge, Mass.: MIT Press, 350-377.

(1971) "The Gender Pattern of Russian," in Selected Writings, Vo1. II: Word and Language, The Hague: Mouton, 184-186.

Janko-Trinickaja, N.A. (1966) "Naimenovanie lic ženskogo i mužskogo roda," in Razvitie slovoobrazovanija sovremennogo musskogo jazyka, ed. by E.A. Zemskaja and D.N. Šmelev, Moscow: Nauka, 167-210.

(1967) "I uvažaemyj ... i uvažaemaja ...," Voprosy kul'tury reči 8, 240-244.

Kačevskaja, G.A. (1969) "Domiško, ambariško," Russkaja reč' 1 , 58-62.

Kamynina, A.A. (1961) "K voprosu o predloženijax s količestvennymi slovami v sostave glavnyx členov," Russkij jazyk $v$ škole 2, 20-25.

Kamyšev, N.S. (1968) Složnye konstrukcii s pridatočnoj čast'ju, utočnjajuščej značenie slova ili slovosočetanija, abstract of Kandidat dissertation, Mos cow.

Katcer, Ju. and A. Kunin (1964) Pis'mennyj perevod $s$ misskogo jazyka na anglijskij, Moscow: Vysšaja škola.

Keenan, Edward L. (1974a) "Subject Properties List," unpublished manuscript.

(1974b) "A Universal Definition of 'Subject of," paper presented at the annual winter meeting of the Linguistic Society of America.

Kimbal1, John P. (1973) "The Grammar of Existence," in Papers from the Ninth Regional Meeting, Chicago: Chicago Linguistic Society, 262-270.

Kirillov, Iv. (1970) Vstreča s Moskvoj, Moscow: Reklama. 
Klenin, Emily (1974) Russian Reflexive Pronouns and the Semantic Roles of Noun Phrases in Sentences, unpublished $\mathrm{Ph} . \mathrm{D}$. dissertation, Princeton.

Klooster, W.G. (1972) The Structure of Underlying Measure Phrase Sentences, Dordrecht-Holland: Reidel.

Kočetkova, N.P. and V.M. Matveeva, eds. (1970) Posobie po sintaksisu russkogo jazyka, Leningrad: LGU.

Kondrašov, N.A. (1962) Slavjanskie jazyki, Moscow: Učpedgiz.

Konopelkin, A.F. (1970) Xrestomatija po musskomu jazyku dlja studentov-inostrancev, 2nd ed. rev., Moscow: Vyš̌aja škola.

Korel'skaja, T.D. and E.V. Padučeva (1973) "Transformacii v simmetričnyx konstrukcijax: sočinenie i èllipsis," Naučnotexničeskaja informacija 2:9, 29-38.

Kostinskij, Ju.M. (1969) "Podležaščee--v roditel'nom padeže?" Russkaja reč' 6, 50-56.

Kotelova, N.Z. and Ju.S. Sorokin, eds. (1971) Novye stova $i$ značenija, Moscow.

Koutsoudas, A. (1971) "Gapping, Conjunction Reduction, and Coordinate Deletion," Foundations of Language 7, 337-386.

Kovtunova, I.I. (1969) Porjadok slov $v$ musskom Ziteratumom jazyke XVIII--pervoj treti XIX v., Moscow: Nauka.

(1973) "Porjadok slov kak predmet grammatičeskogo izučenija," Voprosy jazykoznanija 4, 50-61.

Kozyreva, T.G. and E.S. Xmelevskaja (1972) Sovremennyj russkij jazyk: Imja prilagatel'noe, imja čislitel'noe, mestoimenie, Minsk.

Krysin, L.P. (1974) Russkij jazyk po dannym massovogo obsledovanija, Moscow: Nauka. 
Kuno, Susumu (1974) "Lexical and Contextual Meaning," Linguistic Inquiry 5, 469-477.

Lakoff, George (1969) "On Derivational Constraints," in Papers from the Fifth Regional Meeting, Chicago: Chicago Linguistic Society, 117-139.

(1970a) Irregularity in Syntax, New York: Holt, Rinehart and Winston.

(1970b) "Repartee, or a Reply to 'Negation, Conjunction and Quantifiers," "Foundations of Langrage $6,389-422$.

and Stanley Peters (1969) "Phrasal Conjunction and Symmetric Predicates," in Modern Studies in English: Readings in Transformational Grarmar, ed. by David A. Reibel and Sanford A. Schane, Englewood Cliffs, N.J.: Prentice-Hall, 113-142.

and John Robert Ross (1970) "Two Kinds of And," Linguistic Inquiry 1, 271-272.

Langendoen, D. Terence (1969) The Study of Syntax, New York: Holt, Rinehart and Winston.

(1970) Essentials of English Gramar, New York: Holt, Rinehart and Winston.

Lazova, M.V., ed. (1974) Obratnyj slovar' musskogo jazyka, Moscow.

Lebedeva, I.I., ed. (1968) Kratkij slovar' trudnostej musskogo jazyka, Moscow: MGU.

Lee, Gregory (1971) "Subjects and Agents: II," Working Papers in Linguistics 7, Columbus, Ohio: Computer and Information Science Research Center, The Ohio State University.

Leont'eva, N.N. (1967) "Ustranenie nekotoryx vidov izbytočnoj informacii v estestvennom jazyke," Mašinnyj perevod i prikladnaja lingvistika 10, 93-98. 
Levi, Judith N. (1973) "Where Do All Those Other Adjectives Come From?" in Papers from the Ninth Regional Meeting, Chicago: Chicago Linguistic Society, 332345.

(1974) "On the Alleged Idiosyncracy of Non-predicate NP's," Papers from the Tenth Regional Meeting, Chicago: Chicago Linguistic Society, 402415.

Li, Charles N. and Sandra A. Thompson (1974) "Chinese as a Topic-Prominent Language," unpublished paper prepared for a conference on Sino-Tibetan Languages and Linguistics.

(1975a) "Subject and Topic: A New Typology of Languages," paper presented at the annual winter meeting of the Linguistic Society of America.

(1975b) "Evidence Against Topicalization in Topic-Prominent Languages," paper presented at the Symposium on Subject and Topic, Santa Barbara.

Lobanova, N.A., ed. (1966) Praktičeskoe posobie po sintaksisu russkogo jazyka, 2nd ed., Moscow: Vysšaja škola.

Maksimov, V.I. (1969) "Zagadka suffiksa -in-a," Russkaja reč' $1,45-49$.

(1971) "Ob odnom tipe suščestvitel'nyx obščego roda," Russkij jazyk v škole 5, 68-70.

Maling, J.M. (1972) "On 'Gapping and the Order of Constituents, "' Linguistic Inquiry 3, 101-108.

Malovickij, L.Ja. (1971) "Ob upotreblenii otnositel'nyx mestoimenij," Russkij jazyk v škole 4, 96-99.

McCawley, J.D. (1968) "The Role of Semantics in a Grammar," in Universals in Linguistic Theory, ed. by Emmon Bach and Robert T. Harms, New York: Holt, Rinehart and Winston, 125-169. 
McCawley, J.D. (1972) "A Program for Logic," in Semantics of Natural Language, ed. by Donald Davidson and Gilbert Harman, Dordrecht-Holland: Reide1, 498-544.

(1973) "Syntactic and Logical Arguments for Semantic Structures," in Three Dimensions of Linguistic Theory, ed, by Osamu Fujimura, Tokyo: TEC, 259-376.

Molinsky, Steven J. (1973) Patterns of ElZipsis in Russian Compound Noun Formations, The Hague: Ilouton.

Molotkov, A.I. (1960) "Trudnye slučai leksikogrammatičeskoj xarakteristiki slov èto i to v russkom jazyke," in Voprosy gramatiki: Sbornik statej $k$ 75-Zetiju akademika I.I. Meščaninova, Moscow: AN, 345-361.

Moravcsik, Edith A. (1971) "Agreement," Working Papers on Language Universals 5.

Morgan, J.L. (1972) "Verb Agreement as a Rule of English," in Papers from the Eighth Regional Meeting, Chicago: Chicago Linguistic Society, 278-286.

Mrazek, Roman (1973) "Količestvennyj predikat i ego svjaz' s dvuxbazisnymi strukturami," Ceskoslovenská musistika 18, 117-123.

Mučnik, I.P. (1963) "Kategorija roda i ee razvitie v sovremennom russkom literaturnom jazyke," in Razvitie sovremennogo russkogo jazyka, ed. by S.I. Ožegov and M.V. Panov, Moscow: AN, 39-82.

(1971) Grammatǐ̌eskie kategorii glagola $i$ imeni $v$ sovremennom musskom literaturnom jazyke, Moscow: Nauka.

Mullen, J. (1967) "Agreement of the Verb-Predicate with a Collective Subject," in Studies in the Modern Russian Language, Cambridge: University Press.

Muxin, A.M. (1968) Struktura predložnij $i$ ix modeli, Leningrad. 
Naylor, Kenneth E. (1974) "A Note on the 'Quantification Form' in Russian," paper presented at the SovietAmerican Conference on the Russian Language.

Nikitevič, V.M. (1963) Grommatičeskie kategorii v sovremennom musskom jazyke, Moscow: Učpedgiz.

Okon', Z.P. and V.I. Polovnikova (1964) Sbornik upražnenij po morfologii, vyp. 2: Čislitel'noe, narečie, Moscow: MGU.

Orlov, K.P. (1961) PriZoženie v sootnošenii s gospodstvujuščim slovom $v$ sovremennom musskom literaturnom jazyke, unpublished Kandidat dissertation, Rjazan', Gosudarstvennyj pedagogičeskij institut.

Ožegov, S.I. (1955) "Sklonjaetsja 1i Moskva-reka?" Voprosy kul'tury reči 1, 221-224.

Moscow.

(1973) Slovar' musskogo jazyka, 10 th ed.,

Padučeva, E.V. (1967) "Dva podxoda k semantičeskomu analizu kategorii čisla," in To Honor Roman Jakobson, The Hague: Mouton, II, 1474-1488.

(1969) "O sokrał̌enii sočinitel'nyx grupp s povtorjajuščimisja èlementami, "Noǔno-texničeskaja informacija 2:2, 27-34.

(1971) "O porjadke slov v predloženijax s sočineniem: sočinitel'naja projektivnost'," Noǔ̌notexničeskaja informacija 2:3, 14-17.

(1974) O semantike sintaksisa (Materialy $k$ transformacionnoj grammatike musskogo jazka), Moscow: Nauka.

Panfilov, A.K. (1965) "Uvažaemyj tovarišč ili uvažaemaja tovariß̌, " Voprosy kul'tury reči 6, 189-195.

Panov, M.V., ed. (1968) Russkij jazyk $i$ sovetskoe obšcestvo, Vol. III: Morfologija i sintaksis sovremennogo musskogo literaturnogo jazyka, Moscow: Nauka. 
Partee, Barbara Hall (1970) "Negation, Conjunction, and Quantifiers: Syntax vs. Semantics," Foundations of Language 6, 153-165.

Patton, Helen Benthen (1969) A Study of the Agreement of the Predicate with a Quantitative Subject in Contemporary Russian, unpublished $\mathrm{Ph} . \mathrm{D}$. dissertation, University of Pennsylvania.

Perlmutter, David M. (1972) "A Note on Syntactic and Semantic Number in English," Linguistic Inquiry 3, 243-246.

(1973) "Language-Particular Rules and Explanation in Syntax," in A Festschrift for Morris HalZe, ed. by Stephen R. Anderson and Paul Kiparsky, New York: Holt, Rinehart and Winston, 419-459.

Petrovskij, N.A. (1966) SZovar' russkix Zičnyx imen, Moscow.

Peškovskij, A.M. (1956) Russkij sintaksis v naučnom osvešcenii, 7th ed., Moscow: Učpedgiz.

Postal, Paul M. (1967) "Coordination Reduction," in Specification and Utilization of a Transformational Grammar, AD 667800, ed. by P.S. Rosenbaum, Yorktown Heights, N.Y.: IBM Watson Research Center.

(1969a) "The Derivation of Pseudo-Adjectives," paper presented at the annual winter meeting of the Linguistic Society of America.

(1969b) "Anaphoric Islands," in Papers from the Fifth Regional Meeting, Chicago: Chicago Linguistic Society, 205-239.

Potixa, Z.A. (1970) Sovremennoe russkoe slovoobrazovanie, Moscow: Prosvešcenie.

Pravila musskoj orfografii i punktuacii (1962), 2nd ed., Moscow: Učpedgiz.

Protčenko, I.F. (1961) "Formy glagola i prilagatel'nogo v sočetanii s nazvanijami lic ženskogo pola," Voprosy kul'tury reči 3, 116-126. 
Revzin, I.I. (1969) "Tak nazyvaemoe 'nemarkirovannoe množestvennoe čislo' v sovremennom russkom jazyke," Voprosy jazykoznanija 3, 102-109.

(1970) "O specifike soglasovanija po čislu v russkom jazyke," in Jazyk $i$ čelovek: Sbornik statej pamjati professora Petra Savviča Kuznecova (18991968), Moscow, 230-238.

(1973) "Nekotorye sredstva vyraženija

protivopostavlenija po opredelennosti $v$ sovremennom russkom jazyke," in Problemy grammatičeskogo modelirovanija, ed. by A.A. Zaliznjak, Moscow: Nauka, 121-137.

Roses, Lynn (1973) "Close Appositive Constructions in Russian: A Formal Semantic Explanation for Selection of the Head Noun," paper submitted as a preliminary sketch for a Ph.D. dissertation, University of Pennsylvania.

Ross, John R. (1967) Constraints on Variables in Syntax, unpublished Ph.D. dissertation, MIT.

(1970) "Gapping and the Order of Constituents," in Progress in Linguistics, ed. by Manfred Bierwisch and Karl E. Heidolph, The Hague: Mouton.

Rothstein, Robert A. (1973) "Sex, Gender, and the October Revolution," in A Festschrift for Morris Halle, ed. by Stephen R. Anderson and Paul Kiparsky, New York: Holt, Rinehart and Winston, 460-466.

Rozental', D.E., ed. (1967) Slovar' udarenij dlja rabotnikov radio $i$ televidenija, 2nd ed. rev., Moscow.

(1968) Praktičeskaja stilistika russkogo jazyka, 2nd ed. rev., Moscow: Vysšaja škola.

(1971a) Spravočnik po pravopisaniju i literaturnoj pravke alja rabotnikov pečati, 2nd ed. rev., Moscow: Kniga. 
Rozental', D. ̇̀. (1971b) Review of K.S. Gorbačevič, Izmenenie norm musskogo literatumogo jazyka, in Russkij jazyk $v$ škole 6, 105-108. slovarja-spravočnika), Moscow. ,ed. (1972) Slitno i.li razdel'no lopyt and M.A. Telenkova [1973a] Practical Stylistics of Russian, Moscow: Progress.

(1973b) "Stilistika

Castej reči: stilisticeskoe ispol'zovanie form imen susčestvitel'nyx," Russkij jazyk za mbełom 4, 36-42.

Safaev, A.S. (1962) "O nekotoryx formax soglasovanija v russkom jazyke," Russkij jazyk v uzbekskoj škole, Taškent, 5:1, 11-21.

Schachter, Paul (1974) "Constraints on Coordination," unpublished manuscript.

(1975) "The Subject in Philippine Languages: Topic, Actor, Actor-Topic, or None of the Above?" paper presented at the Symposium on Subject and Topic, Santa Barbara.

Schane, S.A. (1966) A Schema for Sentence Coordination, $\mathrm{AD}$ 640570, distributed by the U.S. Department of Commerce, National Technical Information Service.

Seliverstova, O.N. (1964) "Opyt semantičeskogo analiza slov tipa vse, kto-nibud'," Voprosy jazykoznanija $4,80-90$.

Senkevič, M.P. (1964) Osobye slučai soglasovanija členov predzoženija $v$ russkom jazyke, učebnoe posobie dlja slušatelej otdelenija povyšenija kvalifikacii redaktorov MPI, Moscow: Mosk. poligraf. in-t.

$$
\text { and M.D. Feller (1968) Literaturnoe }
$$

redaktirovanie: lingvo-stilističeskie osnovy, Moscow: Vysšaja škola.

Sgall, Petr (1972) "Fillmore's Mysteries and Topic vs. Comment," Journal of Linguistics 8, 283-288. 
Skoblikova, E.S. (1959a) "Upotreblenie skazuemogo pri podležǎ̌cem, vyražennom količestvenno-imennym sočetaniem," Voprosy kul'tury reči 2, 91-116.

(1959b) "Upotreblenie skazuemogo pri razdelitel'nyx otnošenijax meždu odnorodnymi podležaščimi," Filologičeskie nauki 2, 199-205.

(1961a) "Oformlenie skazuemogo pri soedinitel'nyx otnošenijax meždu odnorodnymi podležaščimi," in Voprosy teorii $i$ metodiki izučenija russkogo jazyka: Trudy vtoroj naucnoj konferencii kajedr russkogo jazyka pedagogieeskix institutov povolæ'ja, Kujbyšev, 162-176.

(1961b) "Soglasovanie opredelenii s odnorodnymi suščestvitel'nymi," in Voprosy russkogo jazykoznanija: K 80-Zetiju A.M. Luk'janenko, Saratov, 181-190.

(1963) "Ob odnoj konstrukcii v slovosočetanijax s odnorodnymi opredelenijami v russkom jazyke," Filologičeskie nauki 6:2, 143-150.

(1967) "Rol' grammatičeskix i smyslovyx faktorov $v$ oformlenii podčinennogo slova pri soglasovanii v rode i čisle," Učenye zapiski Kujbyševskogo gosudarstvennogo pedagogičeskogo instituta im. V.V. Kuby̌̌seva 52, 37-57.

(1971) SogZasovanie $i$ upravlenie v musskom jazyke, Mloscow: Prosveščenie.

Sommerstein, Alan (1972) "On the So-Called Definite Article in English," Linguistic Inquiry 3, 197-209.

Stankiewicz, Edward (1968) Declension and Gradation of Russian Substantives in Contemporary Standard Russian, The Hague: Mouton.

Stepanov, Ju.S. (1973) "Sovremennye svjazi 1ingvistiki i logiki," Voprosy jazykoznanija 4, 62-75.

Stockwe11, Robert P. et al. (1973) The Major Syntactic Structures of English, New York: Holt, Rinehart and Winston. 
Superanskaja, A.V. (1965) "Sklonenie sobstvennyx imen v sovremennom russkom jazyke," in Orfografija sobstvennyx imen, ed. by A.A. Reformatskij, Moscow: Nauka, 117-146.

(1966) Udarenie $v$ zaimstvovannyx slovax $v$ sovremennom russkom jazyke, Moscow: Nauka.

(1969) Stmiktura imeni sobstvennogo,

- Moscow: Nauka.

Suprun, A.E., (1969) Slavjanskie čislitel'nye, Minsk: BGU.

Sussex, Roland (1974) "The Deep Structure of Adjectives

in Noun Phrases," Journal of Linguistics 10, 111-131.

Šajkevič, A.Ja. (1970) "Russkie 1ǐ̌nye imena XX v. (po materialam ZAGSa Frunzenskogo rajona g. Moskvy)," in Ličnye imena $v$ prošlom, nastojascem, budušcem, Moscow: AN, 84-91.

Šanskaja, T.V. (1959) "Slova obščego roda v russkom jazyke," Russkij jazyk v škole 5, 12-17.

(1961) "O rodovoj prinadležnosti slov s suffiksami sub"ektivnoj ocenki," Russkij jazyk $v$ škole $6,13-17$.

\section{(1964a) Rodovaja prinadleznost'}

subcestvitel'nyx $v$ sovremennom muskom jazyke, abstract of Kandidat dissertation, Moscow University.

(1964b) "O rode složnosokrǎ̌cennyx imen sušcestvitel'nyx v sovremennom russkom jazyke," Russkij jazyk $v$ nacional'noj skole 1, 67-70.

Šanskij, N. (1967) "Razvitie slovoobrazovatel'noj sistemy russkogo jazyka v Sovetskuju èpoxu," Russkij jazyk v nacional'noj skole 3, 3-9.

Šapiro, A.V. (1953) orerki po sintaksisu musskix narodnyx govorov: stroenie predzokenija, Moscow: AN.

Šaumjan, S.K. (1965) Struktumaja Zingvistika, Moscow: lNauka. 
Šaxmatov, A.A. (1925) Sintaksis musskogo jazyka, Leningrad: AN.

Ščerbakov, Ju.I. (1969) Upotreblenie sobiratel'nyx čislitel'nyx $v$ sovremennom muskom jazyke, abstract of Kandidat dissertation, Kujbyšev.

Ščukin, A.N. and S.I. Zlatkina (1970) Smotri i govori, Moscow: Prosveščenie.

Šmelev, D.N. (1962) "Nekotorye osobennosti soglasovanija v russkom jazyke," Russkij jazyk $v$ nacional'noj škole $4,25-32$.

Švedova, N.Ju. (1966) "Ob analitičeskix konstrukcijax v sisteme slovosočetanij," Voprosy kul'tury reči 7, $37-59$.

, ed. (1970) Grommatika sovremennogo musskogo literatumogo jazyka, Moscow: Nauka.

Tai, J.H. (1969) Coordination Reduction, unpublished Ph.D. dissertation, Indiana University.

(1971) "Identity Deletion and Regrouping in Coordinate Structures," in Papers from the Seventh Regional Meeting, Chicago: Chicago Linguistic Society, 264-274.

Traugott, Elizabeth Closs (1972) A History of English Syntax, New York: Holt, Rinehart and Winston.

Unbegaun, B.0. (1947) "Les substantifs indéclinables en Russe," Revue des Etudes slaves 23, 130-145.

Uxanov, G.P. (1974) "Pojasnitel'naja svjaz' v ee otnošenii k sočineniju $i$ podčineniju," in Issledovanie po slavjanskoj filologii, ed. by V.A. Belošapkova and N.I. Tolstoj, Moscow: MGU, 336-342.

Vagner, V.N. and Ju.G. Ovsienko (1967) Russian: Učebnik russkogo jazyka dlja lic, govorjaščix na anglijskom jazyke, Moscow: Vyš̌aja škola.

Valgina, N.S. (1973) Sintaksis sovremennogo musskogo jazyka, Moscow: Vysšaja škola. 
Valgina, N.S. et al. (1971) Sovremennyj musskij jazyk, 4th ed. rev., Moscow: Vyš̌aja škola.

Vanek, Anthony L. (1970) Aspects of Subject-Verb Agreement, Edmonton: The University of Alberta.

Vendler, Zeno (1967) "Singular Terms," in his Linguistics in Philosophy, Ithaca, N.Y.: Cornell University Press, 33-69.

Vinogradov, V.V. (1947) Russkij jazyk, Moscow: Učpedgiz.

(1950) "Sintaksis russkogo jazyka akad. A.A. Saxmatova," in Voprosy sintaksisa sovremennogo russkogo jazyka, Moscow, 75-126.

et al., eds. (1960) Grammatika musskogo jazyka, Vol. I: Fonetika $i$ morfologija, Moscow: AN.

and E.S. Istrina, eds. (1960) Grommatika musskogo jazyka, Vol. II: Sintaksis, Moscow: AN, Part 1.

Vomperskij, V.P., ed. (1962) Praktǐ̌eskaja stilistika russkogo Ziteratumogo jazyka, Moscow: MGU.

Vorob'eva, G.F., ed. (1973) Materialy po razvitiju ustnoj reei, Moscow: MGU.

Ward, Dennis (1973) "Appositional Compounds in Russian," Slavonic and East European Review 51:122, 1-10.

Worth, Dean Stoddard (1959) "Grammatical and Lexical Quantification in the Syntax of the Russian Numeral," International Journal of Slavic Linguistics and Poetics 1-2, 117-132.

Xrolenko, A.T. (1972) "Osobyj slučaj vyraženija opredelitel'nyx otnošenij v sovremennom russkom jazyke," Russkij jazyk $v$ škole 1, 82-86.

Zaliznjak, A.A. (1964) "K voprosu o grammatičeskix kategorijax roda $i$ oduševlennosti $v$ sovremennom russkom jazyke," Voprosy jazykoznanija 4, 25-40.

(1967a) Russkoe imennoe slovoizmenenie, 
Zaliznjak, A.A. (1967b) "O pokazateljax množestvennogo čisla v russkom sklonenii," in To Honor Roman Jakobson, The Hague: Mouton, 2328-2332.

Zemskaja, E.A., ed. (1973) Russkaja razgovornaja red', Moscow: Nauka.

Zolotova, G.A. (1973) Očerk funkcional'nogo sintaksisa musskogo jazyka, Moscow: Nauka. 


\section{INDEX}

abbreviations $8,31,45-49,103-104,142$

abstract nouns 146-148, 175-176, 183-185, 196

acronyms 45-47

adverbial-1ike quantifiers 385, 391

adjectival declension/paradigm 12, 14, 51, 53, 58-59, 63, $114,340,399$

adverbial quantifiers $316,324,368-374,376-379,382$, $384-387,390,395-396,404-405,410-412,428-429$

affective suffixes $9-11,13,51,53,55,56,63,80-82$ afterthought $209,211,236,238-239$

afterthought marker 235-238

age expressions 367

Agent (s) 221-223, 226, 233, 235-236, 238, 242-243, 248,

$251,253,311,313,358$

agreement in case 23

ALTERNATIVE NUMBER MANIFESTATIONS IN ASSOCIATION WITH NOUN

PHRASES INVOLVING PARTITIVE QUANTIFIERS 314-428

appositive combinations 15-16, 18-19, 21-22, 25-27, 41,

$107,139-140$

appositive constructions 25-26, 28-31, 110, 112, 144, 273 approximate quantities $352,357,374$

asyndetic subjects $227,272-273$

Attributive Agreement 35-38, 72-73, 99, 117, 134, 137-138, $154,166,207,330,342-343,429$

attributive combinations 21-22, 31, 107

ATTRIBUTIVES ASSOCIATED WITH TWO OR MORE NOUNS 162-208

augmentative suffix -in- $10,79,80$

backward agreement 406-407, 409-413, 415-418, 425, 427-428

backward deletion 279-280, 293-294

"basic" quantifiers 168, 314, 339

classifier(s) 326-327, 330, 339, 342-343, 347, 356-357, $360-362,364-365,367-368,372,376,388-389$

"collective" numeral(s) $114,128,319,321,343,363-364$ collective nouns $148-156,174,224,369,378,394,397$, 415

Comitative phrase(s) 224, 247-250

composite (s) 16-18, 20, 22-26, 31, 39-40, 101-102, $105-107,112,135,139,172,178-179,181,187$,

$193-194,196,198-199,201,205-208,231,247,252$, $267-272,312$

compounds $16-22,26,31,101,107,113,139-140$

conjunctive combinations 19-20, 27 
contextual number $138,159,332$

contextual sex 73-74, 77, 79, 84, 97, 100, 102, 111, $114,134-135$

copulative verb(s) (copula[s]) 28, 126-127, 260, 265, 330, $336-338,404,406-408,410-413,416-418,425,427-429$ count nouns $158,163,173,186,188-189,191-192,194$, $196,199,386$

četvert' 386, 388, 397, 399-400

"definitional" attributive(s) 172, 194, 196-197, 207

determiner(s) (determiner-type attributive[s]) 168-170,

172-173, 176, 191-192, 197, 207, 344, 346-347, 377,

$389,395,404,407,420$

digital quantifiers $385,387,389,391$

diminutive suffixes 10

disjuncts $197-207,209,297-300,303-306$

dislocated subject(s) 29-30, 274, 312

dislocation $104,152,418$

distributive po 153, 156, 352-353

distributive quantifier(s) 168, 191, 197, 273

dva 113-114, 339, 342-343, 347

dvoe $114,128,346$

epicene(s) 69-72, 74,76-83, 85-86,92,98, 100,102, 106 equative/equational sentences 129,427

Essive 227, 233, 405, 411

èto $128,424-427$

exclusive disjunction 297-299, 301-302, 305-307

existential verb(s) 226-227, 233, 241, 243, 349, 363-364, 385

First Declension $11,12,14,46,51,53-54,56-57,61$, 83,91

fractional quantifiers 385-389, 392-393, 399-400, 402 given names $52-55,61,79,91$

GRAMMATICAL GENDER 7-137

GRAMMATICAL NUMBER 138-159

grammatical person $308-312$

grammatical subject $33,324,327-328,331,380,386,392$, 425

hyperbolic quantifiers $385,387,389,391$

Identity Deletion 167, 168-169, 171-173, 175-176, 184, $186-188,191,196,199,202,215-219,231,235,251$, $253,256,265-266,278,279,283-284,286-287,290-$ $291,295,303-304,306-307,311,383$

indeclinable nouns $14,31-32,38-39,47,58-59,69,74$, $86-89,139,141$

intonational break 25, 27, 110, 215-216, 221, 238, 253,

313 
introductory $i$ 225, 250-253, 285, 307

kak ... tak $i$ 258, 295-296, 307

kto 413-424

mass noun(s) 144-149,156,158,184-186, 199

metaphoric reference $83,85-86,123$

ne to ... ne to 307

ne tol'ko ... no $i 307$

negative particle 258, 263-265, 278, 298,

$n i$... ni 307

nicknames 54-55, 61-62, 78, 85, 91

nominal predicate(s) 119-137, 153, 170, 231, 265, 404, 406-407, 411-412, 421, 426

nominal quantifiers $316,324,368,384-386,388-391$, $395-397,400-402,404,408-413,428,430$ noncount nouns $145,163,173,176,185-187,191,194$, 197,207

numerals (numerical quantifiers) 113-114, 315-316, $318-319,321-322,325-326,330,342-344,346-348$, $350,352,354-355,357,360-363,365-373,376-378$, $384-386,388-389,395-396,402,404,412,427,429$ numeral-like quantifiers $385,388-389,391$

oba 113-114, 339

odin 113, 120-121, 321, 342, 347, 365, 368, 380, 390, 405 participle(s) 183-184, 190-191, 202, 308, 344-345, 404 partitive constructions 115-118, 381

Partitive noun/NP 330, 332-333, 356, 360-361, 365, 368,

$373-375,388$

"partitive" quantifiers 168, 314, 339, 365, 368-369

Partitive role $328,359,371$

Patient(s) 223, 227, 235, 328, 371

paucal number $339-340,342,371,399$

place names (toponyms) 22-25, 41, 140

pluralia tantum nouns $128,138-139$

pol- 388, 397-400

poltora 113-114, 339, 343

polite vy $119,121,123-124,129-130,421,424$

postpositive attributive(s) 202, 204-208, 399

postpositive verbal predicate(s) 207, 214, 254, 265-267, 273,279

predicate adjectives $119,121,123-125,127-128,130-132$, $133-136,168,316-317,348,410,418,421,429$

predicate phrase(s) $76-78,100,124,135,170,343$, $406,408-411,413,427-428$

prepositive verbal predicate(s) 209, 213, 218, 226, 231, $238,241-243,251,254,292-293$ 
primary conjunction 167-168, 170, 173, 181, 205, 216, $223,248,252,266,271-272,283,288-289,294-295$, 312

primary disjunction 204, 208, 304-305, 307, 312 proper name(s) $14,16,22-27,31-32,39-44,48,52-53$, $57,59-60,68,78-79,85-86,88-89,91-92,107-109$, $111-113,129-132,140-141,191,291,382$

"provisional" specifications $34,37-38,73,130,138,143$, $157,316,332,380,401,415,423,427$

QP Lowering 329, 334, 337, 355, 372, 375, 390, 401, 405

QP Raising 337-338, 340, 342, 366, 368, 377-380, 390, $399-401,405,411$

quantified noun(s) $318,322,324,335,337,341-342$, $344-345,348,351-353,355,364,368,374,376$, $378-379,381-382,391,402,408,430$

quantifier phrase (QP) 327, 330-334, 339, 343, 346-347, $351-352,357,360-362,365,367,372,374-376,379$, $385-386,388-389,400-401,404$

reduplicative combinations 20

reference modifiers 96, 101-102, 172

Regrouping 165-166, 168-176, 182, 185-186, 188, 191, 194, $197,199,202-203,206-207,215-216,218-219,225$, $231,234,236,242,251-253,256,258,263,265-266$, $271-272,281-289,293-296,301-304,3.11-312,383$ relational adjectives 101,171

relative pronoun(s) $63,136,163,413,420,422-423$ role (s) 218-219, 223, 227, 233, 250, 328, 330, 358, 405 $s$-phrases 250

sam 121

Second Declension 11, 12, 14, 17, 50-51, 53, 56-57, 59-60, $69,71,73,85,90-91,114$

surnames $52-53,59,78,89-91$

Third Declension 11-12, 14, 17, 50, 53, 59-61, 91, 402 time periods 364-365

to .... to 307

to $Z_{i} \ldots$ to $Z_{i} 307$

transposition 262, 278

Unmarked Animate Gender Rule 75-77, 87-88, 100, 102

Verb Agreement 35, 37, 72-73, 99, 110, 123, 139, 143, $154,207,268,309,334,380,386,400,404,406$, $415-416,418,423,427-429$

VERBAL PREDICATES ASSOCIATED WITH TWO OR MORE NOUNS word order 237, 239-240, 242, 245, 318, 322, 332-334, $349,373-375$

$z \alpha$-phrases 250 